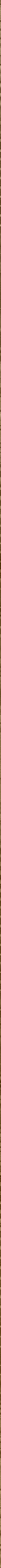


। 


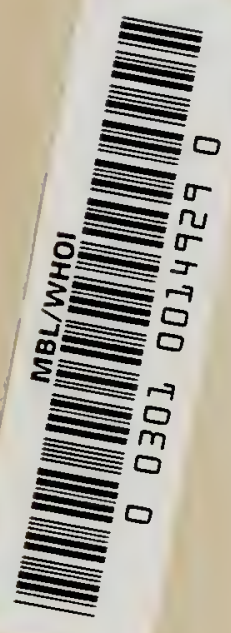




MARK ANNIVERSARY VOLUME 



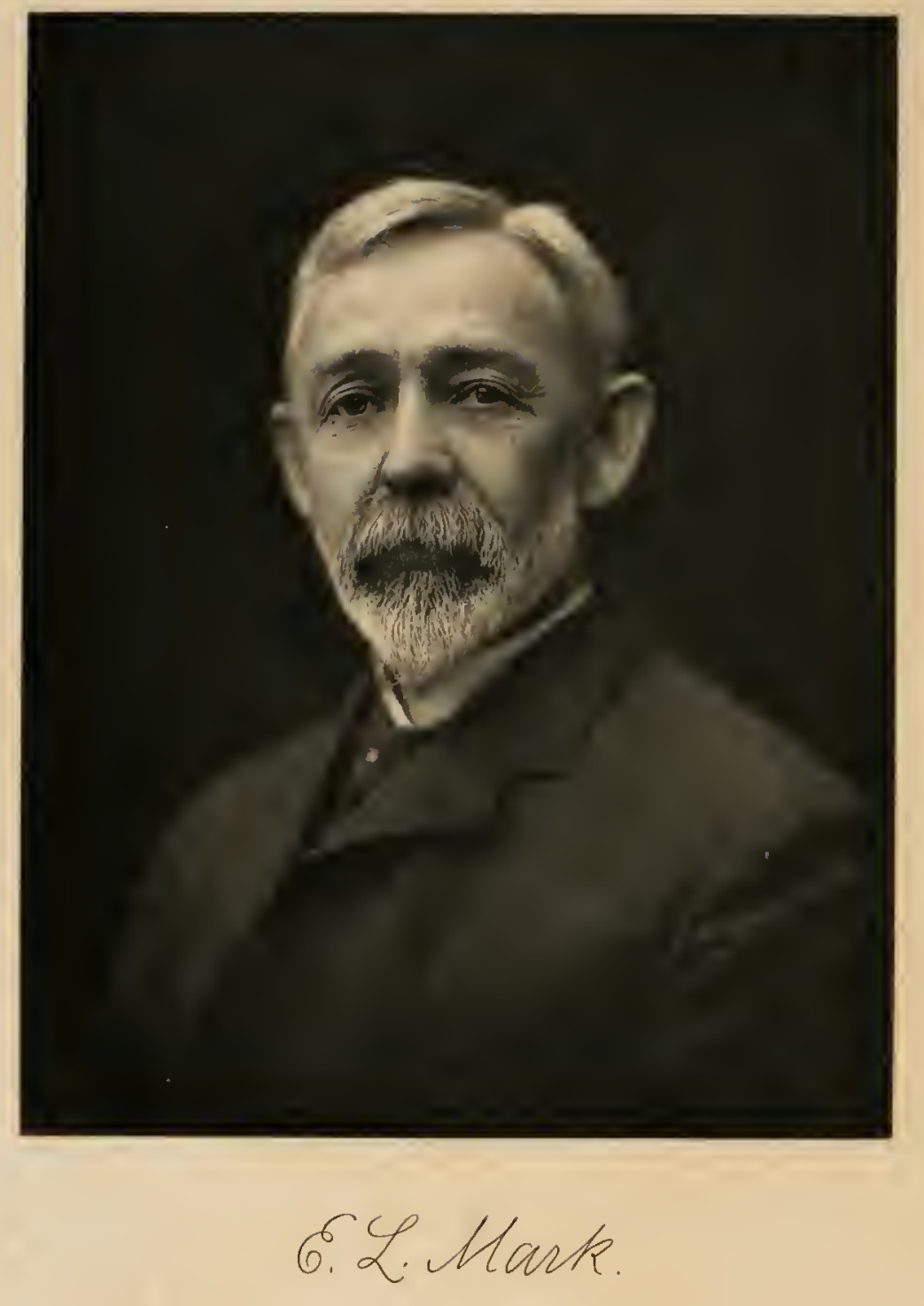




\section{MARK ANNIVERSARY VOLUME}

TO

Edward $\mathfrak{L a u r e n s}$ IIDark

Hersey Professor of Anatomy

and

Director of the Zoölogical Laboratory at Harvard University

in Celebration of

Twenty-five Years of Successful Work for the Advancement of Zoölogy

from bis former Students

1877-1902

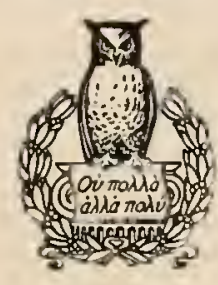

NEW YORK,

HENRY HOLT AND COMPANY

1903 

COMMITTEE OF MANAGEMENT.

Charles B. Davenport, University of Chicago;

C. H. Eigenmann, University of Indiana;

Herbert Haviland Field, Concilium Bibliographicum, Zurich, Switzerland;

Seitaro Goto, First High School, Tokyo, Japan;

William A. Locy, Northwestern University;

Gerritt S. Miller, United States National Museum;

Margaret Lewis Nickerson, University of Minnesota;

JACOB ReIGHARD, University of Michigan;

William E. Ritter, University of California;

Henry B. Ward, University of Nebraska.

EXECUTIVE COMMITTEE.

JaCoB Reighard, Chairman;

. Charles B. Davenport;

Henry B. Ward, Secretary-Treasurer.

EDITOR.

G. H. PARKer. 



\section{Esteemed Master:}

On the completion of your twenty-five years of service at Harvard University, we your pupils seek through this volume to express our devotion to you as our erstwhile teacher, as the advocate of the highest ideals in scientific work, and as the trainer of investigators and teachers in zoölogy.

We recall with pride the service that was done science by the publication of your work on the Maturation, Fecundation, and Segmentation of the Egg of Limax-a work that introduced into America the then new cytological methods in the application of which this country has since reached an elevated position. It likewise introduced into zoölogy a proper fulness and accuracy of citation and a convenient and uniform method of referring from text to bibliography. It marked a step forward, also, in thoroughness and detail, and in the full recognition that, even in zoölogy, as in physics and chemistry, method is hardly less important than matter. These ideals in productive scholarship have been retained throughout the series of researches issued by yourself and your pupils.

Much more personal and more precious to us has been your work in training zoölogists. We call to mind your rigorous preliminary methods that gave us selfreliance, and your constant advice and encouragement; and we have keen and grateful recollections of the critical skill with which you discussed with us our completed studies.

But the memories that we cherish most, the inspiration and the stimulus that have abided longest, depend on certain traits of your character of which this is not the fitting place to make analysis, and of which only your students fully appreciate the influence. Your geniality, your sympathy, and especially your scientific honesty and justice-the influence of these on your pupils no less than your scholarship have inspired this tribute of affection and loyalty.

Glover Morrill Allen, Secretary of the Boston Society of Natural History, Boston, Mass.

James Alderson Bailey, Jr., Barristers Hall, Boston, Mass.

Francis Noyes Balch, Jamaica Plain, Mass.

Frank Watts Bancroft, Instructor in Physiology, University of California, Berkeley, Cal.

Harry Gardner Barber, Teacher of Biology, DeWitt Clinton High School, New York, N. Y. 
Thomas Barbour, Student of Zoölogy, Harvard University, Cambridge, Mass.

Charles Russell Bardeen, Associate Professor of Anatomy, Johns Hopkins University, Baltimore, Md.

William Barnes, Physician, Decatur, Ill.

Elizabeth Emma Bickford, Teacher of Biology, Newton High School, Newton, Mass. Henry Bryant Bigelow, Student of Zoölogy, Harvard University, Cambridge, Mass. Maurice Alpheus Bigelow, Adjunct Professor of Biology, Teachers College, Columbia University, New York, N. Y.

Robert Payne Bigelow, Instructor in Biology and Librarian, Massachusetts Institute of Technology, Boston, Mass.

Mary Alice Bowers, Instructor in Zoölogy, Wellesley College, Wellesley, Mass.

Robert Stanley Breed, Professor of Biology and Geology, Allegheny College, Meadville, $\mathrm{Pa}$.

Edwin Tenney Brewster, Instructor in Natural Sciences, Phillips Academy, Andover, Mass.

Edith Nason Buckingham, Teacher of Science, Concord High School, Concord, Mass.

Charles Bullard, Cryptogamic Herbarium, Harvard University, Cambridge, Mass. Edward Angus Burt, Burr Professor of Natural History, Middlebury College, Middlebury, Vt.

Wendell T. Bush, Brooklyn, N. Y.

Walter Bradford Cannon, Assistant Professor of Physiology, Harvard Medical School, Boston, Mass.

Benjamin French Carpenter, Merchant, Chicago, Ill.

Frederic Walton Carpenter, Edward Austin Fellow in Zoölogy, Harvard University, Cambridge, Mass.

William Ernest Castle, Assistant Professor of Zoölogy, Harvard University, Cambridge, Mass.

Leon Jacoв Cole, Austin Teaching Fellow in Zoölogy, Harvard University, Cambridge, Mass.

Ernest Lee Conant, Attorney at Law, New York, N. Y., and Havana, Cuba.

Francis Whittenore Cragin, Professor of Geology, Mineralogy, and Palæontology, Colorado College, Colorado Springs, Col.

Howard Crawler, Wyncote, Pa.

Charles Augustus Crowell, Jr., Teacher of Science, Winthrop High School, Winthrop, Mass.

Charles Benedict Davenport, Associate Professor of Zoölogy, The University of 
Chicago, Chicago, Ill.; Director of the Biological Laboratory, Cold Spring Harbor, Long Island, N. Y.

Gertrude Crotty Davenport, Chicago, Ill.; in charge of Microscopic Methods at the Biological Laboratory, Cold Spring Harbor, Long Island, N. Y.

Herbert Spencer Davis, Assistant Zoölogist, College of Agriculture and Mechanic Arts, Pullman, Wash.

Mabel Lavinia Earle, Teacher of Science, Miss Winsor's School, Boston, Mass.

Charles Rochester Eastuan, Assistant in Vertebrate Palæontology, Museum of Comparative Zoölogy, Harvard University, Cambridge, Mass.

Carl H. Eigenarann, Professor of Zoölogy and Director of the Biological Station, University of Indiana, Bloomington, Ind.

Herbert Kínibald Faulikner, Physician, Keene, N. H.

Herbert Haviland Field, Director of the Concilium Bibliographicum, Zurich, Switzerland.

Willian Lusk Webster Field, Instructor in Natural Sciences, Milton Academy, Milton, Mass.

Jefferson Butler Fletcher, Assistant Professor of Comparative Literature, Harvard University, Cambridge, Mass.

Rolfe Floyd, Physician, New York, N. Y.

Justus Watson Folson, Instructor in Entomology, University of Illinois, Urbana, Ill. Walter Forchhemer, Physician, Cincinnati, Ohio.

Peter Frandsen, Assistant Professol of Zoölogy and Bacteriology, Nevada State University, Reno, Nev.

Thomas Walton Galloway, Professor of Biology, Milliken University, Decatur, Ill.

Widliam Francis Ganong, Professor of Botany and Director of the Botanic Garden, Smith College, Northampton, Mass.

Frederic Gardiner, Head Master, Yeates School, Lancaster, Pa.

John Hiram Gerould, Instructor in Zoölogy, Dartmouth College, Hanover, N. H. Seitaro Goto, Professor of Biology, First High School, Tokyo, Japan.

Frederic Putnam Gulliver, Science Master, St. Mark's School, Southboro, Mass. Clarence Wilson Hahn, Teacher of Science, Little Falls High School, Little Falls, N. Y. Robert William Hald, Instructor in Zoölogy and Biology, Lehigh University, South Bethlehem, $\mathrm{Pa}$.

John Irwin Hamaker, Professor of Biology and Geology, Trinity College, Durham, N. C. Charles Stedman Hanks, Lawyer, Boston, Mass.

Roland Hayward, Boston, Mass.

Annie Parker Henchinan, Cambridge, Mass. 
viii

MARK ANNIVERSARY VOLUME.

Frank Harris Hiтchcock, Department of Commerce and Labor, Washington, D. C. Arthur Tenney Holbrook, Physician and Surgeon, Milwaukee, Wis.

Freeland Howe, Jr., Biologist, Board of Public Works, Harrisburg, Pa.

Id A Henriette Hyde, Associate Professor of Physiology, University of Kansas, Lawrence, Kan.

Robert Tracy Jacison, Assistant Professor of Palæontology, Harvard University, Cambridge, Mass.

Herbert Spencer Jennings, Assistant Professor of Zoölogy, University of Pennsylvania, Philadelphia, Pa.

Herbert Parlin Johnson, Associate Professor of Bacteriology, University of St. Louis, St. Louis, Mo.

Chancey Juday, Boulder, Col.

Harry McCormek Keldrey, Professor of Biology, Cornell College, Mount Vernon, Iowa. Harris Kennedy, Physician, Roxbury, Mass.

Linus Ward Kline, Department of Education, State Normal School, Farmville, Va. Charles Atwood Kofoid, Assistant Professor of Histology and Embryology, University of California, Berkeley, Cal.

Clarence Haskelu Lander, Teacher of Biology, East High School, Cleveland, Ohio. William Coolidge Lane, Librarian, Harvard College Library, Cambridge, Mass.

Thomas George Lee, Professor of Histology and Embryology, University of Minnesota, Minneapolis, Minn.

Frederic Thomas Lewis, Instructor in Embryology and Histology, Harvard Medical School, Boston, Mass.

Henry Richardson Linville, Instructor in Biology, De Witt Clinton High School, New York, N. Y.

William Albert Locy, Professor of Zoölogy, Northwestern University, Evanston, Ill. George Grant MacCurdy, Lecturer in Anthropology, Yale University, New Haven, Conn.

Alfred Goldsborough Mayer, Curator of the Natural Sciences, Museum of the Brooklyn Institute of Arts and Sciences, Brooklyn, N. Y.

Florence Mayo, Physician, Philadelphia, Pa.

Gerrit Suith Miller, Jr., Assistant Curator, Division of Mammals, United States National Museum, Washington, D. C.

William .J. Moenkhaus, Assistant Professor of Zoölogy, Indiana University, Bloomington, Ind.

Charles Henry Morss, Superintendent of Schools, Medford, Mass.

Herbert Vincent Neal, Professor of Biology, Knox College, Galesburg, Ill. 
Margaret Lewis Nickerson, Instructor in Histology and Embryology, University of Minnesota, Minneapolis, Minn.

Winfield Scott Nickerson, Assistant Professor of Histology and Embryology, University of Minnesota, Minneapolis, Minn.

Adèle Oppenheiner, Teacher of Biology, Wadleigh High School, New York, N. Y.

Bernard Sutro Oppenhemer, Physician, New York, N. Y.

Herbert Osborn, Professor of Zoölogy and Entomology, Ohio State University, Columbus, Ohio.

Janes Leonard Paine, Merchant, Boston, Mass.

George Howard Parker, Assistant Professor of Zoölogy, Harvard University, Cambridge, Mass.

Villian Patten, Professor of Zoölogy, Dartmouth College, Hanover, N. H.

George James Peirce, Associate Professor of Botany and Plant Physiology, Leland Stanford Junior University, Stanford University, Cal.

Helen Perkins, Boston, Mass.

John Walter Perkins, Surgeon, Kansas City, Mo.

Anos Willian Peters, Instructor in Zoölogy, University of Illinois, Urbana, Ill.

John Charles Phildips, Student of Medicine, Harvard Medical School, Boston, Mass.

Newton B. Pierce, United States Department of Agriculture, Division of Vegetable

Physiology and Pathology, Santa Ana, Cal.

James Foster Porter, Architect, Lakeside, Ill.

Frederick Haven Pratt, Student of Medicine, Harvard Medical School, Boston, Mass. Henry Sherring Pratt, Professor of Biology, Haverford College, Haverford, Pa.

Charles William Prentiss, Instructor in Biology, Adelbert College, Cleveland, Ohio. Herbert Wilbur Rand, Instructor in Zoölogy, Harvard University, Cambridge, Mass. Jacob Reighard, Professor of Zoölogy, University of Michigan, Ann Arbor, Mich.

Herbert Maule Richards, Adjunct Professor of Botany, Barnard College, Columbia University, New York, N. Y.

Wilitiam Emerson Ritter, Professor of Zoölogy, University of California, Berkeley, Cal.

Theodore Hilgard Romeiser, Physician, New York, N. Y.

Theodore Roosevelt, President of the United States, Washington, D. C.

William Henderson Ruddick, Physician, South Boston, Mass.

Barney Sachs, Physician, New York, N. Y.

Ernest SAchs, Student of Medicine, Johns Hopkins Medical School, Baltimore, Md. Porter Edward Sargent, Teacher of Natural Sciences, Brown and Nichols School, Cambridge, Mass. 
William Martin Smallwood, Associate Professor of Zoölogy, Syracuse University, Syracuse, N. Y.

Frank Smith, Assistant Professor of Zoölogy, University of Illinois, Urbana, Ill.

Grant Suith, Austin Teaching Fellow in Zoölogy, Harvard University, Cambridge, Mass.

Thorndike Spalding, Attorney at Law, Cambridge, Mass.

Reuben Myron Strong, Carnegie Fellow in Zoölogy, The University of Chicago, Chicago, Ill.

Ralph Stockman Tarr, Professor of Dynamic Geology and Physical Geography, Cornell University, Ithaca, N. Y.

John Eliot Thayer, South Lancaster, Mass.

Martin Buel Tinker, Physician, The Sanitarium, Clifton Springs, N. Y.

William Lawrence Tower, Associate in Embryology, The University of Chicago, Chicago, Ill.

William Trelease, Director of the Missouri Botanic Garden, St. Louis, Mo.

Albert Henry Tuttle, Surgeon, Cambridge, Mass.

Thomas Wayland Vaughan, Assistant Geologist, United States Geological Survey, Washington, D. C.

IVilliam Scott Wadsworth, Coroner's Physician, Philadelphia, Pa.

Frederick Clayton Waite, Assistant Professor of Histology and Embryology, Western Reserve University, Cleveland, Ohio.

Robert Walcott, Boston, Mass.

Ernest de Wolfe Wales, Physician, Boston, Mass.

Henry Baldwin Ward, Professor of Zoölogy and Dean of the College of Medicine, University of Nebraska, Lincoln, Nebr.

Frederic Leonard Wasuburn, State Entomologist of Mimnesota, Agricultural Experiment Station, University of Minnesota, St. Anthony Park, Minn.

Frank Elbert Watson, Teacher in Biology, Springfield High School, Springfield, Mass. Philip Rexford Waughop, Physician to Kealid and Hanalei, Hawaii Kealia, Hawaii. Hollis Webster, Teacher of Botany, Cambridge, Mass.

Arthur Wissivald Weysse, Instructor in Zoölogy, Massachusetts Institute of Technology, Boston, Mass.

Edith Helen Wheeler, Boston, Mass.

Francis Bfach White, Master, St. Paul's School, Concord, N. H.

Worrallo Whitner, Instructor in Zoölogy and Botany, South Chicago High School, Chicago, Ill. 
Edwin Mead Wilcox, Professor of Vegetable Physiology and Pathology, Alabama Polytechnic Institute, Auburn, Ala.

William Albert Willard, Adjunct Professor of Zoölogy, University of Nebraska, Lincoln, Nebr.

Stephen Riggs Williams, Professor of Biology and Geology, Miami University, Oxford, Ohio.

John Gerrish Wood, Superintendent of the Twine Mills of the McCormick Harvester Machine Company, Chicago, Ill.

Frederick Adams Woods, Physician, Brookline, Mass.

Wrlliam McMichael Woodworth, Keeper of the Museum of Comparative Zoölogy, Harvard University, Cambridge, Mass.

Alfred Worcester, Physician, Waltham, Mass.

Robert Mearns Yerkes, Instructor in Psychology, Harvard University, Cambridge, Mass. 


\section{TABLE OF CONTENTS.}

I. Seitaro Goto: The Craspedote Medusa Olindias and some of its Natural Allies. (Plates I-III.) 1

II. Henry S. Pratt: Descriptions of four Distomes. (Plate IV.)................ 23

III. William A. Locy: A New Cranial Nerve in Selachians. (Plates V-VI.)............. 39

IV. JAcoв Reighard: The Natural History of Amia calva Linnæus. (Plate VII.).......... 57

V. Charles A. Koford: On the Structure of Protophrya ovicola, a Ciliate Infusorian from the Brood-sac of Littorina rudis Don. (Plate VIII.)....................... 111

VI. C. B. Davenport: A Comparison of some Pectens from the East and the West Coasts of the

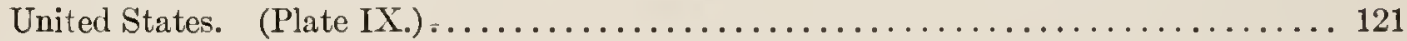

VII. Gertrude Crotty Davenport: Variation in the Number of Stripes on the Sea-anemone,

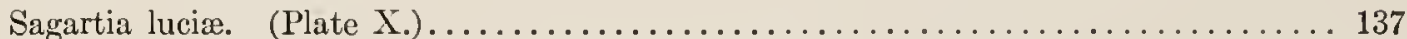

VIII. Frank W. Bancroft: Estivation of Botrylloides gascoi Della Valle. (Plate XI.)....... 147

IX. Carl H. Eigenmann: The Eyes of the Blind Vertebrates of North America. V. The History of the Eye of the Blind Fish Amblyopsis from its Appearance to its Disintegration in

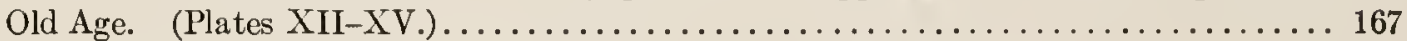

X. Herbert Parlin Johnson: Fresh-water Nereids from the Pacific Coast and Hawaii, with Remarks on Fresh-water Polychæta in General. (Plates XVI-XVII.) . . . . . . . . . . . 205

XI. Henry R. Linville: The Natural History of some Tube-forming Annelids (Amphitrite ornata,

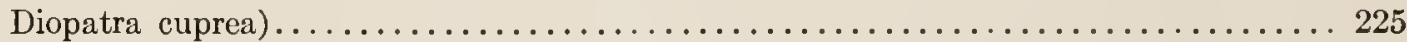

XII. William E. Ritter: The Structure and:Affinities of Herdmania claviformis, the Type of a New Genus and Family of Ascidians from the Coast of California. (Plates XVIII-XIX.) ..... 237

XIII. R. M. Strong: The Metallic Colors of Feathers from the Sides of the Neck of the Domestic

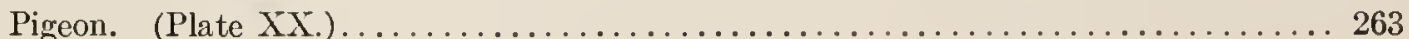

XIV. C. R. Eastman: On the Nature of Edestus and Related Forms. (Plate XXI.)........... 279

XV. H. V. Neal: The Development of the Ventral Nerves in Selachii. I. Spinal Ventral Nerves. (Plates XXII-XXIV.)..................................... 291

XVI. H. S. Jennings: Asymmetry in certain lower Organisms, and its Biological Significance. . . . . 315

XVII. Rolfe Floyd: A Contribution to the Nervous Cytology of Periplaneta orientalis, the Common

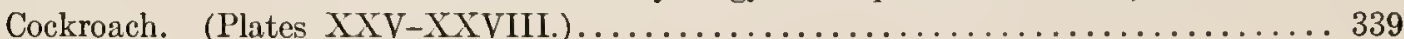

XVIII. Robert Mearns Yerkes: Reactions of Daphnia pulex to Light and Heat............ 359

XIX. W. E. Castle and Glover M. Allen: Mendel's Law and the Heredity of Albinism . . . . . . . . 379

XX. Porter Edward Sargent: The Torus longitudinalis of the Teleost Brain: Its Ontogeny, Morphology, Phylogeny, and Function. (Plate XXIX.)................. 399

XXI. Thomas G. LeE: Implantation of the Ovum in Spermophilus tridecemlineatus Mitch. (Plates

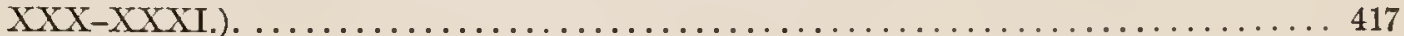

XXII. John H. Gerould: Studies on the Embryology of the Sipunculidæ. I. The Embryonal Envelope and it Homologue. (Plate XXXII.) ....................... 437

XXIII. G. H. PArker: The Phototropism of the Mourning-cloak Butterfly, Vanessa antiopa Linn.

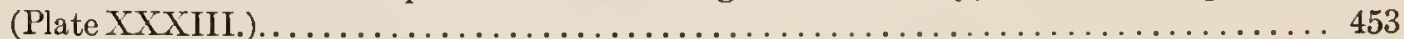

XXIV. IdA H. Hyde: The Nerve Distribution in the Eye of Pecten irradians. (Plate XXXIV.)..... 471 XXV. Henry B. Ward: On the Development of Dermatobia hominis. (Plates XXXV-XXXVI.).. 483 
I.

THE CRASPEDOTE MEDUSA OLINDIAS AND SOME OF ITS NATURAL ALLIES.

(PLATES I-III.)

Seitaro Goto. 


$$
\text { • }
$$




\section{OLINDIOIDES FORMOSA gen. nov., sp. nov.}

For some years past one species of veiled medusa, in particular, has been attracting the notice of the members of the Misaki Biological Station, by its large size, the beautiful variety of its colors, and some peculiarities in the form and arrangement of its tentacles. Attending, among other things, to the study of the veiled medusæ, my attention was naturally drawn to the above-mentioned species, and with the generous assistance of the Director of the Station, I have been enabled to collect enough material for study, the principal results of which are given in the following lines. It is a great pleasure to me to extend my best thanks to Professor Mitsukuri, the Director of the Station.

The medusa in question has proved on study to possess many striking points of resemblance to the Mediterranean species Olindias mülleri Haeckel; but for reasons which will appear farther on I have decided to form a new genus for it, and propose the name of Olindioides formosa for the species. Further, I have come to the conclusion that the genera Gonionema and Halicalyx are closely, and the fresh-water genera Limnocodium and Limnocnida more distantly, related to the new genus, and these relationships will be discussed.

There are some facts connected with the occurrence of the medusa that deserve notice. So far as my experience goes it is found only from December to June or July. The examples collected in December are all immature, with the diameter of the disk not over 20 millimetres or so, and although a few stragglers may be met with in July and August, they generally appear to be in a dilapidated condition. It must, however, be remembered that these limits are subject to variation from year to year. Another fact worth noting is that Olindioides formosa is a bottom species, and none but weakened or injured examples have been caught at the surface. The best season for collecting the medusa is March and April, when a large number of fishermen do trawling at various depths off the Station, and by sailing from one boat to another as the trawls are hauled in, one can, on successful occasions, easily get a few dozen specimens. The medusa appears to confine itself to the depth of from 20 to 30 fathoms, although my experience has not been varied enough to enable me to make any very positive statement on this point. 


\section{THE CRASPEDOTE MEDUSA OLINDIAS AND SOME OF ITS NATURAL ALLIES.}

The umbrella is moderately high, measuring nearly one-half as much as its largest diameter, which is found slightly above the margin (Pl. I, Fig. 1); but in younger examples (Fig. 2) it is relatively higher, as in many other veiled medusæ. The jelly is thick and very consistent. The manubrium is quadrate with distinct lips, and when expanded hangs down into the umbrella cavity about two-thirds the height of the latter. Of some forty specimens that I have examined for the purpose, only three had four radial canals, and all the rest had six, so that there cannot be any doubt that six is the normal number for the species. Two of the canals start from two of the opposite corners of the manubrium, and of the remaining four two together from the other opposite corners. A comparison of a few examples is, however, sufficient to show that the number six is due to the bifurcation of two of the four original radial canals. This is easily seen on the apical view of almost any example, as shown in Figure 7, where two of the radial canals are seen to unite just before entering the central stomach, or as in Figure 8, where four of the radial canals forming opposite couples are seen to have a common root for each couple. Examples with two simple and two $\mathrm{Y}$-shaped radial canals are not rare, and cases of five radia canals are also met with, though seldom.

The gonads are foldings of the subumbrellar walls of the radial canals, and extend the greater part of their lengths, leaving only a small proximal portion and a much smaller distal portion free (Fig. 6). In young examples these foldings are very simple and are clearly continuous (Pl. II, Fig. 13), but in older ones they become more complicated and are sometimes divided into numerous lobes, which are again subdivided into secondary lobes (Pl. I, Fig. 9). In the case of Y-shaped radial canals, the gonads extend upwards only as far as the point of division, and are therefore V-shaped. If the point of division lies very near the manubrium, however, the gonads leave a small proximal portion free, as in the normal case.

The endoderm of the radial canals presents different aspects on the oral and aboral sides. On the latter the cells approach nearly to the cubical form, and the cytoplasm is usually deeply stained and contains a comparatively small number of minute granules, while on the former the cells are tall and contain numerous large granules, which are probably a product of assimilation and form a reserve material. It must be remarked in this connection that the amount of these granules varies a good deal according to the nutritive condition of the example, and that in a specimen which in some way or other had lost its manubrium these granules were almost wholly absent. The endodermal lining of the gonads is composed entirely of these cells containing large granules.

The circular canal is very large, and the endoderm presents the same difference of 
THE CRASPEDOTE MEDUSA OLINDIAS AND SOME OF ITS NATURAL ALLIES. 5

aspect on the inner (oral) and outer (aboral) sides. On the former the cells are nearly cubical, stain deeply, and contain numerous fine granules, while on the latter side the cells are exceedingly tall and are at places almost clogged with large granules, which are exactly similar to those found in the lower walls of the radial canals (Pl. II, Figs. 15, 16; Pl. III, Figs. 17, 18). In some examples these cells are so tall as to project into and considerably narrow the lumen of the canal.

There are numerous centripetal canals of varying lengths in each sextant, lying, as in most other cases where these are found, close to the ectoderm of the subumbrella. They increase in number with the age of the medusa, and the longest lie midway between the radial canals, the next longest between the longest and the next radial canal, and so on. As the centripetal canals increase in number, however, this law is apt to be disturbed. In the specimen represented in Figure 6, for instance, this law holds good only for a short way; and even in small specimens the centripetal canals are not frequently found so regularly graded as in Figure 5. In one and the same specinen the number of centripetal canals varies from sextant to sextant, although within a limited range. To give only two examples, in a specimen with the disk of 75 millimetres in diameter, which is about full grown, the maximum number of centripetal canals was 23 , and the minimum 18; in another of 15 millimetres in diameter the centripetal canals varied between 11 and 14 ; the total number for the former being some 120, for the latter 78 .

The centripetal canals are, in structure, repetitions on a smaller scale of the radial canals, and their endoderm presents exactly the same features as in the former.

The radial, circular, and centripetal canals are connected with one another and with the central stomach by the endorlermal, or vascular, lamella. In younger examples this is a layer of strictly one cell in depth, but in a very large one of about 100 millimetres in diameter the nuclei lay without any order, forming irregular tiers across its thickness. The cell boundaries could not be detected usually, except in very young specimens. The endodermal lamella runs close to the subumbrellar ectoderm, but is separated from it by a thin layer of jelly, and meets the radial, circular, and centripetal canals along the line that separates the different kinds of endodermal cells described above.

There are two sets of tentacles different in structure and position, and presumably also in their main function. From their position I shall call them velar and exumbrellar; both are very numerous.

The exumbrellar tentacles may arise from the exumbrella at any level, from very near the apex to a short distance from the velum, but they are provided with endodermal roots, traversing the jelly and connecting them with the circular canal. 


\section{THE CRASPEDOTE MEDUSA OLINDIAS AND SOME OF ITS NATURAL ALLIES.}

The majority of these tentacles arise just outside the velar tentacles, and in these the roots are very short; but several of them spring at various levels from the surface of the exumbrella (Pl. I, Figs. 1, 2), and in these the roots are not only correspondingly long, but are accompanied by streaks of thickened ectodermal cells loaded with ivory-black pigment granules. These streaks as well as the endodermal roots are narrow near the circular canal, but become broader higher up, and the black streaks are continued for some distance on to the free portion of the tentacles. In younger specimens these exumbrellar tentacles with long roots are very few, and there is no doubt that they increase with age; and the black pigment above mentioned appears to be developed always in conjunction with the union of these tentacles to the exumbrella; for those tentacles which arise a little above their fellows have their proxinal portion tinged with black (Fig. 1). The ectoderm of these black streaks contains nettle-cells, and is the direct continuation of the marginal nettle-ring. There is no objection to calling these streaks "peroniæ." The number of exumbrellar tentacles in an example 15 millimetres in diameter was 72 , and in one 75 millimetres in diameter 264 .

The exumbrellar tentacles have numerous elongated warts arranged across their lengths, formed by tall ectodermal cells containing nettle-capsules. They are slightly enlarged at the tip, where there is an elliptical patch of mucous gland-cells. The terminal portions of the exumbrellar tentacles are slightly curved inwards in a characteristic way, and the glandular patch just mentioned may be found indifferently at the tip or on the oral or aboral surface of the tentacles. In the aquarium the medusa has been observed to anchor itself to the bottom by means of these glands, stretching out and using the exumbrellar tentacles very much in the same way as the tie-ropes of a half-filled balloon. As it is a bottom species there can hardly be any reasonable doubt that these tentacles are used in the same way in its natural surroundings. The tentacles that spring from well up on the exumbrella probably serve to fasten the animal to seaweeds or rocks lying over it.

The cells of the glandular patch above mentioned are very tall, and the cytoplasm contains numerous minute granules which stain well with hæmatoxylin (aqueous glycerin-alum solution after Rawitz), and the secretion is usually seen forming a row of rounded masses, each corresponding to a gland cell and connected with it (Pl. III, Fig. 20).

The endodermal roots of the exumbrellar tentacles lie directly underneath the exumbrellar ectoderm, to which they are closely applied. The cells are large and vacuolated, and are directly continued into the endoderm of the circular canal. On the inner side of these tentacle roots there is a layer of scattered ectoderm cells. The 
exumbrellar ectoderm lying about the tentacle roots is conspicuously thickened, and contains black pigment granules and nettle-cells.

The velar tentacles are very long, slender, and contractile when fully formed, but are found in all stages of development from a mere bulb to a long contractile filament amed with numerous stinging batteries. They are always found close to the base of the velum, and their endoderm is directly continued into that of the circular canal, without the intervention of what may be called "roots." In younger examples, of about 20 millimetres or a little more in diameter, the velar tentacles are all in the condition of bulbs, exactly like the basal bulbs of Gonionema; but in mature specimens (70 millimetres or more in diameter) some of the velar tentacles are exceedingly long and contractile, and are armed with numerous nettle batteries in the form of incomplete rings. These incomplete rings are arranged all with the open point turned towards the oral side, so that there is formed a longitudinal groove on the inner side of the filiform velar tentacle. The ectodermal muscle fibres of these tentacles are at least three times as thick as those of the exumbrellar tentacles and are crossstriped. This is in entire accord with their great contractility in life. These filiform velar tentacles are never very numerous, there being some ten or so in an example of about 60 millimetres in diameter. In the aquarium these tentacles are dragged along passively when the animal swims forwards, but when at rest they are loosely laid out on the bottom and occasionally contracted. I believe they are the principal organs for capturing prey. When strongly contracted, they tend more or less to form a spiral. In an example of 15 millimetres in diameter there were about 100 velar tentacles, all in the condition of bulbs, and in one of 75 millimetres some 325 , of which a dozen or so were filiform.

The velar tentacles are very different in structure in the bulbular and filiform conditions. In the bulbular condition the ectoderm is so clogged with nettle-cells in all stages of development that it is hard to recognize the individual ectoderm cells. It is also to be remarked that none of the numerous nettle-cells are found fully developed. The endoderm is a direct continuation of the external part of the endodermal wall of the circular canal, with which it presents the same histological characters, and the mesoglœa is very thin. In the filiform condition the mesogloa is tolerably thick, the endoderm cells are large and vacuolated, though less so than those of the exumbrellar tentacles. The stinging batteries contain numerous fully developed nettle-cells, and between the ectodermal cells close to the mesogloea are found numerous nettle-cells in the later stages of development. These are placed with their long axes parallel or only slightly oblique to the length of the tentacle, and are, in my opinion, on the way to their destinations, the earlier stages having been passed in the 


\section{THE CRASPEDOTE MEDUSA OLINDIAS AND SOME OF ITS NATURAL ALLIES.}

bulbular velar tentacles. All suspicion that the bulbular and the filamentous forms may be fundamentally different has been dispelled by the presence of numerous intermediate stages. The bulbular velar tentacles as well as the ectodermal thickenings that connect them are then the nisi formativi of the stinging cells, whence they travel in opposite directions, up along the peronia into the exumbrellar tentacles, or down into the filiform velar tentacles. The wandering nettle-cells are much less numerous in the exumbrellar than in the velar tentacles.

The marginal organs are all otocysts, and are present in large numbers, two at the base of the endodermal root of each exumbrellar tentacle. In younger examples they form a single row along the umbrella margin and are situated close to the circular canal (Pl. I, Fig. 3), but in larger ones they no longer keep the same front, and, generally speaking, the older ones are pushed up into the jelly of the umbrella (Fig. 4). They are either spherical or ellipsoidal, and some of the larger ones measure no less than 160 micra across. The vesicle is lined by a flattened epithelium, which presents a local thickening at a place turned towards the circular canal, where probably the sensory cells are found. The otolith is surrounded by some granular protoplasm containing nuclei, and is attached to the wall of the vesicle by means of a short stalk consisting of some granular, well-staining protoplasm containing nuclei. The otolith itself is highly refringent, and, when fully formed, consists of somewhat irregularly concentric layers arranged around a centre. It appears to be very hard and is apt to be detached from sections.

Haeckel says that the structure of the marginal vesicles of Olindias shows it to belong to the Trachomedusæ, but as both Olindias and Olindioides as well as the closely related genera before mentioned appeared to me to present several features which are not commonly met with among the Trachomedusæ, I have paid special attention to the development of the otocyst, which, in the absence of any knowledge of the life history, must be considered the most reliable criterion by which to decide the natural relationship of the veiled medusæ.

I have shown in Figures 15 to 19 (Pls. II, III) some stages in the development of the otocyst. The endodermal roots of the exumbrellar tentacles start from the circular canal at the place where the two kinds of endodermal cells already mentioned meet each other, and the first rudiment of the otocyst is seen in process of formation close to this root. It consists of a small segregation of ectodermal cells hardly distinguishable from the rest, closely applied to the endoderm of the circular canal at the point where the two kinds of cells meet (Pl. II, Fig. 15). At this stage it would be very apt to be overlooked, were it not for the presence of the root of a very young exumbrellar tentacle. There cannot be any reasonable doubt that the rudiment 
consists exclusively of ectoderm cells, since the boundary line between the two celllayers is always distinguishable with a good objective (Zeiss apochromatic oil-immersion), and there is no sign of proliferation in the endoderm. On the contrary, the latter is usually found pushed in by the otocyst rudiment-just the contrary of what one would expect if the endoderm took part in its formation. The first rudiment just described forms, as will appear in the sequel, the otolith and the parts that directly surround it.

In the next stage (Fig. 16) the endoderm is generally found pushed in somewhat more by the otocyst rudiment, and around the latter on the outer side has been formed a cup-shaped cavity lined by a layer of cells, some of which are flattened, while others can hardly be distinguished from the surrounding ectoderm cells. This cavity is the beginning of the vesicle, and the layer of cells around it becomes its lining epithelium. In this stage the cells that formed the first rudiment are all alike.

The next change that takes place consists in the enlargement of the cavity and the differentiation of the central cells into two sorts, namely, those that are transformed into the otolith and those that form its investment and stalk. In the section reproduced in Figure 18 (Pl. III) this differentiation has hardly begun, and the deeply and faintly staining nuclei are found mixed together, although some of the more central ones are larger and clearer than other's. It may also be noted that in this section many of the peripheral nuclei are vesicular in appearance. These differences taken by themselves appear to me to afford only a dubitable clue to the destination of the respective cells, depending as they do on the changing conditions of the nuclear substance. For example, even in one and the same otocyst some nuclei of its lining epithelium are clear and vesicular, while others are darkly stained. In a later stage the cells that are destined to be transformed into the otolith and those that remain as its investment and the stalk are clearly distinguishable, the central nuclei being generally larger, clear and vesicular, while the peripheral ones are deeply stained and are more or less flattened. It must be borne in mind, nevertheless, that these differences are by no means absolute. Sometimes, as is seen in Figure 17, the differentiation of the central cell mass appears to be effected at a very early stage, and in such a case the difference between the two kinds of cells is very striking.

In the last stage described the central cell mass was sessile, resting as it dicl clirectly against the endoderm of the circular canal by a broad base. If double staining is resorted to at such a stage, the cells that are destined to become the otolith stain of the same color as the endoderm, while the lining epithelium and the investing cells stain like the ectoderm; for example, with fuchsin and methyl green the endoderm and otolith cells are violet, and the epithelium, investing cells, and ectoderm are green. 
10 THE CRASPEDOTE MEDUSA OLINDIAS AND SOME OF ITS NATURAL ALLIES.

And one is very apt to interpret such a different behavior towards stains as proving different origin. This is the fundamental principle of double staining, but if applied too liberally it is very apt to lead one into unwarranted conclusions. The researches of Fischer ('99) have taught us that this principle must be checked and rechecked constantly by other considerations to afford justifiable and reliable conclusions. The origin of a structure can be regarded as definitely proved only by being traced to its first beginning.

The cells that are destined to form the otolith gradually undergo histolysis; the cytoplasm becomes more and more attenuated, and the nuclei enlarge and become clearer and vesicular; finally they disintegrate and disappear, leaving in their stead a sparsely granular substance, which at first stains tolerably well, and in which small blocks of chromatin and some irregular fibres can be observed. At this stage the stalk is very distinct and consists of a deeply staining, finely granular protoplasmic mass containing several nuclei (Fig. 19). The otolitic substance gradually becomes more refringent, at the same time losing its affinity for stains, and finally comes to consist of numerous concentric layers. The otolith is surrounded by a nucleated protoplasmic investment to the last. In the stage shown in Figure 19, the lining epithelium of the otocyst is separated from the ectoderm only an exceedingly thin layer of mesogloea; but in older stages the entire organ is pushed far into the jelly and has usually no cellular connection with the ectoderm. Exceptionally, however, such a connection persists through life. The otocysts are throughout life more or less closely applied to the endoderm of the circular canal, from which they are frequently separated by a very thin layer of jelly.

The colors* of the medusa are as follows: for the tips of the exumbrellar tentacles a beautifully transparent, shining lilac, for the next adjoining portion a shining smaragdine-green, and for the peronia and the basal portion of those exumbrellar tentacles that arise some way up the umbrella ivory-black, the latter thinning out and passing into the green portion or separated from it by a short colorless stretch; for the radial and circular canals a deep scarlet, and for the centripetal canals a lighter scarlet. There is also a small smaragdine-green triangular area at each corner of the base of the manubrium, on either side of which is a lilac area of the same color as that of the tips of the exumbrellar tentacles; there is in addition one or two somewhat irregular longitudinal streaks of lilac along the middle of each side of the manubrium. The tips of some of the filiform velar tentacles are occasionally just tinged with green and lilac. The gonads are egg-yellow. In small specimens the more axial portion of the manubrium is egg-yellow, but in larger ones it is almost entirely colorless.

* The names of the colors used in this description are in accordance with the systemn proposed by Saceardo ('94). 
Some histological notes other than those mentioned heretofore may now be added.

The velum is very strongly developed, its mesoglœa is very thick in full-grown examples, and on the subumbrellar side is thrown into numerous vertical folds, forming muscular lamella. The subumbrellar musculature is also vigorously developed, and there is a special muscular ring just inside the base of the velum, adjacent to the nerve-ring. This is due to a special development of the muscular lamellæ, which are here very numerous and closely set, and are also exceptionally tall. The muscular lamellæ are found here and there in all parts of the subumbrella, but they are inconspicuous elsewhere.

The nettle-cells are exceptionally large and cylindrical, and are in general form like those of many actinians. When fully formed they are as large as 30 micra by 7 micra, and the protoplasmic mantle and the nucleus can always be distinguished very clearly. The latter is usually found near the more slender end of the organ and is frequently horseshoe-shaped. When the nettle-cells are placed in their definitive position this slender end is invariably directed inwards, being the closed end of the urticating vesicle.

As before mentioned, the nettle-cells are comparatively few in the exumbrellar tentacles, but are especially numerous in the ring-shaped warts of the velar tentacles, and in these they are imbedded between exceedingly tall ectodermal cells, which are very conspicuous in sections even under a low power. These ectodermal cells are provided with very long stalks which stain deeply with hæmatoxylin, are more or less undulating, and are attached below to the mesogloa. The body of the cell consists of a granular or a somewhat fibrous cytoplasm with a distinct membrane and a deeply staining mucleus situated near the centre. Under ordinary objectives the transition between the stalk and the body of the cell appears sudden, but with a high-power apochromatic system it is seen to be more gradual. These stalks were at first suspected to be muscular in nature, but further observations revealed many transitional forms between these and the ordinary tall ectodermal cells; and further, these stalks look very different from the muscular fibres lying immediately below. It is evident, however, that the protoplasm of the stalks of these cells has undergone a special modification, but its nature has so far remained obscure to me. These cells with deeply staining stalks are also present in the warts of the exumbrellar tentacles; but they are less numerous there and the stalks are shorter.

Olindioides formosa has been observed in the following localities: Misaki; Kanagawa (practically identical with Yokohama, Prof. Mitsukuri); Bay of Tateyama, southeastern extremity of the Bay of Tokyo (Dr. Oka). 


\section{GONIONEMA DEPRESSUM sp.nov.}

This is a pretty species common among the eel-grass growing within the wharves of Yokohama, and specimens can easily be obtained at any hour of the day by towing in such situations by means of a weighted net. I have never seen the medusa on the surface of the water during the daytime. The Woods Hole species, for which Mayer has recently proposed the name of G. murbachii, is stated to come to the surface at night, and the towing for the medusa appears to be performed there only in the evening; but it is probable that the animal never quits the eel-grass entirely, since it is known that the grass grows rank in the eel-pond, where it is always hunted for. The Yokohama species has a rather shallow open umbrella, which may measure 20 millimetres by 8 millimetres or a little more. The smaller examples have the umbrella relatively deeper; one of 4 millimetres in diameter measures just as much in height. The jelly is only moderately thick. The swimming movements are vigorous, but only a few pulsations are made consecutively at a time, after which the animal slowly sinks with expanded umbrella and outstretched tentacles until it touches some object, when it attaches itself to it by means of the adhesive disks of the tentacles. The manubrium is quadrate with distinct lips, and hangs down close to the level of the umbrella margin. The radial canals are four, and the gonads are developed on their lower walls along nearly their entire lengths, leaving only a small proximal and an equally small distal portion free. In very young examples the gonads are simple thickenings of the wall of the radial canals, but in larger ones they are thrown into folds which are arranged alternately on either side of the canal. These folds remain, however, very simple, and, so far as I have observed, are never divided into lobes (Pl. II, Fig. 13).

The tentacles are numerous; in an example of 18 millimetres in diameter there were 59, and in another of 4 millimetres there were $32 ; 64$ was the largest number of the tentacles I have observed so far. They are very flexible, but are not as contractile as the velar tentacles of Olindioides; they are armed with incomplete ringlike warts, in which the nettle-cells are found. The most characteristic feature of the tentacles, however, is that they bear at some distance from the tip each an adhesive disk, by which the animal can securely attach itself to any external object. When the tentacles are expanded, these disks are nearly flat and elliptical, but in contracted tentacles they are more or less saucer-shaped, and are compressed along the length of the tentacle (Pl. II, Fig. 11; Pl. III, Fig. 21). They consist of tall 
cylindrical cells very similar to those of the adhesive disks of Olindioides, and the secretion can be observed almost at any time, forming rounded or elongated masses each corresponding to a mucus cell. The cells stain well with hæmatoxylin, but especially so near their free ends. These disks have been described as "sucking," but a study of their structure reveals nothing capable of exercising a pumping action. In all the known species of Gonionema these disks are situated on the inner side of the tentacles, and cause the characteristic angular bend, which has given rise to the generic name.

On a cursory observation, the tentacles appear to arise from the margin of the umbrella, but a closer inspection shows that they spring always from the exumbrella at a short distance from the margin, just as do the exumbrellar tentacles of Olindioides; and one can easily observe the endodermal tentacle roots traversing the jelly to join the circular canal. In Gonionema these roots are very short, and as a consequence the peronia do not come into view, although the ectoderm lying over these tentacle roots is slightly thickened.

On the inner side of the tentacles, close to the base of the velum, are the basal bulbs of the tentacles, exactly corresponding both in position and number to the former. These bulbs are exactly similar in structure to the rudimentary velar tentacles of Olindioides, that is to say, they contain hollow prolongations of the endoderm of the circular canal, and the ectoderm is clogged with developing nettle-cells. In Gonionema these bulbs never become elongated and filiform, but there is no doubt that they are the homologues of the velar tentacles of Olindioides.

The marginal organs are all otocysts, and are present two at the base of each tentacle. In structure they are also exactly like those of Olindioides; they are, however, generally smaller, a fully developed vesicle measuring only 75 micra in diameter. Again, the majority remain close to the marginal ectoderm containing the outer nerve-ring, and retain a cellular connection with it; but some of the oldest otocysts are pushed far into the jelly, and the cellular connection with the ectoderm disappears. They remain, however, more or less closely appressed to the endoderm of the circular canal (Pl. III, Fig. 22). The otolith, when fully formed, shows a radial arrangement of its constituent pyramids.

The endodermal lamella remains one-layered throughout life, and joins the circular and radial canals along the line that divides the two kinds of cells as in Olindioides. It is separated from the subumbrellar ectoderm by a thin layer of jelly.

The coloration of the medusa is as follows: radial canals, basal bulbs, and the adhesive disks of the tentacles a transparent chestnut-brown; tentacles, gonads, the larger part of the manubrium, and the circular canal a lighter brown, marginal 
14 THE CRASPEDOTE MEDUSA OLINDIAS AND SOME OF ITS NATURAL ALLIES.

area of the manubrium pale green. At the very base of each tentacle there is a speck of shining emerald-green, of the same color as the green portion of the exumbrellar tentacles of Olindioides. These are not eyes.

The musculature is well developed, but less so than in Olindioides, and the muscular lamellæ are confined to the subumbrella. There is, however, a strong muscular ring exactly in the same position as in Olindioides, namely, near the base of the velum, just internal to the inner nerve-ring. Here the mesoglœea, or, as it may be called, the supporting lamella, is thrown into extensive irregular folds, on either surface of which the muscular fibres are closely arranged in a row.

\section{REMARKS ON OLINDIAS MÜLLERI HAECKEL.}

There are some points in Haeckel's description of this medusa that require comment. The following remarks are based on an examination of an excellently preserved museum specimen of about 50 millimetres in diameter from Naples, that has been in the possession of this school for several years, and of a few examples that have recently been obtained from the Naples Zoölogical Station, fixed according to my directions. The latter material is, so far as I have examined, in a rather unsatisfactory condition histologically, due, as I believe, to histolysis having set in before fixing. But so far as the general structure is concerned, these specimens can be safely depended on, the more so as there is the perfect specimen as a control.

The general form of the medusa is very well represented in Haeckel's figure, but the filiform velar tentacles (Fangfäden) are too numerous. In the perfect specimen above referred to there were only some 35 , irregularly distributed along the entire margin, and these are of very unequal length and thickness. There can also be observed various stages in their development from the bulbular to the filiform condition, the bulbular forms being about four or five times as numerous as the filiform ones. Haeckel ('79) also speaks of numerous ocelli situated between the velar tentacles, which, according to him, appear to contain a biconvex lens. These socalled ocelli are nothing but the bases of the exumbrellar or of the filiform velar tentacles, which contain a red pigment in the endoderm, and the supposed biconvex lens is simply the axial cavity of the tentacle viewed in optical section.

The exumbrellar tentacles are armed with incompletely ring-shaped or horseshoe-shaped nettle-warts, and are provided each with an adhesive patch of mucous

cells at the tip. The patch extends on the inner side more than on the outer. The endodermal roots of the tentacles are not very long, but are quite conspicuous. 
In the fully developed condition the gonads consist of numerous lobes, each of which looks somewhat acinous, but a closer examination shows that these lobes are continuous with each other; and a comparison with the lobed condition of the gonads of Olindioides already described leaves no doubt that each gonad of Olindias must have been formed as a single continuous thickening of the subumbrellar wall of a radial canal and became lobed only secondarily. An examination of Haeckel's figure ('79, Pl. XV, Fig. 10) of a young example of about 8 millimetres in diameter bears out this view.

As to the habitat of Olindias mülleri, I have not been able to ascertain it. Haeckel ('79, p. 253) says that it appears to be rather rare, or perhaps to be confined to certain localities, and I am informed by the authorities of the Naples Station that it occurs especially in the months of October and November and then disappears. Considering that the exumbrellar tentacles are provided with adhesive disks, and judging from analogy, it is very probable that Olindias mülleri is a bottom species like Olindioides; and its comparative rareness must at least in part be attributed to this peculiar habit. It appears, however, that the medusa can be obtained without difficulty at the Naples Station in the proper season. The material lately sent me appears to have been collected late in August or very early in September.

\section{NATURAL RELATIONSHIPS OF THE DESCRIBED SPECIES.}

On looking through the published descriptions of the veiled medusæ it will at once be evident to any one that the genera Olindias, Halicalyx, and Gonionema, and the new genus Olindioides must be put together into a natural group, for which we may adopt the name Olindiadæ used by Haeckel. The common characters are very simple and clear: jelly tolerably consistent, radial canals four or six, manubrium well developed and quadrate, with distinct lips, velum well developed, gonads originally a continuous fold of the subumbrellar wall of the radial canals, which may secondarily become lobed, with two sets of tentacles, the velar and the exumbrellar, with an adhesive disk somewhere on each exumbrellar tentacle, at the base of which there is a pair of otocysts. The exumbrellar tentacles are provided with endodermal roots, which more or less traverse the jelly to join the circular canal. Bottom species or living among seaweeds.

The genus Halicalyx, with one species, H. tenuis, was originally described by Fewkes ('82) and recently redescribed by Mayer (:00), who says that it is closely allied to his genus Gonionemoides, but that it differs by the absence of "suctorial" disks on 


\section{THE CRASPEDOTE MEDUSA OLINDIAS AND SOME OF ITS NATURAL ALLIES.}

any of the tentacles. I may, however, be allowed to suggest that the exumbrellar tentacles (stiff tentacles standing out sharply at right angles to the bell and sprinkled over with wart-like protuberances of a deep purple color) will probably be found on a closer examination to be provided with an adhesive disk near the tip. The mucous glands in similar positions of Olindias have been overlooked.

Haeckel says that he at first placed Olindias in the Æquoridæ, but that the structure of the marginal vesicles shows it to belong to the Trachomedusæ. Mayer ('99) also regards Gonionema as a trachomedusan; but Murbach ('95), who has studied its development, says that there is true alternation of generations, the larva passing through a hydrula stage. Haeckel places Gonionema in his leptomedusan family Cannotidæ, which is characterized by the absence of marginal vesicles, the possession of four- or six-branched, forked or pinnatifid radial canals, in the course of which the gonads lie. On the systematic position of Halicalyx neither Fewkes nor Mayer says anything.

It is evident from a perusal of their works that Haeckel and Mayer have been led to regard Olindias and Gonionema as belonging to the Trachomedusæ by the structure of the otocysts, and the only peculiarity of these organs that could have impressed them appears to me to be that the otolith is provided with a stalk, by means of which it is attached to the wall of the vesicle. But the presence of a stalk taken by itself seems to me to be of no systematic importance, since, in all the Leptomedusæ thus far described or observed by me, the otoliths are attached to the wall of the vesicle, and it is simply a question of the comparative length of the intervening portion that determines the presence or absence of the stalk. Further, if one compares the stalk of the vesicle of any of the medusæ above mentioned with that of such undoubted Trachomedusæ as Glossocodon or Liriope, there are some differences, which, taken in conjunction with the observations on the development of the otocyst, point to a fundamental difference between the two. The otolithic stalk in Glossocodon and Liriope is very distinctly set off both from the protoplasmic mass surrounding the otolith and the wall of the vesicle; but in all the genera of Olindiadæe the stalk passes on gradually into the periotolithic mass on the one hand and the vesicle wall on the other. We have also seen that in Olindioides the endoderm takes no part in the formation of the otocyst.

Among the differences set up by the Hertwigs ('78) for the two types of otocysts, one characteristic of the Trachylinæ and the other of the Leptolinæ, is one of innervation. According to the observations of the two brothers, the otocyst is innervated in the former group by the upper (outer) nerve-ring, and in the latter by the lower (inner). In Olindioides and Gonionema the otocysts appear to be supplied from 
the outer nerve-ring; but this coincidence with a character of the Trachylinæ must be due to convergence, and the difference of innervation must not be regarded as absolute for the two types of otocysts. In Olindioides, moreover, the two nerverings are seen in several places to be directly continued one with the other through breaks in the mesoglœa separating the two.

The presence of centripetal canals is another point of resemblance between Olindiadæ and some Trachomedusæ; but it is evidently of no systematic moment, since these canals may be present or absent in closely related genera.

I have spoken of the marginal nettle-ring; but it must be borne in mind that it is unlike the nettle-ring of the genuine Trachomedusæ. For, while in the latter the ring is a very distinct structure continuous throughout, in the Olindiadæ it is brought about merely by the close proximity of the velar tentacles, and in such a form as Gonionema, where the intervening spaces are wider, the ring tends to become more or less discontinuous, and in some sections through such a space the nettle-cells are totally absent. We must also remember that in some Leptolinæ there is a well-developed nettle-ring, as in Laodice (Brooks, '95).

The presence of endodermal tentacle roots in the Olindiadæ is another feature of resemblance to the Trachomedusæ, but we must also remember that these structures may be present in forms which undoubtedly belong to the Leptolinæ (Brooks, '95).

The unsatisfactoriness of Haeckel's system of the medusæ has been pointed out by Brooks ('86, '95), but accepting it we must place the subfamily Olindiadæ in the Leptodmedusæ. It is impossible to put it under the Cannotidæ, to which Gonionema is referred by Haeckel. It appears, to me that it comes with least violence under the Eucopidæ, where our medusæ may find their temporary resting-place.

The genus Gonionemoides formed by Mayer $(: 00)$ is evidently nearly related to our genera, but less so than these are among themselves, and it will perhaps be found advisable to place it in a distinct subfamily.

The fresh-water medusæ Limnocodium and Limnocnida have not found a satisfactory place in the system. Allman ('80) and Fowlel' ('90) think that Limnocodium should be placed in the Leptolinæ, while Lankester ('80) and Günther ('94) bring it under the Trachylinæ, in which the latter also places his genus Limnocnida from Lake Tanganyica. It appears to me that these genera present some features which point to their affinity to the Olindiadæ, near which they can, in my opinion, be placed most naturally. But as I am not able to examine any material of these medusæ, I shall confine myself to some critical remarks on the statements of previous authors concerning points of fundamental importance. 


\section{THE CRASPEDOTE MEDUSA OLINDIAS AND SOME OF ITS NATURAL ALLIES.}

The point of greatest importance in determining the position of these medusæ is of course, in the absence of a definite knowledge of the life history, the origin of the otolithic cells, which, according to Lankester ('80) and Güther ('94, '94a), are produced from the endoderm of the circular canal. Lankester made his observations on the marginal vesicles exclusively by means of optical sections, and it is no discredit to the author to say that none of his figures touching the point in question can be considered as decisive. Günther ('94), on the other hand, carried on his observations on actual sections prepared from materials killed with osmic acid, and by means of the best optical appliances, and he reproduces several figures intended to show the endodermal origin of the otolithic cells. It must, however, be remarked that the figure (Fig. 1) he gives us of the earliest stage that came under his observation in the development of the otocyst represents a somewhat advanced stage, when its constituent parts have all been formed, and these parts have only to enlarge, multiply, and undergo a little differentiation to arrive at the definitive condition; and it is exceedingly improbable that any additional endoderm cell should at this stage wander out to reinforce their precursors, even if these were derived from that source (compare Figures 17 and 18 in the present paper). The absence of the intervening mesogloea must not be taken by itself as a proof of the morphological continuity of the two cell layers, and it is necessary to exercise constantly self-criticism not to be misled into taking appearance for reality. The question of morphological continuity or discontinuity in such a case comes very near to splitting a hair, and it is only by the closest scrutiny that one can draw a safe conclusion.

It may be added in passing that the structure of the otolith which Lankester and Günther regard as unique represents only a developmental stage in other forms, and it is possible that these authors have observed only comparatively young otocysts, and that in older ones the otolith loses its cellular structure. Should the ectodermal origin of the otolithic cells be granted, the structure of the marginal vesicles of Limnocodium and Limnocnida is exactly like that of the same organs of the Olindiadx, except for the peculiar prolongations into the velum of the vesicles in the first-named genus.

The presence of tentacle roots, though of secondary importance, is another feature common to the Olindiadx and the two fresh-water genera.

The young stages of Limnocodium described by Lankester ('80, '81) are supposed by him to have developed from the egg-cell, although he did not observe any mature females, but only males. On examining them, however, one is struck with some features in their anatomy that point strongly to their origin as medusa buds either from a hydroid stock or, more probably in this case, from young female medusæ. 
THE CRASPEDOTE MEDUSA OLINDIAS AND SOME OF ITS NATURAL ALLIES. 19 the presence of a closed subumbrellar cavity, a manubrium, and the radial canals at a stage corresponding in other respects to that of the Trachomedusæ, in which there is as yet none of these parts, is a point that seriously interferes with the supposition that the young medusæ studied by Lankester were derived from the egg-cell (Brooks, '86). Some leptoline medusæ proliferate by budding when young, and produce ova when older.

As to the hydroid described by Parsons, Bourne, and Fowler, it is not known for certain whether it is a member in the life-history of Limnocodium, although this supposition must be allowed to be very probable. Some light will perhaps be thrown on this point by the French naturalists who have recently observed the medusa in a lily tank in the Zoological Garden of Lyon (Vaney et Conte, :01), or by the collection from Mr. Moore's expedition to Lake Tanganyica.

Any one who is acquainted with the Narcomedusx, and especially with their marginal sense-organs, will hardly agree with the proposal of Günther to place Limnocnida, even provisionally, in that group.

In conclusion I shall add a synopsis of the Olindiadx, which will bring forth their distinctive characters and their natural relationships more clearly, though necessarily in a schematic way.

Subfamily: Olindiadæ.-Eucopidæ with two sets of tentacles, velar and exumbrellar, the former springing close to the base of the velum, and the latter at variable distances from it, but always from the exumbrella and connected with the circular canal by endodermal roots. Marginal vesicles numerous, two on either side of the base of the exumbrellar tentacle. Manubrium well developed and quadrate, with distinct lips. Radial canals four or six. Gonads primarily continuous folds of the walls of the radial canals. With an adhesive disk on each exumbrellar tentacle.

SYNOPSIS OF THE GENERA.

1. Velar tentacles just as numerous as the exumbrellar.............

2. Velar tentacles more numerous than the exumbrellar.......... 5, 6 .

3. Velar tentacles all rudimentary, in the form of basal bulbs.... Gonionema.

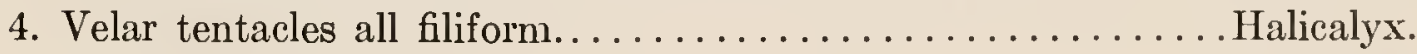

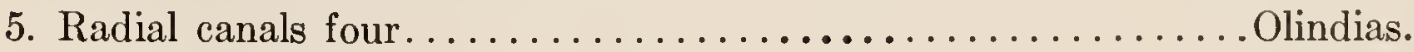

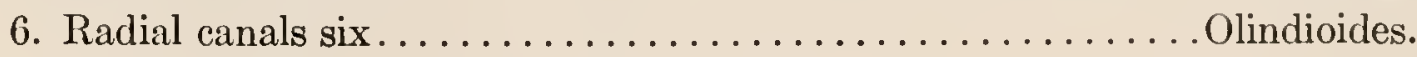

Gonionema (= Gonionemus) A. Agassiz.

Agassiz, '62, p. 350. Haeckel, '79, p. 146. 
20 THE CRASPEDOTE MEDUSA OLINDIAS AND SOME OF ITS NATURAL ALLIES.

G. vertens A. Agassiz.

Agassiz, '62, p. 350. Haeckel, '79, p. 147.

G. murbachii A. G. Mayer.

Murbach, '95. Mayer, :01, p. 5. Morgan, '99.

G. suvaënsis A. G. Mayer, '99, p. 164.

G. aphrodite A. G. Mayer, '94, p. 237; :00, p. 62.

The last two species belong in my opinion to Gonionemoides, since they posesss only four otocysts in each quadrant.

Halicalyx J. W. Fewkes.

Fewkes, '82, p. 277. Mayer, :00, p. 63.

H. tenuis J. W. Fewkes.

Fewkes, '82, p. 277. Mayer, :00, p. 63.

Olindias F. Müller.

Müller, '61, p. 312. Haeckel, '79, p. 252.

O. sambaquiensis F. Müller.

Müller, '61, p. 312. Haeckel, '79, p. 254.

O. mulleri E. Haeckel.

Haeckel, '79, p. 253.

Olindioides S. Goto.

O. formosa S. Goto.

\section{BIBLIOGRAPHY.}

Agassiz, A.

'62. [Description of Gonionemus vertens.] In Contributions to the Natural History of the United States of America by Louis Agassiz, vol. 4, p. 350 .

Agassiz, A., and Mayer, A. G.

'99. Acalephs from the Fiji Islands. Bull. Mus. Comp. Zoöl. Harvard Coll., vol. 32, no. 9, pp. 157-189, pls. 1-17.

Allman, G. J.

'80. On "Limnocodium victoria," a Hydroid Medusa of Fresh Water. Nature, vol. 22, pp. 178-179.

Brooks, W. K.

'86. The Life-History of the Hydromedusæ: A Discussion of the Origin of the Medusæ, and of the Significance of Metagenesis. Mem. Boston Soc. Nat. Hist., vol. 3, no. 12, pp. 359-430.

Brooks, W. K.

'95. The Sensory Clubs or Cordyli of Laodice. Jour. Morph., vol. 10, no. 1, pp. 287-304, pl. 17.

Fewkes, J. W.

'82. Notes on Acalephs from the Tortugas, with a Description of New Genera and Species. Bull. Mus.

Comp. Zoöl. Harvard Coll., vol. 9, no. 7, pp. 251-289, pls. 1-7. 


\section{THE CRASPEDOTE MEDUSA OLINDIAS AND SOME OF ITS NATURAL ALLIES: 21}

\section{Fischer, A.}

'99. Fixirung, Fārbung und Bau des Protoplasmas. Jena, $8^{\circ}, \mathrm{x}+362 \mathrm{pp}$.

Fowler, G. H.

'90. Notes on the Hydroid Phase of Limnocodium Sowcrbyi. Quart. Jour. Micr. Sci., vol. 30, no. 120, pp. $507-514$, pl. 32.

Glinther, R. T.

'94. Some Further Contributions to our Knowledge of the Minute Anatomy of Limnoeodium. Quart. Jour. Micr. Sci., vol. 35, no. 140, pp. 539-550, pl. 40.

Ginther, R. T.

'94:. A Further Contribution to the Anatomy of Limnocnida tanganyica. Quart. Jour. Micr. Sci., vol. 36, no. 142 , pp. 271-293, pls. 18-19.

Haeckel, E.

'79. Das System der Medusen. Erster Theil einer Monographic der Mcduscn. Denkschr. med.-naturw. Gesell. Jena, Bd. 1, Abt. 1, pp. 1-360, Taf. 1-40.

Hertwig, O., und Hertwig, R.

'78. Das Nervensystem und die Sinnesorgane der Meduscn monographisch dargestellt. Leipzig, 4, 186 pp., 10 Taf.

Lankester, E. R.

'80. On Limnocodium (Craspedacustes) Sowerbii, a new Trachomedusa inhabiting Fresh Watcr. Quart. Jour. Micr. Sci., vol. 20, no. 79, pp. 351-371, pls. 30-31.

Lankester, E. R.

'81. On Young Stages of Limnocodium،and Geryonia. Quart. Jour. Micr. Sci.; vol. 21, no. 82, pp. 194-221, pl. 13.

Mayer, A. G.

'94. An Account of some Medusæ obtained in the Bahamas. Bull. Mus. Comp. Zoöl. Harvard Coll., vol. 25 , no. 11 , pp. 235-242, pls. 1-3.

Mayer, A. G.

:00. Some Medusæ from the Tortugas, Florida. Bull. Mus. Comp. Zoöl. Harvard Coll., vol. 37, no. 2, pp. 13-82, pls. 1-44

Mayer, A. G.

:01. The Variations of a newly-arisen Species of Medusa. Sci. Bull. Mus. Brooklyn Inst. Arts and Sci., vol. 1, no. 1, pp. 1-27, pls. 1-2.

Morgan, T. H.

'99. Regencration in the Hydromcdusa, Gonionemus vertens. Amer. Nat., vol. 33, no. 396, pp. 939-951.

Mulller, F.

'61. Polypen und Quallen von Santa Catharina. Arch. f. Naturg., Jahrg. 27, Bd. 1, pp. 312-319, Taf. 9. (Not accessible to the writcr.)

Murbach, L.

'95. Preliminary Notc on the Lifc-History of Gonionemus. Jour. Morph., vol. 11, no. 2, pp. 493-496.

Saccardo. P. A.

'94. Chromotaxia seu nomenclator colorum polyglottus, additis speciminibus coloratis ad usum botanicorum et zoologorum. Patavii, $8^{\circ}, 22$ pp., 2 tav.

Vaney, C., et Conte, A.

:01. Sur lc Limnocodium Sowerbii Ray Lankester. Zool. Anz., Bd. 24, No. 651, pp. 533-534. 


\title{
EXPLANATION OF PLATES I-III.
}

\author{
ABBREVIATIONS.
}

can. crc. Cireular eanal.

ec'drm. Eetoderm.

$c n^{\prime} d r m$. Endoderm.

gl. muc. Adhesive mucous gland.

go.

Gonads.

\author{
ot'cys'. \\ $r x$. ta. Endodermal tentacle roots. \\ ta. ex'ubr. Exumbrellar tentacle. \\ ta. vel. Velar tentacle.
}

\section{PLATE I.}

Olindioides Formosa.

Fig. 1. Adult medusa in natural colors; diameter $55 \mathrm{~mm}$.

Fig. 2. Young medusa in natural colors; diameter $15 \mathrm{~mm}$. at mouth of umbrella.

Fig. 3. Portion of umbrella margin; diameter of umbrella $30 \mathrm{~mm}$. Exumbrellar view; $\times 27$ diameters.

Fig. 4. Portion of umbrella margin; diameter of umbrella about $100 \mathrm{~mm}$. Exumbrellar view; $\times 13$ diameters.

Fig. 5. One sextant with manubrium; diameter of umbrella $15 \mathrm{~mm}$. Subumbrcllar view.

Fig. 6. One sextant with manubrium; diameter of umbrella $75 \mathrm{~mm}$. Subumbrellar view.

Fig. 7. Apical view of radial canals; diameter of umbrella $10 \mathrm{~mm}$.

Fig. 8. Apieal view of radial canals; diameter of umbrella $15 \mathrm{~mm}$.

Fig. 9. Portion of gonad, showing three lobes which are subdivided into lobules; diameter of umbrella $90 \mathrm{~mm}$.

\section{PLATE II.}

\section{Gonionema DEPRESSUM.}

Fig. 10. Adult medusa in natural colors; diameter $18 \mathrm{~mm}$.

Fig. 11. Portion of tentacle, showing the adhesive gland disk. $\times 54$ diameters.

Fig. 12. Portion of umbrella margin including a radial canal; diameter of umbrella $18 \mathrm{~mm}$. $\times 13$ diametcrs.

Fig. 13. Radial canal with gonad and manubrium; nearly adult.

\section{OLINDIOIDES FORMOSA.}

Fig. 14. Terminal portion of a longitudinal section of tentacle, showing the adhesive glandular patch; diameter of umbrella $60 \mathrm{~mm}$. $\times 54$ diameters.

Fig. 15. Portion of a radial seetion of umbrella margin, showing the first traces of otoeyst; diameter of umbrella $10 \mathrm{~mm}$. $\times 570$ diameters.

Fig. 16. Portion of a radial section of umbrella margin; diameter of umbrella $10 \mathrm{~mm}$. $\times 420$ diameters.

\section{PLATE III.}

OLINDIOIDES FORMOSA.

Fig. 17. Portion of a horizontal section of umbrella margin; diameter of umbrella $10 \mathrm{~mm} . \quad \times 420$ diameters. On one side of the tentaele root the otocyst is just cut tangentially.

Fig. 18. Portion of a radial section of umbrella margin. $\times 420$ diametcrs.

Fig. 19. Otoeyst in a later stage of development. $\times 420$ diameters.

Fig. 20. Portion of adhesive glandular pateh; diameter of umbrella $10 \mathrm{~mm} . \quad \times 730$ diameters. The mucus is seen as exudations at the free ends of the cells.

\section{Gonionema DePressum.}

Fig. 21. Portion of a longitudinal seetion of tentaele, showing the adhesive disk. $\times 240$ diameters.

Fig. 22. Otoeyst fully developed; diameter of umbrella $18 \mathrm{~mm} . \times 420$ diameters. 


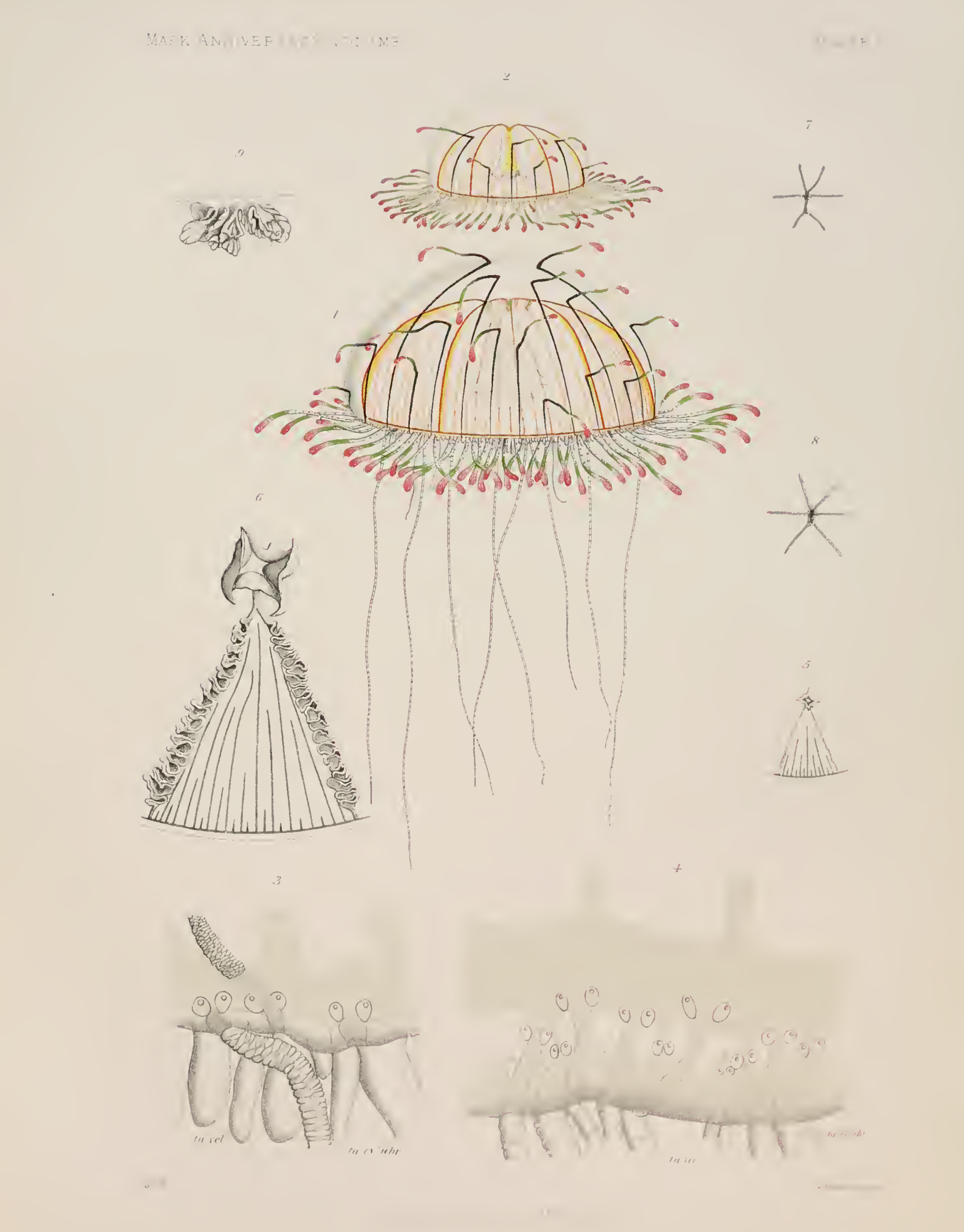




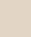



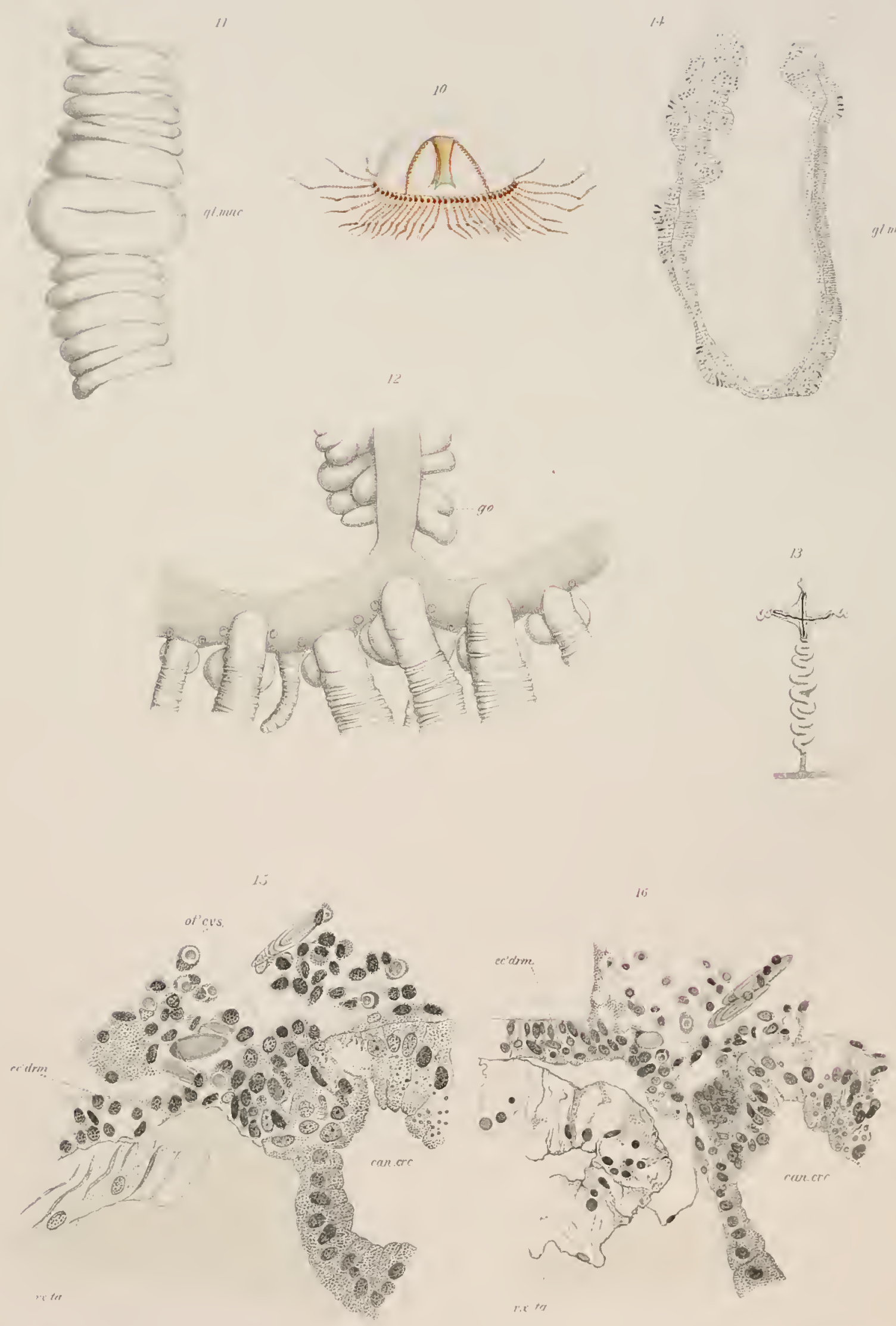

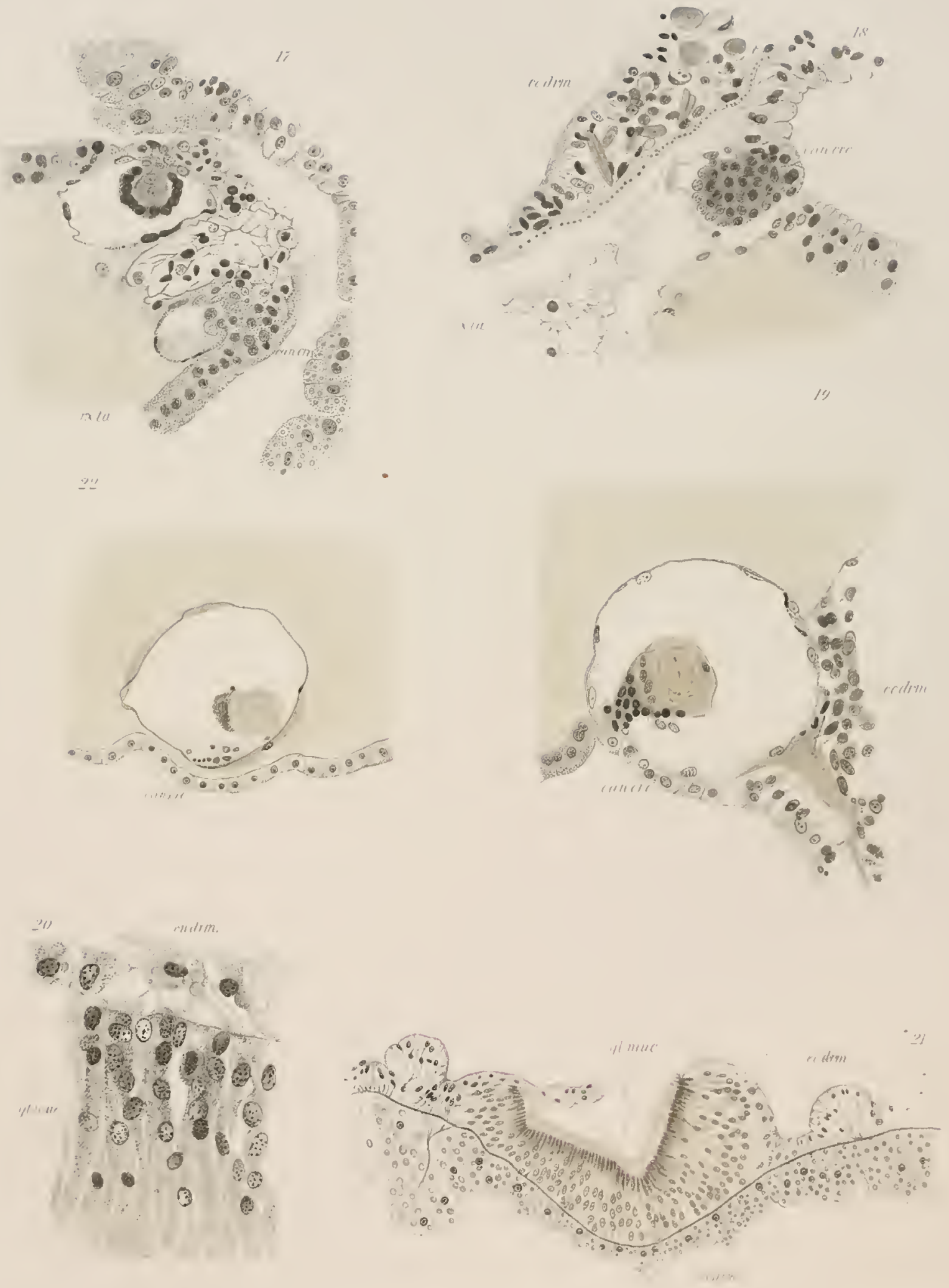

II.

DESCRIPTIONS OF FOUR DISTOMES.

(PLATE IV.)

Henry S. Pratt. 


\section{RENIFER gen. nov.}

The first three worms described in this paper, of which two are new to science, are all very closely related to one another and were found in similar localities, the mouth and air-passages of common North American snakes. They are also so closely allied to a worm recently described by Looss ('99, p. 708) under the name of Styphlodera solitaria, which was found by him in the intestine of Thalassochelys corticata, a sea-turtle, and to one recently described by Volz ('99, p. 231) from the lung of Heterodon platyrhinus and named by him Distomum zschokkei, that no doubt exists in my mind that all five species should be included in the same genus. This genus cannot well be Styphlodera, for reasons I shall give later on, and I have, therefore, created a new genus to contain them. The new genus may be given the following characterization.

Renifer gen. nov.-Small distomes with body more or less elliptical and covered with minute spines or scales. Mouth subterminal; acetabulum somewhat larger than oral sucker and in anterior half of body. Pharynx present; œsophagus short or wanting; intestinal cxca reach about to the middle of the body or a little past it. Excretory vesicle very large, Y-shaped, extending into the forward end of the body. Genital pore in front of the acetabulum of ten to the left or the right of the median line. Testes two, usually lobate, in the same transverse plane near the middle of the body; cirrus-sac often long, containing a vesicula seminalis which bends on itself. Ovary just posterior to the acetabulum and in front of the testes; yolk-glands lateral in position and occupying the middle third of the body; Laurer's canal present; uterus composed of a descending and an ascending limb, and extending to the hinder end of the body; receptaculum seminis absent or minute. Parasitic in the mouth or air-passages of snakes and in the intestines of turtles.

Type: Renifer ellipticus Pratt. Additional species: R. elongatus Pratt, R. variabilis (Leidy) Lühe, R. solitarius Looss, R. zschokkei Volz.

\section{RENIFER ELLIPTICUS sp. nov.}

This worm (Pl. IV, Fig. 1) was found in the mouth of Heterodon platyrhinus, a common non-poisonous suake. It is a small worm, elongated in form and elliptical in outline; its dorsal surface is cylindrical, its ventral surface flat, the cross-section 
forming thus a semicircle. The body of the worm is widest at about its middle, from which region it tapers towards both ends. These are rounded and blunt, the posterior end being, however, less so than the anterior end. The length of the worm varies from 3 millimetres to 4.2 millimetres, its breadth from 1.1 millimetres to 1.6 millimetres, its greatest thickness 0.8 millimetre. The entire body is thickly covered with minute scales, set in transverse rows, except towards the hinder end, where their arrangement is irregular. The suckers are of good size and are sessile. The oral sucker is subterminal, with a diameter of 0.35 millimetre. The acetabulum is situated almost in the centre of the body, but somewhat nearer the anterior than the posterior end and is 0.73 millimetre from the oral sucker in a small worm. It is larger than the oral sucker, measuring 0.41 millimetre in diameter. The genital pore is about half-way between the two suckers, although slightly nearer the anterior one, and is very near the left edge of the body, being 0.07 millimetre from that edge, and in the ventral surface. The excretory pore is at the posterior end of the body.

The digestive tract is made up of pharynx, œsophagus, and intestinal cæca. The pharynx has a length of 0.10 millimetre and the cesophagus is of moderate length and measures 0.24 millimetre; both are surrounded by gland-cells. The intestinal cæca are simple tubes without lateral branches; their width is about 0.2 millimetre. They extend about to the middle of the body, reaching the middle or posterior portions of the testes, and being somewhat longer in the larger specimens than in the smaller ones.

The excretory vesicle is unusually long and voluminous. It is a $\mathrm{Y}$-shaped tube with such delicate walls that it can be traced only in sections. The median portion is very long and wide. It extends forward as far as the ovary, lying dorsal to the uterus and between the testes. Its width in the posterior portion of the body behind the testes is about 0.5 millimetre, and it here occupies a quarter or more of the space within the body walls. The excretory crura are also wide and extend forward, one on each side of the acetabulum, to a position a little in front of the yolkglands. Their width is about 0.17 millimetre.

The testes are two slightly lobate bodies situated side by side near the centre of the body. They measure about 0.3 millimetre in length and width and 0.4 millimetre in thickness. The right testis is a trifle in advance of the left one. The vasa efferentia pass forward to a position just dorsal to the anterior edge of the acetabulum, where they unite to form the vesicula seminalis. This organ, together with the prostate gland and the cirrus, is enclosed in a large cirrus-sac, which measures 0.8 millimetre in length and 0.19 millimetre in width, and passes diagonally across the body to the genital pore at the left. The vesicula seminalis bends on itself in the posterior 
portion of the cirrus-sac and is continued in a short pars prostatica. The cirrus which follows is a large organ, about 0.4 millimetre in length, and occupies more than half of the cirrus-sac.

The ovary (Pl. IV, Fig. 3 ) is an ovoid body about 0.26 millimetre in length and lies partly behind and partly dorsal to the acetabulum and a little to the right of this organ. It is immediately beneath the dorsal body-wall. The oviduct is a short canal which leaves the left side of the ovary and passes to the oötyp; it is entirely surrounded by the shell-gland. A receptaculum seminis is wanting. Laurer's canal, which is present in the form of a delicate tube, passes from the oötyp near the median line first to the right towards the ovary, then dorsally and posteriorly to the external opening, which is to the right of the median line. The yolk-glands consist of about forty rounded or elongated bodies on each side. They lie just beneath the ventral body-wall and immediately ventral to the intestinal cæca and extend from the posterior end of the testes forward a short distance anterior to the acetabulum. They are thus lateral in position and occupy about the middle third of the body. Five or six ducts arise from each yolk-gland at different regions and proceed dorsally to a common point, where they unite to form the transverse yolk-duct. These two vessels, which are dorsal in position, meet in the midst of the shell-gland in the median line, and form a very short median yolk-duct which joins the oötyp. The shell-gland is a rather extensive group of glandular cells that lie against the dorsal body-wall to the left of the ovary with which they are in contact. It encloses the oviduct, Laurer's canal, the transverse and median yolk-ducts, and the beginning of the uterus. This last-named organ is not very voluminous and consists of a descending and an ascending limb. The former passes posteriorly with a serpentine course to within a short distance of the hinder end of the body; the latter passes in a similar way to a point dorsal to the acetabulum and near the posterior end of the cirrus-sac. From this point it passes diagonally alongside the cirrussac to the genital pore on the left side of the body. The diameter of the two limbs is the same in young worms, but in the older and larger ones the ascending limb is much the larger and may become a third as wide as the body itself posterior to the testes. It is filled with a dense mass of dark-colored eggs. The egg measures 0.03 millimetre by 0.019 millimetre. A metraterm is not developed.

The following is a specific diagnosis of Renifer ellipticus: Small, elliptical, semicylindrical worms averaging 4 millimetres in length and 1.4 millimetres in breadth. Oral sucker subterminal, 0.35 millimetre in diameter; acetabulum 0.41 millimetre in diameter, sessile, about 0.73 millimetre from the oral sucker. Body covered with minute scales. Pharynx and œsophagus of moderate size; intestinal cæca extend 
DESCRIPTIONS OF FOUR DISTOMES.

to the middle of the body. Excretory vesicle very long and voluminous, Y-shaped, with a long median portion and long crura. Testes two, side by side, in the middle of the body, behind the acetabulum and the ovary. Ovary immediately behind the acetabulum; yolk-glands lateral, occupying the middle third of the body. Cirrus-sac large, lying diagonally across the body from the acetabulum to the genital pore at the left edge of the body. Egg measure 0.03 millimetre by 0.019 millimetre. Parasitic in the mouth of Heterodon platyrhinus.

This worm shows a remarkable resemblance to R. zschokkei Volz ('99), a worm found in the lung of a specimen of Heterodon platyrhinus which died in a private terrarium in St. Gall, Switzerland. In size the two forms are alike. They are also almost identical as to their anatomy, but the Swiss form differs from the American in the following particulars: it is found in the lung instead of the mouth of the snake; it is without an œsophagus; the genital pore is at the right side of the body instead of the left; and the folds of the uterus in the hinder part of the body have a lateral direction, which is not the case in the American form.

\section{RENIFER ELONGATUS sp. nov.}

This worm (Pl. IV, Fig. 2) was found in the mouth of Heterodon platyrhinus together with the one just described. It is a smaller worm than R. ellipticus, and is relatively more slender; the suckers are relatively longer, the intestinal cæca are also longer, the yolk-glands are less voluminous, and the genital pore is near the median line instead of being near the edge of the body; in other respects, however, the worm is very similar to its neighbor. The length of Renifer elongatus is about 3 millimetres; the greatest breadth is at the beginning of the second third of the body, where the large acetabulum is situated, and is 0.68 millimetre. From this place the body tapers slightly towards the anterior end, to which the large oral sucker gives a rounded form. Towards the posterior end the body tapers to a blunt point. The body has a thickness in the region of the acetabulum of 0.4 millimetre. As is the case with $\mathrm{R}$. ellipticus, the worm is flat on the ventral side and cylindrical on the dorsal. The entire body is thickly covered with minute spines arranged in transverse rows, except towards the hinder end where the spines become less numerous and regular. The suckers are of large size and are sessile. The oral sucker is subterminal and has a length of 0.32 millimetre and a width of 0.33 millimetre. The opening is noticeably small, having a width of 0.06 millimetre. The acetabulum 
is situated about at the beginning of the second third of the body and has a length of 0.4 millimetre and a width of 0.36 millimetre. The genital pore is on the ventral surface near the posterior end of the pharynx, a little to the left of the median line. The excretory pore is at the posterior end of the body.

The digestive tract is made up of the pharynx, the oesophagus, and the intestinal cæca. The pharynx has a length of 0.06 millimetre. A very short œsophagus with a length of 0.02 millimetre follows. The intestinal cxca are simple tubes without lateral projections and have an average width of 0.04 millimetre. They are longer than in R. ellipticus, extending beyond the testes; the right cæcum is somewhat longer than the left one.

The excretory vesicle is very long and voluminous. It has the shape of the letter $\mathrm{Y}$, the median portion extending forward as far as the ovary, and the crura almost reach the branching of the digestive tract. The median portion is not only of great length, but also of great width and depth. Posteriorly to the testes it occupies at least half of the space within the body-wall. Near the ends of the intestine, for instance, it has a width of 0.41 millimetre and a depth (dorso-ventral) of 0.13 millimetre (Pl. IV, Fig. 4), while at the posterior end of the uterine loop it measures 0.20 millimetre by 0.05 millimetre. At the hinder end of the animal the excretory vesicle occupies practically the entire space within the body-walls. Between the testes this vesicle is contracted to a fraction of its width behind those organs, but immediately anterior to them it again expands so that it measures 0.41 millimetre by 0.2 millimetre, the body of the worm itself at this region having a width of 0.66 millimetre and a thickness of 0.29 millimetre. Just behind the ovary the excretory vesicle branches, and each branch has a width of about 0.13 millimetre and a depth of 0.2 millimetre. The branches gradually become smaller toward the anterior end of the animal, where they run alongside the cirrus-sac, to terminate a short distance in front of the acetabulum. Throughout its entire course the excretory vesicle is dorsal in position.

The testes are two elongate, slightly lobate bodies situated side by side near the centre of the body. The right testis is slightly in advance of the left one. They measure about 0.32 millimetre in length, 0.16 millimetre in width, and 0.24 millimetre in thickness, lacking but little of being as thick as the body itself. The vasa efferentia pass from their anterior ends forward to a position dorsal to the posterior edge of the acetabulum, where they unite to form the vesicula seminalis. This organ together with a long pars prostatica and a short cirrus is enclosed in the large cirrus-sac, the length of which is 0.7 millimetre and the width 0.16 millimetre. The vesicula seminalis bends on itself in the posterior portion of the cirrus-sac. The pars prostatica 
is an elongated organ that occupies three-fourths of the space within the cirrus-sac. The cirrus is short and weak.

The ovary is a small ovoid body 0.16 millimetre in length that lies partly behind the acetabulum and partly dorsal to it. It is just to the right of the median line and is dorsal in position. The oviduct is a short tube which proceeds towards the median line through the shell-gland to the oötyp. The shell-gland lies next to the left side of the ovary and in contact with the dorsal body-wall. It is about half the size of the ovary. The yolk-glands consist of about twenty-five glandular bodies on each side. They extend from the anterior end of the testes to the anterior end of the acetabulum. Their position in the body is ventral and between the intestinal cæca and the ventral body-wall. Three or four yolk-ducts leave the yolk-glands on each side and proceed to a common point posterior to the ovary in the dorsal portion of the body, where they meet to form the transverse yolk-ducts. These ducts meet in the median line and form a short median yolk-duct which proceeds to the oötyp. Laurer's canal arises in the oötyp and extends through the shellgland to the external pore a little to the right of the median line. The uterus consists of a descending and an ascending limb, both of which have a serpentine course. The descending limb proceeds from the oötyp between the testes to the hinder end of the body; the ascending limb, which is much the larger of the two, proceeds anteriorly along the median line, and on the left side of the cirrus-sac to the genital pore. The terminal portion of the uterus forms a metraterm. The egg measures 0.035 millimetre by 0.02 millimetre.

The following is a specific diagnosis of Renifer elongatus: Small, elongated semi-cylindrical worms whose length is 3 millimetres and breadth 0.68 millimetre. The oral sucker is subterminal and 0.33 millimetre in diameter. The acetabulum is sessile and 0.36 millimetre in diameter. Body covered with minute spines. The pharynx is of moderate size; the œsophagus is very small; the intestinal crea extend beyond the testes into the beginning of the posterior third of the body. The excretory vesicle is very long and voluminous, Y-shaped, and with a long median portion, and long crura. The testes are two, situated side by side, in the middle of the body, behind the acetabulum and the ovary. The ovary lies immediately behind the acetabulum. The yolk-glands are lateral, between the testes and anterior end of the acetabulum. A Laurer's canal is present, but a receptaculum seminis is wanting. The genital pore, nearly median, lies near the pharynx. The eggs measure 0.035 millimetre by 0.02 millimetre. Parasitic in the mouth of Heterodon platyrhinus. 


\section{RENIFER VARIABILIS (LEIDY) LÜHE.}

Three specimens of this worm were found in the lung of Tropidonotus sipedon, a common non-poisonous. snake. In 1856 Leidy ('56, p. 44) described very briefly two distomes which he named Distomum variabile, Variety $a$ and Variety $b$. His description was as follows:

"Var. a. Body white, variegated with black in the course of the oviduct, clavate, posteriorly obtuse, minutely echinated." "Oral and ventral acetabula nearly equal; the latter one prominent, situated at the base of the neck. Length to 6 lines; breadth of body $\frac{1}{2}$ a line." "Attached to the sides of the cavity of the lungs of Tropidonotus sipedon."

"Var. $b$. Body flattened, ovate, continuous with the head, anteriorly narrowed, posteriorly obtuse, color and echination as in the preceding variety. Length $2 \frac{1}{2}$ lines; breadth 2 lines." Found detached in the mucus of the lungs and trachea of Tropidonotus sipedon.

Variety $b$ has also been described, briefly and without figures, by Max Lühe (:00, p. 559), who obtained his specimens from the Museum für Naturkunde in Berlin. Lühe proposes to confine the specific name variabile to this worm and to consider Variety $a$ a distinct species.

Although the worm found by me differs in some slight degree from Distoma variabile as described by Lühe, I have no hesitation in ascribing it to that species. The following is a description of it. Renifer variabilis (Pl. IV, Fig. 5) is a broad, flat worm between 3 millimetres and 4 millimetres in length and between 1.50 millimetres and 2 millimetres in width; the average thickness is 0.5 millimetre, the dorsal and the ventral surfaces being approximately parallel. The greatest width is just posterior to the middle of the body, from which region it tapers towards the anterior end, while the hinder end is rounded and semicircular in outline. The entire body is thickly set with minute spines which are arranged anteriorly in rows and are more numerous there than posteriorly. Lühe found only the anterior portion of the worm examined by him to be covered with spines, but it is not imposșible that the spines had been present on the hinder portion, but had disappeared as a result of poor preservation, for the worm was an old museum specimen. The suckers are of good size and are sessile. The oral sucker is subterminal and has a diameter of 0.5 millimetre in a large specimen. The acetabulum is about 0.4 millimetre distant from the oral sucker and has a diameter of 0.6 millimetre in a large animal. The 
genital pore is about half-way between the two suckers and very nearly on the median line. The excretory pore is at the posterior end of the body.

The digestive tract consists of pharynx, œsophagus, and intestinal cæca. The pharynx has a length of about 0.2 millimetre. The œsophagus is very short. The intestinal cæca extend posteriorly to about the beginning of the posterior third of the body. In a large worm they extend to the posterior end of the testes; in the smaller one to the anterior end of those organs. They are not simple tubes, but they send out short lateral projections that are most numerous and longest toward their posterior ends.

The excretory vesicle is a long $\mathrm{Y}$-shaped structure, the diameter of which remains approximately the same, 0.08 millimetre, throughout its entire course. The median portion is very long, extending from the excretory pore forward to a point just behind the shell-gland and near the anterior end of the testes, between which it passes. The excretory crura are also long and extend forward to a point near the pharynx. The excretory vesicle is not a simple tube, but, like the intestinal cæca, it sends out short lateral projections which are especially noticeable towards its anterior ends.

The testes are two large, deeply lobate organs situated near the middle of the body, and in very nearly the same transverse plane. The length and width of a testis is about 0.8 millimetre, the thickness is very nearly that of the body itself. The narrow space between the two testes is occupied by the median limb of the excretory vesicle and the ascending and descending limbs of the uterus. The vasa efferentia pass forward to a point near the anterior margin of the acetabulum, where they join to form the vesicula seminalis. This is an organ of the considerable length of 0.6 millimetre. It bends on itself in the cirrus-sac, and from its anterior end a pars prostatica and a short cirrus extend to the genital pore. These organs are contained in a cirrus-sac 0.4 millimetre in length and 0.15 millimetre in width.

The ovary is an organ of irregularly ovoid form about 0.33 millimetre in length. It lies immediately behind and to the left of the acetabulum, its anterior portion lying dorsal to the ventral margin of that organ. The oviduct is a short, delicate tube which passes directly from the ovary to the centre of the shell-gland. A receptaculum seminis is wanting. The shell-gland is a little behind and to the right of the ovary and almost exactly in the median plane. Laurer's canal passes from the oötyp dorsally and to the right, where it meets the dorsal surface to the right of the median line. The yolk-glands consist of about forty rounded or elongated bodies on each side. They lie mostly lateral to the intestinal ceca, and extend from the anterior end of the testes to the level of the genital pore. In a small specimen they occurred 
posteriorly to about the posterior end of the intestinal cæca, as described by Lühe, but in a large worm, in which the cæca are relatively longer, they do not reach the posterior ends of those organs. Two or three yolk-ducts leave each yolk-gland and proceed towards the centre of the body. They join on each side to form a single duct, the transverse yolk-ducts, which meet and form a median yolk-duct. This duct, which proceeds posteriorly, is very short and widens at once to form a small yolk-reservoir 0.06 millimetre long and 0.03 millimetre wide, beyond which it immediately joins the oötyp.

The uterus leaves the oötyp near the centre of the body and proceeds towards its hinder end. This organ is very voluminous and forms a descending and an ascending limb, the former on the left and the latter on the right side of the body. These limbs are both thrown into transverse folds which, posterior to the testes, extend from the centre to the sides of the body. Anterior to the testes the folds do not extend laterally beyond the intestinal cæca. The broad hinder part of the body is entirely filled with these uterine folds. The ascending limb finally passes forward, dorsal of the acetabulum, to the genital pore. No specialized metraterm is present. The uterus is crowded with small dark-colored eggs, the average length of which is 0.034 millimetre, and the average width 0.018 millimetre.

The affinities of $R$. variabilis were indicated by Lühe (:01, p. 561), who called attention to the similarity of structure that exists between it and Styphlodora solitaria Ĺooss.

There seems to me little doubt that these two species belong to a common genus, but I would not ascribe them to the genus Styphlodora. The principal points of difference between them are the possession of a receptaculum seminis by S. solitaria, which is wanting in $R$. variabilis, and the shortness of the median limb of the excretory vesicle in S. solitaria, as compared with that of $R$. variabilis. As regards the first point of difference, the minute size of the receptaculum in $\mathrm{S}$. solitaria deprives it of importance. As regards the second, Looss ('99, p. 708) was unable from lack of material (he possessed but a single specimen) to determine the exact course of the excretory vesicle in S. solitaria, and he mentions the possibility that its median portion may be long instead of short or wanting, as he describes it. He says: "Es hat mir geschienen, als ob ausser diesen Schenkeln noch ein medianer Stamm nach vorn liefe, doch war wegen der Füllung des Hinterleibes mit den Schlingen des Uterus etwas Genaueres nicht zu erkennen."

Looss ('99, p. 592) also seems to express a doubt that S. solitaria belongs to the genus Styphlodora. He states that "Dieser Gattung scheint noch zuzuzählen zu sein St. solitaria." Its generic identity with S. serrata, the type-species of this genus, 
may well be questioned, as a study of the two species will show. If, however, its excretory vësicle proves to possess a long median stem, the essential identity of its characters, with those of Renifer variabilis, as well as with those of $\mathrm{R}$. ellipticus and $R$. elongatus, justifies the creation of this new genus to contain them.

The affinities of Renifer are with the genera Styphlodora and Astia as described by Looss ('99, pp. 592, 590), and forms a connecting link between them. With Astia it agrees in the great length of the median stem of the excretory vesicle and the extent and structure of the yolk-glands. It differs from it in the form and extent of the excretory crura, which are peculiarly formed in Astia and do not extend in front of the acetabulum, in the relative size of the acetabulum, which is smaller than the oral sucker in Astia, in the position of the cirrus-sac, the form of the vesicula seminalis, and the form and position of the testes. Renifer is similar to Styphlodora in the course and extent of the intestine, and in the general disposition of its organs. It differs from Styphlodora in the structure of the excretory vesicle, the position of the testes, the size of the yolk-glands, and the absence of a large receptaculum seminis.

\section{OSTIOLUM FORMOSUM gen. nov., sp. nov.}

Several specimens of this worm were given me some years ago labelled "from the frog." I do not know from what organ they were taken or from what species of frog. It is an elongated, graceful animal (PJ. IV, Fig. 6) between 7 millimetres and 10 millimetres in length, and about 1.5 millimetres in width in the widest region. The thickness averages 0.33 millimetre; the cross-section is elliptical. The outer surface is without spines or scales. The broadest portions of the worm are posterior to the middle. Towards the forward end the body tapers very gradually to the oral sucker; the hinder end is rounded and blunt. The oral sucker is nearly terminal, but slightly subterminal, and measures 0.3 millimetre in width in a large worm. The acetabulum is situated about 2.5 millimetres distant from the anterior end and is distinguished by its small size (Pl. IV, Fig. 8). It is only 0.07 millimetre in diameter, which is about a twelfth of the width of the worm in this region. It is besides very shallow and its musculature is so weak that it can hardly be a functionally active organ. It is much more likely that it is a rudimentary organ which is in process of retrogression; in fact until I sectioned the worm I supposed I was studying a monostomid.

The genital pore is near the anterior end on the ventral surface, a little to the 
left of the posterior end of the pharynx. The excretory pore is at the posterior end of the body.

The digestive tract is made up of pharynx and intestinal creca. The former is 0.19 millimetre in length and 0.13 millimetre in width. There is no œsophagus. The intestinal cæca are wide tubes, without lateral projections, which reach into the posterior extremity of the body. The average width of each is 0.16 millimetre.

The excretory vesicle is $\mathrm{Y}$-shaped, with a very long median portion and short crura. The former extends from the excretory pore forward to the region of the ovary and shell-gland. Its course lies close to the ventral body-wall as far as the posterior testis; it then winds between the testes, near the centre of the body, and passes to the left of the receptaculum seminis and ovary. The excretory crura extend forward, one on each side of the body, parallel and dorsal to the intestinal cæca. They terminate near the anterior ends of the yolk-glands. The diameter of the median portion is about 0.1 millimetre; that of the crus is about 0.07 millimetre.

The testes are two large, ovoid, but somewhat irregular organs situated near the middle of the body. Each testis measures about 1.14 millimetres in length and 0.8 millimetre in width. In thickness they measure about 0.32 millimetre and entirely fill the body of the worm between the dorsal and ventral body-walls. The testes are situated one diagonally behind the other, the anterior testis being on the right side of the body. The vas efferens from the anterior testis leaves its anterior border and passes forward between the receptaculum and the ovary, ventrally to the former and dorsally to the anterior end of the latter. The vas efferens from the posterior testis passes to the left of the anterior testis and of the receptaculum seminis, and meets its fellow near the anterior end of the ovary. The vas deferens, which is formed by their union, runs forward between the intestinal cæca to the genital pore, enclosed the entire distance in a cirrus-sac. The greater portion of the vas deferens functions as a vesicula seminalis. This organ is thus very long, and is still further increased in length by its serpentine course. It is also very broad, having an average width of 0.06 millimetre, and is constantly filled with spermatozoa. The anterior end of the vas deferens forms a short cirrus, which can be protruded from the body. The cirrus-sac is peculiar because of its great length, and also from the fact that it is almost entirely filled by the voluminous vesicula seminalis. The posterior portion of that organ, in fact, exactly fills the cirrus-sac; its anterior portion, however, has a slightly smaller diameter, and leaves a small space within the cirrus-sac.

The ovary (Pl. IV, Fig. 7) is an elongated body which lies in front of the receptaculum seminis and the testes and just behind the acetabulum. It has a length 
of 1 millimetre, a breadth of 0.4 millimetre, and a thickness of 0.28 millimetre. It lies transversely or diagonally across the body, with its posterior end on the right side. The oviduct is a short narrow canal 0.013 millimetre in diameter which leaves the ventral surface of the ovary near its anterior end and proceeds to the oötyp in the centre of the shell-gland. The receptaculum seminis is a large sac about the size of the ovary and is constantly filled with spermatozoa. It has also the shape of the ovary and lies immediately posterior to it. Its duct is a narrow tube, similar in size to the oviduct, which proceeds from the anterior surface and joins the oviduct. The shell-gland is an extensive group of glandular cells situated between the anterior ends of the ovary and the receptaculum seminis, and enveloping the proximal portion of the uterus and also portions of the oviduct and the median yolk-duct. Laurer's canal could not be found.

The yolk-glands are extensively developed and are situated at the sides of the body mostly lateral to the intestinal cæca. They consist of a number of distinct follicles on each side and are joined by a longitudinal duct. The number of these follicles varies from six to eleven on a side, and each follicle is made up of from five to ten rounded glandular bodies. Most of the follicles are between the intestinal cæca and the lateral edge of the body; the extreme posterior and anterior ones, however, may be situated in the centre of the body between the intestinal cæca. The anterior and posterior portions of the yolk-ducts on each side meet ventral to the receptaculum seminis and form thus the two transverse yolk-ducts. These ducts meet near the median plane and form the median yolk-duct. This duct in a large worm measures about 0.3 millimetre in length. It runs anteriorly to the oötyp. About midway in its course it expands to form a small yolk-reservoir, the diameter of which is 0.06 millimetre.

The uterus begins its course at the oötyp, and passes first towards the hinder end of the body. It proceeds, as a small and moderately straight tube, between the testes to the space behind those organs, which it entirely fills with its numerous irregularly transverse folds. It then runs forward, winding in transverse folds between the testes, filling the space between them and the receptaculum seminis, and passing to the genital pore near the anterior end of the body. The uterus is thus very voluminous. It is filled with small dark-colored eggs which measure 0.039 millimetre by 0.017 millimetre. No specialized metraterm is present.

The following is a specific diagnosis of Ostiolum formosum. Elongated, flattened worms. Length between 7 and 10 millimetres; breadth 1.5 millimetres; thickness 0.33 millimetre. No spines or scales are present. Oral sucker subterminal, 0.3 millimetre in width. Acetabulum sessile, minute, 0.07 millimetre in width. Pharynx of 
moderate length, œsophagus wanting; intestinal cxca extend nearly to the posterior end of the body. Excretory vesicle Y-shaped, with a very long median portion and short crura. Testes two, of large size, in the anterior portion of the posterior half of the body, one diagonally behind the other. Ovary immediately behind the acetabulum and in front of the testes; yolk-glands lateral, distributed in six to eleven follicles on a side, extending nearly the length of the body; receptaculum seminis present and very large; vesicula seminalis very long, enclosed in the cirrus-sac; cirrus small. Genital pore at the posterior end of the pharynx. Egg measures 0.039 millimetre by 0.017 millimetre. Parasitic in the frog.

The affinities of Ostiolum are with the genus Hæmatolœechus, as described by Looss ('94). It resembles that genus in the shape and size of the body of the worm, the form and extent of the digestive tract, the form of the excretory vesicle, the position of the testes, the position of the genital pore, the form and length of the cirrus-sac and of the vesicula seminalis, the large size of the receptaculum seminis, the absence of Laurer's canal, the form and distribution of the yolk-glands, the great length of the uterus, the weakness of the acetabulum, and the host which harbors the animal.

It differs principally from Hæmatolœchus in the position of the acetabulum, which is farther forward than in that genus, the size of the testes, which are much smaller than in Hæmatolœchus, in the arrangement of the uterine folds, which have a general longitudinal direction in Hæmatolœchus, and in the length of the excretory vesicle, which extends much farther forward than in Hæmatolœchus. In that genus, also, the worms are often covered by spines, while in Ostiolum these structures did not appear in any of the specimens examined by me.

\section{BIBLIOGRAPHY.}

Leidy, J.

'56. A Synopsis of Entozoa and some of their Ecto-congeners observed by the Author. Proc. Acad. Nat. Sci. Philadelphia, vol. 8, pp. 42-58.

Looss, A.

'94. Die Distomen unserer Fische und Frösche. Bibl. Zool., Heft 16, $296 \mathrm{pp}, 9$ Taf.

Looss, A.

'99. Weitere Beiträge zur İ́cnntniss der Trematoden-Fauna Aegyptens. Zool. Jahrb. Abt. f. Syst., Bd. 12, pp. 521-7S4, Taf. 24-32.

Lihe, M.

:00. Ueber cinigc Distomen aus Schlangen und Eidechsen. Centralbl. f. Bakt. Parasit. u. Infek., Abt. 1, Bd. 2S, No. 17, pp. 555-566.

Volz, W.

'99. Beitrag zur Kicnntniss der Schlangendistomeen. Arch. f. Naturg., Jahrg. 65, Bd. 1, pp. 231-240, Taf. 20. 


\section{EXPLANATION OF PLATE IV.}

All the figures except 3 and 7 were made with the aid of a camera lucida.

\author{
act. Acetabulum. \\ can. Lau. Laurer's canal. \\ cir. Cirrus. \\ cta. Cuticula. \\ $d t . v t$. Yolk-duct. \\ gl. cnch. Shell-gland. \\ gl. phx. Pharyngeal gland. \\ gl. vt. Yolk-gland. \\ in. Intestine. \\ $m h^{\prime} t$. Metraterm. \\ $m u . \lg$. Longitudinal muscles. \\ oa. Ovary. \\ $o^{\prime} d t$. Oviduct.
}

\section{ABBREVIATIONS.}

$\begin{array}{ll}\text { oes. } & \text { Esophagus. } \\ \text { or. } & \text { Mouth. } \\ \text { phx. } & \text { Pharynx. } \\ \text { po. exc. } & \text { Excretory pore. } \\ \text { po. gen. } & \text { Genital pore. } \\ \text { prs. prost. } & \text { Pars prostatica. } \\ \text { rcp. sem. } & \text { Receptaculum seminis. } \\ \text { rsv. vt. } & \text { Yolk-reservoir. } \\ \text { sac. cir. } & \text { Cirrus-sac. } \\ \text { te. } & \text { Testis. } \\ \text { ut. } & \text { Uterus. } \\ \text { vsl. exc. } & \text { Excretory vesicle. } \\ \text { vsl. sem. } & \text { Vesicula seminalis. }\end{array}$

\section{PLATE IV.}

Fig. 1. Renifer ellipticus, ventral view. $\times 30$.

Fig. 2. Renifer elongatus, dorsal view. $\times 33$.

Fig. 3. Diagram showing the arrangement of the female genital organs of R. ellipticus.

Fig. 4. Outline of a cross-section of R. elongatus just posterior to the testes. $\times 78$.

Fig. 5. Renifer variabilis, dorsal view. $\times 24$.

Fig. 6. Ostiolum formosum, ventral view. $\times 14$.

Fig. 7. Diagram showing the arrangement of the female genital organs of $O$. formosum.

Fig. 8. Cross-section of the ventral body-wall of 0 . formosum showing acetabulum. $\times 10$. 

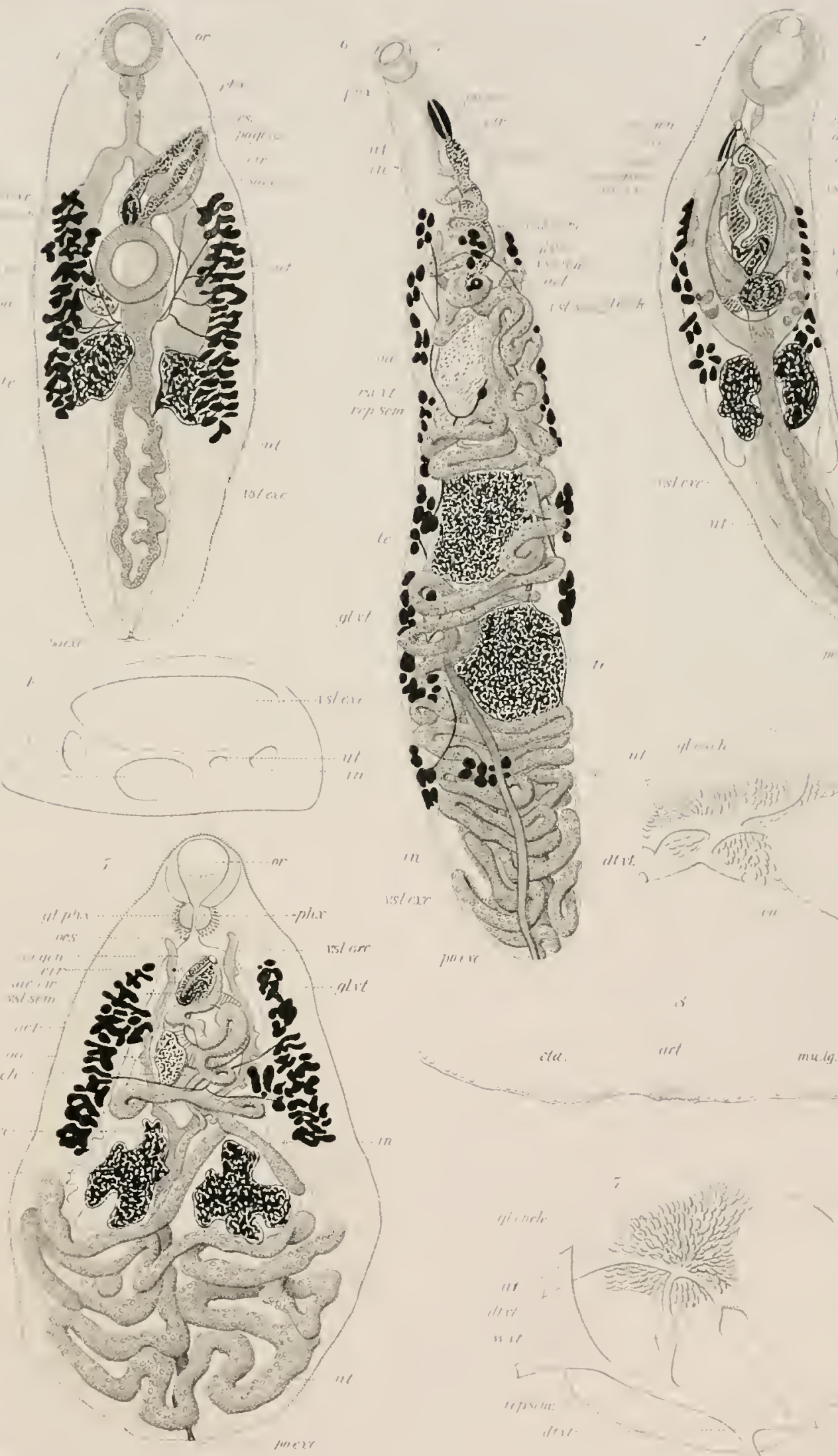


\section{III.}

A NEW CRANIAL NERVE IN SELACHIANS.

(PLATES V-VI.)

William A. Locy. 


\section{INTRODUCTION.}

Explorations in the field of morphology are continually bringing to light new facts which modify our ideas regarding structural features already recognized, and also make it necessary to take account of new ones. This progress is the result of intensive work with, of course, better instruments and better technique. One result of this work has been to concentrate the attention within relatively narrow limits, so that one observer often misses that which will lie in the path of another working on the same material. Of this there is no lack of illustrations, and another case in point is now found in the brain of the selachians. From the time of Busch ('48) through Leuret and Gratiolet ('39-57) to the publication of Fritsch's classical memoir ('78), the brains of various selachians had been carefully examined and figured. From Fritsch's time to the present the brains of Squalus acanthias and other selachians have been among the most frequently examined nervous systems both from the standpoint of structure and of development. In the study of the selachian head the present writer also had a modest part ('95), but a pair of cranial nerves was continually overlooked. I found them first in Acanthias embryos about six years ago, and, published (Locy, '99) an account of their embryonic development in that selachian. At first, very naturally, I looked upon these nerves as of exceptional occurrence, possibly transitory in existence, and probably confined to a very limited number of species. I have, however, continued to find them in all the different adult selachians that I have had opportunity to dissect. In this paper it is proposed to describe these newly observed nerves in six genera of adult selachians and their developmental history in one. Their occurrence in the adult stages of six genera is sufficient to show that they are not transitory structures, nor are they confined to a very limited number of species.

It is a great pleasure to the writer to prepare this paper as an expression of high regard for Professor Mark, under whose stimulating guidance he received his training in morphological method and took his first steps in independent work.

The nerves in question are connected, peripherally, with the olfactory epithelium and terminate, centrally, in the upper part of the corpus striatum. One's first impulse would be to look upon them as possibly representing a pair of bundles of the olfactory system run wild, rather than as new elements in that system, or as inde- 
pendent nerves. But the chief bundles (Edinger) recognized as belonging to the olfactory system are present simultaneously with these nerves, and the anatomical descriptions which follow will make it clear that their fibres have no connection with the olfactory glomeruli, and throughout their course have a striking independence. This, taken in connection with their embryonic history, is what to my mind justifies calling them a pair of "new cranial nerves." It is my hope to be able to complete in the near future observations on the bundles in the olfactory tract, and to publish them in another connection, with a critical examination of the entire olfactory system.

\section{DESCRIPTIONS OF THE NEW NERVE IN ADULT SELACHIANS.}

I. In Squalus acanthias. - The brain of an adult Squalus acanthias is reprerented in Figure 1 (Pl. V). A brief general description of the parts of the forebrain will be given first in order to make clearer the course of the new nerve. In front are the olfactory cups, two hollow bodies in the interior of which the nasal membrane is thrown into plate-like folds. The fila olfactoria, or fibres of the olfactory nerves, arise in cells of the nasal membrane and pass backward, uniting just below the capsules into distinct bundles. The smaller bundles of the fila olfactoria are gathered into two great divisions, one more lateral ( $n$. olf. l.) and one more median in position ( $n$. olf. $m$. in other figures). This partition of the olfactory fibres into two large complex divisions seems to be general among the selachians. The complete separation of the two divisions is well shown in Scoliodon terræ-novæ (Fig. 9); in S. acanthias the sepasation is not so distinct, but it is nevertheless complete. The fibres composing each division cross and mingle in a complicated manner and enter the enlarged end of the olf actory tract (Fig. 1, trt. olf.). There is thus formed a rounded enlargement at the base of the capsule called the bulbus olfactorius. The ends of the fila olfactoria divide into brush-like tufts which come into communication with similar brush-like endings of dendrites, belonging to a different series of cells, situated in the base of the bulbus. The rounded masses formed by the union of the tufts of the filia olfactoria and those of the dendrites are designated glomeruli olfactorii, and they mark the division between the neurons of the first and second order respectively. The neuraxons of the neurons of the second order pass backward in the tractus, and, entering the forebrain, they separate into the various tracts or bundles of the olfactory system.

The front part of the forebrain in S. acanthias is divided by a median furrow into two parts. This extends backward only about one-half the distance to the thalam- 
encephalon and, therefore, the hinder portion of the forebrain is undivided. The epiphysis is not represented in the drawing. Connected with the base of the thalamencephalon are the optic nerves $(n$. opt.). Behind the thalamencephalon come the midbrain (ms'ence.), the cerebellum ( $\mathrm{cbl}$ ), and the medulla oblongata.

The course of the new nerve (Fig. 1, n. nov.) may now be described. It may, for convenience, be spoken of as passing from the brain to the olfactory cups without prejudicing the question of the source of origin of its fibres. Starting deep in the median furrow, it passes forward across the anterior surface of the forebrain; it then curves in the angle formed by the union of the olfactory tract and the forebrain, and finally passes along the inner margin of the tract to reach the median division of the fila olfactoria. It crosses this obliquely and enters the fissure between the two divisions of the fila. These are unequal in breadth-the median one being broader-so that the point at which the nerve disappears in the furrow is about twothirds the space across. Just as the nerve reaches the fissure it branches, unequally, into three stems (not shown in the drawing); a small one passing obliquely backward and downward to unite with the lateral division near its base, another slender one curving upward and inward to unite with the median division, and the chief central stem which runs forward and laterally, uniting with the outer bundle of the lateral division of the fila olfactoria $(n$. olf. $l$ ). This chief stem breaks into anumber of small branches that pass among the fibres constituting the lateral division. This stem also dips downward into the furrow and reaches about the level of the median horizontal plane of the olfactory cup. By separating the fila olfactoria it can be traced close to the membranous covering of the olfactory capsule, and well out along the lateral portion of the olfactory cup. Here it penetrates the connective-tissue covering of the cup and enters (in connection with the fila olfactoria) the nasal epithelium. All this, with the exception of the last item, can be made out by careful work under a dissecting microscope, and has been many times confirmed by repeated observations. One point that forcibly strikes the observer is that this new nerve preserves its independence, often mingling with the fila olfactoria. Actual anastomosis could not be made out. The two sets of fibres commingle very intimately, but in no case have they been seen to unite with each other.

There are two ganglionic enlargements on the nerves in Squalus acanthias that vary in position in different specimens. The more prominent one (Fig. 1, gn.) is near the base of the bulbus, and the other near the angle of union between forebrain and tractus. The nerve is composed of two bundles united within the same envelope of connective tissue. The distinction between the two bundles is well seen in sections at the angle between tractus and forebrain, and, again, within the median 
furrow. In the latter position the two bundles of each nerve separate and penetrate the brain-wall at different points.

Having described the course of the nerve from the median furrow to the olfactory cup, let us now consider its central connections. Near the bottom of the furrow the divided bundles of the nerves penetrate the brain-wall. They enter this a little below the level of the median horizontal plane, and, rising slightly (Pl. VI, Fig. 18, n. nov.), pass toward the inner wall of the brain-ventricle. Sections made in the horizontal plane (Pl. VI, Fig. 17, n. now.) show that the nerves on each side pass backward in the brain substance, dividing into two or three chief branches, which in turn are greatly subdivided. The median branches of each side cross the median plane and spread into a number of twig-like terminations, while the other branches spread out in the brain substance of the same side as that on which they entered. The minuter branches of these nerves terminate near the epithelial cells which form the lining of the brain ventricle.

The portion of the brain substance in which these fibres end apparently corresponds to the epistriatum (Edinger) of the brains of reptiles, etc., although it is on the median wall rather than the lateral wall of the brain ventricle. In the forebrain of Squalus two thickened masses of cells meet in the median plane on the base of the brain, and also unite vertically with an infolding of the cortex from the roof of the brain. In cross-section this presents the appearance of a short pillar with an enlargement above, the cortical infolding, and another below, the corpus striatum; the fibres terminate in the region between the two (the epistriatum?). The fibres can be traced very close to the brain ventricle, but I have not been able to make out the nature of their final terminations.

Figure 18 (Pl. VI) shows the course of the nerve within the brain substance as seen in a sagittal section; Figure 17 shows a partly diagrammatic reconstruction of sections made in the horizontal plane; and Figure 19 shows the position of the nerve in a cross-section.

As to peripheral connections, the study of serial sections shows that the fibres of the new nerve are mainly distributed to the olfactory membrane in the antero-lateral portions of the olfactory cup. There is in S. acanthias, as in other selachians, an obvious division of the olfactory chamber into two parts, one median, the other lateral. The olfactory membrane of these two parts is continuous and, in both, is thrown into similar folds, but membranous flaps, or valves, developed from the firm ring surrounding the entrance to the cavity, are so arranged as to make two openings and separate the chamber into two parts. The separation of the fila olfactoria into two divisions apparently has reference to these two parts. The fibres of the new 
nerve are mainly, but not entirely, distributed to the outer lateral portions of the olfactory membrane, inasmuch as the chief branch of the nerve takes a course to that portion of the olfactory cup. Here the fibres can be traced between the folds of the olfactory epithelium. The nature of their termination within that membrane or their possible connection with cells of it will be especially difficult to determine. After the divisions of the fibres become very minute they are easily confused with the smallest bundles of the fila olfactoria and the tracing of individual fibres is very uncertain. Small bundles of the fibres of the new nerve can, however, be traced between the folds of the olfactory membrane and as far as the base of the epithelial cells. Since writing the above my attention has been called by one of my students, Miss Effie Thayer, to a series of sections in which a fortunate differentiation with iron-hæmotoxylin staining has made a distinction in appearance between even the small fibres of the fila olfactoria and those of the new nerve. I am indebted to her not only for making the sections, but for tracing these fibres, thus seen with greater distinctness than was possible in other sections, into contact with the olfactory epithelium.

The next question in reference to this nerve would naturally be, What is its embryonic history? This has been worked out in Squalus acanthias, and the main facts will be given, after considering the anatomical condition of the nerve in the adult stages of other selachians.

2. In Mustelus canis.-The brain of the smooth hound, Mustelus canis, seen from above is represented in Figure $2(\mathrm{Pl} . \mathrm{V})$. The olfactory cups are relatively of enormous size, showing that the olfactory apparatus is doubtless of great importance in the life of this animal. The tractus olfactorius is shorter than in Squalus, and the forebrain is not divided by a median furrow as in that selachian. The new nerve is more easily detected in Mustelus than in Squalus, for it lies more freely in the membrane of the cranial cavity and is not so closely applied to the tractus. Its point of entrance into the brain-wall is on the ventral surface as shown in Figure 3. Here the nerve enters a small depression on the base of the brain, considerably in front of the optic nerve. From this point it passes towards the olfactory cup, in a course nearly parallel to the tractus, but it does not come to lie close to that structure. As seen from above, it traverses the relatively short space between the anterior wall of the forebrain and the bulbus and then crosses obliquely the median division of the fila olfactoria (Fig. ,2 $n$. olf. m.) and enters the furrow between the two great divisions. Just as it reaches this furrow it branches unequally, the main branch taking a similar course to that described for Squalus. The nerve is, therefore, mainly distributed to the antero-lateral portions of the olfactory membrane. No well-marked ganglion was observed on the course of the nerve in Mustelus. 
3. In Raja.-I have observed this nerve in three species of the genus Raja. Its point of connection with the brain is on the anterior dorsal surface instead of the ventral surface as in Mustelus and other forms to be described later. From its point of attachment to the brain-wall (Pl. V, Fig. 4, n. nov.) it passes over the surface of the forebrain, along the inner margin of the slender tractus, and upon the olfactory cup. Here it runs along the anterior border of the fila olfactoria and dips among the fibres of the latter about midway between the posterior end and the anterior tip of the olfactory cup. In the skate there is no very obvious separation of the fila olfactoria into two divisions as in the other forms described. There is, however, a median blood-vessel that partly separates the fila into two divisions which correspond, I think, to the lateral and median divisions already described. I have not traced the nerve-fibres in the skate into connection with the nasal membrane.

4. In Carcharias littoralis.-Of all the selachians I have examined, the new nerve is most readily seen in the sand-shark, Carcharias littoralis. It is always more or less difficult to see this nerve before the brain has been stained. I have uniformly immersed the entire brain in borax carmine from ten to twenty-four hours in order to secure a surface stain before completing its dissection in alcohol under a dissecting microscope. In Carcharias (Pl. V, Fig. 5) the nerve can readily be detected before staining. It is connected with the ventral surface of the brain (Fig. 6) as in Mustelus, considerably in front of the optic nerve. The course of the nerve from this ventral connection is nearly in a straight line to the olfactory cup. It runs obliquely towards the long slender tractus and, after reaching it, runs for a part of its course directly upon the tractus. The result is that the nerve enters the fissure between the bundles of the fila olfactoria from behind, instead of crossing the median division (n. olf. $m$ ) as in Squalus and Mustelus.

In the Carcharias there is a bundle of the fila olfactoria connecting the two divisions of the olfactory nerve. The new nerve as it enters the fissure branches unequally, sending a small twig to the connecting bundle, and a main stem to the lateral division. This main stem dips into the mass of fila making up the lateral division and, after coming into contact with the enveloping membrane of the capsule, continues its course along the latter in an antero-lateral direction. From time to time it gives off small branches, which penetrate the investing membrane of the capsule and enter the folds of the nasal epithelium. The chief part of the nerve reaches the antero-lateral portions of the cup and there disappears within the nasal membrane. As in other cases, it preserves throughout its course a striking independence.

The nerve has a small ganglionic enlargement near the base of the bulb.

5. In Sphyrna.-A part of the brain of the bonnet-head, Sphyrna tiburo, 
is represented in Figure 7 ( $\mathrm{Pl} . \mathrm{V})$. The forebrain is expanded laterally, but is short antero-posteriorly. The olfactory cups are elongated and shaped somewhat like a long seed-pod. The tractus is relatively slender. The new nerve unites with the brain on the ventral surface (Fig. $8, n . n o v$.) in a depression much nearer the optic nerve than in the other forms described. From this point the nerve passes directly to the base of the fila olfactoria and ningles with them in a manner I was unable to make out clearly in the single specimen of this shark at my command.

There are very well marked ganglia (Fig. $8, g n, g n^{\prime}$ ) on the nerves. In the specimen observed the ganglia were not symmetrical in position. The one on the left side could be seen from above just in front of the brain (Fig. 7, gn'). The one on the opposite side was on the base of the brain, and could be seen only in ventral view (Fig. 8, gn).

6. In Scoliodon terræ-novæ - In a shark from Florida, identified by Mr. A. D. Howard as probably Scoliodon terræ-novæ, the new nerve (Pl. V, Fig. 9, n. nov.) is likewise present. In this shark the separation of the great divisions ( $n$. olf. $l$., $n$. olf. m.) of the fila olfactoria is very striking. Each division is of course made up of a number of bundles of fila.

The nerve enters the brain substance on the ventral surface, in the median plane about midway between the optic nerve and the anterior tip of the forebrain. It is flattened on the ventral surface of the brain, and has an enlargement which is possibly ganglionic. Beyond this swelling the nerve is slender and passes directly to the lateral division of the fila olfactoria, with which it unites. It does not branch in the fissure between the two great divisions as described in several other forms. Near the base of the median division there is a slight enlargement which is also possibly ganglionic.

7. In 0ther Selachians.-I have also determined the existence of this nerve in embryos of the torpedo, and, as mentioned above, in three species of Raja. This makes a total of nine species of selachians in which this nerve has been found. It will be interesting to determine whether it is present or absent in others.*

The anatomical descriptions show that there is considerable variation as to the position on the external surface of the brain at which this nerve enters. In the skate it enters on the anterior dorsal surface; in Squalus it enters the brain in the median furrow, midway between the dorsal and ventral surfaces; and in the other forms examined it enters on the ventral surface, rather posteriorly in Sphyrna, and further anteriorly in the others. As to internal connections there is doubtless

* Since the above was sent to the printer I have identified this new nerve in 19 genera and 24 species of adult selachians. 
greater uniformity. The fibres have been traced into the epistriatum in Squalus, Mustelus, and Carcharias, but they have not yet been studied in the other forms. There is also much variation as regards the ganglionic enlargements on the nerve.

\section{EMBRYONIC HISTORY OF THE NEW NERVE IN SQUALUS.}

The embryonic history of this nerve was described by me (Locy, '99) some four years ago, and the main facts are repeated here. It can be found in embryos of Squalus acanthias about 10 millimetres in length running from the apex of the forebrain near the neuropore to the olfactory epithelium. Its previous history is difficult to clear up. I have given much attention to sections of embryos from 6 to 8 millimetres long, and I have repeatedly observed that there exists a cellular connection between the olfactory plate and the brain-wall as described by Hoffmann ('96). The new nerve has at first a connection (placode) with the thickened surface existing just above the shallow depression that marks the beginning of the olfactory pit. This connection is a group of closely packed cells in which I have failed, at this stage, to recognize fibres. In embryos about 10 millimetres long, however, fibres are to be seen that run from the sides of the neuropore to the olfactory epithelium. These I take to be fibres of the new nerve, but have not been able to satisfy myself as to the position of the neuroblasts that give rise to them. The neural crest is disappearing in this region, and my observations incline me to the view that the neuroblasts of the fibres of the new nerve are derived from the cells of that structure.

For a short time there is a single connection, on each side, between the brainwall and the nasal epithelium. Very soon a second fibrous connection, more lateral in position, is established between the brain-wall and the olfactory pit. The two connections are entirely independent as to their union with the brain-wall, but are close together in the olfactory epithelium. The earliest of these fibrous tracts represents the new nerve, the later one the main olfactory. The latter is present in embryos 13 millimetres long* (and perhaps in still smaller ones).

By the time the embryo has reached a length of 16 millimetres the two independent brain connections are clearly differentiated. The connection belonging to

\footnotetext{
* The length is, of course, no sure criterion as to its age. Those who have compared a large assortment of embryos of any animal must have been impressed with their variations. Some embryos are longer than others which are clcarly more advanecd in development, and there is variation as to the number of gill-clcfts broken through on the two sides of the body as well as in other anatomical landmarks. The differenec between embryos 10 millimetres and 13 millimetres in length is slight, and in individual cases the longer one might be the younger. The chief point is that my sections show stages in which the median fibres arc present and the more lateral ones absent.
} 
the main olfactory is more lateral in position and is composed of two roots; that belonging to the median nerve is on either side of the neuropore and shows a ganglionic enlargement.

A frontal view of a Squalus embryo that had reached a length of 25 millimetres is shown in Figure $10(\mathrm{Pl} . \mathrm{VI})$. At this stage the median nerve is well established, as is also the main olfactory. To obtain this view, the front surface of the brain was completely exposed by first removing the overlying layer of ectoderm, and then sweeping away the mesoderm by the use of an artist's brush and a needle when necessary. The olfactory cups have been left in position. The mark of the closed neuropore is seen in the median plane, and on each side of it the new nerves (n. nov.) with a ganglionic enlargement $(g n$.). From these positions the nerves pass laterally across the front surface of the brain and join the main olfactories, being principally connected with their outer or lateral roots $(n$.olf. l.). It is to be noted that the main olfactory consists of two divisions ( $n$. olf. $l ., n$.olf. m.), each of which is composed of smaller bundles. This condition persists in the adult, as already indicated above.

A frontal view of the right half of the brain of an older embryo, 38 millimetres in length, is shown in Figure 11 (Pl. VI). Part of the olfactory cup has been broken away, exposing the olfactory membrane, which is already thrown into folds. The new nerve (n.nov.) is relatively long and slender; its course and relationships are the same as shown in Figure 10. The two chief divisions of the olfactory nerve (n. olf. $l$., $n$. olf. $m$.) are more complex and composed of several small bundles. The olfactory pit is imperfectly divided into two parts, a median and a lateral portion, and the fibres of the two great divisions of the olfactory nerve are mainly distributed to the corresponding portions of the pit.

The new nerve, as it approaches the main olfactory, becomes flattened and therefore broader. It passes in front of the median division ( $n$. olf. $m$.), then underneath two slender bundles of the lateral division ( $n$. olf. l.), and enters into connection with the largest bundle of that division. It branches very unequally just before passing behind the bundles of the lateral division. As far as I can make out by sections its fibres do not anastomose, but commingle in a very intimate manner with the fila olfactoria. They subdivide and pass mainly to the lateral portion of the nasal membrane in close association with the fila olfactoria.

Figure 12 (Pl. VI) is an almost ventral view of the brain of an embryo 40 millimetres long. On the left the olfactory cup has been completely broken away, while only the anterior part of the right cup has been removed. The new nerve isseen, as in former cases, to cross the forebrain, pass in front of the median division of the olfactory, and behind two slender bundles of the lateral division, to come into con- 
nection, finally, with the large outer bundle of the lateral division. On the left side the principal blood-vessels (va. sng.) are indicated. In the other sketches they have been omitted. The ganglionic enlargement has not been represented in Figure 12.

The brain of an embryo 47 millimetres long is seen from above in Figure 14. On the right side the surface of the olfactory cup and the various bundles of the olfactory nerve have been exposed by dissection, while on the left the tissue covering these parts has not been removed. The new nerve $(n$. nov.) is seen on both sides, and on the right side its connection with the lateral division of the olfactory is represented. This lateral division $(n$. olf. l.) has been broken free from the olfactory lobe in order to show better the point of union.

In Figure 13 is seen the brain of an embryo 68 millimetres long viewed from above. A shallow furrow now divides the forebrain into right and left portions. The epiphysis rising from the roof of the thalamencephalon is shown in the median plane. As in Figure 14, a dissection of the chief bundles of the olfactory nerve has been made to show the course of the new nerve and its point of union with the outer bundle of the lateral division of the olfactory. On the left side the nerve after partly crossing the olfactory lobe disappears in the tissue at the base of the olfactory cup. The new nerve branches very unequally just between the two great divisions of the olfactory, a condition not shown in the figure. Centrally, the fibres penetrate the brain-wall near the median furrow.

The brain of an embryo about 150 millimetres long is shown in Figure 15. This is the stage at which the young are designated as "pup" by the fishermen, and is about the size reached in Squalus before being freed from the oviduct of the parent. The olfactory lobes are now fully formed; the olfactory cups are large and directed forward. The forebrain is divided by a median furrow which, in front, extends from the dorsal to the ventral surfaces and separates the anterior end of the brain into two portions; farther back the furrow is simply a shallow fissure. The new nerve (n.nov.) passes into the furrow in front; near the point where the two sides of the brain unite it enters the brain substance.

The level at which it enters is in some specimens slightly nearer the dorsal than the ventral surface, and in other specimens nearer the ventral surface. The position and the course of the nerve-fibres within the brain substance is shown in Figures 17, 18 , and 19, and has been already described (p. 44).

Within the furrow and also on the front surface of the brain the new nerve is flattened. It becomes rounded in cross-section as it comes into the angle between the brain-wall and the olfactory lobe, and becomes flattened again on the surface of the lobe. After crossing about two-thirds the diameter of the lobe it enters the 
fissure between the two divisions of the olfactory nerve, branching unequally as described for other specimens. The main trunk of the nerve unites, as in other cases, with the outer bundle of the lateral division of the olfactory nerve. There its fibres mingle with those of the fila olfactoria and pass between the folds of the nasal membrane. Some of the fibres of the new nerve reach the extreme antero-lateral portion of the olfactory cup, and others terminate more centrally.

The brain of a half-grown Squalus acanthias, about 90 centimetres in length, is represented by Figure $16(\mathrm{Pl}$. VI). It shows very well a gradation between the "pup" stage and the adult. In the "pup" stage (Fig. 15) the olfactory lobe is well formed, but there is no tractus; in the stage represented by Figure 16 the tractus is forming and the olfactory nerve proper is being removed from its former position near the brain. The tractus with its neurons of the second order form the link between the two. The new nerve is now in all essential particulars similar to its condition in the adult already described (p. 43).

The embryonic history shows that the new nerve is present in embryos 10 millimetres in length, that it arises on the dorsal summit of the forebrain on each side of the neuropore in close connection with elements of the disappearing neural crest. Its fibres are formed slightly before those of the olfactory nerve. I have not been able to locate their neuroblasts with certainty, but the appearances in many sections give some ground for the belief that they are derived from the neural crest.

There are numerous rounded cells distributed among the fibres of the new nerve that give it a different appearance, under the microscope, from the bundles of fila olfactoria. These rounded cells are not seen in the smaller branches; hence the difficulty of distinguishing the two sets of fibres is here greatly increased.

\section{PREVIOUS OBSERVATIONS ON THE NEW NERVE.}

The anatomy and embryology of the new nerve having been considered, there remain two general questions: (1) Are there any references in zoölogical literature as to the presence of this nerve in the selachians? and (2) Has it been observed in any other vertebrates?

The nerve was not described in any selachian prior to the appearance of my paper in 1899, and the only reference I can find as to its existence is in the memoir by Fritsch ('78). In his figure (Pl. I, Fig. 6) of the brain of Galeus canis he represents part of the middle portion of the new nerve in the form of two short slender strands extending from the forebrain straight outward and nearly parallel to each other. These 
appear to arise from the anterior surface of the forebrain on each side of the median depression. This paired structure is designated by Fritsch as a supernumerary nerve ("überzähliger Nerv [Galeus]"). It is not described, however, and there is no suggestion as to its connection with the olfactory cup or with the ventral surface of the brain. It would appear that part of this nerve had been removed by dissection, and, Fritsch recognizing the remainder as an undescribed nerve, designated it as "supernumerary." Although his carefully made figures embrace the brains of some other forms described in this paper, the presence of the new nerve is not indicated in any of them.

As to the second question, the occurrence of the new nerve in other vertebrates than selachians, the publications of Pinkus are of importance. Pinkus ('94) publishes in the Anatomischer Anzeiger under the title "Ueber einen noch nicht beschriebenen Hirnnerven des Protopterus annectens," a preliminary account of a new nerve in this fish. Soon after there appeared in his complete paper ('95) a further description and a reconstruction showing the position of this nerve on the ventral surface of the brain. At the time of writing my paper in the Anatomischer Anzeiger I called attention to this work of Pinkus, but I was not ready to say that the nerve described in Squalus acanthias corresponded to that in Protopterus, for the nerve in Squalus and in the skate is dorsal where it connects with the brain-wall, and in Protopterus it is ventral. At that time the nerve was not known to exist in any selachian except the two forms mentioned. Since observing it in Mustelus, Carcharias, and other sharks in which it has a ventral position, I am strongly inclined to the view that the nerve described by Pinkus is homologous with the new nerve in the selachians.

Pinkus describes the nerve in the adult Protopterus, but gives no facts as to its embryonic history. His summary relating to this nerve in his complete paper ('95, p. 332) is as follows: "Ein bisher nur bei Protopterus nachgewiesener, markloser Nerv, welcher am Vorderende des Recessus præopticus das Zwischenhirn verlässt, lagert sich dem Olfactorius an und verläuft neben ihm bis an das Vorderende der Nase, wo er in einen Zellhaufen am Dach der vorderen Nasenöffnung sich verliert. Eine kolbige Anschwellung dieses Nerven, welche durch die Einlagerung grosskerniger, von allen anderen nervösen Zellen des Protopterus anscheinend verschiedenen Zellen bedingt ist, macht es wahrscheinlich, dass wir es hier mit einem neuen Organ zu thun haben."

In the selachians I do not find the mass of cells described by Pinkus in Protopterus, but I have traced the fibres of the new nerve between the folds of the nasal epithelium. 
Pinkus describes the nerve in Protopterus as connected with the "Zwischenhirn," but in all the selachians I have examined it is connected with the forebrain.

Allis ('97) describes a somewhat similar bundle in both young and adult stages of Amia, which he believes to correspond to the nerve described by Pinkus. I have had opportunity to examine this bundle in the adult Amia. In that form it does not have the striking independence that $I$ have spoken of as characterizing it in the selachians. It is more closely united with the fila olfactoria, and is not nearly so distinct even where it runs over the ventral surface of the brain.

It appears to me now, after observing this nerve more widely in the selachians, that it corresponds to the nerve described by Pinkus in Protopterus and by Allis in Amia, and I believe the conditions justify calling it "a new nerve." Even if it be one of the olfactory bundles in an unusual position, its separateness in origin and differences from all other olfactory radices would still justify the use of the designation "new nerve."

In my paper of 1899 I suggested in a tentative way calling it "accessory olfactory" in the following words: "On account of its close relation with the fibres of the main olfactory and to the nasal membrane, it is best for the present to refer it to the olfactory system and, perhaps, to designate it 'accessory olfactory.' We need to know its central and peripheral terminations and whether it is represented in other animals before saying much about its homology."

This new nerve must not be confused with the thalamic nerve discovered in 1891 by Platt and Froriep, and whose history was so well worked out by Hoffmann in 1897. The thalamic nerve is between the midbrain and the thalamencephalon. The new nerve and the thalamic exist simultaneously in embryos of Squalus acanthias, but the latter is transitory.

I have looked with especial care for traces of this nerve in a number of amphibians and teleosts. Both embryonic and adult stages have been examined in Necturus, Amblystoma, the frog, the toad, the trout, catfish, etc., etc., but in none of these has the nerve been found. It is to be hoped that further observations on a wider range of material may bring us more facts regarding the existence of this nerve in other forms, its history and relationships. 


\section{BIBLIOGRAPHY.}

Allis, E. P.

'97. The Cranial Muscles and Cranial and First Spinal Nerves in Amia calva. Jour. Morph.; vol. 12; no. 3; pp. 487-808, pls. 20-38.

Busch, W.

'48. De selachiorum et ganoideorum encephalo. (Diss.) Berolini, $4^{\circ}, 48$ pp.; 3 tav.

Fritsch, G.

'78. Untersuchungen über den feineren Bau des Fischgehirns. Berlin, $4^{\circ}, 94+\mathrm{xv}$ pp.; 13 Taf.

Hoffmann, C. K.

'96. Beiträge zur Entwicklungsgeschichte der Selachii. Morph. Jahrb.; Bd. 24, pp. 209-286, Taf. 2-5.

Leuret, F., et Gratiolet, L. P.

'39-57. Anatomie comparée du système nerveux. Paris, $8^{\circ}, 2$ vols.; xxxii +592 pp.; xi +692 pp.; atlas, $4^{\circ}$, 60 pp., 32 pls.

Locy, W. A.

'95. Contributions to the Development and Structure of the Vertebrate Head. Jour. Morph.; vol. 11, no. 3, pp. 497-594, pls. 26-30.

Locy, W. A.

'99. New Facts regarding the Development of the Olfactory Nerve. Anat. Anz.; Bd. 16, No. 12, pp. 273-290.

Pinkus, F.

'94. Ueber einen noch nicht beschriebenen Hirnnerven des Protopterus annectens. Anat. Anz.; Bd. 9, No. 18 , pp. 562-566.

Pinkus, F.

'95. Die Hirnnerven des Protopterus annectens. Morph. Arb.; Bd. 4, pp. 275-342, Taf. 13-19.

\section{EXPLANATION OF PLATES V-VI.}

\section{ABBREVIATIONS.}

$c b l$. Cerebellum.

$g n ., g n^{\prime}$. Ganglion.

h'phy. Hypophysis.

lob. olf. Olfactory lobe.

ms'ence. Midbrain.

n. nov. New nerve. poc. olf. Olfactory cup.

$n$. olf. $l$. Lateral division of the olfactory nerve.

$n$. olf. $m$. Median division of the olfactory nerve.

n. opt. Optic nerve.

thl'ence. Thalamencephalon.

trt. olf. Olfactory tract.

va. sng. Blood-vessel.

\section{PLATE V.}

Figures 1 to 6, inclusive, were drawn under the author's direction by Mr. Hayashi; Figures 7, 8, and 9 were drawn by the author. All the figures show the natural sizes of the brains except Figure 4, which has been enlarged twice; and all are dorsal views except Figures 3, 6, and 8, which are seen from the ventral side.

Fig. 1. Brain of an adult Squalus acanthias.

Fig. 2. Brain of an adult Mustelus canis.

Fig. 3. Forebrain and olfactory cups of Mustelus canis; ventral view.

Fig. 4. Brain of an adult skate, Raja sp.?

Fig. 5. Brain of Carcharias littoralis.

Fig. 6. Ventral view of that part of the brain of Carcharias anterior to the optic nerves.

Fig. 7. Forebrain and olfactory apparatus of the bonnet-head, Sphyrna tiburo.

Fig. 8. Part of the brain of Sphyrna seen from below to show the point at which the new nerve enters the brainwall. Note the asymmetry of the ganglia $\left(g n, g n^{\prime}\right)$ on the new nerves.

Fig. 9. Brain of Scoliodon terræ-novæ. 


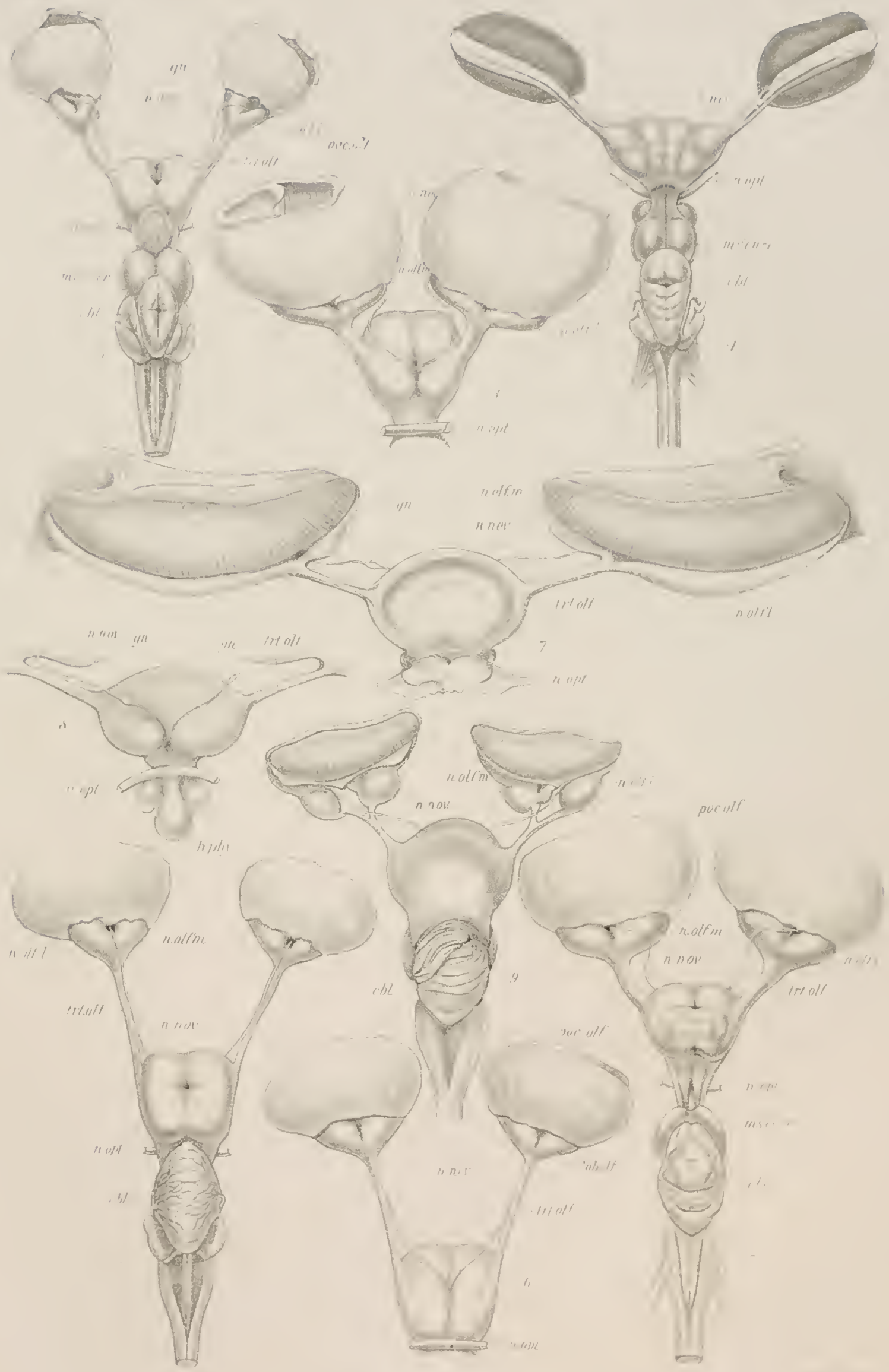


Mark Anniversary Volume.

PLATE VI
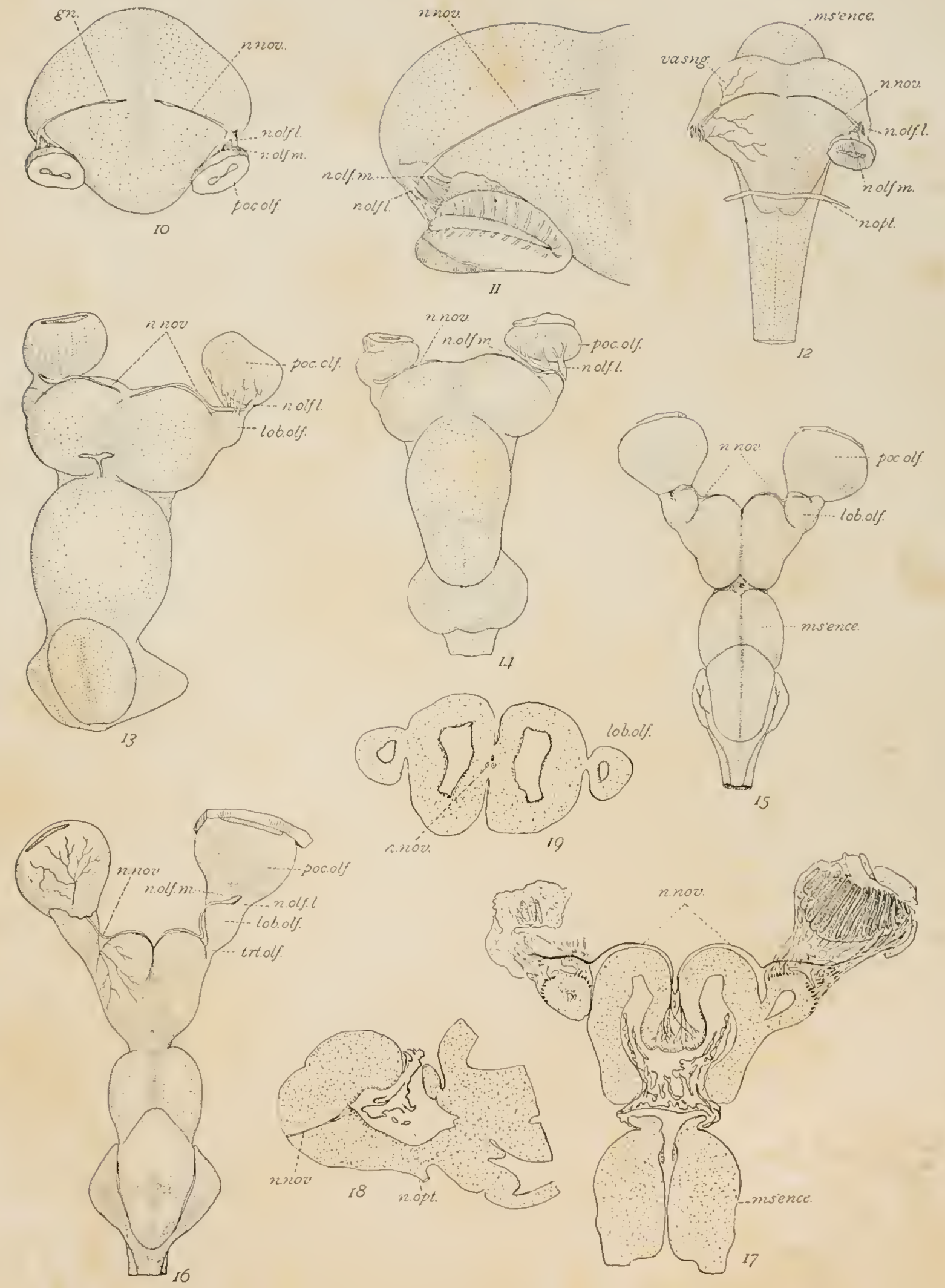



\section{PLATE VI.}

Fig. 10. Frontal view of the brain of an embryo of Squalus acanthias $25 \mathrm{~mm}$. long. $\times$ about 26 .

Fig. 11. Right half of the brain of an embryo of Squalus acanthias $38 \mathrm{~mm}$. long, to show the course of the new nerve and its connection with the lateral division of the olfactory nerve. This stage is before the appearance of the olfactory lobe. $\times$ about 20 .

Fig. 12. Ventral view of the brain of an embryo of Squalus acanthias $40 \mathrm{~mm}$. long. $\times$ about 8 .

Fig. 13. Dorsal view of the brain of an embryo of Squalus acanthias $68 \mathrm{~mm}$. long. On the right side a disscetion has been made of the new nerve and the bundles of the olfactory. $\quad \times$ about 7 .

Fig. 14. Dorsal view of a brain of an embryo of Squalus acanthias $47 \mathrm{~mm}$. long. As in Figure 13, a dissection has been made on the right side. $\times$ about 8 .

Fig. 15. Dorsal view of the brain of Squalus acanthias in the "pup" stage, $150 \mathrm{~mm}$. long. $\times$ about 4 .

Fig. 16. Dorsal view of the brain of a half-grown Squalus acanthias. Compare with Figure 15. Note the beginning of the olfactory tract. Compare also with Figure 1 (Pl. V). $\times$ about 1 z.

Fig. 17. Partly diagramatic figure of a horizontal section of the brain of Squalus acanthias at the "pup" stage, showing the branches of the new nerve within the brain substance. $\times$ about 5 .

Fig. 18. Sagittal section of the brain of Squalus acanthias at the "pup" stage, showing the course of the fibres of the new nerve as seen from the side. $\times$ about 5 .

Fig. 19. Cross-section of the brain of Squalus acanthias at the "pup" stage, showing the position of the main branches of the new nerve. $\times$ about 5 . 



\section{IV.}

THE NATURAL HISTORY OF AMIA CALVA LINNæUS

(PLATE VII.)

JaCOB Reighard. 



\section{INTRODUCTION.}

One who spends much time on the Great Lakes or about the neighboring inland waters comes now and then upon men who have chanced to see the nests of Amia, or the swarms of young guarded by the male. Upon the bits of real fact thus gleaned the fishermen of the region have based certain plausible explanations or myths, to which I shall return. This popular knowledge seems to have first come into print through Dr. Estes (Hallock, '77). From time to time efforts have been made by zoologists to procure the eggs of Amia. Professor Whitman's final success and the further work of Dean, Virchow, Fülleborn, Ayers, and Eycleshymer are discussed in detail by Whitman and Eycleshymer ('97). These observers concerned themselves chiefly with the collection of embryological material. Their observations on the breeding habits of the fish were, for this reason apparently, incidental and fragmentary and have resulted in unfortunate differences of opinion.

Neglecting the earlier account of Dr. Estes (Hallock, '77), the following brief summary is believed to cover the essential facts upon which Fülleborn ('94), Dean ('96, '96', '98), and Whitman and Eycleshymer ('97) are in agreement. In April and May the fish make their appearance in shallow water and there prepare nests, approximately circular areas on the bottom from which the vegetation has been largely removed. The concave bottom of such a nest consists usually of the fibrous roots of water plants, though sometimes of gravel or of the water-soaked parts of dead water plants. The nests are found in water of one to two feet in depth; and the adhesive eggs are attached to their sides and bottoms. The male fish remains over or near the nest for eight to ten days, at the end of which time the eggs are hatched.

The newly hatched young adhere to the material at the bottom of the nest by means of a peculiar adhesive organ at the end of the snout. After a time the young fish leave the nest with the male, and for some weeks they remain together in a dense swarm which is attended by the male and thus protected. When the young fish have reached a certain undetermined size they are no longer found together in swarms.

My own interest in the subject dates from 1891, when I came by chance upon a nest of Amia. From that time until 1898 I collected the eggs nearly every season 
and made incidental observations on the habits of the male fish and the swarms. During the four seasons, 1898 to 1901, inclusive, I attempted a systematic study of the natural history of Amia during the breeding season. In 1901 the work was carried on with other similar work under the auspices of the United States Fish Commission, and owes much to the liberal support of the Commissioner, the Hon. Geo. M. Bowers, as well as to Dr. H. M. Smith, in charge of the scientific work of the Commission. Some brief preliminary accounts of this study have been published, Reighard (:00,:01). All the work has been done on the millponds of the Huron River, within a few miles of Ann Arbor. In order to carry it on continuously a camp was established at the breeding grounds during each of these seasons. Joe Peters, a French-Canadian fisherman, experienced in the use of boats, in handling and mending nets, and in water- and wood-craft, had charge of the camp and rendered invaluable aid. Except when wind and rain interfered with the work, I was almost always in camp, and unless otherwise stated all observations here set down were made by me and recorded on the spot. As soon as a nest was begun it was marked by a numbered stake and a record kept of its subsequent history. During the four seasons records were thus made of one hundred and seventy-seven nests. Certain male fish were found to be readily recognizable through individual peculiarities, and as far as possible these and their swarms were followed from day to day in their wanderings, and their history recorded. The camp seems to afford the only means available for carrying on such continuous observations.

And yet, in spite of nearly continuous observation, sometimes carried through the night, the complete history of an individual fish and of its nest and swarm has not in any case been obtained. Wind and rain often interrupt work. Many nests are never filled with eggs and are after a time abandoned by their builders. From other nests the males are driven, perhaps by the too frequent visits of the observer, perhaps_by so great a fall in the water-level that the nest is left exposed or inaccessible, perhaps by a marauding muskrat. In other cases the male fish, while temporarily absent from his nest, falls victim to some spearman, or, returning, finds the eggs destroyed by minnows or sunfish. When the swarms of young fish have left the nest, their wanderings increase in extent and their movements become more rapid with age. They are apt at all times to remain hidden in shadows or in the midst of aquatic plants, and they hide more effectually as they grow older. The difficulty of following them under these circumstances is increased by the chances of destruction to which both the male and the swarm are subjected. Separated from its protector the swarm is subject to the attacks of other fish or perhaps to those of adult individuals of its own species. The male may meet with some mishap 
and not be able to return to his swarm. In that case the swarm perishes unless, as sometimes happens, it unites with the swarm of some other male and thus gains protection.

From all this it results that observation, as continuous as it can be made, yields only fragmentary individual histories, so that the account which follows must be regarded as the average made by piecing together many such fragments. Even thus numerous details still remain to be worked out.

\section{OBSERVATIONS.}

I. Secondary Sexual Characters. - The descriptions of the adult fish given by systematists, e.g. Jordan and Evermann ('96, p. 113), are sufficient for ordinary purposes, but in work on the habits it is necessary to distinguish the sexes, often at a distance of ten or twenty feet, so that some further account of the secondary sexual characters is desirable.

The males on the average are smaller than the females and are further distinguished from them during the breeding season by their color (see plate in Dean, '98). In the breeding male (Pl. VII, Fig. 4) all the fins, dorsal, caudal, pectoral, and pelvic, are of a bright green, like that of the aquatic plants; the tail-spot, which in the female is small, indistinct, not bordered, and usually stated to be lacking, is large, velvety-black, and bordered by a broad band of orange or yellow, so that as a whole it is very conspicuous. The ventral surface of the male is of a lighter green than the fins, and this green tinges the bronze-green of the sides up to the lateral line and shows everywhere, but especially on the sides, a sheen of orange. The cheeks of the male show the stripes more distinctly than those of the female, and the bronze of his back and sides is both brighter and lighter, and its reticular markings of darker bronze are much more distinct than those of the female.

In the female the colors are duller and darker and the bronze tends to reddish. The fins are never green, but of a brownish-red color. In the discussion of a paper by the writer at the meeting of the Naturalists of the Central States at Chicago in 1899, Professor C. A. Kofoid stated that in the Illinois River near Havana the females of Amia have green fins. Since then many specimens from the Huron River at Ann Arbor have been examined and none have been found with green fins, but all with fins of reddish-brown. A record of twenty-one females taken in a fyke net on the spawning ground between April 18 and April 28, 1899, shows all with reddish-brown fins. The spawning season of 1899 ended on April 30. By means of the green 
fins and the tail-spot it is possible to distinguish easily the male of Amia from the female at a distance of from ten to twenty feet.

In those males taken just before the breeding season the colors are much less brilliant. Thus in 1899 the first males were taken on April 18, and though in breeding dress, the colors were not brilliant. The first nest was found on April 23. On April 24 the breeding dress of the males had reached a maximum in only one fish out of six taken on that day. The number of males in which the breeding colors were at the maximum then increased until April 29, when all males were most brilliantly colored. This brilliancy of color lasts certainly until the middle of June, but beyond that it has not been followed. At all seasons, however, the sexes are distinguishable by their colors.

It is often possible to distinguish individual males by peculiarities of color or by accidents of structure, and thus to identify them as they are encountered from time to time in their native waters. After my attention had been once called to this fact I was able, without taking the fish from the water, to distinguish by color or anatomical peculiarities nearly every male studied.

I have recorded ten such individual fish.

No. 1. The tail-spot on one side was comma-shaped, the tail of the comma directed upward.

No. 2. The tail-spot on one side was comma-shaped, the tail of the comma directed downward.

These fish were not again encountered, but during the season of 1900 of the nine swarms of which record was kept the males of eight were recognized, in some cases repeatedly, by their individual peculiarities, as follows:

No. 3. The green-spot male. A conspicuous elongated bright green spot near the dorsal border of the caudal. Two bright orange spots within the yellow border of the tail-spot caudally; a notch in the caudal fin.

No. 4. The two-spot male. Two tail-spots on the right side. The supernumerary spot was triangular, about two-thirds as large as the normal spot and one inch below and in front of it.

No. 5. The split-tail male. The caudal fin was horizontally split nearly to its base, below the middle.

No. 6. The ring male. The yellow border of the tail-spot was flattened in front and was there formed of two distinct spots-the whole having the appearance of a finger-ring with two stones set in it.

No. 7. The white-spot male. On the right side of the head dorsally a wellmarked white spot in front of the junction of opercle and head. 
No. 8. The red-spot male. A bright red pigment-spot in front of and below the eye on the left side.

No. 9. The deep-split-tail male. Tail split as in No. 5, but the split was higher and deeper.

No. 10. The scarred male. A long, white scar back of the right narial tube.

In order to recognize the individual fish by such characters one must of course be within four or five feet of it. Whether the individual pigment-marks persist through the year was not made out; the accidental anatomical peculiarities are probably transient.

It is of interest to note that the color differences between the sexes, as well as individual peculiarities of color and proportions, form the basis of the species formerly recognized by systematists (see Duméril's Key, '70, p. 417).

In order to see whether the brighter light or the higher temperature to which the male fishes are exposed in shallow water during the breeding season is the stimulus inducing the color change, two males taken on the spawning ground in a net on April 13, 1901, were placed on April 17, the one in an aquarium covered with black cloth, the other in an aquarium uncovered and placed against a west window. Both aquaria were provided with running water, and throughout the experiment with light the temperature in the two aquaria remained the same, not varying more than one degree from $15^{\circ} \mathrm{C}$.

The following notes were made on the colors.

April 13. The two fish placed side by side were identical in coloring. Tailspot moderately bright; no green on the fins or elsewhere.

April 24. Both fish had the pectoral and pelvic fins with a band of green 8 millimetres broad at the tip, fading gradually toward the base of the fin. No green elsewhere.

May 7. Both fish had the entire pelvics very green, a little paler toward the base. Pectorals green except the basal one-third. Anals green, lighter toward base. Ventral surface with faint green sheen. Border of tail-spot light yellow-green. Individual kept in the dark was a trifle brighter.

May 23. Both with anals and pelvics fully green, pectorals green except at base. Caudal slightly green. Both slightly green on ventral surface.

The light not having produced any noteworthy difference in the two fish, the water was now shut off from the dark aquarium and an air-jet used to aerate the water. The temperature of the water was thus raised in this aquarium about $5^{\circ} \mathrm{C}$. above that in the light aquarium. 
June 26. Temperature of dark aquarium $27.5^{\circ} \mathrm{C}$, of light aquarium $22.5^{\circ} \mathrm{C}$. Both fish colored as before and no noticeable difference between them.

Thus neither light nor temperature appears to affect the intensity of the colors. The color change is probably referable to internal causes. The physical cause of the color has not been investigated.

2. Habits Not Peculiar to the Breeding Season. - Little is known of Amia at other than the breeding season. Cuvier ('31) refers to it as feeding on crayfish. Kirtland ('41) found crayfish in the stomach of one individual. Cuvier and Valenciennes ('46) found fish and aquatic insects in the stomach of those dissected. Fülleborn ('94) adds small fish to the diet, while Dean ('98) confirms earlier observations on the food, and adds: "A female measuring twenty-eight inches . . . had eaten, among other things, a pickerel twelve inches in length. Another, a female measuring thirty-one inches, contained the (vertebral) columns of eleven fishes each ... about three inches in length. Another, taken at twilight near the margin of a rubbish heap, had eateu scraps of meat and a lump of a raw potato. . . . I have found no evidence that the dogfish eats fish, or more accurately some fishes, after they are dead. Dead perch and sunfish remain untouched, even in regions where Amia is very abundant." The name "Mudfish," under which Garden's specimen was sent to Linnæus, indicates its habitat, as does that of "Marshfish" given it by Richardson ('36). Kirtland ('38) says of it: "The dogfish is found in Lake Erie, where it is frequently called 'The Lake Lawyer.' It is distinguished by its ferocious looks and voracious habits (unde nomen?). The flesh is rank, tough, and not eatable. To the anglers it is a troublesome nuisance, by taking their bait and of ten breaking their hooks and lines, which it can readily do by means of its large teeth and long jaws." Suckley ('60, p. 365) says: "They readily bite at a hook covered with ordinary bait, and when hooked endeavor to escape by feats of strength and skill equal to those of fish of much higher repute. The flesh is soft and pulpy and is popularly believed to be poisonous."' Hallock ('83) adds: "They have been known to bite a two-pound fish clean in two, the very first snap. They are as tenacious of life as the eel." Fülleborn ('94) notes that they emit a low sound when out of the water, either voluntarily or when the abdomen is compressed. Dean ('96, p. 415) finds that "it feeds mainly during the evening and at night,- - but even then he [the fisherman] meets it occasionally when using the jacklight." Whitnan and Eycleshymer ('97) report that "Amia is very shy and nocturnal in its habits." Dean ('98) later modified his opinion thus: "At night, . . . judging" from my own experience with set lines, the fish is not often taken. And the result of my later observations is not favorable to the view that the dogfish is distinctly nocturnal in 
habits. With a view to determining how active the fish were at night, I have kept them in captivity, and I have also watched them at different hours on their spawning grounds when light was no more than sufficient to enable their outlines to be seen. My conclusions indicate that the dogfish is rather to be regarded as most active at twilight. It takes the hook best shortly after sundown and during the early morning, and at these times I have seen it exceedingly active under natural conditions. In a general way the fish can hardly be described as shy. . . It is certainly less apt to notice one's approach than, for example, many common teleosts. The general habitat of the fish varies greatly at different seasons of the year. In summer it frequents deeper water; in spring it comes into the marshy shallows and makes its way through reedy places where the water is scarcely deep enough to cover its dorsal fin." In winter Ayers, as quoted by Whitman and Eycleshymer ('97, p. 325), finds the fish in Oconomowoc Lake, Wis., "in schools closely huddled together in the bottom of pockets or shallow depressions of the gravelly bed of the lake, among the water-weeds. . . . They lie so close together that occasionally two individuals are impaled on the fish-spear by one throw. When thus disturbed they scatter from their resting-places, moving out a short distance to return quickly after the first few disturbances."

That Amia is a powerful and voracious fish, feeding chiefly on crayfish and small fishes, has been abundantly shown in my own experience. That it remains in hiding by day, usually in deeper water, is clear, since it is not then seen except in the breeding season. As further evidence of this it may be added that during the summer I have often seen it taken from deeper water on the hook in considerable numbers in the daytime. Those who spear with the aid of the jacklight are wont to select the darkest nights and those on which the water is unruffled. On such nights I have seen Amia speared in large numbers throughout the summer, in shallow water, where they had no doubt gone to feed. Amia is thus active and feeding during the twenty-four hours, but seeks the gloom of the deeper water by day and returns to shallow water at night. That it is rarely seen except by those who spear at night is, in a measure, explained by the following from my note-book under date of April 28, 1900: "This morning twenty-two Amias, which had been for some time confined in a crate, were taken in the boat to a point where the water was about a metre deep and the bottom of ooze carpeted with a very low growth of aquatic plants, and there released. When placed in the water the fish at once went to the bottom, approaching it obliquely with the snout lowest. Upon touching bottom with the snout, each with a quick movement of the caudal and a wavelike movement of the dorsal instantly disappeared beneath the aquatic vegetation, 
going apparently into the soft ooze beneath this vegetation. There was no perceptible disturbance of the bottom ooze and no cloudiness of the water. The fish, especially those dropped in head first, disappeared into the earth with incredible swiftness, as if by magic, and left no trace behind them."

3. Nest-building.-A. SEason.-During the four seasons covered by my notes the nest-building, as measured by the first and last nests found, was as follows:

$$
\begin{aligned}
& \text { 1898, April } 19 \text { to May } 1 . \\
& \text { 1899, April } 24 \text { to April } 30 . \\
& \text { 1900, April } 23 \text { to May } 16 . \\
& \text { 1901, April } 24 \text { (about) to June } 1 .
\end{aligned}
$$

In 1900 and 1901 the nest-building was interrupted by cold weather late in April and in May, and was resumed upon the return of warmer weather. The brooding of the young continued until June 20 in 1901 and possibly beyond this. The earliest date at which I have taken eggs is April 15, and they were not over two days old. As a rule the middle of April and the middle of June mark the limits of the breeding season in this locality. Further records as to the breeding season are to be found in Hallock ('77), Fülleborn ('94), Dean ('96, '98), and Whitman and Eycleshymer ('97).

It would be most convenient if one were able to fix the beginning of the nesting season by referring it to definite stages in the growth of aquatic or shore plants or to the appearance of other and more readily observed aquatic animals, such as turtles or breeding frogs or toads. I have made numerous attempts to do this, but without uniform results. A relation established in one season may not, and usually does not, hold for the succeeding season.

Shallow water on the spawning grounds is subject to great daily variations in temperature. The greatest variation noted is $7.5^{\circ} \mathrm{C}$. $\left(9.5^{\circ} \mathrm{C}\right.$. at $8 \mathrm{~A} . \mathrm{M}$. and $17^{\circ} \mathrm{C}$. at 3 P.м.). The water has usually reached its maximum temperature at about 6 P.M., and I have made use of temperatures taken at that hour and at a depth of 20 centimetres, and have found the greatest activity in nest-building to occur at temperatures of $16^{\circ} \mathrm{C}$. to $19^{\circ} \mathrm{C}$, measured in this way. The following table shows the relation of nest-building to temperature. It is made by adding the empty nests found during the seasons of 1898,1899 , and 1900 on all those days when the water was of the same temperature. Temperatures are expressed to the nearest degree. In the upper row the temperatures used are those of the day on which the nests were found; in the lower row the temperatures are those of the day before, and probably express more nearly the temperature of the night on which the nests were 
made. The nests were nearly all without eggs when found, and in the few cases in which they contained eggs these were in early stages from which the date of building the nests could be approximately determined.

TABLE I.

\begin{tabular}{|c|c|c|c|c|c|c|c|c|c|c|c|c|c|c|c|c|c|}
\hline \multicolumn{2}{|c|}{$\begin{array}{l}\text { Temperatures in degrees } \mathrm{C} . \\
\text { at } 20 \mathrm{~cm} \text {. depth. }\end{array}$} & 11 & 12 & 13 & 14 & 15 & 16 & 17 & 18 & 19 & 20 & 21 & 22 & 23 & 24 & 25 & 26 \\
\hline $\begin{array}{l}\text { Number of } \\
\text { nests found. }\end{array}$ & $\left.\begin{array}{c}\text { Temperature } \\
\text { taken } 6 \text { P.M. } \\
\text { same day. } \\
\text { Temperature } \\
\text { taken } 6 \text { P.M. } \\
\text { preceding day. }\end{array}\right\}$ & 0 & 4 & 14 & 12 & 0 & 16 & 10 & 32 & 27 & 1 & 1 & 1 & 0 & 0 & 0 & 2 \\
\hline
\end{tabular}

The table shows the optimum temperature for nest-building as accurately as could be expected under the conditions which obtain. The large numbers in the upper row under 14 and in the lower row under 13 may have been the result of a sudden unrecorded change of temperature. That there is no constant relation observable between nest-building in Amia and plant growth is due to the fact that the optimum water temperature for Amia may occur for several days at any stage in the early spring growth of aquatic plants and may thus bring on the nest-building either while the aquatic plants are still small or after they have reached a considerable growth attained at a temperature below the Amia optimum. The relation of this optimum temperature for Amia to the activities of other aquatic vertebrates is not so clear, but is probably of similar sort.

B. Localities.-The localities selected for nests are quiet bays or inlets well grown with water plants and affording shelter for the nests in the form of stumps, bushes, or fallen trees. Those localities are preferred in which the removal of the growing vegetation leaves a thick mat of fibrous rootlets for the bottom of the nest. One such bay of the Huron River, running back from the Lowell mill-pond, was about two hundred metres long and had a width of thirty metres near its junction with the pond. For three years it contained ench year twenty-four or twenty-five nests. In another locality the nests were built one year among the grass-tufted hummocks (called "têtes de femmes" by the French fishermen) of a submerged meadow. In order to reach thein the fish must follow the tortuous passages between the hummocks, but the rootlets of the meadow grass made ideal nest bottoms.

C. Nests.-Each nest is a saucer-like excavation from 30 to 90 centimetres 
in diameter and from 10 to 20 centimetres deep. The bottom of the excavation is usually of the fibrous roots of water plants, which, freed of all earth, form a thick spongy mass. Sometimes, however, the bottom is of gravel or sand or even of black loam, and in two cases it has been of the dead, brown, water-soaked stems or leaves of cattail or other similar water plants. In one case a stone 20 centimetres in diameter was found on a nest bottom. The sides of the nests are usually of rootlets and of growing plants, though occasionally they are of gravel. The figure by Dean ('96) represents very well many of the nests that I have seen, though the nests vary considerably in different localities. I have never seen a nest in which "the soft weeds and rootlets appear bent and brushed aside in a way that gives it somewhat the appearance of a crudely finished bird's nest" as described by Dean ('96).

D. Nests Built by Males.-That the nests are not made by the circling of the two fish while spawning or before spawning (Dean, '96; Ayers as quoted by Whitman and Eycleshymer, '97), but are built by the male in advance of spawning, as surmised by Fülleborn ('94), and without assistance from the female, and are then, while still empty, guarded by the male, seems to me to be shown by the following observations:

1. Of the one hundred and seventy-seven nests of which records have been kept, eighty-one had not been spawned in when first observed. Forty-seven of these empty nests were observed to be guarded by the male fish. Each of the nests was revisited from day to day so long as it showed anything of interest, and at many of these successive visits the male fish was found guarding the empty nest. This was the case seventy-four times with the forty-seven nests and three times with many of the individual nests. At none of these visits was any female found on or near a nest until the spawning took place. That the male was not seen on all the eighty-one empty nests and was not found at every visit made to the fortyseven nests observed to be guarded is due to the fact that he is frequently absent from the nest. Thus a nest unguarded at one visit is often found guarded at one or more later visits.

2. Of these forty-seven nests six were not yet completed when discovered, and were later found to be completed. In a number of these cases the male was seen at work excavating the nest, as noted in another place (see nest-building). No female was ever seen near such a nest.

3. In the seasons of 1898 and 1900 an attempt was made to get experimental evidence of the part played by the sexes in making the nests. The entrance to one of the little bays extending back from the Lowell mill-pond was closed by a fyke net. The bay selected was one in which there had been about twenty-four nests 
in the preceding season. It measured about thirty metres by two hundred, and was open to the pond at one end. The net was placed about thirty metres from the open end, so that there was left behind it an enclosure thirty metres wide and one hundred and seventy metres long. The net was so placed as to catch any fish attempting to enter the bay, while at the same time it prevented fish placed behind the net from escaping into the pond.

The numbers of Amias taken in the net in the season of 1898 are given in Table II. TABLE II.

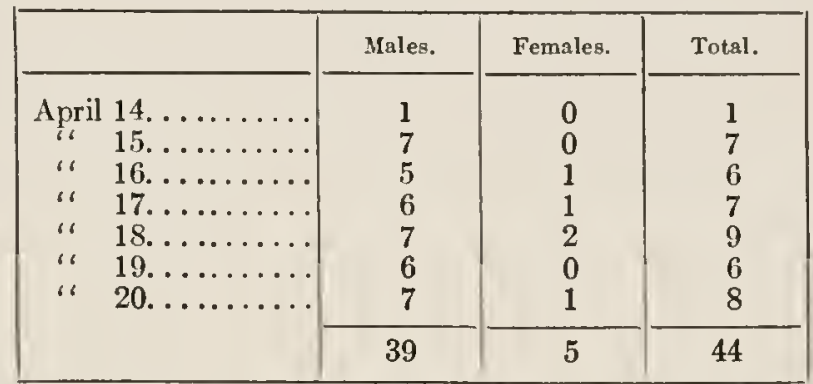

These fish were confined in crates until April 20. At that time all but thirteen of them were released and the net was removed. But one nest had then been found on the spawning ground and no eggs had been laid, so that the spawning season had scarcely begun. During the spawning season of 1898 about twentyfour nests were found in this bay.

In the season of 1900 an experiment was made to learn whether males placed in an enclosure at the natural spawning ground would build nests in the absence of females. The bay was carefully searched on April 18, five days before any attempt at nest-building was noted, and no Amia was found in it. From what has already been said of the habits of the fish it is possible that some adult fish may have remained hidden in the bottom vegetation. The fyke net was then set and care was taken that its wings should reach the bottom throughout their length and that they should extend to dry land at both ends. The net remained in place until May 20, that is, until nest-building had ceased. The results are shown in Table III, in which the spawning season is divided into four nearly equal parts.

TABLE III.

\begin{tabular}{|c|c|c|c|c|}
\hline Periods. & $\begin{array}{c}\text { Number of } \\
\text { Males Taken. }\end{array}$ & $\begin{array}{l}\text { Number of } \\
\text { Females Taken. }\end{array}$ & $\begin{array}{l}\text { Ratio, Males } \\
\text { to Females. }\end{array}$ & $\begin{array}{l}\text { Total Number of } \\
\text { Fish Taken. }\end{array}$ \\
\hline $\begin{array}{l}\text { April } 18 \text { to April } 25 . \\
\text { April } 26 \text { to May } 3 . \\
\text { May } 4 \text { to May } 11 . \\
\text { May } 12 \text { to May } 18 .\end{array}$ & $\begin{array}{r}60 \\
42 \\
6 \\
1\end{array}$ & $\begin{array}{r}22 \\
5 \\
1 \\
0\end{array}$ & $\begin{array}{l}3: 1 \text { circa } \\
8: 1 \\
6: 1 \text { “ }\end{array}$ & $\begin{array}{r}82 \\
47 \\
7 \\
1\end{array}$ \\
\hline Totals for season. & 109 & 28 & $4: 1$ “ & 137 \\
\hline
\end{tabular}


The seventy-four males taken before April 27 were placed in the enclosure back of the net as soon as caught, while the females were confined in crates. Beginning with April 27 all fish were placed in the enclosure.

The bottom on which the net was set was a soft ooze through which it was possible to thrust the hand beneath the net, and therefore through which Amia might force its way. It is of importance, then, to know whether the male fish placed in the enclosure before April 27 were absolutely confined or whether they might pass in and out of the enclosure through the ooze beneath the net. If they were able to pass out, there may not at any time have been seventy-four males in the enclosure, and some of the fish taken in the net may have been fish that had escaped from the enclosure. This, however, would not affect the experiment, which depends on having only males in the enclosure, not upon the number of such males. Those familiar with the fyke net and with the behavior of fish toward nets will readily agree that a fish attempting to enter the enclosure would first explore the net lead and attempt to find an opening through it. In this attempt he would come upon the mouth of the net funnel, enter it and be caught. The fish would not attempt to pass beneath the net unless he had first explored the net lead and found no opening. A fish which was attempting to escape from the bay and which had come upon the net lead and explored it without finding an opening might attempt to pass beneath the net through the bottom ooze. Yet this is extremely unlikely, since fish, through long experience, have learned to pass around obstacles on the deep waterside or over them, and are not wont to seek a passage by burrowing into the earth beneath them. Before April 27 the enclosure then contained a large number of male fish on their natural spawning grounds, and presumably no females.

In this enclosure there were made from April 20 to April 26 twenty-four nests. Previous to April 26 only five of these contained eggs. These five were in two groups, one of two nests, and the other of three nests about five metres apart. There were but few eggs in any one of these nests, and not more in all five than would ordinarily be found in one well-filled nest. The eggs in all five nests were in as nearly the same stage of development as the eggs in a single nest usually are. It is thus probable that the eggs in these five nests were all laid by one or two females, and that these females were in the bay before the fyke net was set. These experiments seem to me to show two things.

First, the experiment of 1900 shows that the whole number of males seeking the spawning ground during the breeding season is about four times the number of females. This is true if no fish escaped from the enclosure, and indicates the ratio of the sexes among sexually mature fish. In this connection it would be of interest 
to know this ratio for those Amias taken in commercial nets at other seasons than the breeding season. The number of fish taken in 1898 would seem to show the males about aight times as numerous as the females. In this case, however, the net was in use during only the first part of the breeding season. The fact that during this first week of the breeding season of 1898 eight times as many males as feniales sought the spawning ground was at first interpreted to mean that the males go first to the spawning ground, but the numbers obtained in 1900 do not admit of this interpretation.

A comparison of the numbers obtained for the two seasons, as indicated in the tables, shows that some of the males may go to the spawning ground in advance of the females (1898) or that the sexes may go together, and that when they do go together the ratio of males to females varies during the season (1900). While the males are engaged in nest-building in the bay described above, the females are probably usually present in considerable numbers in the vegetation of the deeper water at the centre of the bay, where no nests are built.

Secondly, the experiment of 1900 seems to me to show that male fish kept in a sufficiently large enclosure of the natural spawning ground make nests either when no females are present or when very few are present in comparison with the number of males. In this experiment the eggs found in the five nests could not have been laid by more than five females, and were probably laid by one or two, while the number of nests constructed before these eggs were laid was twenty-four. That no more nests were made by the large number of males within the enclosure is due to the fact that there was not space for more, since each male when he has begun his nest drives other males away for five metres or so in all directions in which he has unobstructed view. We cannot suppose that the one to five fenlales present in this enclosure assisted in making the twenty-four nests, and we are this forced to the conclusion that the males alone made these nests.

Since the males are at times seen working at the nests; since the completed nests, while still empty, are guarded by male fish; and since when males are confined in enclosures in which are few or no females, nests are there built in such large numbers that the females could not have assisted in their construction, we may conclude that the males, and the males alone, are the nest-builders. In this respect Amia does not differ from those nest-building teleosts to which reference will be made in another place.

E. Method of Nest-Building.-The method of building the nests is difficult of direct observation. In a nest that has been very recently worked at by the fish the water is still roily when the observer reaches the nest. This condition I have noted 
seven times-six times at night and once by day. That in these cases roiling of the water is not due to the movement of the fish in leaving the nest is shown by the fact that it occurs only on the nest and not outside it (i.e., the fish leaves no trail of roily water), and by the further fact that roiled nests have been seen six times at night and only once by day. Two of these nests were visited at 9 P.M., found to be roiled, and the amount of work done on them noted. They were visited again at 4.30 A.M., and it was found that in the interval the work had been carried much farther. All this shows that the fish works chiefly by night, not by day. On one occasion a male Amia was found lying by day on a half-completed nest, and thinking to see how he worked at the nest, "I watched him continuously for two hours. For one and onehalf hours he remained absolutely quiet, not moving even the fins. During the next half-hour he moved once about six inches and at another time turned around." Since that time males have been reported to me as having been seen assiduously circling on the nests by day, but I have never seen this myself. Only twice have I had evidence of an Amia working at the nests by day. In the first case, "as I came near the nest the tail of the fish could be seen above the water plants, as though he were working head down. Upon approaching, a male was seen lying on a nearly completed nest." In the second case a half-completed nest found at 9 A.M. on April 23 was found completed in the afternoon of the same day. Since the work is done chiefly at night, it is not likely that the method of work will ever be accurately observed.

Over nests that are in process of making or recently finished one often finds floating the young shoots of water plants. These have the appearance of having been sharply cut off and are as a matter of fact probably broken off by rubbing or bitten off by the male fish. Some of these measured 7 to 16 centimetres long and 2 to 5 millimetres in diameter at the base and appeared to be the young shoots of cattail. Another was a cutting of Potamogeton 8 centimetres long. Such cuttings are especially apt to be noted over empty nests visited early in the morning and afford a further indication that the work is done chiefly at night. Often by means of these cuttings I have discovered nests that were so hidden by the floating leaves of the last year's cattails as to have remained otherwise quite undetected.

That the male uses the snout in making the nests is indicated by the fact that in the nesting season the snout of the male is frequently covered with scratches where the epidermis has been removed and the underlying connective tissue shows white beneath it. Probably the male in building the nest breaks off the young shoots with the snout or by the movements of the body or by biting (see also Dean, '98). Prob- 
ably, like many teleosts, he then sweeps the underlying rootlets clean of bottom ooze by the fanning movements of his pectoral and caudal fins. Where he excavates into sand or gravel the work is probably done largely, as in teleosts, by fanning with the caudal and paired fins. This much may be inferred from the fragmentary observations here recorded.

$F$. Location.-The nests are located in the most diverse places. Often they are in the midst of bushes or beneath overhanging branches; again under fallen tree-trunks, beneath the horizontally projecting roots of stumps, or at the sides of logs or stumps. In such cases they are often difficult to find and would almost certainly be overlooked by one not experienced in such matters. Again, and not infrequently, they are located in quite open water. In such cases a round patch of the bottom is thoroughly cleaned, leaving the brown fibrous roots exposed. Nests of this sort, when freshly filled with the yellow-white eggs, are most conspicuous and readily seen, even by the inexperienced, at a distance of six metres or more. In general, where nests are sheltered, they are so placed as to be protected from above and on one side, and at the same time so that the fish has free access to deep water on the opposite side. But even nests built in open water may be wholly concealed by last year's floating vegetation, especially by the floating leaves of cattails. Nests thus concealed may, when fresh, be detected by the cuttings over them or searched for by parting here and there the mantle of cattails and peering beneath. In the season of $1899 \mathrm{I}$ found very few nests during the early part of the season, and was about to give up the search when I discovered that nearly all the nests were concealed under floating cattails. The next year I had all this removed with a rake before the season opened.

The conspicuousness of the nest depends not merely on the openness of the water in which it is, but upon the extent to which the aquatic plants have grown up and upon the number of eggs in the nest. If the aquatic plants are well grown when the nest is made, the nest forms a conspicuous round hole in the midst of them. If there is only a low growth of aquatics when the nest is made, it is correspondingly less conspicuous. Nests with only twenty-five or fifty eggs are of course much less easily seen than those lined with several thousand. The conspicuousness of the nests rapidly decreases as the eggs in their development become darker and as the newly cleaned, light-brown rootlets of the nest bottom darken through exposure to the light. That Whitman and Eycleshymer ('97) found the nests inconspicuous, while Dean ('96, '98') found them at times conspicuous, is probably due to the location, character, and age of the nests seen by these investigators, as well as to the difference in the color of eggs and nest bottom in different localities. 
Sometimes the male does not excavate a nest, but makes use of a natural depression of the bottom formed in suitable material, as shown by the following extract from my note-book: "This nest does not appear to have been built at all. There is a natural depression, the bottom of which is covered by the long slender dead leaves of a shore sedge (?) or grass, leaves of the diameter of a knitting-needle. The little sediment upon the surface of these leaves may have been fanned away. Upon the leaves the eggs are laid, but the fish has apparently not removed any of them, but has merely made use of the natural conditions." Similar instances are noted by Fülleborn ('94), Whitman and Eycleshymer ('97), and Dean ('98).

Small areas on the bottom are often found that are covered with fibrous rootlets and devoid of growing plants, though walled in by such plants. These areas so closely resemble nests as to be frequently mistaken for them. They may be told from nests by the ooze that covers the rootlets in greater or less abundance; but this ooze is often scant in such areas and they are then only to be certainly distinguished from nests by following their further history. These areas are to be found wherever the shade is so deep and continuous that water plants do not grow well. They are especially well marked under floating slabs of wood, floating stumps of small masses of floating cattails which happen to be held in place by adjacent vegetation. This vegetation largely excludes the side light and so deepens the shade and hinders the growth of aquatic plants, but does not prevent the penetration of their rootlets into the shaded spot. A strong wind or a freshet may remove the floating object and leave the nest-like area fully exposed in free water. Such plantless areas are of course the rule under logs, stumps, fallen trees, and bushes; and it is probably not only the shelter afforded, but also the absence of growing plants that leads the fish to select such places for hidden nests. Where the nests are built in the open, the small size of the plant cuttings removed and their relative fewness shows that similar plant-free areas are selected. The fish does not locate such nests on spots previously thickly grown up with water plants and then tear out these plants, for in that case considerable masses of such plants would mark the location of each nest. He selects rather a relatively plantless area surrounded by a wall of growing plants, and from this area removes the few young shoots and cleans up the rootlets. I have no doubt that suitably prepared artificial nests placed on the spawning ground would be utilized by the fish. If this account is correct, the nests are certainly not uniformly "in places to which the sun and warmth always have unhindered access" as stated by Fülleborn ('94).

$G$. Frequencr.-The frequency of the nests depends largely upon the number of male fish as related to the area of available spawning ground; though, owing to the 
fact that in open water each male defends the visible territory immediately about his nest, this frequency can only reach a certain maximum in such water. In sixteen cases the distances between nests located in open water was estimated to vary from two and one-half to eight metres. Sheltered nests so located that the males occupying them cannot see one another may be much nearer together. This is often the case about a $\log$ or on the sides of a narrow projecting point of dry land. In one such case seven nests were found within an area estimated to be six by nine metres, and in another case six nests were counted about a $\log$ within a circle of four metres radius. In still another case three nests were found within a circle of two metres radius. Dean ('98) gives similar measurements, while Whitman and Eycleshymer ('97) "have never found the nests in such close proximity, never more than four or five in a single bay and usually rods apart."

4. Guarding of Empty Nests by Males. - Evidence that the completed nests are guarded by the male fish previous to spawning has been presented in a preceding section, and the frequency with which this has been observed is there noted. The observations of Fülleborn ('94) and of Dean ('96) are thus confirmed, rather than those of Whitman and Eycleshymer ('97, p. 319), who "have never observed either the male or female occupying a nest for a number of days or even one day before deposition." The length of time during which the males remain on guard over the empty nests varies greatly. I have noted most frequently periods of from twenty-four to thirty-six hours (twelve cases of twenty-four hours and two of thirty-six hours). In three instances I have noted a period of forty-eight hours. In one case a half-completed nest found on April 19 was not filled with eggs until April 25, a period of six days. Again, a completed nest was found occupied by the male on April 28 at 8 A.M., and he was still on guard over the nest containing eggs in early cleavage stages, evidently laid the night before, on May 1 at 5 A.M., two and one-half days. A half-finished nest guarded by the male was found at 9 A.M. on April 23. In the afternoon of the same day it had been completed. The male was still guarding the empty nest at 9 A.M. April 26, a period of three days. I have a second record of an empty nest guarded for three days. The longest period that I have observed was thirteen days. The nest was found on May 2 at 5.30 A.M.; the male was still guarding it on May 5 at 9 A.M. It was visited at 4 A.M. on May 15 and an Amia was found on it. In this case, owing to the sudden departure of the fish, it could not be made out whether it was a male or a female; nor can it be said positively that this was the identical fish found guarding the nest on May 2.

Nest 71 was found empty and unguarded on April 25 at 9 A.m. On April 26 
at 11 A.M. it contained eggs in cleavage stages and therefore laid on the night of April 25. The eggs were very few in number. The male was still guarding the nest, and it contained eggs on April 28 at 9 A.M.; but on April 29 at 9 A.M. the eggs had disappeared. The male was guarding the empty nest at 7.30 A.M. on April 30 . This is a period of five days, during three of which the nest contained eggs, but whether in this case the original male had cleaned his nest of its unsatisfactorily few eggs and was awaiting a second female, or whether he had been displaced by a rival male, is uncertain, though the first supposition is by far the more probable.

The periods given above are those observed and are in nearly every case considerably shorter than the actual periods; for it is always likely that the nest was guarded for some time before any observation was made on it, and that when, in later visits, it was found empty the male was often only temporarily absent.

If the female does not appear, the waiting male ceases after a time to guard the empty nest. The nest then becomes gradually obliterated by the deposit of sediment and plant débris, and in some cases by the ingrowth of the adjacent aquatic plants. In most cases the nest returns more or less to the condition of the nest-like areas already described.

5. Spawning.-I have been able to determine the time of day at which Amia spawns in thirty-one cases. In four of these the actual spawning was observed. In two the nests were found empty, and a few hours later they were full of eggs in cleavage stages. In the remaining cases the nests contained eggs in cleavage stages when found, and the time when they were laid has been reckoned by the use of the table given by Whitman and Eycleshymer ('97, p. 321). This table shows that the eight-cell stage is reached about four hours after deposition of the eggs, and the late cleavage ten hours after deposition. By late cleavage I understand a stage in which the upper small cells are just visible with a hand-lens (Whitman and Eycleshymer, '97, p. 339, Fig. 10). The stage of these, as of other eggs, was determined at the time of finding the eggs, by fixing a few in formol-bichromate-acetic acid,* transferring to water after 10 or 15 minutes, removing the shell with needles and examining with a dissecting microscope.

\footnotetext{
* A solution is made containing $2.5 \%$ of potassium bichromate and $10 \%$ glacial acetic acid. To this at the time of use is added commercial formol (40\% formaldehyde solution) in the ratio of one part of formol to twenty of the solution. In preserving cggs for cmbryological use the fluid is allowed to act for 8 to 12 hours, then replaced with $4 \%$ formol, which is changed until it remains clear. The eggs are preserved in the formol. With this fluid the eggs are not distorted by shrinkage of the shcll, the histological details are well preserved, and the yolk cuts more readily than with any other fluid that I have used.
} 
Table IV shows when the eggs were laid in the thirty-one nests.

TABLE IV.

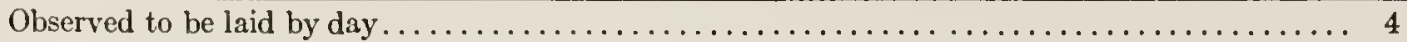

Nest found empty and later on the same day with eggs in early cleavage. ..............

Found at 1 P.M. in 2- to 4-cell stage, estimated to have been laid between 9 and 10 A.M....... 1

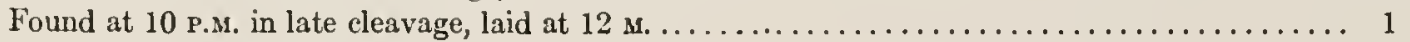

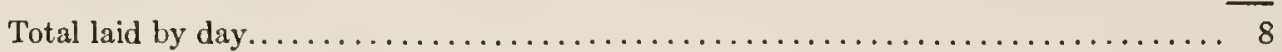

Found in late cleavage 4.30 P.M., estimated to have been laid 6.30 A.M. . . . . . . . . . . . . 1

Found in 2-to 16-cell stage at 5 to 7 A.M., estimated to have been laid between 2 and 4 A.M..... 8

Found in late cleavage 8 A.M. to 12 M., estimated to have been laid between 10 P.M. and 2 A.M.... 14

Total laid at night. $\ldots \ldots \ldots \ldots \ldots \ldots \ldots \ldots \ldots \ldots \ldots \ldots \ldots \ldots \ldots \ldots \ldots$

The rate of development depends upon temperature. In the tables given by Dean ('96), and by Whitman and Eycleshymer ('97), the temperature is not given, and in collecting cleavage stages $I$ did not note it at the time. Nevertheless, in all these cases the eggs were undoubtedly laid at the usual temperature at which Amia spawns, i.e., not far from $18^{\circ} \mathrm{C}$., and the temperature during the few hours following the spawning is not likely to have changed sufficiently to have greatly modified the rate of development of the eggs. The only doubtful case seems to be that of the eggs estimated to have been laid at 6.30 A.M. These may have been laid before daylight or after. In general, we may say that spawning takes place two and onehalf to three times as often by night as by day. In the four cases where spawning was actually observed it occurred between 3 and 4 P.M., 5 and 6 P.M., 10 and 12 A.M., and at 3 P.M. Whitman and Eycleshymer ('97) noted one case of spawning by day and quote Ayers as having observed "some cases in which the eggs were cast in the afternoon." Ayers is further quoted as saying that "The nest-forming process generally begins at early dawn, and the eggs are cast about sunrise."

That the sexes are able to detect one another at considerable distances, and that the females seek the nests prepared by the males, is indicated by the following observations: An empty nest, not yet finished, was found on June 1. On June 3 it appeared to be completed and was occupied by the male. "I then saw the female at a distance of about 12 metres from the nest and with her head pointed toward it. She became frightened and disappeared into deep water." Further evidence of the power of one sex to detect the presence of the other is afforded by the presence of strange males about nests in which spawning is going on and by the following experience: In 1900 twenty-one females were confined in a crate of slats, spaced about 2.5 centimetres apart, so that water could enter between them. The crate was nailed to stakes so that its bottom was about 30 centimetres from the bottom of the pond. At six o'clock on the morning of April 26 a large number of nuales, 
estimated at about twenty, had gathered about this crate. At 9 o'clock five were still there and appeared to be at work beneath the crate. In the mean time all the nests, eight in number and all without eggs, on the opposite side of the bay at a distance of about thirty metres were deserted by their male occupants. On the following day one male was still at the crate and two new nests had been built near it, one at a distance of three metres and one at six metres. The males about the crate were by no means easily frightened, so that one could walk out on the gang-plank to the crate and watch their movements. On April 28 the males were gone, and when the females were removed from the crate there was found a large nest excavated in the ground beneath the crate.

The behavior of the spawning fish was observed in one instance by Whitman and Eycleshymer ('97), but for only a brief period; I too have observed spawning only once, but for a much longer time than Whitman and Eycleshymer. "Nest No. 35 was found April 25, and then contained a moderate number of eggs in early embryonic stages. The male was on the nest at 11 A.M. April 26, and again at 1 P.M. I went to this nest at 3 P.M. April 26, and upon approaching it saw a fishtail appear above the water. I brought the boat to within two feet of the nest, and found the water much roiled. After some time I could make out two fish, a large female and a male, both moving about in the nest. The male was much more active than the female and was engaged in circling about the nest in such a way as to meet the female head on and travel thence toward her tail. As he moved past her he bit her either on the snout, or on the side of the head, or on the body as far back as the middle. When the male attempted to pass the female by circling from her tail toward her head, she, in two cases observed, turned so as to rotate her long axis through one hundred and eighty degrees, thus reversing the direction of the male with reference to her and again making his course from head to tail. This movement appeared to indicate to the male that she was not ready to spawn. If she had not turned, the male would have lain by her side, their heads in the same direction, the spawning position. The movements of the fish kept the water so roiled that details could be seen only occasionally. Several times the circling was interrupted by more violent movements of both fish, the nature of which could not be made out, but at these times the fish were probably spawning. Both left the nest a number of times and then returned to it and resumed their movements. The female left the nest first at such times, and the male remained circling over it. Presently he also left the nest, made a circle of one and one-half to two metres in diameter as though searching for the female, and then returned. At times he made a second circle in the same or in a different direction, and often a third and a fourth. 
On one occasion the circles were thus continued until the neighborhood of the nest on all sides had been explored. Usually before this happened the male returned to the nest with the female, or the female returned while the male was on the nest and the circling movements were then resumed. Several times the male came to the surface, giving out bubbles of gas on the way. He then thrust his whole head out of water and appeared to gulp in air. The female did this once. The fish while circling had their mouths slightly open. Although we were near enough to put our hands on them, they took no notice of us at any time. The movements of the fish lasted one hour and twenty minutes. Some time before this the female failed to return to the nest, but the male remained on it or near it. We then took the eggs. During this operation the male remained near and several times made a savage dash at my hand, once butting it with his head. The eggs were found to be in early precleavage and cleavage stages. Among them were a good many eggs of the original brood, showing well-developed embryos. This is clearly a case of a nest used twice and containing eggs in widely different stages. The male parent is probably the same for both broods. During the above spawning movements two other males were seen near the nest, but neither came to it." This account is taken directly from my note-book. (See also Dean, '98.)

On three occasions Peters, the fisherman, was able to watch the spawning. This occurred once at noon in bright sunlight, while he stood on a stump at the base of which was the nest, and again between 3 P.M. and 5 P.M. In both cases the water was clear and he could see all the details of the behavior of the fish. His account agrees with my own observations, but I add some details:

"The female lies at the side of the nest. When the male approaches her from the front he opens his mouth and takes hold of her snout, both upper and lower jaws. He doesn't bite, but takes hold gently (Peters described this as kissing). Meantime the female lies quiet, moving only her fins. The male then passes his head beneath that of the female and stops thus for an instant, or passes on at once. As he passes on he turns in a circle either toward the centre of the nest or toward the edge. If he turns toward the centre of the nest he makes a small circle and swings his tail up over the back of the female. If he turns toward the edge of the nest his tail sweeps beneath the head of the female. This is kept up for fifteen or twenty minutes. The male then approaches the female and lies by her side, his snout a little back of her pectoral. All his fins and his tail are in vibratory movement. The female lies quiet, moving her dorsal and paired fins, but not her tail. She lists a trifle to one side, but the male remains upright. These positions are maintained for fifteen or twenty seconds, and when the fish separate 
eggs are seen on the bottom of the nest. The circling is then repeated, after which the two fish again come together and eggs are laid. This alternate circling and laying of eggs continues until four or five egg-laying periods have been passed through." (Note-book.) In this case the spawning continued for one hour and forty minutes and the nest then contained relatively few eggs. The next morning the nest contained a much larger number of eggs. I have no doubt of the substantial correctness of these details, which were twice clearly and once less clearly seen by Peters. In no case was there seen any posing of the male with fins spread in front of the female, such as occurs in some teleosts, nor was there any other evidence that the male used his colors as a sexual excitant. Since spawning takes place chiefly at night, such use of the colors of the male is not to be expected. He produces sexual excitation of the female rather by biting, usually gently, and by stroking her with his body and fins in passing.

These observations show that the egg-laying is intermittent in character. In addition to the direct observations given above, as to the length of time occupied in spawning, we have that derived from the eggs in cleavage stages when taken from the nest. My records show three cases in which the eggs were in two- to sixteencell stages, one of four to eight, one of two to four, and one of eight to sixteen. In the other cases of which I have notes the eggs are recorded merely as in early cleavage. The table given by Whitman and Eycleshymer indicates that it takes about three hours for the eggs to pass from the two- to the sixteen-cell stage, and about one hour intervenes between the stages, so that from this evidence the time occupied in spawning by a single pair of fish may be estimated to be between one and three hours, which agrees very well with the actual observations. This conclusion is in harmony with that of Ayers, as quoted by Whitman and Eycleshymer, though they themselves appear to consider the average period of egg deposition as ten to fifteen minutes. Dean ('96) finds in one nest evidence of a period of "about twelve hours, in another a period of about half an hour."

That two females may spawn in the same nest with an individual male is made probable by the history of nest No. 35, as given above. Nests 4 and 41 have a similar history, but in them it is less likely that the male parent was the same throughout the history of the nests. Nest 4 was begun on April 19, and eggs were laid in it at noon of April 25. On the morning of April 26 the nest had apparently been abandoned and small sunfish (Eupomotis gibbosus) were found in it presumably engaged in eating the spawn. At noon of the same day there remained not more than half a dozen of the several thousand eggs originally laid in the nest, and sunfish were still hovering about. At 2 P.M. it contained a male fish, absent 
at 3 P.M. and again in the nest at 4 P.M. On the afternoon of April 29 a male was again in the nest for several hours. On April 30 at 3.30 P.M. two males were seen lying on opposite sides of the nest. At 3.50 P.M. a male and a female were in the nest and the spawning was seen to take place. On the next morning the nest was found to be well filled with eggs.

Nest 41, found on April 25 at 4 P.M., contained then about twenty eggs in a late pre-embryonic stage. On April 26 at 2 P.n. the nest was empty and the male absent. On April 29 at noon the nest was full of eggs in an early pre-embryonic stage. At this time I had not learned to identify individual fish, and since then I have had no opportunity to repeat the observations. In another paper I shall describe a case in which an individual male of Eupomotis gibbosus reared in one nest two broods from eggs laid at quite different times by two females, and I have no doubt that, as indicated by the observations given above, this happens also with Amia (see Whitman and Eycleshymer, '97).

That an individual female may spawn in more than one nest is also highly probable. This, I take it, is what happened in the case of the five nests referred to above, in which eggs were laid in the enclosure supposed to contain only males. These nests were in two groups, one consisting of nests 71 and 73 , near one another, and the other of nests 79,80, and 81, about five metres apart. All five nests contained eggs in nearly the same stage (within two to four hours), and the total number of eggs in the five nests was not more than is often found in a single nest. This indicates that they were laid by one or two females. In this case an individual female upon leaving one nest in an interval of spawning probably found herself near a neighboring nest and was brought into this second nest by its occupant and there spawned. This view is the more probable since this is again precisely what happens in the case of Eupomotis gibbosus, and since in two of the four cases in which the spawning of Amia has been actually observed other males than the owners of the nest have been seen in the neighborhood. If the nests of any season were carefully platted on a map and the stage of development of the eggs carefully noted, I should expect to find frequently that adjacent nests have eggs in nearly the same stage of development, but unfortunately I have not located on my sketch-maps a sufficient number of nests to throw further light on this point.

I have made numerous attempts at artificial fertilization, but I have never found it possible to strip the female fish. Twenty-one females were taken in a fyke net during the spawning season as they were going to the spawning ground. These were confined in a crate, as already described. The fish were removed daily for eight days and examined by an experienced spawn-taker, to see whether they were 
ripe. The abdomen did not become softer, and at no time was it possible to strip them. Finally, three of those that seemed softest were opened, but no eggs were found in the oviducts or body cavity, nor could the eggs be removed from the ovaries without injury. Attempts at artificial fertilization of these eggs failed. Nevertheless a few eggs were laid in the crate and were found adhering to its bottom and sides.

Male and female fish were also placed together in a square enclosure of netting about 5 metres on each side and on the natural spawning ground. Three males in brilliant breeding colors and two apparently ripe females were used. The experiments continued for eleven days, but no nests were made and nothing of importance noted, except that a few eggs were laid along the netting and adjacent vegetation.

The usual course of nest-building and spawning may here be briefly summarized as follows: In water of 30 to 60 centimetres depth with abundant growing plants, males select small areas on the bottom which are relatively free of growing plants and are often concealed, and from these by movements of the body and fins and perhaps by biting they remove the few plants and the bottom ooze so as to leave exposed the fibrous roots of the plants or the sand, gravel, or other subjacent material. The nests are thus excavated in the absence of the females, and chiefly at night. Their proximity to one another varies with the number of males as related to the area of available spawning ground and with the character of the ground. These nests, while still empty, are guarded by the males for usually twenty-four to thirty-six hours, but often for a much longer time. They are then usually approached by the females and the spawning takes place. If the female does not appear, the nest is abandoned. The spawning is intermittent, and the characteristic spawning movements last from one to three hours, during which the fish are very active. During the spawning movements there is no evidence that the male displays his colors before the female. Sexual excitation of the female is produced rather by biting and stroking. In some cases a single female probably spawns in more than one nest. A single male may, after an interval of some days, receive a second female into his nest, and her eggs may be laid along with those previously in the nest or may supplant them. The number of eggs laid in a nest varies greatly. I have seen as few as 25 freshly laid. The maximum number is probably many thousand, but I have never counted them. They may be over the whole inner surface of the nest, on the bottom only, or on one side only, If fibrous roots are present they are invariably on these.

6. Guarding the Eggs; Protective Colors of Male.-While guarding the nest both before and after it is filled with eggs the male lies at times directly on the nest, 
of ten exposed to bright sunlight (see photographs by Dean, '98), while at other times he lies concealed in the natural openings of the adjacent vegetation. I have never observed that he removes any vegetation or that he in any other way prepares a "run" or "bed" for himself. In order to approach the nest one may wade or use a boat, best a flat-bottomed punt propelled by a paddle. For the purpose of finding nests wading permits of more careful examination, but for subsequent visits the boat is to be preferred wherever practicable. In both cases great care must be taken not to cause any sudden disturbance of the water. In wading one must move very deliberately, of ten as slowly as possible, and must be certain that the forward foot is on firm bottom before taking the next step. In lifting the feet. from the water they should be brought out slowly and toe down so as to permit the water to run from the boot as gently as possible. In this way, if no false step has been made, one may usually come directly over the nest without disturbing the male, unless one has happened to come upon him unawares in his hiding-place near the nest. If the fish is not visible or not wholly visible as one stands over the nest, the vegetation which covers him may be gently and very slowly pulled to one side and the fish fully exposed. This I have done often, and in one case, after having exposed the fish and nest in this way to a flood of sunlight, I was able to set up a camera on a tripod directly against the nest and to spend half an hour in attempting to photograph the fish, and all this without causing him to move farther than from one side of the nest to the other. The fish do not react to the visual image of the observer, but to sudden movment whether of the water itself or of the objects outside the water and independent of it. It is therefore only necessary to move slowly enough and without mechanical shock to the water to attain any desired position with reference to the fish.

As the observer approaches the male may move toward him, but not usually beyond the limits of the nest. If frightened, the male goes off with so much rapidity as to leave a wake behind him. I have not observed that at this time he splashes with his tail above water as he does later when attending the swarm of young. After a time the male may be seen to return slowly and quietly to the nest, and if one has waited one may then watch him for any length of time. Males on empty nests take fright much more readily than those on nests containing eggs, and from such nests it is usually not possible to remove the floating vegetation without disturbing the fish, whose senses are then doubtless all alert in expectation of the approach of the female. That the male does not stand guard continuously over the nest is shown by the fact that at many visits he is not found in spite of careful search through all the surroundings. 
In order to see whether the male is on the empty nest more often than on that containing eggs or is on the nest in the morning more often than in the afternoon, the following table was made. It shows the total number of visits made to the sixty-seven nests of the years 1898 and 1899, omitting those visits made after the nests showed signs of deterioration, as though abandoned. It shows also the nunber of times when both the empty nests and the nests containing eggs were guarded in both morning and afternoon.

TABLE V.

\begin{tabular}{l|c|c|c|c|c|c|c}
\hline & $\begin{array}{c}\text { Total Number } \\
\text { of Visits. }\end{array}$ & $\begin{array}{c}\text { Empty Nests } \\
\text { with Male. }\end{array}$ & $\begin{array}{c}\text { Nests with } \\
\text { Eggs } \\
\text { and Male. }\end{array}$ & $\begin{array}{c}\text { Total Nests } \\
\text { with Male. }\end{array}$ & $\begin{array}{c}\text { Per cent } \\
\text { of Nests } \\
\text { with Male. }\end{array}$ & $\begin{array}{c}\text { Empty Nests } \\
\text { without Male. }\end{array}$ & $\begin{array}{c}\text { Nests with } \\
\text { Eggs but } \\
\text { without Male. }\end{array}$ \\
\hline Morning visits.................. & 71 & 10 & 10 & 20 & 28 & 24 & 27 \\
Afternoon visits............... & 68 & 20 & 21 & 41 & 63 & 11 & 16 \\
\hline
\end{tabular}

From this it appears that the empty nests were found guarded quite as frequently as those containing eggs, and that the fish were found on $63 \%$ of all nests visited in the afternoon and on only $28 \%$ of nests visited in the morning; that is, they were absent from the nests about twice as often in the morning as in the afternoon. I have visited nests at night only for the purpose of securing precleavage stages, and have therefore visited chiefly empty nests, and these during only a part of one season, in which, as it proved, a large number of the empty nests were abandoned. In one hundred and sixteen such visits at night the fish was found in twelve cases or in about $10 \%$. These visits were made to twenty-four nests, of which but three were subsequently spawned in, so that it is likely that many of the visits were made after the nests had been deserted. It is possible that the males are often absent from empty nests at night and in search of the females, but this point could be best determined by records of night visits to empty nests which were subsequently spawned in, as well as to nests containing eggs.

While the male guards the nest he lies for the most part motionless or with only slight movements of his fins, but at intervals he moves over the nest and thus by the movement of his fins keeps the eggs free from sediment, which would otherwise soon smother them. With the sediment the fungus spores are doubtless also removed. At the same time the male keeps away other males which at times try to occupy his nest. This I have seen twice. In one instance the two males were seen in the same nest, which was at the time empty. One of them turned suddenly, and rushing at the other struck him with his head in the middle of the side and hurled him two feet from the nest. In the second case a nest containing eggs and guarded by a male fish was approached by a second male, which came to within 30 
centimetres of the nest and then slowly backed away to a distance of about 4 metres and lay quiet with his tail toward the nest. Presently the first male left the nest, went rapidly to the second fish, appeared to bite him in the side, and drove him away. I have never seen the fierce battles described by Whitman and Eycleshymer, but I do not doubt their occurrence. Males are sometimes found with fresh wounds on the head or with the tail partly torn away. These wounds I at first supposed were due to the battles of the males, but in subsequent seasons when I had so arranged it that no Amias were speared on the spawning grounds, I found no more such wounded fish.

Besides guarding the nests against their own kind the males keep off minnows, sunfish, and probably other small fish that feed on the eggs. There is no surer sign of an abandoned nest than to find it occupied by small fish. I have also found turtles and tadpoles in such nests, but this is possibly accidental.

As the male guards the eggs one is struck by certain resemblances between his colors and those of surrounding objects. All his fins are of a green like that of the aquatic vegetation and blend with it readily. The reticular markings on his sides bear a close resemblance to the shadows cast by the intercrossing leaves of the vegetation floating at or near the surface. This resemblance is so close that after prolonged examination at a distance of a foot or two I have been unable to say with certainty which of the reticulations on the side of the male were due to pigment and which were shadows. They could only be distinguished through some slight movement of the fish. Moreover, the tail-spot bears a striking resemblance to certain refraction images that are commonly seen on the bottom in shallow water. These are seen on sunny days wherever minute elevations of the water surface are produced by the projecting tips of water plants. They are of about the size and form of the tail-spots of the male Amia; the colors are the same; the relative width of border and central area is the same; the color of the background on which they are projected is the same. As one looks from one to the other, the likeness, once seen, is remarkable. Besides this, the general brown-green or bronze-green color of the back and sides of the male blends with the brown tone of the pond bottom.

I do not know that the male is less conspicuous than the female when the two are together on the spawning ground, for they are not seen together except when spawning, and the observer is then occupied with other matters. This could be determined by examining recently killed fish side by side in their natural surroundings. Of this much, however, I feel sure, that given the colors of the male it would be difficult to produce a natural color pattern that would render the fish less conspicuous than that which he possesses. Before the extermination of fishing mam- 
mals and birds the males of Amia were doubtless, while on the spawning grounds, much subjected to their attacks, and their coloration must then have been of some use. That the colors themselves were produced in adaptation to these conditions may be doubted, but that the color pattern is such an adaptation and may have arisen through selection is hardly doubtful.

7. History of the Eggs and Young Larvæ in the Nests. - The eggs have been accurately described by Whitman and Eycleshymer ('97). In the eggs found near Ann Arbor the calotte is white and the yolk is of a very light yellow, nearly white. The eggs, seen in mass, are therefore very conspicuous in their earlier stages. I have never seen eggs of the brown color figured by Whitman and Eycleshymer ('97). In the nest the eggs hatch in from eight to ten days at the usual temperature, though as noted by Dean ('96) and Fülleborn ('94) this period may be either prolonged or shortened by temperature. When hatched the larvæ are about 7 millimetres long, colorless and incapable of progressive movement, and they either attach themselves to the nest material by the adhesive organ at the end of the snout and remain suspended in a vertical position or lie on their sides on the bottom. They remain in the nest for about nine days after hatching. In one case noted the eggs hatched on the ninth day and the larvæ were found leaving the nest on the sixteenth day. In a second case the eggs hatched on the ninth day and the larvæ left the nest on the eighteenth day. While the larva are still in the nest the following changes, repeatedly observed in fish taken from the nest from day to day, may be seen:

$A$. Increase in length to about 12 millimetres (see Whitman and Eycleshymer, '97, and Fülleborn, '94). Measurement from five broods about to leave the nest showed 11, 11.5, 11.5, 12, 13 millimetres. Those which measured 11 millimetres had left the nest next day.

$B$. Changes in the size and form of the yolk-sac. At 9 millimetres it is eggshaped as observed by Whitman and Eycleshymer, with the smaller end directed backward. At 11.5 millimetres it is elongated, flat and irregular, about 2.5 by 1 millimetre, and lies on the right side of the larva.

$C$. The pectoral fins become vertical, as noted by Whitman and Eycleshymer. There are as yet no pelvics.

$D$. Black pigment develops gradually until at 12 millimetres the whole body is very dark greenish black or greenish brown, except the ventral surface, which is dirty white. The iris is metallic golden.

$E$. The use of the adhesive organ becomes gradually less, so that by the time the larvæ have reached a length of 12 millimetres it is no longer functional and the larva swim continuously. 
$F$. With the shrinking of the heavy yolk-sac and the atrophy of the adhesive organ the individuals gradually acquire progressive movements which are well marked at the end of twelve to sixteen days. These are effected by the rapid vibration of the pectorals and of the heterocercal caudal, and are intermittent in character, intervals of rapid vibration alternating with shorter intervals during which the fins are at rest or nearly so and the fish merely forges ahead. The progressive movements at this period resemble in their intermittent character those of the adult brook lamprey. By the time the larva are ready to leave the nest, the intervals of rest have been much shortened and the vibratory movements are nearly continuous.

G. Swarms of larvæ are formed and progressive movements are developed within a few hours. Six nests containing larvæ about ready to leave the nest were examined on the morning of May 8 and the following conditions found: "The larvæ are usually bunched together, often in a dense mass with many of the individuals hidden in the fibrous roots of the nest bottom." In nests containing somewhat younger larvæ the masses or swarms are stationary and the individuals composing them are still using the adhesive organ. From time to time the individuals free themselves, swim back and forth through the swarm, then become again attached. In other nests the swarms are also stationary, but the individual fish are no longer using the adhesive organ, but are in continuous movement back and forth within the limits of the swarm. Such swarms are composed of larvæ about 9 millimetres long.

In the afternoon I returned to some of these nests. In some of them the larvæ were no longer to be found, in others they were in the same condition as in the morning, but in one the larvæ were nearly ready to leave the nest. None of them were using the adhesive organ. "They swim together in a swarm which moves in a generally circular direction about the edge of the nest or just outside it. The larvæ, though not progressing continuously as individuals, form a swarm which nevertheless progresses, one way and another, with many internal irregularities. The movement reminds one of the indefinite flowing movements of an Amoba, in which pseudopods are put out this way and that and often withdrawn, but the animal as a whole progresses definitely." These larvæ were 11 millimetres long. How a stationary swarm may thus become progressive I was able to observe at another time in a nest which had been deserted by the male and which, in order to protect it from marauding fish, had been fenced in by placing a frame of boards about it so as to form a square enclosure five metres on each side. The larvæ were in several masses. In one of these "the larvæ formed a dense swarm four inches in 
diameter and near the edge of the enclosure." The movements of the individuals in this swarm were back and forth like trapped Paramœeia, each turning and returning within the swarm upon passing its border. Many individuals frequently move in the same direction at the same time. Occasional shifting of the swarm is produced by an individual or group of individuals moving farther than usual beyond the boundary before beginning to return. There is thus produced a slight pseudopod-like lobe to the swarm. This lasts long enough to permit other individuals of the swarm to enter it, until finally the centre of density of the swarm is shifted and the swarm has moved. When the swarm had moved thus about a foot it became centred about a bunch of five or six erect, loosely aggregated grassstems and there began then a definite rotation of the swarm in a direction opposite the hands of a watch. The individuals moved at this time at the rate of about 1.5 centimetres per second. After six and one-half minutes the movements became again indefinite and the swarm contracted. Shortly it began to rotate in the opposite direction and continued this for four minutes. It then became again contracted and the movements irregular. Fifteen minutes later it was again circling counter-clockwise, and four minutes later in the opposite direction. Five minutes later the swarm again moved to a distance of a foot and then became stationary. Sometimes the swarm remains quiet for three-quarters of an hour. "This quiet state is one in which the individuals are moving indefinitely back and forth, but very slowly, and more slowly at the centre than toward the edge. Indeed they usually stop or nearly stop at the centre. There is thus produced a swarm dense at the centre and loose at the edge, in this case 15 to 18 centimetres in diameter and with its central five centimetres very dense. In the one instance in which I studied the larvæ in the nest at night they were found in a stationary swarm, nearer the bottom than is usual by day. They came a little nearer the surface under the influence of the light.

$H$. The larvæ begin to feed while still in the nests. In bright sunlight one may see numerous small crustacea among the rootlets of the bottom. The larvæ may be seen springing at these, and their success is attested by the strings of fecal matter often seen protruding from their anal openings. Larvæ 11 millimetres long when taken from the nest were found to have the stomach well filled with small crustaceans, chiefly ostracods.

Larvæ which have reached the length of 12 millimetres are then black, the yolk-sac is two-thirds absorbed, the adhesive organ is no longer used, they are swimming by means of intermittent vibratory movements of pectoral and caudal in swarms which move progressively but irregularly, and they are feeding. They 
are now ready to leave the nest. Although Fülleborn says that the larvæ remain in the nest until about 13 millimetres long, Dean ('96, '96 ${ }^{\mathrm{a}}$ ) was unable to find them in a nest which he visited shortly after the eggs had hatched and was inclined to accept the suggestion of his companion, Kosmak, that they had been taken away by the male attached to him by their sucking discs. Whitman and Eycleshymer characterize this as "a bit of romance." Dean ('98) has since very properly abandoned the idea, for which there was at no time evidence, and says: "In 12-15 days a length of 9-11 millimetres is reached. . . . About this time the larvæ are ready to leave the nest with the male fish."

Several times I have heard fishermen relate that they have seen the males of Amia swimming completely enveloped in larvæ. At the same time they have taken other males which were much emaciated and covered with small light-colored spots. From these observations they believe that the young Amias attach themselves to the male and are thus nourished. Thus they account for the spots and the emaciation of the male. Highly improbable at any time, this story is rendered wholly impossible by a knowledge of the fact that the young remain in the nest until the adhesive organ has become functionless. The male is frequently seen enveloped in the swarm of young. The spots observed by the fishermen may have been Arguli. Thus, possibly, is this myth accounted for.

8. History of the Larvæ Outside the Nest.-I have followed the history of the larvæ outside the nest until they were 10 centimetres long. At this time they are like the adult fish except in color, and it is probable that then or a little later the swarms break up and the young Amias begin their independent life. But on the breaking up of the swarms there are no observations.

A. Leaving the nest.-How this takes place I have been able to observe in detail twice. In nest 13 (1901) the larvæ were on the nest in the morning, but upon returning to the nest in the afternoon they "were found about a metre from the nest toward the deep water, and the male was seen half a metre beyond them in the same direction. The male discovered me and went off with great violence. The larvæ were swimming in a circle in a progressive swarm as though on the nest, and when a stick was thrust among them and moved about they showed no signs of fear, but moved toward the stick quite as often as from it. After the male had left, the larvæ continued swimming in a circle. The swarn broke into two and each of these swam in small circles, continually returning to the point of departure, their original location. The two groups sometimes joined and then the mass again separated into two. The movements became rapidly more definite in the sense that the individuals moved more constantly in a fixed direction with the mass. 
The swarm movement became more like that of Amœba verrucosa, whereas hitherto it had resembled the movement of an Amœba proteus with very short pseudopods. After about fifteen minutes the male was seen returning. His inward course was tortuous on account of the hummocks, and in passing between them he frequently, in slipping over shallow places, arched up his back until his dorsal fin was out of water. He made several attempts to reach the swarm, trying first toward the right and then toward the left, but finally coming directly in. He came to within a foot of the swarm and then, apparently without having noted me and certainly without being frightened, he turned slowly and deliberately and retraced his course, going out by the identical route by which he had entered. The swarm of larvæ now gradually made its way out by the same route. This was not accomplished directly, but after much circling and many trials in different directions and very slowly. The larvæ moved as though there were one main channel of exit with many side passages ending blindly. In two swarms they seemed to follow out these side passages until balked and then to return always to the main passage and continue outward. In this way they worked their way out over the course taken by the male to a distance of eight metres from the nest. The male meanwhile had for a second time taken fright. When the swarm was last seen there were many stragglers. Indeed some stragglers were left along its whole course. I watched for an hour and did not see the swarm reunited. The movements of the larvæ became during this time continuously more definitely progressive, and when I finally left them after about an hour and a half the individuals of the fractional swarms were progressing like those of a school of fish." (Note-book.) The swarms had become schools.

As I approached nest 12 (1901) about three o'clock in the afternoon and when I was within three metres of this nest the "green-spot" male, after swimming about, took up a position about half-way between me and the nest. "Then I saw the larva coming toward him from the nest in a long straggling column and apparently following his trail. When they reached him they at once formed a flat circular swarm which remained beneath him and moved with him very slowly to a distance of five metres from the nest. The swarm was usually in the shadow of the male's body, and as it moved it rotated. The male kept usually over it, turning, however, in one direction and another. His pectoral and caudal fins frequently brushed parts of the swarm violently aside." (Note-book.) These larvæ were 12.5 millimetres long.

In thus moving out from the nest the larvæ do not merely pass toward deeper water, since in the case of nest 13 , which was situated among hummocks, the water 
was much interrupted and broken up into irregular channels here shallow, there deep. Nor is the course over which the swarm moves the only one open to it. There are many other channels through which it could pass quite as readily as through the one followed, and many of these lead to deep water quite as directly as the one followed. In short, I could see nothing in the physical environment which could determine the course of the larvæ.

"The whole movement of the swarm when leaving the nest suggests that it follows the trail of the male by scent. The digressions of the swarm from the main course of the male are probably made in following out digressions made by him on his inward trip. These were particularly numerous at the beginning of his inward course, and here the swarm became most spread out and most confused. The swarm appeared here to follow out side lines of scent, and, finding them. to end blindly, to return always to the main line and continue along it. The behavior of the swarm is much like that of a dog trailing a covey of quail." (Note-book.)

The following experiment indicates that this is the real explanation. A rough model of an adult Amia was made and covered with black rubber cloth. A freshly killed male fish was then trussed up and attached to the end of a stick so that he could be readily moved about in the water in his natural position and in a natural manner. The male was then at once taken to a nest on which the larvæ were swimming as though ready to leave the nest, and was made to pass several times over a course leading from the nest to a distance of about a metre. The larvæ soon followed this course and assembled about the male and could then be readily led ahead for a short distance by slowly moving the male fish. When the nodel was substituted they paid no attention to it. It was noticed, however, that they did gather in numbers in the deep water near the heel of my rubber boot, and that after a time the dead fish no longer attracted them, perhaps because the odor of the male had changed. There was no opportunity to repeat the experiment.

$B$. The laArve outside the Nest.-(12 to 100 millimetres.) During their life in swarms or schools, as I shall now call them since the individual and swarm progressive movements are fully developed, the following changes take place in the appearance and behavior of the larva. All measurements of larvæ are from the tip of the snout to the tip of the tail.

a. Color changes.-Larvæ of 12 to 30 millimetres. At 12 millimetres the colors are as already described. As the animals grow older the black of the back and sides takes on a more greenish hue.

Larvæ of 30 to 40 millimetres. Larvæ of 30 to 32 millimetres when taken from the natural waters are colored as follows: very black above and on sides; 
tinged with green on the cheeks and sides; below dirty grayish between anals and pectorals, light metallic green in front of pectorals; iris golden flecked with brown, and brighter at its inner border. At this time the form is that of the adult. The scales are fully developed; the nasal chimney is visible. The anal fin is large, the pelvics are developed, but still small. The tail is still distinctly heterocercal. At 40 millimetres bright colors have appeared. The black has given place to a very dark green on the top of head and back and on the sides of the body. The fins are transparent, but bordered with black. The sides of the head (cheeks and opercles) are now distinctly olive-green, fading to a light green on the lower surface of the head. Three black stripes are left on the head; one extends through the eye and marks also the iris, a second runs beneath the eye, and a third, fainter and narrower, extends backward from below the angle of the mouth. The two upper stripes show a faint border of orange, and the middle of the opercle shows an orange band broader below, and the border behind this band is dark. The basal lobe of the pectoral is tinged with orange. At 50 millimetres a small black tail-spot without orange border is present.

Larvæ of 60 millimetres (Pl. VII, Fig. 1). The form is like that of the 40millimetre larvæ, except that the tail is less strongly heterocercal. The upper parts of the body are still dark olive-green, nearly black, becoming silvery below between anal and pectoral, and metallic greenish white on the lower surface of the head and on the lower part of the cheeks and opercle. There are now four black stripes on the head, ocular, subocular, and mandibular as before, and in addition a gular often bifurcated caudally. The ocular and subocular stripes are bordered with yellow, the subocular more broadly. An oval black tail-spot is present and is bordered with orange. The fins and opercle are all black-bordered, and there is a black stripe lengthwise through the middle of the dorsal not yet developed in the individual figured. The fins, except the pelvic, are no longer transparent, but have a bright orange ground color traversed by indistinct black lines along the finrays. The colors are now most brilliant and striking. They are not noticeably different in larvæ of 65 millimetres. (Compare the description of Amia ornata Lesueur, 61 millimetres long, as given by Duméril, '70.)

Larvæ of 70 millimetres (Pl. VII, Figs. 2,3). The heterocercal tail is now largely masked, and, except for the relatively somewhat smaller paired fins and the somewhat different proportions of the body, the form is that of the adult. There are three noteworthy changes in the color:

(1) A curved black band has appeared crossing the middle of the caudal parallel to its border and composed of discrete blotches on the fin-rays, and a similar black band crosses the anal. 
(2) The portions of the dorsal, anal, and caudal proximal to the black bands have changed from orange to bright lemon, while the portions of these fins between the bands remain a brilliant orange.

(3) On the lower part of the opercle in front of the vertical orange band are three horizontal yellow stripes converging caudally. The larva has now reached its maximum of brilliancy.

Larvæ of 100 imillimetres. Larvæ of this size do not differ essentially in color from those of 70 millimetres. The black bands on the fins are more pronounced and perhaps broader. The chief difference is that the dark reticulations on the sides are now faintly marked. There are as yet no sexual differences in color, though the sexual organs are differentiated. (Compare Wilder's brief foot-note, '76, p. 165, describing larvæ 75 to 100 millimetres long, and Dean, '96 ${ }^{\mathrm{a}}$.)

Larvæ of 170 millimetres. Fish of this size I have not seen living, but through the kindness of Professor Nachtrieb I have some formalin specimens. The dark reticulations on the sides are very distinct and about 3 millimetres wide. The enclosed spaces are irregular, in about three longitudinal rows, and the spaces are about as wide as the reticulations. The dorsal still has the black band and black border, the anal has one band, and outside this reticular markings like those on the body. The anals and paired fins and the body of the caudal and anal are transparent white. The head-stripes are still very prominent. The specimens show no sexual color differences.

Larvæ of 25 centimetres. In order to complete the cycle of color changes a note may be added on several fish 25 centimetres long and probably one year old, speared April 12. The fish have now assumed the adult colors, and the sexes are distinguishable by color. The male is in breeding dress. The orange tinge on the sides is more pronounced than is usual in older fish, and becomes a pure orange at the base of the tail. The reticular markings on the sides are nearly black bands 3 millimetres wide and enclosing areas about 1 centimetre in diameter, and irregularly diamond-shaped. There are about four longitudinal rows of such areas. The tail has three parallel V-shaped bands with caudally directed apices. The tail-spot is well marked and orange-bordered. The female (30 centimetres long) is like the adult female. The reticulations and the $\mathrm{V}$-shaped bands on the tail are scarcely distinguishable. The above descriptions, except that of the 170-millimetre fish, apply only to fish newly taken from the natural waters. Those reared in confinement grow less rapidly and develop larval colors while smaller. Their colors are also less brilliant. 
From the above account it appears that in the male the color changes between 70 and 250 millimetres are three in number. The first of these is the appearance of small green areas in the black or green-black of the back and sides. These areas, at first indistinct, increase in distinctness and size, so that at 170 millimetres a reticular pattern is formed by the black background remaining between the areas. The areas then become larger and of regular form, and at 250 millimetres the adult reticular pattern is established. The development of this pattern is possibly due to migration of black chromatophores and to the consequent concentration into the reticulations of the originally uniformly scattered black pigment. That such a pigment is uniformly scattered over the body in 70-millimetre larvæ appears from the color changes which they undergo (see p. 98). The second color change is an increase of the amount of black pigments in the caudal and dorsal fins. The third change is the substitution of green for the lemon and yellow color of the fins. This green, together with the black of the fins, produces their normal adult color. On the ventral surface of the body orange is developed in the male along with green.

The history of the larvæ from 12 millimetres, when they leave the nest, to 100 millimetres (beyond this I have been unable to follow it) falls into two phases, that during which the larvæ are black, and that during which orange, lemon, and green have been added to the black. In the first period the larvæ are from 12 millimetres to about 35 millimetres long. During the second period they are between about 35 and 100 millimetres long. Larvæ of 30 to 40 millimetres are in transition between the two periods. During the first period the larvæ keep together in dense black schools which are easily visible at a long distance and often seen in open water. Hence larvæ of this period are more often collected than older larvæ. The schools are closely guarded by the males, move slowly, and may be found in nearly the same place when visited from day to day. The larval habit of scattering and hiding when there is mechanical shock to the water is not developed until toward the end of this period. During the second period the schools are found only with great difficulty, since the color of the larvæ is less conspicuous and they keep amongst the aquatic vegetation. Often the schools may be found only by watching for the bubbles of gas emitted by the larvæ in their frequent trips to the surface for air. During this period the schools consist of fewer individuals, which are very active. The schools, consequently, are more loosely aggregated, move rapidly, and no longer confine themselves to a restricted locality. The male does not guard them so closely and there is less need of it. He is generally to be seen at a little distance from the school, and he is much more wary than during the first period. The 
larvæ have now strongly developed the habit of scattering and hiding upon mechanical shock to the watcr.

Before speaking in detail of the characteristics of these two periods, the habit of swallowing air, a habit common to both periods, may be discussed.

b. The habit* of swallowing air.-(Compare Fülleborn, '94.) This habit is developed at a very early period, probably soon after the larva leave the nest. I have noted it in larvæ of 10,40 , and 50 millimetres. The larva comes very slowly to the surface, and appears to gulp in air; at the same time numerous small gasbubbles are seen at the surface of the water, as though gas were bcing ejected from beneath the gill-covers. The larva then retreats rapidly from the surface with quick movements of the tail. The larvæ of a school often come to the surface for air in groups of fifteen or twenty. When the school is crossing deep water and is near the bottom this habit results in a vertical column of larvæ going and returning from the surface. In larvæ of 50 millimetres, as the school moves through the aquatic vegetation, itself quite concealed, the agitation produced by the larvæ as they come to the watcr surface, and by the bursting of gas-bubbles, produces a distinctly audible rustling sound, and gives to the surface of the water an appearance as though rain were falling. At this time the larvæ are extremely active, apparently never at rest, so that one is reminded of the incessant activity of a school of porpoises. It is likely that this great activity of the larvæ is associated with the use of atmospheric air.

The habit of swallowing air and emitting it again, at least in part, from beneath the gill-covers is often obscrved in the male, especially at the spawning and sometimes while with the school of larvæ (see also Wilder, '76).

c. First period of larval history outside the nest.-(12 to 35 millimetres.) I have described the development of the movements of the stationary swarm into those of the progressive amœba-like swarm, and of these into the fully progressive movements of the school of larvx. The movements of the stationary swarms are, however, not lost, but reappear in the schools whenever these schools are at rest. The school movement merely becomes the dominant one as the larvæ grow older.

When the school is undisturbed it moves along slowly with the male, the larvæ feeding as they go. If now the male be frightened away there is a characteristic change in the behavior of the school. The following extracts illustrate this. After the male had been frightened away the larvæ did not scatter or hide, but remained together in a swarm. "They soon began to circle, returning always at the end of

* The term is used as indicating a constantly recurring form of behavior, and without attempt to distin guish habit from instinct. 
each circle to the original spot (not a nest). The circles became gradually larger, and in twenty minutes had expanded from 30 centimetres in diameter to about 2 metres. Meantime the return to the original spot became less frequent and less definite. The school also broke in two during this manœuvre and a good many scattering larvæ were left as stragglers. At the end of twenty minutes a chance movement on my part frightened the male, which had returned to within 20 centimetres of my heel. I then left the school, but within twenty minutes found it again reunited with the male, which was seen to drive away an encroaching sunfish." These larvæ were 16 millimetres long. On another occasion, when I reached the

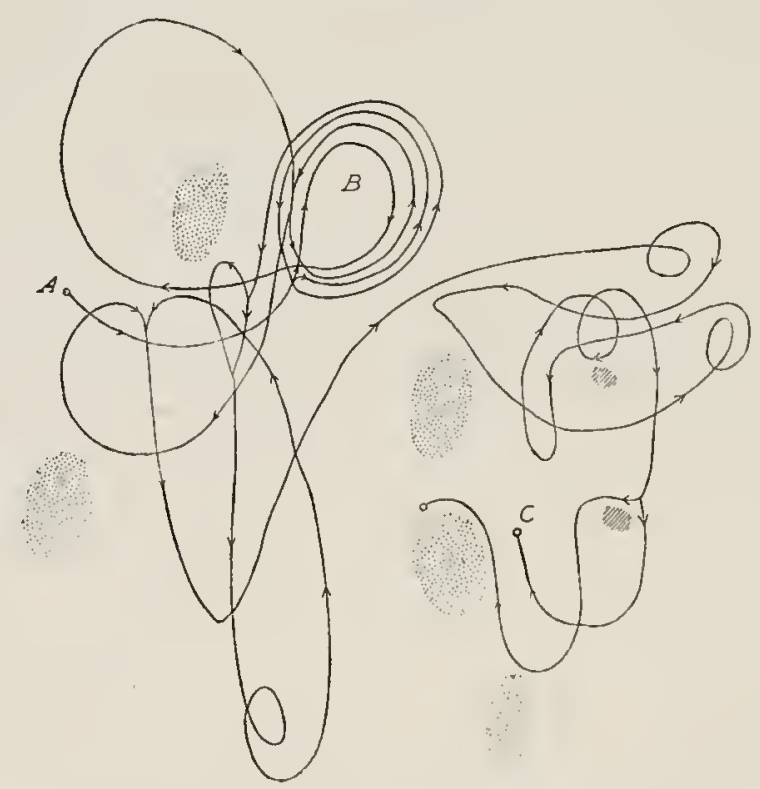

FIG. A.-Plan showing the movements of a school of $20-\mathrm{mm}$. larvæ during firtecn minutes while the male was absent. $A$, point of departure of the school; $B$, point where either the school or the male had probably lain for some time previously; $C$, point to which the male returned and where the school stopped; dotted areas, grass-covered hummocks; lined areas, grass tufts. Scale $\frac{1}{10}$.

swarm the male, which had previously been frightened away, returned to his original position and then retreated to a point some 3 metres from this position and there remained at rest. "The school was now circling widely in three main bodies and in several smaller groups of six or eight individuals. After much circling one of these sub-schools came upon the male and immediately stopped. Later a second sub-school also joined the male, coming to him from the side and in front. As the larvæ approached he turned toward them and moved a few inches in their direction. Several of the smaller groups then joined the male from behind, one after another. 
The male then moved away a short distance, and as he did so the third sub-school, now drawn out into a long straggling train, which followed along the earlier trail of the male, also joined him and the train shortened. Thus all the parts of the school were reunited into a single body."

The accompanying sketch made at the time illustrates accurately the movements of another school after the male had been frightened away. This swarm was among hummocks (dotted areas) and bunches of grass (lined areas), and when the observation began was at $A$. Its subsequent movements, its subdivisions, and the frequent returns to the point $B$, where, without much doubt, either the school or the male had been for some time previously, and its final reunion with the male when, after fifteen minutes, he returned to the point $C$, may all be followed in the figure. These larvæ were about 20 millimetres long.

The rate at which the schools move increases greatly with the age of the larvæ and doubtless also at any age with the conditions, such as abundance of food. In a school of larvæ of about 20 millimetres I have noted a rate of about 16 metres per hour. In another case I have found a school of larvæ of about the same size within 5 metres of the spot on which it was five hours earlier, another within 12 metres of its original location, and another within 30 metres.

By learning to recognize the individual males I have been able to find certain schools from day to day and thus to learn something of their daily wanderings. Connected by a narrow channel with the Geddes mill-pond on which the camp of 1901 was located is a small basin of about two acres extent. The Amia nest here. On May 10 four schools of larvæ could be identified in this basin. These from the peculiarities of the males, previously noted, I have called the "split-tail," the "deepsplit-tail," the "brush," and the "two-spot" schools. I was able to find these nearly every day for eleven days, that is, until May 20. The "deep-split-tail" school occupied a little bay running off from the basin and not more than 2 metres wide and 6 metres long. Here it was found on six different days up to and including May 18, and was still in the basin on May 20. Of the other schools one occupied the east side and one the west side of the basin, and a third frequented the bushes on the north side. They were usually to be found daily in these localities up to May 20; if not found in their usual places, it was because they were temporarily in the centre of the basin. On May 20 the larvæ were 30 to 32 millimetres long, the size at which the brighter colors begin to appear. After this, although one of the schools was found in the basin nearly every day until June 16, it was no longer possible to find them all, and after May 30 only one school could be found. On account of the increased wariness of the inale, the more rapid movement of the school and its habit 
of remaining in concealment, the males of these swarms could not be positively identified after May 20, that is, after the larvæ were 32 millimetres long.

The "green-spot" school found in the hummocks on May 10 was found there on May 16 and 18 within 75 metres of the same spot. On May 18 the school of the "green-spot" male, which had heretofore consisted, as is usual, of larvæ of nearly the same size, was found now to consist of larvæ of two very different sizes, 17 and 23 millimetres. Evidently two swarms had here become commingled.

The "ring" school was found on May 16, and on June 5 was again found entering the basin, a migration of 400 metres.

From the above it appears that each school is local, probably not going more than a hundred metres from the nest until the larvæ are about 30 millimetres long.

The larvæ of all ages show a tendency to keep in the shade, and this becomes more pronounced as they grow older. Larvæ 18 millimetres long, exposed in a glass dish to the diffuse light of a window, show no tendency to go either toward the light or from it. If now one-half the dish (a 9-inch bacteria-dish) be covered with black cloth and so placed that the rays from the window strike it in the direction of the plane separating the light and dark halves, it is found that on the average about twelve times as many larvæ are to be seen on the dark side of the dish as on the light side. The same reaction, but more pronounced, is noted in larvæ of 35 millimetres. If a nine-inch bacteria-dish containing such larvæ be placed on a background half black and half white and the black half covered with black cloth, the larvæ remain on the dark side of the dish. Those that attempt to pass to the light side turn back at once. If the larvæ are hungry this reaction does not take place. It is also noteworthy that when a school of young larvæ is seen with the male in direct sunlight, the school if undisturbed and in open water moves usually in the shadow of the male. It is probably this reaction which helps to keep the schools of young larvæ together. Such a school is a dense black mass, so that a larva passing beyond the borders of this mass tends to react, as does a larva passing beyond the border of a dense shadow-the larva tends to turn back into the black mass of its fellows.

Larvæ of 12 to 20 millimetres show no evidence of such reaction; they may be said to show no fear. If a stick be thrust into such a school and moved about, the larvæ make no effort to escape, but move toward the stick quite as often as from it. They are often seen to be buffeted about by the fins of the male as he moves above the school, but they show no reaction to such stimulus. When the frightened male rushes away from the school, often with great violence, the larvæ do not scatter and hide, but after a little begin to circle in the manner already described. 
At this time the larvæ do not try to escape the net, and the greater part of a school may often be taken with a single sweep.

At precisely what stage in their development the larvæ begin to react to mechanical shock in the water I do not know. Such reaction is present in larvæ about 40 millimetres long, but is perhaps also present in younger larvæ.

d. Second period of larval history (35 to 100 millimetres).-The movements of schools of larvæ of this size are very rapid and increase in rapidity with age. In one case a school of larvæ 40 millimetres long was found crossing from one side of the pond to the other through water 3 or 4 metres deep. The male could not be seen, but was probably at the bottom. The larvæ were in a vertical column formed by the large numbers which came frequently to the surface for air and then returned again toward the bottom. In a few minutes the school had reached the shore a distance of about 150 metres. Schools of larvæ of 70 to 100 millimetres are not often seen, but when seen are moving with great rapidity, sometimes, it seemed to me, as rapidly as .5 metre to 1 metre per second.

The reaction toward light of the larvæ at this period is the same as in the younger larvæ, but more pronounced. The schools are now rarely seen in the open, but rather moving rapidly in the dense shade of the aquatic vegetation or beneath overhanging bushes. The schools consist of fewer individuals, and these are less conspicuous and farther apart. This, added to their rapid movements and habit of keeping in the shade, makes them very hard to find. To the practised eye they often reveal themselves by their habit of coming to the surface for air.

During the second period the larvæ show another light reaction, which is not present in the first period. Larvæ of 70 millimetres which are kept in a darkened dish have the tail-spot and stripes in the head and fin black and the green of the upper part of the body and head almost black (Pl. VII, Fig. 3). Upon exposure to strong light all this black becomes very much less intense. All the stripes on the head and fins fade and the whole upper part of the body and head becomes a light green. The whole color impression made by the fish is then changed so that the light larva seen under strong illumination is much less conspicuous than the dark larva.

I have not attempted to determine the length of time required for this change to take place. It is complete at the end of an hour, but is probably completed in a much shorter time. Its protective character is obvious since it adapts the color of the larvæ to the amount of light falling on them, and consequently in a measure to their environment.

Larvæ of 40 millimetres flee from a stick thrust into the school, and at 60 milli- 
metres they flee from the net with so much skill that it requires an experienced man to capture them. At this time also they react in a characteristic way to the departure of the male. As the male leaves the school he gives a sharp splash at the surface of the water with his tail. This behavior of the male was not noted with the younger schools. The reaction of the larvæ to this stimulus is thus described. "The male went away with a splash of the tail, and it was then noted that the larvæ, which had before been at the surface, easily visible, were no longer seen. They were soon seen working slowly up from the bottom, where they had been concealed in the deep shadows among the weeds. I then struck the water sharply with my stick in imitation of the splash of the male's tail and the larvæ at once disappeared. The utility of this reaction is obvious." In another case "the male was frightened away and the larvæ scattered and hid at the bottom. The male returned after a while, but was again frightened by a slight movement. He soon came back, brushed past my boot and stopped very near me. The larvæ then gradually returned to him from all directions and finally enveloped him so that he was completely hidden. It was then possible to take some of the larvæ with the net without disturbing the male." These larvæ were about 45 millimetres long. This behavior of the larvæ, as suggested by Whitman and Eycleshymer, who have described it ('97), has probably given rise to the myth that the males swallow the young when danger threatens.

e. The breaking up of the schools.-This has not been observed, nor is it likely to be. There is no record of a school of larvæ longer than 100 millimetres (Dean, '96, '98). In the middle of June, when the larvæ are some 90 to 100 millimetres long, the schools are much spread out, consist of few individuals, and are moving with great rapidity. The male, whenever I have seen him, then follows the school at a little distance. At this time, then, there is evidence of a loosening of the relations between the larvæ and between them and the male, and one watching a school feels that it is not likely to hold together long.

9. The Behavior of the Male while with the School.--The headlong rush of the male when frightened from his nest or school, the splash with the tail at the surface when leaving the school, and the subsequent shy return, have been already referred to.

Once I saw a returning male approach the circling fragments of $f_{1}$ his school as though to guide them to the main body. When they came in contact with him they stopped at once and bunched, but they may come within five or six inches of him without stopping. The behavior of a male apparently in search of his swarm I have noted thus: "The 'two-spot' male was found, but without his swarm. He met me as I waded out and then turned and retreated. He then 
returned and swam about my feet and stopped with his nose against my boot or nearly so. He went out 6 or 7 metres or mole in every direction, and returning passed several times through the dense weeds near me, but did not find lis school." Two days later he was again found and with his school. The behavior of a make with a school of 50-millimetre larvæ is thus described: "The male came up against my boots and examined them apparently with great care. He kept well covered and was exceedingly difficult to see in the weeds. During a part of the 15 minutes that I watched he was 1 to 2 metres from the swarm, and returned to it two or three times and again came back to me." The male often comes out to meet the observer thus. "I approached nest 12 (1901) about 3 P.Mr., and when within eight feet saw the male approaching me as though he had detected a movement in the water. He swam to within six inches of my feet, then around me in front, then around me behind. He repeated this manœurve and, as I remained quiet, was apparently satisfied and moved off toward his school." This is commonly the behavior of males with schools when they are approached. Males on the nest when approached usually do not move, and I have never seen them come to meet the observer. They move at most but a few inches toward the observer. If they find nothing and are undisturbed they remain on guard over the nest. If disturbed they dash off.

There are two myths concerning the behavior of the male that may here be mentioned. One of these, already referred to, is that the male disappears into deep water with the young larvæ attached to him and returns later to shallow water with the larger larva now free (Dean, '96). The other affirms that the male takes the young into his mouth when danger threatens (Hallock, '77, who quotes Dr. Fistes). These myths have, as I think, been both correctly explained by Whitman and Eycleshymer. That the male of Amia will eat the larvæ of its own species I know from having fed male Amia kept in aquaria on such larvæ. This is also true of some teleosts, as Polyacanthus viridi-auratus and Ameiurus nebulosus (Smith, :03). It is therefore entirely possible that after the larva are well grown the males swallow their own young. But that the whole swarm is taken into the mouth and that later the "little captives are set at liberty," as thought by Dr. Estes, is beyond belief. Yet it is not impossible that while the larva are still helpless in the nest they are taken into the mouth a few at a time and again ejected for the purpose of cleaning them. This, according to Smith (:03), is the case in Ameiurus nebulosus.

10. Summary of Principal Observations.-1. In the breeding season the sexes of Amia may be readily distinguished at a considerable distance by their colors. 
2. Males may usually be distinguished from one another without taking them from the water by accidental structural peculiarities, or more of ten by color peculiarities.

3. About three times as many males as females come to the spawning ground.

4. The nests are built on selected areas on the bottom, where there are usually fibrous roots and little growing vegetation, and are often concealed.

5. Nest-like areas of the bottom are often seen where the bottom is in dense shade; such areas may be used for spawning with little or no previous preparation.

6. The nests are built by the male without assistance from the female by rubbing, biting (?), and fanning away the vegetation and ooze so as to expose the subjacent material. The nests are built mostly at night.

7. Each nest is the property of an individual male.

8. The nests may be very near one another or far apart. Their frequency depends on the number of spawning fish and on the character and size of the available spawning ground.

9. Each male guards and defends the empty nest for a period of usually twentyfour to thirty-six hours, but this period may be prolonged to six days, or possibly longer.

10. The males are found guarding the nests more often in the afternoon than in the morning.

11. If the females do not appear the males finally abandon the nests.

12. The optimum temperature for nest-building and spawning is $16^{\circ}$ to $19^{\circ} \mathrm{C}$.

13. The spawning is intermittent and occupies a period of from one to three hours.

14. The spawning occurs usually at night; occasionally by day.

15. There is no evidence that the bright colors of the male are in any way sexually selected, and since spawning occurs chiefly at night, this would seem to be impossible.

16. Sexual excitation of the female is produced by the biting and rubbing of the male.

17. Two females may spawn at different times in the same nest with an individual male.

18. There is evidence that an individual female may spawn in the nests of two or more males.

19. The females are not seen on the spawning ground except when spawning.

20. The nests when freshly filled with eggs and in open water are in this locality frequently very conspicuous.

21. The nests containing eggs are guarded by the male until the larvæ are about 12 millimetres long. 
22. The larvæ hatch from the egg, in this locality, usually in from eight to ten days, but this period depends on the temperature.

23. The larvæ are 12 millimetres long and ready to leave the nest in about eighteen days after the eggs are laid or nine days after the eggs hatch.

24. The 12-millimetre larve are black, the yolk-sac is reduced, progressive movements are well developed, the adhesive organ is no longer functional, and the larvæ are feeding.

25. While in the nest the larvæ develop an irregularly progressive swarm movement.

26. The larvæ leave the nest in a swarm with the male and appear to follow him by scent.

27. The larvæ are black until they are 30 to 40 millimetres long.

28. The schools of black larvæ are local in their habit, move slowly, are often in open water, and form conspicuous black masses.

29. A school of black larvæe when separated from the male begins to circle and continues this either as a whole or in fragments until reunited with the male.

30. Black larvæ do not show response to mechanical shock in the water, at least not until their later stages.

31. In strong light black larvæ seek the shade.

32. When between 30 and 40 millimetres long black larvæ begin to show orange and green colors,

33. Schools of bright-colored larvæ have not been observed to circle in search of the male.

34. Schools of bright-colored larvæ respond to mechanical shock in the water by scattering and hiching at the bottom; this reaction may also be present in the later stages of the black larvæ.

35. Bright-colored larvæ in strong light seek the shade more actively than black larvæ.

36. The colors of bright-colored larvæ are brighter in strong light, darker in shade.

37. The schools of bright-colored larvæ move more rapidly than those of black larve, are less conspicuous, and are rarely seen in open water.

38. Larvæ of all sizes above 12 millimetres come frequently to the surface for air.

39. Schools of black larve are more closely guarded by the mate than those of brightly colored larvæ.

40. Schools of larva of greater length than 100 millimetres have not been recorded. The schools probably disperse when the larvæ are of about this size.! 


\section{DISCUSSION.}

I. The Literature.-The literature on the breeding habits of Amia is to be found in Hallock's Sportsman's Gazetteer ('77), where the author quotes the account of Dr. Estes * (this has been copied by Dr. Goode in his Natural History of Uscful Aquatic Animals) and in the papers of Fülleborn ('94), Dean ('96, '96', '98), and Whitman and Eycleshymer ('97). The whole of it covers but forty-seven pages, and yet it would be difficult to find anywhere within the same space so many contradictory statements. That the writers quoted have worked at the natural history of Amia, not continuously, but incidentally while gathering embryological material, seems to be explanation in part of the many discrepancies. If the observations recorded in this paper be correct, each of these writers has been both right and wrong. In the preceding pages only the more important discrepancies have been pointed out, while the easy task of making a more critical examination of the literature has been left to the reader who is curious in such matters. And yet it should not be too hastily assumed that in all respects the habits of Amia are the same in all localities. That the colors of the adult fish may vary somewhat with the locality is probable from the statement of Professor Kofoid quoted above. That the eggs are of a much darker color in the Wisconsin lakes than in this locality is clear from the figure given by Whitman and Eycleshymer, and it can scarcely be doubted that the nests are correspondingly less conspicuous. The frequency of the nests also varies with local conditions. That the time elapsing between the building of the nest and the spawning may be nuch shortened where the fish are very abundant and in seasons in which warm weather comes on suddenly is also probable. It would not be surprising to find in such cases that the nest may be spawned in immediately upon completion, or that at times the fish may spawn on some nest-like bottom area without previous preparation of the area and that such alterations in this area as appear after the spawning may then be merely the result of the movements of the fish at the time of spawning. This seems the more probable when we remember that the fish may spawn in a wooden crate or in an enclosure of the natural bottom which shows no resemblance to a nest either before or after the spawning act.

The time occupied in depositing the eggs varies considerably and may be shorter than any period that has been observed, while the time required for them

* Mr. Halloek kindly writes me that his information was obtained from Dr. Estes "directly" and was first published in the Sportsman's Gazetteer. 
to hatch and for the larva to leave the nest is necessarily dependent on the temperature. Let the future critic then bear in mind that the materials under discussion are variable and that the behavior of the fish is plastic.

2. Characteristic Features of the Breeding Behavior.-A casual acquaintance with Amia leads at once to a comparison of its breeding habits with those of the more familiar birds. A nest is found filled with eggs and guarded by the parent fish. The nest is, therefore, the property of an individual pair of fisl which have preparcd it together, and the fish which guards it is most likely the fenalc. The literature contains many such hasty gencralizations concerning the breeding habits of nest-building teleosts. Thus, to cite a few instances only, Estes (Hallock, '77) refers to the parent which guards the young of Amia as "she." Agassiz ('57) describes the male and female of Eupomotis gibbosus as keeping watch alternately over the nest. Later Stone ('89) describes the female of the same species as the nest-builder and care-taker. My own unpublished observations on Eupomotis gibbosus have convinced me that, as surmised by Gill ('89), the female takes no part in building the nest or guarding it. Again we find Arnold ('83) making the statement that the female of Micropterus is the nest-builder, an error subsequently rectified by Lydell $(: 02)$. In work of this sort the method used to distinguish the sexes should always be stated. This is the more necessary since young males commonly resemble females. Where no suitable method is known to have been used, the account must be rejected in so far as it concerns the participation of the sexes. I have found in the literature no authentic record of a case in which the female, unaccompanied by the male, prepares a nest in advance of spawning. In the Salmonidx the female makes an excavation in the bottom, but she does this in the presence of the male, and the nest itself may be regarded as the result of the movements of the female preparatory to spawning, rather than as a premeditated structure (see the excellent account in Brehm, '92).

Darwin ('83) says of Crenilabrus massa and Crenilabrus melops that both sexes work together in building the nest. Dr. H. M. Smith (:03) has recently shown that in Ameiurus nebulosus, confined in an aquarium, both sexes take part in building the nest, which is prepared in advance of spawning; and I have observed two of these fish, probably male and female, working together at nest-building in their natural habitat. In Ameiurus nebulosus in the aquarium, the care of the young, although shared by both parents, falls more on the male than on the femate, while in Ameiurus albidus (Ryder, '83) the whole care of the young is assumed by the male. I have sevcral times observed the nests and swarms of the young of Ameiurus nebulosus in their natural habitat, but have never found them guarded 
by more than one fish. It is therefore likely that in this species also, under normal conditions, the female merely assists in building the nest, but that when the eggs have been laid the male assumes charge. In all other nest-building teleosts there is no pair of fish.

The nest belongs to an individual male and has been constructed by him in advance of the spawning. Females subsequently approach the nest or are urged to it and the eggs are laid. The relation between the sexes at this time may be described as a promiscuous polygamy. The spawning activities centre about the males which build and defend individual nests. The female spawns in the first nest that she comes into and may subsequently spawn in others. The male, after receiving into his nest the eggs of one female, may receive those of a second, often after a considerable interval. After the spawning is completed the females are no longer seen near the nests. The males may then continue to guard the nests, and in some cases they guard also the young brood. I have observed nest-building by the excavation of the gravel or sand by the male in advance of spawning in Amia and in the following teleosts: Semotilus atromaculatus, Campostoma anomalum, Eupomotis gibbosus, Micropterus dolomieu, Micropterus salmoides (see also Lydell, :02). Kent ('73) has reported nest-building of the same sort by the male in advance of spawning in Labrus mixtus and Cantharus lineatus. Leunis ('83) places Gobius niger and Cyclopterus lumpus in the same category. Brehm ('92) adds Cottus gobio and Nemachilus barbatula. I have been unable to examine the original accounts in the cases cited by Leunis and by Brehm. Guitel ('92, '95) has described the habits of Gobius minutus and of Gobius ruthensparri, the males of both of which excavate nests in the sand beneath shells and guard them in advance of spawning and afterward. Guitel ('93) has also described the habits of Blennius sphynx and of Blennius montagui, the male of the first of which occupies cavities in rocks and guards them in advance of spawning and subsequently, while the male of the second species uses cavities beneath stones and guards them both before and after spawning. In none of the cases described by Guitel is the female present at the nest except while spawning or during the mancuvres preliminary to it. The description given by Guitel ('93a) of the habits of Clinus is not accessible to me.

In fifteen of these cases the nests are excavations of the bottom. The care of the male may cease when the eggs have been laid (Semotilus, Campostoma), may be continued until they are hatched (Eupomotis), or may follow the young fish until they are well grown (Amia, Micropterus).

In addition we have two cases in which the male accumulates material for the construction of the nest, Gasterosteus (Coste, '48, and others) and Colisa vulgaris 
(Carbonnier, '75), and two in which the male constructs a nest of mucous-coated air-bubbles, Polyacanthus viridi-auratus (Carbonnier, '69) and Osphromenus gouramy (Carbonnier, '76). In these four instances the male continues his care for some time after the eggs are hatched.

In addition to these twenty cases there are others in which nests are known, but in which the time and method of building them appear to be unknown (see Budgett, :01, and Kerr, :00).

That in the cases cited the male rather than the female builds the nest and subsequently guards it and the young brood, is made clearer by three considerations: first, that, since fertilization is external, both fish are necessarily present when the eggs are laid; secondly, that the eggs of a single female are laid within a relatively brief time; and thirdly, that of the two parents the male is the more active and has not been weakened by the bringing to maturity of a great mass of eggs. That the habit of guarding the nest and young has been developed in the male rather than the female is no doubt correlated with these facts. If the fertilization were internal so as to make the presence of the male unnecessary when the eggs are laid, and if at the same time the eggs were larger and produced singly, and the egglaying extended over several days, then the brooding habit might develop in the female rather than in the male.

The condition found in Ameiurus and Crenilabrus, in which the female works with the male, although she alone is never the nest-builder, is then exceptional. It may be regarded as a case of transference of male characters to the female, such as, in the opinion of Darwin ('83), has taken place in respect to the colors of certain brightly colored female fish.

\section{LITERATURE.}

Agassiz, L.

'57. [Fishes of Greece.] Proc. Amer. Acad. Arts. Sci., vol. 3, pp. 325-333.

Arnold, 1.

'83. Sueccssful Propagation of Blaek Bass. Bull. U. S. Fish Comm. for 1882, vol. 2, pp. 113-115. Brehm, A. E.

'92. Thierleben. Aufl. 3, Bd. 8, Dic Fischc. Lcipzig u. Wien, $8^{\circ}$, xviii +517 pp., 1 Karte, 11 Taf.

Budgett, J. S.

:01. On the Breeding Habits of some West-African Fishes, with an Aceount of the External Features in Development of Protopterus anneetens, and a Deseription of the Larva of Polypterus lapradei. Trans. Zool. Soc. London, vol. 16, pt. 2, pp. 115-134, pls. 10-11.

Carbonnier, $\mathrm{P}$.

'69. Sur le mode de réproduetion d'une espèce de poissons de la Chine. C. R. Aead. Sei. Paris, vol. 69. pp. 489-491. 
Carbonnier, $\mathbf{P}$.

'75. Nidification du poisson are-en-eiel de l'Inde. C. R. Aead. Sei. Paris, vol. 81, pp. 1136-1139.

Carbonnier, $\mathbf{P}$.

'76. Mœurs des poissons; le Gourami et son nid. C. R. Aead. Sei. Paris, vol. 83, pp. 1114-1116.

Coste, $\mathbf{P}$.

'48. Nidifieation des Épinoehes et des Épinoehettes. Men. Savants Étrang. Aead. Paris, vol. 10, pp. $574-588$.

Cuvier, G.

'31. The Animal Kingdom arranged in Conformity with its Organization. Translated by H. M'Murtrie. New York, $8^{\circ}, 4$ vols.

Cuvier, G., et Valenciennes, A.

'46. Histoire naturelle des poissons. Tome 19. Paris, $8^{\circ}$, xix $+544 \mathrm{pp}$.

Darwin, C.

'83. The Descent of Man. 2 cdit. New York, $8^{\circ}, 804$ pp.

Dean, $\mathrm{B}$.

'96. The Early Development of Amia. Quart. Jour. Mier. Sci., vol. 38, no. 152, pp. 413-444, pls. 30-32.

Dean, $B$.

'96a. On the larval development of Amia calva. Zool. Jahrb. Abt. f. Syst., Bd. 9, pp. 639-672, Taf. 9-11. Dean, B.

'98. On the Dogfish (Amia ealva), Its Habits and Breeding. Fourth Ann. Rep. Comm. Fisheries, Game, and Forests, State of New York. 13 pp., 1 pl. [Reprint.]

De Kay, J. E.

'42. Zoology of New York. Part 4, Fishes. New York, $4^{\circ}, \mathrm{xv}+415$ pp., 79 pls.

Dumeril, A.

'70. Histoirc naturelle des Poissons. Tome 2. Paris, $8^{\circ}, 623 \mathrm{pp}$.

Fille born, F.

'94. Berieht über eine zur Untersuehung der Entwicklung von Amia, Lepidosteus und Neeturus unternommenen Reise nach Nord-Amerika. Sitzb. k. Akad. Wiss. Berlin, Bd. 40, pp. 1057-1070.

Gill, T.

'89. The "Hatehery" of the Sunfish. Nature, vol. 40, p. 319.

Guitel, F.

'92. Observations sur les incurs du Gobius minutus. Areh. de Zool. Expérin., sér. 2, tom. 10, no. 4, pp. 499-555, pl. 22 .

Guitel, F.

'93. Sur les mœurs du Blennius sphynx, Cuv. et Nal. et du Blennius montagui, Fleming. C. R. Acad. S.i. Paris, tom. 117, pp. 289-291.

Guitel, F.

'93a. Observations sur les mours de (rois blenniides Clinus argentatus Blenniu montagui et Blennius sphynx. Areh. de Zool. Expérim., sér. 3, tom. 1, no. 3, pp. 325-384.

Guitel, F.

'95. Observations sur les mœurs du Gobius ruthensparri. Arch. de Zool. Expérim., sér. 3, tom. 3, pp. 263-28s.

Hallock, C.

'77. The Sportsman's Gazettecr and General Guide. New York, $12^{\circ}, 688+208 \mathrm{pp}$.

Jordan, D. S., and Evermann, B. W.

'96. The Fishes of North and Middle America. Part I. Bull. U. S. Nat. Mus. no. 47, pp. i-xl+1-1240.

Kent, W. S.

'73. Permanent and Temporary Variation of Colour in Fish. Nature, vol. 8, p. 25.

Kerr, J. G.

:00. The External Features in the Development of Lepidosiren paradoxa, Fitz. Phil. Trans. Roy. Soe. London, vol. 192 B, pp. 299-330, pls. 8-12. 

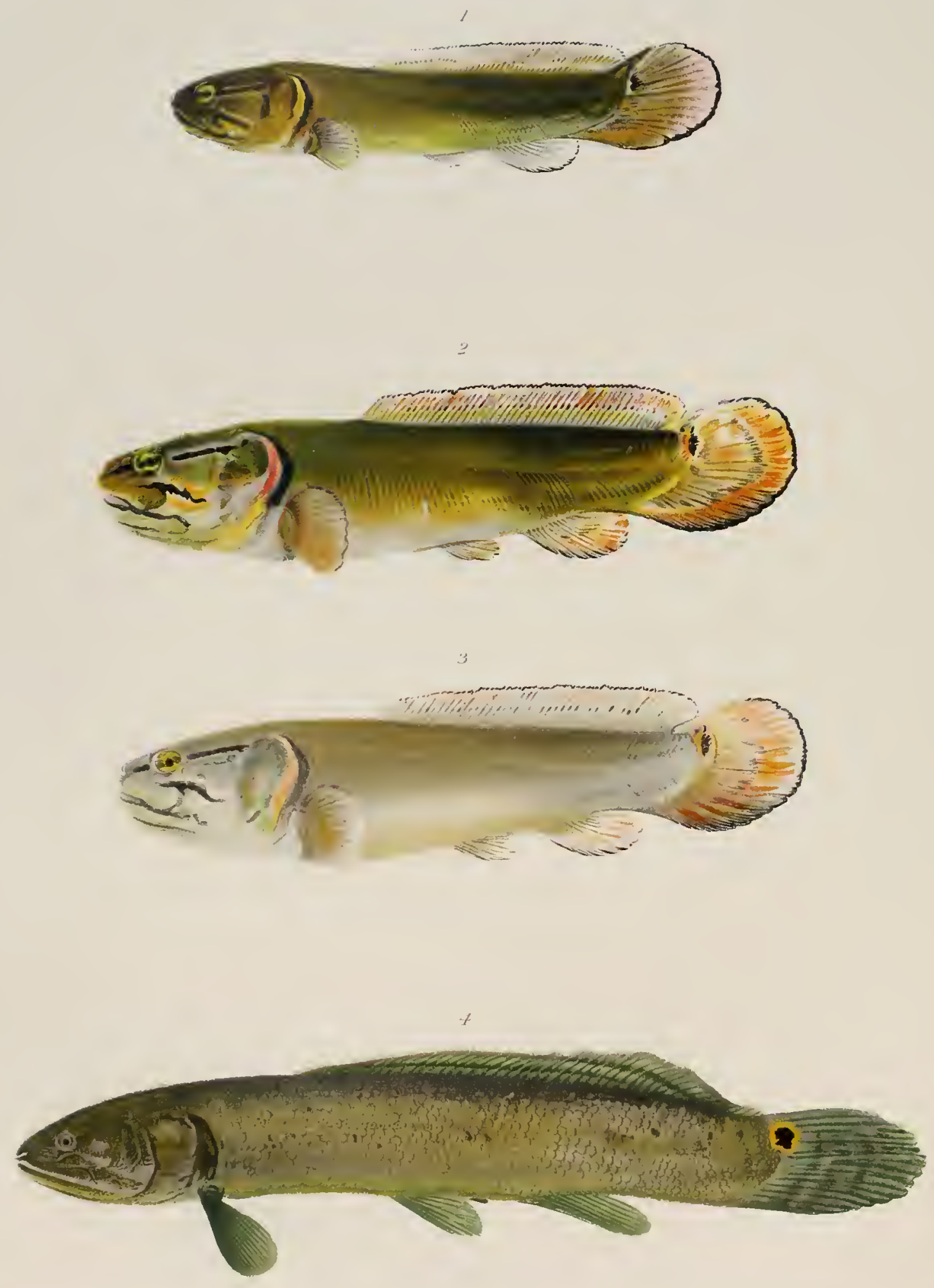
Kirtland, J. P.

'38. Report on the Zoology of Ohio. Columbus, $5^{\circ}$. [Quoted from De Kay; '42, pp. xi and 270.]

Kirtland, J. P.

'41. Descriptions of the Fishes of the Olio River and its Tributaries. Boston Jour. Nat. Hist.; vol. 3, pp. 469-482.

Leunis, J.

'83. Synopsis der Thierkunde. Aufl. 3, Bd. 1. Hanover, $8^{\circ}$, xvi +1083 pp.

Lydell, D.

:02. The Habits and Culture of the Black Bass. Trans. Amer. Fisherics Soc., 31 meeting, pp. 45-57.

Reighard, J.

:00. The Breeding Habits of the Dogfish, Amia calva. First Rep. Michigan Acad. Sci., pp. 133-137.

Reighard, J.

:01. Some Further Notes on the Breeding Habits of Amia. Third Rep. Michigan Acad. Sci., pp. 80-81.

Richardson, J.

'36. Fauna Boreali-americana. Part 3. The Fish. London, $4^{\circ}$, xvi +327 pp., pls. 74-97.

Ryder, J.

'83. Preliminary Notice of the Development and Breeding Habits of the Potomac Catfish, Amiurus albidus (Lesucur) Gill. Bull. U. S. Fish Comm., vol. 3, pp. 225-230.

Smith, H. M.

:03. Breeding Habits of the Yellow Catfish (Ameiurus ncbulosus). Science, n. ser., vol. 17, pp. $243-244$.

Stone, W. L.

'89. The "Hatchery" of the Sunfish. Naturc, vol. 40, p. 202.

Suckley, G.

'60. Report upon the Fishes collected on the Survey. Reports of Explorations and Surveys, etc., for a Railroad from the Mississippi River to the Pacific Ocean, vol. 12, book 2, Zoological Report, no. 5 pp. 307-368, 21 pls.

Whitman, C. O., and Eycleshymer, A. C.

'97. The Egg of Amia and its Cleavage. Jour. Morph., vol. 12, no. 2, pp. 309-354, pls. 18-19.

Wilder, B. G.

'76. Notes on the North American Ganoids, Amia, Lepidosteus, Acipenser, and Polyodon. Proc. Amer. Assoc. Adv. Sci., 24 meeting (Detroit), part 2, pp. 151-194, pls. 1-3.

\section{EXPLANATION OF PLATE VII.}

The figures were all made from photograplss. Those of the larvæ were made with orthochromatıc plates and color screen from specimens anxsthetized with chloretone. That of the male was made from a living specimen in an aquarium out of doors with rapid plates and without color screen. The photographs were printed on platinum paper and colored from the living fish with water colors.

Fig. 1. Larva $60 \mathrm{~mm}$. long.

Fig. 2. Larva $70 \mathrm{~mm}$. long, after having been kept in the dark for one hour.

Fig. 3. Larva $70 \mathrm{~mm}$. long, after having been kept in the light for one hour.

Fig. 4. Adult male $60 \mathrm{~cm}$. long, in breeding dress. 

V.

ON THE STRUCTURE OF PROTOPHRYA OVICOLA, A CILIATE INFUSORIAN FROM THE BROOD-SAC OF LITTORINA RUDIS DON.

(PLATE VIII.)

Charles A. Kofoid. 


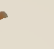




\section{INTRODUCTION.}

While sccuring the eggs of Littorina rudis I found in the brood-sac of the female a small ciliate parasitic upon the ova therein contained. A discussion of the structure and relationships of this parasite, an undescribed spccies, is the purpose of the present paper.

My thanks are due Dr. Alexander Agassiz for the opportunity of obtaining the material upon which this paper is based and for the privilege of beginning this study in his marine laboratory at Newport in the summers of 1892 , '93, and '94.

\section{METHODS.}

The mollusks were removed from the broken shell and the brood-sac was disscetcd out and opened. The ova and parasites together were then washed out into watch-glasses by a spray from a fine pipette and the whole killed in Flemming's fluid, in Merkel's chromo-platinic mixture, or in picro-sulphuric acid. The unstained Flemming material gave excellent results for all details of structure, cxcept the micronucleus. Ranvier's picrocarmine and Benda's iron-hrematoxylin were used for staining and $5 \%$ carbonate of soda for the demonstration of cilia, striæ, and surface markings aftcr the manner suggested by Schewiakoff ('96). Some Flemming material placed in 5\% carbonate of soda for two days and afterwards stained in picrocarmine gave the best demonstration of the micronucleus. The parasites were isolated by means of capillary pipettes either hefore or after staining. Beechwood creasote was used as a clearing agent, and thin xylol-danar for mounting. It was possible by pushing the cover-glass to orient the specinen in any desired position.

\section{PROTOPHRYA OVICOLA gen. nov., sp. nov.}

This species was found in the brood-sac of Littorina rudis Don. More than $50 \%$ of the females of this gasteropod werc thus parasitized, and of ten by great numbers of thesc ciliates. The brood-sac is an expansion of the distal portion of the oviduct with richly glandular walls in whose folds the eggs are retained during their development. L. rudis is ovoviviparous and the eggs are somewhat richly laden with 
yolk, of yellowish color, and are enclosed singly in a spherical membrane 200-300 micra in diameter. The membrane encloses an albuminous fluid which surrounds the egg (Pl. VIII, Fig. 3). The consistency of the membrane and the tension of the contents serve to maintain the spherical contour of the egg throughout the period of development. There is no free veliger stage, and the young snails attain at least two turns of the spire of the shell before leaving the brood-sac.

It is upon the surface of these egg-membranes that this ciliate is found (Fig. 3), several of ten occurring upon a single egg; they slide around upon it in ever-changing directions in such a fashion as to remind one of microscopic Canthons with their spherical egg-receptacles. After having been shaken off from the eggs by the process of dissection they will, after standing for a moment in the watch-glass, gather again about the eggs, due possibly to chemotaxis or thigmotaxis, or a combination of the two. That the normal and usual habitat of these organisms is upon the surface of these spherical egg-capsules is further borne out by the fact that the arc formed by the curved ventral surface of the ciliate coincides with the curvature of the surface of the egg. Repeated examination of the males of the gasteropod host failed to reveal any of these ciliates in or upon the animal save in one instance when a single Protophrya was found in the mantle cavity. The habitat of the parasites is such that they might readily be transferred to the male at the time of copulation, and from the male to other females.

Associated with the host upon a shingly beach in a cove at the laboratory near the mouth of Narragansett Bay were also Littorina littorea and L. palliata. The latter was more abundant upon brown seaweeds near low-water mark, and the former at higher levels, while L. rudis was present between tide-marks, but more abundantly along high-water levels. Neither of these species are ovoviviparous and Protophrya was not found in or upon them, though a number of individuals of both sexes were examined. In so far as this evidence goes it indicates that this parasite has but the single host.

The glandular walls of the brood-sac, the suppression of the free-swimming veliger stage of the embryo, and the retention of the young snail until a late stage of development all indicate that a nutritive fluid of some sort bathes the developing eggs in the brood-sac. It is in the fluid of the brood-sac that the parasite lives, and from it the protozoan doubtless derives its nourishment. The absence in the parasite of mouth, pharynx, and anus further supports this opinion, for such food as that suggested would be available by endosmosis.

The effect of the parasite upon the eggs of the host is seen in the increased percentage of those which disintegrate in heavily parasitized females. In a few instances 
females were found in which not a single normally developing ovum remained. The membranes of the eggs were intact, but the eggs themselves were broken up into smaller yellow spheres or irregular fragments some of which may have been ciliated. Dwarf, abnormal, monstrous, or uncoiled embryos were sometimes seen in parasitized females. I have often found this phenomenon of the breaking up of ova to be common among many gasteropods in which a number of eggs are laid in one capsule, for instance in Purpura, Urosalpinx, and Tergipes. In these cases, however, the unprotected and disintegrating ova are utilized by the normal ones as food. In the case of the disintegrating ova of Littorina rudis the fragments remain within their capsules and they are not used, directly at least, as food by the normal embryos with which they may be associated. The disintegration of the ova of Protophrya does not seem to be an adaptive phase of nutrition, but a result rather of the presence of parasites.

Protophrya does not itself devour the ova, nor does it mechanically modify them in any visible manner. Its influence is probably a chemical one affecting the growth of the ova adversely either directly, or indirectly by interference with the glandular activity of the brood-sac. The products of the metabolisin of the parasites may have a toxic effect upon the ova and the surrounding tissues comparable with that which Vaullegeard (:01) has found in the case of the extracts of parasites of vertebrates upon the tissues of their hosts.

Superficially Protophrya bears some resemblance to Ancystrum mytili described by Quennerstedt ('67) from the mantle cavity of the common mussel, but the absence of oral aperture and pharynx at once make any relationship to this form remote. A full examination of the literature indicates that both in its habitat and in its structure this parasite is somewhat unique. Schweiel (:00) in his exhaustive discussion of parasitic ciliates makes no mention of any form approaching this in structure or host-relationship.

\section{STRUCTURE.}

The outline of the animal seen from the dorsal side is broadly elliptical with symmetrical sides and somewhat similar ends (Pl. VIII, Fig. 1). In some instances the anterior end is slightly narrow and pointed, while the posterior one is broader and more rounded, giving a slightly oval contour to the animal. The usual form, however, is that shown in the figure. In lateral view (Fig. 2) the animal is seen to be curved ventrally at the ends and sicles, in fact around the whole edge, giving it the form of a low hehmet without visor or peak. In cross-section the animal is broadly crescentic. The eurved edges seen in lateral view cover an are of 30 to 40 degrees 
upon an egg-capsule 350 micra in diameter apparently in adaptation to this substratum upon which they are habitually found. The form is quite constant in preserved material and is not subject to great change in living individuals. The only irregularities in the otherwise perfect symmetry of the animal are those caused by the contractile vacuole which lies near the posterior end. When this is at diastole it causes a slight swelling in the dorsal outline near the posterior end (Fig. 2).

Protophrya is a small ciliate, the length of preserved individuals varying from 88 to 102 micra, the width from 71 to 77 micra, and the thickness (total dorso-ventral extension) from 30 to 35 micra.

The body is ciliated throughout, and the cilia are of the same size everywhere excepting along the margin of the ventral face, where they are somewhat longer (Fig. 2) and form a sort of peripheral fringe. They are very fine and closely set and are well preserved in material killed in Flemming's fluid. The cilia are arranged upon the surface of the body in meridional rows very closely set, which give a fine striation to the pellicula. These striæ are longitudinal as a rule, though in much contracted specimens a very slight spiral torsion may be detected. This distribution of the cilia is similar to that in most holotrichous ciliates, but the meridional lines are closely set, more so even than in any other Opalinidæ. There are about forty of these striæ on the dorsal surface and approximately twenty-five on the ventral. The distance between them is but little more than two micra. This is much less than in any other members of the family as figured by Schewiakoff ('96). Even in Opalinopsis sepiolæ (Foettinger, '81) they are three micra apart. It appears that this close-set and abundant ciliation is an adaptation to the habitat of the animal, a structural provision for rapid change in the surrounding medium. It lives in the secretions of the oviduct which are not subject to such regular and frequent change as are the contents of the intestine, the organ in which other members of the family, excepting Opalinopsis, are found. In Opalinopsis sepiolæ the lines of cilia are closely set, but this species is also found where the need of rapid change of the medium is great, in the liver of Sepiola. All members of the family Opalinidæ are endoparasites, and all are more or less marked by the very fine and abundant ciliation which may be an adaptation to the mode of life. In Opalinopsis sepiolæ and in Protophrya we find a maximum development of this ciliation coinciding with parasitism in organs in which the nature of the surrounding medium calls for more rapid change to facilitate the removal of the waste products of respiration and excretion.

The distinction between ectoplasm and entoplasm in this species is somewhat similar to that in other holotrichous forms. The ectoplasm (Fig. 1, ec'pl.) consists of a pellicula (Fig. 4, pell.), an alveolar layer (st. alv.), and the cortical plasma ( $p l . c t x$. ). 
The pellicula (Fig. 4, pell.) is a dense homogeneous layer and with the exception of the strix above mentioned it shows no structural differentiation. The marginal regions (Fig. 4) bearing the peripheral belt of cilia are much thicker than the dorsal and ventral portions. The pellicula is quite thick and serves, together with the cortical plasma, to give constancy in form to the individual.

The alveolar layer (Fig. 4, st. alv.) is about a micron in thickness and consists of a single layer of alveoli formed by partitions which are vertical to the pellicula. I have not been able to distinguish any trichocysts in this layer. Mouth and anus are both absent, the only opening in the pellicula being the pore of the contractile vacuole. The myonemes which lie beneath the meridional lines of insertion of the cilia are feebly developed in keeping with the slight flexibility of the body.

The entoplasm (Fig. 1, en'pl.) in living, preserved, and stained material is less dense than the cortical plasma, and in both iron hæmatoxylin and picrocarmine it stains more deeply. It contains many larger granules (Figs. 1, 4), and its substance is much more fluid than that of the outer layer. Some of the granules are more highly refractive than others, and in staining these granules dye more deeply. There is usually a larger one, 6 to 8 micra in diameter, near the anterior end which at first glance suggests a micronucleus, but its consistency, its inconstancy in different individuals, and the presence of granules which intergrade between it and the less deeply stained ones preclude such a possibility. It seems to be a highly differentiated metaplasmic constituent.

The cortical plasma (Fig. $4, p l$. ctx.) occupies a marginal belt (in dorsal or ventral view) about 8 to 12 micra in width and a much thimner stratum on the dorsal and ventral faces. In living animals it is hyaline and homogeneous. In preserved material it has the appearance of an alveolar structure with denser granules of minute and somewhat variable size scattered throughout its substance Its inner margin is somewhat irregular with short centrally directed angles (Fig. 1), and it is marked by an abrupt change to the more coarsely granular and more mobile entoplasm.

The contractile vacuole (Figs. 1, vac. co'tr., 2, 6, 7) lies at the posterior end in the cortical layer of the ectoplasm. At diastole it is 12 to 15 micra in diameter and of spherical form or slightly flattened in dorso-ventral direction. A trefoil-shape (Fig. 7) was found in one instance in preserved material and may indicate the approach of systole. Even at the time of diastole the outer layer of entoplasm forms a distinct membrane of denser cytoplasm which separates the vacuole from the looser entoplasm of the central region with the exception of a small area at the anterior pole where only the wall of the vacuole intervenes (Figs. 6, 7). 
Leading from the vacuole through the cortical plasma is an efferent canal (Figs. 1, 2, can. eff.) which opens at a short distance dorsal to the posterior margin by an excretory pore (Figs. 1, 2, 6, 7). The pore and canal are not always placed in the median plane, being frequently displaced a little to the right (Fig. 1), possibly as a result of the state of contraction of the animal. This canal and pore are well defined and can be located in all the individuals that I have examined. The pore lies at the summit of a small elevation that sometimes protrudes beyond the posterior margin. The proximal end of the canal connects with the postero-ventral region of the vacuole (Fig. 2). The cytoplasm of the cortical region adjacent to the canal and vesicle stains more deeply and appears to be denser, as though there were a differentiated wall to these regions. This wall also covers the portion of the vacuole which at diastole projects into the entoplasmic region.

Protophrya is the only member of the family Opalinidæ which possesses a single spherical vacuole. In Anoplophrya there are five to thirty, in Hoplitophrya there are two or more, or a longitudinal canal, in Discophrya there is a secreting canal, while in Opalinopsis and Opalina there are no vacuoles at all. Protophrya is thus the least modified member of the family, resembling the non-parasitic and unmodified Holotricha in this particular.

The macronucleus (Fig. 1, mak'nl.) is centrally located, spherical or slightly flattened in a dorso-ventral direction. It is somewhat variable in contour, being subject to very slight irregularities (Fig. 7). These are never sufficient, so far as I have observed, to give it an elliptical or reniform outline. The dianeter in the frontal plane is 20 to 25 micra. Within the nuclear membrane one finds in stained material very many fine chromatin granules or rods evenly distributed throughout the nucleoplasm. In individuals subjected to the action of $5 \%$ sodic carbonate and subsequently stained in picrocarmine (Fig. 5) I find larger granules that grade down to the smaller ones, each surrounded by a clear area. The larger granules were occasionally seen in other nuclei not so treated, but the clear areas surrounding them were not observed. It seems probable that they are due to the solvent action of the reagents. In no other genus of this family is there a single spherical macronucleus similar to that found in Protophrya and most Holotricha. The form in other Opalinidx is elliptical as in Hoplitophrya and Discophrya, or even much elongated as in Anoplophrya, while in Opalinopsis and Opalina there are many small elliptical or spherical nuclei.

The micronucleus (Fig. 1, 5, mik'nl.) is a small elliptical body on the anterior face of the macronucleus. It is froin 3 to 5 micra in length with the long diameter in the transverse direction. In stained specimens it can be detected by its deeper 
dye, but in unstained material it cannot be distinguished from the surrounding granules. It is always closely applied to, in fact flattened against, the macronucleus, and might easily be overlooked. I have not always been able to find it, and have obtained clearest demonstrations of its presence only with a $\frac{1}{1}$ apochromatic objective and ocular 12 or 18 . In one instance (Fig. 7) the micronucleus lay in an indentation on the ventral side of an anterior projection of the macronucleus.

The only other species of the family which is known to possess a micronucleus is Anoplophrya branchiarum Stein. In the possession of a micronucleus and in the spherical form of the macronuchus Protophrya is the most primitive genus of the family, retaining these characters as they appear in many holotrichous forms not modified by parasitism.

Two cases of transverse division of the normal type have been observed in the material at my disposal. Conjugation, encystment, and spore formation have not been detected.

The systematic position and relationships of Protophrya are patent. The character of the ciliation and the absence of mouth and anus place it unquestionably in the Opalinidæ. The following table adapted from Schewiakoff ('96) will serve to locate the new genus Protophrya in this family.

\section{Key to the Genera of the Opalinidex.}

With a single contractile vacuole posterior to a spherical nucleus.......Protophrya. With one or two rows of contractile vacuoles or with longitudinal excretory canals. 1 .

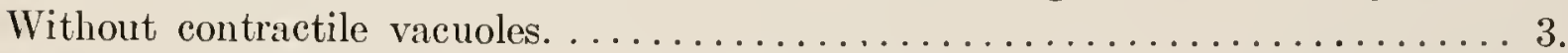

1. Without suckers, hooks, or internal rods; one or two rows of contractile vacuoles:

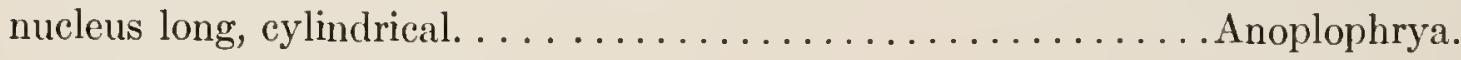

1. With suckers, hooks, or internal rods........................ 2 .

2. With one or two hooks on anterior end or with internal rod; one or two rows of contractile vacuoles; nucleus long, cylindrical............. Hoplitophrya.

2. With suckers on anterior end; longitudinal contractile canal; nucleus ellipsoidal or reniform. . . . . . . . . . .

3. Body vermiform or oval; single long ribbon-like mucleus or many nuclei irregularly

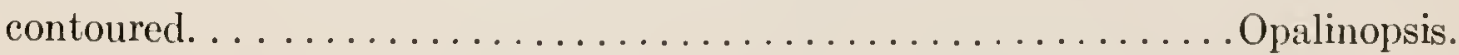

3. Body flattened, asymmetrical; many round nuclei or a single bipartite nucleus.

Opalina.

The primitive condition of the contractile vacuole, the spherical macronucleus, and the absence of special structures such as the hooks or intermal rods of Hoplitophrya stamp this new genus as one of the least specialized members of the family. The presence of a micronucleus may also be regarded a primitive 
character, since it is known to occur in but a single other species of the family, Anoplophrya branchiarum. Its presence in Protophrya ovicola is determined with some difficulty, and a re-examination of other species with the best conditions of magnification and illumination may extend its occurrence. Pending such an examination, it seems best to leave the matter of its absence in other members of the family an open question. The resemblance of Protophrya to such primitive types as Holophrya and Prorodon, the simplest forms of Holotricha, is evident. Its specialization lies in the fine ciliation, the marginal zone of cilia, and the adaptive form of the animal. On account of its primitive characters I place it as the lowest genus in the family and have named it accordingly.

\section{BIBLIOGRAPHY.}

Foettinger, A.

'81. Recherches sur quelques infusiores nouveaux, parasites des Céphalopodes. Arch. de Biol., tom. 2. pp. 344-37S, pls. 19-22.

Quennerstedt, A.

'67. Bidrag till Sveriges Infusorie-fauna. Acta Univ. Lundensis, for 1867, tom. 4, no. 7, 48 pp., 2 tab. Schewiakoff, W. T.

'96. [Organization and Classification of the Infusoria Aspirotricha (Holotricha auctorum).] Mém. Acad.

Schweier, A. W. Imp. Sci. St. Petersbourg, sér. 8, vol. 4, no. 1, ix +395+13 pp., 7 pls. [Russian.]

:00. [The parasitic ciliate Infusoria (endoparasites).] Trav. Soc. Imp. Nat. St. Petersbourg, Sect. Zool., vol. 29 , pp. 1-135, 2 pls. [Russian.]

Vaullegeard, A.

:01. Etude expérimentale et critique sur l'action des Helminthes: I. Cestodes et Nématodes. Bull. Soc. Linn. Normandie, sér. 5, vol. 4, pp. 84-142.

\section{EXPLANATION OF PLATE VIII.}

\section{ABBREVIATIONS.}

$\begin{array}{ll}\text { can. cff. } & \text { Effercnt canal. } \\ \text { cil. } & \text { Cilia. } \\ c c^{\prime} p l . & \text { Ectoplasm. } \\ \text { en'pl. } & \text { Entoplasm. } \\ \text { mak'nl. } & \text { Macronucleus. } \\ \text { mik'nl. } & \text { Micronucleus. }\end{array}$

pell. Pellicula.

pl. ctx. Cortical plasma.

po. exe. Excretory pore.

st. alv. Alveolar layer.

vac. co'tr. Contractile vacuole.

\section{PLATE VIII.}

All drawings, with the exception of Figure 3, were based on outlines made with an Abbe camera lucida.

Protophrya ovicola sp. Nov.

Fig. 1. Dorsal vicw of the whole animal; Flemming's chrom-osmic-acetic; Benda's iron-hæmatoxylin. Leitz homog. imm. apoch., Oc. $4 . \quad \times 1100$.

Fig. 2. The same scen from left side. $\times 1100$.

Fig. 3. Egg of Littorina rudis with Protophrya upon its surface. $\times 75$.

Fig. 4. Marginal zone of Protophrya showing finer structure of ectoplasm and entoplasm. Same preparation as Fig. 1. Leitz homog. imm. apoch., Oc. 18. $\times 3300$.

Fig. 5. Nuclei of Protophrya; Flemming's chrom-osmic-acetic, followed by $5 \%$ bicarbonate of soda for 24 hrs.; Ranvier's picro-carmine. Leitz homog. inm. apoch. $\times 1650$.

Fig. 6. Dorsal view of Protophrya showing contractile vacuole and excretory canal. $\times 500$.

Fig. 7. Dorsal view of Protophrya showing trefoil stage of contractile vacuole. $\times 500$. 

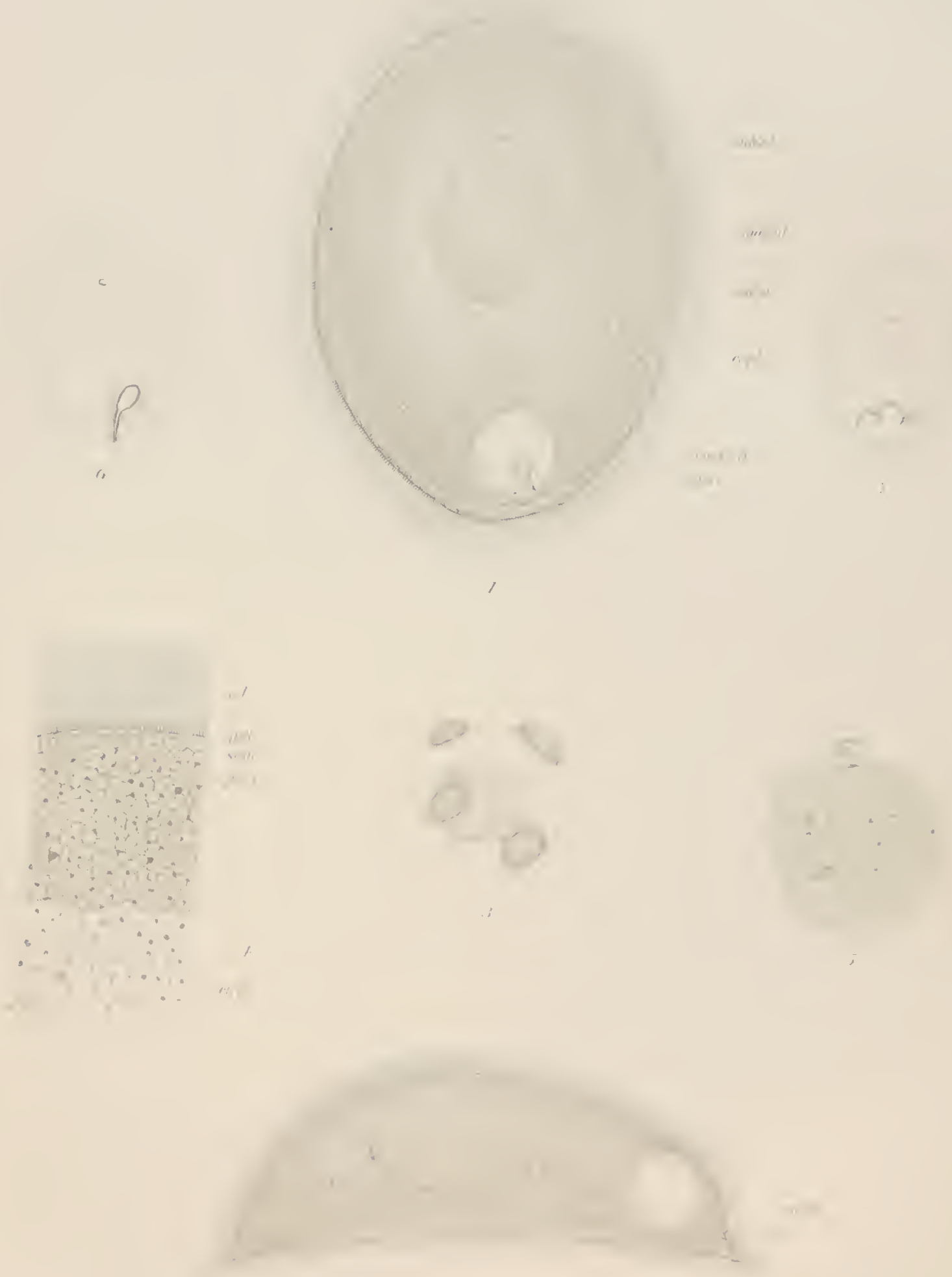

VI.

A COMPARISON OF SOME PECTENS FROM THE EAST AND THE WEST COASTS OF THE UNITED STATES.

(PLATE IX.)

C. B. Davenport. 



\section{STATEMENT OF THE PROBLEM.}

Modern statistical methods in zoölogical study give us a means of expressing variation quantitatively. Such methods are a prerequisite to the discovery of the actual causes of variation. It is frequently stated that an important cause of the difference in variability of two lots of animals from different regions is some sort of unlikeness in the physiographic conditions. The present study tests that assertion by comparing the variability of two lots of Pecten shells of close relationship from localities having very different geological histories and present physiographic conditions.

\section{MATERIAL AND METHODS.}

The material used was of two lots. One came from Dunedin, on the Gulf Coast, fifteen miles west of Tampa, Florida; the other came from San Diego, California. The Dunedin shells were obtained for me by Mr. J. H. Holmes of Dunedin in the summer of 1900. He says in his letter, dated August 2, 1900: "These shells were picked up on the flats commencing off Dunedin and going three-quarters of a mile south toward Clearwater; all were found in this locality." They were all in pairs. The shells from San Diego were received by me from a dealer there who states that they were collected on Coronado Beach.

The Pecten shells from Dunedin have been variously classified and named by systematists. The commoner names have been: Pecten gibbus Linn. and Pecten dislocatus Say. The shells are closely related to the northern P. irradians and connected with it by intergrading forms so that Dall ('98, p. 746) has given the name Pecten (Plagioctenium) gibbus to all these forms and included the Dunedin formunit under the name Pecten gibbus var. dislocatus, or, better, var. gibbus. With reference to the well-known city and bay from near which these shells came they will henceforth in this paper be called merely the "Tampa shells."

The shells from San Diego agree with specimens at the Field Columbian Museum labelled Pecten (Plagioctenium) ventricosus Say, also from San Diego. The species has also been named P. tumidus and $\mathrm{P}$. circularis. It occurs both living and fossil (Pleistocene) south of Santa Barbara, Cal. These shells will henceforth be known as the "San Diego shells." 


\section{CLOSE RELATIONSHIP OF THE TAMPA AND SAN DIEGO SHELLS.}

Dall ('98, p. 711) calls P. ventricosus the Pacific coast analogue of P. dislocatus Say. I cannot doubt that there is more than an analogy between the species. The grounds that lead me to conclude that there is a close relationship are as follows:

I. General Aspect of the Shells of the Two Lots. - The maximum size is about the same for Tampa and San Diego shells, 65 millimetres and 62 millimetres respectively. In the two lots studied by me, however, the mode of the Tampa shells was 54 millimetres and the mode of the San Diego shells was 40 millimetres, so that the San Diego shells run smaller than those of the Gulf, which is possibly due to the fact that they were collected at a different time of the year, i.e., were younger. The weight and symmetry of the valves, the form of the rays, and the general color are also similar, although the lower valves of the Tampa shells are whiter and the upper valve more strikingly variegated than is the case with the San Diego shells.

2. Color Markings.-The color markings show resemblances in detail (Pl. IX, Fig. 1). In both lots the right (lower) valve may be without markings, though the San Diego form never has the pearly-white color of the Tampa form. Thus the color formula* of the unmarked Tampa lower valves is W. 87, N. 13; of the San Diego valves, W. 45, N. 20, Y. 23, R. 12. Likewise the right valves from both localities show a mottling of brown to blue-black on a uniform ground. In extreme cases the entire shell has a dirty red-orange ground color which, near the beak, is expressed in the case of the Tampa species by W. 13, N. 18, Y. 12, O. 34, R. 23, but in the San Diego species is less orange and red, as the following color formula shows: W. 25, N. 22, Y. 18, O. 20, R. 15. The ground color of the upper valve varies in the Tampa lot from an ebony black to a very dirty orange red: W. 5, N. 41, Y. 10, O. 22, R. 22. In the San Diego form there is, in the darkest valves, $10 \%$ to $20 \%$ of white, and the valves with the greatest amount of orange have the formula: W. 22, N. 29, Y. 27, O. 22. Thus in both valves of the San Diego shells yellow seems to replace the red of the Tampa shells.

The upper valve of the Tampa Pectens has in the midst of the dark ground certain . light-colored rays, henceforth called the "white" rays, although by no means always white. The most constant of these is a nearly middle rib. This white ray usually lies nearer the posterior than the anterior end of the series; in only about $2 \%$

* The formula represent the proportions, per cent, for the standard colors in the Maxwell color mixer made by the Milton Bradley Company. The letters are the initials of the primary colors; also, W. =white; $\mathrm{N}$, $=$ black (nigrum). 
of the cases is there one more rib behind it than in front; in $6 \%$ there is the same number. The anterior exceeds the posterior number of ribs

\author{
by one in $36 \%$ of all cases; \\ by two in $39 \%$; \\ by three in $16 \%$; \\ by four in $1 \%$.
}

Thus, typically, the shifting of the white rib forward by one would place it in the middle of the series. In addition to the middle white rib nearly all of the upper valves show a trace of a white rib lying to one side of the median or of two ribs lying one on either side. Of these the anterior rib is the more constant. In the majority of cases, $72 \%$, this rib is separated from the middle white rib by four ribs; in $22 \%$ by three ribs; in $6 \%$ by five ribs. When the posterior white rib is present it is usually separated by three ribs from the median white rib ( $84 \%$ of all cases); more rarely by four ribs ( $16 \%$ of cases). The white ribs, either median, anterior, or posterior, may be uniformly light, but very frequently there are only patches of white which give the whole shell a mottled appearance. These light-colored ribs, most frequently the middle one, are found in the Pectens irradians from Cold Spring Harbor in corresponding positions. So they are characteristic of the East Coast species. Especially important for our purpose is the fact that, while these white rays are not a common phenomenon in the genus Pecten, they occur also in the lot from San Diego. Here the number of ribs anterior to the median white rib exceeds the number posterior to it in every case; the excess is one rib in $47 \%$ of the cases; two ribs in $47 \%$; and three ribs, for instance, $11: 8$, in $6 \%$. The lateral ribs are much less constant in occurrence than the middle one, being distinguishable in only about $10 \%$ of all left shells, and then almost exclusively anterior to the middle rib. The number of ribs between the anterior and the median light-colored rays is modally four. Here, again, the white rib is rarely completely colorless, but there are frequently dark bars across it giving, again, a mottled appearance to the shell.

Now, the foregoing resemblances in the details of color markings cannot be accidental; they point to a blood-relationship of the Gulf and San Diego forms.

3. General Proportions. - In both lots of shells, as in general in Pecten, the posterior partial length exceeds the anterior.* The excess is only about $6 \%$ in the Tampa form; it is $15 \%$ in the San Diego form. But the skewness of even the San Diego shell is slight as compared with that of some other Pacific Coast species, for

* That part of the anterio-posterior diameter of the valve that lies in front of the plane passed perpendieular to the hinge at the beak may be ealled the anterior partial length; the remainder is the posterior partial length. 
instance, Pecten latiauratus. The proportions of the dorso-ventral diameter to the transverse half-diameter (height of a single valve) are closely similar in the Tampa and San Diego lots. Thus the ratio of transverse half-diameter to dorso-ventral diameter is as follows:

$\begin{array}{lcc} & \text { Tampa. } & \text { San Diego. } \\ \text { Right valve......... } & .32 & .34 \\ \text { Left valve . . . . . . . } & .265 & .295\end{array}$

Consequently, applying even the delicate test of proportions, the Tampa and San Diego shells show a close similarity. I conclude, then, that the Tampa and San Diego Pectens are closely related and that, environmental factors being the same, the variability should be the same. Any considerable difference of variability is probably due to a difference in the action of environment.

\section{RELATION OF THE FOREGOING FACTS TO THE THEORY OF MIOCENE CONNECTION ACROSS THE ISTHMUS OF PANAMA.}

Having demonstrated the close relationship between the Tampa and San Diego Pectens the question arises: How is it possible to have so closely related forms separated by so great a distance of coast-line? In this dilemma, as in many similar ones, assistance is given by the fact now well ascertained that the Pacific Ocean on the one side and the Caribbean Sea and the Gulf of Mexico on the other were continuous in Miocene times. At this period, no doubt, many of the species of the two sides of Central America were identical. Pecten irradians-gibbus-ventricosus was one of those. Since the uplift at the end of the Miocene most of these common species have become differentiated so as to be distinct. But it has been estimated (see Fischer, '87, p. 169) that three per cent. of the mollusks of the two sides of the Isthmus are still practically identical. The Tampa and San Diego Pectens, while still easily distinguishable, have not differentiated so far that their specific proximity is obscured. The present dissimilarity between "ventricosus" and "gibbus" is in fair harmony with the prevailing view of former oceanic connections.

\section{THE SPECIFIC IDENTITY OF PECTEN VENTRICOSUS.}

I do not propose to discuss this point in any detail, but I may point out that the common littoral Pecten of Cold Spring Harbor (Pl. IX, Fig. 5) is as easily distinguished from that of Tampa as the latter is from that of San Diego. Indeed, in many respects, such as details of color markings and number of rays, the Tampa 
and San Diego forms are more closely similar than those of Tampa and Cold Spring Harbor or even those of Tampa and Beaufort. For the modal number of rays of the Cold Spring Harbor and Beaufort shells is 17, that of Tampa is 20, while that of San Diego is 19. Yet Dall has placed the Cold Spring Harbor and Tampa shells in one species and left the San Diego lot in another. The justification for this is, I presume, the presence of intergrades between the Atlantic Pectens and their absence between those from Tampa and from San Diego.

\section{METHOD OF MEASURING THE SHELLS.}

To measure rapidly a large number of shells a special apparatus was devised that I have found very convenient. Rising perpendicularly from the periphery of a circular disc of iron ten centimetres thick and planed flat on both sides is a millimetre scale with a vernier caliper-arm sliding upon it and reaching out over the centre of the plate. On the basal plate close to the inner edge of the vertical scale and perpendicular to the caliper-arm is drawn the base-line for the horizontal measurements. The plate itself serves as the base for vertical measurements. Upon the basal plate is pasted a piece of millimetre paper ruled in squares, the rulings running respectively parallel and perpendicular to the horizontal base-line. One of the perpendicular rulings of the paper is parallel to the centre line of the caliper-arm and serves as a zero point for measurements of the partial anterio-posterior diameters of the shells, as the horizontal base-line serves as a zero point for the dorso-ventral diameter of the shells.

The method of using the instrument is this: A single valve is placed on the base with the middle of its beak touching the inner edge of the vertical scale. The hinge is placed parallel to the horizontal base-line. The caliper-arm is lowered until it strikes the shell (at its highest point). The width, anterior and posterior half-length, anterior and posterior half hinge-lengths, and the height of the valve are quickly read and then the shell is removed and the number of internal grooves counted. With a person to record measurements, forty valves may thus be measured and data concerning each recorded in an hour.

\section{RESULTS.}

The results gained refer to the following characters: 1. Variability in the number of rays; 2. Variability in transverse half-diameter in relation to dorso-ventral diameter; 3. Variability in symmetry of the single valve-anterior partial length 
compared with posterior partial length. The general methods of calculating are those laid down in my Statistical Methods (Davenport, '99) and are for the most part based on Pearson's ('94, '95) work.

1. Variability in the Number of Rays. - The distributions of frequencies of ray numbers are given for the right and left valves. In the case of the Tampa lot the right and left valves were from pairs.

Distributions of Frequencies of Grooves on InNer Face of Shell.

\begin{tabular}{|c|c|c|c|c|} 
& \multicolumn{2}{|c|}{ Right Valve. } & \multicolumn{2}{c|}{ Left Valve. } \\
\cline { 2 - 4 } & Tampa. & San Diego. & Tampa. & San Diego. \\
\hline 16 & & & & 1 \\
17 & & 7 & & 8 \\
18 & 7 & 47 & 4 & 89 \\
19 & 59 & 191 & 54 & 159 \\
20 & 195 & 184 & 163 & 63 \\
21 & 167 & 40 & 193 & 17 \\
22 & 59 & 4 & 73 & 2 \\
23 & 15 & 1 & 13 & \\
24 & & & 2 & \\
\hline
\end{tabular}

The constants derived from these seriations are:

\begin{tabular}{|c|c|c|c|c|}
\hline & \multicolumn{2}{|c|}{ Right. } & \multicolumn{2}{c|}{ Left. } \\
\cline { 2 - 3 } & Tampa. & San Diego. & Tampa. & San Diego. \\
\hline$n$ & 502 & 471 & 502 & 344 \\
$A$ & $20.512 \pm 0.030$ & $19.459 \pm 0.0 S 7$ & $20.645 \pm 0.030$ & $18.985 \pm 0.033$ \\
$\varepsilon$ & $0.991 \pm 0.021$ & $0.885 \pm 0.019$ & $0.993 \pm 0.021$ & $0.907 \pm 0.024$ \\
$c$ & $4.83 \% \pm 0.10$ & $4.55 \% \pm 0.10$ & $4.81 \% \pm 0.10$ & $4.77 \% \pm 0.12$ \\
\hline
\end{tabular}

From these constants we conclude that, in respect to the rays, the Tampa lot has the greater average number. This greater number of rays of the Tampa lot may be related to temperature or the specific gravity of the sea-water. The Tampa lot has, indeed, the greatest number of rays of any lot I have examined, and it comes from a water with the highest mean annual temperature (about $26^{\circ} \mathrm{C}$.) and highest specific gravity (about 1.0270 to 1.0275); whereas the San Diego lot, like that of Cold Spring Harbor, experiences a mean annual temperature of nearer $14^{\circ} \mathrm{C}$. and a specific gravity of, say, 1.026. (See Murray, '95, Maps 1, 2.)

The index of variability $(\varepsilon)$ of the rays is slightly less at San Diego than at Tampa, but if the coefficients of variation (c) be compared the differences appear insignificant since they are either little greater or much less than the sum of their probable errors. It seems not unlikely that in a long series of variants, like the rays, the variability 
should be associated with the size of the series. Accepting this view we may conclude that the variability of the rays of the Tampa and San Diego lots is sensibly the same.

2. Variability in the Transverse Half-diameter of the Shells ("Height" of Valve). -The absolute "height" of the valve depends partly on the absolute size of the shell and varies with the age of the scallop. In comparing the variability of the heights of the two lots of shells from Tampa and San Diego we must, accordingly, compare shells of the same dorso-ventral dimension (width). We may do this by means of the usual correlation surface (see Appendix, Table I). In such a surface the various heights for each width of shell is given. The average of the indices of variability of height for the different widths is given by the formula $\sigma^{\prime}=\sigma \sqrt{1-r^{2}}$, in which $r$ is the coefficient of correlation as determined by the Galton-Pearson-Duncker method, and $\sigma$ is the index of variability of widths in general. Since in graduated variates the coefficient of variation $\left(c=\frac{\sigma}{A}\right)$ is more significant than the index of variation, $\sigma$, we may substitute $c$ in the above formula and obtain the average coefficient of variation, $c^{\prime}$, of the heights corresponding to the different widths. A comparison of the $c$ 's of the Tampa and the San Diego lots will give the best measure of the relative variability of the height of the valve from the two places. The results are given in the following table.

\begin{tabular}{|c|c|c|c|c|}
\hline & \multicolumn{2}{|c|}{ Right Valve. } & \multicolumn{2}{|c|}{ Left Valve. } \\
\hline & Tampa. & San Diego. & Tampa. & San Diego. \\
\hline 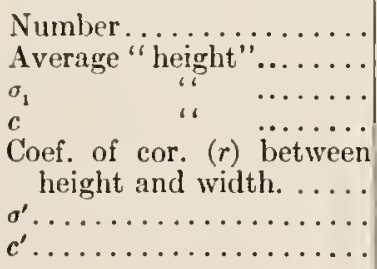 & $\begin{array}{l}501 \\
17.344 \mathrm{~mm} . \pm 0.040 \\
1.327 \mathrm{~mm} \cdot \pm 0.02 \mathrm{~S} \\
7.65 \% \pm 0.16 \\
0.800 \pm 0.009 \\
0.7962 \\
4.590 \%\end{array}$ & $\begin{array}{l}581 \\
13.445 \mathrm{~mm} . \pm 0.052 \\
1.868 \mathrm{~mm} \cdot \pm 0.037 \\
13.90 \% \pm 0.27 \\
0.8811 \pm 0.0046 \\
0.8733 \\
6.616 \%\end{array}$ & $\begin{array}{l}502 \\
13.832 \mathrm{~mm} \cdot \pm 0.031 \\
1.010 \mathrm{~mm} \cdot \pm 0.022 \\
7.40 \% \pm 0.18 \\
0.685 \pm 0.013 \\
0.7356 \\
5.393 \%\end{array}$ & $\begin{array}{l}340 \\
11.753 \mathrm{~mm} . \pm 0.046 \\
1.259 \mathrm{~mm} . \pm 0.033 \\
10.71 \% \pm 0.28 \\
0.714 \pm 0.015 \\
0.8813 \\
7.498 \%\end{array}$ \\
\hline
\end{tabular}

Expressed fully, these quantitative results tell "us that, using the coefficient of variation as a basis of comparison, the San Diego Pectens are from 1.8 to 0.5 times as variable in "height" as those of Tampa; and San Diego Pectens of a constant width are, on the average, 1.6 to 1.4 times as variable in "height" as the average of Tampa Pectens. In a word, the San Diego Pectens are $50 \%$ more variable in transverse half-diameter than those of Tampa.

3. Variability in Symmetry of Single Valves. Comparison of Anterior and Posterior Half-lengths. - The following table gives, for the right valves only, the average dimension, in millimetres, of the anterior and posterior partial lengths; the corresponding 
indices of variability, $\sigma$; and the coefficient of variation, $c$. The left valves, since they have the same symmetry as the right, were not studied.

Right VALVE.

\begin{tabular}{|c|c|c|}
\hline & Tampa. & San Diego. \\
\hline Anterior partial length: & & \\
\hline Average. . ........... & $27.138 \pm 0.066$ & $19.113 \pm 0.076$ \\
\hline 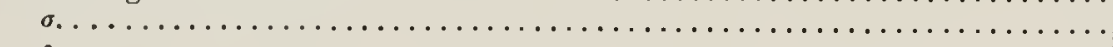 & $2.205 \pm 0.047$ & $2.716 \pm 0.054$ \\
\hline 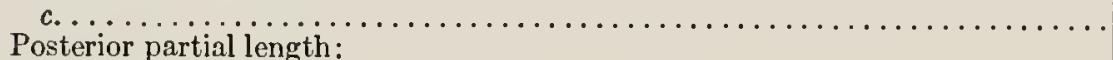 & $8.32 \pm 0.18$ & $14.21 \pm 0.28$ \\
\hline Average. ............ & $28.679 \pm 0.066$ & $22.095+0.096$ \\
\hline$\sigma \ldots \ldots \ldots \ldots \ldots$ & $2.199 \pm 0.049$ & $3.436 \pm 0.068$ \\
\hline c. $\ldots \ldots \ldots \ldots \ldots \ldots \ldots$ & $7.67 \pm 0.16$ & $15.55 \pm 0.31$ \\
\hline Coefficient of correlation $(r)$ between posterior and anterior partial lengths. & $0.829 \pm 0.007$ & $0.913 \pm 0.003$ \\
\hline Average $\sigma$ of arrays of posterior for given anterior partial lengths. ....... & 1.224 & 1.402 \\
\hline Average $c$ of arrays of posterior for given anterior partial lengths. . & $4.28 \%$ & $6.34 \%$ \\
\hline
\end{tabular}

Expressed fully these quantitative results show that, using the coefficient of variation $(c)$ as a basis of comparison, the San Diego Pectens have an anterior partial length 1.7 times as variable as those of Tampa. Also, that the posterior partial length of the San Diego shells is twice as variable as the corresponding length of the Tampa lot. Finally, for shells of a given anterior partial length the posterior partial length is 1.5 times more variable in the case of San Diego shells than in the case of Tampa shells.

To summarize: In all proportions measured, the San Diego Pectens show themselves from $50 \%$ to $100 \%$ more variable than those of Tampa.

\section{CONCLUSIONS.}

Up to this stage we have not left the solid ground of ascertained fact. We must now traverse the alluring but unsteady ground of logical analysis to arrive at an explanation of the greater variability of the San Diego shells.

We have dealt in the present paper only with slight, individual or, as I prefer to call it, "trivial" variation, using the word in its older sense of "common" rather than its newer sense of "trifling."

1. Trivial variation is, in general, due to one or several of the following causes:

$a$. The very complexity of the developmental process makes it impossible that two exactly similar forms should be produced. The effect of this cause may be measured by comparing "identical" twins, or the offspring of the isolated blastomeres of a sea-urchin or other animal. Perhaps also by comparing the different embryos from one batch of eggs developed under identical conditions. We find, very frequently, that the variability of these individuals, although sensible, is unusually small. 
$b$. The individuals in their development have been subjected to diverse conditions. The importance of such diverse conditions upon form is very great. Every external factor has its modifying influence on development. Just because the chemical, osmotic, aqueous, molar, gravitational, photic, and thermic agents do not act at all times to the same degree and in the same direction upon all the individuals, the individuals in any generation are unlike.

c. The individual shells have not exactly the same ancestry. It is quite probable that some contain the blood of incipient races that the others do not. When the form-unit was nascent, at least, some degree of intermingling with adjacent forms probably occurred, but this did not affect all individuals alike. Even when the commingling forms did not belong to distinct races or species, but were only "sports," their influence would be felt through remote generations.

2. Two lots may have unlike variability partly because causes $a, b$, and $c$ may have acted unequally upon them and partly also because in one locality different selective factors may have been at work from those acting in a second locality. There is some evidence (Bumpus, '98) that where selection acts most rigidly variability is most diminished. Finally, unlike variability may arise as a result of changing environment whereby a preferential selection of the more plastic-the more accommodating, i.e., the more variable (Pfeffer, '94; Baldwin, '97)-may take place.

To judge which factors have brought about the diverse variability of the Tampa and San Diego forms we need to consider more fully the geographical histories of the Tampa and the San Diego communities.

3. The Dunedin Pectens are inhabitants of the mud-flats and shallow waters of the Gulf of Mexico. The shore is of old Miocene date and contains no overlying Pliocene deposits, according to Dall and Harris ('92). It is only 25 miles from the mud-flats that surrounded the "Eocene Island" of Florida. Although this shore-line has doubtless experienced some fluctuations, on the whole it has long remained such a mud-flat as it is to-day.

4. Unlike southern Florida the coast of southern California is one of bold relief. Mud-flats are few and consequently the places where our Pecten can develop are far between. But these conditions have not always existed in, geologically speaking, rather recent times. Elevated sea-cliffs in which Pectens indistinguishable from the living species are found afford indisputable evidence that the whole coast about San Diego was 800 to 1500 feet lower than it is now, and that the depression occurred during Pliocene (pre-glacial) time. Lawson ('93) states that "as a consequence of the general uplift of the coast the physiography of the country has been radically changed in the most recent geological times. 
During the Pliocene depression many of the valleys which had been developed in the post-Miocene interval of high altitudes, were filled to the brim with delta deposits. . . Numerous islands, large and small, fringed the coast of California. There were numerous submerged valleys, so that the coast was well supplied with harbors. In a word, the coast of California at the close of the Pliocene had the aspect of an archipelago. The archipelagic condition endured into the early Pleistocene, and from this condition it [the coast] has been gradually recovering up to the present day." From the beginning of the Pleistocene, then, the available areas for the littoral Pectens have been rapidly diminishing. This has been a time of stress for the shallow-water fauna, a period of violent, relentless selection.

Considering the causes of variation in connection with what has been stated as to differences of the geographic history of the two regions, this conclusion scems to be justified: The greater variability of the individuals from San Diego is due to the more varied present environment which tends to make some shells deviate one way and others in another, and to the past rapid changes in the physiographic conditions which have favored the more responsive, adjustable individuals, and so have given a race of which the different individuals are easily modified by the diverse environments offered. The geographic history has given San Diego a plastic race; the diversity of the present environments of San Diego have determined the excessive variability of that race.

5. If the greater variability of the San Diego Pectens is the result of the geographical changes of the Californian coast, then we should expect to find other species of this coast exceptionally variable. Unfortunately few quantitative studies have been made on the variability of American animals. Eigenmann ('95, '95') has stated that "in all families but the Cyprinodontidæ with more than one species on the Pacific slope the extent of variation is greater than in the same families on the Atlantic slope." Eigenmann's method of measuring variability by the total range is not altogether satisfactory. So far as they go, however, his studies on river fishes lead to the same conclusion as these on Pecten-the aquatic species of the Pacific coast are extremely variable owing to the great physiographic changes which that coast has undergone.

Baldwin, J. $\mathbf{M}$.

\section{BIBLIOGRAPHY.}

'97. Organic Selection. Nature, vol. 55, p. 558.

Bumpus, H. C.

'98. The Variations and Mutations of the Introduced Littorina. Zool. Bull., vol. 1, no. 5, pp. 247-259, charts 1-14.

Dall, W. H.

'98. Contributions to the Tertiary Fauna of Florida. Part 4. Trans. Wagner Free Inst. Sci. Philadelphia, vol. 3 , pt. 4 , pp. i-viii, 571-947, pls. $23-35$. 
Dall, W. H., and Harris, G. D.

'92. Correlation Papers-Neoeene. Bull. U. S. Geol. Survey, no. \$4, 349 pp., 3 pls.

Davenport, C. B.

'99. Statistical Methods, with speeial referenee to Biologieal Variation. New York, 16, $148 \mathrm{pp.}$

Eigenmann, C. H.

'95. Leueiseus balteatus (Richardson): a Study in Variation. Amer. Nat., vol. 29, no. 337, pp. 10-25.

Eigenmann, C. H.

'95'. Results of Explorations in western Canada and the Northwestern United States. Bull. U. S. Fish Comm. for 1894, vol. 14, pp. 101-132, pls. 5-8.

Fischer, P.

'87. Manuel de Conchyliologie et de Paléontologie Conchyliologique. Paris, $8^{\circ}$, xxiv +1369 pp., 23 pls.

Lawson, A. C.

'93. Post-plioeene Diastrophism of the coast of Southern California. Bull. Dept. Geology, Univ. Califor nia, vol. 1, no. 4, pp. 115-160, pls. 8-9.

Murray, J.

'95. Report on the Seientifie Results of the Voyage of H. M. S. Challenger during the years 1872-76. A Summary of the Seientifie Results. Seeond Part. London, $4^{\circ}$, xix pp., pp. 797-1608.

Pfeffer, G.

'94. Die Umwandlung der Arten, ein Vorgang funetioneller Selbstgestaltung. Verl. naturw. Verein, Hamburg, 1893, Folge 3, Bd. 1, pp. 44-87.

Pearson, $\mathbf{K}$.

'94. Contributions to the Mathematical Theory of Evolution (I). Phil. Trans. Roy. Soe. London, vol. 1S5, A, pp. 71-110, pls. 1-5.

Pearson, K.

'95. Contributions to the Mathematieal Theory of Evolution.-II. Skew Variation in Homogeneous Material. Phil. Trans. Roy. Soc. London, vol. 186, A, pp. 343-414, pls. 7-16.

\section{APPENDIX.}

TABLE I.

CORRELATION BETWEEN HEIGHTS AND WIDTHS OF RIGHT VALVES (TAMPA).

$n=501 . A_{h}-17.3439 \mathrm{~mm} . ; \sigma_{h}=1.327 \mathrm{~mm}$.

$A_{w}=54.2475 \mathrm{~mm} . ; \sigma_{t U}=3.930 \mathrm{~mm}$.

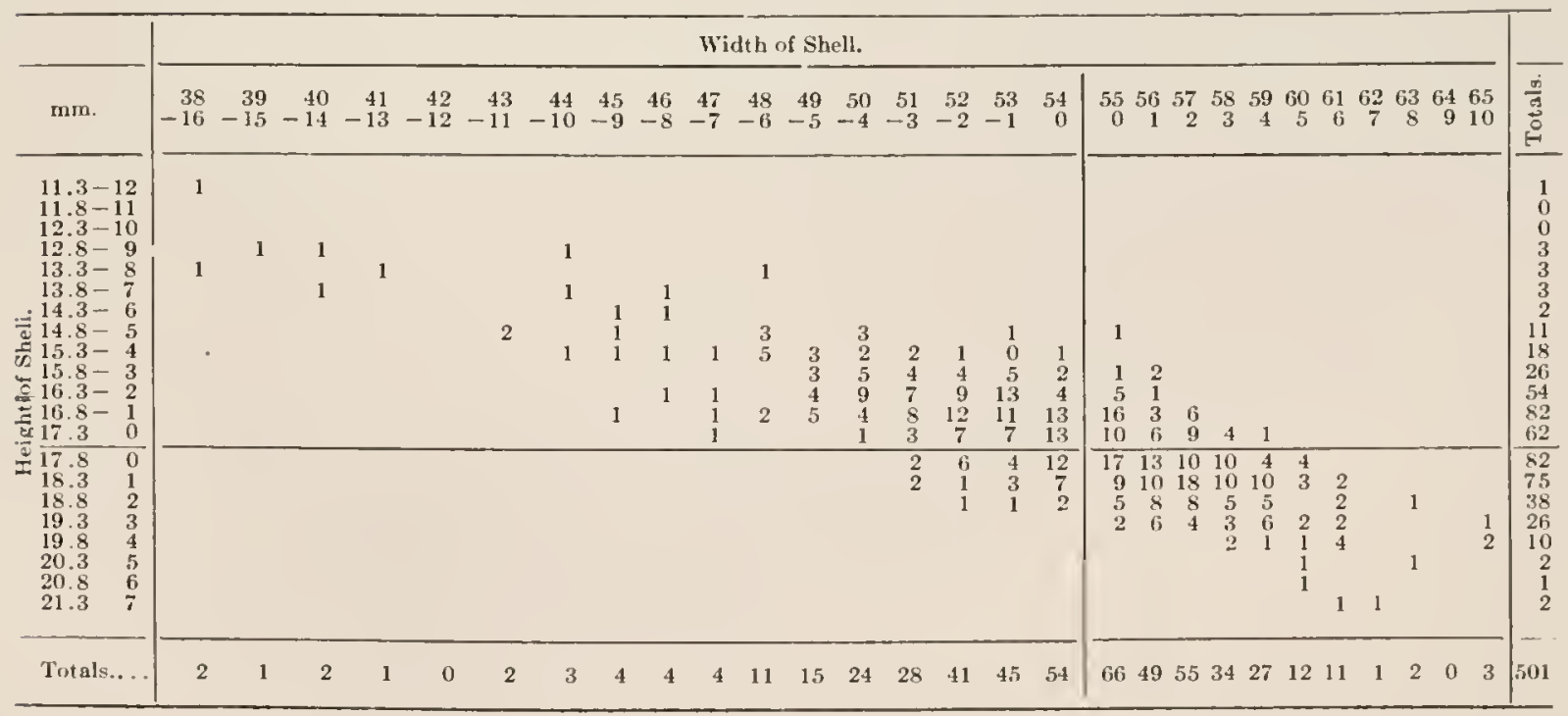




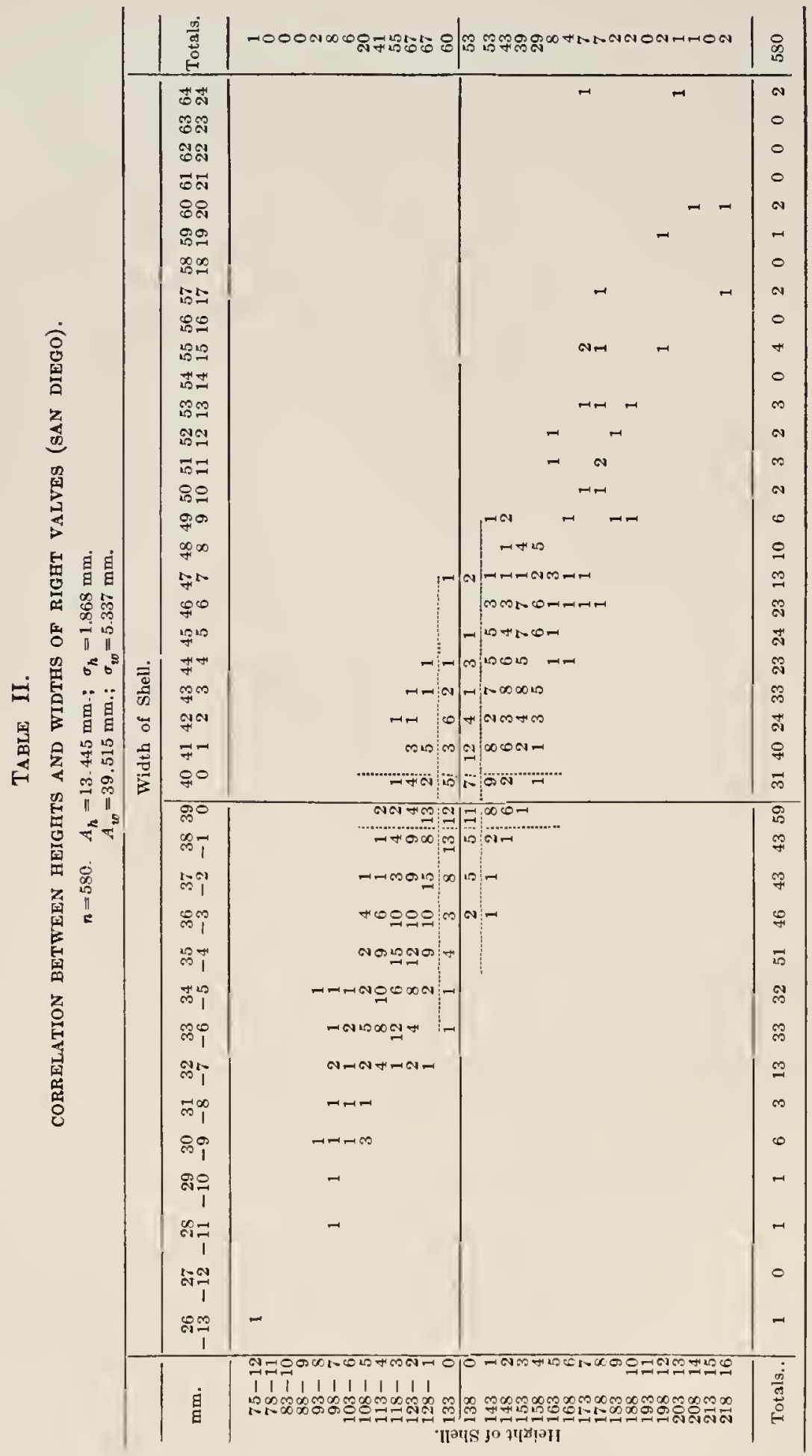




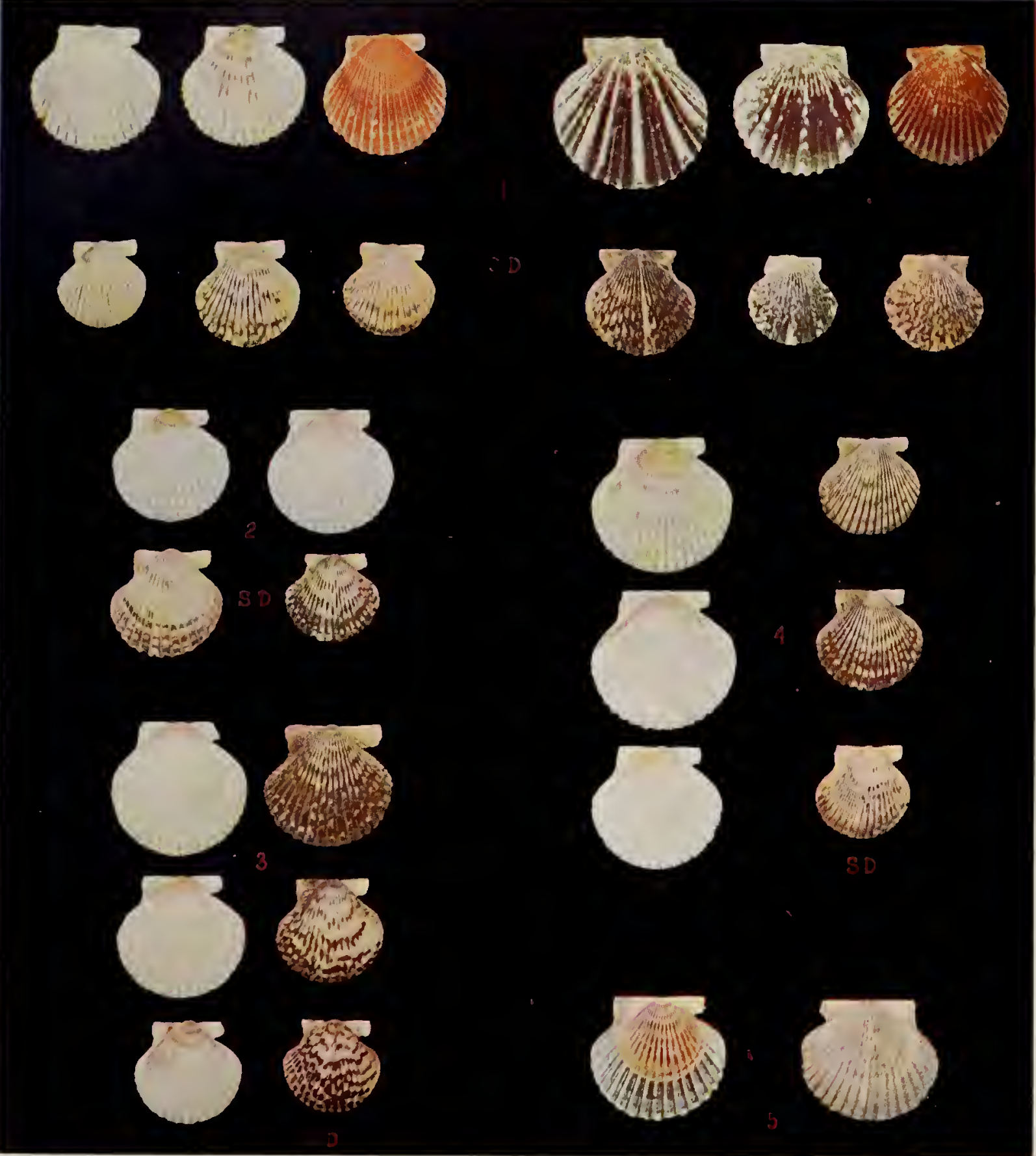

C. B. DAVENPORT-PECTENS. 
TABLE III.

CORRELATION BETWEen posterior and anterior partial lengtis of right VAlves (TAMPa).

$A_{\mathrm{a}}=27.138 \mathrm{~mm}$; ${ }_{\mathrm{a}}=2.205$.

$n=501 . \quad A_{p}=28.679 \mathrm{~mm} . ; \sigma_{p}=2.199$.

\begin{tabular}{|c|c|c|c|c|c|c|c|c|c|c|c|c|c|c|c|c|c|c|c|}
\hline & \multicolumn{18}{|c|}{ Posterior Partial Jength. } & \multirow[b]{2}{*}{ Totals. } \\
\hline & $\begin{array}{r}20 \\
-8\end{array}$ & 2 & $\frac{1}{7}$ & $\begin{array}{r}22 \\
-6\end{array}$ & $\begin{array}{r}23 \\
-5\end{array}$ & $\begin{array}{r}24 \\
-4\end{array}$ & $\begin{array}{r}25 \\
-3\end{array}$ & $\begin{array}{r}26 \\
-2\end{array}$ & $\begin{array}{r}27 \\
-1\end{array}$ & $\begin{array}{r}28 \\
0\end{array}$ & $\begin{array}{r}29 \\
0\end{array}$ & $\begin{array}{r}30 \\
1\end{array}$ & $\begin{array}{r}31 \\
2\end{array}$ & $\begin{array}{r}32 \\
3\end{array}$ & $\begin{array}{r}33 \\
4\end{array}$ & $\begin{array}{r}34 \\
5\end{array}$ & $\begin{array}{r}35 \\
6\end{array}$ & $\begin{array}{r}36 \\
7\end{array}$ & \\
\hline 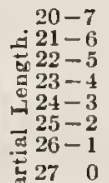 & 1 & & $\begin{array}{l}4 \\
1\end{array}$ & & $\begin{array}{l}1 \\
2 \\
1\end{array}$ & $\begin{array}{l}3 \\
2 \\
1\end{array}$ & $\begin{array}{l}9 \\
1 \\
7 \\
2 \\
1\end{array}$ & $\begin{array}{r}2 \\
4 \\
13 \\
6 \\
1\end{array}$ & $\begin{array}{r}6 \\
20 \\
26 \\
12\end{array}$ & $\begin{array}{r}2 \\
8 \\
15 \\
23\end{array}$ & $\begin{array}{r}3 \\
18 \\
56\end{array}$ & $\begin{array}{r}1 \\
3 \\
14\end{array}$ & $\frac{4}{9}$ & & & & & & $\begin{array}{r}6 \\
2 \\
2 \\
15 \\
15 \\
53 \\
74 \\
116\end{array}$ \\
\hline 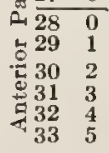 & & & & & & & - & & $\frac{6}{2}$ & $\begin{array}{l}10 \\
6\end{array}$ & $\begin{array}{r}38 \\
14 \\
3\end{array}$ & $\begin{array}{r}26 \\
23 \\
12\end{array}$ & $\begin{array}{r}12 \\
19 \\
13 \\
5\end{array}$ & $\begin{array}{l}3 \\
4 \\
4 \\
1 \\
1\end{array}$ & $\begin{array}{l}2 \\
4 \\
2 \\
2\end{array}$ & $\begin{array}{l}1 \\
1\end{array}$ & $\begin{array}{l}1 \\
2\end{array}$ & 1 & $\begin{array}{r}95 \\
71 \\
36 \\
10 \\
4 \\
2\end{array}$ \\
\hline Totals. & 1 & & 5 & 1 & 4 & 6 & 20 & 26 & 72 & 64 & 132 & 79 & 62 & 13 & 10 & 2 & 3 & 1 & $501 \%$ \\
\hline
\end{tabular}

TABle IV.

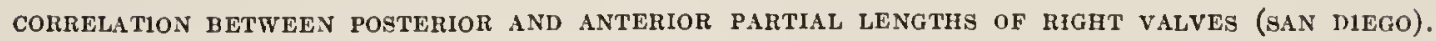

$n=580 . \quad A_{a}=19.113 ; \quad \sigma_{a}=2.716$.

$A_{p}=22.095 ; \quad \sigma_{p}=3.436$.

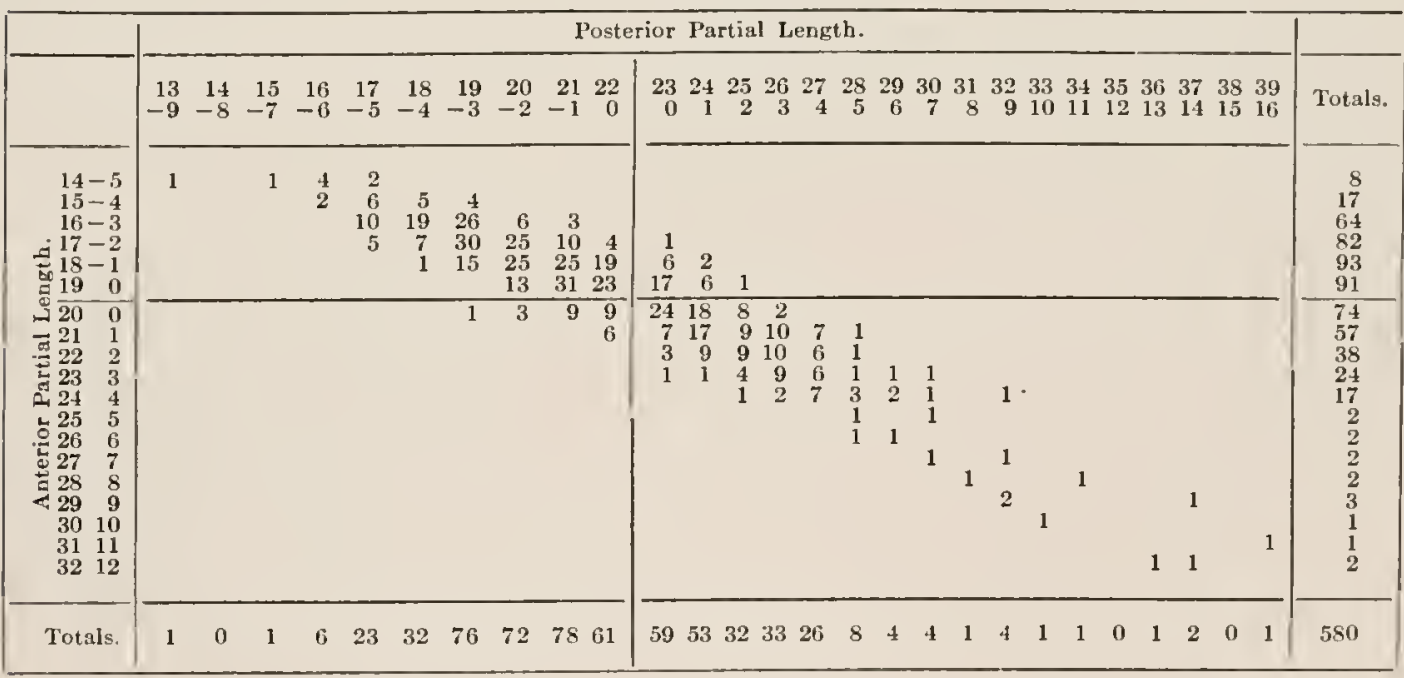

\section{EXPLANATION OF PLATE IX.}

Photograph by the three-color process of the original objects.

Fig. 1. Three right (lower) and three left (upper) valves of Pectens from the Tampa (T., above) and from the San Diego (S. D., below) lots for comparicon of color and markings. The six valves to the left are lower valves; the six to the risht are upper valves.

Fig. 2. Comparison of right valves with the greatest and smallest number of rays from Tampa (T.) and San Diego (S. D.) 
Fig. 3. Comparison of three valves from Tampa (T.) and three from San Diego (S. D.) to show variation in the transverse half-diameter (height of valve). The ratio of height to width (dorso-ventral diameter of the three Tampa shells is, in order, $\frac{16.9}{57}$, the smallest ratio $; \frac{16.8}{53}$, the modal ratio $; \frac{16.8}{45}$, the largest ratio. For the three San Diego shells the corresponding ratios are: $\frac{16.1}{52}, \frac{15.7}{45}, \frac{15.9}{41}$.

Fig. 4. Comparison of shells from Tampa (T.) and San Diego (S. D.) with respect to symmetry.

Tampa.

a. Modal condition........... 31:29

b. Most symmetrical.......... 31:31

c. Least symmetrical......... $31: 25$
San Diego.
mm.

23: 20

23: 22

$23: 17$

Fig. 5. Right and left valves from Cold Spring Harbor, Long Island, for comparison. Notice that the San Diego valves are not less unlike those of Tampa than those of Cold Spring Harbor, L. I. 
VII.

VARIATION IN THE NUMBER OF STRIPES ON THE SEA-ANEMONE, SAGARTIA LUCIA.

(PLATE $X)$

Gertrude Crotty Davenport. 

A small, olive-green sea-anemone, Sagartia lucix, occurs in countless numbers at Cold Spring Harbor, Long Island, on stones, docks, eel-grass, shells of living or dead oysters, clams, and mussels-wherever, indeed, it can obtain a foothold near shore. It is apt to seek situations where it is exposed to the air and sometimes even to the sun during low tide, and it may occur where the water is brackish, especially at low tide. Yet it is so hardy that it thrives under all these diverse conditions. When taken into the laboratory, it will survive for weeks in a cupful of sea-water even after enough evaporation has gone on to increase considerably the salinity of the water. When detached for removal to the aquaria, especially when injured somewhat, it may delay attaching itself again for days. At times, too, when the water becomes foul or from other causes it may voluntarily detach itself and float about the aquarium or hang upside down from the surface film. Gosse ('60) speaks of several varieties of Sagartia troglodytes that will detach themselves and roll about the aquaria even for months. The Dixons ('91) have observed that Metridium dianthus and Actinia equina have the power of floating with the base up.

The generic name Sagartia was proposed by Gosse in reference to a passage in Herodotus, who in describing the methods of warfare of the Sagartians states that they caught their enemy by means of missile cords. The long thread-like acontia of Sagartia, armed with nettling cells are weapons of offence and defence. They are thrust out and drawn back again through special openings in the body wall. The specific name was applied by Verrill ('98) in honor of his daughter, who first called his attention to the anemone. Professor Verrill first observed this actinian in the summer of 1892 at New Haven. In his account of it Professor Verrill says that he carefully studied the region about New Haven from 1865 to 1890, and that about Woods Hole from 1871 to 1887 , without finding a single specimen of this actinian. It is now very plentiful in both these localities. "We must conclude," says Professor Verrill, "that it has very much increased in numbers in this region within a few years, like several other species. It may have been introduced from farther south on the oysters that are annually brought north in large quantities and planted in our waters."

Sagartia luciæ may easily be distinguished from Sagartia leucolena, which is also plentiful at Cold Spring Harbor, by its habit of attaching itself in exposed situations. It seeks the tops and sides of shells and stoncs, while S. leucolena is either 
attached to the under side or more frequently to stones that are buried a half-inch or so under the sand. When expanded S. leucolena extends above the surface of the sand, but when disturbed it contracts out of sight into the sand. S. luciæ lias a shorter column, is of a dark olive-green color, and is marked by a number of bright, parallel, orange- or lemon-colored stripes that extend from the oral opening to the base and mark the position of mesenterial interspaces. S. leucolena is very shy when in its natural surroundings. Thus a shadow caused by the hand or by the flight of a crow is at times sufficient to cause it to retreat into the sand. To stupefying and killing reagents, however, it responds more satisfactorily than S. luciæ, which must be killed at the very moment of complete stupefaction in order to be preserved expanded. If allowed to stand in a state of complete stupefaction even for a short time, it begins to regain sensitiveness. A strong solution of magnesium sulphate is the most satisfactory stupefier. If the anemone inclines to contract during stupefaction it can be induced to expand again by gently swaying the dish back and forth. Both species must be stupefied and killed while attached to some foreign object, as it is impossible to handle them directly without their contracting. Warm corrosive sublimate or picro-sulphuric acid are usually satisfactory killing reagents. Unfortunately the orange bands fade out within a half-hour in whatever way the anemone is killed.

Professor Verrill gives the number of these orange stripes as " 12 (sometimes 24)." The stripes were counted on 751 individuals at Cold Spring Harbor. The number varied from 0 to 20 . In plotting these counts the resulting curve is a multimodal one (Pl. X, Fig. 15) with five maxima. The highest mode occurs at 12, with secondary maxima at $16,8,4$, and 1 . At first sight such a variation in the number of stripes seems almost meaningless. A clue to the interpretation of this variation was obtained when several pairs of individuals were found in close proximity with a groove or fold on each leading from the oral opening to the base. The stripes on these pairs were arranged in the proportions 9-3, 4-8, 5-7, respectively (Figs. 3, 4, 5). The sums of 9 and 3 , of 4 and 8 , and of 5 and 7 each make 12, the number of stripes previously observed as the most frequent condition. Other pairs with stripes arranged in the proportions 3-3 (Fig. 6) and 7-1 (Fig. 7) were also observed.

The question at once followed, are not these pairs derived from a single individual by longitudinal division? The apportionment of the stripes would then depend on the position of the plane of division and upon the amount of regeneration accomplished before another division occurs. When observed immediately after a division there would be little time for regeneration and hence for the assumption of new stripes. 
In order to settle this point it was necessary first to observe actual cases of division and apportionment of stripes. Attempts were first made to observe division by stocking a large aquarium with many individuals. Into the aquarium a quantity of mussels covered with anemones was thrown. The anemones soon crept from the mussels and covered the glass sides of the tank. Here a great many cases of division were followed part way, but, owing to the fact that the individuals may move several inches a day and the length of time spent in division often consumes a night as well as a part of a day, the resulting individuals were not recognizable with absolute certainty. The aquarium, however, taught me that longitudinal division is very frequent in this anemone, and that it begins at the basal end and may easily be overlooked from the expanded oral end until practically completed.

A few individuals were then isolated in small dishes. By this method the opportunity to find dividing individuals came necessarily more slowly. In this way, however, several cases of longitudinal division were followed through all stages, and in each instance division began at the basal end and was aboral-oral in direction as described by McCrady ('59, p. 275) for Actinia cavernosa and by Carlgren ('93, p. 3) for Protothea simplex and as observed by Torrey ('98) in some cases of the Californian Metridium. The division, in all cases observed by me, passed through the short axis of the mouth so that one pair of directives was given to each of the resulting individuals. Thus a monoglyphic S. luciæ is the result of longitudinal division of a diglyphic form. This fact, as Torrey has already pointed out from his observations on the Californian Metridium, precludes the possibility that either the monoglyphic or diglyphic types can have the values of "varieties" as suggested by Parker ('97). I have never observed the plane of division to separate the components of a pair of directives as Torrey states for Metridium, nor have I certainly observed a case of division of a monoglyphic individual, although the rapidity with which division follows division, judging from the great reduction in the number of stripcs to one (Fig. 12) or even to zero, inclines me to believe that such division may occur. I have found individuals dividing and others almost scxually mature on one and the same pebble. Multiplication by division and by sexual methods may go on at one and the same time among radiates, as Lang ('86) has shown for Gastroblasta raffaelei. Parker ('99) suggests that the diglyphic type may be the result of sexual reproduction. I have never positively observed the metamorphosis of a monoglyphic to a diglyphic type, although I had one individual under observation which I thought to be producing new directives. Unfortunately the dish in which I kept it was appropriated by another. However, I have observed that, at the period of greatest activity, in longitudinal division monoglyphic types are the more numerous, while at other 
times not many days afterwards diglyphic forms are numerous. White lines lead from the margins of the oral opening to the directive tentacles. This fact makes the directives easy of determination aside from the fact that their length is greater and that they are situated at the angles of the mouth. Division usually takes place in less than twenty-four hours and proceeds more rapidly in confinement if the individual is exposed to the air for a time and then covered with fresh sea-water in imitation of exposure to air and water occasioned by the tide. Division is very apt to be accomplished at night, but in two instances it was accomplished within a few hours during an afternoon. In nature it seems probable that division is accomplished during high tide only, for during low tide, while exposed to the air, the animal contracts and is not infrequently covered with an envelope of slime. At such a time it remains apparently quiescent.

Experiments were made to see if it is possible to delay or prevent the completion of division when once begun. Three individuals that showed evident and equal constrictions were chosen. Two of them were gorged with food, while one was not fed. The unfed individual completed its division in the normal time. The other two lost outward signs of constriction and spent twelve to fourteen hours digesting their meal. One began three days later to divide again, but the other showed no such tendency after two weeks.

Two individuals were divided each into two parts by a longitudinal cut to see if the resulting parts would regenerate or become normal individuals. One anemone was cut as nearly as possible into halves. When first cut the halves drew over so as to press the cut edge to the surface of support only in a little greater degree than do recently self-divided individuals. By the following morning both parts had the cut edges rolled in toward the central axis-a condition observed for self-divided individuals (Figs. 3, 4, 5, 6, 7). From one side of another individual only a small fragment was shaved. After twelve hours this one seemed to be a perfectly normal individual, and even the fragment after a few days had rounded itself up into the shape of a very small half-contracted anemone and possessed a few short tentacles. Three days later this fragment showed external evidences of seven mesenteries and had one orange stripe. Three days later seven more mesenteries and two orange stripes were evident. In nature one frequently finds a large anemone surrounded by a number of small individuals. The latter, I believe, are produced by basal fragmentation.

A few cases of tryglyphic individuals were observed. In one case eighteen (Fig. 8) and in another fourteen stripes were noted. In such individuals I have not had the good fortune to observe division. 
It is very easy to determine the number of mesenteries on a living individual. Their unions with the outer wall show as longitudinal dark green lines. The number is commonly not symmetrical, a peculiarity common to the genus (Dixon, '88). But in a uniformly twelve-striped individual four such dark lines occur between every two orangc stripes (Fig. 1). The orange stripes are represented in the figure by the dark patches in the margin between the primary mesenteries. Thus there are 48 mesenteries in a symmetrically twelve-striped form. On section it appears that both the primary mesenteries, that is those that connect with the cosophagus, and the secondary that fall short of it, occur in pairs. In a twelve-striped form these pairs alternate (Fig. 1). The orange stripes occur on the spaces between the primary mesenteries. In such a uniformly arranged individual the new mesenteries arise as in Figure 2 and the orange stripe will appear in the region marked $x$. But such perfect symmetry does not always occur even in a twelve-striped individual. Figures $9,10,11,13$, and 14 illustrate some of the more striking asymmetrical arrangements of the orange stripes. The broader bands in these figures represent the older stripes, and the part of the anemone included between them constitutes the old or original part that came to the anemone as the result of division. This part is of a dark olivegreen color and the stripes are of a bright orange. Opposed to the old part with the broad orange stripes is the regenerated part, which is of a light, almost transparent green. In this recently regenerated part no stripes may develop for some time as in Figures 12 and 13, or else faint lemon-yellow lines at first appear. These stripes in the regenerated part may appear only long after the primary mesenteries have united with the csophagus, or they may appear early and even in such numbers as to lie between each and every pair of mesenteries (Figs. 9, 11). With age the stripes become broader and of a deeper tint until the characteristic orange color is acquired. By the developnent of more mesenteries the stripes become pushed apart. Thus there is considerable variation both in regard to the time at which the stripes appear and in regard to the frequency or numbers that are first produced in the regenerated part. The rate and time of development of the stripes seems to be correlated with the rapidity and amount or vigor of regeneration. Along the stripes occur the openings for the exit of the acontia, the cinclides. These are in rows of two, three, or even five. In some cases, however, only one cinclis may be present on a single stripe. These stripes then mark the positions of the cinclides. May not their presence perhaps be considcred as a case of warning coloration? 


\section{CONCLUSIONS.}

1. Longitudinal division is very common in Sagartia luciæ and may take place in a few hours.

2. Multiplication by basal fragmentation is also probably common in nature.

3. Pieces made by artificial cuts regenerate new individuals. A piece without tentacles will produce a normal individual with tentacles in from five to seven days.

4. The regenerated tissue is easily recognizable on account of its lighter color.

5. By longitudinal division the stripes are apportioned to the two daughter individuals.

6. As a study of the frequency curve of the stripes shows (Fig. 15), 8-4 is a common apportionment of the stripes, as is likewise $5-7$ and $9-3$.

7. The condition of 0,1 , or 2 stripes is much less common and is the result of rapid and repeated division correlated with slow regeneration of stripes at least.

8. Stripes are brought to the new individual on the old tissue and are produced anew on the regenerated tissue.

9. The old stripes are broader and are of a deep orange color. The new stripes are narrower and are at first of a lemon-yellow color.

10. When regeneration is most vigorous, the more numerous are the new stripes produced.

11. The new stripes may appear early in the regenerated tissue, and in such numbers as to lie between each pair of mesenteries.

12. The new stripes may delay appearance in the regenerated tissue until many mesenteries are formed, and then they tend to develop between the primary mesenteries only.

13. Twelve stripes and forty-eight mesenteries is the most common condition.

14. When division is delayed for an unusual length of time more than forty-eight mesenteries and twelve stripes occur, but this condition obtains only in a small proportion of the individuals.

15. Triglyphic forms occur and are apt to possess more than twelve stripes.

16. Division may occur before the state of twelve stripes is attained.

17. The individuals are always tending by means of regeneration in the direction of twelve stripes and forty-eight mesenteries.

18. By division of the twelve-striped condition or by division before the twelvestriped condition is attained, the mass of the individuals fall short of twelve stripes. 

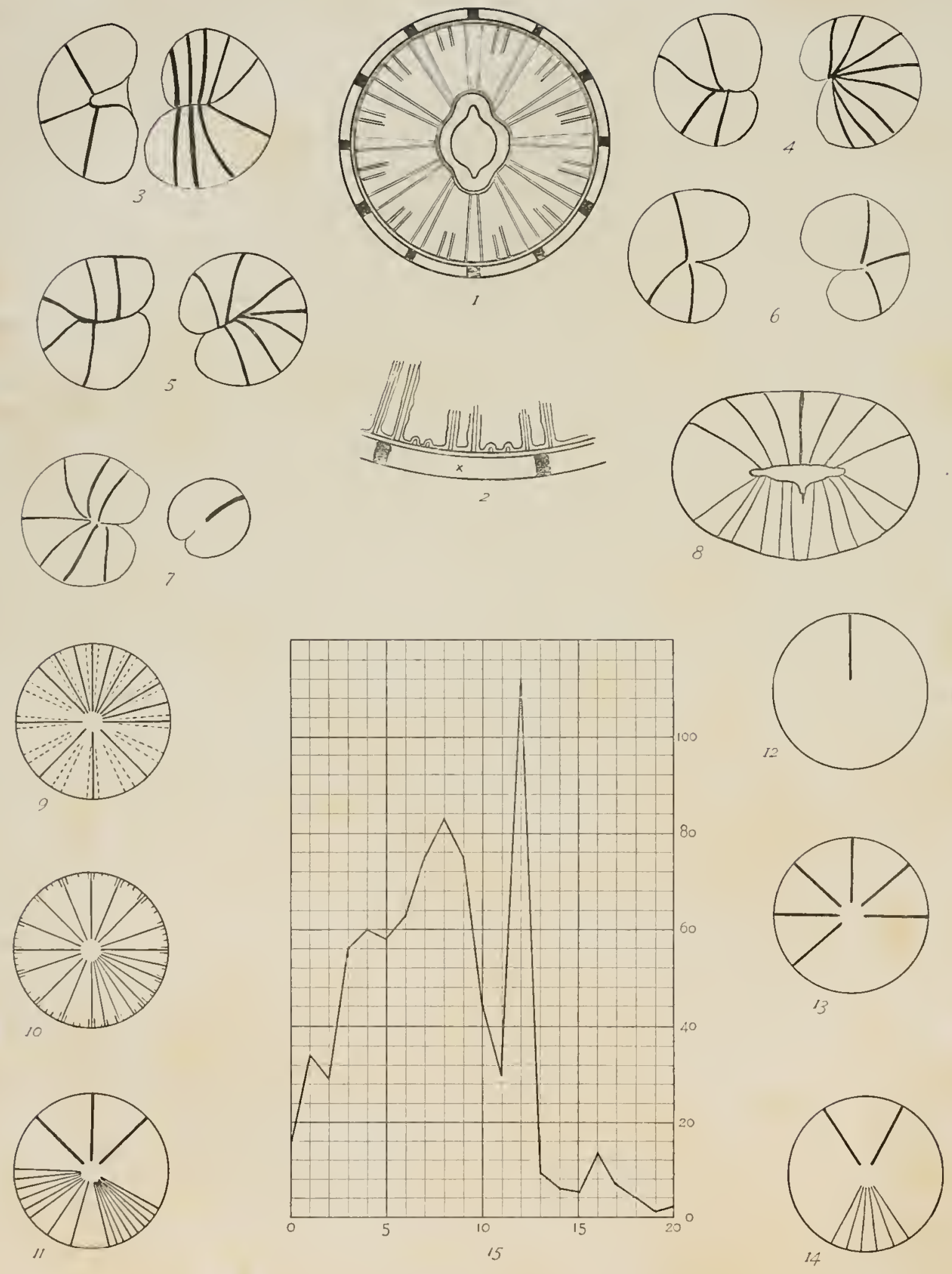

G. C DaveinPort. - SaGartia. 


\section{BIBLIOGRAPHY.}

Carlgren, 0 .

'93. Studien über nordische Actinicn. Kongl. Svenska Vet.-Akad. Hdlgr. N. F., Bd. 25, No. 10, pp. 1-148, Taf. 1-10.

Dixon, F.

'88. On the Arrangement of the Mesenteries in the genus Sagartia, Gosse. Sci. Proc. Roy. Dublin Soc., new ser., vol. 6, pp. 136-142, pls. 1-2.

Dixon, G. Y., and Dixon, A. F.

'91. Report on the Marinc Invertebrate Fauna near Dublin. Proc. Roy. Irish Acad., ser. 3, vol. 2, pp. 19-33.

Gosse, P. H.

'60. Actinologia Britannica. A History of the British Sca Anemones and Corals. London, $8^{\circ}, \mathrm{xl}+362$ pp., 12 pls.

Lang, A.

'S6. Gastroblasta Rafiaelei. Eine durch eine Art unvollständiger Theilung enstchende Mcdusen-Kolonie. Jena. Zeit. f. Naturw., Bd. 19, pp. 735-763, Taf. 20-21.

McCrady, J.

59. Instance of incomplete longitudinal Fission in Actinia cavernosa Bose. Proc. Elliott Soc. Nat. Hlist. Charleston, S. C., vol. 1, pp. 275-278.

McMurrich, J. P.

'91. Contributions on the Morphology of the Actinoza. III. The Phylogeny of the Actinozoa. Jour. Morph., vol. 5, no. 1, pp. 125-164, pl. 9.

Parker, G. H.

'97. The Mesenteries and Siphonoglyphs in Metridium marginatum Milne-Edwards. Bul. Mus. Comp. Zoöl. Harvard College, vol. 30, no. 5, pp. 259-273, 1 pl.

Parker, G. H.

'99. Longitudinal Fission in Metridium Marginatum Milne-Edwards. Bull. Mus. Comp. Zoöl. Harvard College, vol. 35 , no. 3 , pp. 43-56, pls. 1-3.

Torrey, H. B.

'98. Observations on Monogencsis in Metridium. Proc. California Acad. Sci., scr. 3, zoölogy vol. 1, no. 10. pp. $345-360, \mathrm{pl} .21$.

Verrill, A. E.

'98. Descriptions of ncw American Actinians, with critical notes on other spccies, I. Amer. Jour Sci.. scr. 4, vol. 6, pp. 493-498, 6 figs.

\section{EXPIANATION OF PLATE X.}

Figures 1 to 14 are from Sagartia lucix.

Fig. 1. Diagram of the most frequent condition with 12 stripes and 48 mesen'eries.

Fig. 2. Diagram illustrating the point of origin of new mesenterics and stripes $(x)$.

Fig. 3. Pail of recently divided inclividuals with 3 and 9 stripes respectively.

Fig. 4. Pair of recently divided inclividuals with 4 and 8 stripes respectively.

Fig. 5. Pair of reccntly divided individuals with 5 and 7 stripes respective $y$.

Fig. 6. Pair of recentiy divided individuals with 3 and 3 stripes respectively.

Fig. 7. Pair of recently divided individuals with 1 and 7 stripes respectively.

Fig. 8. Triglyphic individual with 18 stripes. 
Fig. 9. Diagram illustrating a case of observed asymmetrical arrangement of mesenteries and stripes. The heavy lines represcnt the stripes and the dotted ones the mesenteries.

Fig. 10. Diagram illustrating asymmetry of stripes and mesenteries. The long lines represent the stripes and the short lines the mesenteries.

Fig. 11. Diagram illustrating a case in which three of the stripes (rcpresented in heavy lines) eame with the divided piece, while the other stripes (fainter and nearer together) were the product of regeneration.

Fig. 12. Diagram of a specimen with only one stripe present and that one handed down with the old piece of tissue; none have as yet devcloped in the regenerated part.

Fig. 13. Diagram of a speeimen with six stripes from the old tissue; none developed in the new.

Fig. 14. Diagran of a speeimen with two stripes from the old tissue; six regenerated in the new.

Fig. 15. Curve illustrating the distribution of the number of stripes in 751 individuals. 0 to 20 are the abscissæ; 0 to 112 the ordinates. 
VIII.

ESTIVATION OF BOTRYLLOIDES GASCOI DELLA VALLE.

(PLATE XI.)

ERANK W. BANCROFT. 

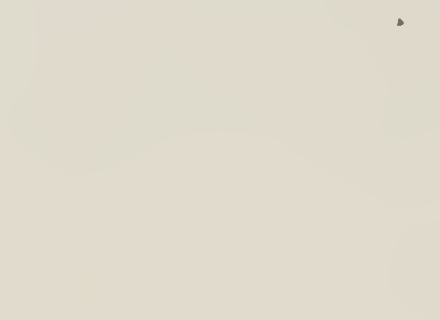


\section{INTRODUCTION.}

Although numerous observations have been published describing a partial dying down of ascidian colonies during certain seasons of the year, nothing of this kind, so far as I kllow, has as yet been described for any member of the Botryllidæ. At Naples, however, during the summer of 1899 it was my good fortune to have the opportunity of observing such an occurrence in the case of Botrylloides gascoi.*

The colony in question had been received from Dr. Lo Bianco on March 24. It was cut in pieces, and these tied to slides which were set out in the bay where the environment was perfectly normal. These were left undisturbed with only an occasional examination until April 20, when one of the slides was removed to the Zoölogical Station and kept in a small aquarium with running water. There it grew well for a while, retaining the coloration normal for this species, but was not quite so vigorous as the parts of the colony that were kept in the bay. This loss of vigor was manifested by an increase in the time required to change from one generation of zoöids to the next.

On June 29, however, a decided change was observed. At one end of the colony a large lobe had grown out, which, so far as could be seen in the living colony, contained nothing but ampullæ, no zoöids nor buds. This lobe did not have the blue and red color of the species, but was a bright lemon-yellow. $t$ The other part of the colony had also undergone a change. It was now lilac in color, about half as thick as it had been, and all of the zoöids had degenerated, leaving nothing that could be distinguished from ampulke, and nothing in which beating hearts could be seen. In spite of this lack of zoöids, however, the ampullæ were keeping up a vigorous circulation, which was most rapid near the yellow lobe.

On July 10 the blood had stopped flowing in the lilac part, which was dead and disintegrating. The yellow part, however, was still maintaining a vigorous circulation. On July 15 buds had appeared in the yellow part of the colony. This had

* I wish to express my thanks to Harvard University for the advantages of a Parker Fellowship which I enjoyed, and to the Smithsonian Institution, whose table at the Naples Zoölogical Station was put at my disposal while this investigation was under way.

$\dagger$ This lobe had been notieed some time before, but no particular importanee was attached to it. The changes in the other part of the colony, however, were not noticed until the latter had reached the eondition described for June 29. I think that these changes could not have begun before June 22 or they would eertainly have been detected. 
continued growing, and had been occupying new parts of the slide. Two portions could now be distinguished: first, a thick opaque part in which the ampullæ were visible only at the edges and on the surface by reflected light, and on which no buds could be seen; and secondly, a thin translucent part, with larger and fewer ampullæ and some good-sized buds. The smaller of these buds were the size of ampullæ and could hardly be distinguished from them. They looked as if they were being developed from ampullæ, and half of the colony was preserved and sectioned to see if this actually was the case.

\section{MINUTE ANATOMY.}

The sections showed many small buds scattered all through the colony, even in the opaque part, but no transitions between ampullæ or masses of blood-cells and buds. The smallest buds had inner vesicles less than 30 micra in diameter (Pl. XI, Figs. 10, 11), while the largest ones were zoöids which were nearly ready to open their siphons and had begun to produce buds. In all cases the cell-layer that corresponded to the outer vesicle or ectoderm of the bud was a continuation of the wall of some blood-vessel or ampulla. But the relation of this outer cell-layer to the inner vesicle was very variable. Frequently this layer was closely applied to the inner vesicle (Fig. 11). Often there was between the two a wide space filled with blood-cells, thus giving the impression that the inner vesicle was contained in an ampulla (Fig. 12). Finally, in two cases, vesicles were seen that were not at the end of one of the branches of the vascular system, but rested against the wall of a vessel as if fixed in transit (Fig. 10). From these observations it seems probable that some of the inner vesicles of the young buds are transported from place to place by the blood current and develop wherever they happen to lodge. Thus, properly speaking, the buds cannot be said to have any outer vesicle at all, especially in their early stages, but wherever they begin to develop, the ectodermic wall of the vascular system develops into the ectoderm of the bud.

This conclusion is of some general importance in view of the explanations that have been offered for the differences between the oögenic and blastogenic ascidian development. Thus Seeliger ('84), Hjort ('95), and Ritter ('96, p. 210) have said that the reason why, in the bud, the ectoderm takes no part in the development is because it is not an embryonic but a differentiated cell-layer with a special function to perform. It is already a functional part of the ectoderm of the adult before it becomes the outer vesicle of the bud. To this argument it might possibly be objected that there is no reason why a portion of the ectoderm (for instance, that over the bud- 
ding zone in Botryllus) might not remain undifferentiated and retain the power of entering into the development just as does the ectoderm of the larva. In the case of this æstivating colony, however, no such objection could be made, for buds may happen to lodge anywliere in the vascular system and development ensue. Thus, if any part of the ectoderm is to remain undifferentiated so as later to develop buds, the whole of the ectoderm of the blood-vessels would have to do so.

\section{DEVELOPMENT OF THE BUDS.}

The details of the development of these buds have not been followed, as the material was scanty and the conditions rather unfavorable on account of the masses of degenerating cells that filled the blood-vessels. But enough was seen to make it probable that the process is about what has been described in the cases of Botryllus and Goodsiria. However, a few minor differences have been noted. Thus, a part of the wall of the undifferentiated inner vesicle is several cells thick, while the rest is very thin (Figs. 11, 12). The developmental processes beginning with the folds producing the peribranchial sacs start when the bud has reached a greater size than in the case of buds which are still attached to their parent zoöids.

\section{ORIGIN OF THE ISOLATED BUDS.}

As has already been said, no evidence for the development of zoöids from ampullæ was observed. The buds wherever seen were perfectly well defined, and never presented the appearance of being formed by an aggregation of blood-cells, although in some cases the cavity of the inner vesicle was almost entirely closed.

Herdman ('86, pp. 59, 90) describes the origin of buds from aggregations of bloodcells for Sarcobotrylloides wyvillii and Colella pedunculata. It appears, then, that in these species there are buds in vessels just as in Botrylloides gascoi. But in all three cases the buds may have been produced elsewhere and have migrated into the vessels.

As no evidence in favor of an intravascular nor intra-ampullar origin of the isolated buds was detected, I feel convinced that they were developed from the zoöids of the original colony before these had degenerated entirely. The buds must have severed their connections with the parent zoöids, and must have been carried into the yellow lobe that was then being formed. There they remained dormant for a while, nourished by the circulation maintained by the ampullæ, until 
finally they developed again into zoöids. They were probably carried into the yellow lobe both by the general circulation, and by the growth of the vessels containing them. Unfortunately, however, I have no observations on any of these points, for at the time when the yellow lobe was developing $I$ had no idea of its significance. It is to be hoped that some future investigator will preserve and section the early stages of the development of the yellow lobe before the degeneration of the rest of the colony, and discover why in this case the buds separate from the parent zoöids at such an early stage.

\section{PERIOD OF REJUVENESCENCE.}

The life of the rstivating colony may be conveniently divided into two periods:

1. The Fstivation proper, June 29 to July 15, during which the colony contains no functional zoöids, that is, zoöids with open siphons. During this period life is at its lowest ebb, food comes exclusively from stored material, and the circulation is kept up almost entirely by the contractions of the ampullæ. In fact, during the greater part of this period, after the hearts of the old zoöids stop beating, and before the hearts of the older buds begin, the ampullæ alone maintain the circulation.

2. The Rejuvenescence, July 15 to September 17, during which the colony gradually assumes the condition normal to the species. This is the period which is now to be discussed.

The dates and main facts in the life of the colony are given in Table I, which renders a detailed description unneccssary.

We may now pass on to a few facts of interest in connection with the rejuvenating colony.

I. Correlation between Growth and Vigor.-Here we see that, just as is the case with colonies of Botryllus (Bancroft, :02),* vigor is always associated with growth. The tendency was not towards a stationary condition. There was either advance or retrogression. Thus the yellow lobe grew out and the rest of the colony degenerated and died. The yellow lobe became differentiated into an opaque part which

\footnotetext{
* In the paper referred to it was shown that the normal eondition of Botryllus at Naples is one of aetive growth. When this stops, the colony degenerates and soon dies. Among the parts of each eolony the same eonditions usually obtain. Thus the edge, and the new parts of the eolony generally, are growing and vigorous; while the eentre or older parts are stationary or degenerating. Pizon ('99, pl). 39, 41) has deseribed a similar ease where the zoöids developed best at the edge of the eolony and almost all the life beenme coneentrated there, the eireulation near the eentre having almost stopped. I think that the reason the zooids begin to do better at the periphery of the eolonies is that the great majority of the ampullæ is loeated ther.. As the contraetions of the ampullæ aid the eireulation very materially, the zoöids at the periphery will be nourished better, espeeially in their younger stages, and thus be more vigorous.
} 
TABLE I.

\begin{tabular}{|c|c|c|c|}
\hline \multicolumn{2}{|c|}{ Dates. } & $\begin{array}{l}\text { No of Buds } \\
\text { and Zoöids. }\end{array}$ & Remarks. \\
\hline $\begin{array}{l}\text { Mareh } \\
\text { April }\end{array}$ & & & Reeeived the eolony and set it out in the bay. \\
\hline $\begin{array}{l}\text { April } \\
\text { April }\end{array}$ & $\begin{array}{l}20 . \\
29 .\end{array}$ & & $\begin{array}{l}\text { Put one piece in an aquariur } \\
\text { It is changing zoöids. }\end{array}$ \\
\hline May & & & $\begin{array}{l}\text { The old zoöids have disappeared; the eloacal orifices of the young zoöids have not } \\
\text { vet opened. }\end{array}$ \\
\hline June & 29. & & $\begin{array}{l}\text { Yellow lobe formed, zoöids have degenerated. }\end{array}$ \\
\hline & 1. & & Condition of June 29 retained. \\
\hline July & 10. & & Lilae part dead and disintegrating. \\
\hline July & 15. & 5 & $\begin{array}{l}\text { Buds have appeared in the translueent part of the yellow lobe. Two have their } \\
\text { siphons open. (Half of colony fixed and seetioned.) }\end{array}$ \\
\hline July & 18. & 5 & All the buds have greatly degenerated. \\
\hline July & 20. & 7 & New small buds are bunched together on the edge of the eolony. \\
\hline July & 22. & 7 & Separated into two groups. \\
\hline July & 24. & & The buds have again degenerated. \\
\hline July & 27. & 10 & $\begin{array}{l}\text { The new buds are of medium size, siphons elosed; they lave appeared in the same } \\
\text { plaee. }\end{array}$ \\
\hline July & 28. & 10 & Bunehed on edge, no systems, no siphons open. \\
\hline July & 29. & 13 & Three new buds in a separate lot. No siphons open (Fig. 1). \\
\hline July & 30. & 10 & $\begin{array}{l}\text { The new buds have degenerated, and the ten large ones have formed a system. } \\
\text { Siphons open (Fig. 2). }\end{array}$ \\
\hline Aug. & 12. & 14 & $\begin{array}{l}\text { Zoöids of July } 30 \text { have degenerated, new zoöids have appeared on a different part } \\
\text { of colony and have formed two systems. }\end{array}$ \\
\hline Aug. & 15. & & One system has degenerated, the other persists (Fig. 3 ). \\
\hline Aug. & 16. & $5,6(?)$ & Siphons open. Some zoöids degenerating rapidly (Figs. 4, 5). \\
\hline Aug. & 17. & 1,13 & Only onc zoöid remains, but many small buds have appeared (Fig. 6). \\
\hline Aug. & 18. & 1,13 & The old zoöid still persists; 13 buds (Fig. 7 ). \\
\hline $\begin{array}{l}\text { Aug. } \\
\text { Aug. }\end{array}$ & 19. & 1,13 & The old zoöid still persists; the tip has grown $1.4 \mathrm{~mm}$. sinee Aug. 18 (Fig. 8). \\
\hline Aug. & 20. & & $\begin{array}{l}\text { One system formed, siphons open. The tip has grown } 1.6 \mathrm{~mm} \text {. since Aug. 19. Two } \\
\text { buds that were left behind are degenerating (Fig. 9). }\end{array}$ \\
\hline Sept. & 10. & & The opaque part has died; the eolony has completely reeovered. \\
\hline $\begin{array}{l}\text { Sept. } \\
\text { Sept. }\end{array}$ & $\begin{array}{l}17 . \\
22 .\end{array}$ & 48 & $\begin{array}{l}\text { Two systems. } \\
\text { Changing zoöids. }\end{array}$ \\
\hline Sept. & 27. & 100 & New systems established. \\
\hline Oet. & 1. & 115 & Changing zoöids; the 115 zoöids are all young. \\
\hline Oet. & 5. & 114 & New systems formed. \\
\hline $\begin{array}{l}\text { Oct. } \\
\text { Oet. }\end{array}$ & 6. & & One end of the colony is changing zoöids. \\
\hline Oct. & 13. & 97 & Two systems formed. \\
\hline Oct. & 20. & & Has changed zoöids; these are one or two days old. \\
\hline
\end{tabular}

did not grow, contained but few buds, and a translucent part which grew rapidly and developed most of the buds. Accordingly it was found that the whole new colony was developed from the transparent part, and that the opaque part died on September 10 .

This law of growth held not only for different parts of the colony, but also for the individual buds and zoöids. Not only did the buds usually arise in that part of the colony that was growing most rapidly, but they grew along with it in its wanderings over the substratum. This growth or wandering was not always in a centrifugal direction. At one time, the growing part apparently experienced too much resistance in growing over the glass and turned back accompanied by its buds and zoöids, and progressed over the inert opaque part of the colony (Figs. 7, 8, 9). This progression of the buds and zoöids seemed in great measure to be an active process on their part, 
for the buds were in the front rank of the growing tissue (Figs. 1, 2, 8,9), and they were so placed that their anterior, branchial ends lookecl in the direction of growth; just as these ends do when the young buds push away from the parent zoöid by the elongation of the stalk (Figs. 1, 8).

But the most interesting fact to be noted in connection with this correlation between growth and vigor is that those buds which appeared elsewhere than in the growing region, or which failed to accompany the growing region, always, so far as noted, degenerated considerably sooner than those in the growing region, and were not so liable to be followed by other buds (Figs. 1, 2, 3, 7, 8, 9). Thus, at the top of Figure 1 are represented the outlines of three buds that were not visible on the day before and were not located in the growing region of the colony with the rest of the buds. On the next day these buds had entirely disappeared without reaching even approximately the stage when the siphons open to the exterior. The two circles at the top of Figure 3 mark the place where three days previously there was a collection of six buds, some of them quite as large as any in the lower group which later formed the system represented in Figure 3. But this upper group of zoöids was not near the growing edge on which the lower group was located, and by August 15 it had entirely degenerated, while the lower group had prospered. Again, in Figures 3 to 9 , drawn at intervals of one day or less, it can be distinctly seen that even in the same system (Fig. 3) the zoöid next the growing edge persisted for at least four days, while the zoöids farthest from this edge had ahready degenerated on the second day. Finally, in Figures 7 to 9 the growing part of the colony with the zoöids is represented as extending over the opaque portion of the colony, and the hole $(r)$ in the latter gives us a stationary point to measure from. Here comparison of the figures shows the direction and rapidity of the growth, and it can be easily seen that the buds that were not in the group at the point of greatest growth failed to develop.

The comparative prosperity of the buds nearest the growing edge was, I think, due to the larger proportion of nourishment at their disposal. Though it is impossible to prove this, as there is no way of measuring the food in such an animal, several facts point strongly in this direction: first it was on the edge that growth was most considerable, not only among the buds but also among the blood-vessels, and growth requires food; secondly, it was there that the greatest vigor was manifested in the ampullar contractions as in other things. Since near the edge the circulation was more vigorous, the blood-supply better, the amount of food carried to the buds by the vessels must have been greater. This matter of the unequal distribution of food throughout the colony and the lack of coördination in the development and disappearance of systems will be discussed later. 
The vascular system seemed to be the mechanisin chiefly concerned with the growth of any region of the colony. The ampullæ were always at the edge of the growing region, secreting the test substance and pushed forwards by the constant elongation of the vascular stalks. Even in the case of the buds and zoöids I think that the motive power was also the elongation of the connecting vessels. It may be that the buds and zoöids had some power of locomotion by means of their ectoderm cells apart from the influence of their connecting vessels; and it is hard to explain the formation of systems in Botryllus without assuming some such power. But in Botrylloides all the growth seemed easily explicable as a result of the vessels alone, for there were always one or more vessels connected with the buds, and the growth of the vessels would tend to push the buds forwards. Furthermore, these vessels were usually attached to the posterior part of the bud which progressed on this account (as has been shown above) with its anterior or branchial end in advance.

2. Lack of Coördination in Budding and in the Formation of Systems. - In the preceding section it has been shown that there was considerable variation in the times of appearance and disappearance of the buds and zoöids. This subject will now be taken up somewhat more in detail.

The most striking feature of the activities of the Botryllidæ, which was already known to Krrohn ('69, '69a) in the case of Botrylus, is the exactness of the coördination, between zoöids of the same generation, in budding and in the formation of systems. Thus there is only one generation of adult zoöids present in the colony at any one time, and all the members of this generation are of the same age and their buds and embryos are of the same age. All of the zoöids of this generation degenerate together and leave similar buds to replace them. When these buds, by opening their siphons to the exterior, first assume the functions of adult zoöids they are not arranged in the circular or oval systems, each with a common cloacal orifice, characteristic of Botryllus, but at this stage each young zoöid has a separate cloacal as well as a separate branchial orifice, and it is only by a rearrangement of these that the new systems are formed. Thus these new systems have no genetic continuity with the old systems, and Krohn stated correctly that the buds produced by the zoöids of one system may form a single system, or separate into two groups to form two systems; or the buds from zoöids belonging to two systems may unite to form a single one.

These results have been abundantly confirmed by later investigators, especially by Pizon ('99,:00), who has also worked with living colonies and found that these facts held for Botrylloides rubrum as well. All of my observations on living colonies of 
Botryllus, Botrylloides rubrum, and Botrylloides gascoi pointed in the same direction except in the case of this rstivating colony.

Before discussing this question for the æstivating colony I shall give a brief summary of Pizon's results, as they are the only quantitative observations that have been published, and I shall compare with these some results of my own which were obtained under somewhat different conditions. Pizon determined carefully the length of the following periods:

1. The period between the beginning of the degeneration of the old zoöids, as marked by the closing of their siphons, and the first opening of the siphons of the nest generation. (During this period there are no functional zoöids in the colony.)

2. The period of the adult life of the zoöids, measured by the time during which the siphons are open.

3. The period of degeneration, during which the old zoöids, after the closure of their siphons, gradually disappear.

The lengths of these three periods in days are briefly expressed in the following table:

TABLE II.

\begin{tabular}{|c|c|c|c|}
\hline & Period 1. & Period 2. & Period 3. \\
\hline Botrylloides rubrum, small colony, averages of three to six generations.... & 6 days & 6 days & 6 days \\
\hline 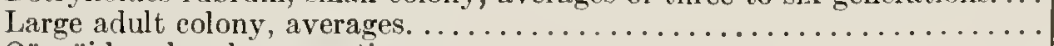 & $7 \quad \because$ & $\therefore$ & $4+\therefore$ \\
\hline 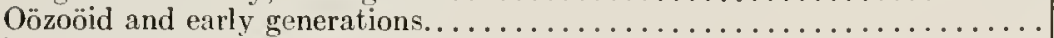 & $4-5$ “ & $5-6 \lll$ & \\
\hline 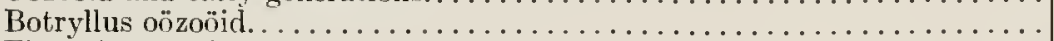 & & “ & ، \\
\hline 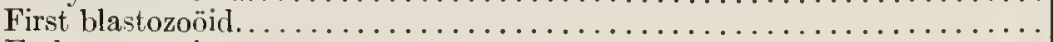 & $4-5 \lll$ & “ & “ \\
\hline Early generations.................... & $4-5 ،$ & $4-5 \lll$ & $3-4$ ، \\
\hline Later $\quad$ " $\quad \ldots \ldots \ldots \ldots$ & $6 \quad 6$ & $5-6 \quad$ ، & \\
\hline B. violaceus in April, extreme length........ & 10 & $8 \quad$ " & \\
\hline
\end{tabular}

My observations on this subject are not nearly so detailed as those of Pizon, as I did not give it special attention. My impression, however, of the changing from one generation of zoöids to the next in colonies of Botrylloides rubrum and B. gascoi kept in aquaria was that it took place about as slowly as described by Pizon, or perhaps a little more rapidly. But the colonies of Botryllus that I studied were growing on glass slides which were kept fastened to the lower side of a board floating in the harbor near where Botryllus was growing naturally. In this way a perfectly natural and very favorable environment was obtained, and it was noted that the length of Period 2, the adult life of the zoöid, was about the same as that observed by Pizon, but Period 1 and Period 3 were very much shorter, lasting usually less than one day. So rapid was the change of generations that, when observations were made only once a day, considerable care was necessary to make sure that there had been any such change. On one day there would be adult zoöids with small buds, and on the next 
day adult zoöids with large buds would be seen, all remains of the previous genertion having disappeared. In one case Period 1 was omitted entirely, the siphons of the younger generation opening before those of the older one had closed. The following table gives some scattered quantitative data recorded at the time when the observations were made.

TABLE III.

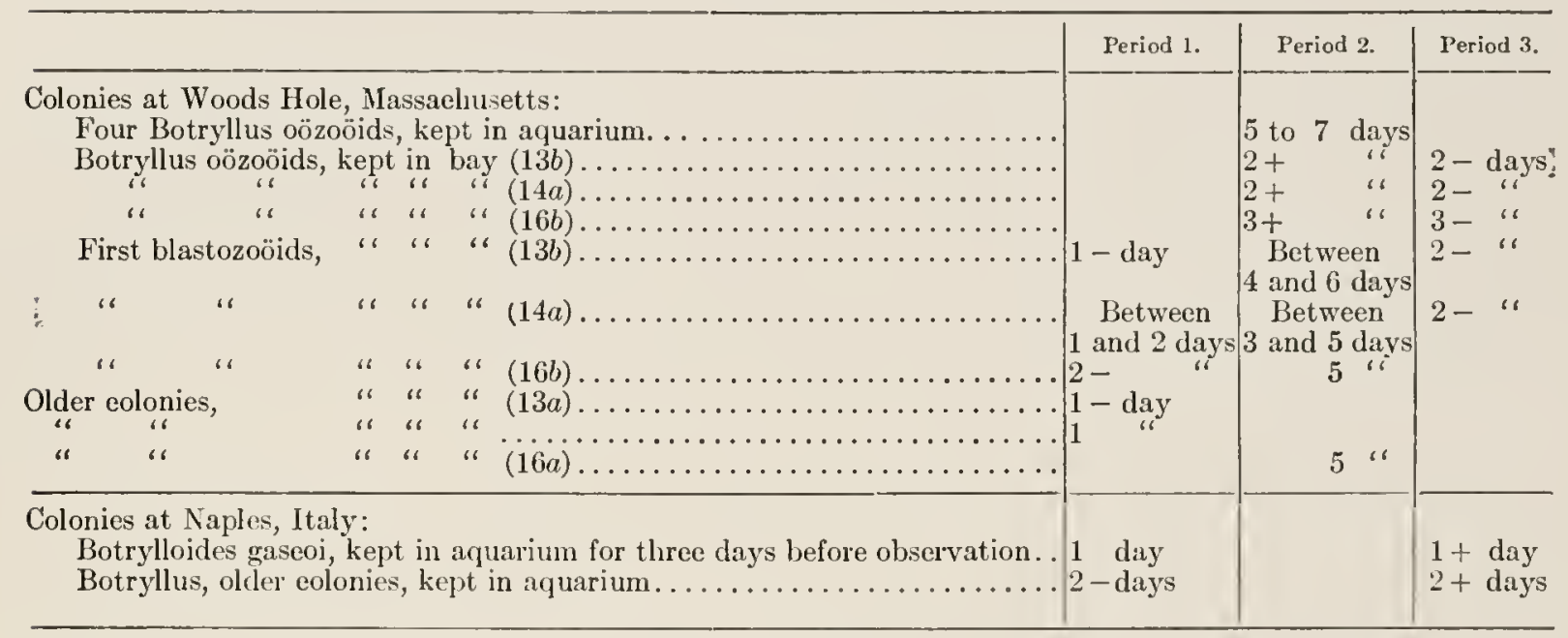

$A+$ or - after a figure means the period in question lasted a little longer or shorter than the number indicates.

A. INCREASE IN INTERVAL BETWEen ADUIT zOÖIDS.-From the foregoing facts it is seen that as the conditions become more unfavorable the length of Periods 1 and 3 between successive generations of adult zoöids increases. Now, when the æstivating colony of $\mathrm{B}$. gascoi is considered in this connection it is seen that here we have the extreme so far as the length of Periods 1 and 3 is concerned. For in this instance we have Period 1 lasting sixteen days. Even after buds have begun to appear in the colony it may sometimes happen that all the buds degenerate before any open their siphons, thus leaving out the period of adult existence altogether. Usually, however, a few of the buds manage to open their siphons, but frequently close then very soon after.*

? It is seen, then, that when analyzed this difference between the rstivating and normal colony reduces itself to an excessive lengthening of the interval between succeeding generations of adult zoöids. The cause of the lengthening seens to be unfavorable conditions, either external or internal, for by comparison with two other cases it is seen that when the environment is perfectly normal, and hence probably most

* It must not be supposed that in these eases the buds have been of no benefit to the eolony, for their liearts begin to contract very early, and will thus be of service in helping to maintain the eireulation. 
favorable, this interval becomes shortest. Just what it is that makes the conditions unfavorable I am unable to say.

$B$. Absence of regular generations.-The second difference between the rejuvenating colony and normal ones is that the usual coördination which results in all the zoöids of a single generation budding and dying at the same time was lost. There was no longer the former regular succession of generations, and buds and zoöids appeared so irregularly that it was frequently impossible to tell to which generation they belonged.

I will briefly describe the budding of the colony with reference to this point, so that the evidence may be perfectly clear. Thus, on July 15, a few days after the first buds appeared, an inspection of the living colony showed buds in all stages of development, from some whose siphons were open to others which could hardly be distinguished from ampullæ. A further examination of sections of part of the colony showed that there were many more smaller buds scattered through the colony. But here, also, great variation in size was observed and no generations of buds could be distinguished. Furthermore, it is quite probable, though I have no direct evidence on the subject, that, as the yellow lobe was present for a week or more before the rest of the colony degenerated, buds from more than one generation of zoöids passed into it. All of the first lot of buds that could be seen in life degenerated on July 18 and only part of them were followed by others. The buds, or rather the zoöids, that degenerated and were not followed by others probably did produce buds, but these remained dormant. The new buds which appeared (July 20) in the same place where the other zoöids disappeared were probably produced by these zoöids, and may be spoken of as Generation 2. But Generation 2 had a very short life, having vanished on July 24 , leaving only a few very small buds visible. These small buds were probably produced by Generation 2 and may be called Generation 3, but here there is more doubt as to the genetic continuity. The buds of Generation 3 were bunched together. On July 28 they were quite large, and were all in the same stage of development. It looked, at last, as if a good healthy generation had been formed, and the colony was about to resume its wonted aspect. But on the next day, July 29 (Fig. 1), three new buds had appeared in another part of the colony, and it was impossible to tell to which generation these newcomers belonged. However, the new buds were not on the growing edge, and had vanished on the next day (July 30). On the same day the young zoöids of Generation 3 had rearranged themselves and had formed the first system of the rejuvenating colony (Fig. 2). The next step is again somewhat surprising. Generation 3 disappeared without leaving a trace, and the next buds that appeared were in an entirely different part of the colony. The 
region of greatest growth had left the place where the first system was formed and had migrated back over the opaque part of the colony, apparently causing an entirely new lot of buds, which had been lying dormant hitherto, to develop. By August 12 two incipient systems had been formed in this region. On August 15 (Fig. 3) one of these had entirely disappeared and the other had formed the second well-defined system of the rejuvenating colony. But the point to be noted here is that there was no definite genetic relation between the first and second systems. They may have belonged to the same generation of buds, but it is more likely that the second was produced from an earlier generation that was lying dormant until stinulated by the abundant food furnished by the migration of the region of greatest growth.

The last generation will be called Generation $x$. It began to degenerate on August 16, one day after the formation of the second system; but the various zoöids degenerated at very different rates. One in particular (Figs. 3-9, 3) was so slow in degenerating that it still had its siphons open on August 19, when the next generation $(x+1)$ was nearly adult. On the next day the zoöids of Generation $x+1$ opened their siphons and formed the third system, but it is doubtful whether zoöid 3 was a member of this system or had degenerated entirely.* From August 20 on, the budding progressed normally until about September 10, when the opaque part of the colony had died and the transparent growing part had entirely regained its former vigor.

It seems, then, that the facts given in this section fully bear out the statement made at the beginning, that, in the rejuvenating colony, the usual reproductive coördination is lost. I think that the cause of this clifference between the normal and rejuvenating colony is to be sought in the difference of the circulation maintained in the two cases. In the normal colony the hearts of the zoöids and buds everywhere keep up a vigorous circulation, and this is still further assisted by the contractions of the ampullæ, which are also distributed throughout the colony, but are more numerous about its edges. Hence a vigorous circulation is kept up in all parts of the colony and all the food is evenly distributed. In the rejuvenating colony, however, the food-supply did not seem to be large enough to maintain all parts of the colony in a vigorous condition. For this reason, or possibly for some other, only a small part of the colony could be maintained in a vigorous condition. This part I called the growing edge, as it was the only part of the colony that was occupying new ground. On page 154 it was indicated that the growing edge was also the region where the ampullæ contracted most vigorously and maintained the best circulation. As the vigor of the circulation varied in different parts of the colony it follows that the food must

* On August 19, in that part of the eolony where the incipient system disappeared August 15, a single smal] bud appeared, but had almost entirely degenerated on the next day. It probably belonged to Generation $x+1$ : 
have been unevenly distributed. Consequently in some parts of the colony there was not enough food to stimulate the buds to any growth, and they remained dormant. In other parts the food was sufficient to start development, but not to keep it going for long, and the buds soon stopped growing and began to degenerate. On the growing edge, however, the food was sufficient, and it was here that the buds developed most normally, and ultimately reconstructed a vigorous colony. It is to be noted, however, that the smaller the part of the colony we observe the more uniform will be the conditions in it, and actually it was found that buds which were near together almost always developed and degenerated together.

$C$. The systems.--The third difference between the normal and rejuvenating colony concerns the systems. Normally systems are present most of the time, but in the rejuvenating colony they formed the exception. One reason for this was undoubtedly the fact pointed out before that the period of the adult existence of the zoöids was so much shortened. I am inclined to believe that this is the sole reason, and that buds in the Botryllidæ do not tend to form systems at all until about the time when they open their siphons and become adult zoöids. On the other hand it may be that there was a tendency for the buds in the rejuvenating colony to form a system before they reached the adult condition, but they were prevented from doing it by the rapid movement that they were undergoing in connection with the rest of the growing edge. Whatever the cause may have been, however, it is certain that in normal colonies one does not see masses of closely crowded buds with their branchial ends all pointing one way and no indication of a system, such as have been represented in Figure 8 and especially in Figure 1.

3. Color.-Della Valle ('77) describes the zoöids of B. gascoi as being violet in certain definite regions and lemon-yellow or white in others. The ampullæ are lemonyellow. Before æstivation the colony here described, which was closely similar in color to other colonies brought into the laboratory, corresponded in general quite well with Della Valle's description except that it was also colored red in some places. The young buds were yellow, and the ampullie were both violet and yellow. At the time when all the zoöids died, leaving the colony differentiated into a lilac and a yellow part, the blood-vessels and ampullæ of each part had the characteristic color. When the buds began to appear in the rejuvenating colony they and everything else were colored a uniform yellow; and this color was retained by all portions of the colony as long as it was observed. The rejuvenated colony was exactly like the original one in every respect except that of color. But in this regard it did not resemble B. gascoi at all, but corresponded closely to Botrylloides luteum von Drasche ('84). In its transparency, which allowed the stigmata to be easily seen in life, it 
still further resembled von Drasche's species. Here, then, it is evident that as a single colony successively assumed the characters of two described species these two must be united into a single one, B. gascoi Della Valle.*

4. Cause of Estivation.-I think that during the entire period of xstivation and rejuvenescence the temperature of the water was slowly rising, so that it was hotter when the colony had recovered than when it was astivating. But my records are not full enough to make this opinion certain. It seemed also that other conditions in the aquarium were nearly constant, but no attempt was made to measure them. Accordingly, I cannot say whether the æstivation was a contrivance for tiding over a rapid unfavorable change in the external conditions and rejuvenescence took place upon the re-establishment of the former state of things, or whether the environment was practically the same but unfavorable, and the rstivation and rejuvenescence were processes which actually gave increased vigor to the colony and enabled it to cope with surroundings which formerly it could not deal with. I think it probable, however, that the latter alternative was the true one.

5. Hibernation and Estivation. - As the process here described is so closely akin to hibernation, it may be well to see in how far the general results that have been arrived at concerning wintering apply to this case. Among the authors who have studied bibernation Caullery ('95), more than any one else, has discussed the general aspects of the question, and, on that account, I will consider chiefly his conclusions. He says ('95, p. 28) that we must renounce the conception of latent life in the colony and the formation of special dormant buds as a response to the stimulus of the cold. The changes which take place he thinks are due to other causes than the cold. Even when they occur in winter (which is not always the case) they are more probably brought about by a senescence of the colony after sexual reproduction; and then winter appearing retards the new development of the colony. The species among which the most pronounced cases of hibernation occurred were members of the Polyclinidæ. Ordinarily that part of the colony containing the thoraxes and abdomens of the zoöids degenerated, leaving only the postabdomens, which then formed the buds destined to produce the next zoöids. In some species these buds developed into adult zoöids during the winter, in others they did not mature until the next spring.

In a later article Giard and Caullery ('96) describe the hibernation in Clavelina lepadiformis Müller. Here both zoöids and buds entirely disappeared, and the colony

\footnotetext{
* This variation is not surprising when compared with results at which I have arrived in the case of Botryllue. It i : probable that if the colony had been kept longer and put out in the bay it would gradually have regained it: forner color. It may be that the red spots described by von Drasche in B. luteum were the first step in such a color change.
} 
was represented only by portions of the stolons containing stored reserve matter and an epicardial septum without buds. In conclusion the authors stater that the accumulation of reserve matter should be interpreted as a normal process pernitting the latent life of the colony for a certain time.

I have no fault to find with either of these two conclusions; and although they appear somewhat contradictory, the xstivation of Botrylloides might be included in either of the two categories. It is, however, necessary to be more precise in defining what we mean by latent life. Certainly, when compared with the life of the normal colony, the rstivating Botrylloides and, still more, the hibernating Clavelina may be said to be in a dormant condition, or to have only latent life. On the other hand, if by latent life is meant the condition that obtains in seeds or in a dried rotifer it would not be justifiable to apply the term to these cases, for in Botrylloides we always have a vigorous circulation kept up by the ampullæ, and the statement of Giard and Caullery that, in the Clavelina stolon, certain cells seem to be multiplying shows that they think that there is considerable metabolism going on. Indeed, I think it extremely probable that if the hibernating stolons of Clavelina could be induced to grow on glass where they could be carefully examined alive, it would be found that contractions of the ectoderm cells are maintaining a circulation.

The power of executing slow contractions seems to be quite widely distributed among the epithelia of the Ascidians. Thus not only do the ampullæ and blood-

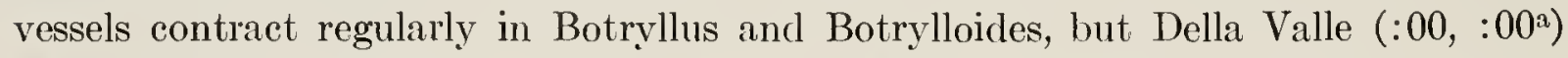
has found that at times the ectoderm of the vascular projections of Diplosoma listeri and Styela plicata execute vigorous contractions. I have also observed in Botryllus that tissues, which were not destined by nature to propel the blood, behave like the ampullie when subjected to similar conditions. Thus, in one experiment a young bud was isolated with a few ampullæ, but, instead of developing itself, its buds were stimulated to rapid growth, while the original bud became a hollow chamber which kept up a vigorous circulation by slow contractions of its walls. In another case both buds were cut away from an adult zoöid which was left attached to some bloodvessels. Here, too, the zoöid was transformed into a blood-pumping organ. If the ectoderm of the hibernating Clavelina stolon maintains a circulation, as in these other cases, there would be still less justification in comparing its condition to the latent life of seeds.

Concerning the other conclusion of Caullery, that the degeneration of the colony is due to its senescence, and is not a direct response to the environment, I believe that it is correct for Botrylloides as well as for the species that he studied. But, as already indicated (p. 161), ny data are not sufficient to prove this point. In the case of 
Botryllus, however, a long series of observations proved that there was such a senescence, and that degeneration follows it. But here, as there was no process corresponding to hibernation or xstivation, the colonies had no power of rejuvenescence and died.*

When the question is considered from the point of view of the amount of retardation that occurs in normal budding, it is seen that the process in Botrylloides is intermediate between that of the Polyclinidx and of Clavelina. For in the Polyclinide the buds are formed normally and develop normally, but at a very slow rate. In Botrylloides the buds are presumably formed normally, but do not develop normally. While in Clavelina the buds are not formed at all until after the hibernation is over.

As regards the correspondence of the æstivating or hibernating processes with the normal ones, Botrylloides as yet occupies a somewhat unique position, for, as has been pointed out, a number of processes occurred here which lave not yet been observed in other colonies. Of the observations so far described as occurring in the Botryllide the only ones that are at all similar to those here described are some by Pizon ('99, pp. 15, 25, 26, 37, 44). This author has described many cases of premature degeneration of buds and zoöids, and has noticed that the zoöids that tend to degenerate are those which are more than usually separated from the majority of zoöids. It has already been seen that the premature degeneration of the buds which were not near the growing edge was characteristic of the æstivating colony, but even if this character is left out there are still the three following features:

(1) The formation of a special lobe of the colony containing no zoöids;

(2) The separation of the buds from the parents at a very early stage, and their removal to a distance from the zoöids; and

(3) The great irregularity in the appearance of the buds which makes it impossible to say whether they belong to the same generation or not.

All of these are phenomena which among the Botryllidæ have hitherto only been observed in this æstivating colony of Botrylloides gascoi.

* In Botrylloides rubrum also there seems to be no such power, for Pizon, who has had the speries undes observation for long periods, has not noticed anything of the kind. I, too, have kept the colony in unfavorable conditions in an aquarium for long periods; and though it was more hardy than Botrylus, it became considerably redueed in sizc, but still did not rstivate. 


\section{SUMMARY.}

1. In a colony of Botrylloides gascoi Della Valle kept in an aquarium a yellow lobe containing no zoöids was developed.

2. Later all the zoöids degenerated, and finally all of the colony except the yellow lobe died.

3. The ampullæ kept up a circulation in the isolated lobe for about two weeks, after which buds reappeared in it.

4. An examination of sections of half the colony showed that there were small isolated buds, probably produced by the zoöids which had degenerated, scattered all through the colony.

5. The colony gradually recovered its former condition except that it always retained its yellow color which is characteristic of Botrylloides luteum v. Drasche. Therefore this species is a seasonal variation of $\mathrm{B}$. gascoi.

6. During the rejuvenescence of the colony it differed from the normal colony in the following additional particulars:

$a$. The intervals between generations of adult zoöids were longer.

$b$. Buds were liable to appear at any time and at any place in the colony, and to degenerate at any time, so that frequently regular generations could not be distinguished.

c. A certain part of the colony, the growing edge, was constantly wandering about occupying a new substratum. In this part most of the buds appeared. They accompanied it in the wanderings and moved so that their branchial ends were alwavs directed forwards. Consequently aggregations of good-sized buds were seen which were not grouped into systems.

7. The cause of these deviations from the norm seems to be the inadequacy of the food-supply. This was not enough for the whole colony and so the most vigorous part, whose ampullæ maintained the best circulation, got most of the food. Consequently the buds situated in this region got more food and developed more rapidly than those of other regions.

8. This case of æstivation is in general similar to the hibernation described for the ascidians. 


\section{BIBLIOGRAPHY.}

Bancroft, F. W.

'99. A new Function of the Vascular Ampullæ in the Botryllidæ. Zool. Anz., Bd. 22, No.601, pp. 450-462. Bancroft, F. W.

:03. Variation and Fusion of Colonies in Compound Ascidlians. Proc. California Acad. Sc., ser. 3, vol. 3, no. 5 , pp. $137-186$, pl. 17.

Caullery, M.

'95. Contributions à l'étude des Ascidies composées. Bull. Sci. France et Belgique, tom. 27, pp. 1-158, pls. 1-7.

Della Valle, A.

'77. Contribuzione alla storia naturale delle Ascidie composte del Golfo di Napoli. Napoli, 14 pp.:

Della Valle, A.

:00. Intorno ai movimenti delle appendici ectodermiche del Diplosoma listeri. Rend. Accad. Sci., fis. mat. Napoli, ser. 3, vol. 6, p. 172.

Della Valle, A.

:00:. Osservazioni intorno alle migrazioni delle colonie di Diplosoma listeri. Monit. Zool. Ital., anno 11, Suppl., pp. 33-34.

Drasche, R. $\nabla$.

'S4. Die Synascidien der Buclit von Rovigno (Istrien). Ein Beitrag zur Fauna der Adria. Wien, $4^{\circ}$, $41 \mathrm{pp} ., 11 \mathrm{pls}$.

Giard, A., et Caullery, M.

'96. Sur l'hivernage de la Clavelina lepadiformis Müller. C. R. Acad. Sci. Paris, tom. 123, no. 5, pp. 318-320.

Herdman, W. A.

'86. Report on the Tunicata collected during the Voyage of H. M. S. Challengcr; Part II.-Ascidix Compositæ. Chall. Rep., Zoöl., vol. 14, pp. 1-432, pls. 1-49.

Hjort, J.

'95. Beitrag zur Kcimblättcrlehre und Entwickelungsmechanik der Ascidienknospung. Anat. Anz., Bd. 10, No. 7, pp. 215-229.

Krohn, A.

'69. Ueber die Fortpflanzungsverhältnisse bei den Botrylliden. Arch. f. Naturg., Jahıg. 35, Bd. 1, pp. 190-196.

Krohn, A.

'69a. Ueber die frühcste Bildung der Botryllusstöcke. Arcl. f. Naturg., Jahrg. 35, Bd. 1, pp. 326-333, Taf. 14.

Pizon, A.

'99. Etudes biologiques sur les 'Tuniciers coloniaux fixés, 1. Bull. Soc. Sci. nat. Ouest Nantes, 1om. ?, pp. $1-55,16$ pls.

Pizon, A.

:00. Etudes biologiques sur les Tuniciers coloniaux fixés, 2. Bull. Soc. Sci. nat. Ouest Nantes; tom. 10, pp. 1-72, ${ }^{5} 2 \mathrm{pls}$.

Ritter, W. E.

'96. Budding in Compound Ascidians, based on Studies on Goodsiria and Perophora. Jour. Morph.', vol. 12, no. 1, pp. 149-238, pls. 12-17.

Seeliger, 0 .

'84. Die Entwicklungsgeschichte der socialen Ascidien. Jena. Ze.t. f. Naturw., Bd. 18. Heft. 1, pp. 45120 Taf. 1-8. 


\title{
EXPLANATION OF PLATE XI.
}

\author{
ABBREVIATIONS.
}
a. Ampulla.
B. Bud.
r. Hole in the eolony.

$1,2,3$, etc., indieate the same zoöids in all the figures.

\section{PLATE XI.}

Figs. 1-9. Outline camera drawings of the living colony during rejuvenescenee, showing some of the buds, zoö:ds; and ampullæ. The opaque parts of the colony are indicated by stippling. $\times 12$.

Fig. 1. Outline of a living eolony showing all the buds to be secn July 29; a indieates a eharaeteristie group of ampullæ that serves as a fixed point to measure from.

Fig. 2. The same eolony as shown in Fig. 1, on July 30. The buds have moved farther away from a and have formed the first system. The buds marked $\beta$ in Fig. 1 have degenerated.

Figs. 3-9. A series of drawings at daily intervals, or less, of all the buds (except one) and the zoöids in the rejuvenating colony, from the degeneration of the sccond to the formation of the third system.

Fig. 3. Aug. 15, 2 P.s. The more abundant stippling indicates the more opaque part of the eolony. The two eircles above are not buds, but mark the plaee where some zoöids degenerated.

F g. 4. Aug. 16, 12 м. System 2 degenerating.

Fig. 5. Aug. 16, 6 р.м. Same as Fig. 4; small eireles are buds.

Fig. 6. Aug. 17, 8.30 A.M.

Fig. 7. Aug. 18, 9 A.M.

Fig. 8. Aug. 19, 10 A.M. There is a bud in another part of the colony, not ineluded in this figure

Fig. 9. Aug. 20, 9.30 A.M. The bud not ineluded in the figures is degenerating.

Figs. 10-12. From sections through half of the eolony, preserved on July 15; Davidoff's fluid; Benda's iron hæmatoxylin, $\times 850$.

Fig. 10. The smallest bud seen, situated in a blood-ves el.

Fig. 11 A typieal bud, showing the varying thiekness of the inner vesiele, and the eonneetion of the outer vesicle with an ampulla.

Fig. 12. A bud with a small ampulla for an outer vesicle. 
Mark Anniversary Volume.

PLATEXI
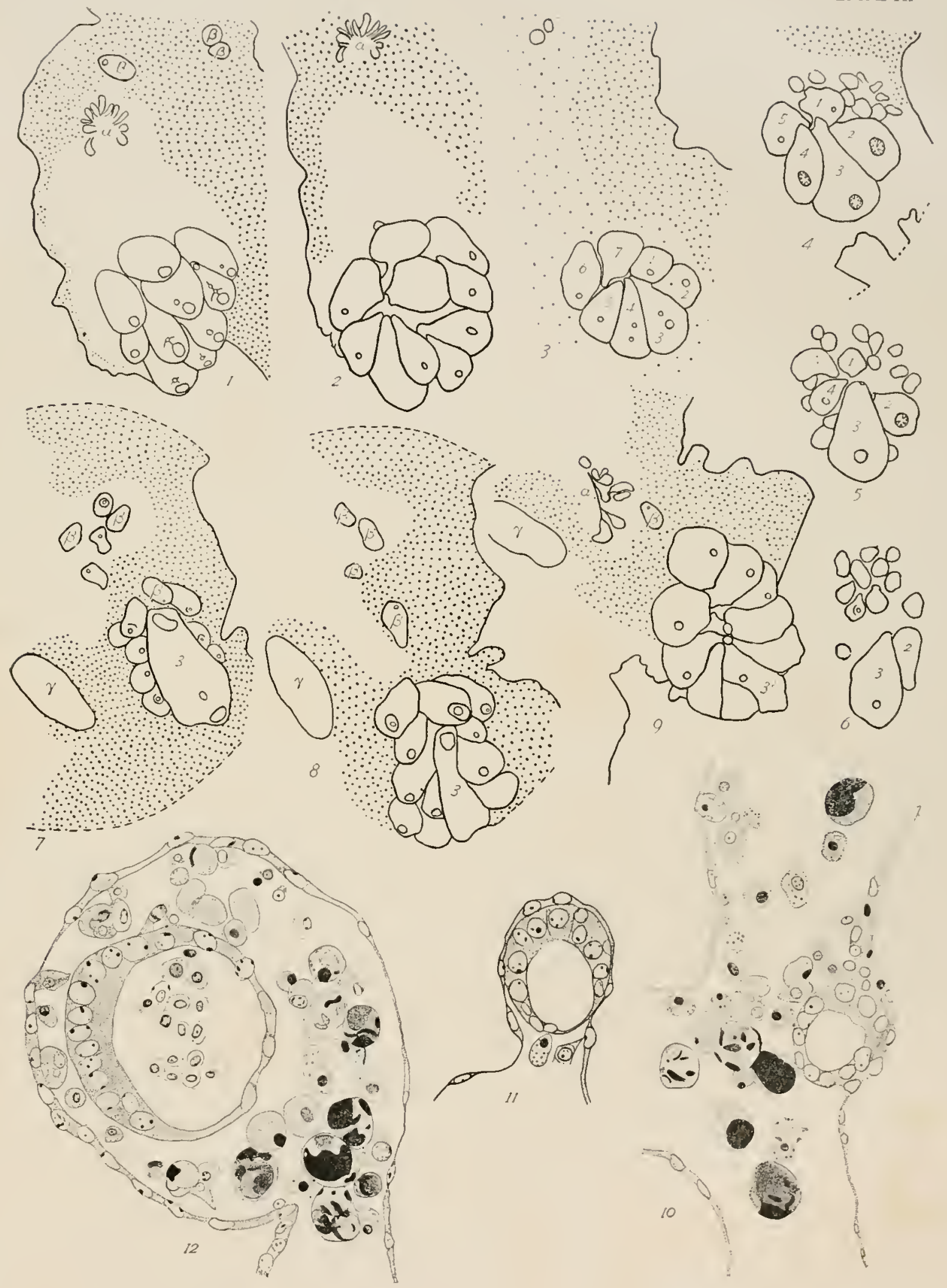
IX.

THE EYES OF THE BLIND VERTEBRATES OF NORTH AMERICA.

V. THE HISTORY OF THE EYE OF THE BLIND FISH AMBLYOPSIS FROM ITS APPEARANCE TO ITS DISINTEGRATION IN OLD AGE.

(PLATES XII-XV.)

Carl H. Eigenmann. 
"The final step would be a thorough anatomical study of the species found in the cave, with extensive comparison of allied species, found clscwherc; next, an investigation of the embryology of all of them, and when fully prepared by such rescarches, an attempt to raise embryos of the species found in the cave, under various cireumstances, different from those in which they are usually found at present.

"If physical circumstances ever modificd organized beings, it should be easily ascertained here. For my own part, however, I think that the blind animals of the cave would only show organs of vision during their embryonic state in eonformity with the normal development of the respective types to which they belong, that even when placed under a moderate influence of light, incapable of injuring them, but sufficient to favor the growth of their eyes in the allied species provided with them, the young of those species peculiar to the cave would gradnally grow blind, while the others would acquire perfect cycs; for I am convinced, from all I know of the geographical distribution of animals, that they were created under the circumstances in which they now live, within the limits over which they range, and with the structural peculiarities which characterize them at the present day. But this is a mere inference, and whoever would settle the question by direct experiment might be sure to carn the everlasting gratitude of men of science. And here is a great aim for the young American naturalist who would not shrink from the idea of devoting his life to the solution of one great question."-Agassiz. 


\section{INTRODUCTION.}

In the present paper I propose to describe the developmental stages of the eye of the blind fish Amblyopsis spelæus and the modifications the eye undergoes during growth, maturity, and old age. Questions of special interest in the history of this very degenerate organ are:

1. Do the rudiments of the eye make their appearance as early as usual or later?

2. How much does the eye grow from the time of its appearance?

3. When does each part of the eye reach its maximum $(a)$ in size, $(b)$ in morphogenic development, $(c)$ in histogenic development?

4. When does the eye as a whole reach its maximum development?

5. Are there evidences of a slowing down of the rate of the developmental processes: $(a)$ cell division, $(b)$ cell arrangement, $(c)$ cell differentiation?

6. Are there evidences of a cutting off of late developmental stages, that is, are there any parts of the normal eye that are not developed?

7. Does the eye develop directly toward the condition of the adult or does it follow palingenic paths and then retrograde to the condition found in the adult?

8. What parts of the eye degenerate first?

9. What is the comparative rate of the ontogenetic degenerative modifications of the various parts of the eye, and how does their rate compare with the rate of phylogenetic degeneration implied by the structure of the adult eye of Amblyopsis and the different stages of degeneration reached by other members of the family?

10. Is there any evidence for or against the dictum of Sedgwick that structures which have disappeared from the adult organization are retained in the embryo only if the organ was of use to the larva after it had ceased to be of use to the adult?

The material on which this paper is based was collected at various times since 1896, in part by a grant from the trustees of the Elizabeth Thompson Science Fund, and in part by a grant from the American Association for the Advancement of Science. All of it came from caves near Mitchell, Indiana, on the Monon Railroad, to whose officials I wish to express my indebtedness for many favors.* By legislative act these

* We have found that the specimens of Cambarus pellucidus coming from these caves have an eye structure much more degenerate than specimens of the same species from Mammoth Cave. I have not been able to secure Amblyopsis from Mammoth Cave to see whether there is a similar difference in the eyes of the fishes from the two localities. 
caves with some 180 acres of land about their entrances have become the property of Indiana University.

I am indebted to Dr. Jacob Reighard, under whose direction Mr. Lewis H. Weld made a series of photographs of entire eggs and embryos for me, and to Professor D. W. Dennis, who prepared the photomicrographs of the eyes.

\section{EARLIER WORK ON THE EYE OF AMBLYOPSIS.}

In a former paper (Eigenmann, '99) I gave an outline of the work done by previous authors and described the structure of the adult eye of the species under consideration and also the eyes of the related species of the Amblyopside inhabiting the caves and surface streams of the Mississippi valley and the Atlantic slope of North America. It was found that the different members of the family have eyes in different stages of degeneration, from the eyes of the various species of Chologaster, which are nearest the normal, to those of Troglichthys, which are the most degenerate eyes of any vertebrate yet described. The eye of Amblyopsis, the species now under consideration, reaches a maximum diameter of about 200 micra, with an average of but 143 micra. This eye is practically without vitreous body or vitreous cavity. The ganglionic layer forms a solid funnel-shaped mass of cells in the centre of the eye. The inner reticular layer is well developed; the inner and outer nuclear layers are merged into one. Rods are not found, cones are occasionally developed. The pigment-layer is well developed. It entirely invests the eye, is free from pigment over the distal face and variously pigmented over the sides and back. A small lens was described, but this body is probably something else. It was so designated because no other structure could be identified as a lens and because it was not known what this structure was if not a lens. The pupil is frequently closed, and then the iridian part of the eye is recognizable only by some elongated nuclei.

\section{BREEDING HABITS.}

The peculiar breeding habits of Amblyopsis have already been described by me (Eigenmann, :00, p. 117). In contradiction to the then universally accepted view that this fish brings forth living young, I showed that the female deposits her eggs, to the number of about seventy, in her gill-cavity, where they are retained until the yolk is practically all absorbed and the young fish has reached a length of 10 millimetres. All of the embryos and larvæ described in the following pages were taken from the gill-cavities of different females. The earliest date at which segmenting 
eggs were taken was March 8 , the latest date May 4. For reasons given in the paper quoted, it is probable that the spawning season extends through the year, but during March the spawning season is evidently at its beginning, and it is during this month and April and May that the early stages may be looked for with the greatest confidence.

\section{METHODS.}

The usual gamut of killing and fixing reagents was used in preserving the material, chief among which were Perényi's fluid, Flemming's fluid, Hermann's fluid, vom Rath's fluid, and various mixtures of formalin and corrosive sublimate. Series of sketches and measurements were made on living larva and embryos. Surface preparations and sections were made of the various stages.

No eggs were deposited in the laboratory. Females with eggs in the gill-cavities had to be sought for in the caves. When one containing favorable stages was captured she was isolated in a small aquarium and the number of eggs needed freed from the gill-cavity by gently raising the edge of the operculum. The rest of the eggs were permitted to remain in their natural surroundings until another lot was wanted. During the early stages of development the edges of the operculum are closely pressed to the neck and there is no danger of freeing more eggs than are wanted unless the fish is roughly handled. During the later stages of development the tension of the operculum is relaxed and eggs or larva can be much more easily removed, but there is a correspondingly greater danger of liberating more young than are wanted. If the female is disturbed or confined during the latest stages of brooding, some or all of the young will escape. The eggs freed from the gill-cavity will continue their development uninterruptedly, but the gill-cavity of the female offers such a unique and self-regulated hatchery that they were usually left in it.

\section{THE EGG AND GENERAL DEVELOPMENT.}

The eggs are large, measuring 2.3 millimetres in diameter. The yolk is translucent, of various tints of amber. The yolk measures 2 millimetres in diameter and contains a large oil-sphere 1 to 1.2 millimetres in diameter. When the egg is deposited the yolk is flabby and composed of yolk-spheres of various sizes loosely put together. After the egg has been in water for some time, the yolk forms a tense rounded mass. The egg is heavier than water. The oil-sphere lies uppermost in the egg, and the germinal disk forms at the side of the egg. Attempts at artificial fertilization have not been successful beyond obtaining well-developed germinal disks. 
The rate of development will probably be found to vary considerably with the temperature of the water. In a series of eggs in which the gastrula covered half the yolk when observations began, the blastopore was reduced to the size of the oil-sphere in nine hours, when the embryo encircled about one-third of the yolk. Sixteen hours later the blastopore was closing. There is a regular change in the position of the embryo with development. The blastoderm is formed at the side of the yolk. When the gastrula covers half the yolk the egg has rotated so that the gastrula covers more of the lower than of the upper surface of the yolk. Still later, some hours before the closing of the blastopore the latter structure lies to one side of the yolk-sphere, which always occupies the upper pole of the egg; the embryo extends from this region obliquely over the yolk. After the formation of the tail the embryo is always found coiled about the upper half of the yolk.

The embryo hatches when it is about 5 millimetres long (Plate XII, Fig. 1). The metamorphosis of the larva into the definitive fish is completed before it leaves the gill-cavity of the mother. The longest individuals I have secured from the gill-cavity measure about 10 millimetres.

\section{THE DEVELOPMENT OF THE EYE.}

I. Earliest Stages to a Length of Three Millimetres. - The development of the eye has been followed in several series of living embryos and in sections of these embryos. I shall describe the earlier stages of the eye as they were observed in the series obtained on May 4,1901** Where advisable other series will be described also. The first indications of the eye are seen in living specimens when the embryo is about 1.5 millimetres long, at about the time of the formation of the first protovertebra. This size was reached in the present series in two and a half to three days from

\footnotetext{
* The rate of development of the series of eggs taken in May was as follows, the mother eontaining the eggs having been kept in a small aquarium without ehange of water and at the temperature of an ordinary living room. The temperature of the water in the eave is $12^{\circ} \mathrm{C}$, that in the room was $22^{\circ} \mathrm{C}$.

May 4, 9.00 P.M. Gastrula eovers half of the yolk.

“ 5, 6.00 A.м. Blastopore $1.2 \mathrm{~mm}$. in diameter; embryo surrounds about one third of the yolk.

“ 5, 2.30 P.M. Embryo $1.6 \mathrm{~mm}$. long and with four protovertebræ.

4 5, 6.00 P.M. Embryo $1.76 \mathrm{~mm}$. long and with six protovertebræ.

“ 5, 10.00 P.м. Blastopore elosing, embryo $1.92 \mathrm{~mm}$. long and with ten protovertebræ; eyes well formed.

“ 5, 11.30 P.M. Some embryos $2.4 \mathrm{~mm}$. long.

6, 6.00 А.м. Twelve or thirteen protovertebræ; neural eavity formed.

: 6, 8.00 A.m. Embryo $2.4 \mathrm{~mm}$. long.

6, 11.00 A.M. No marked ehange.

\&s 6, 6.00 P.м. Tail beginning to bud out; embryo, $3 \mathrm{~mm}$. long, eneireles half the yolk; 17 protovertebræ present.
} 
fertilization. The time when the eye begins to form is exactly as in fishes with normal eyes.

At 11.00 A.M., May 5, 1901, the head was slightly raised so that its outlines appeared definite and clear, while the remaining outlines of the embryo were hazy. It was not possible at that time to distinguish eyes (Pl. XIII, Fig. 13). At 2.30 P.M., when the embryo has reached a length of 1.6 millimetres, the eyes form prominent lobes on either side of the brain. The lobes are distinguishable in living embryos, but stand out much more prominently in embryos mounted entire. In an embryo prepared in this way, a camera outline of which is reproduced in Figure 14, the eye protuberance $(o c$.) has a length of 80 micra and projects 36 micra beyond the lateral margin of the brain. 'Sections of embryos at this stage of development show the brain to be still joined with the ectoderm. There is no indication of any cavity in the central nervous syștem at this time, and the eye-lobes are solid, symmetrical lateral protuberances with their anterior margins but 48 micra from the tip of the brain. At 6.00 P.x. the embryo had reached a length of 1.76 millimetres and six protovertebræ had been formed. The eye was no longer a symmetrical swelling on the side of the brain, but its outer, posterior angle was now distinctly farther back than the posterior inner angle. In other words, the lobes had grown laterad and were bent backward. The lateral projection of the eye beyond the contour of the brain amounts to 48 micra and has a longitudinal extent of 100 micra. The greatest diametermeasured from the anterior inner angle of the eye to the posterior outer-was 116 micra. Sections show the nervous system, inchuding the eye, to be still a solid mass of cells, which anteriorly is still continuous with the ectoderm. Histologically there is no difference between the cells composing the optic lobes and those composing the brain. There is a slight indication in the arrangement between the two optic lobes suggesting a lateral traction of the cells (Fig. 15). At 9.00 P.м. the characters of the eye shown at 6.00 P.M. had become intensified without other material change. The embryo had reached a length of 1.92 millimetres and ten protovertebræ had been formed. The optic lobe was still broadly united with the brain, but its lateral growth was largely represented in the lobe extending back. There was no cavity as yet in the nervous system. A little later the canal of the central nervous system made its appearance, for at 12.00 P.M. it was well formed. There was probably some fluctuation as to the rate of growth in length and the degree of differentiation the tissues reach, for, in embryos of another series, some individuals had a well-developed canal, while others of the same size did not. At 12.00 1'.M. the embryos had reached a length of 2.4 millimetres (Fig. 16). At 5.30 A.M., May 6, the eyes had become a pair of flaps lying along the sides of the brain or diverging from near its anterior end 
and connected only in front by the contracted optic stalk (Fig. 17). The split in the optic lobe which separates it into an outer and an inner layer had developed to such an extent that it could readily be made out in living embryos. At 8.00 A.m. some of the embryos were still but 2.4 millimetres long and twelve to thirteen protovertebræ had been formed (Fig. 18). The changes in the eye from 12.00 P.M., May 5, to 12.00 M., May 6, were not very great, and consisted chiefly in the constriction of the optic stalk and the consequent gradual separation of the optic lobe from the brain. The skin had not yet begun to thicken to form the lens (Figs. 19, 20). The changes from noon till 6.00 P.M., May 6, when the last embryo of this series was preserved, consisted largely in the shifting of the optic vesicles as the result of the development of the olfactory pits. Seventeen protovertebræ had developed and the cmbryo was about 3 millimetres long.

For later stages I am compelled to draw on another series of embryos which I also observed through the earlier stages described above. They were taken from a female that was captured March 11, 1898, and that contained on March 12 eggs in the early stages of gastrulation.

The eyes had reached a stage seen at about two and a half to three days from the beginning of development. An outline of the development may be given to connect this series with that just described. The rate of development was considerably slower than in the preceding series. Figure 21 (March 13, 10 A.M.), was taken from a living specimen, showing five protovertebre. Sections demonstrated that at the stage represented by Figure 21 the neural tube was still a solid structure. The distance from edge of eye to edge of eye measured 164 micra.

About one day later the larvæ were 2 millimetres long. The neural canal had been formed and extended out into the now well-formed vesicle through a distinct optic stalk. Sections slowed that the epidermis was still unmodified over the eye, with no indication of a thickening to form the lens.

Figures 22 and 23 (Pl. XIV) show horizontal sections through the base of the optic stalk and through the middle of the optic vesicle respectively.

During the next twenty-four hours the enbryo grew to a length of 2.4 millimetres. At this stage the tail was free for .4 millimetres of its length. Embryos twenty-four hours older than the last were found to be 2.5 to 2.8 millimetres in length. The latter, while not longer than the oldest embryos of the first series described, are evidently farther along in the development of the eyes. In all of these specimens (Figs. 24, 25, $26,27)$ the eyes have become greatly modified. The secondary optic vesicle has been formed by the thickening of the skin to form the lens. The retinal wall of the vesicle is three series of cells dcep, while the wall destined to form the pigment 
epithelium has become thin and is composed of a single series of cells. The eye, at this stage, does not differ materially from the eye of a Cymatogaster larva about half as long (compare Figs. 27, 28).

There is no indication of a differentiation of an iris. The secondary cup is a shallow, bowl-shaped structure, the depression being entirely filled by the thickening of the skin which is giving rise to the lens (Figs. 25, 27).

2. Four-millimetre Stages. - In specimens 4.4 nillimetres long the eye had become a deeper cup than it was during the 3-millimetre stage. The lens, which no longer fills the entire cavity, has become a spherical mass of cells, solid in some cases (Fig. 32) but with a cavity in others. It is still connected with the skin. In one case the lens was a vesicle with a distinct epithelium bounding the cavity (Fig. 33). In the other cases there seemed to be no regularity in the arrangement of the lens-cells.

The pigmented layer has become very thin compared with the thickness of the rest of the retina. Its thickness increases toward the margin of the cup. The retina is very thick, with about five layers of nuclei; these are crowded except at the free margin of the retina, which is free from nuclei. There is no histological difference between the different cells of the retina unless there is an appreciable elongation in the cells at the margin of the cup.

Optic fibres are not yet developed.

3. Five-millimetre Stages. - The embryo is hatched at the beginning of this period.

The least differentiated eye of this stage is represented in vertical section in Figures 34 and 35 . The secondary vesicle has become more definitely formed. The vitreous cavity is reduced in size and the retina has become distinctly thicker but shows as yet no differentiation into different layers.

In a larva 5 millimetres long the eye is still in contact with the epidermis on one side and the incipient dura mater on the other. The epidermis is distinctly thimner over the eye, reaching an extreme thimness of 16 micra as compared with a thickness of 40 micra at a distance of 100 micra below the eye and of .24 micra at 100 micra above the eye.

The lens lies directly beneath the skin. In this particular eye (Pl. XV, Fig. 36) it is an ellipsoid, 30 micra by 38 micra ( 36 by 28 in another eye). It is entirely separated from the skin and takes on a deeper stain. The cells of the lens are not very regularly grouped, but apparently they are arranged about a median point or space. The lens lies entirely outside of the eye in contact with the outer face of the dorsal part of the iris.

The eye proper is a subspherical solid mass with only a shallow depression below 
the lens representing the vitreous cavity and choroid fissure. In the eye more particularly described here the depression is filled largely with blood-corpuscles (Fig. $36, c p l$. sng.).

The pigmented layer is not more than 4 micra thick, and is very sparingly pigmented over the posterior face of the eye. At the iris and the lower margin of the choroid fissure it is continuous with the inner layers of the retina through cells whose nuclei are distinctly elongated. The retina proper, from the pigmented layer to the vitreous cavity, is 64 micra thick.

It is differentiated into a nuclear layer (the outer and inner together) and the ganglionic layer, separated by the incomplete inner reticular layer.

The ganglionic layer is composed of two sorts of cells. Those nearer the vitreous cavity have much more distinct nucleoli than those nearer the reticular layer.

Cell multiplication is still going on.

The optic nerve is well developed, forming a solid strand of fibres, 12 micra in diameter, readily traceable to the brain.

The muscles are represented by strands of cells closely crowded. No striation is evident.

4. Six-millimetre Stages.-In embryos 6 millimetres long the cells giving rise to the oblique muscles and those for at least two of the recti can be distinguished. Scleral cartilages are not yet formed.

In three of the specimens sectioned there was no indication of a lens. In others it was well developed. Cell division was still going on in the retina.

The optic vesicle was very shallow. The rim of the vesicle was wide and still continuous with the choroid fissure, which showed as a shallow groove along the ventral surface. The choroid fissure, instead of leading into a central secondary optic cavity, led to the mass of ganglionic cells (Fig. 38). This condition of the choroid fissure and its relation to the interior of the eye leads me at this point to say a few words concerning the general structure of the eye. In the description of the eye of the adult I considered that the central ganglionic mass was the result of the collapsing of the eye with the disappearance of the vitreous body and cavity. I was justified in this conclusion by the process of degeneration going on in the eye of Typhlomolge, Typhlichthys, and Typhlogobius. Whatever may have been the phylogenic process in Amblyopsis, it is evident that ontogenically the mass of cells does not arise as imagined. It appears from the embryos that the condition of the adults arises more as the result of a contracting of the retinal area without a corresponding decrease in the size of the eye as a whole than as the result of the collapsing of a vesicle followed by the coalescence of the walls brought together by the collapse. Sagittal sections of 
the eye (Fig. 38) show the lips of the choroid fissure drawn apart with the contraction of the retina, only the dorsal two-thirds of the eye reaching full development. From a study of the embryos of this size the point of exit of the optic nerve which marks the proximal end of the choroid slit alone gives evidence that potentially, at least, we have to do with an eye from which a central cavity has disappeared.

The optic nerve is well developed, arising apparently from the ventral cells of the ganglionic mass, that is, those immediately lining the potential optic cavity.

The pigment cells are well developed and have a varying depth in different parts of the eye. They are low and without pigment over the front of the eye and the ventral surface near the choroid slit.

The retinal layers proper are differentiated into the ganglionic layer or mass which occupies the central and lower part of the interior of the eye. Apparently only the more centrally placed cells of this mass give rise to fibres. The inner reticular layer surrounds the ganglionic mass above and partly on the side, not at all below. The nuclear layers are well developed, without a differentiation into outer and inner layers or any indication of an outer reticular layer. The latter structure is apparently never formed at all.

5. Seven-millimetre Stages. - The variability in the rate of development of the eye is well seen in a series of specimens about 7 millimetres long and whose eyes are little if any beyond the stage of development reached in other specimens only 5 millimetres long taken from another female. In the former the eye is in contact with the dura proximally, but is withdrawn from the epidermis by 36 micra or more. A strand of cells extends from the eye upward and outward to the thinnest part of the epidermis. The epidermis is distinctly thinner over the eye than in neighboring regions.

The eyeball is subspherical with a shallow groove along its ventral surface representing the choroid slit (Fig. 40).

In half of the specimens of this size examined no lens could be detected. In one the lens was a comparatively large pear-shaped structure whose cells were undergoing degeneration, if the numerous dark granules in them were indicative of degeneration. In one individual in which no lens could be found on one side, a small group of cells lying between the eve and the skin of the other side was probably the lens. The cells were breaking apart and the outline of the structure as a whole was irregular. In all cases the lens lies outside the iris, and in fact the entire vitreous space is not large enough to hold the lens in such eyes as still show this structure.

The pigment layer is pigmented over the dorsal part of the eye. In vertical sections $n o$ pigment appears below the entrance of the optic nerve. The iridian part of the layer is, as usual, without pigment. The ganglionic cells, as in the last stages 
described, are exposed to the exterior through the choroirl fissure, or where this is not evident there is no differentiation into different layers along the line of the choroid fissure. The ganglionic cells placed at the distal face of the eye give off fibres to the optic nerve. Fibres have not been definitely traced to the cells of the same series occupying the proximal or middle position. The optic nerve reaches a thickness of 20 micra and breaks up into bundles a short distance within the eye. These bundles radiate, forming an incomplete funnel-shaped structure. The incomplete inner reticular layer only partially separates the ganglionic and the nuclear layers. "The relative development of the pigment layer and the inner reticular layer both show a less degree of differentiation than the same layers in the eyes of another series of larvae only 6 millimetres long. This is due to the individual variation in the rate of development, not to degeneration since the last stage.

Dividing cells are found in the nucleated layer.

In the nuclear layers some nuclei elongated in a vertical direction are probably the nuclei of the Muillerian fibres.

6. Nine- to Ten-millimetre Stages.-In larvæ 9 to 10 millimetres long the eyes lie from 60 to 100 micra removed from the epidermis and in contact with the braincapsule or but little separated from it. Their average measurements are: longitudinal diameter 114 micra, antero-posterior 98 micra, vertical 106 micra (Plate XV, Figs. 45-49).

The epidermis over the eye has assumed the thickness found over neighboring regions, and from now on till death by old age there are no external modifications to indicate the former position of the cornea.

The pupil is still open, and also the choroid fissure in the region of the pupil (Pl. $\mathrm{XV}$, Figs. 45, 47). In the proximal parts the choroid fissure is indicated by the absence of pigment along the ventral line (Fig. 46). The vitreous cavity is a shallow depression in the distal face of the eye with a very narrow slit, sometimes a line, separating the iris from the solid mass of cells representing the retina. The vitreous cavity formed by the ventral invagination, that is, proximal of the iris, is obliterated in some individuals except in so far as the absence of pigment along a median line and in the union of the ganglionic layer with the pigmented layer along this line indicates its presence. The choroid fissure has been noted in an individual over 100 millimetres long, so that evidently in some cases it may not close. Blood-vessels are still present in the vitreous cavity as far as it is developed. The distance from the exit of the optic nerve to the ventral margin of the pupil is considerably less than,the distance between the exit of the optic nerve and the dorsal margin of the pupil. A few nuclei, probably the reninants of the hyaloid membrane, lie over the distal face of theretina. 
In ter specimens sectioned, all of them from 9.5 to 10 millimetres long, the lens has disappeared without leaving any trace.

The pigmented layer increases in thickness from the iris to the exit of the optic nerve. Its pigmentation also increases from the iris to the optic nerve. Within any one cell the pigment is uniformly distributed. In the dorsal part of the eye the pigment reaches to the iris, while in the ventral it does not reach so far, and in fact in a line from the optic nerve to the iris very few (only about three) cells are pigmented. The maximun thickness of this layer is 12 micra.

The inner cells of the iris have taken on their elongated shape which distinguishes them in the eye of the adult, where the region of the iris and pupil cannot otherwise be distinguished.

The layers of the retina are now well developed except that the ganglionic mass of cells occupying the centre of the eye is continuous with the outer nuclear and the pigmented layers along the ventral line.

The outer and inner nuclear layers were represented by about four rows of nuclei immediately within the pigmented layer. The cells represented by these nuclei were not separable into an outer and an inner layer histologically, nor was there any break indicating the presence of any outer reticular layer. The cells formed a compact layer of approximately uniform thickness. There were no indications of cones in any of the eyes examined.

The inner reticular layer was well developed except along the region of the choroid fissure, where, as has been said above, the nucleated layers of the retina metThere is possibly one exception to this in one of the eyes, in which the reticular layer surrounded the optic nerve at its entrance to the eye (Pl. XV, Fig. 46).

The space ventral to the central axis of the eye was occupied by the mass of ganglionic cells. This mass was irregularly trumpet-shaped, with the narrow end of the trumpet at the entrance of the optic nerve and the wide end at the distal part of the retima, where its cells were continuous with those of the nuclear layers. In the distal face of the trumpet, in what would be its hollow end, there was a distinct conical area free from cells and abundantly supplied with fibres (Fig. 47). It is post sible that this represents the optic fibre layer. The optic nerve was well developed, but its fibres seemed to go to their respective cells directly without first going to this apparent optic fibre layer.

The outer nuclear layers measured about 20 micra, the inner reticular about 8 micra, and the ganglionic layer about 32 micra in thickness.

No specimens between 10 and 25 millimetres have been captured. The changes taking place during this period are insignificant. (Compare Figs. 4, 5.) 


\section{THE EYE OF THE ADULT.}

The eyes of adult individuals from 25 to 75 millimetres long were fully described in my first paper (Eigenmann, '99), and the eyes of very old individuals were mentioned briefly. The most highly developed eye found was that of an individual 75 millimetres long (Pl. XII, Fig. 3). This eye is much above the average in the development of its pigmented layer, etc. Perhaps 25 millimetres represents the stage at which the eye as a whole reaches its maxinum development (Fig. 4). It is not my intention to redescribe the eyes of these stages, but I wish to make a few corrections in the account of the adult eye given in my first paper.* It was stated (Eigenmann, '99, p. 566) that blood-vessels did not enter the eye of the adult. I have since found small vessels in the remnant of the vitreous cavity. The choroid slit in a few individuals of all stages up to the very oldest remains open. A detailed account was given of the supposed lens (Eigenmann, '99, p. 569). From the evidence of embryology it seems even more doubtful than when that account was written that the lens ever persists till maturity. The structures described as the lens are probably something else. The eyes of senescent individuals will be sufficiently described under a later head.

\section{AMOUNT AND RATE OF GROWTH OF THE EYE FROM THE TIME OF ITS APPEARANCE.}

The question of the rate and amount of growth of the eye from the time it appears can best be answered by the following table of measurements of the eyes of successive sizes of embryos. Attention should be called to the great variability of the size of the eye in any one stage or in successive stages of development.

It is seen from this table that the eye reaches the full vertical and longitudinal diameter of the adult when the embryo is only 2 millimetres in length. Since the eye does not make its appearance till the embryo has reached a length of 1.5 millimetres and the lens does not begin to develop until 1 millimetre has been added to the length attained by the embryo after the eye has reached its full size, that is, not until it has reached a length of 2.5 millimetres, it is apparent that from the beginning the eye is in longitudinal and vertical diameter equal to the full adult eye.

* The last paragraph on page 566 of this paper and the first two of 567 should be transferred to eome immediately after the first paragraph of paze 565. 
Table of Measurements of the Ere from the Time of its First Appearance to Maturity.

All measurements are given in miera exeept lengths of embryos which are in millimetres.

\begin{tabular}{|c|c|c|c|c|c|c|c|}
\hline $\begin{array}{l}\text { Condition of Lubryo: Liv- } \\
\text { ing, or if Preserved, Direc- } \\
\text { tion of the Sections. }\end{array}$ & $\begin{array}{l}\text { Lengt h } \\
\text { of Erabryos. }\end{array}$ & $\begin{array}{l}\text { Number } \\
\text { of Embryos } \\
\text { Mcasured. }\end{array}$ & $\begin{array}{l}\text { Longitudinal } \\
\text { Diaraeter. }\end{array}$ & $\begin{array}{c}\text { Yertical } \\
\text { Diameter. }\end{array}$ & $\begin{array}{l}\text { Axial Diameter of } \\
\text { Eye frum Cornea } \\
\text { to Optic Nerve. }\end{array}$ & $\begin{array}{l}\text { Diameter } \\
\text { of Lens. }\end{array}$ & $\begin{array}{l}\text { Diameter } \\
\text { of Optic } \\
\text { Nerve. }\end{array}$ \\
\hline 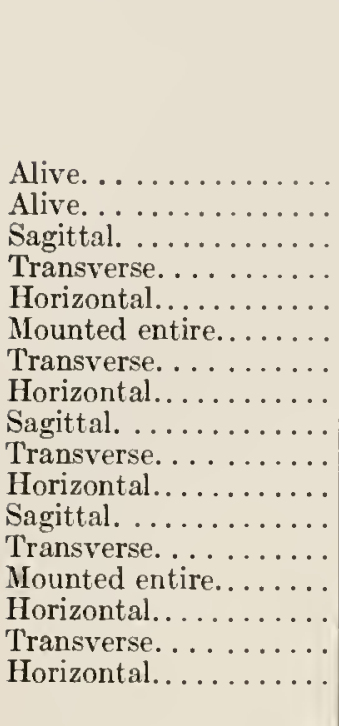 & $\begin{array}{l}1.6 \\
1.76 \\
2 \\
2.5 \\
2.8 \\
4 \\
5 \\
6 \\
6 \\
6 \\
6.5-7 \\
5.5-7 \\
6.5-7 \\
9-9.5 \\
9-9.5 \\
9-9.5 \\
10 \\
10 \\
10 \\
25 \\
25 \\
35 \\
60-108\end{array}$ & $\begin{array}{l}1 \\
1 \\
3 \\
2 \\
1 \\
1 \\
1 \\
7\end{array}$ & $\begin{array}{r}80 \\
100 \\
135 \\
190 \\
170 \\
200 \\
144 \\
136 \\
\\
136 \\
160 \\
152 \\
108 \\
108 \\
114 \\
120 \\
135 \\
120 \\
192\end{array}$ & $\begin{array}{r}150 \\
134 \\
85 \\
70 \\
\\
160 \\
126 \\
\\
106 \\
\\
112 \\
108 \\
130 \\
160 \\
115\end{array}$ & $\begin{array}{c}36 \\
48 \\
100 \\
100 \\
\\
\\
100 \\
80 \text { and } 108 \\
99 \\
115 \\
88 \\
90 \\
98 \\
109 \\
\\
128 \\
160 \\
144 \\
139\end{array}$ & $\begin{array}{l}16-36 \dagger \\
18-50 \dagger\end{array}$ & $\begin{array}{l}15 \\
17 \\
11 \\
12 \\
12\end{array}$ \\
\hline
\end{tabular}

* The individual measurements of the eyes of the seven speeimens whose average is here given is:

\begin{tabular}{|c|c|c|c|c|c|c|c|}
\hline Number of the speeimen........... & 1 & 2 & 3 & 4 & 5 & 6 & 7 \\
\hline Longitudinal diameter. . . . . . . & 176 & 160 & 136 & 172 & 160 & 160 & 128 \\
\hline Vertieal diameter........... & 144 & 128 & 112 & 160 & 144 & 128 & 128 \\
\hline Lens. . ... & $4 S$ & & & 16 & & & \\
\hline
\end{tabular}

† Or none.

\section{THE HISTORY OF THE LENS.}

The lens begins to develop when the embryo is about 2.5 millimetres long ( $\mathrm{Pl}$. XIV, Fig. 25). It forms as a thickening of the skin where the optic vesicle is in contact with it. It is still connected with the skin when the embryo has reached a length of 4.5 millimetres (Fig. 32). (Compare Figures 25, 27, 32, 33, and 43 with Figures 28, 29 , and 30 , the latter representing the development of a normal lens.) The history of the lens after this stage is somewhat uncertain. It is well established that the cells composing it never lose their embryonic condition, that they are never differentiated into fibres. In many eyes, certainly in all in which a lens could be detected in later stages, the lens becomes separated from the skin (Fig. 33). The separation is completed when the larva has reached a length of 5 millimetres (Pl. XV, Fig. 36). From this stage on, the lens begins to be resorbed; in some 6-millimetre larvæ it could no 
longer be found (Fig. 37). In 7-millimetre larvæ exactly half the eyes were without a lens (Figs. 42, 43,44), and in 9- to 10-millimetre larvæ no trace of a lens could be detected. The history of the lens is completed. Judging from this rapid and universal disappearance of the lens in the young I am inclined to the opinion that the structure described in the adult eye as a lens is not a lens.

The lens is the first organ to stop developing, the first to begin to degenerate, and the first to disappear.

\section{THE HISTORY OF THE SCLERAL CARTILAGES.}

Attention was called in my first paper (Eigenmann, '99, p. 563) to the variation of the scleral cartilages. A study of the devclopment of the cartilages has enabled me to detect perhaps a greater degree of uniformity of plan if not of structure in these cartilages than I was able to make out from a study of the adult alone. It would seem that there are normally two cartilaginous bars of variable shape developed. nat. history 83

One or both of them may be replaced by two or more smaller cartilages. One of the cartilages is found over the distal face of the eye and the other on the posterior face caudad of the optic nerve. The earliest stages at which cartilages were noticed were 9.5 to 10 millimetres (Pl. XV, Figs. 47, 48, 49) long. In one fish 10 millimetres long there were in the right eye about ten cartilage-cells, all directly over the pupil and iris. In the left eye there were about twenty-two cells, all over the dorsal part of the iris, none of them in front of the pupil. There were no traces in these eyes of scleral cartilages elsewhere. The cartilage-cells were still for the most part isolated, not bound together into a definite cartilage.

In another fish 10 millimetres long the cclls were definitely bound together into a small cartilage in each eye, that of one side encroaching on the pupil, that of the other side not.

In a fish 25 millimetres long there were two cartilaginous masses in each cye. One of these was over the distal face of the eye, the other over the caudal face of the eye caudad of the exit of the optic nerve (Pl. XII, Fig. 4). The one over the distal face curved ventro-caudad.

In a fish 30 millimetres long the cartilages were confined to the caudal half of the eye and were developed in such proportions that they encroached on the eye. The development of these cartilages to such unexpected size indicates that these cartilages are self-determining and not conditioned by the stimulus to growth by the eye with which they are in contact. In the right eye of this fish there were two 
cartilages in close contact with each other over the distal face. A third cartilage lay on the dorsal surface of the proximal part of the eve. The larger one of the two distal cartilages measures 63 by 32 by 65 micra, with a maximum diameter of the eye of 12 micr1a.

In a fish 33 millimetres long there were no cartilages on the proximal faces of the eye. In the right eve there was a cartilage 128 micra long by 40 micra thick, curved along the ventral part of the distal face. In the left eye there were two much smaller cartilages on the distal face of the eye.

In a fish 35 inillimetres long there were two cartilages in the left eye placed as in the fish 25 millimetres long, but they were larger. In the right eye the distal cartilage was represented by two cartilages in contact with each other.

From the above it is seen that the distal cartilage arises first (10 millimetre-stage), the proximal ones not till much later (25- to 30-millimetre stage). The cartilages did not reach their maximum size till later, and there is no evidence of degeneration in them even in the oldest fish.

The distal cartilage in older fishes is frequently nodular and lies in front of the eye, where it was taken to be the lens by one of the earliest observers. In a specimen 90 millimetres in length a globular cartilage 62 micra in diameter lay just over the pupil of the eve, which had a total diameter of 84 micra. One or other cartilage not infrequently encroached on the general outline of the eye.

In the left eye of an individual 105 millimetres long there were no traces of a scleral cartilage; the right eye was not examined.

In the right eye of an individual 108 millimetres long there was a single large cartilage, 134 micra by 208 micra, lying at one side of the centre of the distal face of the eye.

In the right eye of an individual 123 millimetres long a minute cartilage was found on the proximal face of the eye. It was not determined whether one occurred over the distal face. In the left eye of the same fish a large cartilage lay over the distal face (Pl. XII, Fig. 8).

In the left eye of the largest fish a single large cartilage 64 micra by 96 micra in section occupies the region to one side of the distal face (Fig. 9). In the right eye (Fig. 10) the distal cartilage measured 48 micra by 160 micra in section, and two smaller proximal ones were also present, one of them 24 micra by 32 micra in section.

The scleral cartilages are the last structure to appear in the development of the eye; they grow during the greater part of life, and retain their structure to the end. 


\section{THE HISTORY OF THE OPTIC NERVE.}

The details of the formation of the optic nerve have not been followed. No indications of it were seen in the eyes of the embryos 4.4 millimetres long. In the eyes of embryos 5 millimetres long it is well developed, forming a solid strand of fibres 12 nicra in diameter which is readily traceable to the brain. The optic nerve increases but little, if any, after its formation. Its development was rapid. In subsequent stages it was not always traceable from all the cells forming the ganglionic mass. In the 6-millimetre larvæ its fibres were distinctly traceable from the cells nearest the choroid fissure, while in later stages they were more distinctly traceable from the distal cells of the ganglionic group. The optic nerve can be followed to the brain in all the larval stages and in the young fish up to 25 millimetres in length (Pl. XII, Fig. 4). The optic nerve is evident within the eye in older stages up to about 100 millimetres; in the very oldest ones it could not be found. In individuals much more than 25 millimetres long it was not possible to follow the nerve to the brain, though it could usually be followed for some distance from the eye.

The fibres are never medullated, and I have not so far been able to give them a differential stain.

\section{THE HISTORY OF THE DEVELOPMENT, MATURITY, AND DEGENERATION OF THE EYE.}

The history of the eye of Amblyopsis may be divided into four periods. The first period extends from the appearance of the eye till the embryo reaches 4.5 millimetres in length. This period is characterized by a normal palingenic development except that cell division is retarded. The second period extends from the end of the first period till the larvie are 10 millimetres long. It is characterized by the direet development of the eye from the normal embryonic stage reached in the first period to the highest stage reached by the Amblyopsis eye; its latter half is further characterized by the entire obliteration of the lens. The third period extends from the second period to the beginning of old age (10 millimetres to about 80 or 100 millimetres). It is characterized by a number of changes which, while not improving the eye as an organ of vision, are positive as contrasted with degenerative. There are, however, also distinct degenerative processes taking place during this period. The fourth period is characterized by negative or degenerative processes only. It begins with senescent degeneration * and ends with death at old age.

* It is questionable whether the ehanges are senescent in the usual sense of the word. They occur in old age, but at a time when there are no indications of senescence in the fish as a whole. It may be urgcd that the end produet of these degenerative changes should be regarded as the typical structure of the eye of Amblyopsis. In the prescnt paper the structure of the eye at the end of distinctly develef mental stages is considered typical. The ehanges here considered cannot in any way be considered developmental. 
I. The First Period.-During the first period the eye arises as a solid outgrowth from the solid central nervous system when the embryo is about 1.5 millimetres long. The outgrowth increases rapidly in size during the next .5 millimetre of growth in length. The solid lateral outgrowth is bent back along the side of the brain, and its connection with the brain becomes constricted into the optic stalk. A cavity approximately central arises in the optic lobe at the same time that a cavity appears in the central nervous system, which occurs when the embryo is about 2 millimetres in length. The two layers of the optic vesicle formed by the appearance of the cavity are of about equal thickness. A little later the secondary optic vesicle is formed by the thickening of the skin over the eye and the consequent cupping of the distal face of the eye. The process reaches its culmination when the embryo has a length of 4.4 millimetres. The lens is still connected with the skin and the two layers of the secondary vesicle have become very different, the proximal one being one-layered, the distal one several-layered. The details of the changes of this period have been given in the preceding pages.

At any time up to this length the eye might, as far as its structure is concerned, give rise to a perfect eye in the adult. The eye so far follows phylogenic paths with the reservation that no adult ancestor is supposed to have had eyes like these embryonic stages.

2. The Second Period.-The development during the second period is direct and leads to the condition obtaining at the end of that period. Some of the processes are palingenic, some are of purely ontogenic significance, while still others (if I may make the distinction) are degenerative.

The optic nerve develops at the beginning of the period in an undoubted phylogenic way. As in the case of the eye as a whole, the nerve develops directly into its full size. The details of its history are given under the head of the optic nerve. The latter half of the history of the lens belongs entirely to this period. Its history is also given under another head. The changes the lens undergoes during this period are all katagenic, and some time before this period closes the lens has disappeared.

The direct development of the optic vesicle of the beginning of this period into the eye as found at the end of this period is very difficult to interpret satisfactorily.

A conparatively very narrow margmal part of the secondary optic vesicle is converted into the epithelial part of the iris. The lens is almost always entirely excluded from the optic cup when the iris develops. The extrene shallowness of the optic cup and the comparative thickness of the retina would lead one to expect the choroid fissure proper to be a very short structure. The shallow cup develops into the adult eye by processes like those that take place in normal eyes. These purely 
palingenic processes operating on so deficient material give rise to conditions that are not palingenic. In the closing of the choroid fissure of the normal eye the thing of chief concern is the union of the infolded margins of the optic cup from the margin of the pupil to the point of exit of the optic nerve and the closing in of the retina around the optic nerve at its exit from the eye. In Amblyopsis the former process has become insignificant, and the latter the proninent process. This is further complicated by the fact that the vitreous cavity has ontogenically disappeared nearly as much as phylogenically, so that, while the processes of changing the optic cup into the eye are palingenic, the material operated upon being quite different from that normally obtaining in fish embryos, the resulting stages of the eye are not palingenic.

The choroid fissure, which is distally a distinct slit leading into what remains of the optic cavity, becomes proximally a groove in a solid mass of cells. The closing of this groove takes place at various times, or it may remain permanently open. This condition has undoubtedly been brought about by a contraction of the area of the retina and the consequent heaping up of cells, either concomitantly with, or as the result of, the obliteration of the optic cavity. The funnel-shaped mass of cells in the centre of the Amblyopsis eye is thus the result of the phylogenic rather than the ontogenic disappearance of the optic cavity.

I must confess that an easier way of explaining the developmental stages would be reached by assuming that the central mass of cells, through which the optic nerve passes, is not really ganglionic - that only the distal cells of the mass are ganglionicand that the proximal ones are the homologues of the cells found at the point of entrance into the eye of Chologaster (Pl. XV, Fig. 50). This would imply that a cavity has not disappeared from the centre of these cells (because there never was one), and that the entire vitreous cavity has been reduced to that now found in the embryo, and that no part of the cavity has disappeared in toto. This interpretation is especially suggested by Figure 38. This would account for the fact that the optic nerve does not form a central strand through the funnel of ganglionic cells, but passes through it in several strands as it does througl the mass of cells at the entrance of the optic nerve (Fig. 50). The objection is that it would not account for the position of the exit of the optic nerve, which should, according to this view, be at the proximal end of the choroid fissure. The second objection is found in the phylogenic stages of degeneration indicated in different eyes, notably that of Typhlomolge. Furthermore, it would not account for the groove that is undoubtedly found along the ventral side of the larval eye, nor would it account for the presence of the inner reticular layer around the optic nerve. It would moreover make it necessary to assume that the cells found about the entrance of the optic nerve in Chologaster (Fig. 50) have 
been retained in Amblyopsis out of all proportions to the other structures of the eye. These objections seem to me fatal to this second supposition.

During this perior the differentiation of the several layers of the retina also takes place. At the beginning of the period the pigmented layer is represented by a layer of thin cells without pigment. At the end of the period it is composed of cylindrical cells 12 micra high which are markedly pigmented. Pigment granules first make their appearance when the larva is about 5 millimetres long. The remainder of the retina is at the beginning of the period several cells deep without any differentiation into layers. The inner reticular layer first appears as a number of irregular spaces separating the ganglionic from the nuclear layer when the embryos are 5 millimetres long. These spaces soon unite into a single layer, but this does not occur till the very latest stages of the period when the choroid fissure has been closed for some time, and in fact they may never form a layer entirely around the ganglionic cells. In earlier stages the layer extends between the dorsal and lateral parts of the ganglionic and nuclear layers. The nuclear layers never become separated into outer and inner ones, nor is an outer reticular layer ever formed. There is no indication of cones such as are seen in some adult eycs. Müllerian fibres are well formed in older individuals at this period.

The development of the scleral cartilages described under another head also takes place toward the close of this period.

No dividing cells have been found in the eyes of specimens more than 7 millimetres long.

The nuclei of the retina in the 10-millimetre stage are all granular and measure 4 to 5 micra in diameter.

3. The Third Period.-This extends from the time the fish has reached a length of 10 millimetres till marked senescent changes begin, which take place when the fish approaches 100 millimetres in length.

The nuclei of the retina, when the fish has reached a length of 25 millimetres, are no longer alike. There are two types of cells in all layers: cells with larger granular nuclei, and cells with smaller compact or dense nuclei. The difference is perhaps due less to histogenesis than to the process of degeneration which has already set in. The cells with smaller nuclei are probably degenerate. In the oldest fish only cells of the second type are found.

A number of changes take place during the third period, some of which can be classed neither as progressive nor as retrogressive. As the fish grows the eyes are farther and farther removed from the surface. In the fish 25 millimetres long they are nearly 1 millimetre below the skin, and in the largest specimen examined they 
are as much as 5 millimetres beneath the surface of the skin. The scleral cartilages develop progressively probably during the entire period, in some cases encroaching on the regular outline of the eye. Other processes which are progressive nevertheless do not tend to make the eye a more perfect organ of vision. The pupil, for instance, becomes closed in many cases, or reduced to a very minute opening. The vitreous cavity, which was still evident, becomes, concomitantly with the closing of the pupil, entirely obliterated. The pigmented layer becomes a variable structure, the pigment granules being in many cases entirely absent. Rarely the pigment layer changes to a high columnar epithelium. The stages of this period have not been successively observed as in the younger period, and the genetic relationship of different stages is not always apparent.

4. The Fourth Period.-This extends from the time the fish has reached a length of about 100 millimetres to the end of its life. There are distinct features that characterize the eye of this stage (Pl. XII, Figs. 6-10).

The fibrous capsule enveloping the eye is distinctly thicker than in younger stages. The scleral cartilages are as well developed as at any time.*

The eye-muscles, as far as present, show no indication of degeneration, and their striation can readily be made out in all individuals.

The most marked changes take place in the size of the eye itself. The pigmented layer becomes distended to form a thin-walled vesicle of two or three times the diameter of the eye in previous stages (Figs. 7, 10). This development of the pigmented layer beyond the requirements of the retina has also been observed in the eyes of Rhineura and other blind vertebrates. The cells of this layer become spherical or attenuated and the columnar epithelium converted into a thin epithelium thickened in places. Within this vesicle, whose sides may be compressed as in Figure 10, the rest of the retina forms an insignificant little ball of tissue. In an eye of an individual 105 millimetres long whose pigmented epithelium forms a vesicle 320 micra in diameter the rest of the eye forms a small sphere 60 micra in diameter in contact with the iridian part of the pigment (Fig. 7). The elements composing this little ball and representing the retina have also undergone a marked senescent modification. The optic nerve is no longer evident. $\dagger$ The ganglionic cells no longer form a compact mass, but are either midentifiable or irregularly scattered. The cells of the outer nuclear layer are

* In th. left eye of a specimen 105 millimetres long no cartilages were found. It is not possible to say whether they had disappeared or were never developed. Beeause of the irregularity in the derelopment of these eartilages and their large size in other individuals of this period, I an inclined to think cartilages never appeared in this specimen.

† The optic nerve can be traced as a very delicate filament through the pigment layer in an individual 123 millimetres long. In this eye the choroid fissure was still open. 
also less regular. While in the second period and up to 95 millimetres in length two sorts of nuclei are distinguishable, some of them small and dense, others larger and granular, in these later stages they are all small and dense, no granular ones being present, and their outlines are less well defined than in the young.

In a fish 25 millimetres long the smaller nuclei measure 2.5 micra, the larger ones measure 3.5 to 5 micra. In the specimen 123 millimetres in length the nuclei measure but 2 to 3 micra. Evidence that the smaller nuclei in the younger specimen are degenerate is furnished by the fact that optic fibres cannot be traced to the smaller ganglionic nuclei in a 25 -millimetre specinen.

The most disorganized eye found is the left one of the largest fish examined, 130 millimetres long (PI. XII, Fig. 9). The fibrous sheath (sclera) is thick; the cartilage is large, 64 by 96 micra in section. The eye itself is a disintegrated mass abundantly provided with granular pigment and without well-defined outline or structure. The right eye of the same specimen is less degenerate (Fig. 10). It is an elongated vesicle 60 by 256 micra in section, with a large cartilage to one side of its distal half, 48 by 160 micra in section, and two smaller proximal ones, one of which measures 24 by 32 micra in section. Associated with the retina of this eye is a structure that I described as a possible lens in my first paper. It consists of a few nuclei about which there are concentric layers of a homogeneous tissue. Considering the fate of the lens in all the young fishes examined it seems very doubtful, if not impossible, that this structure should be a lens.

That the eyes of these largest individuals belong to the fourth period is seen in the fact that they become distended vesicles whose parts are finally resorbed after undergoing degenerative changes. The scleral cartilages offer an exception to this general fate.

\section{THE COMPARATIVE RATE OF ONTOGENIC AND PHYLOGENIC DEGENERATION OF THE PARTS OF THE EYE.}

In my first paper (Eigenmann, '99) I gave an outline of the probable phylogenic history of the eye of Amblyopsis. In the present paper the rate of ontogenic degeneration and its extent has been found to vary in different parts of the eye. It has also been found that certain parts begin to degenerate earlier than others. We shall now attempt to discuss briefly the ratio between the rates and extent of ontogenic degeneration and the rate and degree of phylogenic degeneration implied by the structure of the eye. The discussion is somewhat intanglible, but certain definite results can be obtained by it. 
In order to compare the ratio between the ontogenic and phylogenic rates of degeneration, it is necessary to use some stage in the development of the eye as the point where phylogenic degeneration has been reached. For such a point we shall use the optimum reached by various parts of the eye during their development. It is certain that the phylogenic stage is below this optimum, that some of the degeneration in individual eyes is due to phylogeny, but since we do not know how much of the descent from the optimum is due to heredity and how much to the peculiarities of the environment and the resulting functionless life of the parts during the life of the individual, it will be best to take the optimum as above indicated.

All phylogenic time is taken as a unit, although some parts of the eye have been degenerating longer than others.

The ontogenic degeneration leads from the optimum to the vanishing point for most parts of the eye.

I. The Lens.-Ontogenically the lens degenerates very rapidly, reaching its vanishing point from its optimum during the period in which the fish grows not more than 5 milhmetres in length. The rate of its phylogenic degeneration must have been proportionately rapid, for at its optimum in Amblyopsis it is minute and its cells are undifferentiated. In the epigean relatives of Amblyopsis the lens is one of the parts least affected, so that it must have degenerated very rapidly in its later phylogenic history, after the fish had entered the caves.

2. The Vitreous Body.-At its best the vitreous body is so inappreciable in amount that I have not been able to consider its ontogenic degeneration. Its phylogeny has approached the vanishing point toward which most parts of the eye are heading.

3. The Retina.-The retina may be considered in its extent and in the degree of the histogenic differentiation of its parts. In the matter of its extent or size there is little change from its optimum until its disintegration in old age. Its ontogenic changes are slight. Its optimum is comparable with that of the lens and indicates a rapid and great reduction from the lowest retina of epigean relatives. The ontogenic and phylogenic rates of degeneration in the extent of the retina differ greatly, the former having come practically to a standstill.

In its histogenic differentiation the retina is not comparable with the lens, for it rises above the embryonic phases. In fact in its histogenic differentiation the retina rises far above the requirements of the case, and the most highly developed eye of Amblyopsis approaches the lowest of its epigean relatives. Over any given area it is doubtful whether the ganglionic and inner reticular layers are more degenerate or as degenerate as the same parts in the eyes of Chologaster cornutus. It is certain 
that in their highest development the parts between the inner reticular and the pigmented layers are below the lowest point reached by the corresponding parts in the epigean species mentioned. The same is true of the pigmented epithelium.

The simplification of the structure of the retina from its maximum to its minimum in ontogeny is of greater extent than its simplification from the lowest differentiated retina found in epigean species to the maximum found in Amblyopsis.

From the foregoing we may conclude that there is no constant ratio between the extent and degree of ontogenic and phylogenic degeneration, and that the observed rate of ontogenic degeneration is not necessarily proportionate to the rate of phylogenic degeneration inferred from the degree of degeneration of the eye at its optimum.

\section{THE FUTURE OF THE EYE.}

There can be no doubt that the phylogenic fate of the eye, exclusive of connective tissue, sheaths, sclera, etc., is total disappearance. (There is no indication that the scleral cartilages will meet a like fate.) The most degenerate ontogenic eye indicates as much. There are no relatives of Amblyopsis that have reached this condition, but Troglichthys has an eye distinctly more degenerate than that of Amblyopsis. It may offer a clue as to whether any of the ontogenically degenerate eyes, such as are found in old specimens of Amblyopsis, are prophetic of the condition through which the eye will pass in its route to the vanishing point. The most highly developed eye found in any specimens of Troglichthys (Pl. XII, Figs. 11, 12)is comparable in a general way with the eyes of the old of Amblyopsis. The pigmented epithelium is larger than the requirements of the eye in both cases, and the scleral cartilages are disproportionately developed in both cases. The ganglionic cells extending through the centre of the eye of the younger Amblyopsis are absent in both cases.* When we attempt a closer comparison our efforts fail.

We may conclude that if Troglichthys indicates one of the steps through which the eye of Amblyopsis will pass in its annihilation, the degenerative phases seen in the oldest specimens of Amblyopsis indicate only in a general way the phylogenic path through which the eye will pass in the future.

\footnotetext{
* Only three cells have been found in this region in all the eyes of Troglichthys examined.
} 


\section{RETARDATION AND THE CUTTING OFF OF LATE STAGES OF DEVELOPMENT.}

In the first paper of the present series (Eigenmann, '99, p. 596) I said: "Cessation of development takes place only in so far as the number of cells are concerned. The number of cell generations produced being continually smaller results in an organ as a consequence, also smaller. In this sense we have a cessation of development (cell division, not morphogenic development) in ever earlier stages. That there is an actual retardation of development is evident from Amblyopsis and Typhlichthys in which the eye has not reached its final form when the fish are 35 millimetres long."

I am convinced now that this statement does not go far enough. There is, indeed, a gradual retardation in all processes of development which frequently terminates in a complete arrest of development before the final stages of normal eves are reached. In discussing the changes it will be best to keep the three groups of processes concerned in development separate.

I. Cell Division.-The proof of the limiting of the number of cell divisions mentioned has been brought in the present paper. It has also been seen that the rate of division is very much retarded. In the retina it stops altogether at the time the fish has reached a length of 5 to 7 millimetres, and very rarely more than two dividing cells are found in any eye. In its first stages the eye is thus about equal in size to the adult eye. Cell division stops earlier in the lens where no new cells are formed after it is cut off from the skin. The lens is at this time relatively as well developed as the retina. In both the retina and the lens cell division ceases in late stages and the total number of cell generations is very much limited. The lens is looked upon as phylogenically a new structure, and we have, by the stopping of its later stages of cell division, a step in the elimination of a phylogenically new structure. This is, however, of no consequence because it is not differential, for the retina, a phylogenically older structure, suffers a similar stoppage. There is no evidence, then, that phylogenically younger structures lose their power of cell division earlier than phylogenically older ones.

2. Morphogenic Processes.-The retardation of the morphogenic processes, cell arrangement, movement, union and separation, etc., is conspicuous in the delay of the closing of the choroid fissure and all that this implies. There is no conspicuous stopping of this process except in the occasional failure of the choroid fissure to close at all.

3. Histogenesis.-Histogenic processes are also distinctly retarded, and in conspicuous instances suffer an entire stoppage. While the eyes of 3 -millimetre speci- 
mens of Cymatogaster or Carassius and Amblyopsis are nearly alike, in the former two the tissue differentiation has progressed vastly farther by the time the fishes have reached a length of 10 millimetres. Histogenesis is carried surprisingly far in many degenerate eyes. In Rhineura, for instance (Eigenmann, :02), the layers of the retina are differentiated far beyond the requirements of the case. In Amblyopsis the process, as far as it can be made out with the methods available, falls short of the normal development.* The cells of the lens never lose their embryonic characters; they are never transformed into lens-fibres. Cones are rarely if ever developed in the retina, and an outer reticular layer never. In normal development the cones and the outer reticular layers are the last to differentiate, so that we have certainly a cutting off of late ontogenic stages. The question whether these are also phylogenically young may be passed over.

4. Conclusion.-The total evidence from the three processes is that none of them proceed with the push and rapidity found in normal structures, and though they are normal they grow weaker with development and frequently give out altogether. But with all this lack of vigor, while there is more variation in each structure developed than has been noted in normal eyes, the point to which cell division, cell arrangement, and histogenesis are carried, in different individuals, is about the same. The causes leading to the changed development are of approximately equal value in different specimens from the same locality.

\section{CAUSES OF RETARDATION AND CESSATION IN THE DEVELOPMENT OF THE EYE.}

The retardation and arrest in the development of the eye of Amblyopsis may be due to one of several possible causes. They are either conditioned by something outside the cells composing the eye, or they are inherent or predetermined in the eggcell from which the eye is ultimately derived. The conditioning factor, if it lies outside the eye, may be a peculiarity in the physical and chemical environment in which the fish lives, or a lack of stimulation or an inhibition exercised by some other part of the body. Unless we assume that the eye of Amblyopsis has reacted and does now react differently to the physical and chemical environment from that of some of the relatives of Amblyopsis, physical and chemical factors may readily be eliminated as contributing directly to the retardation and cessation.

Although, in discussing the phylogenic degeneration of the eyes of cold-blooded

\footnotetext{
* The difficulties, for instance, of differentiating with Golgi methods the bipolar cells of an eye whose total diameter falls short of .2 millimetre ean readily be imagined.
} 
vertebrates in general, I have insisted that cross-country conclusions must be guarded against, I then saw no objection, and now see none, to considering the different members of the Amblyopsidæ as homogeneous material within the bounds of which we may expect similar causes to effect similar results. The different stages (phyletic) of development found in the eyes of the different members of the Amblyopsidæ are all referable to the difference in time during which they have been subjected to their present environment.

The only environmental condition surrounding the developing eggs of Amblyopsis to which the peculiarities of development might be attributed is the total absence of light.

Temperature, oxygen pressure, chemical composition, etc., of the surrounding medium may be entirely excluded from the possible agents affecting the eye, inasmuch as normal eyes are developed by other fishes in the same water and under all possible fluctuations of the above conditions within the limits of the possibility of fish life. But the same objection holds in attributing the lack of development to the absence of light. Chologaster agassizii, a member of the Amblyopsidæ, which always lives in caves in exactly the same conditions under which Amblyopsis lives, has nevertheless normally developed, though small, eyes.

While guarding against the possibility of attributing too much weight to the results obtained in other families of animals, it still may be mentioned that many fishes living perpetually in total darkness develop normal eyes. This is also true of the young of all viviparous animals which develop in more or less complete darkness.

If, then, so closely related fishes as Chologaster and Amblyopsis are subjected to the same environment which is minus a certain element and both develop their normal parental structure, one developing a normal eye, the other a very abnormal degenerate one, it is scarcely warrantable to say that the abnormal structure in one of them is due to the absence of the one element (light) from the enviroument. Moreover, if the development is controlled by the absence of light, there is no reason why development should be normal even to the extent of forming a normal start and should then be arrested or retarded. The fact that the presence or absence of light is not the controlling factor in the retarded development of the eye of Amblyopsis does not vitiate the supposition that a certain amount of change may not be produced on the eyes of an individual by rearing it in the light. Such change would, however, stand on a par with the ontogenic degeneration of the eye with age in the absence of light; that is, it would be a functional adaptation due to use.

Experiments have been in progress to test the effect of light. So far only negative results have been obtained. One young has been reared till it was six months 
old. It was obtained from the caves at a time when it was ready to swim about freely, that is, when the eye was already fully formed. There was no difference in the gross anatomy of the eye of this individual as compared with that of others. The minute anatomy, as the result of an accident, was not available for study. The others examined in earlier stages have not been reared beyond a length of a few millimetres, and the effect of the light, if any, was not appreciable. From the observations on the development of the eyes-which show that some processes are arrested very early-it would seem that the only rational way to determine the effect of light on the total development is to colonize the adults in an outdoor pool where the young can be reared, from the fertilization on, in normally lighted waters. Such a colony has been planted, but so far without success in rearing young.*

The lack of development of the eye not being chargeable to any factor in the environment, is there any factor within the fish that inhibits its development, or whose absence fails to furnish the stimulus necessary to the development? If so, this factor must be present or absent at the time the retardation begins or some time before.

The inhibition, if any, might operate through a mechanical crowding on the part of a neighboring organ or the greater selective power in eliminating the food requisite for the development of the eye. The first may be eliminated, for there is no evidence whatever of crowding other than that found in normal eyes; in fact in all stages beyond the earliest the eye is much smaller than the optic sockets can easily accommodate.

The question of selective food elimination is not so readily disposed of. The ophthalmic artery provides the eyes abundantly with blood, so it is not an absence of this that causes the supposed starving. Indeed if the retardation were due to a lack of blood-supply we would be removing the problem one step from the eye without solving it. Besides, Loeb's ('93) experiments have shown that the action of the heart may be greatly diminished without affecting the rate of growth of the larval fish. The blood-supply being abundant, is there any otler organ that may drain it of the nutriment necessary for the proper growth of the eye? Leaving aside the question whether an organ can be starved by having the nutriment requisite for development withdrawn from the blood by another organ, I can think of no organ or set of organs that attain an unusual growth aside from the tactile organs of the skin. This system of organs is undoubtedly very highly developed in the adult and has also attained a remarkable degree of development at the time the fish is 10 milli-

* Since writing the above the whole eolony has been destroyed. 
metres long. It is, however, not unusually developed in the earlier stages before hatching, and shortly thereafter when the cessation of cell division, the most important element of the stunted optic development, takes place. Besides this the tactile organs of Chologaster, which possesses normal eyes, are very highly if not so elaborately developed as in Amblyopsis. I have experimentally determined by eliminating the eyes altogether that the tactile organs in Chologaster papilliferus are amply developed to enable the fish to live indefinitely without the use of its eyes. The same must also be true of Chologaster agassizii, which lives permanently in caves. While not impossible, it seems, therefore, very improbable that the tactile organs affect the development of the eyes in Amblyopsis and not in Chologaster.*

I know of no other organs in Amblyopsis whose development differs from that of Chologaster in a degree sufficient to make it a successful contestant for a foodsupply in Amblyopsis and not in Chologaster.

What has been said concerning organs whose presence might affect the development of the eyes is equally true concerning organs whose absence might deprive the eye of the necessary stimulus to reach normal development. I know of no organ, either in Amblyopsis or Chologaster, whose absence in the one and presence in the other might account for the difference in the degree of development reached by the eyes in the two fishes.

The conclusion is forced upon us by the above considerations that neither in the environment nor in the fish itself is there a factor sufficient to account for the early arrest in cell division, the retardation of the morphogenic processes, and the stopping of the histogenic processes. We are therefore entirely justified in assuming that the determining cause of the method of development lies in the cells themselves and is inherited. The great development of the scleral cartilages beyond the needs of the eye also tend to locate the formative or hereditary power in the cartilages themselves rather than in the stimuli to their development that they receive from their contact with the developing eyes, for they develop entirely beyond the needs of these eyes.

The causes operating in ontogeny and phylogeny that have led to the limited power of development and differentiation I have fully considered in my first paper (Eigenmann, '99, p. 596) in a chapter which was also published in the Popular Science Monthly. It was there concluded that the phylogenic degeneration, which is equivalent to saying the limited power of development found in the cells entering into the

\footnotetext{
* As an example bcaring on this subject it may be permitted to call attention to the tactile apparatus of the Siluridæ, which is certainly in many instances more elaborate than that of Amblyopsis and yet the eyes are normal though small.
} 
eye of the indivichal, is the result of functional adaptation during the lifetime of past indivicluals to the total disuse of the eye. This adaptation, it was concluded, was transmitted to a certain extent to the succeeding generation through the usual vehicles of transmission. There has always been and is yet a serious objection to the latter conclusion, because the method of the transmission of functional adaptations to the organization of the egg so as to limit or extend its powers is not known.

Recently, while admitting that functionally adaptive structures arise developmentally without reference to function, Driesch ('99) has maintained that: "Wer hier von 'Vererbung' früher einmal functionell 'erworbener' Eigenschaften reden will, verlässt den wissenschaftlichen Boden, denn wir wissen von solcher Art der Vererbung gar nichts."

Possibly we might find a warrant for the assumption of the transmission of functional adaptation to the germ-cells in the writings of Driesch himself, though he might not thank us for it. He maintains that certain developmental results whose proximal cause he is not able to determine may be produced by factors working in a distant part of the embryo. Without entering into a discussion of the validity of these factors working at a distance, if they are really factors and capable of acting, as Driesch imagines, why may not functional modifications effect changes in the hereditary cells in a similar manner?

I conclude that retardation and cessation in development are not due to ontogenically operating causes, but they are inherent in the fertilized ovum and are inherited.

\section{THE EYES OF AMBLYOPSIS AND THE LAW OF BIOGENESIS.}

During recent years the law variously termed von Baer's law, Agassiz's law, Haeckel's law, or the law of Biogenesis, has been frequently called into question. Its general tenets are : (1) Every individual in its development repeats in brief the development of the race; (2) closely related forms have a similar ontogeny, and the nearer two animals are related the longer their embryos are alike; (3) the embryos of high animals pass through stages resembling the adult stages of lower animals; and (4) in every ontogeny there are, among the truly ancestral stages, stages which are adaptive and have been acquired during ontogenic development.

No objection has been raised to the fourth tenet in so far as its acceptance does not commit to the acceptance of the first. In objection to the first of these propositions Hurst ('93, p. 399) writes: "I do not deny that a rough parallelism exists in some cases between ontogeny and phylogeny. I do deny that the phylogeny can so 
control the ontogeny as to make the latter into a record of the former-even into an imperfect record of it." "Vestiges, and these only, can give any embryological clue to past history which could not be equally well made out from comparative anatomy."

Zittel finds cases in paleontology both in support of and against this first proposition.

"All know that it (development of Antedon) does not in the remotest manner agree with the facts of paleontology." "No observations of embryology would warrant our imagining the former existence of graptolites or stromatophores. No stage in the development of any living brachiopod informs us that numerous spine-bearing genera lived in Palæozoic and Mesozoic times. . . . The beautiful researches of Hyatt, Würtemberger, and Branco have shown that all ammonites and ceratites pass through a goniatite stage, and that the inner whorls of an ammonite constantly resemble, in form, ornament, and suture-line, the adult condition of some previously existing genus or other."

Smith (:00, p. 226) finds that "the development of Placenticeras shows that it is possible to decipher the race history of an animal in its individual ontogeny."

But it is not the intention to review the numerous expressions of opinion pro and con which have appeared on this subject in recent years. A full discussion of the literature to 1897 has been given by Keibel ('98).

The eye of Amblyopsis presents, however, such an excellent opportunity to test an opinion vaguely expressed by Balfour in his Embryology, and carefully and clearly stated by Sedgwick ('94) and reiterated by Cunningham in his Sexual Dimorphism $(: 00)$ and in other places, that the facts presented in the foregoing pages may be re-exanined in their relation to this point.

Balfour says ('S5, vol. 2, p. 361): "Abbreviations take place because direct development is always simpler, and therefore more advantageous; and, owing to the fact of the fotus not being required to lead an independent existence till birth, and of its being in the mean time nourished by food-yolk, or directly by the parent, there are no physiological causes to prevent the characters of any stage of the development which are of functional importance during a free but not during a foctal existence from disappearing from the developmental history. .... In spite of the liability of larvæ to acquire secondary characters, there is a powerful counterbalancing influence tending towards the preservation of ancestral characters in that larvæ are necessarily compelled at all stages of their growth to retain in a functional state such systems of organs, at any rate, as are essential for a free and independent existence. It thus comes about that, in spite of the many causes tending to produce secondary changes in larvæ, there is always a better chance of larvæ repeating, in an unabbreviated form, 
their ancestral history than is the case with embryos which undergo their development within the egg."

The most concrete critique of the law of biogenesis has been offered by Sedgwick ('94). After rejecting the second proposition by showing that, while in many cases the adults differ more from each other than the young, in other cases the embryos differ more from each other than the adults, he takes up the main question stated in the first proposition by a consideration of "The Significance of Ancestral Rudiments in Enıbryonic Development" ('94, p. 40). It is, indeed, around this phase of the subject that the discussion has centred. His views are best given by a series of excerpts from his paper. Thus Sedgwick ('94, p. 41) states that ". . . The tendency in embryonic development is to directness and abbreviation and to the omission of ancestral stages of structure, and that variations do not merely affect the not-early period of life where they are of immediate functional importance to the animal, but, on the contrary, that they are inherent in the germ and affect more or less profoundly the whole development."

"The evidence is of this kind: (1) Organs which we know have only recently disappeared are not developed at all in the embryo. For instance, the teeth of birds, the fore limbs of snakes, reduced toes of bird's foot (and probably of horse's foot), the reduced fingers of a bird's hand.... (2) Organs which have (presumably) recently become reduced or enlarged in the adult are also reduced or enlarged in the embryo. . . (3) Organs which have been recently acquired may appear at the very earliest possible stage. . . ." (p. 42).

"The latter arrangement ["ancestral organs have disappeared without leaving a trace"] seems to be the rule, the former the exception" (pp. 44-45).

"I think it can be shown that the retention of ancestral organs by the larvæ" (embryos?) "after they have been lost by the adult is due to the absorption of a larva, or inmmature free stage into embryonic life" (p. 46). A larval character thus absorbed into the embryonic life, "its disappearance is no longer a matter of importance to the organism, because, the enbryo being protected from the struggle for existence, the pressure of rudimentary functionless organs is unimportant to it" (p. 48).

"Characters which disappear during free life disappear also in the embryo, but characters which, though lost by the adult, are retained in the larva may ultimately be absorbed into the embryonic phase and leave their traces in embryonic development" (p. 49).

"To put the matter in another and more general way. The only, functionless ancestral structures which are preserved in development are those which at some time or another have been of use to the organism during its development after they 
have ceased to be so in the adult. . . . But another explanation is possible, which is that organs which are becoming functionless, and disappearing at all stages, may in some cases disappear unevenly, that is to say, they may remain at one stage after they have totally disappearcd at another" (p. 50).

The question seems to me not quite so simple as imagined by Sedgwick.

Degenerate organs may or may not be better developed in the young than they are in the adult. 1. They are better developed in the young if they are still functional in the young while they have become functionless in the adult. 2. They may be better developed in the young, if they were of use to the young, after they ceased to be of use to the adult. 3. They may be well developed in the young after complete disappearance in the adult if the material is used for other purposes in later life. 4 . They are better developed in the young if their presence is essential to provide the necessary stimulus to bring about or to inhibit cell movements or cell differentiation in the development of other organs. 5. They are supposcd to be no better developed in the young than in the adult if they have never been of use to the young after they had lost their use in the adult.

The material entering into the formation of the eyes is not used for the building up of other organs, and it is uncertain whether the eyes positively or negatively influence the devclopment of other organs so that a discussion of numbers 3 and 4 of the above possibilities is not profitable. Inasmuch as both young and adult live permanently in total darkncss, and the eye of the young cannot be functional under the present mode of existence, the first possibility is also eliminated from the discussion.

In Amblyopsis, which carries its young in its gill-cavity, we are undoubtedly dealing with an animal in which the eyes are useless in the young as well as in the adult and in which they became totally useless in the young at the same time that they became totally useless in the adult, that is, at the time the species took up permanent quarters in the caves. Do the eyes in this casc repeat the phylogenic history of the eye or have the eycs in the embryo degencrated in proportion to their degeneration in the adult? In this form the question is whether a perfect or better eye is produced to be finally metamorphosed into the condition found in the adult, or whether development of the eye is direct.

We have seen in the preceding pages that the foundations of the eye are normally laid, but that the superstructure instcad of continuing the plan with new material completes it out of the matcrial provided for the foundations, and that in fact not even all of this (lens) material cnters into the structure of the adult eye. The development of the foundations of the eye are phylogenic, the stages beyond the foundations are direct. 


\section{BIBLIOGRAPHY.}

A list of the papers dealing with the eyes in blind vertebrates is given in my first paper (Eigenmann, '99, p. 611). I add here the papers published since that time, together with those dealing with the general problem under consideration and not referred to in my earlier papers.

Balfour, F. M.

'85. A Treatise on Comparative Embryology. London, 2 ed., $S^{\circ}, 2$ vols., $x i+591+x x i i i ; x i+792+x x i v$ pp. Cunningham, J. T.

:00. Sexual Dinorphism in the Animal Kingdom. London, $8^{\circ}, \mathrm{x}+317 \mathrm{pp}$.

Driesch, H.

'99. Resultate und Probleme der Entwickelungsphysiologie der Tiere. Ergeb. Anat. u. Entwickg., Bd. 8, pp. 697-846.

Eigenmann, C. H.

'99. The Eycs of the Blind Vertebrates of North America. I. The Eyes of the Amblyopsidx. Arch. f. Entwick.-mech., Bd. 8, Heft 4, pp. 545-617, Taf. 11-15.

Eigenmann, C. H.

:00. The Blind Fishes. Biol. Lectures from the Mar. Biol. Lab. Woods Holl, 1899, pp. 113-126.

Eigenmann, C. H.

$: 00^{a}$. The Eyes of the Blind Vertebrates of North America. II. The Eyes of Typhlomolge rathbuni Stejneger. Trans. Amer. Micr. Soc., vol. 21, pp. 49-60, pls. 3-4.

Eigenmann, C. H.

02. The Eyes of the Blind Vertebrates of North America. IV. The Eyes of Rhineura floridana Baird. (In press.)

Eigenmann, C. H., and Denny, W. A.

:00. The Eyes of the Blind Vertebrates of North America. III. The Structure and Ontogenetic Degeneration of the Eyes of the Missouri Cave Salamander. Biol. Bull., vol. 2, no. 1, pp. 33-40, 1 pl.

Herbst, C.

:01. Formative Reize in der thierischen Ontogenese. Leipzig, $8^{\circ}, 125 \mathrm{pp}$.

Hurst, C. H.

'93. The Recapitulation Theory. Nat. Sci,, vol. 2, no. 13, pp. 195-200.

Keibel, F.

'98. Das biogenetische Grundgesctz und die Cenogenese. Ergeb. Anat. u. Entwickg., Bd. 7, pp. 722-792.

Loeb, J.

'93. Ueber die Entwicklung von Fischembryonen ohne Kreislauf. Arch. ges. Physiol., Bd. 54, pp. 525-531. Sedgwick, A.

'94. On the Law of Devclopment commonly known as von Baer's Law; and on the Significance of Ancestral Rudiments in Embryonic Development. Quart. Jour. Micr. Sci., vol. 36, no. 141, pp. 35-52.

Smith, J. P.

'97. The Development of Glyphioceras and the Phylogeny of the Glyphioceratidæ. Proc. California Acad. Sci., scr. 3, Geology, vol. 1, no. 3, pp. 102-128, pls. 13-15.

Smith, J. P.

'98. The Development of Lytoceras and Phylloceras. Proc. California Acad. Sci., ser. 3, Geology, vol. 1 , no. 4, pp. 129-160, pls. 16-20.

Smith, J. P.

:00. The Development and Phylogeny of Placenticeras. Proc. California Acad. Sci.; ser. 3, Geology, vol. 1 , no. 7 , pp. 181-240, pls. 24-28.

Zittel, K. .

'95. Paleontology and the Biogenetic Law. Nat. Sci., vol. 6, pp. 305-312. 


\section{EXPLANATION OF PLATES XII-XV.}

Unless othcrwise stated the figures are from specimens of Amblyopsis spelæus. The anterior end of a horizontal section or the dorsal part of a cross-section or sagittal section is invariably toward the top of the plate. All the drawings were made with the aid of the Abbé camera and usually the 2-mm. apochromatic and the No. 4 or the No. 6 compensating eyepieces of Zeiss. Credit for the photographs is given under the head of acknowledgments.

\section{ABBREVIATIONS.}

\begin{tabular}{|c|c|c|c|}
\hline$a m l$. & $\begin{array}{l}\text { Amyloid bodies of the pigment } \\
\text { epithelium. }\end{array}$ & $\begin{array}{l}n l . c o n \\
n l . g n\end{array}$ & $\begin{array}{l}\text { Cone nuclei. } \\
\text { Nuclei of ganglionic cell. }\end{array}$ \\
\hline bac. & Rod. & nl. Muel. & Müllerian nuclei. \\
\hline bac. + con. & Rods and cones. & $o c$ & Eye. \\
\hline chd. & Choroid. & prc. $n l$. & Process of the cone nucleus. \\
\hline con. & Cones. & pupl. & Pupil. \\
\hline cpl. sng. & Blood-corpuscles. & $r$ & Right side. \\
\hline crt. scl. & Scleral cartilage. & sb'orb. & Suborbital. \\
\hline & Dorsal aspect of eye. & scl. & Sclera. \\
\hline $\begin{array}{l}\text { e'th. pig. } \\
\text { fis. chd. } \\
\text { fv. olf. }\end{array}$ & $\begin{array}{l}\text { Pigment epithelium. } \\
\text { Choroidal fissure. } \\
\text { Olfactory pit. }\end{array}$ & st. gn. & $\begin{array}{l}\text { Ganglionic layer. The nuclei of this layer } \\
\text { are conventionally marked with a large } \\
\text { dot. }\end{array}$ \\
\hline hyl. & Hyaloid membrane. & st. nl. ex. & Outer nuclear layer. \\
\hline$i r$. & Iris. & st. $n l . e x .+i n$. & Outer to inner nuclear layer. \\
\hline$i r{ }^{\prime}$ & Outer laycr of iris. & st. nl. in. & Inner nuclear layer. \\
\hline$i r . "$ & Inner layer of iris. & st. opt. & Optic fibre layer. \\
\hline$l$. & Left side of eye. & st. rct. ex. & Outer reticular layer. \\
\hline $\begin{array}{l}\ln s . \\
m u .\end{array}$ & $\begin{array}{l}\text { Lens. } \\
\text { Eye-muscle. }\end{array}$ & st. ret. in. & $\begin{array}{l}\text { Inner reticular layer. This layer is con- } \\
\text { ventionally marked by dashes. }\end{array}$ \\
\hline n. opt. & Optic nerve. & $v$. & Ventral aspect. \\
\hline$n l$. & Nucleus. & vit. & Vitreous body. \\
\hline$n l .^{\prime}$ & $\begin{array}{l}\text { Elongated nuclei of the } \mathrm{p} \\
\text { ciliaris. }\end{array}$ & & \\
\hline
\end{tabular}

PLATE XII.

Fig. 1. Larva at the time of hatching when it has a length of about $5 \mathrm{~mm}$.

Fig. 2. An older larva in the process of metamorphosis. The yolk is partly absorbed and the yolk-bag has changed shape. The caudal, the dorsal, and the anal fins are developing. The tactile organs show as prominent warts on the anterior half of the body and on the head.

Fig. 3. Cross-section of the eye of a fish $75 \mathrm{~mm}$. long. The most highly devcloped eye found.

Fig. 4. Dorsal face of a horizontal scction of the left eyc of a fish $25 \mathrm{~mm}$. long. The optic ncrve is directed forward and iuward.

Fig. 5. Horizontal scetion of the right eye of a young fish $9.5 \mathrm{~mm}$. long. Compare with Figure 47 (Pl. XV.)

Fig. 5a. The same eye as that shown in Fig. 3 lcss highly magnified This figure is inverted in reference to Fig. 3.

Fig. 6. Cross-section of the left eye of a fish $100 \mathrm{~mm}$. long, showing the large scleral cartilage; the rest of the eye is an irregular vesicle immediatcly below the cartilage.

Fig. 7. Cross-section of the right eye of a fish $105 \mathrm{~mm}$. long, showing the Iarge vesicle formed by the pigment cpithcliun and the rest of the retina as a small nodule on its distal facc.

Fig. 8. Antcrior facc of a transverse section of the left cyc of a fish $123 \mathrm{~mm}$. long. The scleral cartilage is at the extrenc lcft. The pigment epithelium forms an elongated vesicle with an invagination oppositc the scleral cartilage. The rest of the retinal clements form an irregular mass in the centre.

Fig. 9. Transverse section of the left eyc of a fish $130 \mathrm{~mm}$. long. No definite structures are distinguishable aside from the scleral cartilage. 

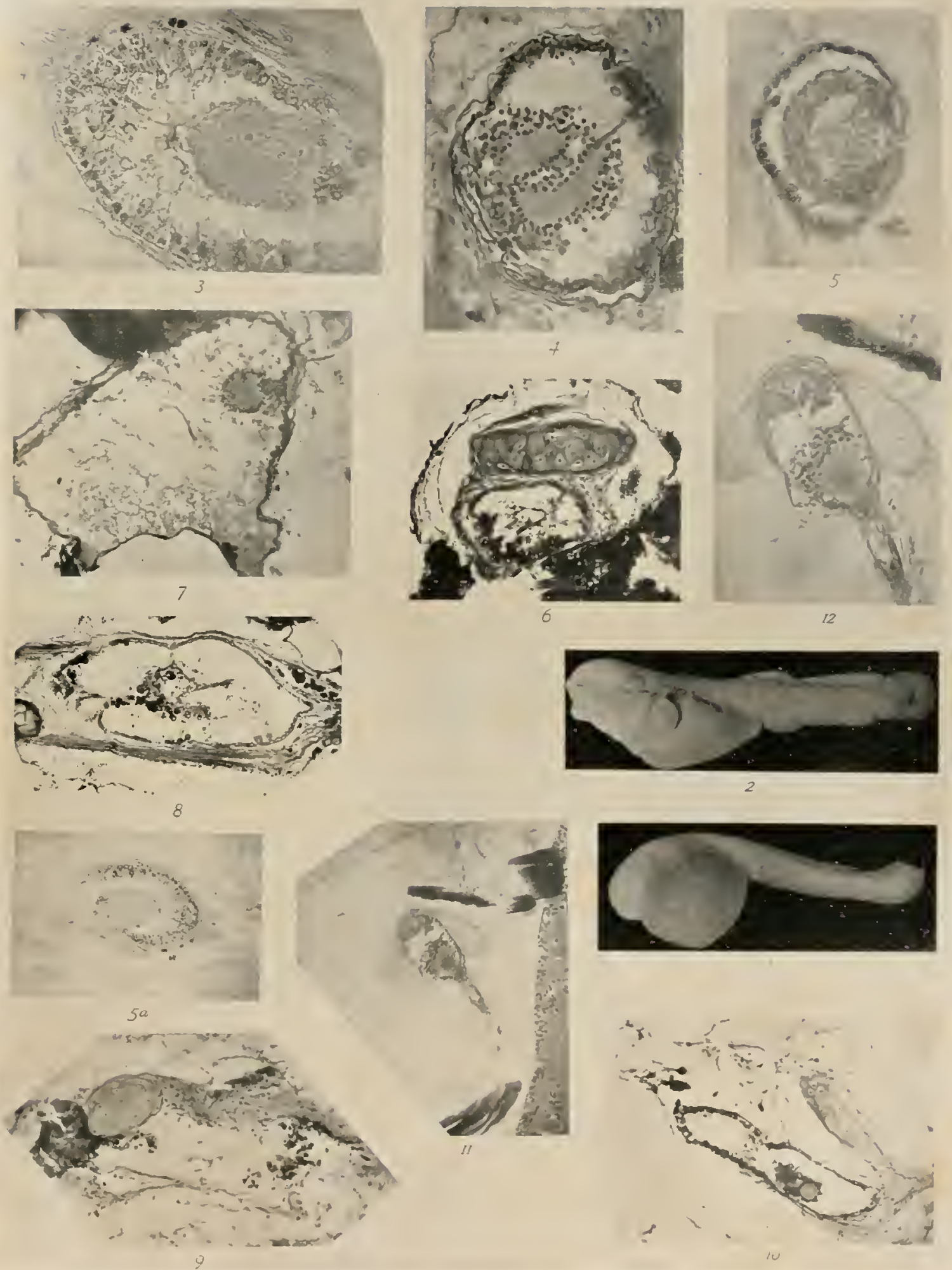
Mark Anniversary Volume.

Plate Y III
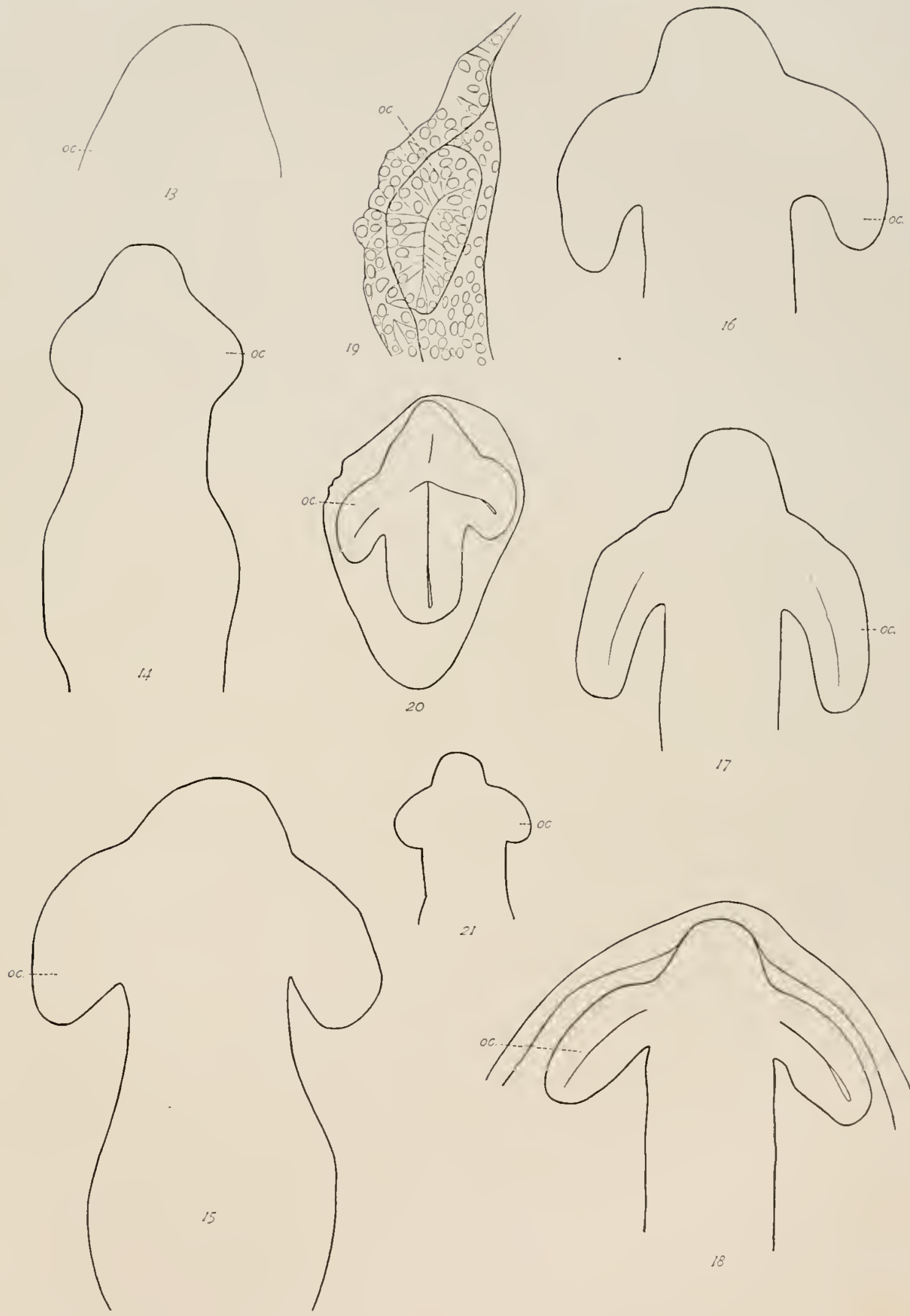

17

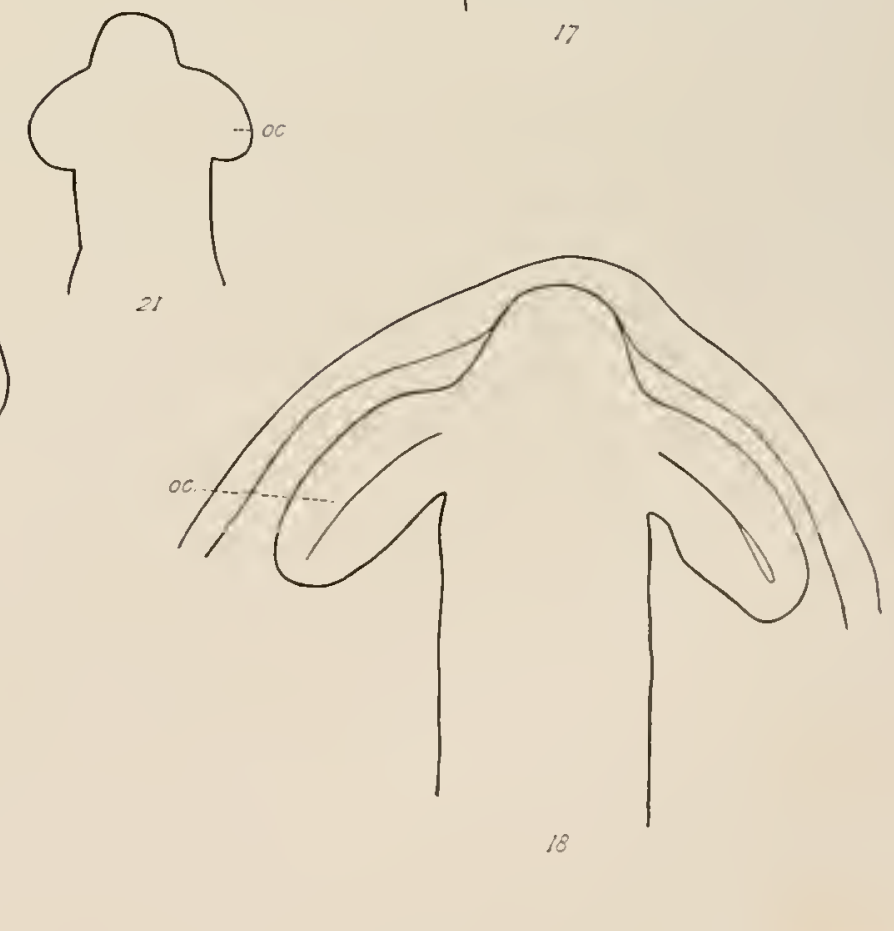

EIGENMANN. AMELYOPSIS EYE II. 
MARK ANNIVERSARY Volume.

Plate XIV.
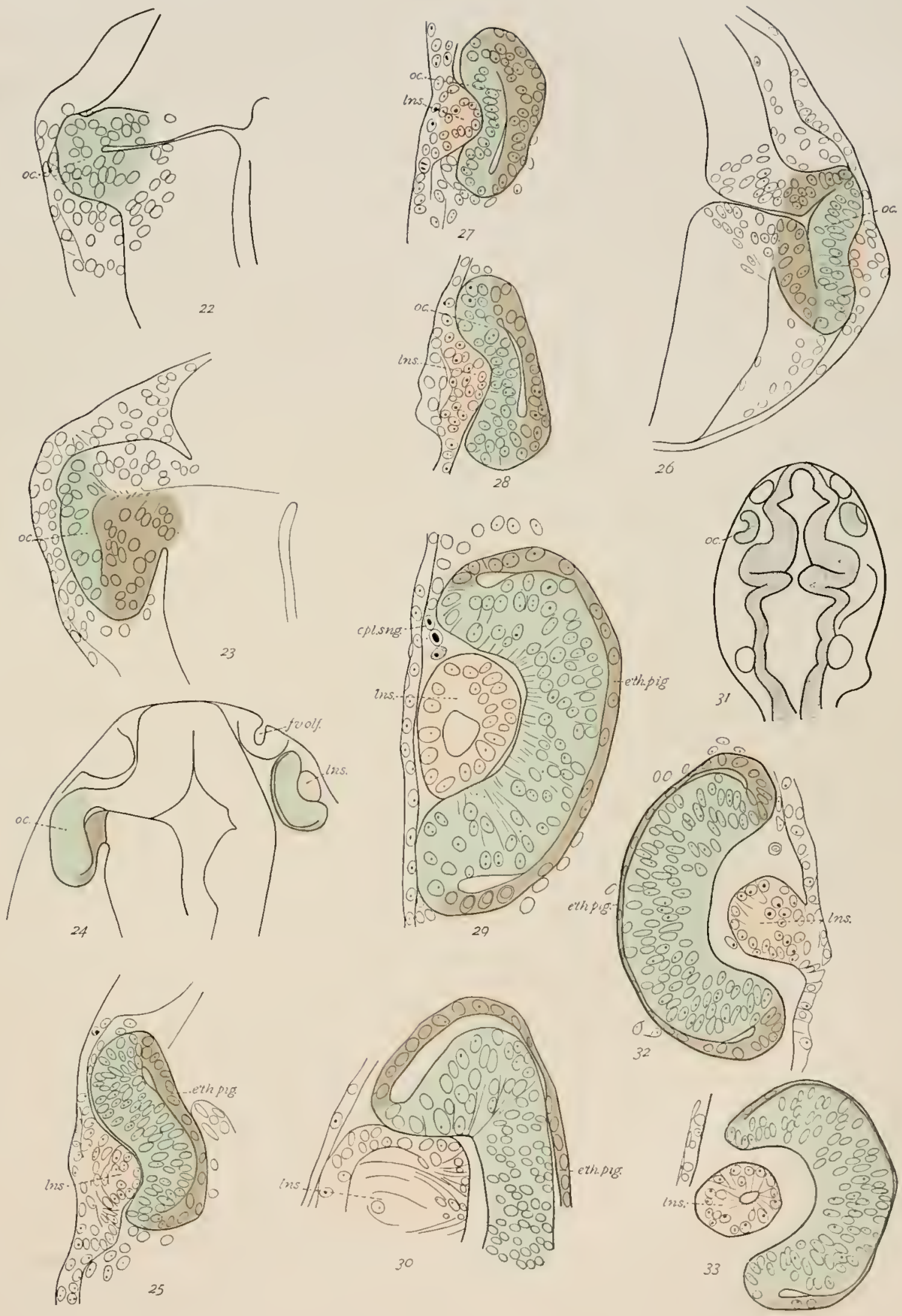

Eigeimann. - Amelyopsis Eye III. 



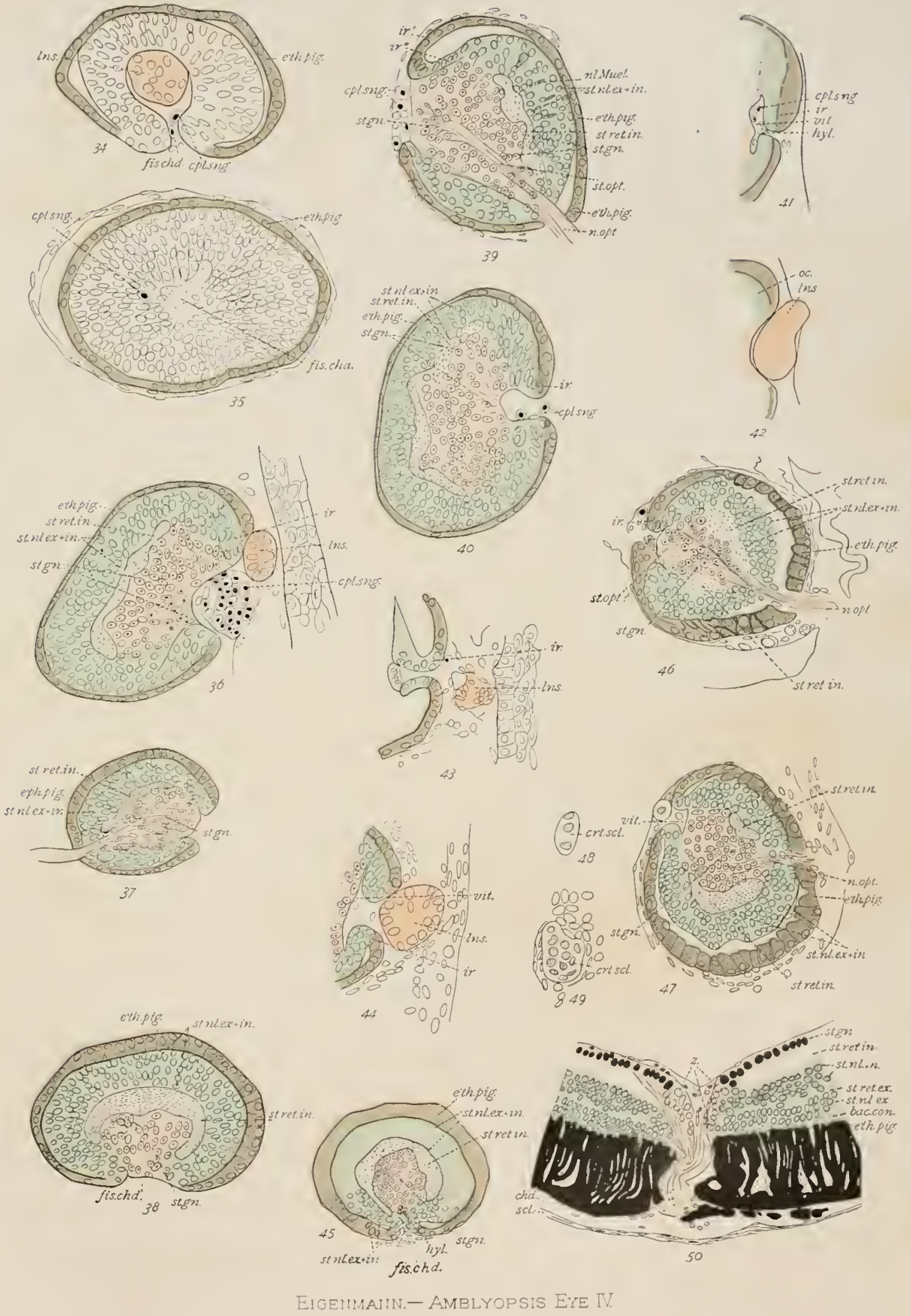



Fig. 10. Transverse section of the right eye of the fish from which Figure 9 was taken. A large scleral cartilage is present. The pigment epithelium forms an clongatcd vcsicle. The rest of the retina is an irregular mass within the vesicle. A spherical lens-like body is secn at the right.

Fig. 11. Horizontal section of the left eyc of a Troglichthys showing its position relative to the brain.

Fig. 12. An enlarged view of the same eyc as that represented in Figure 11 showing the large scleral cartilages and the different layers of the eye.

\section{PLATE XIII.}

Figures 13 to 20 were made from a series of embryos taken succcssively from one mother. Figure 22 (Plate XIV) begins another series. Later cmbryos and larvæ were taken from different mothers.

Fig. 13. Outline of the head of an embryo betwecn 1.3 and $1.5 \mathrm{~mm}$. long.

Fig. 14. Outline of the brain and optic thickening in a mounted embryo $1.6 \mathrm{~mm}$. long, with four protovertebræ (2.30 P.M., May 5).

Fig. 15. Outline of the brain and optic thickening in a living embryo $1.92 \mathrm{~mm}$. long, with ten protovertebræ (9 P.м., May 5).

Fig. 16. Outline of the brain and optic vesicle of a living embryo $2.4 \mathrm{~mm}$. long, with ten protovertebræ (12 P.s.; May 5).

Fig. 17. Outline of the brain and optic vesicle of a living embryo between the sizes of those shown in Figures 16 and 18 (5.30 A.M., May 6).

Fig. 18. Outline of the brain and optic vesicle of a living embryo $2.4 \mathrm{~mm}$. long, with twelve or thirteen protovertebræ (8 A.M., May 6).

Fig. 19. Horizontal section through the left cye of an embryo about $2.44 \mathrm{~mm}$. long, two sections ventrad of the one represented in Figure 20.

Fig. 20. Horizontal section through the head of the same individual showing the optic vesicle (11 A.M., May 6).

Fig. 21. Outline of the brain and optic vesicle of an embryo $1.68 \mathrm{~mm}$. long, with five protovertebræ from a living specimen.

\section{PLATE XIV.}

Figs. 22, 23. Horizontal sections through the optic stalk (Fig. 22) and the optic vesicle (Fig. 23) of an embryo of the second series. This embryo was $2 \mathrm{~mm}$. long and in about the same stagc of development as those 2.8 $\mathrm{mm}$. long of the first series.

Fig. 24. Horizontal section of the head of an embryo $2.5 \mathrm{~mm}$. long, the two sides at different levels.

Fig. 25. Left eye of the same embryo as that from which Figure 24 was taken, showing the first indication of the lens.

Fig. 26. Transverse section through the dorsal part of the optic stalk of an embryo $2.7 \mathrm{~mm}$. long.

Fig. 27. Optic vesicle and the beginning of the lens in another specimen $2.7 \mathrm{~mm}$. long.

Fig. 28. Transverse section of the optic vesicle and beginning of the cye of a Cymatogaster* larva, $1.5 \mathrm{~mm}$. long.

Fig. 29. Transverse section of the eye of a Cymatogaster larva $3.2 \mathrm{~mm}$. long.

Fig. 30. Transverse scction of the eyc of a Cymatogaster larva $4.5 \mathrm{~mm}$. long.

Fig. 31. Horizontal section of an Amblyopsis embryo $4.4 \mathrm{~mm}$. long.

Fig. 32. Scction of the right cye of a larva $4.4 \mathrm{~mm}$ long. The nuclei were all drawn without a change of focus.

Fig. 33. Vertical section of the eye of another larva $4.4 \mathrm{~mm}$. long.

\section{PLATE XV.}

Figs. 34,35 . Two vertical sections of an eyc of an individual about $5 \mathrm{~mm}$. long. Fig. 34 is taken through the lens, vitreous cavity, and choroid fissurc. Fig. 35 is the second section proximal to that from which Fig. 34 was drawn and passes through the innermost part of the vitrcous body. The layers of the retina have not yet begun to be differentiatcd.

* Cymatogastre is a teleost with large and wcll developed eyes. Figures 28, 29 and 30 (Cymatogastre) should be compared with Figures 27, 32, and 33 (Amblyopsis). J 


\section{THE EYES OF THE BLIND VERTEBRATES OF NORTH AMERICA.}

Fig. 36. Anterior face of a transverse section of the left eye of a larva $5 \mathrm{~mm}$. long. The sections run obliquely in such a way that the right eye is cut first, the series beginning in front. The divergence from the spherical outline is due to the pressure of the brain on the proximal face and the epidermis on the distal face.

Fig. 37. Anterior face of a transverse section of the left eye of a larva $6 \mathrm{~mm}$. long. There is no lens in connection with this retina.

Fig. 38. Parasagittal section of an eye of a larva $6 \mathrm{~mm}$. long, showing ventrally the choroid fissure represented by the space between the pigmented layers and the vitreous cavity represented by the shallow depression on the ventral face. The retina is differentiated into ganglionic, inner reticular, and nuclear layers.

Fig. 39. Anterior face of a transverse section through the right eye of a larva $7.5 \mathrm{~mm}$. long.

Fig. 40. Horizontal section through the middle of the eye of a larva $7 \mathrm{~mm}$. long, showing the choroid groove.

Fig. 41. A horizontal section 10 micra dorsad to that given in Fig. 40, and showing the iris and vitreous cavity.

Fig. 42. Outline of the lens of the same eye as that shown in Figs. 40 and 41, but at a level 30 micra dorsad of Fig. 41.

Fig. 43. Region between the eye and the epidermis of a larva $7.5 \mathrm{~mm}$. long, showing the degenerating lens.

Fig. 44. Lens of a larva about $7 \mathrm{~mm}$. long.

Fig. 45. Vertical section near the centre of the right eye of a fish $9.5 \mathrm{~mm}$. long.

Fig. 46. Anterior face of a transverse section through the eye of a fish $9.5 \mathrm{~mm}$. long.

Fig. 47. Horizontal section through the left eye of a fish $9.5 \mathrm{~mm}$. long.

Fig. 48. Scleral cartilage of the right eye of the same fish as that from which Fig. 47 was taken.

Fig. 49. Scleral cartilage of the left eye of another fish of the same size.

Fig. 50. Exit of the optic nerve from the eye of Chologaster papilliferus showing the ganglionoid cells (z.) at the entrance of the optic nerve. 
$\mathrm{X}$.

FRESH-IVATER NEREIDS FROM THE PACIFIC COAST AND HAWAII, WITH REMARKS ON FRESH-WATER POLYCHÆTA IN GENERAL.

(PLATES XVI-XVII.)

Herbert Parlin Johnson. 



\section{INTRODUCTION.}

At different times during the past seven years specimens of three undescribed species of fresh-water Polychæta, all belonging to the Nereidæ, have come into my hands. Since unusual interest attaches to any form of animal life existing in an environment so different from that of the majority of its congeners, I have thought it worth while to give a brief account of these nereids.

For the material I am primarily indebted to Dr. Gustav Eisen, of San Francisco. From him I received in 1895 a specimen of a small Nereis which he had collected at Lake Merced, near San Francisco. This led me to explore the lake, with the result that this species, unlike any Nereis yet discovered in the neighboring sea, was found in abundance. Subsequently Dr. Eisen placed at my disposal a minute nereid which he had collected in 1892 in a mountain stream of the Sierra Laguna, Lower California, at 7000 feet above sea-level. This species is of peculiar interest, not only on account of its extraordinarily elevated habitat, but because it is the type of a new genus almost perfectly intermediate between the very distinct and isolated genera Lycastis and Ceratocephale. The first specimen of the third form, a new species of Lycastis from the Hawaiian Islands, was also the gift of Dr. Eisen. Additional specimens of this species have at my request been collected and sent me by Professor L. H. Miller of Oahu College, Honolulu. It is a pleasure to express my grateful acknowledgments to Dr. Eisen and Professor Miller for their great kindness in supplying me with this material.

There is no reason to doubt that all three species live in perfectly fresh (drinkable) water. Lake Merced is a part of the water system by which San Francisco is supplied; Lycastis hawaiiensis is reported by Professor Miller as living in a spring; while the elevated habitat of the species from the Sierra Laguna is sufficient guarantee that the water is not brackish. Unfortunately, further data concerning its interesting habitat are lacking.

Iake Merced, the only known habitat of Nereis limnicola, is a body of water of irregular shape about two miles in length occupying a submerged river valley among the sand-dunes of the San Francisco peninsula. It is within a quarter of a mile of the ocean, from which, according to Lawson, it has in very recent geological time been shut off by the shifting sands. Lawson ('95, p. 474) says in regard to it: 
"This lake is a remarkable feature of the topography. It lies in a depression which is a structural valley and which is separated from the ocean by a very narrow ridge. Though thus lying in a structural valley, the form of the shore contours of the lake, the stream cliffs by which it is bounded, and its relation to the drainage of the valley all demonstrate that the immediate basin of the lake is a drowned valley of stream erosion.

"The bottom of Lake Merced is ten feet below sea-level, and this fact demonstrates a recent submergence. The drowned valley undoubtedly once had free access to the ocean at tide level, but sand-dunes choked the channel and dammed back the waters till they stood ten feet above tide. Since then the lake has been artificially raised another ten feet."

I am indebted to Professor Lawson for calling my attention to his published account of Lake Merced, from which the foregoing is taken; also for the statement, in private communication, that "the date of the invasion of the salt water was in late Quaternary time." This was probably the time when the marine life became established in the lake.

At present there is no access of the sea, and the water, for economic reasons, is kept fresh at all times. The marine forms found in the lake may therefore be regarded as its permanent and thoroughly established inhabitants. The vegetation and most of the animal life is such as occurs generally in the fresh waters of the Northern Hemisphere; but along with the fresh-water creatures and apparently as much at home as they, we find besides the Nereis two species of marine isopods and one schizopod, Neomysis mercedis Holmes. The isopods, Sphæroma oregonensis and Corophium spinicorne, as I have been informed by Dr. Holmes, not infrequently enter streams and go up into fresh water, sometimes miles inland.

\section{NEREIS LIMNICOLA sp. nov.}

The living worm is a rich brownish-red in color, the red being due to the highly developed vascular system and the brown to epidermal pigment which is especially abundant on the antero-dorsal surface and its appendages. It is unpigmented beneath. The size is moderate for a nereid. A large specimen measures 47 millimetres in length, 5 millimetres in transverse diameter, including parapodia, and 3 millimetres not including the parapodia. In small and medium specimens the form is club-shaped, being thickest anteriorly, between the fifth and tenth somites, thence 
rapidly diminishing towards the small prostomium, and very gradually towards the pygidium. The club shape is much less apparent in large specimens. The somites are 75 in a large example. The trunk is considerably depressed (Pl. XVII, Fig. 29). The posterior region is so fragile that few complete specimens are obtained.

Except perhaps for its small size, the prostomium (Pl. XVI, Fig. 1) presents no unusual feature. It is two-thirds as broad as long; the palpi extend considerably in front of the tips of the antennæ, which are decidedly short, not exceeding onethird the length of the prostomium. The peristomial cirri (Fig. 1) are likewise very short for this genus, the longest pair (posterior dorsal) extending over no more than three and one-half somites, and are less than the transverse diameter, even in young examples. The eyes are black, large, and conspicuous, the posterior pair are slightly nearer the median line than the anterior. No lens has been detected even in sections. The peristomium deviates from the typical form for the genus in being little if any longer than the somites inmediately following.

The proboscis is armed with paragnaths of the usual type (Figs. 2, 3) which exhibit the typical form and arrangement for the genus Nereis.

The parapodia (Figs. 4, 5,6) are rather long for the diameter of the body. Posteriorly this is especially striking on account of the tapering of the trunk. In none of the specimens that I have seen is there any indication of the "epitokous" or "heteronereis" condition. The worm attains sexual maturity in the ordinary or "atokous" state. The parapodia, therefore, as the figure of the fifth (Fig. 4), of the thirty-first (Fig. 5), and of the sixtieth (Fig. 6), clearly show, form a uniform series, becoming simpler posteriorly.

In the most anterior region the dorsal ligules are large and triangular; the ventral ligules are of the same form, but smaller. The dorsal cirrus springs from the dorsal ligule, about one-third the distance out from its base; the ventral cirrus, almost exactly the same size and shape as the dorsal, arises at the extreme base of the ventral ligule. The dorsal lips are very unequal in size, the smaller bearing a fascicle of $\mathbf{1 2}$ to 13 setæ; the other approximates the shape of the ligules. The ventral lips bear two fascicles of setæ-supra- and infra-acicular-of which the lower contains about twice as many setæ as the upper, and all but two of the falcate ones.

The acicula are black throughout their length, are nearly parallel, tapering towards the distal tips, which curve away from each other.

As we pass towards the posterior extremity both ligules, but more particularly the ventral, become smaller (Pl. XVI, Fig. 5); finally, in the most posterior parapodia the ventral ligule becomes very muclı reduced, or may even disappear (Fig. 6). A corresponding reduction of the lips does not occur except in some of the most 
posterior parapodia (Fig. 6). The dorsal cirrus remains large and moves out further on the ligule. The number of setæ in both rami diminishes greatly.

The first and second parapodia have a well-developed dorsal ligule, but no dorsal lip, setæ, or aciculum.

The setæ are in nowise remarkable (Pl. XVI, Figs. 7-10). The only form worthy of special notice is the stout, falcate type in the ventral fascicles of the most posterior parapodia, in which the appendage is firmly anchylosed to the shaft, the whole forming one continuous piece (Fig. 10).

I have not found Nereis limnicola generally distributed in Lake Merced. All my specimens have been taken at the outlet of a "slough" on the eastern side of the southern arm of the lake. At this point the shore is composed of a softer and finer sand than usual, and in this sand the Nereis burrows to the depth of about eight inches. It also lives in the moist sand of the shore under driftwood, much as earthworms frequent similar places. No tube is formed. If given a little sand in which to burrow it stands confinement for weeks and even months.

\section{III." LYCASTIS HAWAIIENSIS sp. nov.}

The material at hand for the study of this interesting species consists of two female adults, both of which lack the most posterior somites, and one young specimen. One of the adults and the young one were collected by Professor Miller in a spring near Honolulu. The exact locality in the Hawaiian Islands where the other adult was collected is not known.

The form of the adult is long and slender, the larger specimen measuring 105 millimetres in length and 3.5 millimetres in greatest transverse diameter, including parapodia. Its somites number over 190; a few of the most posterior are absent. The young specimen has a length of 22 millimetres, a transverse diameter of 2 millimetres, and only 99 somites. Both adults carry nearly ripe eggs. The trunk of one is so turgid as to be cylindrical; the other is considerably depressed, and the young specimen still more so.

The prostomium ( $\mathrm{Pl}$, XVII, Figs. 17, 19,) is longitudinally divided by a sharp median furrow, and is very broad in proportion to its length $(2: 1)$. The antennæ are very short, thick, and horn-shaped; the palpi are extremely stout, with spherical terminal articles. The eyes are placed far back on the prostomium, well over towards its sides. The anterior pair are the larger, and a little further apart than the posterior pair. The eyes of both pairs are destitute of lenses.

The peristomium is as short as, or even shorter than, the somites that immediately 
follow. The peristomial cirri are short, thick, and rapidly tapering to fine points. They extend but little beyond the tips of the palpi when forwardly directed. The basal joints are extremely thick and of considerable length. The tips of the dorsal posterior pair are yellow. This is the only pigmentation in any part of the animal.

The proboscis (Pl. XVII, Fig. 19) is divided, into the usual maxillary and basal portions by a circular groove, but is entirely devoid of paragnaths, or even papillæ representing them. The jaws are of the usual form and possess seven teeth.

The posterior extremity of the young specimen (99 somites) has a pygidium a little shorter than the combined length of the two preceding somites, and no broader than these. The anus is nearly terminal. The anal cirri are almost exactly the same in shape as the dorsal cirri, and but little longer (Pl. XVII, Fig. 18).

The parapodia (Pl. XVII, Fig. 20), as in all species of Lycastis, are destitute of ligules. The entire dorsal ramus is absent, the only indication of it being a dorsal aciculum. The foot, therefore, is an example of extreme reduction in this genus. It is approximately conical, with a retractile tip (Pl. XVII, Figs. 20, 21). This I believe to be a characteristic feature of the foot of Lycastis and Lycastoides. Although figured by Gravier ('01, Figs. 2, 5, 7) for L. ouanaryensis, and apparently for L. brevicornis by Audouin et Milne-Edwards ('32-'33) it has not been mentioned by these authors nor by any others who have dealt with Lycastis. The dorsal cirrus, conical in form and of moderate dimensions in the most anterior parapodia, attains the length of the foot and setre in the middle of the trunk and becomes thinner and more lanceolate. In the posterior third (young specimen) it reaches beyond the tips of the setæ and exceeds the breadth of the trunk. The setæ, 7 to 10 in number, are inserted both above and below the ventral aciculum. Two or three are arastate* (Pl. XVI, Fig. 11), are moderately heterogomph, slender, have long, slender, gradually tapering, and finely serrate aristæ, and are inserted above the aciculum. Stouter setæ with moderately long appendages (Pl. XVI, Fig. 12) are inserted between the foregoing and the typical falcate setæ (Pl. XVI, Fig. 13). The two latter kinds are extremely heterogomph, their appendages have a few coarse serrations and a wide notch near the base, while their tips are smooth. The setæ exhibit a variety of color; some are colorless and translucent, others nearly opaque and yellowish-brown of different shades. The acicula are blunt at their distal ends, perfectly straight, and diverge at a very narrow angle. They are black throughout nearly their entire length.

The presence of large ova in both adult specimens suggests that they breed where found. This, however, is not necessarily the case, if the stations are easily accessible from the sea.

*I adopt the term arista to designate the elongated ("grätenförmig") appendage of certain setæ. 
Professor Miller's note as regards the color states that they are "flesh-color, changing to green in formalin." The living coloration is evidently due to the blood, the peripheral vascular system being very richly branched. Without the blood the worm would be colorless or white.

L. hawaiiensis is evidently most nearly allied to those species of the genus with extremely reduced dorsal rami, short tentacular cirri, and much enlarged foliaceous dorsal cirri. Perhaps it comes nearest to L. ouanaryensis of French Guiana (Gravier, :01) and to L. senegalensis (Saint-Joseph, :01). It differs sufficiently from both of these to require the establishment of a new species.

An interesting feature in Lycastis hawaiiensis is the penetration of the peripheral blood-vessels into the epidermis until they actually come into contact with the cuticula (Pl. XVII, Fig. 22, vessels solid black; Fig. 23). In this species the vascular loops in the dorsal cirri are exceedingly numerous and near together, as may be seen in a young specimen cleared with glycerine, and as appears in a section taken parallel with the flat surface of the cirrus (Fig. 23). These cirri, therefore, like the broad dorsal ligules of Nereis virens, function as gills; and it is to secure better aeration for the blood that the vessels have penetrated the thick epidermis.

\section{LYCASTOIDES ALTICOLA gen. nov., sp. nov.}

The species from the Sierra Laguna, Lower California, presents such an exactly intermediate condition between Ceratocephale (Malmgren, '67) and Lycastis that it is impossible to say to which it is the more nearly allied. It is therefore necessary to establish a separate genus for it. Roughly speaking, this genus may be said to have the prostomium of Ceratocephale and the foot of Lycastis. The single specimen available for study exhibits one character so aberrant, not alone for a nereid but for any polychæte (although we see it slightly developed in the Polynoida and in Chrysopetalum) that I am tempted to regard it as an abnormality. I refer to the greatly elongated common basal joint of the posterior pair of peristomial cirri ( $\mathrm{Pl}$. XVII, Fig. 24, right side). On the left the shorter ventral cirrus of this pair is wanting.

The prostomium (Pl. XVII, Fig. 24) is bilobed by a deep median sulcus. Anteriorly these lobes pass insensibly into the antennæ, just as in Ceratocephale. There are no eyes. The palpi are short and globose, their terminal articles almost completely retracted. The peristomium is large as compared with the prostomium, and the latter is partially hooded by it - a feature more fully developed in Nereis cyclurus of Puget Sound (Harrington, '98; Johnson, :01). The peristomial cirri are 
articulated, the dorsal posterior ones having five joints and the longer pair of anterior ones the same number.

The plarynx is retracted. In the specimen mounted in balsam no paragnaths can be seen, but the jaws are visible, and are seen to have very few teeth-not over three or four.

The parapodia (Pl. XVII, Fig. 25) are similar to those of Lycastis hawaiiensis, but have a dorsal cirrus that, compared with the same organ of L. hawaiiensis, is proportionately longer on the anterior somites, shorter on the posterior ones, slenderer, and terete throughout the series. There are fewer but stouter setre, 5 to 7 in number. They are unusually large (Pl. XVI, Figs. 14-16) for so small a species, but otherwise present no unusual character.

The specimen is small, measuring only 15 millimetres in length and 1 millimetre in breadth. 'The number of somites is 55 .

In this species, as well as in L. hawaiiensis, the tip of the foot can be retracted. In these preserved specimens most of the tips are protruded, and practically all are in L. hawaiiensis. The setxe seem to be always inserted into this retractile portion, and the cone of retractor muscle-fibres is clearly seen both in optical and in actual sections (Pl. XVII, Figs. 21, 26).

Lycastoides gen. nov.-Prostomium small, bilobed anteriorly, the lobes produced to form antennæ; proboseis without paragnaths; no eyes; parapodia without ventral ligules or dorsal rami, tip retractile.

A study of sections reveals in all three species a remarkable thinness of the bodywall, and evident weakness of the musculature. The vascular system, on the other hand, has acquired a very high development. While not a few of the smaller and strictly marine nereids have body walls so thin and translucent that the bloodvessels shine through with wonderful distinctness, the muscular development in proportion to the size of the worm is rarely so slight as in these fresh-water forms. For comparison I have chosen Nereis agassizi Ehlers, a North Pacific species that bears a fair degree of resemblance to $\mathrm{N}$. limnicola both as to size and general aspect. The striking difference in the longitudinal musculature of the two forms is best appreciated by comparing transverse sections (Pl. XVII, Figs. 28, 29). In N. limnicola the circular inusculature is so thin that it is practically a mere line except in certain places where it thickens somewhat; but on the other hand it is not much thicker in $\mathrm{N}$. agassizi, while there is great disparity in the development of the longitudinal muscles.

As regards the longitudinal musculature, much the same condition obtains in Lycastis hawaiiensis and in Lycastoides alticola as in Nereis limnicola. In the species 
from Hawaii and from Lower California there is considerable thickening of the epidermis in places, particularly on the sides in Lycastis hawaiiensis (Pl. XVII, Fig. 22). Making due allowance for the smaller size of the species it is about as thick in the same regions in Lycastoides alticola.

\section{CONCERNING LYCASTIS.}

The recently published memoir by Gravier $\left(: 01^{\mathrm{a}}\right)$ on this genus might be thought sufficient for the present, particularly as I have so little that is new to add; but unfortunately Gravier's paper is not accessible to all who may be interested in this remarkable section of the Nereidæ. Hence this brief account is offered.

The genus Lycastis was founded by Savigny ('20) for the reception of Nereis armillaris O. F. Müller,-which, however, proved to belong to the genus Syllis. The name was afterwards adopted by Audouin et Mihe-Edwards ('32-'34, p. 199) for a new nereid, Lycastis brevicornis, which they had discovered on the west coast of France. The type-specimen remains unique; no one, apparently, has rediscovered the species. Seven species have since been added, all but one of them tropical. The known species are:

L. brevicornis Aud. et M.-Edw. ('32-'34), IV. coast of France.

L. quadraticeps Gay ('49), Chile.

L. abiuma Grube ('72), Desterro, Brazil.

L. littoralis " " " "

L. senegalensis St. Joseph (:01), Senegal R., W. Africa.

L. ouanaryensis Gravier (:01), French Guiana.

L. geayi

" " "

L. hawaiiensis sp. nov., Hawaii.

It is seen that the "metropolis" of the genus is the east coast of South America, within the tropics, where half the known species belong. Two other tropical species have been described, and only two extra-tropical ones. The genus, therefore, is principally one of the tropics.

The foot of Lycastis is remarkable among the Nereidæ for invariably lacking, almost if not quite, the whole of the dorsal ramus. In all species the dorsal cirrus remains. It is often much enlarged, becomes highly vascular, and is flattened to form a leaf-like structure which functions as a gill. L. quadraticeps and L. littoralis are exceptional, for in both the dorsal cirrus is small. It should, however, not be 
designated as "rudimentary" in L. quadraticeps, as Gay ('49, p. 25) has done. Specimens of this species from Punta Arenas, kindly sent me by Dr. Michaelsen, possess a dorsal cirrus, small indeed but not "rudimentary." The entire foot is very small in this species. In no known species is there the least trace of a dorsal or ventral ligule. The dorsal ramus in all is extremely rudimentary; in some (L. geayi, L. senegalensis, and L. littoralis) it is a mere setigerous knob on the upper side of the ventral ramus; in others (L. ounaryensis, L. abiuma, L. quadraticeps, and L. brevicornis) it is represented only by one or more setæ and the aciculum; finally, in L. hawaiiensis nothing remains but the aciculum. The retractile tip of the foot, apparently a constant character of this genus, has already been described. (See p. 211.)

Horny jaws are present in all species of Lycastis, the number of teeth varying from 4 in L. senegalensis to 20 in L. geayi. In no species are there any paragnaths, or even soft papillæ, on the proboscis. - This absence of paragnaths, however, is not peculiar to Lycastis, but is shared by Lycastoides, Ceratocephale, and Dendronereis.

It remains to be discovered whether the extensive system of intraepidermal blood-vessels present in $\mathrm{L}$. hawaiiensis is characteristic of the entire genus.

The most remarkable physiological character of the genus is the facility with which the different species establish themselves in fresh and brackish water. No fewer than five of the eight known species have fresh-water or brackish-water habitats. Not one, however, lives remote from the sea, and, with the possible exception of L. Lawaiiensis, not one is known to be landlocked. In two instances, at least, the forms have a wide range, extending from a purely marine environment, through brackish water, to fresh water. L. quadraticeps (Ehlers, '97, :01) and L. ouanaryensis (Gravier, :01) are the best instances of this extreme euryhalinism.

Apparently the sexes are usually distinct in Lycastis. At least no instance of hermaphroditism has been reported. I find, however, that the specimens of $\mathrm{L}$. quadraticeps received from Dr. Michaelsen are all hermaphrodites, containing in the same segment both ova and spermatozoa. The species is minute,-certainly one of the smallest of the Nereidæ, as my largest specimens do not exceed 25 millimetres in length and are scarcely 1 millimetre in transverse diameter. The ova are very few and immensely large for the size of the animal. There is usually but one ovum in each somite, seldom two, and very rarely three. By no means every somite contains ova. There is always a considerable but variable number of anterior somites that have none, and a smaller but also variable number of posterior somites that are also without them. The spermatozoa always extend a few somites further cephalad and caudad than the ova. 


\section{GENERAL CONSIDERATIONS.}

Within the past two years several short papers on fresh-water Polychæta have appeared, interest in the subject having been aroused by the publication of Nusbaum's account(:01) of two new sabellids from Lake Baikal'(Dybowscella baicalensis, D. godlewskii). By the addition of these, of Saint-Joseph's (:01) Lycastis senegalensis, of Gravier's (:01) three French-Guiana species, and of the three herein described, the list of fresh- and brackish-water Polychæta has rapidly lengthened. The euryhaline $*$ species at present recorded are the following:

\begin{tabular}{|c|c|c|c|}
\hline Name. & Habitat. & Medium. & Authority. \\
\hline $\begin{array}{c}\text { Eunicidz. } \\
\text { Lumbriconereis sp...... }\end{array}$ & Island of Trinidad & Fresh water & von Kennel, '83. \\
\hline $\begin{array}{c}\text { Nereidæ. } \\
\text { Nereis sp. . . . . . }\end{array}$ & Lake Palæostrom, Mingrelia & Fresh water & Leuckart (teste Gravier, \\
\hline Nereis sp........... & Island of Trinidad & " व & $\begin{array}{c}\text { :01). } \\
\text { von Iiennel, '83. }\end{array}$ \\
\hline N. culveri Webster... & Coast of New Jersey & $\left\{\begin{array}{l}\text { Se aw a t er ; brackish(?) } \\
\text { water : fresh water (exper.) }\end{array}\right.$ & Webster, '79. \\
\hline 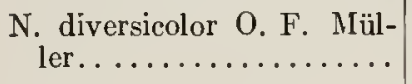 & $\begin{array}{c}\text { European coasts (Der } \\
\text { Frische Haff, Irönigsberg) }\end{array}$ & $\begin{array}{l}\text { Marine; brackish water; sa- } \\
\text { lines; fresh water (exper.) }\end{array}$ & $\begin{array}{l}\text { Mendthal, '90; Nusbaum, } \\
\text { :01' ; Gravier, :01b. }\end{array}$ \\
\hline N. linnicola sp. nov. ....... & Lake Merced, Cal. & $\left\{\begin{array}{c}\text { Fresh water; sea-water } \\
\text { (exper. })\end{array}\right\}$ & Johnson. \\
\hline N. virens M. Sars. ..... & $\begin{array}{l}\text { Northern coasts, Europe and } \\
\text { N. A. (Charles R., Mass.) }\end{array}$ & $\left.\begin{array}{l}\text { Marine; brackish; fresh } \\
\text { water (exper.) }\end{array}\right\}$ & Hamaker, '98; Johnson. \\
\hline $\begin{array}{c}\text { Perinereis } \quad \text { longipes St. } \\
\text { Joseph............... }\end{array}$ & $\begin{array}{l}\text { Coast of France (R. la Vie, } \\
\text { Vendée) }\end{array}$ & Marine; brackish & Gravier, : $01^{\mathbf{b}}$. \\
\hline P. cultrifera Grube.... & $\begin{array}{l}\text { Mediterranean; European } \\
\text { coasts }\end{array}$ & 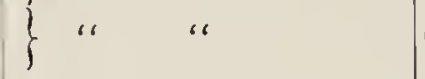 & Gravier, : $01^{b}$. \\
\hline $\left.\begin{array}{r}\text { Platynereis dumerilii Aud. } \\
\text { et M.-Edw. . ........... }\end{array}\right\}$ & Coasts of Europe & Marine; brackish water & Gravier, : $01^{\mathrm{b}}$. \\
\hline Lycastis quadraticeps Gay & $\begin{array}{l}\text { Chiloe (Chile); Str. of Ma- } \\
\text { gellan }\end{array}$ & $\left.\begin{array}{r}\text { Marine; brackish; fresh } \\
\text { water }\end{array}\right\}$ & Ehlers, '97, : 01. \\
\hline L. senegalensis St. Joseph. . & Senegal R., W. Africa & Brackish water. & Saint Joseph, :01. \\
\hline L. ouanaryensis Gravier. . & $\begin{array}{l}\text { French Guiana coast and } \\
\text { Ouanary } R \text {. }\end{array}$ & $\left.\begin{array}{l}\text { Marine; brackish; fresh } \\
\text { water }\end{array}\right\}$ & Gravier, : 01 \\
\hline $\begin{array}{l}\text { L. geayi Gravier. . . . . . . } \\
\text { L. hawaiiensis sp. nov..... }\end{array}$ & $\begin{array}{l}\text { Ouanary R. } \\
\text { Hawaiian Islands (Honolulu) }\end{array}$ & $\begin{array}{l}\text { Fresh water } \\
\text { Fresh water }\end{array}$ & $\begin{array}{l}\text { Gravier, : } 01 \\
\text { Johnson. }\end{array}$ \\
\hline $\begin{array}{l}\text { Lycastoides alticola gen. } \\
\text { nov., sp. nov.......... }\end{array}$ & $\begin{array}{l}\text { Sierra Laguna, Lower Cali- } \\
\text { fornia }(7000 \mathrm{ft}) \text {. }\end{array}$ & Fresh water & Johnson. \\
\hline $\begin{array}{l}\text { Spionidæ. } \\
\text { Polydora ciliata Johnston. } \\
\text { Capitellidæ. }\end{array}$ & Cosmopolitan & $\left\{\begin{array}{c}\text { Marine; brackish water; } \\
\text { salines. }\end{array}\right\}$ & Gravier, :01. \\
\hline $\begin{array}{c}\text { Eisigella ouanaryensis } \\
\text { Gravier. . . .......... } \\
\text { Sabellidæ. }\end{array}$ & Ouanary R., French Guiana & Fresh water & Gravier, :01. \\
\hline 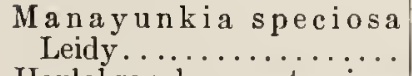 & $\begin{array}{l}\text { Schuylkill R., Pa.; Absecom } \\
\text { Pd., N. J. }\end{array}$ & $\begin{array}{l}\text { Fresh water; sea-water (ex- } \\
\text { per.) }\end{array}$ & $\begin{array}{l}\text { Leidy, '59, '84; } \\
\quad \text { (unpub.). }\end{array}$ \\
\hline 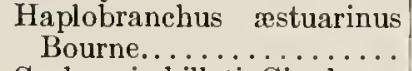 & $\begin{array}{c}\text { Estuaries of Thames and } \\
\text { Liffey }\end{array}$ & \} Brackish water & Bourne, '83. \\
\hline Caobangia billeti Giard. ... & Tonquin & Fresh water & Giard, '93. \\
\hline 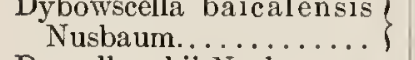 & Lake Baikal & Fresh water & Nusbaum, : 01 \\
\hline $\begin{array}{l}\text { D. godlewskii Nusbaum.... } \\
\text { Fabricia stellaris Blain- }\end{array}$ & " " " " & " 6 & Nusbaum, :01. \\
\hline $\begin{array}{c}\text { Fabricia stellaris Blain- } \\
\text { ville................. }\end{array}$ & $\left.\begin{array}{l}\text { Coasts of Europe and } \\
\text { North America }\end{array}\right\}$ & Marine; fresh water (exper.) & Moore (unpub.). \\
\hline
\end{tabular}

* This convenient term has been introduced by Moebius to designate forms capable of enduring considerable change in the salinity of the water. Its opposite is "stenohaline." 
It is seen from the foregoing list that the euryhaline Polychxta are not numerous, considering that many hundreds of species belong to this order. Furthermore, we discover the interesting fact that notwithstanding the euryhaline forms have been found in nearly all parts of the world and in both tropical and temperate latitudes, they belong to only five out of the forty-odd families of the Polychæta; and of the five, three have each but a single species in fresh or brackish water. Two families, the Nereidæ and the Sabellidæ, furnish 87.5 per cent of all known euryhaline polychætes; and the Nereidx alone afford 15 out of a total of 24 , or 62.5 per cent of the entire list! That this ratio is being more than maintained in these days of active faunistic and experimental investigation is demonstrated by the fact that of the 14 euryhaline species added to the list during the past decade, there are 9 species of Nereidæ and 4 of Sabellidæ,--nearly 93 per cent of the entire number added.

We may therefore safely regard these two families as having the strongest tendency towards euryhalinism of all the Polychæta. Yet neither of them has been held as in the remotest likelihood the progenitor of the Oligochæta or of any freshwater invertebrates. Whatever the duration of their residence in lakes and streams, the fresh-water members of these widely different families have not so far diverged from the parent stock as to create the slightest doubt regarding their affinities. With the possible exception of Caobangia, none of them requires the establishment of any group higher than the genus. According to our present knowledge, on the other hand, there are almost as many fresh-water genera as there are thoroughly established fresh-water species. In other words, to borrow a convenient term from the ornithologists, fresh-water polychætes are apt to belong to monotypic genera. Thus we have Caobangia, Eisigella, Lycastoides, Manayunkia, and Dybowscella, most of them represented by a single species and none of them with any known marine representatives. So far as known, every species belonging to these genera is strictly limited in its natural habitat to fresh water. It must be admitted, however, that our present knowledge is very incomplete, and certain experimental data indicate that we are likely to find these forms living somewhere in marine or brackish-water habitats.

A point of considerable interest is the close relationship between Manayunkia and Dybowscella. There is here no need of separate genera-a fact that Zykoff (:01) has already pointed out. There are three closely allied species: one, Manayunkia speciosa, long ago described by Leidy ('59, '84), Potts ('85), and Foulke ('85) as occurring in perfectly fresh water in the Schuylkill River, and in a pond near Absecom, New Jersey; and two, Dybowscella baicalensis and D. godlenskii, described by Nusbaum (:01), living in Lake Baikal. Zykoff is even of the opinion that M. speciosa and 
D. baicalensis are of the same species; but this is evidently not the case, as seen by comparing the uncini, as they are figured by Leidy and by Nusbaum.

All thoroughly established fresh-water forms must necessarily breed in their new habitat. Leidy ('84) found this to be the case with Manayunkia, in which, as usual with fresh-water invertebrates, the development is direct. The discovery of the young of Nereis limnicola in Lake Merced in May, 1899, these young having only 18 to 20 somites, but well beyond the metamorphosis-if there was one-proves that this species breeds in fresh water. Unfortunately, younger stages have not yet been obtained. That fresh-water breeding is not always possible for euryhaline polychætes is evident from the observations of Mendthal ('90) on Nereis diversicolor. This species occurs in the "Frisch Haff" near Königsberg, Prussia. The Frisch Haff, although having intermittent connection with the Baltic Sea, is almost perfectly fresh, and has a fresh-water fauna and flora. N. diversicolor, perhaps the most euryhaline of all European nereids, is the only polychrete found there, and according to Mendthal it does not breed in the Frisch Haff, where only adults are found. N. diversicolor cannot therefore be regarded as fully established, even as a brackish-water inhabitant, although as an adult it can apparently live indefinitely in water of very weak salinity.*

A significant fact in the physiology of certain thoroughly acclimated, and, so far as known, exclusively fresh-water-dwelling Polychæta, is that they can easily be made to live in ordinary sea-water. It is only necessary to make the transition a gradual one. I have subjected Nereis limnicola to the experiment of passing it through a series of aquaria of ever-increasing salinity until after a few days it was living in undiluted sea-water without apparent discomfort. The same experiment has been tried with equal or greater success on Manayunkia by Dr. J. Percy Moore, who has kindly permitted me to make use of his unpublished results. Manayunkia endured the change with ease and lived for four months in pure sea-water. It is obvious that the complete success or partial failure of such experiments may be dependent upon the food-supply.

The reverse experiment of passing marine or brackish-water forms into fresh water has often been tried with more or less success. Eisig ('87, p. 798), by making the dilution very gradual, was able in the course of four months to bring Capitella capitata into a medium consisting of four parts of sea-water and ten parts of fresh water, the reduction in specific gravity being from 1.034 to 1.0088 . The worms did not long endure so great a reduction of the salinity, so this form cannot be reckoned as among the strongly euryhaline species. Spio fuliginosus under the same condi-

* The Frisch Haff is stated by Mendthal to contain only .0035 per cent of chlorine. 
tions began to die off when a specific gravity of 1.014 was reached. Eisig gives a careful statement regarding the changes brought about in the worms by the gradual reduction in the salinity of the medium and attributes death to the hæmolytic action of the fresh water, which naturally is much more striking and immediately fatal when the worms are plunged directly into it. In view of the long held and generally accepted theory that the Oligochæta have sprung from capitellid-like ancestors, the imperfect euryhalinism of Capitella capitata and the recent discovery in the Ouanary River, French Guiana, of a fresh-water capitellid, Eisigella ouanaryensis Gravier (:01), would no doubt be regarded as important evidence in favor of this theory were it not for the numerous euryhaline Nereidæ and Sabellidæ.

As would naturally be anticipated, the Nereidæ afford many subjects favorable for experimentation in this direction. N. diversicolor, as already stated, lives in brackish water of very slight salinity, and it will endure transfer to fresh water without difficulty (Nusbaum, :01; on the authority of Giard). According to Webster's ('79) statement, Nereis culveri of the New Jersey coast is equally euryhaline, although this species is not known to live naturally in fresh water, or apparently even in brackish water of greatly reduced salinity. Yet, according to Webster,* the worms can be put directly into well-water without causing their death or checking the flow of the blood, which he states is the immediate result of subjecting $\mathrm{N}$. limbata to the same experiment. The dwarfish examples of $\mathrm{N}$. virens living in the muddy banks of the Charles River in the vicinity of Boylston Bridge, Cambridge, where the water is decidedly brackish (Hamaker, '98) can also be placed directly in fresh water without checking the circulation, changing the color of the blood, or apparently doing it the slightest injury. I have found it will live for at least a week in ordinary tap water - death resulting, apparently, from lack of food. The experiment of transferring littoral specimens of $\mathrm{N}$. virens to fresh water remains to be tried.

The important experiment of transferring a form not known to be naturally euryhaline, living nowhere in fresh or even in brackish water, but having a near ally that lives exclusively in fresh water, has been tried with Fabricia stellaris Blainville by Dr. Moore, and with perfect success. The change to fresh water is easier for Fabricia than the change to sea-water for Manayunkia. As originally pointed out by Leidy ('59) Fabricia of all marine Sabellids is most nearly allied to Manayunkia. Without doubt both Manayunkia and Dybowscella are offshoots of Fabricia stock. That both Fabricia and Manayunkia, although not exhibiting euryhalinism in their habitats, are in reality both very euryhaline and in nearly equal measure, is possibly as good evidence of their relationship as any afforded by

* Mr. J. E. Benedict, of the National Museum, kindly called my attention to Nereis culveri. 
similarity of structure; but such evidence can by no means be employed in systematic zoölogy until we know more about the essential nature of euryhalinism, regarding which at present we are profoundly ignorant. These experiments on Manayunkia and Fabricia indicate that euryhalinism is a quality of living animals of the most persistent and fundamental sort, and that it is not lost (as shown by the experiments with Nereis limnicola and with Manayunkia) by very prolonged residence in fresh water. Nor can we predicate that it does not exist in a marine form that is nowhere found living in fresh or brackislı water.

On a priori grounds we might infer that forms of small size and comparatively simple structure would most likely be able to endure the change in passing from sea water to fresh water. Forms that obtain their food by creating a vortex through ciliary action, and are able to feed omnivorously upon microscopic organisms, would also seem to have a distinet advantage. The various dwarfish and apparently degenerate fresh-water and brackish-water Sabellidæ are examples which seemingly justify this inference; but such rules break down completely when we attempt to apply them to the Nereidæ. Many of the euryhaline members of this family, it is true, are smaller than the average of their exclusively marine congeners; but not all of them are. Lycastis ouananyensis is stated by Gravier (:01) to be from 120 to 200 millimetres in length and 7 millimetres in breadth. L. hawaiiensis is also a worm of goodly dimensions. The fresh- or brackish-water habitats of such forms as Nereis limnicola and $N$. virens may quite as reasonably be regarded as the cause of their small size as in any mcasure the result of it. Such habitats no doubt often entail a diminished food-supply, and nearly always a much less severe struggle for existence. We note in nearly all fresh-water invertebrates puny size and lack of vigor, as compared with marine invertebrates of the same groups.

The possibility of a marine animal establishing itself in fresh water is determined by four essential factors, two of which are intrinsic, and two extrinsic:

1. The possession of euryhalinism, enabling it to endure the diminished specific gravity of its medium.

2. Presence of a suitable fresh-water habitat, accessible from the sea, with intermediate brackish-water stations.

3. Possibility of obtaining food in the new habitat.

4. The capability of breeding in the new environment.

The degree of saltness of the water to which euryhaline Polychæta can accommodate themselves, often exceeds that of the ocean. Such forms occur in salines. As Ferronnière (:01) has pointed out, there is a similarity between the faunas of salines and of brackish water. 


\section{BIBLIOGRAPHY.}

Audouin, J. V., et Milne-Edwards, H.

'32-'33. Classifieation des Annélides, ct Description de celles qui habitent les côtes de la France. Ann. Sci. Nat., tom. 27, pp. 337-447; tom. 28, pp. 187-247; tom. 29, pp. 195-269, 388-412; tom. 30, pp. 411-425.

Bourne, A. G.

'83. On Haplobranchus, a New Genus of Capitobranchiatc Annclids. Quart. Jour. Micr. Sci., vol. 23, no. 89, pp. 168-176, pl. 9.

Ehlers, E.

'97. Polychaeten. Hamburger Megalhaensischc Sammelreise. Hamburg, $8^{\circ}, 148$ pp.; 9 Taf.

Ehlers, E.

:01. Die Polyehaeten des megellanisehen und chilenisehen Strandes.? Festschr. k. Gesell. Wiss. Göttingen; Abh. math.-phys., Cl., pp. 1-232, Taf. 1-35.

Eisig, H.

'87. Monographie der Capitelliden des Golfes von Neapel. Fauna u. Flora Neapel, Monogr. 16, pp. xxvi $+906,27$ Taf.

Ferronniere, G.

:01. Études biologiques sur la faune supralittorale de la Loire-Inférieure. Nantes.

(Known to me only through Gravier's, :01b, refcrence.)

Foulke, S. G.

's5. Some Notes on Manayunkia speciosa. Proc. Acad. Nat. Sei., Philadelphia, 1884, pp. 48-49. '

Gay, C.

'49. Historia fisica y politica de Chile, zoologia. Paris, $8^{\circ}$, tom. $3,547 \mathrm{pp}$.

Giard, A.

'93. Sur un type nouveau et aberrant de la famille des Sabellides (Caobangia Billeti). C. R. Soc. Biol.; sér. 9 , tom. 5, pp. $473-476$.

Gravier, C.

:01. Sur trois nouveau Polyehètes d'eau douce de la Guyane Française. Bull. Soc. Hist. Nat. Autun, tom. 14, pp. 1-19.

Gravier, C.

:01a. Sur le genrc Lycastis. Bull. Soe. Hist. Nat. Autun, tom. 14, pp. 21-27.

Gravier, C.

:01 b. Sur les Annélides Polychètes d'eau douee. Bull. Soc. Hist. Nat. Autun, tom. 14, pp. 29-36.

Grube, E.

'72. Uebcr die Gattung Lycastis und ein par neue Arten dersclben. Jahrcsber. Schles. Gesell. f. vaterl. Cultur, 1871, pp. 47-4S.

Hamaker, J. I.

'9S. The Nervous System of Nereis vircns Sars. Bull. Mus. Comp. Zoöl., Harvard College, vol. 32, no. 6, pp. 89-124, pls. 1-5.

Harrington, N. R.

'98. On Nereids Commensal with Hcrmit Crabs. Trans. New York Acad. Sci.; vol. 16, pp. 214-222, pls. 16-18.

Johnson, H. P.

:01. The Polychaeta of the Puget Sound Region. Proc. Boston Soc. Nat. Hist.; vol. 29, pp. 381-437, 19 pls.

Kennel, J. $\nabla$.

'S3. Biologisehe und faunistische Notizen aus Trinidad. Arb. Zool. Inst. Würzburg, Bd. 6, pp. $259-286$.

Lawson, A. C.

'95. Sketch of the Geology of the San Francisco Peninsula. Fifteenth Ann. Rep. U. S. Geol. Surv.; 189394, pp. $399-476$. 
Leidy, J.

59. (Manayunkia speciosa.) Proc. Acad. Nat. Sci., Philadelphia, 1858, p. 90.

Leidy, J.

'84. On Manayunkia. Proc. Acad. Nat. Sci., Philadelphia, 1883, pp. 302-303.

Malmgren, A. J.

'67. Annulata polychaeta Spetsbergiae, Grönlandiae, Islandiae et Scandinaviae hactenus cognita. Ofversigt Kiongl. Vet. Akad. Förhandl., Stockholm, Arg. 26, pp. 127-325, 14 Taf.

Mendthal, M.

'90. Untersuchungen über die Mollusken und Anneliden des frischen Haffs. Schrift. phys.-oekon. Gesell. Koenigsberg, Jahrg. 30, pp. 27-42.

Nusbaum, $\mathrm{J}$.

:01. Dybowscella baicalensis nov. gen. nov. spec. Ein im Süsswasser lebendes Polychaet. Biol. Centralbl.; Bd. 21, No. 1, pp. 6-18.

Nusbaum, $J$.

:01 ${ }^{\mathrm{a}}$. Noch ein Wort über Dybowscella baicalensis mihi und einige andere Süsswasserpolychaeten. Biol. Centralbl., Bd. 21, No. 9, pp. 270-273.

Potts, E.

'85. Note on Manayunkia speciosa. Proc. Acad. Nat. Sci., Philadelphia, 1884, pp. 21-22.

Saint-Joseph, le Baron de.

:01. Sur quelques invertébrés marins des cotes du Sénégal. Ann. Sci. Nat., zool., sér. 8, tom. 12, pp. 217248, pls. 8-9.

Savigny, J. C.

'20. Système des Annelides, principalement de celles des Côtes de l'Égypte et de la Syrie. Description de l'Égypte, Hist. Nat., tom. 1, 128 pp.

Webster, H. E.

'79. Annelida Chætopoda of New Jersey. 32 Ann. Rep. New York State Mus. Nat. Hist., pp. 101-128, 7 pls.

Zykoff, w.

:01. Bemerkung über Dybowscella baicalensis Nusb. Biol. Centralbl., Bd. 21, No. 9, pp. 269-270.

\section{EXPLANATION OF PLATES XVI-XVII.}

All the figures, excepting Figure 1, are from camera-lucida drawings of preserved material. The setæ were mounted in glycerine.

\section{PLATE XVI.}

Figs. 1-10, Nereis linicola sp. nov.

Fig. 1. Anterior extremity of a young specimen, drawn from life. $\times 14$.

Fig. 2. Dorsal aspect of proboscis. $\times 12.5$.

Fig. 3. Ventral aspect of proboscis. $\times 12.5$.

Fig. 4. Posterior aspect of fifth foot. $\times 23$.

Fig. 5. Posterior aspect of thirty-first foot. $\times 23$.

Fig. 6. Postcrior aspect of sixtieth foot. $\times 23$.

Fig. 7. Profile of a seta from the dorsal fascicle. $\times 350$.

Fig. 8. Profile of a falcate seta, ventral fascicle. $\times 350$.

Fig. 9. Profile of a stout, falcate seta, ventral fascicle thirty-fourth foot. $\times 350$.

Fig. 10. Profile of a seta with anchylosed appendage, ventral fascicle of a foot near posterior extremity. $\quad \times 350$.

Figs. 11, 12, 13. Profiles of setæ of Lycastis hawaiiensis sp. nov. $\times 350$.

Figs. 14, 15, 16. Profiles of setæe of Lycastoides alticola sp. nov. $\times 350$. 

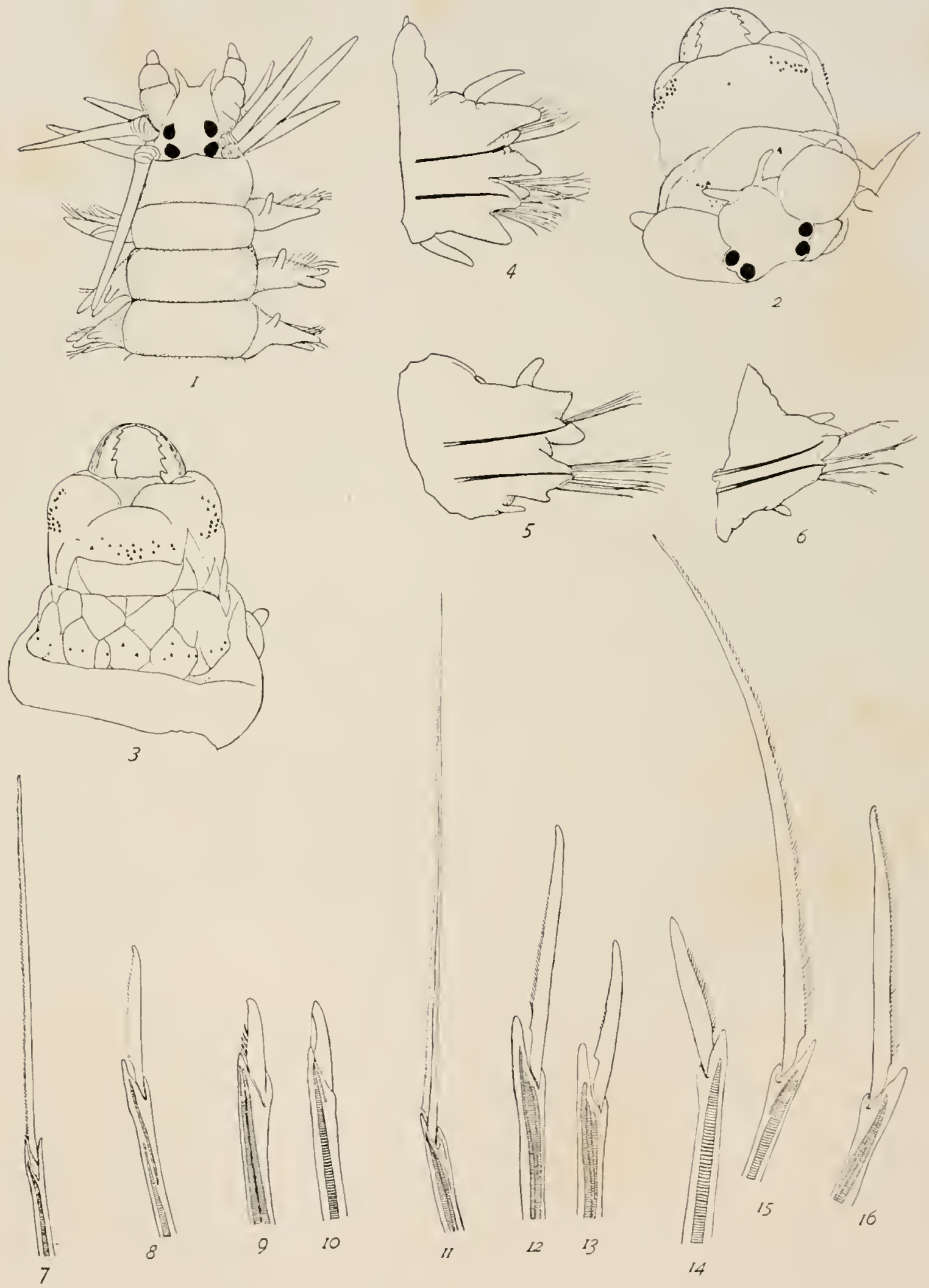

JOHNSON - NEREIDS I 


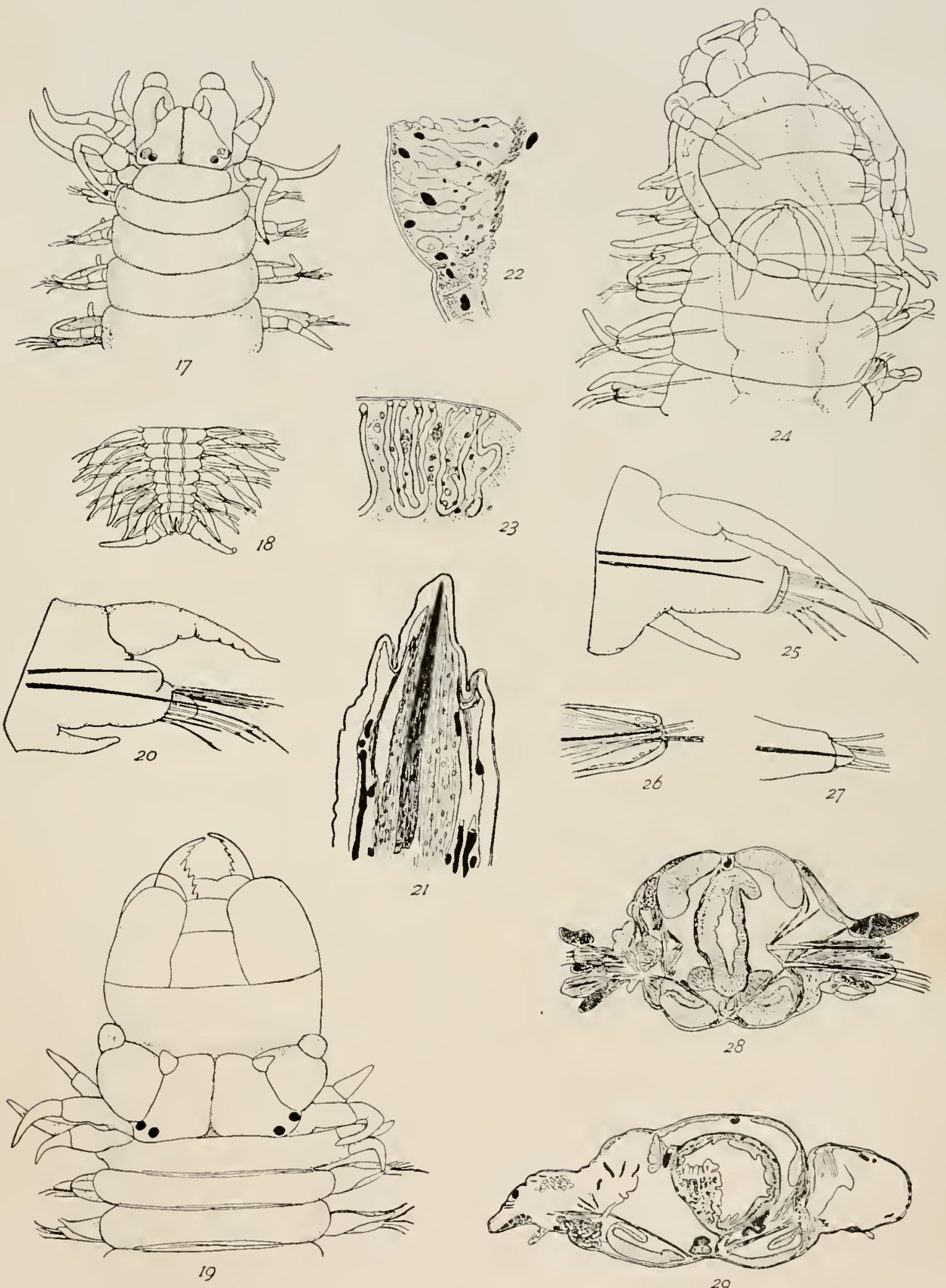

JOHNSON - NEREIDS II 


\section{PLATE XVII.}

Figs. 17-23, Lycastis hawainensis sp. nov.

Fig. 17. Anterior extremity of a medium-sized specimen. $\times 16.5$.

Fig. 18. Postcrior cxtremity, young specimen. $\times 23$.

Fig. 19. Antcrior extremity with cverted proboscis, largest specimen. $\times 17$.

Fig. 20. Posterior aspect of eightecnth foot. $\times 40$.

Fig. 21. Longitudinal section of distal extremity of foot, sliowing retractile tip extruded. $\times 150$.

Fig. 22. Section of epidermis and circular musculature, with blood-ressels in solid black, penctrating the cpidermis. $\times 275$.

Fig. 23. Horizontal section of a dorsal cirrus, showing vascular loops. Their cut cnds are almost in contact with the cuticula. $\times 275$.

Figs. 24-27, Lycastoides alticola gen. nov.; sp. nov.

Fig. 24. Anterior extremity. The specimen is mounted in balsam, hencc the jaws, pharynx, etc.; are visible. $\times 40$. Fig. 25. Postcrior aspect of a foot from the middlc region (tip partially retracted). $\times 75$.

Fig. 26. Optical section of distal extremity of foot with fully retracted tip, in cedar oil. Basal portions only of the setæe are shown. $\times 75$.

Fig. 27. Foot with fully protruded tip. $\times 75$.

Fig. 28. Transverse section of N. agassizi Ehlers, for comparison with Fig. 29. $\quad \times 23$.

Fig. 29. Transverse section of Nereis linnicola, showing the depresscd form and slight development of the musculaturc. The blood-vesscls are represented in solid black. Diagrammatic as to histological detail. $\times 23$. 
XI.

THE NATURAL HISTORY OF SOME TUBE-FORMING ANNELIDS. (AMPHITRITE ORNATA, DIOPATRA CUPREA.)

Henry R. Linville. 



\section{AMPHITRITE ORNATA VERRILL.}

It is not my purpose to present an exhaustive account of the habits of tubeforming annelids, but rather to put into concise form a description of some of their more or less well-known activities, with occasional suggestions as to the significance of certain details.

It appears that the most of what is known about the manner of living of annelids has been learned by those whose chief interest lay in economic relations, taxonomy, or embryology, rather than in the consideration of minute adaptations of structure to function. It seems to me the latter point of view is likely to be the most fruitful one in taking up the investigation of the liabits of animals.

Amphitrite forms a thick-walled, U-shaped tube of mud and sand, colored brown on the inside by mucus from glands. The exact location of the tube in the submerged mud-flat at low water may be known by characteristic miniature hills, not more than one inch high, with a slight depression at the center. Two or three tentacles of the animal may always be seen extending from the crater of the little hill, down its sides, and over the level to a distance of three to five inches. The tentacles are covered with fine particles of sand, and, ordinarily, would be almost indistinguishable, if it were not for their constant, slight movement.

As a rule, Amphitrite has its tube in a partially clear space in the eel-grass area, or along the margin of it. It is not always possible to demonstrate from the surface of the mud that both arms of the U-tube come to the free water, because the tide and the activities of other animals may result in the temporary disappearance of such evidence. However it is easy to follow the tube by digging and thus to show that it is always shaped like the letter U. In one stretch of beach examined, where these annelids were large and fairly numerous, the greatest number appeared to be distributed about a few large boulders, the lower portions of which were always under water. There were probably two factors influencing this local distribution. The first of these was the firmness of the mud about the boulders, for the coarse gravel caught in the swirl of the tides finds lodgment near the boulders, rendering more firm the sand and mud in that region. Amphitrite, being somewhat helpless, needs a firm enveloping mud. The second factor is connected with the first. While the tide flows more swiftly about the boulders, it brings to the animals there a greater 
supply of food than may pass a given point out in the open. Support may be found for the latter suggestion in the great abundance of many species of sessile worms and other forms to be found in the mud in narrow passages of shallow water, where, during certain phases of the tide, the water passes through in great quantities and at a considerable rate of speed.

Amphitrite does not always live in a tube of mud and sand. At the northeastern point of Nova Scotia I found, just beneath the rubble stone of an exposed beach, a few small specimens with a partially formed tube about them. These small specimens, when taken to the laboratory, appeared to be quite active, and, in some instances, very much more active than larger specimens obtained in the vicinity of Wood's Hole, Mass., where all were large, and provided with complete tubes.

In order to study the special activities of Amphitrite to the best advantage, and in as nearly their natural surroundings as possible, I collected fresh specimens from time to time in such a way as not to injure them, or to separate them from the tube. Taken to the laboratory with some of the native mud and sand, they were placed in aquaria with running water under conditions nearly normal.

As already stated, the specimens obtained at Wood's Hole were large. In collecting these specimens, it sometimes happened that a few were brought to the laboratory without any part of the tube on the body. Invariably the naked specimens failed to reconstruct even the beginning of a tube, but continued to carry out what seemed to be the same activities which, in partially enveloped specimens, resulted in the formation of a complete tube. The mud and sand collecterl during the normal tube-forming activities were heaped up under the body until the animal in its contortions moved from the place and collected a heap elsewhere. I have many times observed the same helplessness in specimens that I had dug up on the beach, and lost on account of the clouded condition of the water. On returning to the place later in the day, I have found the animal active, and still entirely uncovered. I have tried in the laboratory the effect of covering part of the body of the naked animal with mud, but never succeeded in getting them to perfect, or to continue the covering. The Nova Scotia specimens were much smaller than any I ever saw on the New England coast, but the percentage of adults found was, presumably, as great in one place as in the other. Hence, the first suggestion that would occur, that the great facility the Nova Scotia specimens displayed in forming a new tube in any condition, could be accounted for on the basis of an instinct recently acted upon as in youth, will not serve as an explanation. There is, however, something in the nature of the environment which may be suggestive of an explanation. The 
Nova Scotia specimens live among the rubble stone, where the violent action of the waves frequently changes the position of the sand particles that fill the interspaces. It is quite likely that the imperfectly and incompletely formed tubes of these small Amphitrite are frequently broken into by the action of the waves. The reflex of initiating the process of tube-forming may thus be brought into play frequently, whereas in the larger, less exposed specimens the function of beginning the formation of a tube may never be a necessity except once after the completion of the larval period. A small portion of the tube of a large Amphitrite may serve as a stimulus to the reflex of building more. With the removal of the entire tube, however, the stimulus of an encircling substance is no longer present, and the annelid is not able to originate an action which at one time was instinctive.

The details of tube construction can be followed without difficulty by placing a bare, or partially bare, specimen in a glass vessel with some mud and sand. I found the smaller race much more favorable for study, as they could be confined in a microscope stage aquarium at times when I desired to observe certain activities very minutely.

The general method of tube-forming is as follows. The tentacles in great number extend in sinuous movement in all directions horizontally over the sand, the tips appearing to feel their way through the water and along the bottom. Immediately granules of mud and sand cling to the tentacles, but the tentacles continue to extend until they seem to reach their full length. Then various ones begin to contract and to bring along slowly and with seldom interrupted progress the adhering masses of material. There is an entire lack of co-ordination in these movements; many are at full extension, while others are at full contraction, and still others either contracting or extending. Even single tentacles, for a brief period, manifest at the same instant contraction in the proximal portion and extension in the distal portion.

Examination with a hand lens shows that material is held here and there along the tentacle in a long, shallow depression. Strands of mucus can be seen stretching from the tentacle into and about the sand. Numerous small setæ extend from the tentacles, and undoubtedly these also help to hold material temporarily. In among the setx and extending to about half their length are minute, active cilia. These, with the setæ, are found from the base of every tentacle, even to the tip of it. The setæ move their points slightly under varying muscular tension, and the cilia lash constantly toward the proximal end of the tentacle.

The material brought from all sides is collected in a ring behind the bases of the tentacles and the gills. As fresh material is brought, the part already formed as the beginning of a tube is pushed backward by the action of narrow ridges of muscle 
on the ventral surface of the anterior somites, and by the setæ of the rudimentary lateral appendages. An expanded lip-like process, ventral to the mouth also, at least in the early stages of the formation of a tube, helps to place the material on the edge of the tube. By frequently turning about in the tube, Amplitrite adds on new portions with some appearance of order. At first a recently formed tube is rather brittle, being held together by a very small amount of mucus, but within a few hours the tube has become hardened by the mucus exuded by the body glands.

The tube-forming habit of Amphitrite seems to have a mixture of purpose. Under certain conditions, it is most certainly protective, for the process is continued vigorously until all, or nearly all, the body has been covered with mud. Then, sometimes, the anterior end disappears within the tube and the building continues slowly, and as the tube increases in length, often to one or two feet, the anterior end follows about two inches behind the advancing edge of the tube. Occasionally an animal, when its body is nearly covered with a reconstructed tube, will cease building the tube and begin to bore into the mud and sand with the lower lip and prostomium. As it bores further and further into the mud, the recently constructed tube is left behind and is not used again. In aquaria where the amount of building material is scant, the length of tube built is greater than in aquaria where building material is plentiful. The excessive length of tube constructed seems to be the result of a continuous search for a greater mass of material into which to bore for permanent concealment. While engaged in this search, the annelid frequently doubles on itself and extends its tentacles from the part of the tube near which its posterior end has been. The habit of doubling is made possible by the loose-fitting character of the tube, and is of much importance as a protective function. When Amphitrite is attacked, as by the collector, it quickly retreats many inches into the hole, carrying itself back on the points of its parapodal setæ. If time were permitted, it might continue to retreat entirely into the other arm of the $U$, where it could easily double and lie with the anterior end near the surface of the mud.

As I have stated in a preceding paragraph, the tentacles are covered with a continuous mat of cilia. It is not likely that the cilia themselves have anything to do with tube construction. Their function is to create currents by which the microscopic food of the animal is brought to it. It seems probable also that much of the animal's food may be brought to the mouth region in the material used for the construction of the tube. In nature, where the tube of each Amphitrite has been formed completely, the extending and withdrawing of the tentacles proceeds as continuously as it does in the aquarium. Masses of mud and sand are brought to the crater, and much of it washed away again, while some of the food carried 
in the midst is sent on down to the mouth by the converging currents from the cilia.

Amphitrite ornata has three pairs of gills, each gill having a main stem and numerous dichotomous branches. The gills are almost constantly extending and contracting, especially when the animal is lying in a tube. The evident purpose of the movement is to bring in oxygen-bearing water.

The nerve-action controlling the movement of the gills is not correlated; in fact it is only occasionally that all the gill-stems contract or extend in unison. Although the movement of the gills is not symchronous there is a regular periodic extension and contraction of the large posterior gills, at least when the animal is in its tube. The number of "respirations" per minute is fairly constant for each individual. For example, one specimen repeatedly extended and contracted its posterior gills twenty times a minute. Some specimens breathed as many as twenty-five to twenty-seven times per minute.

\section{DIOPATRA CUPREA AUDOUIN ET EDWARDS.}

While digging in the sand and mud on Ram Island, Wood's Hole, Mass., in the summer of 1901, I came upon a worm tube about ten inches in length. Six inches of the tube was thickly covered with small pebbles and bits of shell. The remainder seemed to be continuous with the lining of the roughly covered part, and was made of thick, tough, leather-like material. On examining the tube at the laboratory I found it to be inhabited. The annelid was a good specimen of Diopatra cuprea, the natural history of which has been described at some length by Verrill, in his report on "The Invertebrates of Vineyard Sound." Being curious to know how the tube came to be covered with pebbles and shells while the animal lived in a region of fine sand and mud, I placed it in a ressel of sea water, and distributed over the bottom the large pieces of its old tube with some other material. In a very sloort time the annelid began to form a new tube. I watehed the operation closely during the formation of this tube, and found that the tube-forming activities agree in outline with the description given by Verrill. As that author says, the animal crawls partially out of its tube to collect pebbles, and then places them in position at the margin of the forming tube. The stages in this process and certain rariations of method were not detailed by Verrill nor by any of the older observers, so far as I know; hence I have thought it worth while to record them.

The tubes of Diopatra in the region about Wood's Hole are frequently orer twelve inches in length. From one-third to two-thirds of this length is composed of a sand- 
covered, whitish, tough, leather-like portion, which extends more or less directly into the mud and sand. Near the outer end of the tube the pieces of shell appear much less worn than those toward the other end. When discovered the shelly portion of the tube is usually lying more or less flat in the sand, with only one or two inches of the upper end uncovered. Undoubtedly all the shelly portion is free at one time, but is subsequently covered by the drifting sand. Judging from the manner in which Diopatra constructs the shelly part of the tube that portion must be uncovered at the time of formation. In all cases examined the lower end of the tube was open. Whether it is necessarily so is a question I am unable to decide. The animal can turn within its tube, and in the construction of the lower end it very probably dug the sand aside or carried it out. It may be that the tube is left open incidentally, as the annelid ceases to build at the lower end of its tube from time to time. The lower part of the tube may be considered both as a protection from other boring animals and also as an anchor while it is living in the outer portion.

The free end of the tube is extended on the surface into a sort of hood, which may act as an additional protection while the animal is resting at the opening. The edge below this hood is worn smooth and round by the animal while moving out and in during food-getting. The end of the tube is kept open permanently for convenience in feeding and breathing. I have never witnessed the process of obtaining food, although I have left pieces of other annelids in the aquaria within its reach, and even in the tube-opening, but except for an occasional bite at the piece with its mandibles and a push that sent it from the tube-opening, the animal gave no response to the presence of food.

In the aquarium, as it rests with the tips of the longer tentacles extending beyond the edge of the tube, Diopatra is constantly engaged in moving the anterior end of the body up and down. This movement proceeds at the rate of forty-four times per minute with great regularity. The movement is undoubtedly for the purpose of creating currents in the water to carry oxygen to the gills, which lie on the dorsal surface. Tests with waste particles show that currents of water are passing in and out at the mouth of the tube constantly. When the animal is removed from its tube, and is not moving about, the breathing process is carried on by the periodic waving outward and inward toward the mid-dorsal line of the series of gills which extend upward from the dorso-lateral region. In each of the two series there are about thirty of these miniature fir-tree-like gills, with a central slender stem, and, more or less distinctly, eight vertical rows of minute branches. Adjacent to, and extending alongside each gill on its outer surface is an elongated dorsal cirrus from the parapodia. The function of these cirri is probably to protect the gills 
from physical injuries. While the outward and inward, almost simultaneous, waving of the gills is not going on, two other means of creating currents in the water are employed. One is an alternate spiral contraction and the reverse spiral extension of an entire gill, this operation taking place independently of similar spiral movements $i_{n}$ any other gill. The other movement is a much less noticeable waving a way from and toward the central stem of the minute branches themselves. The slow waving of the gills, the spiral contraction, and the movement of the minute branches may all occur at the same instant. During locomotion these minute activities are unnecessary and are not performed. When disturbed outside its tube the animal coils, with the dorsal surface outermost, contracting the gills close against the body.

Locomotion outside the tube, either when the animal is wholly outside or only partly out, is accomplished by the creeping movement of the ventral rami of the five pairs of parapodia on the anterior five trunk somites, aided by a pair of large, ventral palps. Posterior from the fifth pair of parapodia the ventral ramus disappears, except for the basal portion, which is transformed into a pad-like secreting surface for the material that forms the leather-like lining of the tube. The dorsal ramus, the cirrus of which becomes the gill-protecting organ already described, remains, but does not aid in locomotion except inside the tube, where their horizontally extended setæ can reach a point of leverage. Sometimes when Diopatra is forced from the tube it immediately begins a series of spiral contractions of extreme rapidity, made with the tail in advance. It is altogether likely that this movement is quite abnormal, as it is not progressive, and occurs only at this time of extreme stimulation.

Diopatra can be forced to leave its tube by thrusting any pointed object against the posterior end or the head. Frequently a great quantity of mucus comes out at the same time. On reaching the water the animal usually goes through the contortions just described, although in some instances it simply creeps away. Whenever there is suitable material at hand the animal begins at once to form a tube by crawling first under a mass of sand and organic waste. Using this as a foundation it reaches out, testing the surrounding objects tactually with its two pairs of lateral and its middorsal cephalic cirri, and with its pair of large ventral palps. The one pair of eyes are placed dorsally, and could not be of much service for vision immediately in front, unless the objects extended above the level of the eyes. When an object of suitable size is discovered the ventral pair of later cirri test it more carefully, and if the particle proves light and small, it is picked up by the strong ventral pair of palps. If the object is too heavy to be moved by this means, the mandibles are thrust out to grasp it. The gravel or piece of shell is carried backward by the contraction of the 
body, and placed on that part of the tube where it is needed. If the object is too heavy to be lifted from above, the animal crawls with its head beneath the mass, and, grasping the object with palps and cirri, and extending the mandibles, it lifts and carries the object to its proper place. If, again, the object is too heavy to be carried by grasping from above, or not convenient to crawl under, Diopatra pushes the object into position by extending the palps over the edge, as I have observed it do with heary pieces of broken glass. After a few pieces have been placed in position the animal ceases to collect materials, and begins the process of gluing together that already collected. This is done by repeatedly pushing outward, and, as it does so, rubbing the ventral glands, which begin at the sixth trunk somite, forcibly against the inner surface of the tube. The process is continued, if not interrupted, until the new part of the tube is glued all round. The animal may then, or after adding more material, double on itself, the dorsal surface always inward (protecting the gills), and build and glue at the other end. I have tried, while the animal was energetically engaged in gluing, to see if that function could be interrupted. I held before it a small piece of shell so as to touch the cirri. At once gluing ceased, and the piece was grasped and placed in position. The annelid then continued for some time collecting more material. At no time was there evidence of a choice between kinds of objects for tube construction, pebbles, bits of shell, and even glass, being taken indiscriminately.

During the process of collecting material the animal frequently cleans its cephalic cirri by bending them down one at a time and catching them between the dorsal and ventral rami of the second or third parapodium. Even the mid-dorsal tentacle is cleaned in this way. The setæ are the actual cleaners.

In a small aquarium where there is plenty of waste for building, but no mud to bore into, Diopatra will construct within an hour or less a serviceable tube to cover the entire body, or that part of the anterior region remaining after the animal has broken itself, as it sometimes does. The length of tube thus completed is at least three inches. One Diopatra on which I experimented reformed its tube three times within two days, but the third time it appeared to be considerably exhausted. Nevertheless, the animal lived without food two weeks longer. Specimens placed in a vessel containing mud, sand, and waste, such as pebbles and pieces of shell, will first bore into the mud and along near the surface. This operation is kept up for some time. Then the animal begins to collect waste for protecting the portion above ground. No pebbles were found in these aquarium-built tubes below the surface. The reason is plain - the pieces could not be put in position conveniently.

In only two instances were perfect Diopatra found, and these, on being forced from their tubes, constricted at about the middle until the animals had broken them- 
selves in two. The posterior part squirmed and contorted itself vigorously for a considerable time. The anterior parts of the divided specimens immediately began to form new tubes in an apparently normal manner. This result recalls the interesting experiments of the late Professor Norman.

One specimen was found, on opening the natural first-formed tube several days after it had been collected, to have a very minute regenerated head and the first five or six somites. I could not be sure, however, that the head had regenerated in captivity.

For many kindnesses offered while making these observations I desire especially to thank Professor R. Ramsay Wright, in charge of the Dominion Biological Station at Canso, Nova Scotia, and also Dr. H. M. Smith of the U. S. Fish Commission Station, Wood's Hole, Mass.

\section{BIBLIOGRAPHY.}

Audouin, J. V., et Milne-Edwards, H.

'33. Classifieation des Annélides, et Deseription de eelles qui habitent les côtes de la Franee. (Suite I.) Ann. Sei. Nat., tom. 28, pp. 187-247, pls. 9-10.

Bosc, L. A. G.

'30. IIistoire Naturelle des Vers. Paris, 16, Ed. 2, 3 tom., 387, 354, 342 pp.

Claparede, E.

'68. Les Annélides Chétopodes du Golfe de Naples. Mém. Soe. Physique. et Hist. Nat. Genère, tom. 19, pp. 313-581, pls. 1-16.

Claparède, $\mathrm{E}$.

'68 ${ }^{a}$. Les Annélides Chétopodes du Golfe de Naples (pt. 2). Mém. Soe. Pliysique et Hist. Nat. Genève, tom. 20, pp. 1 225, pls. 17-31.

Grube, E.

'55. Besehreibungen neuer oder wenig bekannter Anneliden. Areh. f. Naturg., Jahrg. 21, Bd. 1, pp. 81136, Taf. 3-5.

Mead, A. D.

'97. The Early Development of Marine Annelides. Jour. Morph., vol. 13, no. 2, pp. 227-326, pls. 10-19. Müller, F.

'53. Einiges über die Annelidenfauna der Insel Santa Catharina an der brasilianisehen Küste. Areh. f. Naturg., Jahr. 24, Bd. 1, pp. 211-220, Taf. 6-7.

\section{Quatrefages, J. L. A. de.}

'65. Histoire Naturelle des Annéles marins et d'eau douee. Paris, $8^{\circ}$, tom. 1, pp. vii +588 .

Verrill, A. E.

'73. Report upon the Invertebrate Animals of Vineyard Sound and the Adjaeent Waters, with an Aecount of the Ihysieal Charaeters of the Region. Report of the U. S. Commissioner of Fish and Fisheries for 1871 and 1872 , pp. 295-778, pls. 1-35. 



\section{XII.}

THE STRUCTURE AND AFFINITIES OF HERDMANIA CLAVIFORMIS, THE TYPE OF A NEW GENUS AND FAMILY OF ASCIDIANS FROM THE COAST OF CALIFORNIA.

(PLATES XVIII-XIX.)

William E. RitTter. 


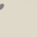




\section{INTRODUCTION.}

At the seventh annual meeting of the American Morphological Society held in Boston and Cambridge in December, 1896, I presented a brief paper on a new ascidian from the coast of California. As my primary aim there was to treat of a few points in the embryology of the animal, I left it nameless and located it in a general way only among its congeners. A shor't synopsis of this paper was printed in "Science". of the following twelfth of March (Ritter, '97).

I take the present opportunity to make known in greater detail the anatomy and relationships of this new form.

The conspicuous place which it will have to be accorded among ascidians makes it not unworthy to bear the name of the most distinguished contemporary authority on this group of animals. It consequently affords me great pleasure to honor the new genus to which it belongs with the name Herdmania * after my esteemed friend Professor W. A. Herdman of University College, Liverpool, England. This genus, as will be at once recognized by ascidiologists, must stand as the type of a new family, the Herdmaniidæ, the characterization of which follows.

\section{HERDMANIID $Æ$, fam. nov.}

I. General Character of the Colony.-Composed of crowded but entirely free zoöids arising by budding from short, much-branched, closely interwoven stolons (Pl. XVIII, Fig. 1).

2. General Character of the Zooids.-Large, long, and narrow body consisting of three regions, namely, thoracic, digcstive, and cardiogenital; these, however, not constricted off from one another superficially (Figs. 1, 2).

Siphons. Both six-lobed, the lobes of the branchial of unequal size (Fig. 4).

Tentacles. Branchial numerous, simple, circle interrupted; atrial not present (Fig. 5).

* Metcalf (:00) proposed the name Herdmania for a supposed new genus of Molgulidx. Before, however, his paper was published he discovered that the new form belonged to Traustedt's genus Bostriehobranchus. He consequently withdrew the name (:00, p. 583$)$, although it was too late to suppress it in some of the earlier pages of his paper. 
Branchial Sac. Without folds or internal longitudinal vessels; membranes of transverse vessels and dorsal languets present; stigmata straight, simple (Fig. 3).

Neural gland situated on ventral side of cerebral ganglion (Fig. 5), provided with a long rapheal duct.

Digestive Tract. Loop of intestine straight, very long, the cesophagus constituting one of the limbs; stomach wall deeply futed (Fig. 2).

Genitalia. Ovary situated some distance behind the intestinal loop, oviduct serving as a uterus in which the embryos go through their development to nearly the period of metamorphosis (Fig. 2). Testis in the form of numerous lobes which may extend from the intestinal loop to a considerable distance behind the ovary.

Heart. Situated in the postabdomen behind the ovary (Fig. 2).

Epicardiac Tubes. Two, separate throughout their length.

\section{DETAILED DESCRIPTION OF HERDMANIA.}

I. General Character of the Colony.-Although the ascidiozoöids are never enveloped in a common test, they usually arise very close to one another from the much-branched stolon, and are consequently closely crowded in the colony. The colonies are of considerable size, their area frequently covering 100 to 200 square centimetres. More frequently than otherwise a considerable quantity of sand and detritus is spread over the colonies, and this usually adheres more or less to the test. The zoöids are often buried for half their length in these foreign substances. The colonies are found on rocks more commonly than on other objects. Their most usual position is the upper surfaces of the rocks among the roots of various seaweeds. The bathymetric range of the species appears to be quite restricted. It rarely if ever occurs much above extreme low tide, and it has never yet been taken with the dredge. The fact must be borne in mind, however, that the dredge is a very inadequate means for exploring rocky bottoms. It has not yet been taken north of Half-moon Bay, California, or south of San Pedro. It is an abundant species at most points throughout its range, though perhaps most so in Monterey Bay.

2. Ascidiozoöids.-These are long and slender and distinctly thicker at the anterior than at the posterior end. The average length is about 20 millimetres, though exceptional individuals may reach twice this length. The anterior, larger end, the thorax, is somewhat compressed laterally. Its greatest diameter is about 4 millimetres. The body is not set off into distinct regions, although an obvious diminution in the dorso-ventral diameter occurs at the posterior end of the thorax. From this point back the body is circular in section and narrows gradually to its junction with 
the stolon, into which it merges imperceptibly. The diameter at the base is about 2 millimetres. The younger zoöids frequently appear to arise from the lower portion of the body of the larger ones, rather than from the stolons (Pl. XVIII, Fig. 1). Since, however, the place of origin appears to be wholly indeterminate excepting in that it is confined to the region a little below the heart and genitalia, any portion that produces buds must be regarded as stolon even though superficially it appears to be a part of the body of the zoöid. Sometimes the individuals are quite straight and erect, but more frequently they bend over at various angles and in various directions, and the bodies are not infrequently considerably curved.

Normally the animals are translucent; but this condition is frequently disguised by foreign matter adhering to the surface. A slight greenish shade is usually recognizable, and not infrequently a very decided dull, dirty green film covers the surface of the test, particularly of the middle and posterior portions of the body.

The organs of the body are disposed in three regions, namely, thorax, abdomen, and postabdomen. These regions are not, however, obvious on surface inspection, and it is only with careful study that the postabdomen, in the strict sense in which the term is applied in the Polyclinidx, is recognized. In full-grown specimens that are not contracted the abdomen is about five times the length of the thorax, and the postabdomen is about equal to, or somewhat shorter than, the latter division, though its proportional length is variable (Fig. 2).

3. The Test.-This rarely if ever reaches the thickness of 1 millimetre. It is rather soft and pliable. Its surface is smooth excepting where it has become eroded through age and the action of external agents, as diatoms, etc. It is quite clear and transparent normally, that is, when not covered by foreign matter or eroded.

The cells are generally few; in fact I know of no other ascidian in which they are so scattered as they are here. The cells are more than usually uniform in size and shape. There are no vessels in the test, and the matrix is very uniform in structure.

4. Musculature of the Mantle.-This is moderately well developed, especially as regards the longitudinal fibres. These extend the entire length of the animal. In the thorax they have a tendency to be arranged in bands; but in other portions of the body they constitute a uniform layer. Circular fibres are confined to the thoracic region and are most numerous at the anterior end and in the siphons. They are disposed in bundles of about six, eight or ten fibres each. These are numerous, and anastomose with one another at short but irregular intervals.

5. Branchial Apparatus. - The general form of the siphons as they appear in a specimen dissected from the test is shown in Figures 2 and 3 (Pl. XVIII). They are not prominent before removal from the test, but afterwards they are decidedly so. The 
branchial siphon is considerably larger than the atrial, and is bent over toward the ventral or endostylar side, so that the plane of the orifice usually forms almost a right angle with the plane of the section of the siphon at its base. The orifice is six-lobed, the dorsal lobe being much larger than any of the others. An average condition of the lobes and orifice when the latter is nearly closed is shown in front view in Figure 4. The atrial siphon is considerably smaller than the branchial; it is nearly straight, though inclined somewhat away from the branchial, and is also six-lobed, the lobes being in general of about equal size.

Branchial tentacles are numerous. There are thirty or forty or more that are well developed, and in addition a variable number of small ones. The arrangement is peculiar. There is a bunch of about ten or twelve immediately in front of the hypophysis; on each side of this bunch comes a considerable area entirely devoid of tentacles; then, following these bare areas, come the majority of the tentacles uniformly distributed over the remaining portion-somewhat more than one-half-of the circle. The individual tentacles are simple, rather long and slender, with enlarged bases, and nearly round in cross-section. The outermost tentacles are close to the peripharyngeal band. Figure 5 illustrates these several points, although a portion of the tentacular field of the specimen from which this figure was taken was broken away.

No atrial tentacles are present.

The peripharyngeal band is well developed. The area between it and the first series of branchial stigmata is small.

The branchial sac is without folds, internal longitudinal vessels, or papillæ.

There are usually twelve series of stigmata, but the number may vary in either direction by one or two series. Each series has about forty stigmata of quite regular form, size, and arrangement.

The transverse vessels carry membranes that project prominently into the interior of the branchial sac. There is a single, moderately developed dorsal languet for each of these vessels (Fig. 6).

The two rapheal muscle-bands are well developed and extend the entire length of the sac (Pl. XVIII, Fig. 5; Pl. XIX, Fig. 15, mu.rph.). They are as usual situated close along the dorsal blood-sinus. There are also two or more muscle-bands running lengthwise of the animal ventral to the endostyle, that should be regarded as belonging to the branchial sac rather than to the mantle, since they are situated near the endostyle inside the circular muscles of the mantle instead of outside, as are the longitudinal mantle fibres proper.

The dorsal or rapheal blood-vessel of the branchial sac is large (PI. XIX, Fig. 15, 
va. $r p h$.). It is situated between, and ventral to, the rapheal muscle-bands. There is no doubt that this vessel has an endothelium that is almost if not wholly complete.

6. The Neural Gland and its Duct.-These, as seen from the interior of the branchial sac, are shown in Figure 5. The gland is of liberal size, is somewhat pear-shaped, with the broad end directed forward, and is situated on the ventral side of the ganglion and somewhat farther back than this structure.

The duct is short and trumpet-shaped, with a broad, simple, elliptical mouth transversely placed. The mouth is situated slightly to the right of the sagittal plane, and the duct in its course backward makes a sharp turn to the left so as to enter the gland somewhat to the left of the median line. (Frequently the duct is relatively shorter, and the gland is farther back with reference to the ganglion than in the specimen shown in Figure 5.)

The duct branches sparsely within the gland, but the branches do not penetrate deeply into the glandular substance (Pl. XIX, Fig. 14, rm. dt.). Its main portion within the gland, which as usual is very slender, continues on beyond the gland into the dorsal raphe, along which it can be traced through the whole length of the branchial sac, even into the anterior portion of the abdomen, where it disappears. Whether or not the "rapheal duct" possesses a continuous lumen throughout its length I have not been able to determine. A very small lumen is undoubtedly present in some places, even far back in its course (Pl. XIX, Fig. 16, $d t$. rph.). In many sections I am, however, not able to detect the opening and am inclined to believe it does not exist everywhere. It is always exceedingly small and gives the impression of being in a rudimentary condition. The wall of the duct where a lumen is recognizable is composed of a few rather large, nearly globular cells. At some points the duct or strand is enlarged somewhat, and seems even to give off small blunt processes, which project inward (Fig. 16, dt. rph').). The duct turns rapidly dorsad after leaving the gland, and from here is situated throughout the branchial sac in the dorsal blood-sinus close in contact with its dorsal wall, and between the two rapheal muscle-bands. The relation of this duct to a possible rapheal nerve I shall consider later.

The histology of the gland itself deserves a few words. I have stated above that the duct branches sparsely within the gland. As this is a matter that may have some bearing on the question of the affinities of the animal, I shall consider it a little more fully. The duct lies as usual on the dorsal surface of the gland; or, to be more exact, the gland proper is a developinent of the ventral wall of the duct, its lumen being here restricted to the portion belonging to the dorsal, unmodified half of the wall, so that the duct appears in cross-sections of the organ as a small trough lying 
bottom upward on the surface of the gland, as it does in Fragaroides and other forms (Maurice, '88, Pl. 16a, Fig. 29).

A section showing the extent of the ramification of the duct in the gland of Herdmania is shown in Figure 14. Not more than three or four branches in any one gland have been seen. These never penetrate beyond the centre of the gland, and usually not even as deep as that.

The lumina of these branches are obscure, but the branches themselves are distinct enough from the contrast of their compact, well-stained cells with the vesicular cells of the gland proper in which they are embedded. The branching of the duct within the gland, interesting as it is, rarely if ever occurs in compound ascidians, though this condition is common among the simple ones. The gland-cells proper are of the vesicular type commonly found in this organ. The cytoplasm is reduced to a narrow zone at the surface of the cell, and in this, at one side, the deeply stained, crescent-shaped nucleus is a conspicuous object. The interior of the cell is clear in a majority of cases and seems to be empty; but a slightly granular mass, very little affected by hæmatoxylin, more or less completely fills the cavity of many of the other cells. The substance in the cells is probably, as is usually held, the secreted material characteristic of the gland. It is, however, an interesting fact that cells in the blood are common in many parts of the body and closely resemble those here described. The crescent-shaped nuclei on the surfaces of these cells have their counterparts in the gland-cells.

The bodies within the gland-cells described by Metcalf for Polycyclus and Fragaroides and called by him paranuclei I have not seen in Herdmania.

7. The Central Nervous System.-The ganglion requires no special description. It is nearly spherical, is of large size, and is situated on the dorsal side of the neural gland and slightly in advance of it.

If a dorsal or ganglionated nerve exists in the adult of this species, its connection with the rapheal duct is so intimate as to render it impossible to distinguish the two.

There can hardly be a doubt, I suppose, that what I have described as the rapheal duct, Figures 15 and 16, is the same structure as that described and figured by Maurice ('88) in Fragaroides, and by Seeliger ('93-:02) in Ciona and Clavelina, though both these authors regard the structure as nervous. But from the observations of several zoölogists, particularly of Metcalf, the association of the two is so intimate as to make it actually impossible to distinguish them. In Herdmania my observations make it seem to me that the strand should be regarded as belonging to the gland rather than to the ganglion. In my description of the ventral processes on the rapheal duct 
the reader may suspect he sees nerve-branches comparable to those reported by Kowalevsky ('74) in Distaplia and Phallusia. I can, however, find little to support this view. They are wholly fibreless; they end abruptly without reaching a length to make them of any consequence as nerves; they do not run to any organ or tissue; and they are wholly median and unpaired. While I can see no reason for regarding them as abortive nerve-roots, I have no alternative suggestion as to their significance. The lumen of the duct undoubtedly extends into some of them, as shown in Figure 16; and I have tried to find it communicating with the rapheal blood-sinus, but have not been successful.

8. The Digestive System.-The intestine is in the form of an extremely long, straight, narrow loop. A rather pronounced constriction marks the junction of the thorax and intestine, but from this point on to its end the loop holds a very uniform size. The osophagus constitutes almost the whole of the rentral limb of the loop, the stomach being situated far back. The portion of the loop behind the stomach is about one and one-half times the length of the stomach. The ascending limb of the loop, the intestine proper, is considerably thicker than the œsophagus. A distinct constriction at the bend in the loop marks off what may be called a duodenal section of the intestine. This is much smaller at its gastric end, the pyloric opening of the stomach being, as is likewise the osophageal opening, much smaller than the parts of the digestive tube to which they respectively belong (Pl. XVIII, Fig. 2).

The asophagus becomes strongly compressed laterally as it approaches the stomach, so that its cross-section is a narrow ellipse. That this compression is a structural matter and not due to collapse merely is proved by the fact that along the dorsal edge the epithelial wall falls away abruptly to about half its normal thickness. The relation of this edge to the stomach wall, to be described presently, is also evidence of its constancy.

The stomach is a well-defined organ. It has the general form of a barrel. Its length is approximately once and a half its thickness. Its wall is thrown into seven prominent, nearly equal folds which extend its entire length, and an eighth much smaller one which usually does not reach quite to the posterior end. These folds are arranged as follows: on the side next the rectum there is an area of plain wall of somewhat less than one-third the entire circumference of the organ. The seven large folds are distributed nearly uniformly over the remaining two-thirds of the wall. The small eighth fold is situated between the second and third large folds counting from the foldless area on the dorsal side (Pl. XVIII, Fig. 7). The small fold is consequently somewhat to the right of the dorsal line of the stomach. This small fold is in direct continuation at its osophageal end with the narrow dorsal edge of the 
œsophagus. The epithelium constituting this small fold is hardly half as thick as that of the large folds. Posteriorly it disappears without reaching the end of the stomach, the thinner wall continuing, however, to the end and marking the edge again of the compressed duodenal portion of the intestine. This scheme of folding appears to be pretty constant,--rather more so than in most other species, so far as I have observed,--but considerable deviations from it are not uncommon, particularly in the direction of increase in the number of large folds.

The lacteal system is well developed. It communicates with the posterior end of the stomach by a single distinct though not large duct. The duct has no cœcum. The tubules ramify over the rectal portion of the intestine from the loop to near the branchial sac.

From the loop of the intestine to a region somewhat farther forward than the stomach the digestive tract is usually so completely surrounded with yolk-laden mesenchymatous cells, to be described more fully later, as to render difficult the tracing of the digestive tube in an entire zoöid.

9. The Heart, Pericardium, and Epicardiac Tubes. - The heart is situated in the postabdomen, behind the ovary and testis, though the latter when ripe may extend as far back as the heart.

The pericardium is very large (Pl. XVIII, Figs. 9, 10; Pl. XIX, Fig. 11, pi'cr.). It nearly fills the abdominal space in its region, and the heart occupies but a comparatively small part of its cavity. The heart $(c r$.$) is horseshoe-shaped. It is sit-$ uated toward the dorsal side of the body, the plane of the loop being at nearly a right angle to the sagittal plane of the body. The cardiac raphe runs along the outer edge of each limb of the loop for most of its length, but toward the base of the loop it shifts gradually to the ventral side. It seems to be entirely closed for part of its course. One limb of the loop, namely, the left, is considerably longer than the other (Figs. $10,11)$.

There are two epicardiac tubes extending throughout the length of the animal. These are always wholly separate from each other so far as their cavities are concerned, but a thin laminar bridge connects their walls in many places. This bridge is, however, of mesenchymatous origin. The true epithelial walls of the two tubes are wholly distinct (Pl. XIX, Fig. 13). This figure shows how the connection is formed. The membranes which line the body spaces adjacent to the tubes become closely applied to the latter, reaching across from one to the other. These frequently inclose between them mesenchyme cells and thus make the bridge seem in some places to be actually a connection between the epithelial walls. 
The epicardiac tubes are situated ventrad from the abdominal viscera, and are strongly compressed dorso-ventrally. One of them, the right, is considerably larger and thinner-walled than the other (Pl. XVIII, Fig. 8, e'cr. $d x$., e'cr. s.). In many places the wall of the smaller tube attains a considerable thickness, the cells becoming cuboid and easily stainable. More frequently than otherwise in the regions where the wall is thickened the lumen of the tube is more or less completely filled with a fine granular or flocculent substance which does not stain readily and which contains no cells. There is little doubt that this is a secretion from the walls of the tube. In some places-not everywhere-this substance grades into the cytoplasn of the cells so gradually as to leave hardly a question that here the cell substance is becoming transformed into the secretion. Even where the secretory process is going on, the portion of the cell on the outside of the nucleus from the lumen of the tube is much more finely grained than the secretion; in fact it generally appears almost perfectly clear and structureless (Pl. XIX, Fig. 12). I have never seen any of this secreted substance in the larger tube. In a few places, however, the wall of this tube is also found to be thickened somewhat. This is particularly true along the edge adjacent to the other tube.

The relation of the tubes to the pericardium is as follows: The larger thinwalled one lies ventrad to the pericardium and is in close contact with it. Whether an actual fusion of the two walls exists or not in the adult I have not determined, but in the embryo zoöid the pericardium arises from this tube. The smaller tube is situated, at its posterior extremity, on the dorsal side of the pericardium; so that here the two tubes are on opposite sides of the organ as they are in Fragaroides (Maurice, '88). It soon passes, however, on its way forward, to the left side of the pericardium and so reaches the position it occupies for the most of its course alongside the other tube. The two tubes, distinct from each other, can be followed with great ease forward into the posterior end of the thorax. A little before reaching this they diverge from each other and pass one to each side of the œsophagus. Whether their original connection with the branchial sac is ever retained in the adult is somewhat difficult to ascertain. It is certain, however, that such is not usually the case. This I have determined with certainty on several zoöids. That the connection was with the branchial sac and not with the peribranchial is proved by the position occupied by the detached ends. The branchial sac projects backward slightly in two broad shallow pockets on each side of the osophagus at its posterior extremity. On the outer sides of each of these rest the posterior tips of the peribranchial sac, and on their inner sides the free ends of the epicardiac tubes. 
The origin of the tubes in Herdmania, then, agrees perfectly with what is known of them in Clavelina and the merosomatous* ascidians. The presence of two epicardiac tubes in full development is not the least among the many particularly interesting facts in the structure of this unique ascidian.

There is no known species in the whole range of bud-producing tunicates quite like the present one. The tubes, where they occurred, were indeed primitively double without much doubt in all ascidians, but in all without exception, so far as we now know, one of the tubes has been more or less completely merged into the other, so that for most of the length only a single tube is present. In all cases, probably, the two are distinct at their origin; but they everywhere fuse to produce the epicardiac sac (Van Beneden et Julin, '86).

In Fragaroides (Maurice, '88) and probably in the other Polyclinidæ the double character of the tube appears again at its posterior extremity where it forks, one limb being dorsal and the other ventral to the pericardium. Herdmania has in this respect, then, more in common with the Polyclinidæ than with any other group. In both, the heart and pericardium are situated far back in the postabdomen, and in both the pericardium is placed between the ends of two epicardiac tubes. $\dagger$ But in Fragaroides and all other Polyclinidæ the tubes become fused together a short way above the pericardium, and continue in this condition almost up to the pharynx.

Could we interpret the posterior extensions of the peribranchial sacs of Botryllus as epicardiac tubes, as Pizon ('93) and Garstang ('95) have done, we should have a sort of agreement between these two genera. But both Hjort ('96) and Ritter ('96) have shown that these structures in Botryllus cannot be homologized with the epicardia. The Botryllidæ and Polystyelidæ in reality have no epicardiac tubes.

Furthermore, the raphe of the heart in Herdmania, as in the Polyclinidæ, is not in such relation with the wall of the epicardium as to be closed by it as is the case in Clavelina. $\$$

It is possible to institute a suggestive comparison between the stolon of Herdmania and that of Doliolum, though no great confidence can be placed on the comparison until we have more exact knowledge about the origin and prospective value of the various elements that enter into the structure of the stolon of Doliolum and until we also know how the bud originates in Herdmania. I consequently merely indicate the homologies that seem most suggestive. The comparison which I make

* This term, proposed by Sluiter ('95) and adopted with some modification by Herdman ('99), is a very useful one.

† Compare Figures 9, 10 (Pl. XVII) and Figure 11 (Pl. XIX) with Maurice's ('88) Figure 70 (Pl. XIX).

† Compare Figure 10 (Pl. XVIII) and Figure 11 (Pl.XIX) with Figure $6 b$ (Pl. X) by Van Beneden et Julin ('86). 
is on the basis of Uljanin's ('84, p. 93) interpretation of the ventral stolon of Doliolum. This investigator finds seven strands of cells in the stolon, all within a common ectodermal envelope. On one side there is a large unpaired strand which gives rise to the central nervous system; under this, occupying the centre of the stolon, another unpaired mass gives rise to the pharynx and intestinal tract. Beneath this there is still another unpaired strand from which the pericardium and heart take origin. In addition there are two pairs of lateral strands one of which, the pair adjacent to the forming nerve, produces the muscles of the future animal; while the remaining pair are the beginnings of the genital glands.

If now it should turn out that both epicardia of Herdmania contribute to each bud, the dorsal tube (dorsal at the pericardium, Figure 11) giving rise to the branchial sac at least, and the ventral one to the pericardium and heart at least, we should have the homologues in the Herdmania stolon of two of the most important cell-masses of the Doliolum stolon. It would then be in order to search with great care in the first bud generation of Herdmania for the homologues of the Doliolum genital and neural strands; and the organ-continuty from parent to bud which several authors have believed to take place in all blastogenic ascidians would be realized.

So far as Herdmania is concerned this is a perfectly reasonable speculation. There should be no great difficulty in determining whether or not it corresponds to what actually happens in bud production. Up to the present time I have not been successful in getting any light on the origin of the buds, but $\mathrm{I}$ hope to be able to give the matter the attention it deserves before long.

ro. The Sexual Organs.-Both ovary and testis are situated behind the intestinal loop in the postabdomen; the latter, however, is not marked off in any way, superficially, from the abdomen.

The ovary is a simple oval structure situated about as far behind the loop of the intestine as the extremity of the loop is behind the stomach. It is of small size. The ova leave it before reaching maturity, further growth and maturation taking place in the oviduct. Two views of the same ovary are shown in Figure 2 (Pl. XVIII) and Figure 18 (Pl. XIX). Figure 19 (Pl. XIX) shows a section from the posterior end of an active ovary, and Figure 20 one from the middle portion of the same ovary. A section from the anterior end of the organ shows essentially the same structure as that represented in Figure 19. In other words, at each end of the active ovary the germinal epithelium is in the form of a plain disk or pad with no suggestion of bilaterality. In the middle of the organ (Fig. 20) this pad becomes thrust out into a deep ditch, which, however, does not draw into it the entire pad; so that here the germinal epithelium becomes arranged in the form of a letter $T$. A few short branches 
are produced on the stem of the $\mathrm{T}$, in connection with which the ova ready for discharge are found.

In the smallest ovaries that I have observed the evagination of the disk has not taken place, the disk, being here in the form of a plain pad, sections in all portions of which are similar to that shown in Figure 19. There is, in other words, no intimation of bilaterality in the ovary in its immature state in adult zoöids. I have not followed its development in the embryo.

The ovary, then, resembles that of Fragaroides (Maurice, '88) much more closely than it does that of Clavelina. Van Beneden et Julin ('86) have shown that in all its stages in the blastozoöids the ovarian epithelium of the latter genus is more or less distinctly bipartite, and that the two parts are apparently related to the bilaterality of the zoöid.

The oviduct leads off from the anterior side of the ovary and holds a direct course up to the thorax. It passes to the right of the intestinal loop. Its position throughout most of its length is toward the ventral side of the abdomen a little to the right of the œsophagus. During the breeding period (which appears to be limited to the summer months) the anterior two-thirds or three-fourths of the duct become greatly enlarged in diameter and serve as a uterus in which the embryos are developed to a late stage in larval life (Pl. XVIII, Fig. 2, ut.). This uterus is capable of containing eighteen or twenty embryos at a time, which are arranged in a single series one behind the other, the oldest farthest anterior, or toward the atrial end, the youngest nearest the ovary. The conversion of the oviduct into a uterus or broodpouch in Herdmania is wholly unique among the Ascidiacea, as indeed it is among all the Tunicata unless the embryonic chamber of Salpa be regarded as a part of the oviduct.

One may justly raise the question as to whether the condition here is essentially different, morphologically, from that presented by various compound ascidians, particularly of the family Distomidæ, where the embryos develop in the atrium or an incubatory pouch produced from the atrial wall. It may appear at first sight that a gradual transition from the oviducal wall to that of the atrial wall, and then as a consequence, of a similar transition of oviducal cavity to that of the atrial cavity might take place, so that in reality the difference between the brood-chamber of Herdmania and that of Colella or Distaplia, for example, would not be important. As a matter of fact, however, no such transition from oviduct to atrium occurs in Herdmania. On the contrary I have grave doubts as to whether the embryos ever reach the atrium. Certain it is that the oviduct in all the many gravid zoöids examined by me narrows down rapidly, as it approaches the atrium, to a most insignificant 
opening. Indeed I am unable to make certain of any opening at all in some cases. I have never seen the least suggestion of the passage of an embryo into the atrium, which is always, so far as I have observed, very restricted in size. I am inclined to believe the real method of escape will be found to be by rupture of the uterine and body walls of the zoöid.

The relative size of the gravid uterus and oviduct proper, that is, the duct a short distance in front of the ovary, is shown in Figure 2, o'dt., ut., and in Figure 7, $o^{\prime} d t$., and Figure 8, ut. The uterus measures when containing full-grown embryos about .855 millimetre in diameter, while the oviduct proper varies from .095 to .148 millimetre.

That the great distention of the uterine portion is not due to mere passive stretching by the growing embryos is clear from the fact that in reality the wall is considerably thicker in the uterus than it is in the empty duct, and further by the fact that the size of the uterus is nearly as great at intervals between two embryos, even where the distance is considerable, as it is where an embryo is lodged.

At no time do the embryos contract a placental relation with the uterine wall as those of some of the Polyclinidæ are reported to do by Salensky ('92).

The testis consists of a considerable number of lobes each connected with the vas deferens by its own branch (Fig. 2, te.). A few of the anterior lobes may extend so far forward as to be situated alongside the intestinal loop; but by far the greater number are behind the loop in the postabdomen. The testis may extend back considerably farther than the ovary. The usual thing is for the ova and sperm to ripen at different times in the same individual. Only exceptionally have I found a zoöid in which both were ripe at the same time. The vas deferens is of necessity very long. Its course is parallel with that of the oviduct, on whose inner side it lies.

II. The Mesenchymatous Tissue and the Subepicardiac Space.-The entire body mass around the organs of the abdomen and postabdomen is made up of (1) a coarse network of extremely delicate membranes; (2) long branching nucleated fibres or strands, which might be called connective tissue; and (3) quantities of free cells, varying greatly in form and structure, though probably all modifications of a single kind of cell.

The membranes are arranged in irregular festoons from the mantle musculature; so that when the spaces are filled with free cells, as is usually the case, they appear on cross-sections of the body disposed in more or less regular columns cut across (Fig. $8, c l$.). These columns may often be distinctly seen in the whole animal, and can be traced, also, for long stretches through series of sections. Sometimes they are nearly cylindrical, sometimes distinctly angular, and sometimes much flattened. 
They are undoubtedly comparable with the "Fächer" first described by Kowalevsky ('74) in the postabdomen of Amaroucium. The membranes themselves are exceedingly delicate. Flattened nuclei are found in them here and there, though these are not numerous (Pl. XIX, Fig. 13, mb.). I describe these as membranes because the assumption that they are essentially of this nature accounts best for the retention of the free cells in distinct masses and columns. It is probable, however, that in reality they are composed of a much flattened network of fine fibres.

The columns are not altogether indefinite in arrangement. The most constant are the four situated on the ventral side of the body in relation with the two epicardiac tubes. Each tube has typically one on its ventral and one on its dorsal side. Between the two on the ventral side there exists a large, distinct, constant space. The membrane lining this space, which is of the same character as that already described as enveloping the columns, is recognizable in nearly all sections, even where the free mesenchyme cells are absent. This channel is always empty except for small irregular masses of coagulum here and there. This I designate the subepicardiac space (Fig. 8, sb'e'cr.). Other spaces around the viscera, evidently of the same nature, are recognizable in many zoöids; but they are less constant. These are probably blood-spaces, though the almost entire absence of cells within them is difficult to understand on this supposition, for the possession of a great quantity of cells of many varieties is one of the most characteristic features of ascidian blood.

The free cells of the mesenchyme evidently play an important rôle of some sort in the economy of the animal-as they do in so many other ascidians. The usual supposition that this rôle is in connection with the nutritive processes is probably correct, though direct evidence of this is wanting. Kowalevsky ('74) described the abdomen of Amaroucium as being filled with fat cells, and Caullery ('95, p. 70) who has given some attention to the development of the granules in Circinalium is also inclined to consider them to be fat.

A series of the cells becoming gradually filled with the yolk granules is shown in Figures 17 to $17 c$. Before the granules appear the cells are as a rule nearly globular (Fig. 17). Not infrequently, however, they display irregularities in the form of angles and short broad processes (Fig. 17a). The cytoplasm is peculiarly dense and homogeneous, there being no fibrillar or alveolar or granular structure discoverable even with the best powers (Zeiss oil immersion $2.0 \mathrm{~mm}$., 1.30 ap.), at least so far as concerns well-preserved tissues treated by the ordinary histological methods. In these cells the cytoplasm stains uniformly and distinctly with hæmatoxylin after formalin fixation. The first recognizable step toward the development of the granules consists in the appearance within the cytoplasm of several round clear areas which do 
not at first displace all the cytoplasm. Frequently from their regular arrangement around the nucleus these give the cell a rosette-like appearance (Figs. $17 b$ and 17c). As they appear before the cell has become enlarged at all, and are of considerable size, usually only a little smaller than the nucleus, they form as a rule at this stage a single layer around the nucleus. From this condition the cells increase in size, the increase being associated with the multiplication of the clear bodies. The stainable portion of the cytoplasm becomes less and less until finally it disappears entirely and the cells, two or three times as large as at the beginning, are wholly made up of the nucleus which has not yet changed its size or character, and the clear bodies (Figs. $17 e$ and 17f). The cell now breaks easily and the clear bodies are frequently found scattered about in the body space. The freed bodies or granules are spherical in form, are moderately refractile, and have a slight yellow tinge. It frequently happens that the cells filled with granules appear to possess two nuclei, one situated in the interior, the other upon or very near the surface (Fig. 17f). The one situated within is the nucleus proper to the cell. It is the one which undergoes the changes above described. The nature of the superficial one is in some doubt. Almost certainly, however, it belongs to some tissue, probably in the nature of connective tissue, that is present in small quantity within the granule-producing cell-masses. These nuclei persist after the granule-cells and their nuclei have disappeared.

I have mentioned above that some writers have regarded these granules as fat. They are not of this nature in Herdmania. In the first place they are more definite and persistent in form than one would expect to find in fat granules. But direct test fails to prove them to be of this nature; for example, they are not affected by ether, neither are they colored in the least by Sudan III, nor by osmic acid, at least in any kind of preserved material tried by me. My belief is that they are more in the nature of yolk; this belief rests, however, entirely on their microscopic appearance. I have no experimental proof to this end. The fate of the granules I have not followed. We must suppose, however, that they are used up as food by the permanent tissues, probably of both parent and growing embryo.

The fate of the nuclei of the granule-producing cells is noteworthy. By the time the granules are mostly scattered or absorbed the nucleus has fully doubled its size; and the chromatin elements, which at the outset were distinct, have entirely disappeared, the nuclear substance having become homogeneous. The original globular form of the nucleus is lost, an irregular more or less angular outline being assumed. It still stains distinctly, though less intensely than does the chromatin of the earlier stages. In fact the nuclei come to have much the same size, form, and staining reaction as does the cell-body at the stage immediately preceding the ap- 
pearance of the granules. A little later clear spots appear in the nuclei, their substance stains less distinctly, they become more and more vacuolated or alveolar, until finally they disappear entirely. I believe that they too are absorbed.

\section{BUDDING.}

Although I have searched carefully through a large quantity of material for young buds, I have not thus far been able to get more than a fragmentary view of the process of bud reproduction. Half-grown blastozoöids are of notinfrequent occurrence, and a considerable number of only partially differentiated ones have been found first and last. Just where and how the bud arises, however, I have not determined. I have not yet found any buds still connected with the stolonic partition, and it is likely that they become completely severed from this normally at an early time as they do in Distaplia and Amaroucium. My studies on this point have, however, all been made on preserved specimens; and the stolonic partition is certainly given to breaking up considerably on preservation. I am consequently still much in the dark as to the exact relation of the zooids to one another. Most of the partly grown zoöids that I have thus far seen appear to spring from the posterior third of the older zoöids rather than from the stolon (Fig. 1), and on the whole I am inclined to believe that it will be found that the buds originate not far behind the heart, so that in reality the proliferating stolon is the portion of the zoöid behind the heart, which may be of considerable length. In the older parts of the colony, however, where the zooids are all fully grown, there usually appears to be a large, much-branched, creeping stolon. But this might be produced by the settling down upon the substratum of the united body parts behind the point of origin of the buds as the colony extends and becomes older. However, only further study on living colonies can settle the several interesting questions relating to the asexual reproduction of the species. For example, the question whether the two epicardia produce buds each for itself, or whether both contribute to the same bud, is of much interest. As stated above, the heart takes its origin from the larger right tube in the embryo. This makes it highly probable that this tube is concerned in bud production. Does it give rise to all the internal organs of the bud as does the primitive inner vesicle, derived from the single tube, in other stolonic ascidians? If so, then what is the use of the left tube? The answer to these queries will be of great interest. 


\section{SOME POINTS IN THE EMBRYOLOGY OF HERDMANIA.}

The developmental history of this new form lies beyond the purpose of this paper. It may not be amiss, however, to summarize a few of the more important results thus far reached by my studies under this head.

1. After cleavage begins, the ova are surrounded by a very large number of testcells (Pl. XVIII, Fig. 8, cl. tst.). These take no direct part in the production of the embryo. They are perfectly distinct from the tissue of the embryo throughout their whole existence; and their gradual disintegration and resorption can be easily followed.

2. The peribranchial sacs arise as two very long, narrow, ectodermal invaginations on the dorsal side of the embryo. The endoderm does not contribute at all to the formation of these sacs, or only to the slightest extent.

3. A single pair of very large, nearly round, protostigmata are the only communication between the branchial and pouch-like peribranchial organs for some time before any of the definitive stigmata are formed; so that the Appendicularia stage in the ontogeny is unusually clear. The definitive stigmata all arise by perforations wholly independent of the protostigmata.

4. The origin of the ganglion and neural gland from the common ectodermal anlage can be followed with great ease and distinctness.

5. The entire embryonal and larval development are passed within the uterus. The larval period is greatly abbreviated, and there probably is no free-living larval stage.

\section{AFFINITIES.}

Having now obtained a somewhat detailed acquaintance with the structure of the new ascidian we are in a position to devote with profit some attention to the question of its affinities. To facilitate this I arrange its leading characteristies in tabular form on the basis of their similarity to those of the nearest allies. The types of three fanilies must enter into the comparison: Amaroucium (Polyclinidæ), Clavelina (Clavelinidæ), and Distoma (Distomidæ).*

* Polyclinopsis of Gottschaldt appears to have some intercsting resemblances to Herdmania. Concerning the embryos Gottschaldt (94, p. 355) says "dass bei jüngeren Personen sich ein Tubus dorsal direkt unter dem Ektoderm durch das Postabdomen hinzielıt; derselbe ist mit Eiern angefüllt, die vorzugstreise hintereinander liegen und jugendliche Stadien zeigen. Bei fortgeschrittencren Personen finden sich dichtc Eihaufen, rings das Entodermrohr einschliessend und dasselbe teilweise einengend, am oberesten Teile des Postabdomens in allen Stadien der Entwickelung (s. Taf. XXV, Fig. 3); bei anderen liegen dieselben Eimassen mitten in Kienendarm. Hicraus kann man wohl, ohne einen Fehlschl uss zu thun, folgern, dass die im Postahdomen hereangereiften Eier sich am oberen Ende desselben sammeln, in den Kienendarm eindringen und diesen als Brutraum benutzen." The nature of the "Tubus" here mentioned is a matter of much interest. One might suppose it to be the oviduct did not the author expressly state on the preceding page that this duct seems to be wanting. 
TABLE I.

COMPARISON OF HERDMANIA AND ITS ALLIES.

\begin{tabular}{|c|c|c|c|}
\hline $\begin{array}{l}\text { Characters in common with } \\
\text { Amaroucium. }\end{array}$ & $\begin{array}{l}\text { Characters in common with } \\
\text { Clavelina. }\end{array}$ & $\begin{array}{l}\text { Characters in common with } \\
\text { Distoma. }\end{array}$ & $\begin{array}{l}\text { Characters peculiar to } \\
\text { Herdmania. }\end{array}$ \\
\hline $\begin{array}{l}\text { Three divisions of the body } \\
\text { of the zoöid: thorax, abdomen, } \\
\text { and postabdomen. } \\
\text { Well-marked lobes on bran- } \\
\text { chial and atrial siphons. } \\
\text { Folding of stomach wall. } \\
\text { Structure and position of } \\
\text { pericardium and heart. } \\
\text { Sexual glands in postabdo- } \\
\text { men. } \\
\text { Structure of ovary. }\end{array}$ & $\begin{array}{l}\text { Character of colony: } \\
\text { General form of zoöids. } \\
\text { Number of tentacles. } \\
\text { Small amount of yolk in } \\
\text { eggs. }\end{array}$ & $\begin{array}{l}\text { Intestine bends toward } \\
\text { dorsal side to produce loop. } \\
\text { Great length of cesoph- } \\
\text { agus. }\end{array}$ & $\begin{array}{l}\text { Inequality of lobes of } \\
\text { branchial siphon. } \\
\text { Arrangement of bran- } \\
\text { chial tentacles. } \\
\text { Oviduct functioning as } \\
\text { uterus. } \\
\text { Two epicardiac tubes. } \\
\text { Great quantity of test- } \\
\text { cells. }\end{array}$ \\
\hline
\end{tabular}

From this table it is seen that Herdmania has rather more in common with the Polyclinidæ than with any other group, and I have little doubt that its closest of kin is here in spite of its strong superficial resemblance to Clavelina. The similarity of its intestinal tract, particularly in the length of the oesophagus and the dorsal position of the ascending limb of the intestine, to that of some species of Distoma, is an instructive example of parallel evolution, but cannot in itself be regarded as evidence of close relationship.

In attempting to determine the degree of consanguinity of Herdmania with Clavelina we are confronted with the old question of the classificatory importance of the presence or absence of a common investing testicular mass. The extension of our knowledge is certainly diminishing this importance more and more. Witness, for example, the unsatisfactory efforts to arrange in genera on this basis a considerable series of species of the Clavelinidæ, Stereoclavella Herdman ('91), Pycnoclavella Garstang ('91), Synclavella Caullery (:00), and probably others. But the most striking instance of the ready passage from the free-zoöid state to the completely invested state afforded by the "social ascidians" is probably that of Perophora annectens Ritter ('94). Neither is the opposite tendency wanting, namely, for the zoöids in genera and families of strictly compound ascidians to become freed from the common investing test mass; for example, Distoma pulchra Ritter ('01).

In Herdmania the freedom of the zoöids is so complete and constant that it may be regarded as a good generic character, but not more, I should say; so that it camnot be appraised at a greater value than, for instance, the yolkless condition of the ova, in estimating the true relationship of Herdmania and Clavelina.

The most fundamental difference, according to our present knowledge, between 
Herdmania and its nearest relatives is its possession of two distinct epicardiac tubes. As pointed out in the description, in this character it is wholly unique among ascidians. This count alone would certainly securely establish the family rank of the genus. It shows as conclusively as morphological evidence can that the evolution of the species has been on an independent course for a long way. But the condition of the fused tubes in Fragaroides, particularly the short separation of their posterior

I'olyclinid branch.

(Synoicum, Fragarium

Amaroucium, Polyclinum, ctc.)

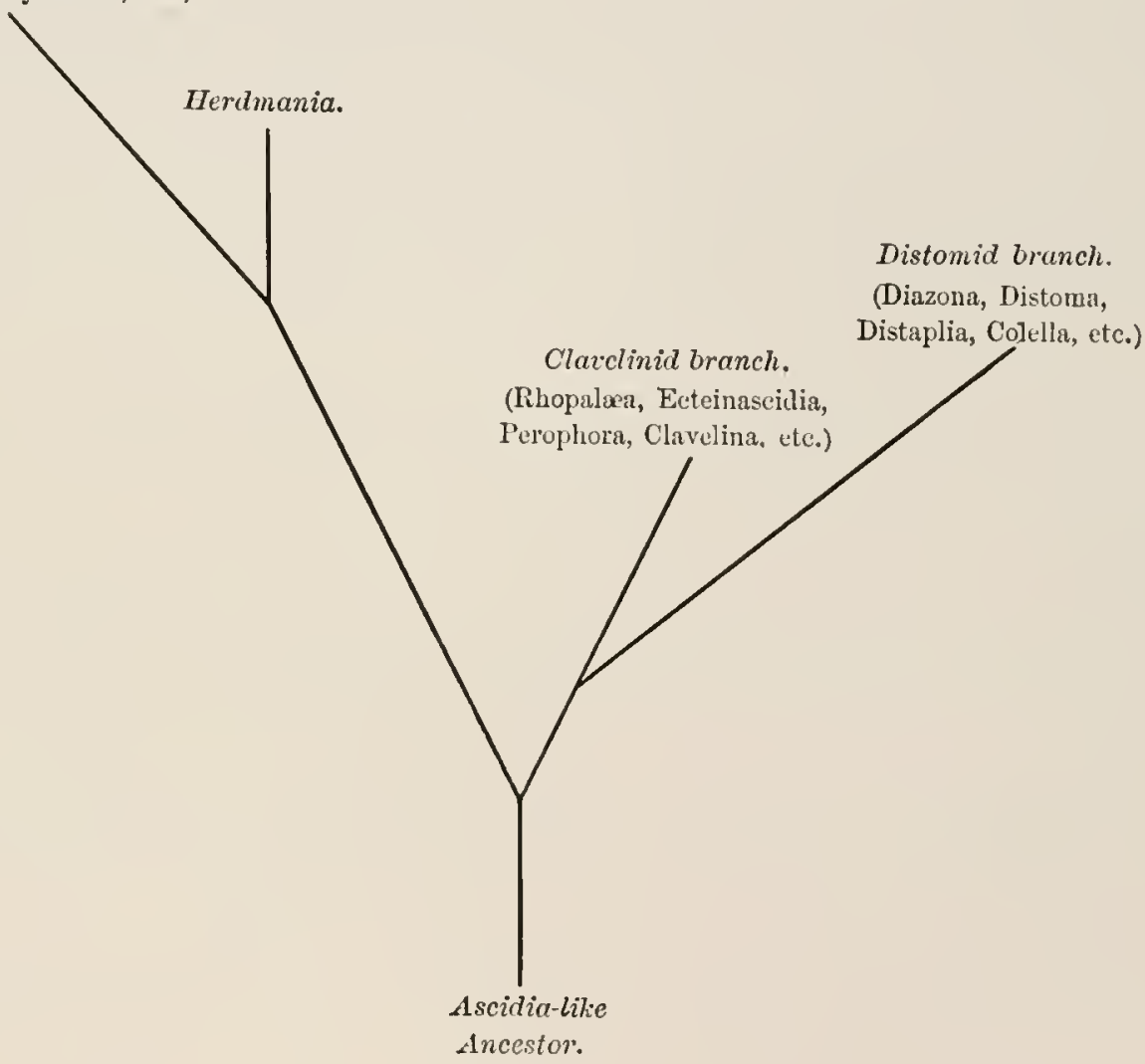

FIg. A.

ends and the relation of these to the pericardium and heart, shows as positively, it seems to me, that the two forms had a common ancestor not greatly renote; that is, less remote than the common ancestor from which this ancestor and the clavelinid stock arose. Numerous other characters of varying but subsidiary value likewise testify to the nearer relationship of Herdmania to the Polyclinida. The most important of these, in the order of their importance, are: the position of the genital glands, 
the structure of the stomach wall, and the presence of lobes on the siphons. The large number of branchial tentacles, the yolklessness of the eggs, and the traces of tubular or alveolar structure of the neural gland are all features that take the ancestral line far back toward the simple ascidians. The uterine function of the oviduct, the peculiar breaking up into groups of the branchial tentacles, and the inequality of the lobes of the branchial siphon show finally that the evolutionary way has been a lone one, for a considerable distance.

Phylogenetic trees are out of vogue just now with fashionable zoologists. Nevertheless I venture to believe that well-constructed ones always have had, and will ever continue to have, real scientific value. We can make out here with a good deal of confidence not a whole tree, indeed, but only a small branch with a few of its branchlets. The course of things that has produced the merosomatous ascidians, using this term in Herdman's restricted sense, through the "social" phases may be represented by Figure A, page 257. I try to represent here three things: (1) relationships; (2) degree of divergence from ancestral stock; and (3) degree of specialization.

\section{BIBLIOGRAPHY.}

\section{Caullery, M.}

'95. Contributions a l'étude des ascidies composées. Bull. sci. France et Belg., tom. 27, pp. 1-158, pl. 1-7. Caullery, M.

:00. Sur des Clavelines nouvelles (Synclavelina n. g.) constituant des cormes d'ascidies composées. C. R. Acad. Sci., Paris, tom. 130, pp. 1418-1420.

Garstang, W.

'91. Report on the Tunicata of Plymouth. Part I.--Clavelinidæ, Perophoridæ, Diazonidæ. Jour. Mar. Biol. Assoc., new ser., vol. 2, no. 1, pp. 47-67, pl. 2.

Garstang, W.

'95. Budding in Tunicata. Sci. Progress, vol. 3, no. 13, pp. 43-67.

Gottschaldt, R.

'94. Die Synascidien der Bremer Expedition nach Spitzbergen in Jahre 1889. Jena. Zeitschr., Bd. 28, pp. 343-369, Taf. 24-25.

Herdman, W. A.

'91. On the Genus Ecteinascidia, and its Relations, with Deseriptions of Two New Species, and a Classification of the Family Clavelinidx. Proc. and Trans. Biol. Soc., Liverpool, vol. 5, pp. 144-163, pls. 6-7.

Herdman, W. A.

'99. Descriptive Catalogue of the Tunicata in the Australian Museum, Sydney, N. S. W. Australian Museum Catalogue, no. 17, xviii +139 pp., 45 pls.

Hjort, J.

'96. Germ-layer Studies based upon the development of Ascidians. The Norwegian North-Atlantic Expedition, 1876-1878, vol, 7, Zool., 72 pp., pls. 9-12. 


\section{Kowalevsky, A.}

'74. Ueber die Ǩnospung der Ascidicn. Arch. mikr. Anat., Bd. 10, pp. 441-470, Taf. 30-31.

Lefevre, G.

'97. Budding in Ecteinascidia. Anat. Anz., Bd. 13, No. 18, pp. 473-483.

Maurice, C.

'88. Études monographique d'une espèce d'Ascidic Composée (Fragaroides aurentiacum, n. sp.). Arch. de Biol., tom. 8, pp. 205-495, pls. 16^-19.

Metcalf, M. M.

:00. Notes on the Morphology of the Tunicata. Zool. Jahrb., Abt. f. Anat., Bd. 13, Heft. 4, pp. 495-602, pls. $34-40$.

Pizon, A.

'93. Histoire de la Blastogénèse chez les Botryllides. Ann. Sci. Nat., Zool., sér. 7, tom. 14, pp. 1-386, pls. 1-9.

Ritter, W. E.

'94. Tunicata of the Pacific Coast of North America. I.-Perophora annectens n. sp. Proc. California Acad. Sci., ser. 2, vol. 4, pp. 37-85, pls. 1-3.

Ritter, W. E.

'96. Budding in Compound Ascidians, based on Studies on Goodsiria and Perophora. Jour. Morph., vol. 12 , no. 1, pp. 149-238, pls. 12-17.

Ritter, W. E.

'97. Notes on the Structure and Development of the Type of a new Family of so-called Social Ascidians from the Coast of California. Science, n. ser., vol. 5, no. 115, pp. 434-435.

Ritter, W. E.

:01. Papers from the Harriman Alaska Expedition. 23. The Ascidians. Proc. Washington Acad. Sci. vol. 3, pp. 225-266, pls. 27-30.

Salensky, w.

'92. Ueber die Thätigkeit der Kalymmocyten (Testazellen) bei der Entwicklung einiger Synascidian. Festschrift Lcuckarts, pp. 109-120, Taf. 14-15.

Salensky, W.

'93. Morphologische Studien an Tunicaten. II. Ueber die Metamorphose der Distaplia magnilarva. Morph. Jahrb., Bd. 20, pp. 449-542, Taf. 16-20.

Seeliger, 0.

'93-:02. Tunicata. Bronn's Klassen und Ordnungen des Thierreichs, Bd. 3, Supplement, pp. 1-560, Taf. 1-25. (Incomplete.)

Sluiter, C. P.

'95. Tunicaten. Semon, Zool. Forschungsreisen in Australien und dem malayischen Archipel. Jena. Denkschrift, Bd. 8, pp. 161-186, Tf. 6-10.

Dljanin, B.

'84. Die Arten der Gattung Doliolum im Golfe von Neapel und den angrenzenden Meeresabschnitten. Fauna u. Flora Neapel. 10 Monographie, viii +140 pp., 12 Taf.

Van Beneden, E., et Julin, C.

'86. Recherches sur la Morphologie des Tunicers. Arch. de Biol., tom. 6, pp. 237-476, pls. 7-16. 


\section{EXPLANATION OF PLATES XVIII-XIX.}

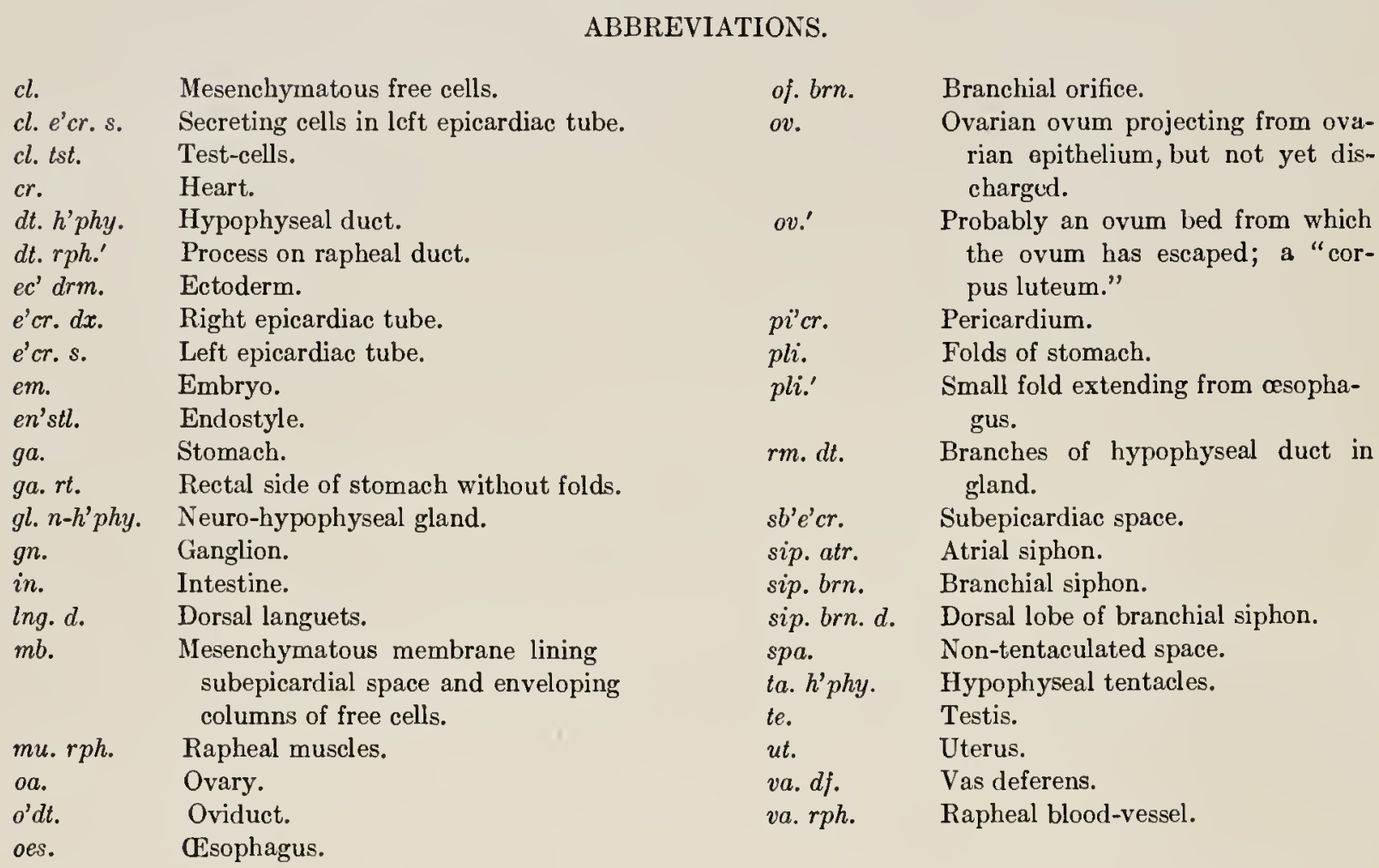

PLATE XVIII.

Fig. 1. A few zoöids from a large colony showing the general relations of the full-grown zoöids to the stolons; of the younger zoöids to the older ones; and the form of the zoöids.

Fig. 2. A single zoöid removed from the test diagrammatically drawn. The internal organs of the portion of the abdomen between the stomach and thorax may be studied without great difficulty on the cntire animal; from about the stomach back, however, the large quantity of reserve material in the mesenchyme cells renders the body opaque, so that this part of the figure has to be reconstructed from dissections and microtome sections.

Fig. 3. A typical branchial sac with the test removed.

Fig. 4. Typical front view of the branchial orifice in a preserved specimen.

Fig. 5. The peripharyngeal field, with tentacles and neuro-hypophyseal structurcs, seen from within. The rupture of the tentacular circle and the pcripharyngeal band is unfortunate, but otherwise the specimen was particularly favorable for drawing.

Fig. 6. A fragment of the dorsal part of the branehial sac, showing dorsal languets and transverse membranes.

Fig. 7. Transverse section of the stomach to show the typical arrangement of the folds.

Fig. 8. Transverse section of an abdomen in about the middle region. The embryo here cut is in the early blastula stage. The mass of cells on the upper side of the cmbryo is a small portion of the test-cells of the next embryo.

Figs. 9, 10. Two scetions of the same series from the region of the pericardium and heart. They are in order from behind forward. A third section in this same series is shown in Figure 11 (PI. XIX). 


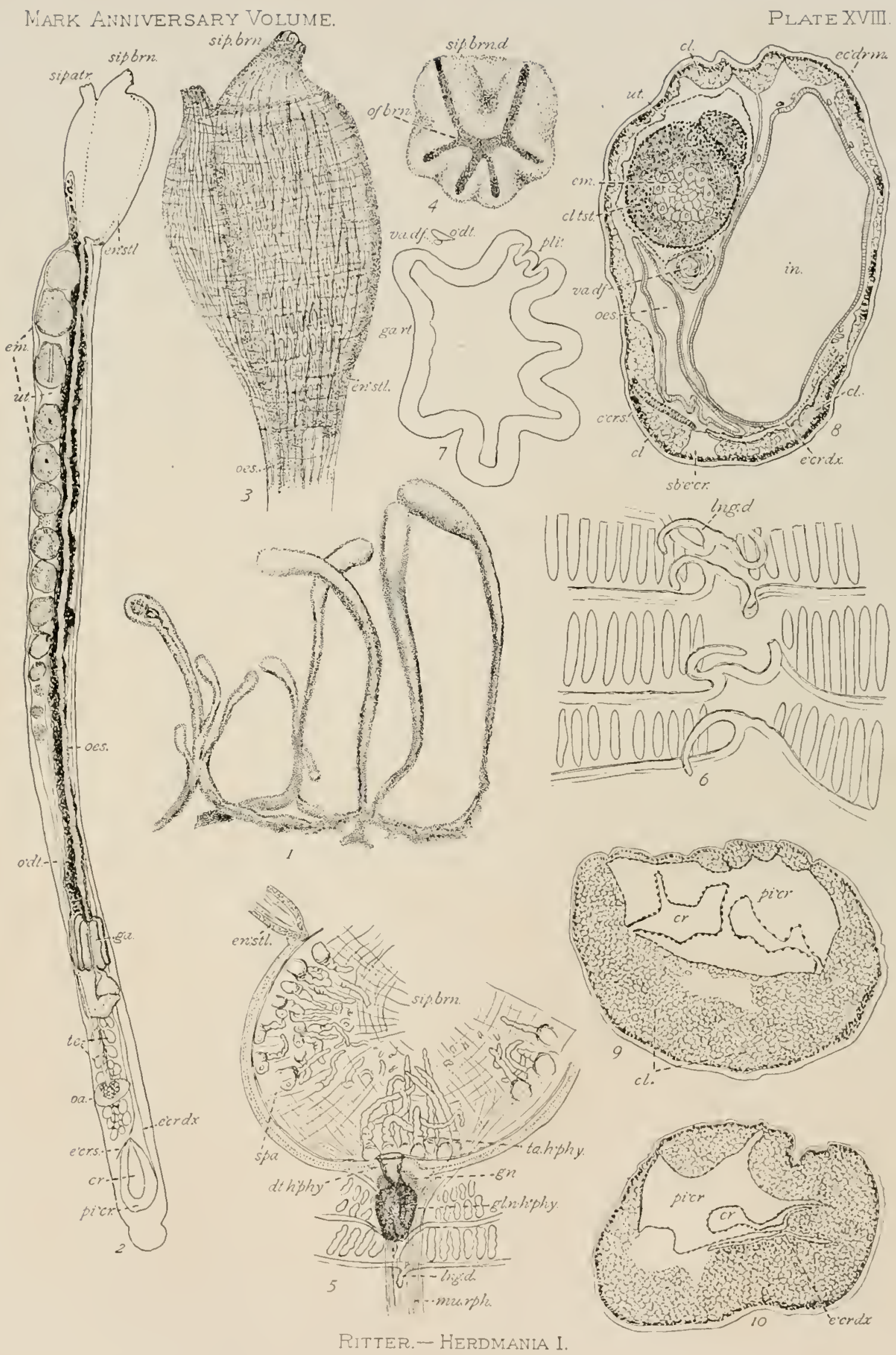





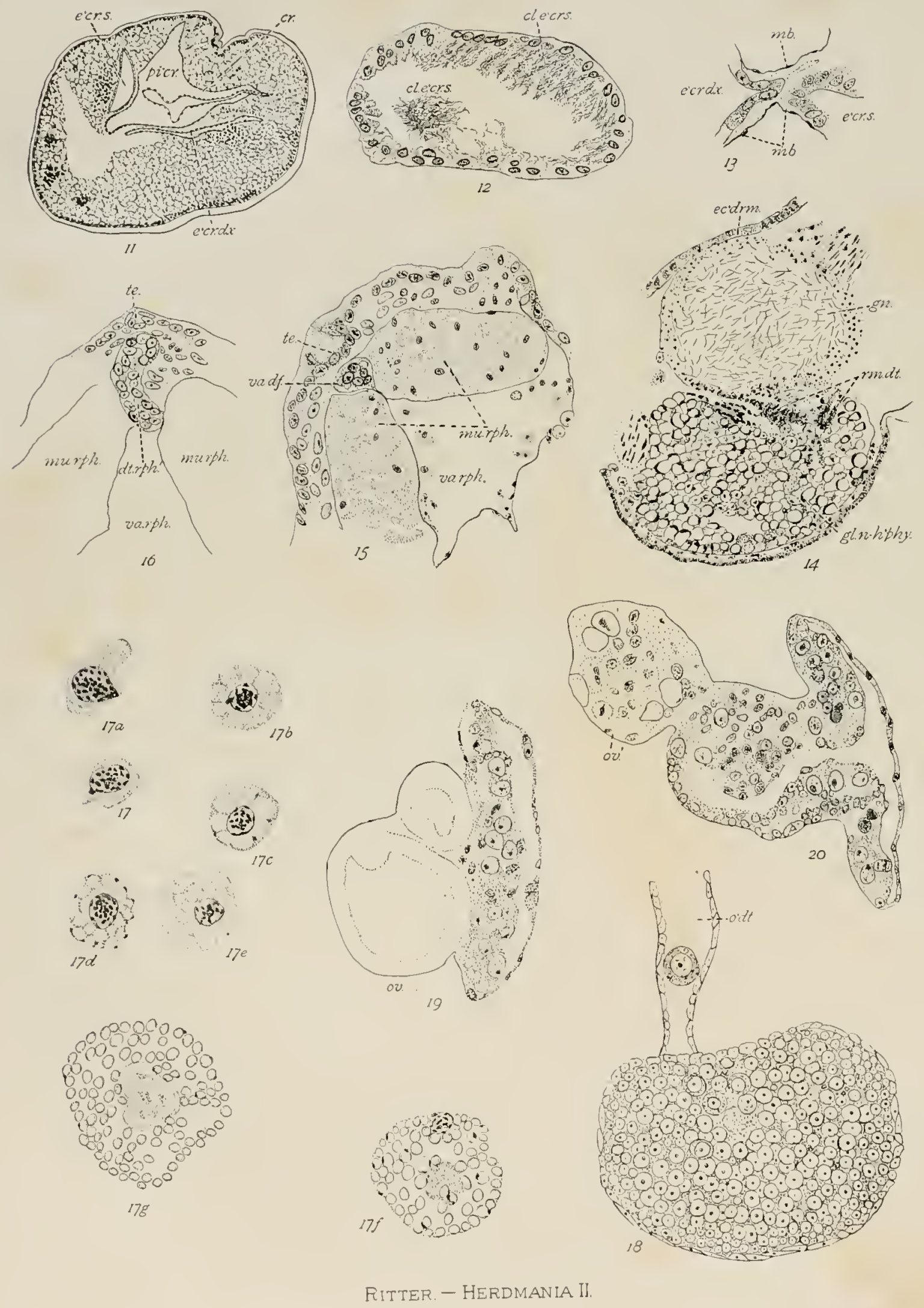


\section{PLATE XIX.}

Fig. 11. A section of the same serics from which Figures 9 and 10 (Pl. XVIII) were drawn, but from a more anterior position. The right epicardiac tube, $e^{\prime} c r . d x$, is seen on the ventral side of the pcricardium, and the left one, $e^{\prime} c r$. s., on the dorsal side.

Fig. 12. A section of the left epicardiac tube showing the thick epithelial wall on one side, and the process of secretion going on on the other side.

Fig. 13. A section of the part of the two epicardiac tubes at their contact-edges, to show that the epithelial walls are distinct from each other, and that the bridge between the two tubes is mesenchymatous.

Fig. 14. An oblique section of the ganglion and gland. A few branches, $r m d t$., of the duct within the gland are shown, as are also the large vesicular gland-cells.

Figs. 15 and 16. Two transverse sections of the rapheal region from the same series as that from which Figure 14 was drawn. In both, the lumen of the rapheal duct is undoubted. It, however, is not recognizabie in some sections of the same series. The ventral process from the duct is shown in Figurc 16.

Figs. 17 to $17 \mathrm{~g}$. A series of stages in the development of yolk-granules in the free mescnchyme cells. Figure $17 g$ shows the nucleus in a late granular stage of the cell, after it has become hypertrophied and homogeneous, and of jrregular outline. From this on it takes less and less stain, until finally it disappears entirely.

Fig. 18. An ovary as seen in a total preparation. The beginning of the oviduct and a contained ovum with as yet but a slight development of the test-cells is shown.

Fig. 19. Section from near the posterior end of an ovary showing the undivided condition of the germinal epithelium in this region. The ovum, ov., projecting from the germinal epithelium is nearly ready to escape. Its connection with the stem of the $\mathrm{T}$ of the ovary appears in sections farther forward.

Fig. 20. Section from the middle portion of the same ovary showing the prominent evagination of the epithelium in this part; ov.' is a remnant of an ovum evagination from which the ovum has escaped, a "corpus luteum" in other words. 


\section{XIII.}

THE METALLIC COLORS OF FEATHERS FROM THE SIDES OF THE NECK OF THE DOMESTIC PIGEON.

\section{(PLATE XX.)}

R. M. Strong. 


\section{INTRODUCTION.}

During the summer of $1901 \mathrm{I}$ began a study of variations in the finer structure of pigeon feathers as a basis for a study of variations in the so-called physical colors of pigeons. Among my material were a series of feathers from the necks of domestic pigeons which exhibited metallic colors or iridescence. In a former paper (Strong, :02), I have given a preliminary statement of my results with these feathers. In this paper I shall attempt to give a more complete account of my observations.

I wish here to express my thanks to Professor C. O. Whitman of the University of Chicago for the material used and for numerous courtesies received in connection with this work.

The sides of the necks of the pigeons under consideration give more or less brilliant color effects by reflected daylight. If the observer stands between the source of light and the bird, with consequent small angles of incidence and reflection, the feathers appear metallic green. If, however, the bird is placed between the light and the observer and the neck is viewed with rather large angles of incidence and reflection, purplish effects are obtained. Various attempts have been made to explain such appearances in feathers.

Altum ('54, '54 ${ }^{\mathrm{a}}$ ) and Brücke ('61) suggested that the metallic colors of feathers are interference colors due to thin laminx. Fatio ('66) did not consider the metallic colors of feathers interference phenomena, but thought they are due to conditions producing colored rings (" anneaux colorés"), which, however, he did not describe. He noted modifications in structure for metallic-colored feathers and an arrangement of pigment granules in patches corresponding to the cells composing the fundaments of the barbules.

Gadow ('82) advanced a novel but inconceivable hypothesis. He attempted to explain these phenomena as due to simple refraction, and he represented the transparent portions of barbules $*$ as acting like refracting prisms.

The following statement with reference to the metallic colors of feathers was made by Haecker ('90, p. 85): "Bei metallischen Federn sind die Fiedern II. Ordn. die Träger des Metalglanzes. Bei denselben finden sich stets Längsrillen und Längs-

* In the legend accompanying a figure, however, he calls the supposed refracting structure a "barb." I have called attention to this possibly typographical error elsewhere (Strong, :02a). 
streifen, welch Beugungserscheinungen hervorzurufen scheinen." In a subsequent paper, however, Haecker und Meyer (:01) refer to the whole subject of metallic colors as an unsolved problem.

Newbigin ('98) has also called attention to modifications in structure associated with metallic colors and to the presence of a considerable amount of dark pigment.

\section{METHODS AND MATERIAL.}

Most of my work has been done with neck feathers from the homer pigeon, but metallic-colored feathers from other birds have been examined. I have depended largely upon dissections and teased preparations of the dry feathers. Sections of feather germs were also prepared, however, by the methods described by myself in another paper (Strong, :02 $2^{\mathrm{a}}$. The sections of barbules shown in Figures 11 and 12 (Pl. XX) were obtained from cross-sections of the feather germ near its distal end, where conification was complete and the barbs were arranged approximately at right angles to the plane of section. The barbules were consequently cut somewhat obliquely, as can be seen by drawing a line across the barbules in Figure 4 at right angles to the long axis of the barb.

For the measurement of the angles made by the incident and reflected rays of light, the following simple apparatus was devised. An axis (Pl. XX, Fig. 15, d.) passing through the centre of a protractor (e.) at one end, was mounted in a pasteboard box. The feather to be examined was fastened with its dorsal surface upward on a piece of stiff black paper. This paper was glued on the axis. Various inclinations of the plane of the feather could then be measured on the protractor by an indicator $(f$.$) . Another indicator (g$.) revolving about the axis as a centre but independent in motion, was used in measuring the position of the eye. Parallel rays of sunlight were secured by reflecting sunlight from the mirror $(a$.) through a slit $(b$.) in the side of the dark chamber to the feather at $c$. I use the expression incident rays for rays of sunlight coming from the slit $(b$.) to the feather at the position $c$. The course of reflected rays, as the expression is used in this paper, was measured by means of the indicator $(g$.$) .$

\section{OBSERVATIONS.}

I. Non-metallic Color Conditions. - In order to understand properly the "modifications that accompany the production of metallic colors, we shall first consider the structure and arrangement of those portiens of the feather that do not give metallic colors. 
On plucking a single feather, one finds that the distal portion only (Fig. 1, dst'.) gives metallic colors and only from the dorsal surface. The remainder of the feather including the whole ventral surface gives dull grays and browns. It is furthermore very noticeable that the transition from the region of metallic colors to that of nonmetallic colors is abrupt.

An examination of the barbs shows that they do not differ essentially in either case. The barbules, however, present very great differences. It will be seen in Figure 1 that a single barb may have its distal portion in the region of metallic colors and the proximal part in the region where metallic colors do not occur. The barbules of both the distal and the proximal rows at the proximal end of the barb have the usual typical form for those of body coverts. They are flattened in their proximal portions and have long distal attenuated portions (Figs. 3, 5, 8). The distal barbules (Fig. 3, brbl. dst., Fig. 5) are provided with barbicels, and the proximal barbules (Fig. 3, brbl. prx., Fig. 8) have the usual recurved margin for the attachment of the hooklets of distal barbules. There is a comparatively sparse pigmentation with typical rod-shaped granules of melanin. It will be noticed that this pigmentation is in patches (Figs. 7, 9, mac. pig.) for all the barbules figured. The clear intervals between the patches are the positions of inter-cell boundaries (Figs. 7, 10, 13, $c l^{\prime}$. int.), a barbule being composed of a chain of cells placed end to end. The ventral parts of the barbules are thinner than the dorsal and have little pigment.

Both the distal and proximal rows of barbules are arranged so that their broad sides are nearly perpendicular to the plane of the feather and are, therefore, barely visible in a dorsal view. There are comparatively wide spaces between the barbules.

2. Modifications in Structure Associated with Metallic Colors.-I have shown in Figure 2 a portion of a barb and its barbules from the region of transition. It will be observed that there is a rapid modification in the form of the barbules in a comparatively short distance, correlated with the transition in color. The attenuated portion of both distal and proximal barbules are reduced and the barbicels are mostly absent. The broad flattened portions of both rows of barbules are lengthened at the same time.

In the ontogeny of these barbules, the cells composing the distal parts are not differentiated into a long attenuated extremity as is usual (Strong, :02 $2^{\mathrm{a}}$ ). They simply take the course of differentiation followed by the more proximal cells and contribute to a flattened structure. There is then a loss rather than an increase in differentiation. (Compare Figs. 5-10.)

Accompanying the changes just described is a great increase in pigmentation 
until we have the dorsal half of the barbule deep black by transmitted light except for the narrow spaces where inter-cell boundaries occur.

There is also a great change in the arrangement of the barbules. Instead of lying with their broad sides at right angles to the plane of the feather, they are turned so that one sees the flat side and not simply the dorsal margin (compare Figs. $3,4)$. The dorsal margins then rest on the median region of the next more distal barbules (Fig. 4) and the ventral sparsely pigmented halves are hidden from view. By this arrangement, only the heavily pigmented portions of the barbules are visible and a much greater amount of reflecting surface is obtained. Similar conditions were noted by Fatio ('66) in the metallic-colored feathers of some other birds. There is some variation in the sizes of these modified barbules, those near the distal end of the barb being the shortest. Individual contiguous barbules also vary a little both in size and form. They are also, as shown in Figures 2 and 4, not strictly uniform in position, there being some variation in the amount of surface hidden from view.

In Figure 4 are shown unpigmented angular processes $(b r b c$.$) at the distal ends$ of the barbules. As they make a considerable angle with the sides of the barbule they are not noticeable in the lateral views of single barbules given in Figures 7 and 10, though Figure 7 shows a portion of such a process. They seem to be vestigial barbicels.

These barbules are somewhat irregularly concavo-convex, the convex side being dorsal in Figure 4. In Figure 11 are shown sections of scveral barbules, the sections from left to right being successively nearer to the proximal end of the barbule. It will be readily seen that the concavity and convexity vary in different parts of the barbule, and a comparison of several such groups of barbule sections shows that there is considerable individual variation for different barbules in this respect.

It will be noticed on examining the two most proximal barbules in Figure 4 that the amount of unpigmented surface appears small as compared with that shown in the lateral views of single barbules given in Figures 7 and 10 . This is due to the sharp convexity of the barbule near its middle. The heavily pigmented dorsal half of the barbule makes a very small angle with the plane of the feather, whereas the ventral sparsely pigmented half makes a much larger angle and dips more or less sharply downward. (Compare Figs. 4 and 11.)

The dorsal portions of the barbules are much thickes than the ventral (Fig. 11), and the dorsal margins are rounded. There is a thin transparent layer of keratin less than one micron in thickness which encloses the cell cavities (Figs. 11, 12,tu.). This layer is very uniform in thickness and its surface is relatively smooth. The cell 
cavities are closely packed with spherical granules of melanin pigment which I frequently find lying loose outside of the barbule cell cavities in cross-sections of the feather germ. There is no indication of fusion, and the granules are of pretty uniform size. Though I have examined during the past three years many sections of fully cornified barbules containing the ordinary rod-shaped melanin granules, I have never found the granules lying loose and detached from the barbule in this way. They are usually grouped together in irregular masses and if not actually fused, they are so closely packed as to make it impossible in many cases to distinguish individual granules. Furthermore, they seem to be actually imbedded in the horny mass of the barbules which possesses no conspicuous cell cavities. In these barbules giving metallic colors, however, the spherical granules do not appear to be imbedded at all, but are simply packed in a chamber once occupied by the cytoplasm of the cell just as balls are packed in a box.

In the ontogeny of these barbules, they receive rod-shaped granules of melanin from typical pigment-cells or chromatophores in the manner described by myself (Strong, :02 ) and others. During the differentiation of the barbule cells, however, these granules are metamorphosed from the rod-like shape to a spherical form. In a single cross-section of the feather germ, one sees sections of both metallic and nonmetallic barbules. Sections of non-metallic barbules occur in the dorsal half of the feather-germ section, and sections of metallic-colored barbules in the ventral half. The rod-like shape is retained permanently in the former, whereas in the latter the spherical form is assumed. The barbule walls approach each other in the ventral half of the barbule until they are separated by an interval less than the diameter of a pigment sphere (Figs. 11, 12). This explains the very slight pigmentation of the ventral halves of the barbules.

I have not been able to find strix, ridges, pits, or knobs sufficiently numerous on the surface of the outer transparent layer to account for the observed colors by diffraction. There are sometimes suggestions of irregular strix which I believe, however, are usually optical effects only. Moreover, if these appearances are actual striæ, they do not occur frequently enough to produce the strong metallic colors of these feathers. A study of many cross-sections reveals no observable irregularities in the surface of the barbules, though views of the entire barbule show slight elevations here and there.

3. The Nature of the Color-producing Structures.-The complex details in structure that we have just noticed make interpretations of physical relations difficult. Instead of a simple prism of glass, a soap-bubble film, or an artificial diffraction grating with its precise regularity in detail, we have here many reflecting sur- 
faces of very variable form and of exceedingly small size. The color effects obtained without the aid of a microscope are necessarily mixtures of light rays from many sources.

With small angles of incidence, practically the whole barbule surface visible in Figure 4 gives green. When, however, we have the larger angles of incidence necessary for purple effects, it is easy to see that only limited portions of the barbules can give a metallic color; either the incident or the reflected ravs will be intercepted by the adjacent barbules except on the more elevated portions or when the incident rays have the directions* indicated by the arrows $g$ or $h$, Figure 4 . When the incident rays do take the direction of the arrow $g$ for instance, or a direction opposite to it, they must cross the proximal barbules at a considerable angle with consequent loss. In such a case, the distal barbules give a maximum of purple, and the proximal barbules a minimum amount. If, however, the incident rays have the direction indicated by the arrow $h$, the proximal barbules, instead, will give the maximum amount of purple, and the distal the minimum amount.

If, for instance, the incident rays pass from left to right in Figure 11, and make small angles with the plane of the feather, it is apparent that the convexity of one barbule acts as a screen for all of the next barbule surface except the corresponding convexity. If the angle of inclination is large enough to allow the incident rays to reach most of each barbule surface not actually covered by adjacent barbules, we go out of the range of purple effects and get green. When, however, the incident rays lie in the vertical plane indicated by the arrows $g$ or $h$, Figure 4 , they find no intercepting convexities. The limitations to the amount of purple that we have just noted explain the lesser brilliancy of the purple effects in feathers giving brilliant greens also.

If a single barbule is detached from the barb and examined under a $\frac{2}{3}$-inch objective by reflected light coming from the side, red or purple effects appear, mostly on the margin nearest the source of light. Over the broad surface all the colors of the spectrum are frequently seen, but green is greatly in excess of the others.

The barb itself may act as a screen when the angle of incidence is very large, and may thereby assist in reducing the amount of purple reflected.

4. Measurements of Color Ranges. - Measurements of the ranges of green and red for various inclinations of the feather with reference to the source of light and for various positions of the eye have been made by means of the apparatus described on page 266. If, for instance, the feather is placed so that the incident rays have the

* The inclination of the feather with reference to the incident rays is of course not shown by the arrow, which only indicates a vertical plane in which the incident rays pass, making various angles with reference to the feather. 
direction indicated by the arrow a, Figure 4, we may obtain a series of results with this apparatus such as are shown in Figures 16 to 21.

The least possible angle of inclination vielding a metallic color is about $10^{\circ}$ (Fig. $16, a$.). This angle seems to be limited, in the case of the proximal row of barbules, simply by the screen-like action of one barbule upon another, for I get red effects from single barbules when the angle is still smaller. In the case of the distal barbules, the barb is a screen and the slight downward dip of the barbules distally helps to keep them out of reach from the incident rays. At $24^{\circ}$ inclination (Fig. 16, b.) there is a greater amount of barbule surface reflecting purple with a consequently stronger color. Purple rays reach the eye through a range of about $50^{\circ}$; i.e., from $30^{\circ}$ to $80^{\circ}$ elevation above the plane of the feather (Fig. 16, c. to d.). Reflected rays at angles greater than $80^{\circ}$ give only traces of green from limited regions; and at less than $30^{\circ}$ a dull brown obtains.

If we make the angle of inclination $28^{\circ}$ (Fig. $17, a$.), we get a small amount of green from limited regions on the barbules through a range for reflected rays of angles more than $67^{\circ}$ (Fig. $17, b$. to a.). When the angle of inclination for incident rays is $48^{\circ}$ (Fig. $18, a$.), a limited amount of purple is reflected through a range from $7^{\circ}$ to $41^{\circ}$ (Fig. 18, b. to $c$.). Both red and green effects are obtained at elevations from $41^{\circ}$ to $57^{\circ}$ (Fig. 19 , $b$. to $c$.). At angles of elevation greater than $57^{\circ}$ (Fig. 20,a.) a brilliant green is obtained through a range up to the point where the observer's head cuts off the incident rays (Fig. 20, b. to a.). If we make the angle of inclination for incident rays $60^{\circ}$ (Fig. 21, a. ) the range of green rays begins at about $40^{\circ}$ (Fig. 21, b.).

A comparison of these results shows that when the angle made by the incident and reflected rays is about $90^{\circ}$ to $100^{\circ}$, we get a transition region between green and red for the reflected rays. Individual barbules viewed singly under the microscope, with the incident and reflected rays making an angle of about $90^{\circ}$, were found likewise to give both colors.

The inclinations and angles corresponding to those shown in Figures 16 to 21 are slightly changed when the incident rays have the general direction indicated by the arrow $b$, Figure 4. This condition seems to be due to a slight inclination of the plane of a barb and its barbules with reference to the plane of the feather. The distal ends of the proximal barbules are therefore lower than the distal ends of the distal barbules. This is necessary at the proximal end of the barb especially in order that the distal barbules may lie dorsal to the proximal barbules and be attached to them by means of their ventrally arranged barbicels. The smallest angle of inclination possible to secure purple effects, for instance, is then about $30^{\circ}$ instead of $10^{\circ}$ (Fig. $16, a$.). 
As has been stated before in this paper, these measurements are only approximate estimates. The complex individual variations in the color-producing structures make attempts at greater precision of no value in a paper of this nature.

We may sum up these observations as follows: (1) when the sum of the angles of incidence and reflection is less than about $90^{\circ}$ and the incident rays make an angle of at least $48^{\circ}$ with the plane of the feather, a brilliant green is obtained; (2) when the sum of these angles is greater than $100^{\circ}$ and less than $140^{\circ}$, purple effects are obtained; (3) when the sum of the angles is greater than $140^{\circ}$, no metallic colors appear.

The refraction-prism hypothesis of Gadow ('82) requires that the angle or series of angles just described be more than $180^{\circ}$, a physical impossibility here, for the following reasons: (1) either the incident or the reflected ("refracted") rays would be intercepted by the contiguous barbules or by the barb; (2) metallic colors do not appear unless this angle is more than $140^{\circ}$. "Refracted" rays that could possibly reach the eye would require a source for the incident rays ventral to the feather, whereas the illumination is necessarily dorsal.

5. The Nature of the Metallic Colors._Even if the surface of the barbule were covered with ridges or striæ, it is inconceivable that they could produce these metalliccolor phenomena. Reflection gratings give nothing comparable to these effects; they require special conditions of illumination with parallel rays of light passed through a narrow slit, whereas the feather is iridescent in diffused daylight. Having satisfied myself that the metallic colors under consideration are not reflecting-grating effects produced by striæ, ridges, knobs, or pits on the barbule surface, I was led to favor the thin-plate hypothesis of Altum ('54, '54') and Brücke ('61). The outer transparent layer (Figs. 11, 12,tu.) is thin enough to produce interference colors, being not more than three half green-wave lengths in thickness. Furthermore, it is very uniform in thickness and has a comparatively smooth surface, as I have pointed out before in this paper. The constant occurrence of pigment granules of a spherical shape only in the barbules giving metallic colors, however, seemed too significant to warrant accepting the thin-plate hypothesis without qualification.

At first I had regarded the function of the pigment simply that of an absorbing background. I mounted a feather on a pad of paper and placed the mount on the stage of a microscope. By means of a mirror, strong sunlight was reflected from the side on the feather, and portions of single barbules were examined with a Leitz No. 7 dry objective. The view obtained was exceedingly suggestive. There was no uniform glow of diffracted light such as is ordinarily obtained from thin plates. On the contrary, there appeared a large number of small glowing dots in a black field. 
All the colors of the spectrum were visible, especially towards the margin, where the reds were in excess. Over the broad surface of the barbule the luminous dots* were yellowish green to pure green.

It at once occurred to me that there was a direct connection between the metallic colors of the feathers under consideration and the pigment granules. The size and distribution of the luminous dots corresponded with the size and arrangement of the spherical pigment granules lying next to the transparent outer wall.

I had often observed the upper portions of these granules outlined against the transparent enclosing layer, along the dorsal margin (Figs. 12, 13). In this view by reflected sunlight minute beads of either white, red, or yellow light were outlined just where I had so often seen the dark forms of the pigment spheres by transmitted light. It occurred to me at first that the pigment spheres were producing diffraction effects such as the well-known interference colors of small particles described by Tyndall ('69), Rayleigh ('99), and others. It seems more likely that we have thin-plate interference or Newton's-rings effects where each pigment granule touches the thin, outer transparent layer. The pigment granules act as a reflecting mirror. Often they lie a little above the level of the outer surfaces of surrounding pigment granules, and in such cases they are easily seen to be the centre of light dispersion. When small fragments of a harbule are obtained by crushing, the relation in position of the color phenomena to individual pigment granules is seen to advantage. The pigment also plays a very important rôle in absorbing light not reflected to the eye as metallic color. Where the pigment is absent or sparsely distributed, there is a flood of white light which destroys metallic color effects if they occur at all. It is for this reason that the ventral side of the feather is not iridescent. The spherical pigment granules also present the phenomena of "anomalous dispersion." By transmitted light they are dark brown,-almost black; with reflected light, however, they are a light metallic or yellowish brown. In strong, reflected sunlight, they appear as brilliantly glistening bodies as is characteristic of bodies of such small size.

The colors observed with the naked eye are mixtures of light rays coming from innumerable small points. Individual cells of the barbule vary in the color given for a single position of the feather with reference to the source of light and the eye, but the color is fairly uniform over the surface of a single cell.

* When the barbules are immersed in cedar oil and xylol, fluids having approximately the same index of refraction as keratin, these appearances disappear to a greater or less extent. 


\section{SUMMARY.}

1. The metallic colors or iridescence of the sides of the neck of gray domestic pigeons are confined to the dorsal surfaces of the distal portions of the feathers. Other parts of the feather give dull browns and grays.

2. Individual barbs have more or less of their proximal portions in the nonmetallic region. The transition from metallic colors to non-metallic colors is abrupt, and there is a correlated modification in the structure and pigmentation of the barbules.

3. The barbules of the proximal, non-metallic-colored region are of the typical form for body coverts. In the distal, metallic-colored region the barbules are turned so that one side faces upward. Barbicels and attenuated portions are absent. A much greater reflecting surface is obtained by this arrangement.

4. The barbules giving metallic colors are much more heavily pigmented in their dorsal halves than those with non-metallic colors. The ventral halves have very little pigment, but they are concealed in a dorsal view by overlapping adjacent barbules.

5. Individual metallic-colored barbules are irregularly concavo-convex, the convex side being dorsal. The dorsal halves are much thicker than the ventral. There is an outer transparent wall of keratin which encloses cell-cavities filled with pigment. This layer is quite uniform in thickness and less than one micron thick.

6. The pigment of the metallic-colored barbules is in the form of spherical granules of melanin, whereas the non-metallic-colored barbules have typical rod-shaped granules imbedded in irregular masses in the horn substance of the barbule. In the ontogeny of the feather, typical pigment-cells or chromatophores are formed which distribute melanin pigment-rods to the barbule cells in the usual manner. In those cells composing the fundaments of metallic-colored barbules, however, these pigment-rods are metamorphosed into spherical granules.

7. I have observed no striæ, ridges, knobs, or pits on the outer surface of the barbule sufficiently numerous or uniform enough to produce the observed colors by diffraction.

8. The structures producing metallic colors have many complex variations in surface. Individual barbules and the barb itself act as screens for portions of adjacent barbules when the angles of incidence and reflection are large, thereby reducing the total amount of surface producing metallic colors. 
9. Green is obtained from these feathers when the angle made by the incident and reflected rays is less than about $90^{\circ}$ and the incident rays make an angle of at least $48^{\circ}$ with the plane of the feather. Purple effects appear when the angle of incident and reflected rays is greater than $100^{\circ}$ and less than $140^{\circ}$, the incident rays making an angle of at least $10^{\circ}$ with the plane of the feather. At angles greater than $140^{\circ}$ non-metallic colors appear.

10. The refraction-prism hypothesis of Gadow ('82) is untenable, for it requires that the incident rays make an angle of more than $180^{\circ}$ with the reflected ("refracted") rays-a physical impossibility in such a structure as the feather where the illumination and color effects are necessarily dorsal.

11. The metallic colors of these feathers are probably thin-plate interference colors or Newton's-rings effects which are produced where spherical pigment granules come in contact with the outer transparent layer. The pigment also has the very important function of absorbing light not reflected to the eye as metallic color. The colors seen without a microscope are mixtures of colors from innumerable small points.

\section{BIBLIOGRAPHY.}

Altum, B.

'54. Ueber den Bau der Federn als Grund ihrer Färbung. Jour. f. Ornith., Jahrg. 2, pp. xix-xxxv.

Altum, B.

'54 $4^{\mathrm{a}}$. Ueber die Farben der Vogelfedern im Allgemeinen, über das Schillern insbesondere. 'Naumannia, Jahrg. 1854, pp. 293-304.

Bricke, E.

'61. Ueber den Metallglanz. Sitzungsb. Akad. Wiss. Wien., math.-naturw. Cl., Bd. 43, Abt. 2, pp. 177-192.

Fatio, V.

'66. Des diverses modifications dans les Formes et la Coloration des Plumes. Mém. Soc. Phys. et Hist. Nat. Genève, tom. 18, pt. 2, pp. 249-308, 3 pls.

Gadow, $\mathbf{H}$.

'82. On the Colour of Feathers as affected by their Structure. Proc. Zool. Soc., London, 1882, pp. 409421 , pls. 27-28, 3 text figures.

Haecker, V.

'90. Ueber die Farben der Vogelfedern. Arch. f. mikr. Anat., Bd. 35, Heft 1, pp. 68-87, Taf. 4.

Haecker, V., und Meyer, G.

:01. Die blaue Farbe der Vogclfedern. Zool. Jahrb. Abt. f. Syst., Bd. 15, Heft 2, pp. 267-294, Taf. 14.

Newbigin, M. I.

'98. Colour in Nature. A study in Biology. London, $8^{\circ}$, xii +344 pp.

Rayleigh, Lord.

'99. On the Transmission of Light through an Atmosphere containing Small Particles in Suspension, and on the Origin of the Blue of the Sky. Phil. Mag., ser. 5, vol. 47, pp. 375-384. 
Strong, R. M.

:02. The Metallic Colors of Feathers from the Neck of the Domestic Pigeon. Biol. Bull., vol. 3, nos. 1 and 2 , pp. 85-87.

Strong, R. M.

:02 . The Development of Color in the Definitive Feather. Bull. Mus. Comp. Zoöl. Harvard Coll., vol. 40 , no. 3 , pp. 147-185, pls. 1-9.

Tyndall, J.

'69. On the Blue Colour of the Sky, the Polarization of Skylight, and on the Polarization of Light by Cloudy Matter generally. Phil. Mag., ser. 4, vol. 37, pp. 384-394.

\section{EXPLANATION OF PLATE XX.}

Figures 1-14 were outlined with the aid of an Abbé camera lucida. Figures 2-10 were drawn from dissected preparations mounted dry on the slide. Figures 11-14 are from preparations mounted in balsam. Figures 5-10 are lateral views of single barbules. All figures were made from the feather shown in Figure 1 or from a similar feather.

\begin{tabular}{llll} 
& \multicolumn{3}{c}{ ABBREVIATIONS (Figs. 1-14). } \\
brb. & Barb. & $d s t$. & Distal. \\
$b r b c$. & Barbicel. & $d s t^{\prime}$. & Distal iridescent portion of feather. \\
$b r b c^{\prime}$. & Vestigial barbicel. & gran. pig. & Pigment-granules. \\
$b r b l$. & Barbule. & mac. pig. & Pigment-patches. \\
$b r b l . d s t$. & Distal barbule. & marg. & Recurved margin. \\
$b r b l . p r x$. & Proximal barbule. & $n l^{\prime}$. & Position of nucleus. \\
$c l^{\prime} . i n t$. & Inter-cell boundary. & $p r x$. & Proximal. \\
$d$. & Dorsal. & $t u$. & Outer transparent layer of barbule. \\
$d^{\prime}$. & Dorsal iridescent face of barbule. & $v$. & Ventral.
\end{tabular}

\section{LATE XX.}

Fig. 1. Dorsal view of a feather from the side of the neck of a homer pigeon giving metallic colors. Only the darkened distal portion $\left(d s t^{\prime}\right.$.) shows these colors. $\times 1$.

Fig. 2. Dorsal view of a barb and its barbules in the region of transition from non-metallic to metallic colors. $\quad \times 37$.

Fig. 3. Dorsal view of a portion of a barb and its barbules near the proximal end of the barb, from the right side of the feather shown in Figure $1 . \times 100$.

Fig. 4. Dorsal view of barbules from the metallic-colored region of the barb used for Figure 3 ; $b r b c^{\prime}$., vestigial barbicels. $\times 100$.

Fig. 5. Distal barbule from the region shown in Figure $3 . \times 100$.

Fig. 6. Distal barbule from the transitional region shown in Figure $2 . \quad \times 100$.

Fig. 7. Distal barbule from the region shown in Figure $4 . \times 100$.

Fig. 8. Proximal barbule from the region shown in Figure $3 . \times 100$.

Fig. 9. Proximal barbule from the transitional region shown in Figure $2 . \quad \times 100$.

Fig. 10. Proximal barbule from the region shown in Figure $4 . \quad \times 100$.

Fig. 11. Cross-sections of several barbules cut somewhat obliquely. Section prx'. represents a barbule near its attachment to the barb, and section $d s t^{\prime}$. a more distal portion of another barbule. $\times 540$.

Fig. 12. Cross-section of a barbule similar to those shown in Figure $11 . \times 1080$.

Fig. 13. A lateral, sectional view of a metallic-colored barbule near its middle. $\times 540$. 


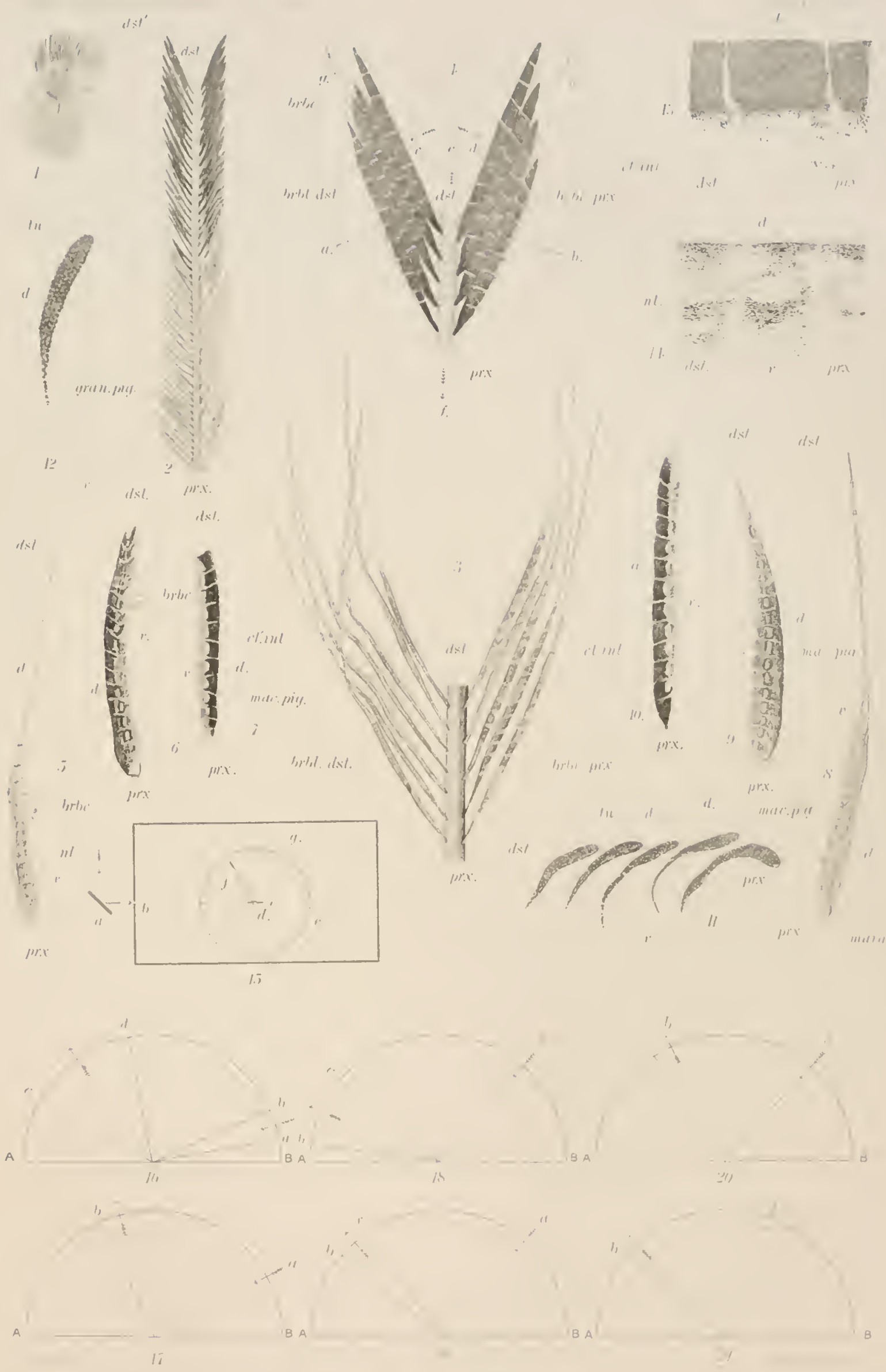



Fig. 14. A lateral sectional view of a non-metallic-colored barbule from the proximal end of a barb. $\times 540$.

Fig. 15. Diagrammatic sectional view of the apparatus used in mcasuring color ranges. $a$, mirror; $b$, slit in wall of dark chamber; $c$, position of feather; $d$, axis; $e$, protractor; $f$, indicator of inclination of feather; $g$, indicator for position of eye.

Figs. 16-21. Diagrams indicating relative positions of the observer's eye and the feathcr with respect to parallel rays of sunlight, for metallic colors. The line $A B$ represents the plane of the feather. The arrows indicate the direction of the light from its source to the feather (incident rays) and thence to the eye (reflected rays). The source of light is always on the right side. (See pp. 270-272.) 



\section{XIV.}

ON THE NATURE OF EDESTUS AND RELATED FORMS.

(PLATE XXI.)

C R. Eastman. 
, 


\section{THE NATURE OF EDESTUS AND RELATED FORMS.}

In that rich treasure-house of anatomical information, Owen's Anatomy or Vertebrates, under the caption of the Skull of Osseous Fishes, we read as follows: "It is truly remarkable, writes the gifted Oken, what it costs to solve any one problem in Philosophical Anatomy. Without knowing the what, the how, and the why, one may stand, not for hours or days, but weeks, before a fish's skull, and our contemplation will be little more than a vacant stare at its complex, stalactitic form."

If such bewilderment is possible, nay rather, if it be the common experience of students in their initial attempt at homologizing the bones of the head in recent vertebrates, how much more intricate is the problem confronting the palæozoölogist when surveying only fragmentary remains, and deprived of all save the most meagre points of orientation? And yet it not unfrequently happens in palæontology that, through some fortunate discovery or other, a fresh clue is found, or a new point of view obtained, and that which was formerly obscure suddenly becomes illuminated. The what, the how, and the why no longer elude our grasp, and once enigmatical structures or organisms assume their proper place in an orderly system.

A striking example of this nature is furnished by the history of Edestus and kindred fossil remains occurring in the Carboniferous and Permian rocks of Europe, North America, and Australia, concerning which much diversity of opinion has existedOccurring as they do singly, and always in a detached condition, these objects have been most frequently looked upon as selachian fin-spines, although their correspondence with dental structures has been patent to nearly all writers. Originally regarded by Leidy ('56, p. 414) as part of a fish-jaw segmented like that of Lepidosteus, and compared by L. Agassiz (see E. Hitchcock, '56, p. 229) with the rostral prolongation of Pristis, the remains of Edestus were later classed'by Leidy ('57, p. 301) and Owen ('61, p. 123) with dermal defences of sharks or skates, and referred to a position in advance of the dorsal fin. The resemblance between their segmented character and that of the pectoral fin-spines of Protosphyræna ("Pelecopterus") was pointed out by Cope ('75, p. 244) and by H. Woodward ('86, p. 120). Newberry ('88, p. 120) suggested that the fused segments of Edestus may correspond to a series of spines such as occurs upon the tail in some species of Trygon, and in furtherance of the same general idea, Dean ('98, p. 67) supposed them to have had a metameral origin in the anterior muscles of the trunk, from which position they "may have mi- 
grated forward," being located in at least one species "somewhere upon the headregion, perhaps above or behind the eye."

Trautschold ('84, p. 160) revives the original hypothesis of Leidy, and Miss Hitchcock agrees with both of these authors in recognizing the odontological nature of Edestus. In a paper of which only abstracts have been published ('87, p. 260), she compares these fossils with the intermandibular arch of Onychodus, and locates the segments definitely in the mouth region. The reasons which invalidate her interpretation have been pointed out by Newberry, Dean, and Karpinsky ('99, p. 446), although a somewhat analogous position has been suggested by the latter in his discussion of Helicoprion. The Russian Director, as an alternative hypothesis to regarding the thrice-coiled spirals of Helicoprion as caudal spines, advances the conjecture that the whorls protruded freely from the mouth-cavity above the head in front, and served as formidable weapons for defence and offence, each individual possessing but a single organ of this kind. In an appreciative review of Karpinsky's memoir, entitled "Helicoprion, Spine or Tooth?" A. S. Woodward (:00, p. 33) inclines to the opinion that of the two rival theories regarding the nature of Edestus, that one is the more plausible which claims them as dental structures. In support of this view Dr. Woodward cites various examples of coiling amongst both crushing and piercing forms of sharks' teeth, although admitting that "the conception of a gigantic shark armed in both jaws with several series (whorls) of teeth, like those now described under the name of Helicoprion, is indeed sufficiently startling."

Following closely upon Woodward's critique, three short notices appeared, those by Jaekel $(: 00$, p. 147) and by Fuchs (:00, p. 6) affirming, and that by Klaatsch $(: 01$, p. 433) denying, its dental nature; and the form was also reported by Koken (:01, p. 225) as occurring in the Salt Range of India.* Helicoprion is compared by the firstnamed author with Janassa, and directly referred to the Petalodonts, and by the second it is held to be analogous to the existing Raja. Klaatsch, per contra (:01, p. 433), asserts that "es besteht kein Grund für die Annahme, dass die HelicoprionStacheln in der Mundregion gesessen haben." This author puts forward the extraordinary proposition that the segments were not coiled during the life of the creature, the spiral form having been brought about by posthumous deformation,a speculation that may be dismissed without further comment.

Some comparisons with Palæozoic coiled teeth were made by the present writer (:00, p. 581) in still another review of Karpinsky's memoir, and although he rejected both of the Russian author's hypotheses, no new position was assigned for these problematical bodies at that time. A year later, however, after a fortunate dis-

* It is now known also from Japan (Yabe, :03, p. 3). 
covery of Campodus by Prof. E. H Barbour had thrown new light on the whole matter, they were positively determined as arched or coiled series of symphysial teeth belonging to cestraciont sharks. The evidence for this was presented by the writer before the Denver meeting of the American Association for the Advancement of Science, and in the published abstracts of that paper (:01, p. 795) the arrangement of the symphysial series in Campodus variabilis (N. and W.) was briefly described. The most recent contribution to the literature of this subject is contained in the current volume of the Bulletin of the Museum of Comparative Zoölogy (Eastman, :02), where the same interpretation is still further elaborated.

It will be seen from the foregoing review that authors have been about equally divided between the two leading theories of Edestus, one of which ascribes them to the jaws, the other to the external dermal armor of a shark or skate, and that until recently, confirmation of either by direct evidence has been wanting. Attention is now invited to lately acquired evidence of this nature, which is alone competent to decide the issue. This evidence is furnished by three remarkable specimens of Campodus variabilis (N. and W.) from the Coal Measures of Kansas and Nebraska, which together afford a complete understanding of the dentition in the group of cestraciont sharks to which this species belongs. The thesis is maintained that the fused segments of Edestus, Campyloprion and Helicoprion are veritable teeth corresponding to the symphysial series of Campodus, which are enormously enlarged as compared with those of Cestracion and other recent sharks; and also that these four Carboniferous and Permian genera together constitute a remarkable series, in which the progress of evolution is readily traceable. Beginning with Campodus, we are enabled to note in the species of Edestus and Campyloprion the progressive stages by which the typical orodont dentition of the Lower Carboniferous passed into the excessively modified spirals of Helicoprion before the close of the Palæozoic.

Before proceeding to develop our present thesis, however, we may briefly consider the arguments which have been urged for excluding Edestus and related forms from the mouth region. The question as to what portion of a fish is represented by Edestus has been ably discussed by three recent writers,-Newberry, Dean, and Karpinsky. From Dean's concise statements ('98, p. 66) we quote as follows:

"Accepting as a logical necessity that the fossil is elasmobranchian, the choice of its location cannot be a wide one; it must have belonged either in the mouth region or on the body surface, in the latter case evidently as a spine. As to its belonging in the mouth region the segmented nature of its base has ever precluded the view that it was in any way connected with Meckelian or palato-quadrate structures. And as an intermandibular element its position is even less plausible. For ... one 
would have to assume that this intermandibular, which in the only teleostome in which it occurs is in its basis a dermal structure, has not merely been paralleled by the far different jaw conditions of an elasmobranch, but has been paralleled in a cartilaginous tissue. Moreover, even granting the possibility of this, the comparison with an intermandibular element could not yet be made, for in Edestus the shaft is segmented, and in Onychodus its basal portion is unquestionably a single piece."

Newberry's line of argument ('88, p. 118), in his discussion of the same question, is as follows:

"The suggestion of Miss Hitchcock, that Edestus is an intermandibular bony arch carrying teeth, is not incompatible with its bilateral symmetry; but we here meet the difficulty already suggested, that Onychodus, the only fish known which had such an intermandibular arch of bone, was a scaled ganoid allied to Polypterus, and has left abundant bones besides its intermandibular arch. . . . It is of course not impossible that this singular form of dentition might have been borrowed by some plagiostome which used it to accomplish a similar function; but no facts are yet known to warrant this supposition.

"Edestus davisii is more like the intermandibular crest of Onychodus than are the other species of the genus. . . Taken by itself, it renders the suggestion of Miss Hitchcock quite plausible. But it cannot be taken by itself, for wherever that species goes, E. minor, E. heinrichi, and E. giganteus must follow; and while we can imagine a fish ten feet long with an arch of bone like E. davisii held between the extremities of the mandibles, it requires a much greater stretch of the imagination to conceive of a shark of such size that this relatively insignificant organ was twenty inches long and seven or eight inches wide. Certainly such a monster would seem very much out of place in the lagoons of the coal marshes. Again, E. heinrichi is nearly straight, a foot long, rounded and massive at one end, thin and acute at the other; but the succession of denticles was by additions at the acute end, which must have been behind, and if it was situated in the symphysis, the blunt rounded end would have formed the apex of the arch of the lower jaw-a condition of things scarcely comprehensible.

"If now we transfer this spine to the position of the post-dorsal fin, and bury it in the soft parts all except the denticles, the elongation backward by the successive addition of sheaths and denticles becomes intelligible and natural."

Karpinsky's reasons ('99, pp. 446 and 469) for excluding the fused segments of Edestus and Helicoprion from the mouth cavity are very positively stated, as will be seen from the following extract:

"Die äusseren Merkmale der von uns besprochenen Helicoprion-Reste entziehen 
auch der Vermuthung, die Spirale hätte, sich in der Mundhöhle befunden, den Boden, sowohl in dem Sinne, wie er anfänglich von Leidy und Hitcheock angenommen wurde, sondern auch im Sinne eines 'intermandibular arch,' wie Miss Hitcheock vermuthete, was am besten auf Edestus davisii, d.h. auf die Gattung Helicoprion anwendbar schien. . . Ferner kann man noch hinzufügen, dass auch der Bau der Basis der Spiralwindungen der Hypothese von Miss Hitcheock widerspricht.

"Nur die Schlusse: (1) dass die Edestiden in der That zu den Elasmobranchiern gehören, (2) dass die Spirale von Helicoprion und das entsprechende Organ von Edestus nicht frei gestanden hat, d.h. dass ihre Segmentbasen in die Weichtheile des Thieres eingebettet gewesen sind, (3) dass die besprochenen Organe in die Medianebene des Thieres zu verlegen sind, und (4) dass der grösste Theil der Helicoprionspirale, sowie das entsprechende Organ von Edlestus äusserlich angebracht gewesen ist, können als ausgemacht gelten. Alle übrigen Schlussfolgerungen in Betreff der Morphologie der Edestiden dagegen werden vermuthlich noch lange in den Augen der Forscher als unbewiesene Hypothesen dastehen.

"Und es liegt keineswegs ausserhalb des Bereichs der Wahrscheinlichkeit, dass in der Folge solche den Edlestidenresten ähnlichen Organe entdeckt werden, von denen wir im Augenblick noch keine Ahnung haben."

It is thus clear that the objections to referring Edestus-like structures to the mouth region are altogether of a theoretical nature, due partly to a priori conceptions, and in still larger measure to ignorance of the extent to which certain peculiarities in the growth of teeth prevailed amongst Palæozoic sharks. For instance, we have only recently gained the information, through a study of such forms as Protodus, Periplectrodus, Campodus, and certain cochliodonts, that there were not only Palæozoic sharks with crushing teeth, but also others with sharp, piercing teeth, which were never shed, but became fused into whorls as the animal grew. And without a knowledge of the symphysial dentition in Campodus, certainly no one could have suspected such enormous disparity in size to exist between this and the lateral series. According to our thesis, we must look to this latter circumstance for a key to the solution of the whole problem of the "Edestidx."

With the enlightenment furnished by Campodus in this respect, we are enabled to appreciate the force of the following considerations, namely, the histological structure of Edestus and related genera is entirely in accord with their interpretation as teeth; the segments in all these forms exhibit the same general pattern, are similarly arranged, similarly fused, and similarly nourished by a continuous nutritive canal. And as a logical necessity from their being homologous structures in every respect, it follows that they were all located like Campodus in the mouth cavity. For the 
sake of comparison, we may briefly summarize the characters of the four genera in question, arranged in the order of their progressive modifications, as follows:

I. Campodus. - Symphysial dentition consisting of a median azygous arched series of fused teeth in one jaw, presumably the lower, opposed to which in (presumably) the upper jaw is a paired series of corresponding teeth mutually separated, and interlocking with the first. These series consist of at least thirteen greatly enlarged teeth which are but little laterally compressed, whose coronal buttresses are directed anteriorly, and whose crowns are inclined in the same direction, but without being bent so as sensibly to override one another. Coronal apices very stout and prominent, rather obtuse, their anterior and posterior margins sharp and smooth or but faintly wrinkled. Lateral dentition consisting of about 20 transverse series of Orodus-like teeth, arranged after the same general pattern as in Cestracion. Other parts of the skeleton unknown. Carboniferous. Type, C. agassizianus de Koninck.

2. Edestus. - Symphysial dentition consisting of a moderately arched series of fused teeth, which are fewer in number ( 5 to 8 ) than in the preceding genus, and more laterally compressed. The segments are bent forward in such manner that the base (corresponding to the enormously produced root) of each tooth ensheathes those lying next in front. Coronal apices prominent, usually acuminate, and with coarsely serrated anterior and posterior cutting margins, the latter more steeply inclined than the former. Remainder of crown (corresponding to lateral extensions of Campodus) greatly reduced. Lateral series and other parts of the skeleton unknown. Upper Carboniferous. Type, E. vorax Leidy.

3. Campyloprion. - Symphysial dentition consisting of a strongly arched series of fused teeth, which are relatively more numerous (14 to 20 or more) than in the preceding genera, higher-crowned, and more laterally compressed. Teeth reflected forward so as to override one another toward their extremities, and fused for the greater portion of their length. Coronal apices acuminate, finely serrated, and more closely apposed to one another than in preceding genera. Series traversed by a median longitudinal channel along the base, but without lateral grooves. Lateral series and other parts of the skeleton unknown. Carboniferous. Type, C. lecontei Dean.*

4. Helicoprion. - Symphysial series consisting of upwards of 150 fused teeth, very similar to the last in form, but coiled into approximately $3 \frac{1}{2}$ whorls. Teeth much compressed laterally, bent forward so as to override one another toward the base, and traversed by a double lateral groove, as well as by a median longitudinal channel along the base. Coronal apices acuminate, finely serrated along their an-

* Substituted in place of C. annectans, which, according to Karpinsky (litt. 1902), approaches very closely the type of Helicoprion. 
terior and posterior margins, and closely apposed to one another. Lateral series and other parts of the skeleton unknown. Permo-Carboniferous. Type, H. bessonowi Karpinsky.

A comparison of the individual segments in these closely related genera is instructive, more especially so between Edestus and Campodus. Reckoning the latter as the least specialized member of the series, we find that the symphysial teeth are but little differentiated from the lateral, except that they are excessively enlarged. They are only moderately compressed from side to side, the lateral extensions of their crowns are directed simply forward, without appreciable curvature toward the base, and their fused roots are supported by the Meckelian cartilage without being anteriorly produced. The coronal apices are very stout, rather obtuse, and with sharp, non-crenulated cutting edges, although faint wrinkles sometimes appear in the youngest-formed teeth. The transverse ridge extending over the coronal surface, and so prominent in the lateral series slightly ectad of the median line of the teeth, is obsolescent in the symphysial series. And finally, the series is not more strongly arched than is the case in Cestracion or other recent sharks having the symphysial cartilage well developed; nor does it comprise a larger number of segments, Campodus having at least thirteen, and Cestracion sometimes as many as fifteen.

In the evolution of Edestus and the more strongly coiled genera, the symphysial teeth have become considerably differentiated in form from those of the lateral series, their chief modifications consisting in a greater compression of the crown from side to side with serration of its apical margins, a pronounced forward curvature toward the base, and, in Edestus, an extreme elongation of the latter into a succession of gouge-like troughs or sheaths. With increasing compression of the segments, their basal portions become more closely crowded together, and more intimately fused at their extremities into a common mass of vasodentine, in consequence whereof a spiral enrollment of the series follows as a matter of course, since the individual segments can no longer be shed during growth. In Helicoprion the lateral compression, fusion, multiplication, and involution of symphysial teeth is carried to an extreme degree, the progressive stages which lead up to this condition being indicated by the species of Campyloprion.

Progressive modification takes place in two directions amongst these genera, starting with Campodus. In Campyloprion and Helicoprion, the tendency is toward enlargement of the apical at the expense of the basal portion of the teeth, with increase in the number of segments. A divergent series, however, is represented by the species of Edestus, in which the relatively few segments are not very intimately fused, while their coronal portions become reduced pari passu with the enormous 
development of the base. In fact, about all that remains of the crown in Edestus is the apical portion, the two processes corresponding to the buttressed lateral faces of Campodus appearing as slender, pointed processes, which soon lose themselves in the root (sheath). The type species of Edestus is also the least compressed from side to side of the series.

Information regarding the mode of growth of Edestus is afforded by the detached segments of E. heinrichi and E. minor which are known. Successional teeth are formed in the same way as in Campyloprion and Helicoprion, the only difference being that the bases of the newer-formed segments ensheathe the older to a much greater extent. The first-formed or "terminal segment" of E. heinrichi is not a "solid bone" as stated by Newberry ('88, p. 120), but possesses a gouge-like base like the rest. In the specimen figured by him as a supposed terminal segment, only the "denticle" (crown) is preserved, and the carbonaceous matrix which originally filled the interior of the sheath might readily be mistaken at first sight for vasodentine. A few specimens exist in which the mode of succession is clearly discernible, perhaps the best preserved being that recently figured by the writer $(: 02, p .76)$, the original of which is preserved in the Museum of Comparative Zoölogy at Cambridge. It is interesting to note that the first to have discovered detached segments of Edestus and to have commented upon their arrangement-although reversing the relations of anterior and posterior-was Orestes H. St. John (:02, p. 658), who was familiar with both E. minor and E. heinrichi.

Cope, E. D.

\section{BIBLIOGRAPHY.}

'75. The Vertebrates of the Cretaceous Formations of the West. Report U. S. Geol. Survey, Territories, vol. 2,302 pp., $57 \mathrm{pls}$.

Dean, $\mathrm{B}$.

'98. On a New Species of Edestus, E. lecoutei, from Nevada. Trans. New York Acad. Sci., vol. 16, pp. $61-69$.

Eastman, C. R.

:00. Karpinsky's genus Helicoprion. Amer. Nat., vol. 34, no. 403, pp. 579-582.

Eastman, C. R.

:01. On Campodus, Edestus, Helicoprion, Acanthodes, and other Permo-Carboniferous Sharks. Science, n. ser., vol. 14, p. 795.

Eastman, C. R.

:02. Some Carboniferous Cestraciont and Acanthodian Sharks. Bull. Mus. Comp. Zoöl. Harvard College, vol. 39 , no. 3 , pp. $55-99,7$ pls.

Fuchs, T.

:00. Ueber die Natur der Edestiden, mit besonderer Rücksicht auf die Gattung Helicoprion. Sitzb. kais Akad. Wiss., Wien, math.-naturw. Cl., Bd. 109, Abt. 1, pp. 5-9, 1 Taf.

Hitchcock, E.

'56. Account of the עiscovery of the Fossil Jaw of an extinct Family of Sharks, from the Coal Formation.

Proc. Amer. Ass. Adv. Sci., 1855, pp. 229-230. 

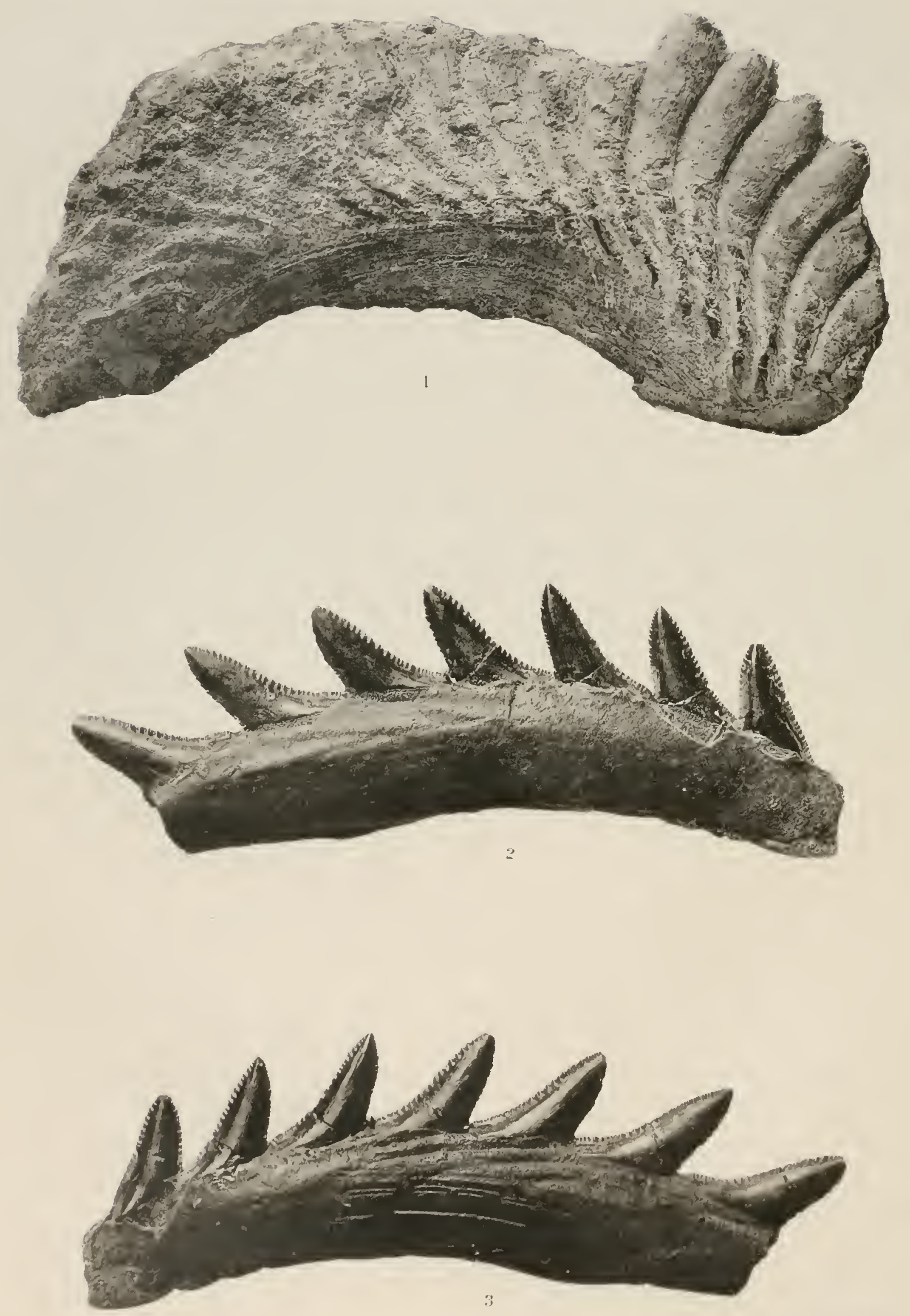


\section{ON THE NATURE OF EDESTUS AND RELATED FORMS:}

\section{Hitchcock, F, R. M.}

'87. On the Homologies of Edestus. Amer. Nat., vol. 21, pp. 847-848.

Jaekel, 0.

:00. A. Karpinsky: Ueber dic Restc von Edesticlen und die neue Gattung Hclicoprion (Referat). Neues Jahrb. f. Mineral., Jalırg. 1900, Bd. 2, pp. 144-14S.

Karpinsky, A.

'99. Ueber dic Reste voln Edestiden und die ncue Gattung Helicoprion. Verlı. russ.-kais. min. Gesell. St. Petersburg, Ser. 2, Bd. 36, pp. 361-476, Taf. 1-4.

Klaatsch, H.

:01. Zur Deutung von Helicoprion Karp. Centralbl. f. Mineral., Jahrg. 1901, No. 14, pp. 429-436.

Koken, E.

:01. Heliocoprion im Productus-Kalk der Saltrange. Centralbl. f. Mineral., Jahrg. 1901, No. 8, pp. $225-227$.

Leidy, J.

'56. Indications of five Spccies, with two new genera, of extinct Fishes. Proc. Acad. Nat. Sci. Philadelphia, vol. 7, p. 414.

Leidy, J.

'57. Remarks on certain extinct Speeies of Fishes. Proc. Acad. Nat. Sci. Philadelphia, vol. 8, pp. $301-302$. Newberry, J. S.

'SS. On the Structure and Relations of Edestus, with a Description of a gigantic new Species. Ann. New York Acad. Sci., vol. 4, nos. 3-4, pp. 113-122, pls. 4-6.

Owen, $\mathrm{R}$.

'61. Palæontology. Second Ed. Edinburgh, $8^{\circ}, \mathrm{xvi}+463 \mathrm{pp}$.

St. John, O. H.

:02. (Obscrvations on Edestus and Cochliodus.) Amer. Nat., vol. 36, no. 428, pp. 658-659.

Trautschold, $\mathbf{H}$.

'84. Ueber Edestus und einige anderc Fischreste des moskauer Bergkalks. Bull. Soc. Imp. Nat. Moscou, tom. 58, pt. 2, pp. 160-174, pl. 5 .

Woodward, A. S.

:00. Helicoprion-Spine or Tooth? Geol. Mag., n. ser., decadc 4, vol. 7, pp. 33-36.

Woodward, $\mathrm{H}$.

'86. On a Remarkable Ichthyodorulite from the Carboniferous Series, Gascoyne, Western Australia. Geol. IIag., n. ser., deeade 3 , vol. 3 , no. 1, pp. 1-7, pl. 1 .

Yabe, $\mathrm{H}$.

:03. On a Fusulina-Limestone with Helicoprion in Japan. Jour. Geol. Soc. Tokyo; vol. 10, no. 113, pp. 1-13, pl. 2.

\section{EXPLANATION OF PLATE XXI.}

Fig. 1. Campyloprion annectans Eastm. Portion of symplysial dentition, right lateral aspect. $\times 3$.

Fig. 2. Fulcstus minor N. and W. Symplysial dentition, right lateral aspect. $\times \frac{2}{3}$.

Fig. 3. Edestus minor $N$. and W. Symphysial dentition, lcft lateral aspect. $\times \frac{2}{3}$.

The original of Figure 1 is preserved in the Muscum of Comparative Zoölogy at Cambridge, Mass.; that of Figures 2 and 3 is the property of Amlerst Collcge. 

$\mathrm{XV}$.

THE DEVELOPMENT OF THE VENTRAL NERVES IN SELACHII.

I. SPINAL VENTRAL NERVES.

(PLATES XXII-XXIV.)

H. V. Neal. 



\section{INTRODUCTION.}

The present study of the histogenesis of spinal ventral nerves has grown out of an attempt to determine the morphology of the eye-muscle nerves. If the eyemuscle nerves are morphologically comparable to spinal ventral nerves, with which they have been so often compared, their mode of development should be similar. If differences appear these should be explicable on the ground of specialization. The necessity of embryological confirmation of morphological conceptions is so generally recognized that it is not a little surprising to find that in most discussions of the morphology of the eye-muscle nerves their actual histogenesis has been generally disregarded. As Minot ('96) says with characteristic clear-headed incisiveness, "the attempt has been made to solve the most difficult questions of the morphology of cranial nerves without answering the inconvenient question of nerve-fibres and their sheaths." The need for renewed investigation of the histogenesis of not only the eye-muscle nerves in Selachii, but also of the spinal ventral nerves with which they have been compared, is known to all familiar with the literature dealing with this problem. Not even the fundamental question of ventral-nerve histogenesis, viz., whether fibres grow as processes of medullary cells or by the fusion of cell-chains, which has been settled for Amniota in favor of the "process theory," can be regarded as settled for Selachii. Beard ('96, p. 395) even goes so far as to say that "any one who has devoted time and pains to the study of Elasmobranch embryology could not but be very curious to see a work on this group, proving that the nerves of these fishes always arise as processes of neuroblast cells." Beard, at least, has the right to claim, in view of the differences in the results of investigators, that the question of nerve histogenesis for the group of Selachii "is still an open one."

A priori reasoning as well as observations have led to divergent opinions. His ('89), for instance, writes that no clear-headed investigator will maintain that the mode of nerve formation in selachians is fundamentally different from that in other vertebrates. If in higher forms ventral nerves are fibrous outgrowths they must be so in lower forms. Yet Gegenbaur ('98, p. 722) on a priori grounds reaches a very different conclusion. He says that in invertebrates, cell nuclei appear in the course of the nerves, from which we may infer that cells participate in the formation of nervefibres. In the vertebrates also similar relations appear in the branches of both 
medullated and non-medullated nerves. In the case of the former the medullary sheaths and in the latter the axis cylinder, are directly enclosed in a delicate nucleated membrane (neurilemma). This neurilemma has been regarded as something added to the nerve from the connective tissue. Of this the proofs are as yet uncertain, and it is more probable that the nuclei of the neurilemma belong to cells which have served in the formation of the fibre. Thus a priori reasoning works both ways, depending on the point of departure.

Observations also on the histogenesis of ventral nerves differ. Concerning their histogenesis in the Amniota there is practically a consensus of opinion in favor of the "cell-process" theory. There is still debate concerning nerve histogenesis in the Anamnia. His ('89), von Lenhossék ('92), and Neal ('98) claim to have discovered the same mode of ventral-nerve histogenesis in Anamnia as in Amniota. Yet the latest investigation of nerve histogenesis in Anamnia, viz., that of Raffaele (:00), confirms the "cell-chain theory" supported by Balfour, Dohrn, Beard, Gegenbaur, and others. Von Lenhossék ('98, p. 114), however, holding with His and others, that there is but one mode of nerve development for all vertebrates, easily disposes of such results as those of Dohrn and Beard by claiming that their technical methods are unsuited for purposes of nerve study. They make the mistake, says von Lenhossék, of attempting to solve one of the most difficult histological problems on the basis of an inadequate method, and again the second greater error that, when fine and more suitable methods for the investigation have been invented, they cling to old methods and disregard the more recent discoveries, because these cannot be made by the older methods. While it must be admitted that this criticism is in a measure just, nevertheless, in view of the fact that neither von Lenhossék nor any one else who has applied the Golgi method-which von Lenhossék evidently regards as an eminently suitable method-to the study of nerve histogenesis has been able to effect a successful impregnation of nerves in the early stages of development concerning which the results of investigators differ most, the criticism does not really invalidate the results based upon the older-"borax-carmine"-methods. In fact, "borax-carmine" preparations will give positive results in early stages of nerve development where the Golgi method completely fails. These are the very stages, moreover, in the development of the anamniotic embryo, which afford evidence of the migration of medullary elements into ventral nerves and of the much-disputed cellular nature of embryonic nerves. If the claim should be made that it does not matter whether the development of neuraxones is studied in earlier or later stages, inasmuch as it may be safely assumed that neuraxones grow in all stages alike, the reply may be made that the truth of this assumption is not certain. At any rate, 
observations of the early stages of development are necessary to prove the truth of the assumption, which is by no means self-evident. The discovery by von Lenhossék through the Golgi method of a motor fibre showing the terminal swelling characteristic of a growing fibre in a 20 -millimetre selachian embryo does not exclude the possibility that the "cell-chain" mode of nerve development may also occur in ontogeny. It is but just that those who differ from Dohrn, Beard, and Raffaele should, before seeking to discredit the results of these investigators on the ground that the methods used are unsuitable for the special purpose of nerve study, make a more extended investigation of nerve histogenesis in the Anamnia than they have done. Beard's request ('96, p. 395) for an extended work upon selachian-nerve histogenesis, with at least a single plate of figures in disproof of the cell-chain hypothesis, has not yet been granted.

Instead of criticism of technical methods and a priori reasoning, renewed investigations by the best methods applicable, covering all stages of nerve development, from first appearance until adult conditions are attained, are needed. In this conviction the present investigation was undertaken. While not all the problems of nerve histogenesis come within the scope of the present paper, which covers only enough of the general problem to afford a sufficient basis for comparison with the histogenesis of the eye-muscle nerves, positive conclusions concerning some of the more important questions have been reached. These are:

1. The neuraxones of spinal ventral nerves of selachians develop like those of Amniota as processes of neuroblast cells. In their growth they are secondarily surrounded by sheath cells.

2. Medullary cells, but not those which form the neuraxones, migrate into the ventral nerves in early stages of development. Their presence in the embryonic ventral nerves gives rise to the "cellular structure" in these early stages of development and thus obscure, in preparations made by the conventional embryological methods, their fibrillar structure. Suitable methods show that neuraxones are present in the earliest as in all later stages.

3. The migrant medullary cells form the neurilemma sheaths, but take no part in the formation of the neuraxones or ganglia of ventral nerves.

4. The epineurium and perineurium sheaths are in chief part added to the embryonic nerve from the adjacent mesenchyme. This addition of mesenchyme cells, however, occurs in somewhat advanced stages of development.

These results confirm generally accepted opinions except as regards the question of the migration of medullary cells and the participation of these in the formation of nerve sheaths, which have usually been regarded as of mesenchymatous origin. 
If any advance upon the results of former investigators of selachian-nerve histogenesis has been made in this research, this may be attributed chiefly to the application of somewhat improved neurological methods to very early stages of nerve histogenesis and to a more extended study of selachian nerves in all stages of development than has been previously made. The work was done chiefly at the Marine Biological Laboratory at Wood's Hole during the summers of 1898 and 1900. To the directors of the laboratory, Dr. C. O. Whitman and Dr. F. R. Lillie, my sincere thanks for the free use of an investigator's room and for many unusual privileges are here gladly given.

\section{METHODS.}

The main results of the present investigation are based on the study of Squalus acanthias (spiny dogfish) embryos treated after the vom Rath ('93, '95) method. For purposes of comparison Hermann's, Flemming's, and Davidoff's fluids, followed by anilin safranin or iron hæmatoxylin, were used. With the exception of a few embryos in advanced stages of development, the Golgi rapid method, which was tried upon over a hundred embryos, failed to give any results.

The vom Rath method, which has been used with considerable success in the study of the nervous system of annelids, but never, so far as I know, recommended for the study of nerve histogensis in vertebrates except by the present writer ('98), is as follows:

1. The embryos are killed and fixed in either of the following mixtures, in which they remain at least twenty-four hours:

$A$. vom Rath's ('93) formula:

a. Saturated and filtered solution of picric acid. . . 500 c.c.

b. Glacial acetic acid................... 3 c.c.

c. Platinic chloride (dissolved in 5. c.c. water).... 5 gms.

$d$. Osmic acid...................... 2 gms.

$B$. vom Rath's ('95) formula:

a. Saturated solution of picric acid........... 200 c.c.

b. Glacial acetic acid...................... 2 c.c.

c. Platinic chloride (dissolved in 10 c.c. water).... $1 \mathrm{gm}$.

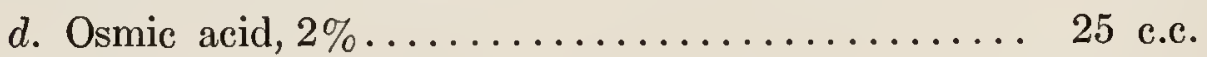

Larger embryos, 30-50 millimetres, are better preserved by leaving them in the fixing fluid-which is changed for fresh every day-for three to four days. In making these changes of fluid and subsequent changes it is necessary to avoid shaking 
the embryos violently, for they become extremely brittle and fragile. All subsequent changes, including the embedding, should, therefore, be made in a single glass dish.

2. The fixing fluid is siphoned off and replaced by methyl alcohol for five minutes. According to vom Rath this bath may be safely omitted.

3. The methyl alcohol is replaced by a weak (about .5\%) solution of pyrogallic, acid or by crude pyroligneous acid in which the embryos are kept for six to twentyfour hours in the dark. Preparations made with the pyroligneous acid, the action of which is somewhat uncertain and difficult to control, are apt to be overblackened, but are more permanent than those made with pyrogallic acid. The best preparations of large (over 30 millimetres) embryos were obtained by the use of pyroligneous acid in which they remained twenty-four hours after a four days' immersion in vom Rath's fluid $(A)$.

4. The embryos are subsequently passed slowly through the alcohol grades $35 \%, 50 \%, 70 \%, 85 \%$, and $95 \%$, in which they remain with occasional change to fresh fluid until the picric acid ceases to be extracted, a process that takes weeks.

5. The embedding should be done in very hard paraffin, as it is necessary to cut thin sections, and the embryos are so brittle that they break badly when cut in the usual grades.

While there is considerable variation in the action of the method upon different embryos, successful preparations show the nervous system to be of a steel-gray color, and the muscles slightly yellow from the picric acid. Sections should be mounted in balsam with or without a cover-glass. When a cover-glass is used the sections near the edge of the cover-glass retain their stain perfectly, while those near the centre of the cover-glass fade in time to a dull yellow.

Hermann's fluid used instead of vom Rath's mixture gives very similar results, but the shrinkage of the embryos is much greater. The shrinkage is less with Flemming's fluid, but the latter does not permit of subsequent treatment with pyrogallic acid. Treated by either of these two methods without pyroligneous or pyrogallic acid, the embryos deteriorate somewhat when kept in paraffin, so that they stain much less readily with safranin than when cut soon after embedding. Material treated by the vom Rath method and preserved in paraffin showed no signs of fading or deterioration after five years.

The vom Rath method has the following advantages and disadvantages: First, it causes less shrinkage or swelling than any embryological method known to the writer. Neuraxones are stained deeply in the early stages of development and cell boundaries are brought out with beautiful distinctness. On the other hand, the tissues are so blackened that very thin sections are necessary. The method is in- 
applicable to yolk-ladened embryos (amphibians, teleosts, and Petromyzon in early stages of development). It is a neurological rather than a histological method.

\section{THE HISTOGENESIS OF VENTRAL NERVES.}

The chief constituents of a differentiated ventral nerve are: (1) the nidulus or "motor nucleus," which is in the ventral horn of the neural tube and consists of multipolar ganglion-cells and dendritic processes; (2) the nerve-fibres, each of which is composed of a neuraxon (axis-cylinder process), a neurilemma (Schwann's sheath), a medullary sheath, and a motor termination; and (3) the connective tissue sheath (epi- and peri-neurium).

The histogenesis of intracellular structures such as centrosomes, neurofibrillæ, etc., does not come within the scope of the present paper, the purpose of which is to present evidence bearing on the question of the morphology of the eye-muscle nerves. This evidence will be presented under three chief heads: the development of the nidulus, the histogenesis of the neuraxon and the neurilemma, and the development of the epi- and peri-neurium.

I. The Development of the Nidulus. $-A$. Historical. Most of our knowledge of the histogenesis of the nidulus of ventral nerves we owe to His ('79, '89). The chief facts, as stated by His, are as follows: At the time of closure of the neural tube its lateral walls are composed of undifferentiated columnar epithelial cells. Out of these are soon differentiated two kinds of cells: (1) epithelial cells, which undergo no further division and which form the neuroglia cells of the adult ("spongioblasts" of embryonic stages, His); and (2) germinative cells, rounded cells near the lumen of the neural tube, which retain the power of multiplication. The germinative cells migrate laterad in the neural tube (Herms, '84), become pear-shaped, and develop neuraxon processes which grow toward the adjacent myotomes. They thus become "neuroblast cells," a group of which gives rise through their neuraxon processes to a ventral nerve and constitute the nidulus or "motor nucleus" of that nerve. The dendritic processes of these cells are formed considerably later than the neuraxon processes. The researches of von Kölliker ('85, '92, :00), Vignal ('88), Schaper ('94), and Giglio-Tos (:02) have made it probable that the "Keimzellen" or germinative cells of His are simply ordinary epithelial cells in mitosis and that they do not give rise exclusively to neuroblasts. The only other disputed point is the extent of the migration of the neuroblasts. Dohrn ('88) maintained that some of these migrate from the neural tube into the roots of the nerve. His in a later study ('89) denied 
this. Dohrn ('91) afterwards admitted that his conclusions concerning the migration of cells into the spinal ventral nerves were more than doubtful, though he still maintained that medullary cells migrate into the roots of the oculomotorius.

$B$. Histogenesis of the Nidulus in Squalus. When the closure of the neural tube takes place in Squalus, its lateral walls are formed of undifferentiated columnar epithelial cells. The cells whose processes form the neuraxones of the ventral nerve in its earliest stages (Pl. XXII, Figs. 1-4) are in every way similar to adjacent epithelia cells. Neuroblasts and spongioblasts in Squalus are undifferentiated in the early stages of ventral nerve development. A few of the neuroblasts, but not all, are clearer and more transparent than the adjacent cells. In Squalus, then, the first neuroblasts are not developed from rounded "germinative" cells (His) but directly from epithelial cells indistinguishable from those of the surrounding epithelium. The formation of the neuroxon processes of these cells before any migration takes place is a further point of difference between nerve histogenesis in Squalus and in the forms studied by His ('89).

In later stages of development (Pl. XXII, Figs. 9-11; Pl. XXIII, Figs. 12, 13) the neuroblasts migrate laterad toward the developing ventral nerves and lose their primary connection with the membrana limitans interna of the neural tube. During migration they become pear-shaped, as described by His, and stain more deeply than the adjacent epithelial cells. In the meantime, the lateral walls of the neural tube which were primarily formed of a single layer of epithelial cells become many-layered by the multiplication of cells lying near the lumen of the tube (Pl. XXII, Figs. 10, 11). Proof that the mitotic (germinative) cells become directly metamorphosed into neuroblasts, or that they actively migrate between the cells lying lateral to them, is lacking in Squalus.

Regarding the extent of the lateral migration of the neuroblasts and also the question whether the neuroblasts leave the neural tube to enter the roots of the nerve, the following considerations are important:

First, at no stage of development can a cell body with a neuraxon process be found in a developing veutral nerve. On the other hand, such cells are found within the neural tube at all stages of ventral nerve development. Because of the deeply staining properties of neuroblasts in early stages of development, were such present in ventral nerves as in dorsal nerves, their presence could easily be detected.

Second, while nuclei may be found half in and half out of the neural tube in early stages of ventral nerve development, and while this evidence of migration is correlated with the appearance and multiplication of nuclei in the forming nerve, there is no evidence that these are the nuclei of the cells which form the neuraxones. 
Evidence that they are the nuclei of the cells which form the neurilemma sheath will be given later.

Third, in the adult, as in the early stages of development, the neuraxones whose cellular connections have been traced are found to be processes of neuroblasts (ganglion cells) in the ventral horn of the neural tube. This fact and the fact that no ganglion cells are found in the ventral nerves of the embryo or the adult cannot be reconciled with the assumption that neuroblasts migrate into the nerves, unless the further assumptions are made to the effect that the neuroblasts become metamorphosed into neurilemma cells and that the proximal processes of such cells effect a secondary union with ganglion cells in the ventral horn of the spinal cord. I have looked in vain for evidence to support either of these assumptions. The conclusion seems unavoidable that the migration of the neuroblasts is confined within the wall of the neural tube. The cause of migration appears to be the multiplication of cells in the inner layer of the medullary walls.

The neuroblasts take a ventro-lateral position in the wall of the neural tube just within the marginal veil of fibres forming the white matter of the cord, where they soon become multipolar by the development of dendritic processes. The latter first appear after migration has ceased. His ('89) regards the formation of the marginal veil and of the neuroglia network as the mechanical cause for the cessation of neuroblast migration. The two phenomena appear correlated in Squalus, but it is difficult if not quite impossible to say that the relation is a causal one.

Four chief stages in the differentiation of the nidulus of a ventral nerve may then be distinguished: (1) the stage of the undifferentiated columnar epithelium; (2) the formation of the neuraxon process;* (3) the lateral migration of the pear-shaped unipolar neuroblast; and (4) the formation of dendritic processes.

2. The Histogenesis of the Neuraxon and the Neurilemma.- $A$. HistoricaI. Although many subordinate problems are involved in the general one of the histogenesis of nerve fibres, only the three following are discussed in this paper:

$a$. Is the neuraxon of a ventral nerve fibre multicellular in origin or the process of a single medullary cell?

$b$. Are the cells which form the neurilemma emigrated medullary elements (ectodermal) or mesenchymatous (mesodermal) cells?

$c$. Are the ventral nerves $a b$ initio connected with their terminal organs and how intimate is this connection?

None of these three questions, about which the greatest morphological interest centres, has been finally answered for Selachii.

* It is probable that for some neuroblasts the second and third stages are reversed. The proportion of such neuroblasts to the whole number of neuroblasts has not been determined. 
a. Is the neuraxon of a ventral nerve fibre multicellular in origin or the process of a single medullary cell? Three answers have been given to this question. The first and oldest one is that neuraxones are formed by the fusion and differentiation of the axial protoplasm of chains of spindle-shaped cells. Harmonizing with the early opinions of nerve structure as stated by Remak and Schwann, this hypothesis seemed to receive embryological confirmation in the observations of the cellular structure of embryonic selachian nerves by Balfour ('81) and others and in the more detailed studies of selachian nerve histogenesis by Dohrn ('91, '92) and by Beard ('92, '96). According to Dohrn ('91) the histogenesis of the neuraxon and neurilemma in a spinal ventral nerve is as follows: One of the cells composing the growing nerve separates from its envelopes, elongates into a slender structure in the middle of which lies a spindle-shaped nucleus and differentiates within its cytoplasm a neuraxon, one end of which forms the nerve fibre while the other penetrates between the muscle fibres and effects the first connection between the nerve and its end organ, the muscle. The remainder of the cytoplasm becomes the neurilemma.

Dohrn confirms the opinion of Goette ('88) that "ganglion cells" have no genetic relation with neuraxones which are formed by "nerve cells" in the manner just described. On the basis of observations upon the structure of adult nerves, Apáthy ('89-'90) makes the same distinction between ganglion cells and nerve cells. The evidence of the "cellular structure of embryonic nerves" given by Balfour ('81), Van Wijhe ('89), Beard ('96), Dohrn ('91, '92), Béraneck ('87), Kupffer ('94, '95), Hoffmann ('97), Capobionco e Fragnito ('98), and Raffaele (:00) has been generally but fallaciously thought to favor the cell-chain hypothesis of nerve histogenesis. The considerations advanced by various advocates of the cell-chain hypothesis in support of this view are as follows: first, embryonic nerves are cellular; secondly, the nerves of invertebrates are cell chains; thirdly, by analogy with the differentiation of muscle fibres, we should expect the nerve fibres to develop in situ by a differentiation of cell cytoplasm; fourthly, the direct observations of Dohrn ('91) of the differentiation of the neuraxon fibre within the cytoplasm of the nerve cell; fifthly, the improbability that a cell can give rise to a process twenty thousand times as long as the diameter of the cell; and finally, the adult structure of the nerves as demonstrated by Apáthy's method.

According to the second theory of neuraxon histogenesis, the neuraxon is an extraordinarily long process of a ganglion cell, and every nerve fibre from beginning to end is to be understood as a product of a single cell (von Lenhossék, '97). This theory, first stated by Kupffer in 1857 and established on an empirical basis by His ('79) has been confirmed most conclusively through the use of the Golgi method by 
von Kölliker, von Lenhossék, Ramón y Cajal, Retzius, and others. In support of it the following facts are urged: First, in adult ventral nerves the neuraxones are demonstrably (most convincingly by the Golgi method) processes from medullary cells. In embryonic amniotes ventral nerves in their early stages are purely fibrillar structures to which cells are secondarily added. These fibres are seen to be processes of medullary cells. By the Golgi method various stages in the elongation of the neuraxon may be demonstrated. In the fibre tracts of the brain and spinal cord are found in regions devoid of cells extremely elongated neuraxones which must, therefore, be processes of a single cell. A similar extension of neuraxones in the peripheral nervous system is consequently not improbable. Finally, experiments upon the regeneration of neuraxones strongly support the conclusion that these structures are processes of a single cell.

A third hypothesis of nerve histogenesis has been advanced by Sedgwick ('94), who regards nerves as local differentiation of a cytoplasmic reticulum connecting cell with cell. Sedgwick regards the embryo as a protoplasmic syncytium and the nerves as specialized strands of the protoplasmic network. Too little constructive work has been done in the study of nerve histogenesis from this point of view to give this hypothesis a standing comparable with that of the other two stated above. The problem of ventral nerve histogenesis in Squalus is therefore stated-Are neuraxones formed by the fusion of cell chains or by cytoplasmic outgrowths from medullary cells?

b. Are the cells which form the neurilemma emigrated medullary elements (ectodermal) or mesenchymatous (mesodermal) cells? Many embryologists, Balfour ('81), Dohrn ('88, '91, '91ª), Beard ('92), Van Wijhe ('89), Béraneck ('87), Miss Platt ('91), Kupffer ('94, '95), Hoffmann ('97), and Raffaele (:00), have shown beyond a doubt that embryonic nerves are cellular. The origin of the cells is in doubt. Dohrn ('88, '91) gave strong evidence that in Selachii they are emigrated medullary elements. He found that not only are the nuclei of ventral nerves larger than those of the mesenchyme, but that similar nuclei lie nearer the medullary wall while other similar ones lie half in and half out of the wall, and in later stages a greater number of such cells are seen apparently in the very act of emerging. In a later paper ('91ª he regarded this conclusion as more than doubtful for spinal nerves, but still maintained its truth for the oculomotor. Van Wijhe ('89) found the ventral nerves cellular in selachian embryos, but with characteristic cautiousness of statement gives no opinion concerning the origin of the cells. His ('89), von Kölliker ('92, :00) and von Lenhossék ('97) have assumed them without sufficient evidence to be mesenchymatous origin in Selachii. Von Kupffer ('94, '95) found in Petromyzon and Acipenser a marked simi- 
larity in the development of dorsal and ventral nerves, in as much as both were composed of cells ectodermal in origin. Hoffmann ('97) and Harrison (:01)* confirmed Dohrn's first opinion that medullary cells wander from the neural tube into spinal ventral nerves. Thus while observers agree that embryonic selachian nerves contain cells, the source of these cells is in dispute. Similarly in doubt is the question of the part that these cells play in nerve histogenesis.

$c$. Are the ventral nerves $a b$ initio connected with their terminal organ and how intimate is this connection? All observers are agreed that from their first appearance spinal ventral nerves are connected with the myotomes. The only question under discussion is that of the intimacy of this connection. Hensen ('64) and. Sedgwick ('94) have maintained that nerve fibres are in immediate protoplasmic continuity with their terminal organ. A similar intimate cell to cell continuity seems involved in the "fibrillar theory" of Apáthy. Bardeen ('98), on the other hand, states that it is only comparatively late in embryonic development that terminal fibres enter into intimate relations with the tissue elements of the part they are to supply. Barker ('99, p. 193) also implies that this is true, for, according to him, peripheral nerves, like blood-vessels, follow in their growth the channels of least resistance.

B. Histogenesis of Neuraxon and Neurilemma in Squalus. $a$. Is the neuraxon multicellular in origin or the process of a single medullary cell in selachians? The following evidence seems to me to favor the process theory and to confirm the conclusions of His and von Lenhossék:

First, in their earliest stages of development (Pl. XXII, Figs. 1-6) spinal ventral nerves are made up of processes from medullary cells, and are wholly devoid of nuclei.

Second, in all later stages of development after nuclei have made their appearance in the nerve, the processes of the medullary cells can be traced into the fibrillar portion of the forming nerve (Pl. XXII, Figs. 9-11; Pl. XXIII, Figs. 12-16).

Third, the number of neuroblasts whose neuraxones can be traced from each neuromere into the forming nerve corresponds closely with the estimated number of the neuraxones in the nerve. As the number of neuraxones increases in the nerve the number of neuroblasts whose neuraxones can be traced to the nerve increases.

These facts, however, do not prove that all of the neuraxones in the nerve are formed as processes from medullary cells. They only make it probable that most of the neuraxones are such processes. The possibility still remains that some of the

* Harrison (:01) finds that, in the salmon, ventral nerves are formed as proeesses of neuroblast eells in the ventral half of the neural tube. In mueh later stages of development, nuclei migrate out of the neural tube into the nerve to form motor elements in the sympathetie ganglia. 
neuraxones may be formed by the cells which early in development appear in the forming nerve (Pl. XXII, Figs. 6-9). Indeed the presence of these cells has led some embryologists to infer that they have a genetic relation to the nerve fibres. The similarity of dorsal and ventral nerves in early stages and the fact that some of the cells of the dorsal nerve have genetic relation to neuraxones might seem by analogy to afford presumptive evidence that some of the cells of ventral nerves have a similar relation. But it is evident that the presence of cells in the ventral nerves, even if they be of ectodermal origin, does not prove that they form neuraxones, for many, indeed most, of the cells of the dorsal nerves have no genetic relation to the neuraxones.

I am convinced that the cells of the ventral nerves have nothing to do with the formation of neuraxones for the following reasons:

First, in the early stages of development when the number of neuraxones increases most rapidly (Pls. XXII, XXIII), the cells of the forming nerves are distinctly peripheral with relation to the fibrous portion of the nerves.

Second, none of the cells of ventral nerves at any stage shows the deeply staining properties characteristic of embryonic ganglion cells in the dorsal ganglia. The cells seen in ventral nerves are without exception vacuolated, granular, and lightly stained.

Third, the cells of the forming ventral nerves show no change in shape or size correlated with the growth of the neuraxones, but such changes are always seen in the nerve-forming cells of the dorsal ganglion. The cells of the ventral nerves lie in the periphery of the fibrillar portion of the nerves with their long axes perpendicular to the fibres, an anomalous position for cells supposed to be in process of nerve formation.

Fourth, in no instance was anything resembling a neuraxon, either formed or in the process of formation, to be found within the cytoplasm of the cells of the forming ventral nerves.

If the cells of ventral nerves in Squalus do not form neuraxones, what is their fate? They form the neurilemma. Their transformation from simple epithelial cells in the periphery of the forming nerves to spindle-shaped cells lying among and around the neuraxones, and finally to the tubular structures of the adult neurilemma, have been followed and are shown in the figures that accompany this paper (Pls. XXII-XXIV). That some of these cells may also contribute to the formation of the connective-tissue sheaths of the nerves and to the sympathetic is not improbable.

$b$. What is the origin of the neurilemma? My observations confirm the conclusion of von Kupffer ('94, '95), Hoffmann ('97), and Harrison (:01), that the cells on the forming ventral nerves are emigrated medullary elements and therefore of ectodermal origin like the cells of dorsal nerves. This conclusion is based on the following facts: 
First, the first cells found in the forming nerve appear at the base of the nerve where it joins the medullary wall. Other similar cells lie half in and half out of the medullary wall. As the cells of the nerve grow more numerous, more nuclei appear in process of migration from the neural tube. The marked change in the contour of the ventral wall of the tube (Pl. XXIII, Figs. 20-23) indicates the great extent of this migration.

Second, like the neural tube, the forming nerve has a membrana limitans which is continuous with the limiting membrane of the neural tube. Such a relation would not be expected were the cells of the nerve added from the adjacent mesenchyme. The presence of this membrane makes it possible to distinguish easily in all earlier stages (Pl. XXIII, Figs. 12-19) between the cells of the forming nerve and those of the adjacent mesenchyme.

The cells of the young forming nerve are all of medullary origin. The question arises whether all of the cells which form the neurilemma of the adult nervefibres come from a similar source. I regard this as improbable and I am led to assume the participation of the mesenchyme in the formation of the neurilemma on the following grounds. The extensive migration of cells from the neural tube into the forming nerve ceases at an early stage (Pl. XXIII, Fig. 19). At this and stages immediately following I have never been able to count more than one hundred cells (nuclei) in the nerve. I am not able to say with positiveness that at this stage all medullary emigration has ceased. There is some evidence of an inconclusive kind that cells may leave the neural tube in later stages.

Among the emigrated cells I have seldom seen any mitoses. Hoffmann ('97) says that they are very rare. If we admit a cloubling of the number through mitosis and another doubling through additions from the neural tube the number of nuclei in a spinal ventral nerve would then be only four hundred. But there are in my judgment over a thousand nuclei in the neurilemma of an adult spinal ventral nerve. The estimate is difficult to make because of the union with the dorsal nerve, the formation of the sympathetic and the impossibility of deternining accurately the length of the individual neuraxones. The number given above is, however, a very conservative estimate. It follows that the neurilemma must receive accessions from the mesenchyme. Sections, indeed, show cells of the mesenchyme closely applied to the growing nerve at its termination, but whether these form neurilemma cells or a part of the connective tissue sheath I am unable to say.

Thus, while I am certain of the ectodermal contribution to the neurilemma the participation of the mesoderm is less certain though probable. Indeed, if the facts 
are as they appear to be, the mesodermal contribution is in the end greater than the ectodermal.

I have been unable to find evidence of the participation of the emigrated medullary cells in the formation of the sympathetic ganglia (Harrison :01), though I am unwilling to deny this.

$c$. Are the nerves $a b$ initio connected with their terminal organs? In the sense used by Van Wijhe ('89) and Hoffmann ('97) this question must be answered in the affirmative. But I agree with Bardeen ('98) that the connection of the ventral nerve and somite (myotome) is not at first an intimate neuromuscular attachment. The end of the nerve grows freely along the median surface of the myotome. None of my sections show any protoplasmic connection even of the most attenuated kind between the somite and the neural tube, before the first neuraxon makes its exit from the neural tube. The thick outer limiting membranes of the neural tube and the somite seem to preclude a primary protoplasmic connection between nerve and muscle cell.

C. The Development of the Epi- and the Perineurium. The connective tissue sheaths of ventral nerves have always been regarded as products of the mesenchyme adjacent to the nerves. Miss Platt and Goronowitsch have made it probable that much of the embryonic connective tissue in the head is of ectodermal origin. This is not true, however, of the connective tissue surrounding the embryonic ventral spinal nerves. Most of the many layers of cells in the perineurium of Squalus are probably mesodermal, since they are added to the nerve from the adjacent mesenchyme. But since from very early stages the nerve is surrounded by a sheath of cells of ectodermal origin which can be traced as a continuous sheath into the adult, I am inclined to believe that for spinal ventral nerves as well as for cranial nerves (Platt, Goronowitsch) the ectoderm participates in the formation of the connective tissue sheaths, epineurium, and perineurium.

The growth of the perineurium takes place by the addition of successive layers of mesenchymatous cells, resulting in the lamellated condition characteristic of the adult nerve (Pl. XXIV, Fig. 32).

\section{SUMMARY.}

1. Neuroblasts and spongioblasts are undifferentiated in the early stages of the ventral nerve in Squalus.

2. The first neuraxones are formed before the migration of the cells which produce them. 
3. The "germinative cells" of His are simply mitotic cells.

4. No neuroblasts migrate from the wall of the neural tube. Their migration is entirely within the wall and is the passive result of the multiplication of cells near the lumen of the tube.

5. Neuraxones of spinal ventral nerves are formed exclusively by medullary cells.

6. The cells of ventral nerves are not concerned with the formation of neuraxones. They form the neurilemma and possibly also in part the connective tissue sheaths of the nerves. Mesenchymatous cells also probably contribute to the formation of the neurilemma and connective-tissue sheaths.

7. The cells of the forming ventral nerve are migrant medullary elements, to which are later added cells from the adjacent mesenchyme.

8. The first connection of ventral nerve and myotome is not an intimate neuromuscular attachment. There is no primary cellular connection such as has been postulated by Sedgwick ('94).

\section{BIBLIOGRAPHY.}

Apáthy, S.

'89-90. Nach welcher Richtung hin soll die Nervenlehre reformirt werden? Biol. Centralbl., Bd. 9, No. 17, pp. 527-538; No. 19, pp. 600-608; No. 20-21, pp. 625-648.

Balfour, F. M.

'S1. A Treatise on Comparative Embryolngy, vol. :. London, $8^{\circ}$, xi+655 $+\mathrm{xxij} p \mathrm{p}$.

Bardeen, C. R.

'98. The Development of the Musculature of the Body-wall in the Pig, including its Histogenesis and its Relations to the Myotomes and to the Skeletal and Nervous Apparatus. Johns Hopkins Hospital Reports, vol. 9, pp. $367-399,10$ pls.

Barker, L. F.

'99. The Nervous System and its Constituent Neurones. New York, 8, xxxii 1122 pp., 2 pls.

Beard, I.

'92. The Histogenesis of Nerve. Anat. Anz., Bd. 7, No. 9-10, pp. 290-302.

Beard, $J$.

'96. The History of a Transient Nervous Apparatus in eertain Iehthyopsida. Zool. Jahrb., Abt. f. Anat., Bd. 9, Heft 2, pp. 319-426, Taf. 22-29.

Beraneck, E.

'87. Etude sur les replis médullaires du poulet. Reeueil Zool. Suisse. tom. 4, no. 3, pp. 305-364, pl. 14.

Capobianco, F.

:00. Della prima genesi delle eellule nervose della midolla e dei ganglii spinali. Anat. Anz., Bd. 1S, Ergänzungsheft, pp. 213-214.

Capobionco, F., e Fragnito, 0.

'98. Nuove rieherche su la genesi et i rapporti mutui degli elementi nervosi e nervogliei. Ann. neurol. Milano, fase. 2-3, 40 pp., 3 tav.

Chiarugi, G.

'94. Jo sviluppo dei nervi oeulomotore e trigemello. Nota preliminare. Monit. zool. ital., anno 5, no. 12, pp. 275-280. 
Diron, F.

'96. On the Development of the Branches of the Fifth Cranial Nerve in Man. Trans. Roy. Dublin Soc.; ser. 2, vol. 6, pp. 19-76, pls. 1-2.

Dohrn, A.

'SS. Studien zur Urgeschichte des Wirbelthierkörpers. 14. Über die erste Anlage und Entwicklung der motorischen Rückenmarksnerven bei den Selachiern. Mitth. Zool. Sta. Neapel, Bd. 8, Heft. 3-4, pp. 441-461, Taf. 22 .

Dohrn, A.

'91. Studien zur Urgeschichte des Wirbelthierkörpers. 16. Über die erste Anlage und Entwicklung der Augenmuskelnerven bei Selachiern und das Einwandern von Medullarzellen in die motorischen Nerven. Mitth. Zool. Sta. Neapel, Bd. 10, Heft 1, pp. 1-40, Taf. 1-5.

Dohrn, A.

'91'. Studien zur Urgeschichte des Wirbelthierkörpers. 17. Nervenfaser und Ganglienzelle. Histogenetische Untersuchungen. Mitth. Zool. Sta. Neapel, Bd. 10, Heft 2, pp. 255-341, Taf. 16-23.

Dohrn, A.

'92. Die Schwann'schen Kerne der Selachierembryonen. Anat. Anz,, Bd. 7, No. 12, pp. 348-351.

Gaskell, W. H.

'89. On the Relation between the Structure, Function, Distribution and Origin of the Cranial Nerves; together with a Theory of the Origin of the Nervous System of Vertebrata. Jour. Physiol., vol. 10 , pp. 153-211, pls. 16-20.

Gegenbaur, C.

'98. Vergleichende Anatomie der Wirbelthiere mit Berücksichtigung der Wirbellosen, Bd. 1. Leipzig, $8^{\circ}$, pp. xiv +978 .

Giglio-Tos, E.

:02. Sulle cellule germinative del tubo midollare embrionale dell'uomo. Anat. Anz., Bd. 20, No. 19-20, pp. $472-480$.

Goette, A.

'88. Ueber die Entwicklung von Petromyzon fluviatilis. Zool. Anz., Bd. 11, No. 275, pp. 160-163.

Gurwitsch, A.

:00. Die Histogenese der Schwann'schen Scheide. Arch. f. Anat. u. Physiol., Jahrg. 1900, Anat. Abt., pp. $85-94$, Taf. 5 .

Harrison, R. G.

:01. The Histogenesis of the Peripheral Nervous System in Salmo salar. Biol. Bull., vol. 2, no. 6, pp. $352-353$

Harrison, R. G.

$: 01^{\mathrm{a}}$. Ueber die Histogenese des peripheren Nervensystems bei Salmo salar. Arch. mikr. Anat., Bd. 57, pp. 354-444, Taf. 18-20.

Hensen, $\mathrm{V}$.

'64. Zur Entwickelung des Nervensystems. Arch. f. path. Anat. u. Physiol., Bd. 30, pp. 176-186, Taf. 8.

Herms, E.

'84. Ueber die Bildungsweise der Ganglienzellen im Ursprungsgebiete des Nervus acustico-facialis be, Ammocoetes. Sitzb. Münclıen Akad., math.-phys. Cl., Bd. 14, pp. 333-354, 2 Taf.

His, W.

'79. Ueber die Anfänge des periphcrischen Nervensystems. Arch. f. Anat. u. Physiol., Jahrg. 1879, Anat. Abt., pp. 455-482, Taf. 17-18.

His, W.

'89. Die Neuroblasten und deren Entstehung im embryonalen Mark. Abh. sächs. Gesell. Wiss. Leipzig, Math.-phys. Cl., Bd. 15, No. 4, pp. 313-372, 4 Taf. Also in Arch. f. Anat. u. Physiol., Jahrg. 1889, Anat. Abt., pp. 249-300, Taf. 16-19.

Hoffmann, C. $\mathbf{K}$.

'97. Beiträge zur Entwicklungsgeschichte der Selachii. Morph. Jahrb., Bd. 25, Heft 2, pp. 250-304, Taf. 13-14. 
Krlliker, A. v.

'85. Histologische Studien an Batrachierlarven. Zeit. wiss. Zool., Bd. 43, Heft 1, pp. 1-40, Taf. 1-2.

Kölliker, A. $\nabla$.

'92. Ueber die Entwickelung der Elemente des Nervensystems, contra Beard und Dohrn. Anat. Anz., Bd. 7, Ergänzungsheft, pp. 76-78.

Kölliker, A. v.

:00. Gegen die Entstehung von Nervenfasern aus Zellensträngen. Anat. Anz., Bd. 18, No. 20-21, pp. 511-512.

Kupffer, C.

'94. Studien zur vergleichenden Entwicklungsgeschichte des Kopfes der Kranioten. 2. Heft. Die Entwicklung des Kopfes von Ammocoetes Planeri. München und Leipzig, 8, 79 pp., 12 Taf.

Kupffer, C.

'95. Studien zur vergleichenden Entwicklungsgeschichte des Kopfes der Kranioten. 3. Heft. Die Entwicklung der Kopfnerven von Ammococtes Planeri. München und Leipzig, $8^{\circ}$, $80 \mathrm{pp.}$

Lenhossék, M. $\nabla$.

'92. Beobachtungen an den Spinalganglien und dem Rückenmark von Pristiurusembryonen. Anat. Anz., Bd. 7, No. 16-17, pp. 519-539.

Lenhossék, M. $\nabla$.

'97. Nervensystem. Ergeb. Anat. u. Entwickg., Bd. 7, pp. 110-207.

Marshall, A. M.

'81. On the Head Cavities and Associated Nerves of Elasmobranchs. Quart. Jour. Micr. Sci., vol. 21 , no. 81, pp. 72-97, pls. 5-6.

Minot, C. S.

'92. Human Embryology. New York, $8^{\circ}$, xxiiit 815 pp.

Minot, C. S.

'96. Die frühen Stadien und die Histogenese des Nervensystems. Ergeb. Anat. u. Entwickg., Bd. 6, pp. $687-738$.

Neal, H. V.

'98. The Segmentation of the Nervous System in Squalus acanthias. A Contribution to the Morphology of the Vertebrate Head. Bull. Mus. Comp. Zoöl. Harvard Coll., vol. 31, no. 7, pp. 147-294, 9 pls.

Parker, G. H.

:00. The Neurone Theory in the Light of Recent Discoveries. Amer. Nat., vol. 34, no. 402, pp. 457-470.

Platt, J. B.

'91. A Contribution to the Morphology of the Vertebrate Head, Based on a Study of Acanthias vulgaris. Jour. Morph., vol. 5, no. 1, pp. 79-112, pls. 4-6.

Platt, J. B.

'96. Ontogenetic Differcntiations of the Ectoderm in Necturus. Study 2-On the Development of tlie Peripheral Nervous System. Quart. Jour. Micr. Sci., vol. 38, no. 152, pp. 485-547, pls. 36-38.

attaele, $F$.

:00. Per la genesi dei nervi da catene cellulari. Anat. Anz.; Bd. 18, No. 15-16, pp. 337-344.

Ratn, O. vom.

'93. Beiträge zur Kenntnis der Spermatogenese von Salamandra maculosa. Zcit. wiss. Zool., Bd. 57, Heft 1, pp. 97-185, Taf. 7.

Rath, O. rom.

'95. Zur Conservirungstechnik. Anat. Anz.; Bd. 11, No. 9, pp. 280-288.

Schaper, A.

'94. Die morphologische und histologische Entwicklung des Kleinhirns der Teleostier Morph. Jahrb.; Bd. 21, Heft 4, pp. 625-708, Taf. 18-21. 
Sedgwick, A.

'94. On the Inadequacy of the Cellular Theory of Development, and on the Early Development of Nerves, particularly of the Third Nerve and of the Sympathetic in Flasmobranchii. Quart. Jour. Micr. Sci., vol. 37 , no. 145 , pp. 87-101.

Van Wijhe, J. W.

'39. Ueber die Mesodermsegmente des Rumpfes und die Entwickelung des Excretionssystems bei Selachiern. Arch. mikr. Anat., Bd. 33, pp. 461-516, Taf. 30-32.

Vignal, W.

'88. Recherches sur le développenent des éléments des couches corticales du cerveau et du cervelet chez l'homme et les mammifères. Arch. physiol. norm. et path., sér. 4, tom. 2, pp. 228-254, 311-338, pls. 5, 6, 9-12.

Wlassak, $\mathbf{R}$.

'98. Dic Herkunft des Myelins. Ein Beitrag zur Physiologie des nervösen Stützgewebes. Arch. f. Entwick-mech., Bd. 6, Heft 4, pp. 453-493, Taf. 26-29.

\section{EXPLANATION OF PLATES XXII-XXIV.}

\section{ABBREVIATIONS.}

$\begin{array}{ll}\text { ao. } d . & \text { Dorsal aorta. } \\ \text { cd. } d . & \text { Chorda dorsalis. } \\ \text { cl. } c r s . n . & \text { Neural crest cells. } \\ \text { cl. n'bl. } & \text { Neuroblast cells. } \\ e^{\prime} n . & \text { Epineurium. } \\ g n . \text { spi. } & \text { Spinal ganglion. } \\ \text { la. ct. } & \text { Lamina cutis. } \\ \text { la. mu. } & \text { Lamina muscularis. } \\ \text { mb. cl. } & \text { Cell membrane. } \\ \text { mb.lim. } & \text { Limiting membrane. } \\ \text { ms'ec'drm. } & \text { Mesectoderm. } \\ \text { ms'ench. } & \text { Mesenchyme. } \\ \text { ms'en'drm. } & \text { Mesentoderm. }\end{array}$

$\begin{array}{ll}\text { my'tm. } & \text { Myotome. } \\ n^{\prime} a x . & \text { Neuraxon. } \\ n ' d . & \text { Nodus. } \\ \text { nidl. } & \text { Nidulus. } \\ n l . & \text { Nucleus. } \\ \text { p'n. } & \text { Perineurium. } \\ r x . v . & \text { Ventral root. } \\ \text { sb'sta. } \imath^{\prime} f b r l . & \text { Interfibrillar substance. } \\ \text { so. } & \text { Somite. } \\ t b . n . & \text { Neural tube. } \\ t u . \text { med. } & \text { Medullary sheath. } \\ t u . \text { Schw. } & \text { Schwann's sheath. } \\ \text { vac. } & \text { Vacuole. }\end{array}$

All the figures were drawn with the Abbé camera. Except Figures 29-32, Plate XXIV, all were drawn from sections of embryos of Squalus acanthias. All the specimens from which the drawings were made were fixed in vom Rath's picro-osmo-aceto platinic chloride mixture and treated subsequently with either pyroligneous or pyrogallic acid.

\section{PLATE XXII.}

All the figures are camera drawings of cross-sections except Figures 10 and 11, which are frontal sections. With these exceptions all are viewcd posteriorly, so that right in the figure corresponds with right in the embryo. The sections are all taken in the postcrior half of the body, Figures 1-3 from an 8-mm. embryo and Figures 4-10 from a $10-\mathrm{mm}$. embryo. The portions of the cross-sections represented in the figures are indicated by a circle in Figure 5. In some cases the devcloping nerve of the left side and in others that of the right side is represented. Taken as a whole the figures of Plate XXII represent a series of stages in the development of a spinal ventral nerve from the time of its first appearance as a process of a single neuroblast cell until the developing nerve contains its chief constituents, neuraxones and neurilemma cells. The series also presents evidence of the migration of cells from the neural tube. 

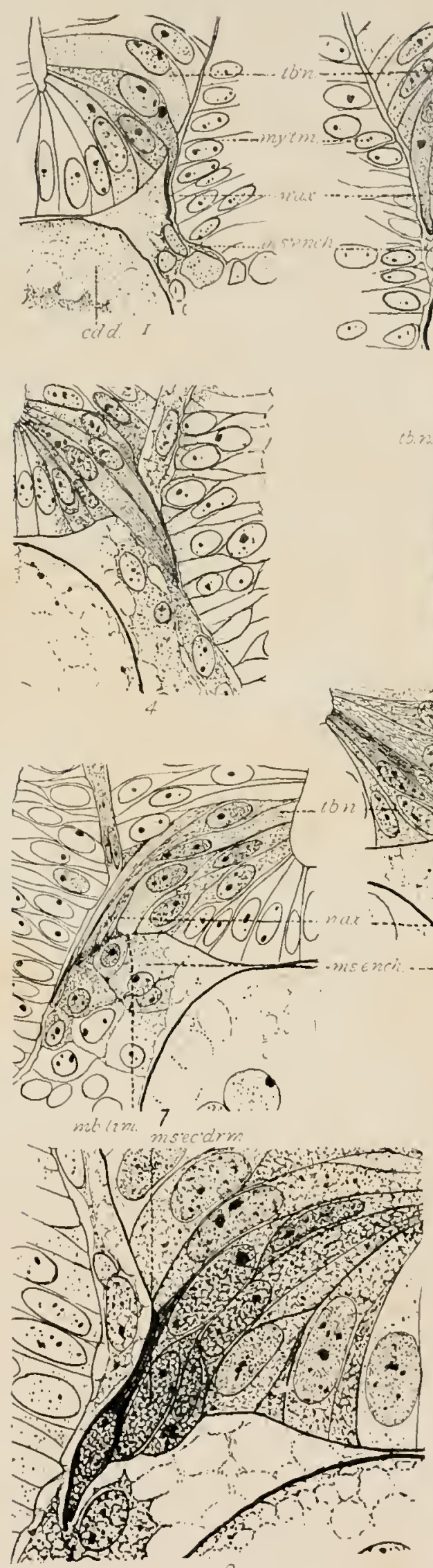

JEAL - NERVE DEVELOPMENT
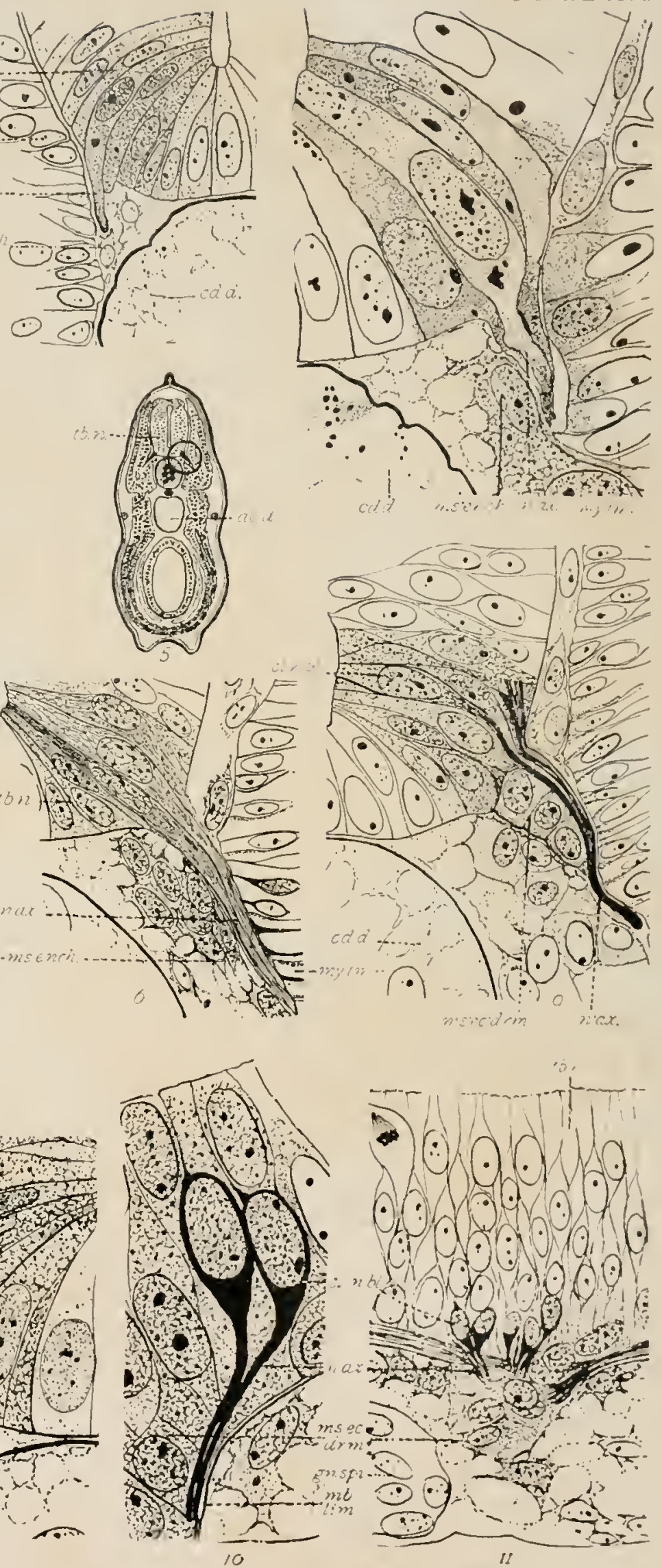
Fig. 1. A cross-scction of an 8-mm. embryo showing the most posterior and youngest ventral nerve of the embryo. The nerve consists of a single decply stained process of a medullary cell. The process extends a short distance along the median surface of the myotome. Exeept for the possession of a process the eell is not different from the adjaeent epithelial eells. The nigration of mescnchyme cells from thic sclerotome of the somite has begun. Oc. $1, \mathrm{obj}$. $\frac{1}{\mathrm{I}^{2}}$ lomogeneous oil immersion.

Fig. 2. The ventral nerve of the left side of the second inetamcre, anterior to that shown in Figure 1. The processes of several medullary cells now form the nerve, and these have extended farther along the face of the myotome. The peripheral termination of the nerve shows no intimate connection witl the muscle, i.e., a cell membrane separates them. Magnifieation as Figure 1.

Fig. 3. The ventral nerve of the right side of the metamere next anterior to that shown in Figurc 2. Thic proeesses of four or five medullary cells may be traced into the forming nerve, of which the peripheral termination is seen to lie median to the myotome. The protoplasm of the neuroblast cclls is vacuolated and granular like that of adjaeent epithelial cells. Comp. Oc. 6, obj. it $^{\frac{1}{2}}$ homogencous oil immersion.

Fig. 4. A cross-section of a $10-\mathrm{mm}$. embryo showing one of the more posterior of the forming ventral nerves. The nerve is in a stage of development slightly in advance of that slown in Figure 3. The ncrve is slightly more elongated and some evidence of fibrillation appears in the cell processes that eompose the nerve. Oc. 1, Zeiss 4.0 apochromatie objective.

Fig. 5. The entire cross-section from which Figure 4 was drawn. A circle indicates the portion shown in that figure. The other figures on this plate and the next were taken from similar regions.

Fig. 6. The ventral nerve of the second metamere anterior to that shown in Figure 4. Coinpared with the lattcr the nerve is more elongated and fibrillar. No nuclei have yet appeared in the course of the nerve. Magnification as in Figure 1.

Fig. 7. The nerve of the third metamere anterior to that shown in Figure 6 . The section shows only the posterior portion of the nerve and gives evidence of the beginning of the migration of medullary cells from the neural tube. The unbroken eontinuity of the outer limiting membranc of the neural tube and of the nerve makes it possible to distinguish betwcen cells of medullary origin and those of the adjacent mesenchyme. Magnification as in Figure 1.

Fig. 8. The posterior portion of the nerve next anterior to that shown in Figure 7 . The exit of medullary cells and the continuity of the outer limiting membranes of the ncural tube and the nerve ean be clearly secn.

Fig. 9. The ventral nerve from the third segment anterior to that of Figure 8 , showing the two chicf constituents of the ventral nerve: neuraxon processes of medullary eells, and cells whose medullary origin is shown by comparison with earlier stages and by the continuity of outer limiting membranes of the ncrve and neural tube. In the section shown, the process ( $n^{\prime} a x$.) of a ncuroblast cell $\left(c l . n^{\prime} b l.\right)$ ean be elearly traced into the nerve as a very deeply stained fibre. The migrating medullary eells at this stage all lie ventral and posterior to the ncuraxonic processes. Magnification as in Figure 1.

Fig. 10. A frontal scetion of a 9-10-min. embryo, showing neuroblast eells with deeply stained neuraxones extending into the nerve. The latcral migration of the neuroblasts lias begun, and they have lost their connection with the inner limiting membrane of the neural tube. In some cases traces of this connection remain as dceply staining processes which extend toward the inner membrane. Comp. Oc. 6 , obj. $\frac{1}{I^{2}}$ homogeneous oil immersion.

Fig. 11. A frontal section of a much latcr stage (14-mm. embryo) showing the increased thiekncss of the wall of the neural tube as the result of multiplication of cells, and the increased scparation of the neuroblast eells from the inncr limiting membrane. Evidenee of the continued migration of medullary cells into the nerve is also shown. Magnifieation as in Figure 1.

\section{PLATE XXIII.}

All the figures are camera drawings of portions of eross-sections of a Squalus acanthias cmbryo of 12-13 mm. All cxcept Figures 20-23 are magnified 358 diameters. Figures 12 to 19 form a scrics, of which Figure 12 is the most posterior, and show the histogenesis of ventral nerves in stages immediately following that representcd in Figure 9 (PI. XXII). Figure 14, however, is a drawing of onc of the so-callcd transient ganglion cells (Bcard, '96). In all figures are seen the two chief elements of ventral nerves, the fibrillar (neuraxones) and the cellular (neurilemma), the relations of which are secn to change gradually in the series until the cells completely surround the neuraxones as shcaths (Fig. 19). The relations of the cclls in the forming nerve to the ncuraxones do not justify 
the inference that they are concerned in the formation of the neuraxones. The connection between the neuraxones and neuroblast cells in the neural tube, however, is seen at all stages of development.

Fig. 12. A portion of a cross-section of a 12-13-mm. Squalus embryo, showing a ventral nerve at a stage of development slightly in advance of that shown in Figure 9 (Pl. XXII). The neuraxon processes of the medullary cells can be traced into the nerve, and the cells of the nerve are obviously of medullary origin. The fact that the long axes of the cells of the nerve are at right angles to the neuraxones is against the assumption that these cells form the neuraxones. The fact also that they are granular and vacuolated points in the same direction. The continuity of the external limiting membrane of the neural tube with that of the nerve points to the medullary origin of the cells in the nerve.

Fig. 13. The nerve of the left side of the same metamere as that in Figure 14, showing clearly the double nature of the nerve and the typical relations at this stage of the two components. The conditions do not differ essentially from those shown in Figure 12.

Fig. 14. A "giant ganglion cell" (Beard) from the same metamere as that drawn in Figure 13, showing a stage in the development of its neuraxon process when the latter extends to a region between the somite and the ectoderm. This single large neuraxon illustrates well the method of development of the neuraxones of ventral nerves as protoplasmic processes of medullary cells. Such neuraxones as the one figured have been traced from the time when they barely protrude beyond the medullary wall until they have twice the extent of the one represented in this figure. All the evidence points to the conclusion that this neuraxon is $a b$ initio connected with its terminal organ, but not in the intimate way maintained by some histologists.

Fig. 15. The ventral nerve of the second metamere anterior to that shown in Figure 13, giving a more advanced stage in the development of a ventral nerve. The number of cells in the nerve has increased entirely through the migration of medullary cells. Neuraxon processes of medullary cells can be traced into the nerve. There is no evidence that the migrated medullary elements (ms'ec'drm.) are concerned in the formation of the fibrillar (neuraxon) portion of the nerve.

Fig. 16. The ventral nerve (left side) of the metamere anterior to that shown in Figure 15. A slightly more advanced stage. This section shows the migration of neurilemma (ms'ec'drm.) cells to the dorsal side of the nerve, to form a cellular sheath around the neuraxones, that is, around the fibrillar portion of the nerve. This dorsal migration of the cells is correlated with the growth of the neuraxones dorsad along the myotome.

Fig. 17. The ventral nerve (right side) of the metamere anterior to that shown in Figure 16. The division of the fibrillar portion of the nerve into a ramus ventralis and a ramus dorsalis is clearly seen. The vacuolated neurilemma cells give no evidence of participation in the genesis of the neuraxones. On the other hand; the deeply stained and (in some cases clearly) fibrillar processes of the medullary cells can be traced into the nerve.

Fig. 18. The ventral nerve (left side) of the second metamere anterior to that shown in Figure 17. The section shows two important conditions: first, the sharp demarkation between the fibrillar and the cellular portions of the nerve, such as would not be expected did the cells "spin" the neuraxones; and secondly, the continuity of the external limiting membrane of the neural tube with that of the nerve, evidence pointing to the medullary origin of the cells in the nerve.

Fig. 19. The ventral nerve (right side) of the eighth metamere anterior to that given in Figure 18, showing a considerably more advanced stage in development. Except in the matter of length, however, the conditions in the two stages are practically the same. In this stage and in subsequent stages there is no evidence of a further migration of cells from the neural tube into the nerve. The processes of medullary cells can be traced into the nerve.

Figs. 20-23. A series of camera drawings of four stages in the development of ventral nerves from a 12-mm. embryo; magnified about 50 diameters, of which the section shown in Figure 20 is the most posterior. The series illustrates the change in the ventral contour of the neural tube accompanying the migration of medullary cells, and the cessation of this migration. 

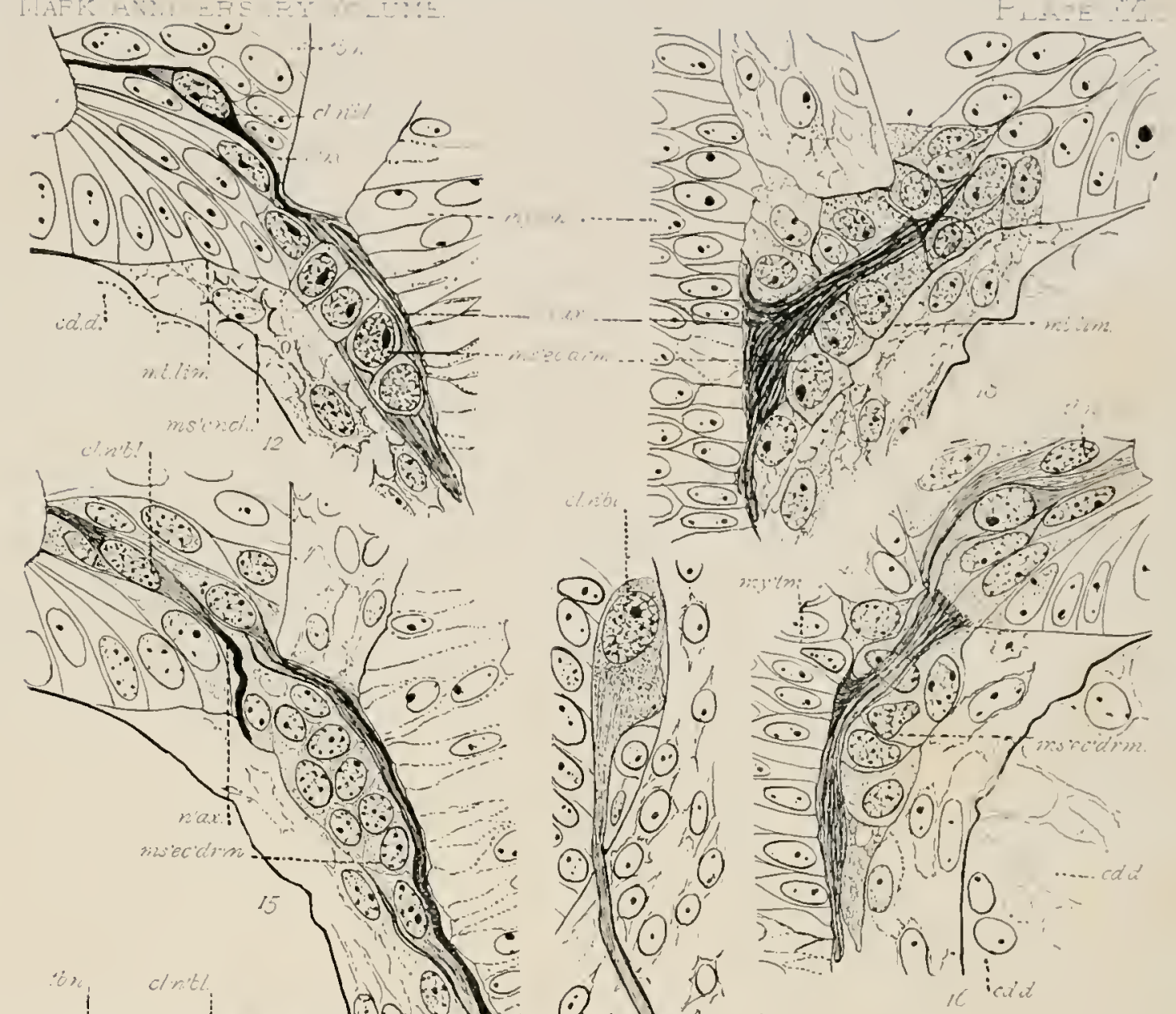

- Rinlor
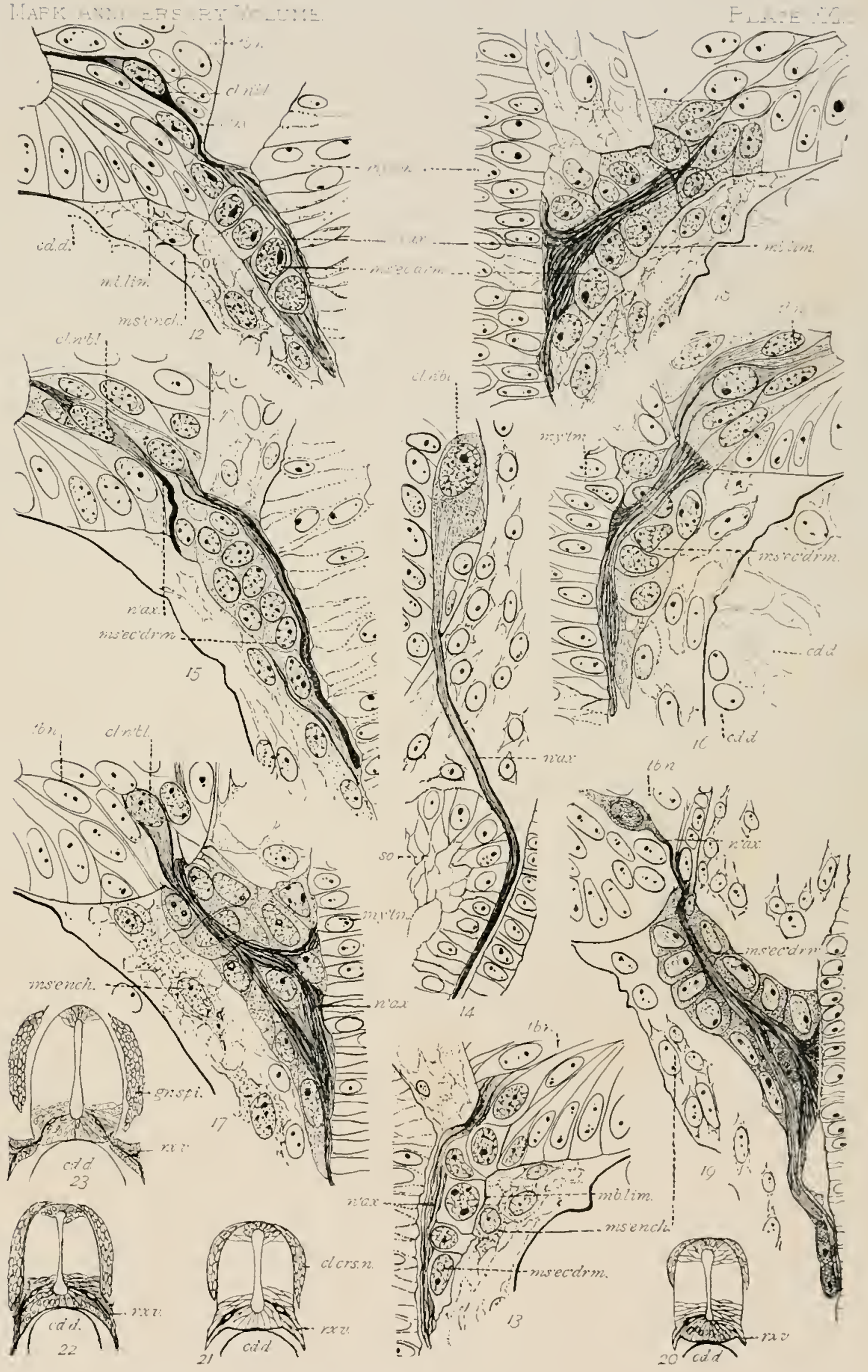
. 

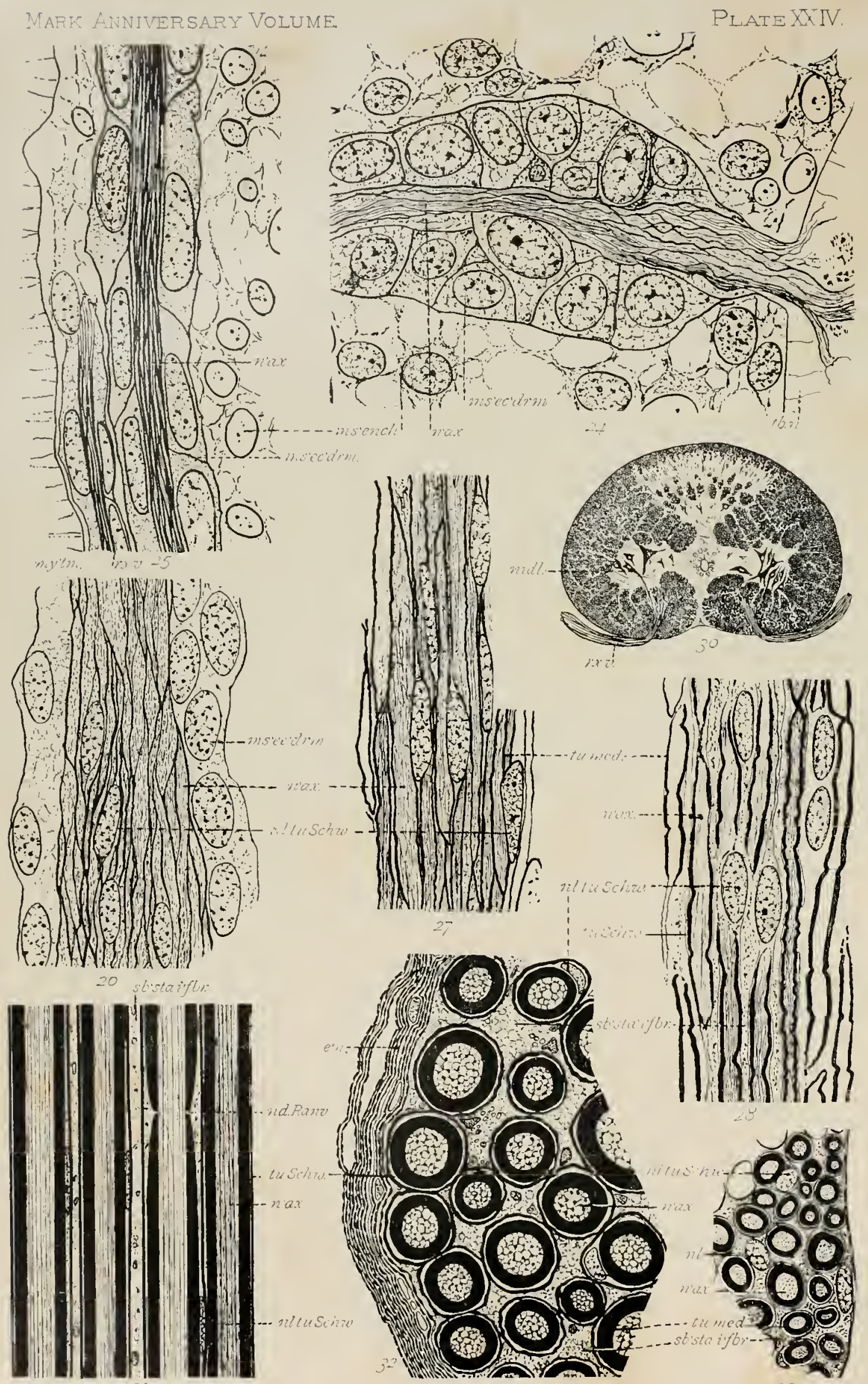


\section{PLATE XXIV.}

All figures except Figures 29, 30, and 32 represent longitudinal sections of spinal ventral nerves in different $s$ tages of development. Figures 29 and 32 were drawn from cross-sections of spinal ventral ncrves. All, except Figure 30, are camera drawings with compensation ocular 6 and 1/ $^{\frac{1}{8}}$ oil-immersion objective.

Fig. 24. The proximal portion of a nerve showing the bundle of neuraxones surrounded by a ccllular sheath, whose medullary origin has been traced. The section gives no evidence that the cells of the sheath participate in the formation of the neuraxones.

Fig. 25. A more distal portion of the same nerve, showing the same marked difference betwcen fibrillar and cellular components as in Figure 24. The sheath-cells are peripheral in position, as in the proximal portion of the nerve. No mitoses were found at this stage nor in any of the previous stages figured.

Fig. 26. A portion of a nerve from a 55-mm. embryo. Cells appear among the neuraxones as well as in the peripheral sheaths. Since there is no other more probable source for the interfibrillar cells than the peripheral sheath, they must be regarded as having migrated inward from this. They are, therefore, ectodermal (medullary) in origin. They are destined to form the neurilemma. The bending of the neuraxones makes exact longitudinal sections impossible.

Fig. 27. A portion of a ventral nerve from an embryo of $125 \mathrm{~mm}$. The nuclei of the neurilemma are more abundant than in the last section, and the medullary sheath appears on the neuraxones.

Fig. 28. A portion of a nerve of a 200-mm. embryo, showing conditions which are practically the same as adult. Between the fibres, which now have medullary sheaths and ncurilemma, a vacuolated interfibrillar substance has made its appearance.

Fig. 29. A cross-section of the same nerve as that shown in Figure 28, giving the typical elements of a nerve in their well-known relations.

Fig. 30. A cross-section of the spinal cord of a $200-\mathrm{mm}$. embryo, showing the nidulus of a ventral nerve at a stage like that shown in Figures 28 and 29.

Figs. 31 and 32. Longitudinal and cross-sections of the ventral nerve of an adult Squalus. 

XVI.

ASYMMETRY IN CERTAIN LOWER ORGANISMS, AND ITS BIOLOGICAL SIGNIFICANCE.

H. S. Jennings. 


\section{INTRODUCTION.}

The conclusions which are set forth in the following pages concerning the biological significance of unsymmetrical form and structure in a number of organisms have been reached in carrying on two very distinct lines of work. The first was a series of researches on the behavior and reactions of the Infusoria (Jennings, '97-:02), in which the relation of the prevailingly unsymmetrical form of these creatures to their method of life and their reactions was strongly impressed upon me. The second was a systematic study of a family of Rotifera, the Rattulidæ, the results of which have not hitherto been published.* The Rattulidæ have an unsymmetrical form, and in searching for the significance of this asymmetry I was again led to recognize its relation to the behavior and method of life of these creatures. I shall draw upon both these lines of work in the present paper, giving in especial detail the results on the Rattulidæ.

Before inquiring as to the biological significance of asymmetry, it will be well to recall the generally accepted views as to the significance of radial and bilateral symmetry among organisms.

Radial symmetry is as a rule characteristic of fixed animals, such as Hydra, Metridium, corals, crinoids, and the like. In such organisms the body extends freely from the substratum, and all sides of the animal come into similar relations with the environment. There is thus no reason for the sides becoming different; dorsal and ventral surfaces are not developed, and the animal remains radially symmetrical. Where freely moving animals have retained radial symmetry, it is usual to explain this as due to their recent origin from fixed forms.

The differentiations shown by bilaterally symmetrical animals are similarly brought into relation theoretically with their methods of life and movement. Anterior and posterior ends differ because they come into different relations with the environment, owing to the forward movement. In the same way dorsal and ventral surfaces differ because they come into different relations with the environment,- the ventral surface being more commonly in contact with a surface, the dorsal not thus in contact, but subjected to the light and other influences coming from above. On

\footnotetext{
* The detailed systematic results of this work are to appear in the Bulletin of the U. S. Fish Commission.
} 
the other hand, the two sides, right and left, have similar relations to the environment, there being no influence which acts upon one differently from the way it affects the other. Hence the two sides are alike.

Now, besides the radially symmetrical and bilaterally symmetrical forms, we may distinguish another type of structure, having an equally definite relation to the method of life, which has hitherto not been recognized, at least not as having a definite relation to a widespread method of movement and life. This is what may in general be characterized as a spiral type of structure, or at least as a one-sided, unsymmetrical, type. This type of structure is found in organisms which move in such a way that no two sides have the same relation to the environment.

Movement of this sort is found in those organisms which swim in a spiral course. Such, for example, are the free-swimming Ciliata and Flagellata; such also are most of the Rotifera and many other small aquatic organisms. In order to appreciate why unsymmetrical structure should be characteristically associated with spiral movement, it will be necessary to examine the nature of such movement (see Jennings, :01).

When a minute organism starts to swim through the open water in a given direction there is an indefinite number of possibilities that it may go astray. To follow a straight line is difficult in any case, and in the free water it is possible to swerve from the straight line not only to the right or to the left, but also up or down or in any intermediate direction. Most of these lower organisms do not have image-forming eyes, so that we cannot suppose them to be guided at every stage by sight. In the open water they are therefore in much the same situation as the wanderer in a blizzard on a trackless prairie, with the added possibility of wandering from the course as well up or down as to the right or left.

Under these conditions it would require a most accurately adjusted structure to avoid swimming in a circle. Any small imperfection or difference in the form or structure of one side of the animal would cause a swerving toward or away from that side, and the result would be movement in a circle, so that no progress would be made. As a matter of fact, as we shall see, most of these organisms are more or less one-sided.

So, if there were no special device to avoid this difficulty, most of these organisms would swin in circles, making no progress. But there is a special device which does avoid the difficulty. The organisms revolve on their long axes as they swim. As a necessary mechanical result, the curved course becomes a spiral one (Fig. A). The animal continually swerves from the straight line toward one side, but, owing to the revolution in the axis of progression, this side takes continually a new posi- 
$\vdots$ tion. The divergence from the straight line is therefore compensated, and the path becomes a spiral. A spiral has of course a straight axis, so that the organism can make progress in this way as well as by swimming without any divergence whatever.

Thus the spiral course may be considered as a very simple device to enable an organism to make progress in a given direction through the free water without fulfilling the difficult condition of making all sides identically alike, or of making the differences exactly balance each other.

\section{INFUSORIA.}

As will appear from the foregoing discussion and from Figure $\mathrm{A}$, the organism swimming in a spiral course keeps its body in a definite position with relation to the axis of the spiral. The same side always faces the outside of the spiral; the opposite side always faces the axis. Thus in Paramecium (Fig. A) the oral groove always faces the axis of the spiral, while the aboral side always looks to the

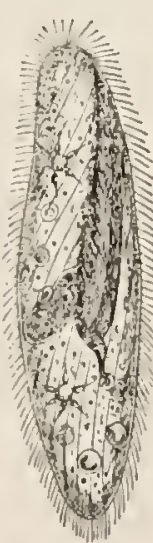

Fig. B.
FIG. A.

FIg. A.-Spiral Path of Parameeium; the aboral side always toward the outside of the spiral. ( 1 and 3 are supposed to lie in the plane of the paper, 2 above, and 4 below this plane.)

FIg. B.-Parameeium, after Bütsehli, showing spiral strueture. outside. Paramecium thus swerves continually toward its own aboral side.

Now, many of the organisms that swim in such a spiral path have the body so formed as to adapt it to this motion. This is the case, for example, in Paramecium (Fig. B). Here the body has really a partially spiral form. The oral groove, as is well known, passes in a curve from the middle of the body obliquely toward the anterior end and to the left. The animal follows a spiral path, of such a nature that the oral groove forms a segment of the spiral, the groove always facing the axis of the spiral. The body is thus unsymmetrical; it cannot be divided by any plane into similar halves.

An unsymmetrical form is characteristic for 
most of the ciliate infusoria, as is well known; this will be appreciated by examining the plates in Bütschli's ('87-'89) great work on this group. From many of the figures it will be evident further that the body has really a tendency to a spiral structure,-and the spiral form is really present in many species where it is not evident from the figures. The spiral feature may appear in the

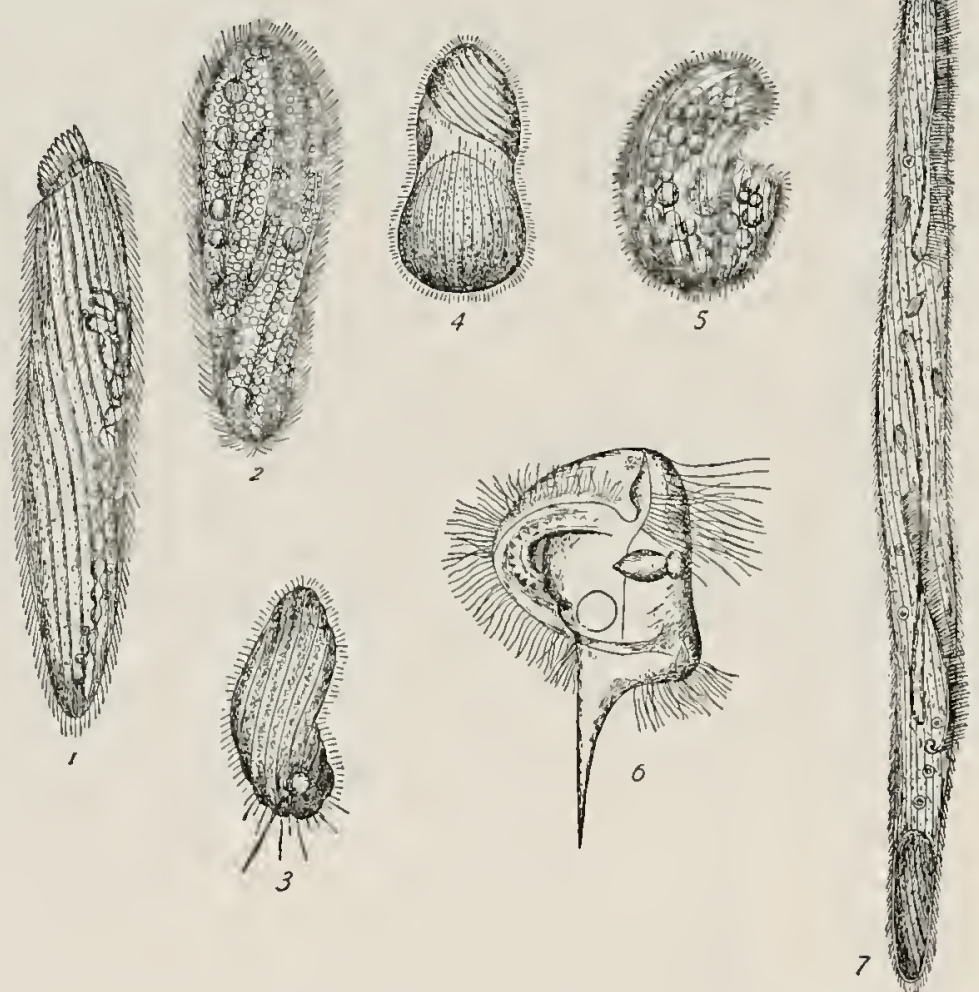

Fig. C.-Figures of Ciliate Infusoria, after Bütschli, showing the spiral form.

1, Condylostoma patens O. F. M.; 2, Anoplophrya branchiarum Stein; 3, Uronema torta Maupas; 4, Colpoda cucullus O. F. M., ventral view; 5, the same, right side; 6, Caenomorpha medusula Perty; 7, Spirostomum ambiguum Ehrbg. (dividing).

general form, the position and form of the peristome, and in the arrangement of cilia on the body. In Figure $\mathrm{C}$ are shown a number of cases in which the spiral character is particularly noticeable.

In all cases studied by the author the unsymmetrical form of the ciliate has been correlated with a spiral path, the body of the organism maintaining a constant relation to the axis of the spiral.

In the Flagellata asymmetry is likewise widespread, and in many of these organisms the spiral form is especially striking. This is the case, for example, in the species shown in Figure D. In many other species the form is really partly spiral, though this does not always appear in figures. These unsymmetrical 
Flagellata, when swimming through the free water, follow a spiral course such as is favored by the form of the body. Thus in Chilomonas the animal follows a spiral path, with the smaller lip at the anterior end directed always toward the outside of the spiral.

The unsymmetrical structure of the ciliate and flagellate Infusoria is thus closely correlated with the usual locomotion of these creatures. But this is not all. The unsymmetrical structure is equally closely bound up with the method of reacting to stimuli in these animals. They may be said to have an unsymmetrical method of reaction, as well as an unsymmetrical form. When one of these organisms is stim-
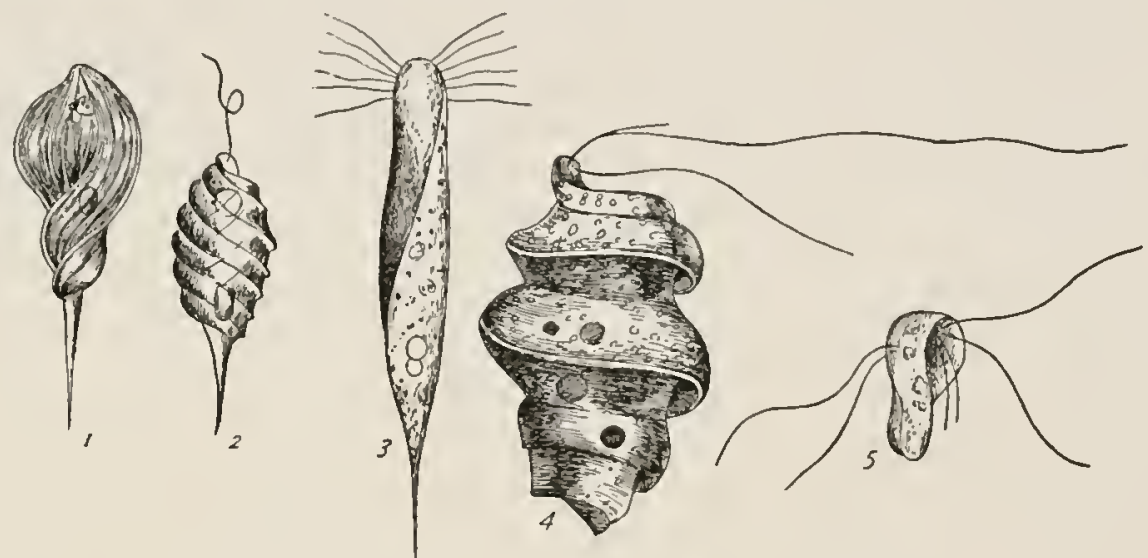

FIG. D.-Figures of Flagellata, showing the spiral form.

1, Phacus longicaudus Elrbg., after Stein, from Kent; 2, Phacus pyrum Ehrbg., after Stein, from Kent; 3, Spironema multiciliatum Klebs, after Klebs; 4, Heteronema spirale Klebs, after Klebs; 5, Trepomonas steinii Klebs, after Klebs.

ulated in almost any manner, the way in which it reacts is conditioned by its unsymmetrical structure.

Most higher organisms govern their movements with close relation to the position of external objects; in other words, they react with reference to the localization of the stimulus. Thus, if we touch sharply a leech or flatworm on the left side, it will turn away, to the right; if we touch it on the right, it will turn to the left. This necessarily involves a somewhat complicated mechanism; a stimulus on one part of the body causes a reaction in a different region from that caused by a stimulus in another part of the body. A much simpler (though of course less effective) plan would be to have the organism so constructed that it would react in the same manner whereever the stimulus, - that it would turn in the same direction whichever side is stimulated. This extraordinarily simple plan is what we have realized in the Infusoria. They are so constructed as to turn always when stimulated toward the same side, and the external manifestation of this is the unsymmetrical form. Paramecium, 
Colpidium, Loxodes, Spirostomum, always turn, when stimulated in almost any way, toward the aboral side; all the Hypotricha, toward the right side (which is perhaps equivalent to the aboral side). This is especially striking when localized stimuli are used. If with a fine glass rod we tap Stylonychia on the left side, it turns toward the right (hence away from the source of stimulus); if we tap it on the right side, it still turns toward the right side (hence in this case toward the source of stimulus). The reaction is the same whatever the nature of the stimulus; heat, cold, chemicals of any sort, mechanical shock, an electric shock, or a sudden change in the direction of an electric current passed through the animal-all produce in Stylonychia the same reaction, a turning toward the right side. This method of reaction is characteristic for many, perhaps most, Infusoria, both Flagellata and Ciliata.

It is thus evident that in these organisms the characteristic unsymmetrical structure is closely correlated with the method of life and behavior. Among the Ciliata we find two groups of organisms which show interesting examples of a tendency toward a modification of this characteristically unsymmetrical form. The Hypotricha are a group in which, owing to their habit of creeping along surfaces, dorsal and ventral sides have been developed; in other words, bilateral symmetry is becoming superposed on the primitively spiral form, though the process has not gone far. In the Peritricha, with their fixed method of life, radial symmetry is becoming superposed on the primitive spiral form, though the latter is still very evident.

\section{ROTIFERA.}

Passing now to the Rotifera, we find in these, in contradistinction to the Infusoria, a group of organisms which are primitively and typically bilaterally symmetrical. But among these bilateral organisms we find a family, the Rattulidæ, which are almost throughout unsymmetrical in structure. We wish to inquire into the significance of this asymmetry.

No thorough account of the structure of these animals has ever been given in such a way as to bring out clearly the nature of the unsymmetrical characteristics. Such an account I shall attempt to give in the following pages, and this will be concluded by a discussion of the biological significance of the asymmetry.

The Rattulidæ are a small family of free-swimming Rotifera, containing all together about forty to forty-five species. They are found as a rule among aquatic plants, in the quiet parts of lakes and streams. In such regions they are often among the most abundant of the Rotifera. 
The species of this group are usually of small size, and the body is covered with a somewhat stiff shell, or lorica, formed by the hardened cuticula. At the anterior end is a ciliated area or corona, by means of which the animal swims; this may be retracted within the lorica. The body is usually elongated and nearly oval or cylin-
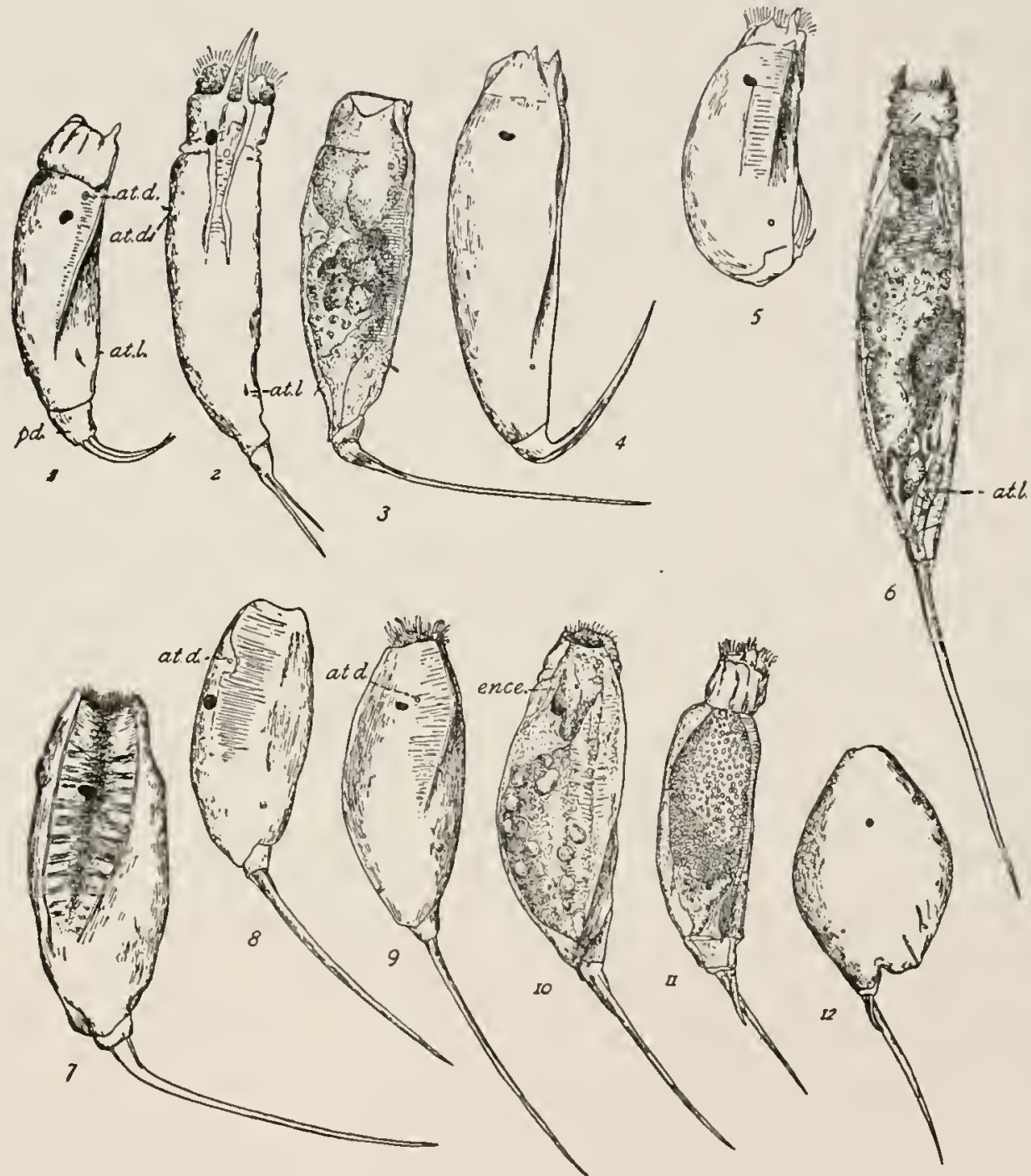

FIG. E.-Dorsal views of a number of speeies of Rattulidæ (original). Abbreviations: at.d., dorsal antenna; at.l., lateral antenna; ence., brain; pd., foot.

1, Diurella tigris Müller; 2, Diurella stylata Eyferth; 3, Rattulus scipio Gosse; 4, Diurella insignis Herriek; 5, Diurella poreellus Gosse; 6, Rattulus elongatus Gosse; 7, Rattulus bieristatus Gosse; 8, Rattulus rattus Müller; 9, Rattulus earinatus Lamarek; 10, Rattulus lophoessus Gosse; 11, Rattulus graeilis Tessin; 12, Rattulus Iatus Jennings:

drical in form. At the posterior end is a small separate joint, known as the foot. To the foot are attached one or two bristle-like structures which are usually called the toes. All these features will be appreciated by an examination of Figure E. The 
internal organs comprise an alimentary canal, nervous, muscular, excretory, and reproductive organs, together with certain mucous glands and reservoirs. In the following, such of these organs as are concerned in the asymmetrical structure will be taken up in detail.

r. Form.-The unsymmetrical structure of these animals is at once evident in a cursory examination of the body form. If we examine dorsal views of a number of the Rattulidæ (Fig. E), we find that all are curved, so as to be concave to the right, convex to the left. The curve is of ten not a simple one, but is of such a nature that the body forms a segment of a spiral. This is perhaps best seen in Figure E, 1, representing Diurella tigris Müller. This is a characteristic which it is difficult to represent in a figure, though often very noticeable in the animal itself.

2. Lorica.-The lorica, or shell, covers the body completely, being without openings at its sides, but there is an anterior opening for the protrusion of the corona, and a posterior one for the protrusion of the foot.

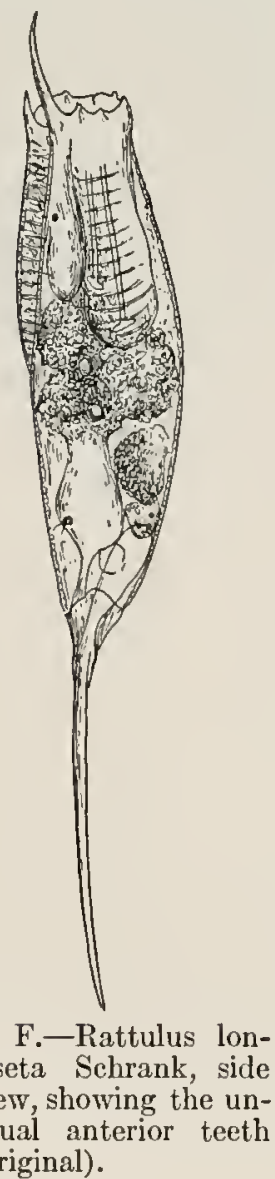

3. Head-sheath. - The anterior part of the lorica is usually set off from the remainder of the body by a slight constriction. This anterior portion covering the head may be called the headsheath. The head-sheath frequently has longitudinal plaits, which allow the sheath to fold when the head is retracted within the lorica.

Especially interesting from the present point of view are the teeth, or spines, which are found in many species at the anterior margin of the head-sheath. When present at all there are one or two of these, and they lie as a rule not in the dorsal median line, nor at equal distances on each side of the middle line, but distinctly to the right of the dorsal line. These teeth are shown in Figure E, 1-5, and in Figure F. They form prolongations of the "striated area" of the lorica, described below. Where two teeth are present, as in Figure E, 2, 4, 5, and in Figure F, they are usually not equal, but the right one is considerably longer than the left. (In Diurella stylata, Figure E, 2, however, they are nearly equal.) One of the two teeth, when two are found, lies nearly in the middle line, while the other lies distinctly to the right of this line.

4. Striated Area and Ridge. - One of the most peculiar characteristics of the Rattulidæ is the presence on the lorica of a dorsal longitudinal area, striated transversely, which extends from the anterior edge backward to the 
middle of the lorica or farther. This area shows the most varied differentiations in different species, in some appearing as a single high ridge, in others as two ridges, in still others as a depression, while in yet other cases there is no change in the surface of the lorica in this region except the transverse striations.

This area is unsymmetrical in position, beginning at the anterior margin at the right of the middle line, and passing obliquely backward and toward the left sicle. Its sides are, as a rule, rather sharply defined, frequently appearing as two slight thickenings or ridges.

This striated area is really a flexible portion of the lorica, and the transverse striations are muscle-fibres, by means of which the edges of the area can be brought closer together, thus permitting an increase or decrease in the circumference of the body. The fibres are attached at the middle and at the two sides of the area (Fig. E).

In different species of the Rattulidx we find the following different conditions of this area: (1) in a very few species both edges of this area are elevated into ridges, leaving a deep groove between them (Fig. E, 7); (2) in some species the median part of the area is depressed, so that a shallow groove is formed; (3) in other cases the area lies at the general level of the lorica; (4) in the condition which may be considered typical for the Rattulidx, and which is found in the greatest number of species, the right edge of the area is elevated to form a high ridge, while the left is not elevated at all. Thus, in these typical cases, shown in Diurella tigris Müller (Fig. E, 1), Rattulus carinatus Lam. (Fig. E, 9), and Rattuhus lophoessus Gosse (Fig. E, 10), there is a high oblique ridge passing from the right sicle at the anterior end backward and to the left, and sloping strongly to the right. The edge of the ridge is thus directed toward the right, and the right side is either perpendicular or concave. Why the right side of the striated area should have thus developed rather than the left will be brought out in our general discussion of asymmetry.

A word further should be said as to the relation of the striated area to the teeth or spines at the anterior margin of the lorica. These are formed as outgrowths of one or both of the thickened edges of the striated area. Where two teeth are present both edges project, that formed by the right edge being usually the larger. When only one tooth is present it is formed by a projection of the right edge of the area.

5. Foot.-The foot is a short conical structure attached to the body at its posterior end (Fig. E, 1, pd.). The attachment to the body is usually unsymmetrical, the joint between the foot and body being generally oblique, extending farther back on the left (or left dorsal) side than to the right. This is well shown in Figure $\mathrm{E}, 6$, of Rattulus elongatus Gosse. In some cases the posterior edge of the lorica projects backward some distance over the foot on the left side, but not on the right (Fig. E, 10). 
The foot is thus attached to the lorica in such a way that it can bend to the right, but not to the left.

6. Toes.-The toes form perhaps the most peculiar characteristic of the Rattulidæ. Most of the Rotifera have two short posterior appendages attached to the foot, placed side by side, and, like most paired organs, similar in form and size. But in the Rattulidæ we find the two toes in the majority of cases unequal, sometimes strongly so, and not side by side. In some species one of the toes has almost disappeared, while the other has become immensely developed, forming a straight rod as long as the body (Fig. E, 6-12).

The steps in the series of changes by which this is brought about may be clearly followed by comparing the toes of different species. In a few species (Diurella tigris Müller, Diurella rousseleti Voight, etc.) the two toes are still equal, as in other rotifers. One of these will serve best as a starting-point. We will select Diurella tigris Müller, whose toes are shown in Figure G, 1. The toes form two long, curved, pointed spine-like rods, of equal size. At the base of each are four small, flattened spines (so-called substyles), which usually lie closely applied to the toes. The two toes in Diurella tigris Müller are not placed exactly side by side, as they are in most rotifers, but they partake of the prevailing asymmetry of the animals. The attachment of the toes to the foot is oblique, like that of the foot to the body, so that the right toe lies at a higher level than the left. The arrangement will be best understood if we conceive it to have been formed as follows. The toes, originally curved downward, have been twisted at their attachment to the foot, so that the concavity of the curve now faces to the right instead of down, and the right toe lies above the left (Fig. E, 1). The toes and foot can therefore now bend only to the right-not toward the ventral side, as in most other rotifers.

Now the right or upper toe begins to degenerate, until in some species there is hardly a trace of it to be detected, while the left or lower toe becomes further developed. The steps in this process are easily traceable, and are shown in Figure G. In Diurella stylata Eyferth (2) and D. brachyura Gosse (3) the toes are almost equal, but the left is a little longer. In D. porcellus Gosse (4) the difference is greater. In D. insignis Herrick (5) and D. tenuior Gosse (6) the right toe is about half as long as the left. In Rattulus gracilis Tessin (7) it is about one-third the length of the left. The right toe now forms a small rudimentary spine, which has its tip bent beneath the main or left toe, and lies against the latter. Rattulus lophoessus Gosse (8) shows a further step; R. elongatus Gosse (9), R. longiseta Schrank (10), R. scipio Gosse (11), R. carinatus Lamarck (12), R. mulitcrinis Kellicott (13), and R. pusillus Lauterborn (14) still further ones in the reduction of the right toe and corresponding increase 
in the left one. In the last five or six species named the rudimentary right toe has usually been classed with the substyles, though it can as a matter of fact be recognized when a comparison of a series of species is made. Finally, there are certain
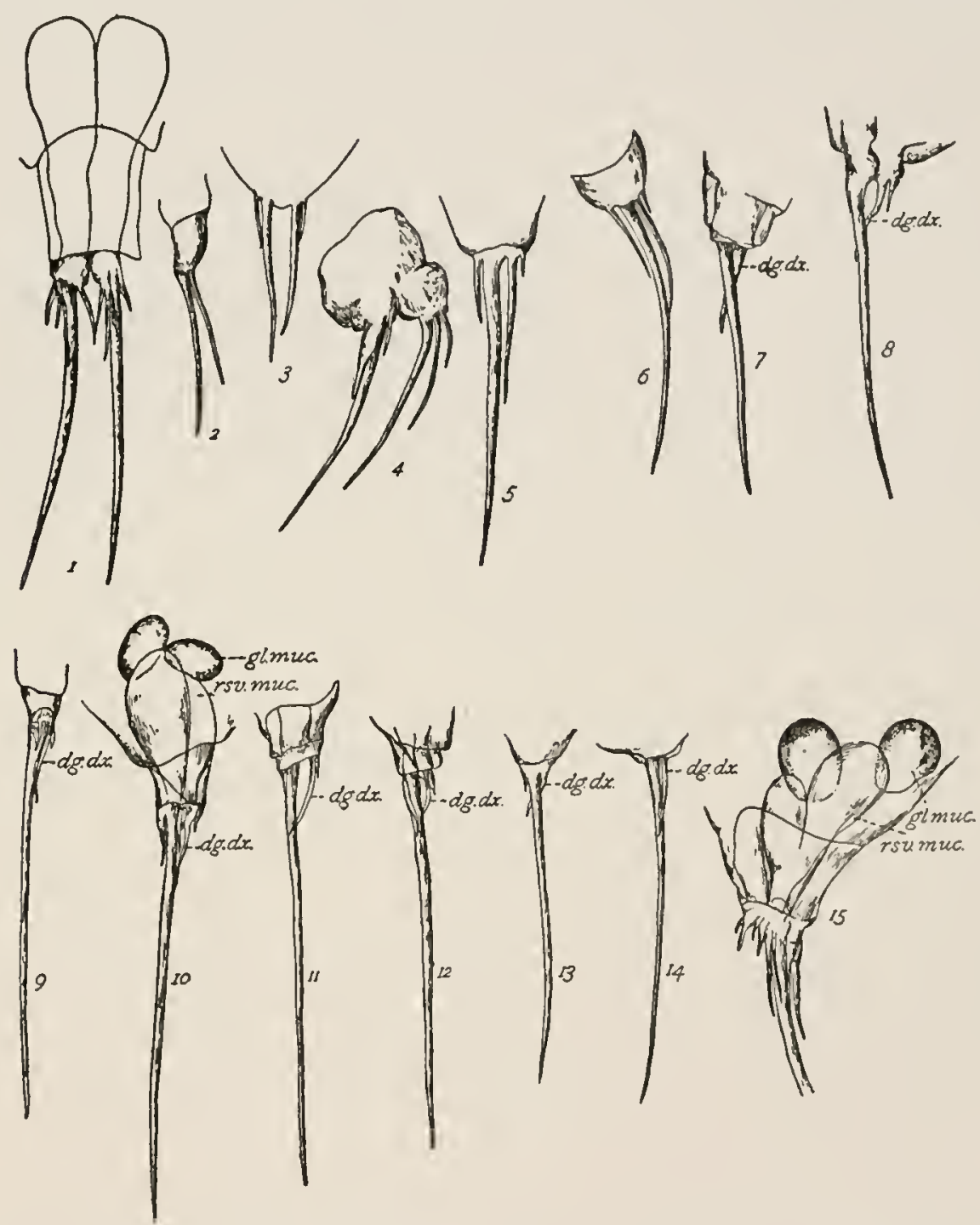

FIG. G.-Toes of a number of species of Rattulidx, viewed from the dorsodextral side, showing stages in reduction of the right toe (original). Abbreviations: $d g . d x$., right toe; gl.muc., mucous gland; rsv.muc., mucous reservoir.

1, Diurella tigris Müller; 2, Diurella stylata Eyferth; 3, Diurclla brachyura Gosse; 4, Diurella porcellus Gosse; 5, Diurella insignis Herrick; 6, Diurella tenuior Gosse; 7, Rattulus gracilis Tessin; 8, Rattulus lophnessus Gosse; 9, Rattulus elongatus Gosse; 10, Rattulus longiscta Schrank; 11, Rattulus scipio Gosse; 12, Rattulus carinatus Lamarck; 13, Rattulus multicrinis Kellicott; 14, Rattulus pusillus Lauterborn; 15, Rattulus bicristatus Gosse (proximal part of toe).

species, as Rattulus bicristatus Gosse (15), in which it is difficult or impossible to distinguish between the rudimentary right toe and the substyles. 
Connected with the toes are two sac-like mucous reservoirs, shown in Figure G, $1,10,15$. These pour out upon the toes a tenacious substance by which the animals may attach themselves to surrounding objects. Hand in hand with the reduction in the right toe goes a reduction in the mucous reservoir which is connected with it. The reduction of the reservoir is not so extensive as that of the toe, however, and it never completely disappears. Stages in this reduction are shown in Figure G, 10, 15.

7. Antennæx.-Of the other external structures in the Rattulidæ, it is chiefly the so-called antennæ in which the asymmetry is evident. These are small projections through the lorica, bearing at the tip a bunch of setæ, supposedly sensory in character. There are three of these antennæ, one dorsal and two lateral.

The dorsal antenna (Fig. E, at.d.) is found, in most rotifers, on the dorsal surface, some distance back from the anterior edge of the head. The position of the dorsal antenna probably indicates the dorsal median line, so that its position in the Rattulidæ, in which it is difficult to locate with certainty the median line, owing to the twisted form, is of interest. It lies usually to the left of the oblique ridge above described, usually at about the left edge of the striated area (Fig. E, 1, 8, 9).

The lateral antennæ are placed in most other free-swimming rotifers (as in the Notommatidæ, from which the Rattulidæ are in all probability derived), on each side, in the posterior tliird of the body, symmetrically with relation to each other. Many species of Rattulidæ have preserved nearly this primitive condition, though usually with slight variations (Fig. E, 1, 3, 6, 9). But in some cases there is a very remarkable asymmetry in the position of the two antennæ. In Diurella stylata Eyferth (Fig. E, 2) and in Rattulus cylindricus Imhof the left antenna lies in front of the middle of the body, while the right one is far back, near the posterior end.

8. Internal Organs. - The internal organs partake to a considerable degree of the asymmetry so characteristic of the external anatomy of the Rattulidæ. I shall mention here only those features in which the asymmetry is shown.

The brain (Fig. E, 10, ence.) is frequently formed of several lobes, the left one of which bears at its posterior end the eye. The mastax, or muscular pharynx, is likewise frequently shown as an unsymmetrical form, this being a consequence of the asymmetry of the trophi, to be described at once.

The trophi, or chitinous jaws, usually show a considerable degree of asymmetry, though there is much variation in this among the different species. Taking the trophi of Rattulus longiseta Schrank (Fig. H, 1, 2) as a type, we may distinguish the following parts. There are two lateral portions, known as mallei, and a central structure, the incus. Each of these is composed of several portions. Each malleus consists of two 
chief parts, a long distal rod, the manubrium (Fig. H, 2, mab.), and a shorter proximal portion, the uncus (un.). The incus or central portion consists of three main parts. There is a long median curved rod, the fulcrum ( $f u l$. ), which bears at its proximal end two large structures known as the rami $(r m$.$) . These articulate with the$ fulcrum and enclose a space between them. At their proximal ends they bear a number of teeth. The rami have their lower or distal end produced into a long process, which with Gosse we may call the alula (al.).

In the trophi of Rattulus longiseta Schrank (Fig. H, 2) it will be noticed that the left side is somewhat better developed than the right. The left manubrium is stouter, the left uncus is thicker and bears teeth, while the right one is slender and
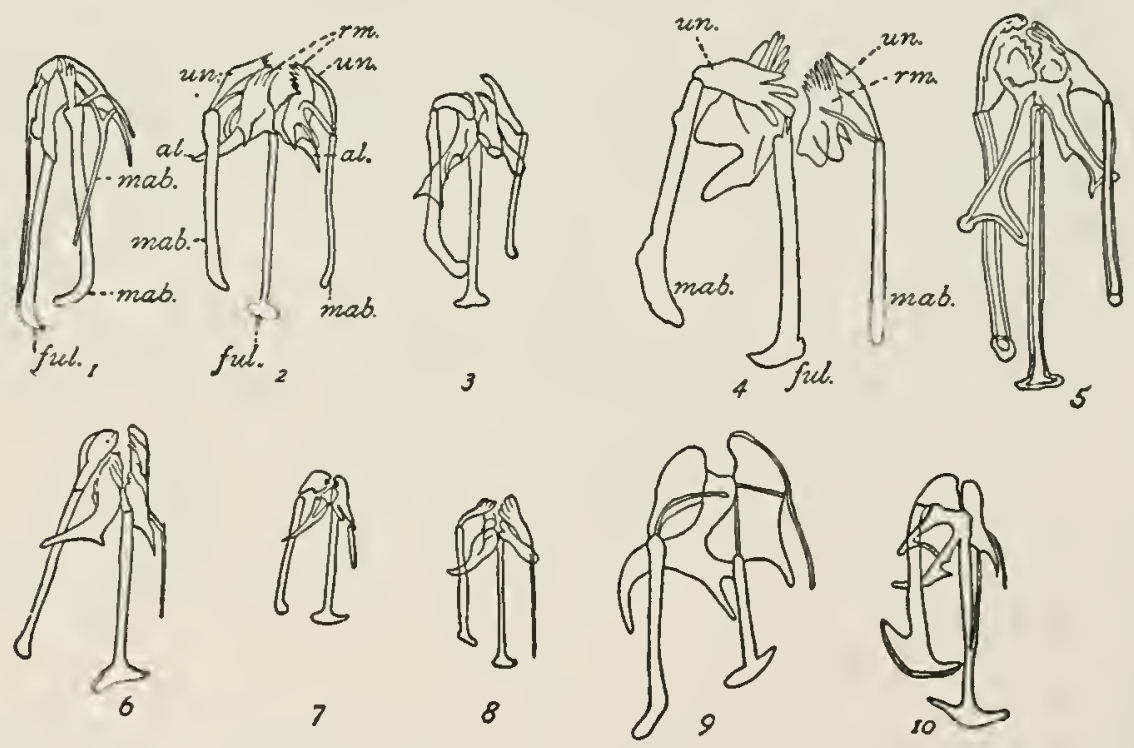

FIg. H.-Trophi of a number of species of Rattulidæ, dorsal view (except 1) (original). Abbreviations: al., alula; ful, fulerum; mab., manubrium; rm., ramus; un., uneus.

1, Rattulus longiseta Selırank, side view; 2, the same, dorsal view; 3, Rattulus bicuspes Pell; 4, Rattulus bieristatus Gosse; 5 , Rattulus elongatus Gosse; 6 , Diurella suleata Jennings; 7, Diurella tenuior Gosse; 8, Diurella poreellus Gosse; 9, Rattulus mueosus Stokes; 10, Diurella tigris Müller.

without teeth; the left alula is longer than the right. These differences are characteristic for the whole family, but are much more pronounced in some species, as a glance at Figure $\mathrm{H}$ will show. In such cases as Diurella sulcata Jennings (Fig. H, 6) and D. tenuior Gosse (Fig. H, 7 ) the right side is much smaller than the left, while in D. tigris Müller (F'ig. $\mathrm{H}, 10$ ) the right manubrium and uncus have almost disappeared.

Altogether, then, we find that all the Rattulidx are more or less unsymmetrical in many features of their body structure. If we seek for a general statement which shall express the nature of this asymmetry, we shall find it most fully set forth as follows: Conceiving the middle of the body to be a fixed point, the anterior part of the body seems to be twisted to the right, the posterior part twisted to the left. 
This will perhaps best be appreciated by examining the figure of Diurella tigris Müller (Fig. E, 1). The anterior part of the ridge is considerably to the right of the median line, as is also the anterior tooth. At the posterior end, on the other hand, the indications are that what was primitively dorsal has passed to the left, while the righthand one of the paired structures has taken a dorsal position. The body has become not only twisted on its primitive straight axis, but bent also, so as to form a segment of a spiral. As a result of this the left side has become convex, the right side concave. These features are of course much more marked in some species than in others. The remainder of the unsymmetrical characteristics, as we shall see, may be considered secondary results of this twisting and bending, so that it is with the latter that we are primarily concerned.

What is the significance of this peculiar twisted condition in the Rattulidæ?

The key to the asymmetry of this group is to be found, as in the case of the Infusoria, in the movements and behavior of the animals. The unsymmetrical condition in the Rattulidx is of course not primitive, for these animals were originally bilaterally symmetrical. The fundamental plan of structure is still that of bilateral symmetry; certain parts have been reduced or changed in position, so that asymmetry has resulted, but the bilateral ground-plan is easily traceable.

The nearest relatives of the Rattulidæ are still bilaterally symmetrical. Probably no one familiar with the Rotifera will be inclined to question the view that the Rattulidæ are derived from the Notommatidæ. Almost all investigators that have expressed themselves in the matter have taken this view, and indeed it is clearly evident.

The Notommatidæ are typically creeping forms. They live among the weeds, on the surfaces of which they creep about by means of their cilia, keeping the mouth as a rule against the surface. It is true of course that they can also swim freely through the water, but their characteristic movement is along a surface. The species least differentiated in special ways (Proales) are those of which the creeping habit is most characteristic.

In animals which thus creep about, keeping one side against a surface, we may naturally expect bilateral symmetry. Such animals fulfil all the conditions which were set forth in the beginning of this paper for bilateral symmetry. It is not surprising, therefore, that we find the Notommatidæ to be bilaterally symmetrical.

But in the Rattulidæ we find that the characteristic movement is no longer that of creeping along a surface; they are more frequently found swimming about in the free water. And if we examine their movements carefully, we find that, as in the Infusoria, they swim in a spiral course. 


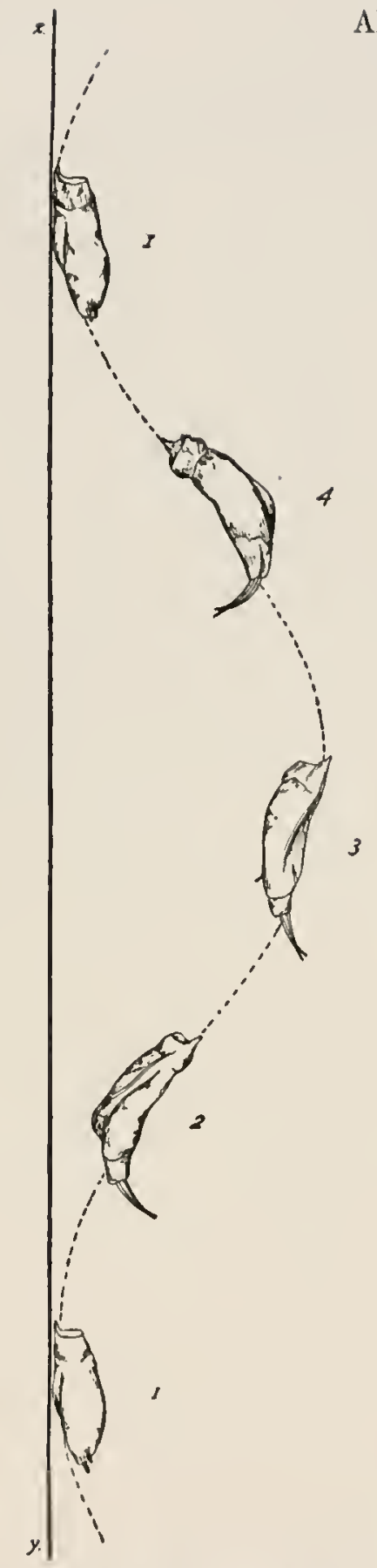

Frg. I. - Spiral Path followed by Diurella tigris Müller when freely swimming. It will be noticed that the side bearing the tooth and ridge is always toward the outside of the spiral (2 and 4 are supposed to lie in the plane of the paper, while 1 is below and 3 is above this plane). If $x-y$ is a plane surfaee to which the spiral path is tangent, it will be observed that the side bearing the tooth is the only one to touch the plane.

Now, as we have already seen, many organisms which habitually make use of this method of progression have a form which is adapted to it. In this way is to be explained the asymmetry of the Infusoria.

In the Rattulida we have a group of animals, fundamentally bilateral, which are taking on the spiral, unsymmetrical form as an adaptation to their method of movement.

If we examine in detail the behavior of one of the Rattulidæ, taking for example Diurella tigris Müller (Fig. E, 1), we find that it swims through the water in a spiral, of such a course that its twisted body forms a segment of the spiral path (Fig. I). The animal revolves to the right and swerves continuously towards its dorsodextral side as it progresses. The result is a path almost exactly that which would be formed if the animal were moving on the inside of a hollow cylinder and the dorsodextral spiral lidge ran in a groove on the inner surface of the cylinder, which fitted it precisely and had the same curvature. The effect is the same as that produced by the spiral grooves on the inner surface of a rifle-barrel, giving the ball a rotary motion in the axis of flight. The result is, here as in the rifle-ball, to make the axis of movement a straight line.

It is apparent, therefore, that the general form of the body is exactly adapted to the path which the body follows through the water. And this general form is produced by the twisting of the body from its original bilateral symmetry into the condition already minutely described. The reason why only the right half of the striated area is, as a rule, developed into a ridge, which slopes to the right, and why the ridge has an oblique course are entirely evident from the methor of movement. The Rattulidx always revolve to the right as they swim, so that the ridge sloping over to the right is exactly fitted for aiding this movement; if both sides of the area were elevated, the left one of the ridges so (n) 
formed would operate against this method of moving. The reason why the right side is convex, the left concave, is likewise evident; this is a necessary result of making the body a segment of a right spiral.

The asymmetry of the internal organs may be recognized as a consequence of the external form. Since the right side has become concave, there is less space here than in the convex left side; hence we find a tendency for some of the organs on the right side to become reduced. This is especially noticeable in the trophi or laws, in which, as we have seen, the right side is usually small or rudimentary.

There are some points which still need elucidation, however. Why are the teeth at the anterior dorsal margin of the lorica confined to the right side? Why has the foot become twisted into such a position that the toes can be bent only to the right? And why does the right toe degenerate?

These points will be better understood if we examine the behavior a little further. As we have seen, the animals continually swerve toward the dorsodextral part of the body-that which bears the ridge. This result is due to two components: first, a tendency to swerve toward the dorsal side, as when lifting the body from the bottom (a tendency which is present in almost all free-swimming rotifers); and secondly, the revolution toward the right. The resultant of these two components is a swerving toward the dorsodextral region.

Now the delicate head bearing the cilia and sense-organs, is the only portion of the body which is not protected from injury by the lorica as the animal swims. Owing to the continual swerving toward the dorsodextral side, if the delicate head ever strikes against any object, it must be on the dorsodextral side. Hence the tooth or teeth are placed in this region, where they will receive any blows which would otherwise fall upon the unprotected head. This striking against objects is by no means rare in the ordinary swimming of the animal. It of ten swims along with its spiral path tangent to a surface, almost every turn bringing the animal against the surface. But it is of course always the dorsodextral angle which comes in contact with the surface, the tooth or teeth here protecting the soft head from injury. This will be appreciated by an examination of Figure $\mathrm{I}$, if the line $x-y$ is conceived to be the surface tangent to which the animal is swimming.

Moreover, the usual reaction to a stimulus in the Rattulidæ is, as in the Infusoria, closely related to the method of locomotion and to the unsymmetrical form. When a Diurella or Rattulus while swimming freely through the water meets an obstacle, it alters its course simply by turning still farther than usual toward the dorsodextral side. If the obstacle is small, it is thus at once avoided. If the obstacle, on the other hand, is large-for example, a flat surface which prevents farther movement in the 
axis of the spiral,- the animal continues to swerve toward the dorsodextral side till its general direction is completely changed. Figure $J$ represents such a reaction in Diurella tigris Müller.

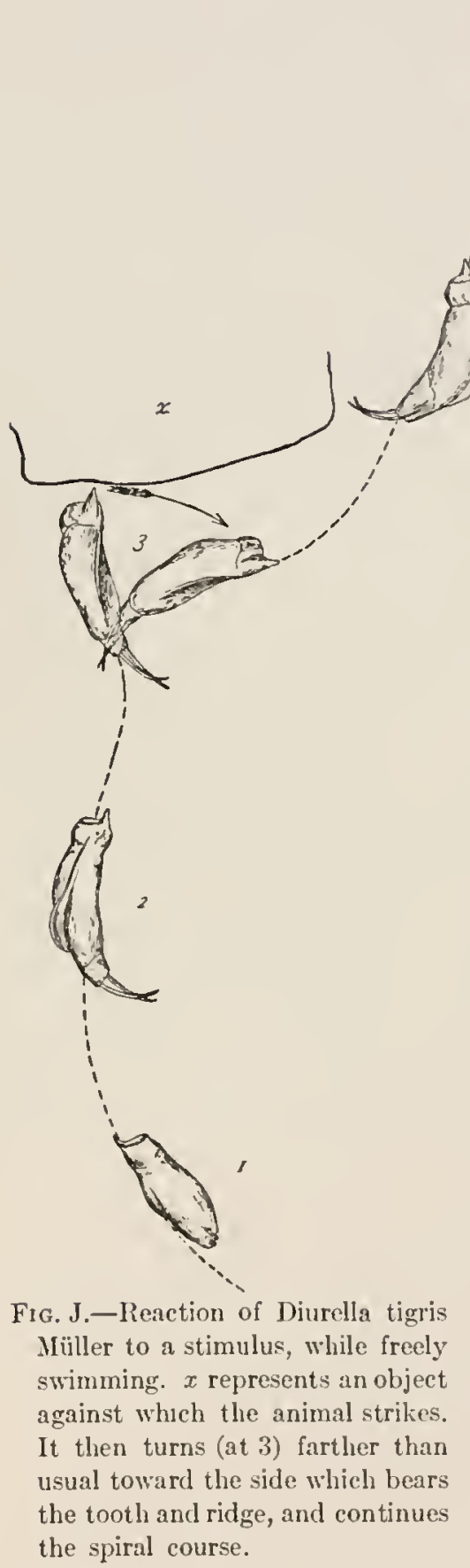

Now it is evident that if in this turning as a result of a stimulus the animal strikes its delicate head against anything, it will always be the dorsodextral angle which is thus struck, and we see again why the tooth should be at this point.

Sometimes the animal runs forward into a small angle, where it cannot directly turn, as, for example, between the surface film of water and the bottom of a watch-glass. In this case the animal turns, as usual, toward the dorsodextral side, but as a result it may merely bump its head against the bottom. It nevertheless perseveres, trying to turn in the same direction, while it revolves also on its long axis. Thus the head will be dragged and bumped along the surface, until the dorsodextral side (through the revolution on the long axis) becomes directed toward the free water. Then of course the animal swerves off in this direction.

No one who has seen this peculiar performance (which is not at all uncommon) can remain in doubt as to what is the significance of having the tooth or teeth at the dorsodextral side of the anterior end of the lorica. These teeth take all the "bunping," while the animal is turning, in place of its falling on the delicate corona. The teeth are placed just where they will serve to protect the head when the anterior end comes in contact with anything. No teeth are found in the corresponding position on the left side, because they would serve no purpose there.

Finally, the twisting of the foot and toes so that they can bend only to the right finds its explanation along the same line. The entire animal is constructed on the plan of turning to the right, both during its 
forward course and when stimulated to change its course. The arrangement of the toes is merely another adaptation to this. If the toes were so arranged as to bend downward, a sudden stroke with them would turn the organism toward the ventral side, quite in opposition to the other tendencies of the animal. But with the toes turning to the right, their action is brought into harmony with the rest of the behavior of the organism. On getting to a place where it can go forward no farther or upon other strong stimulation, the animal turns its toe or toes suddenly and strongly to the right and forward. By this the usual turning to the right is strongly accentuated; the path of the animal is suddenly changed.

The degeneration of the right toe and increase in size of the left can hardly be considered to follow directly from the factors thus far adduced. This change, perhaps, becomes intelligible, however, as an adaptation to another habit of the animals not yet considered. The Rattulidæ frequently use the toe or toes as an axis of rotation while maintaining a fixed position, in the following manner. There are two mucous glands in the posterior part of the body (Fig. G, 10, gl.muc.) which secrete a tenacious fluid that is stored up in two large mucous reservoirs (rsv.muc.). From these the secretion passes out between the base of the toe and the substyles, being directed by the latter clown along the surface of the toe. From the tip of the toe it trails off into the water, like a spider's web, and attaches itself to any object with which it comes in contact. The animal then remains suspended in the water like a spider from its thread. It spins about on its long axis, remaining meanwhile nearly in the same position, or it may of course move in the circumference of a circle about the object to which it is attached. While thus attached, the action of the cilia brings food to the mouth, just as in the case of the Rotifera that are permanently fixed by their posterior ends. The free-swimming rotifiers which have this mucus secretion have the advantage, therefore, of being able to change temporarily their roving method of life into a fixed one.

This habit is one of the most characteristic features in the behavior of the Rattulidæ, and at such times, as stated above, the animal rotates about its point of attachment as on a pivot. Now it is very evident that a single long toe would serve much better as such an axis of rotation than would two short toes side by side. In the latter case much resistance to the rotation would be caused.

It is probably, then, as an adaptation to this habit that the right toe has degenerated, while the left toe has increased in size. Favorable conditions for such a change have been established by the unsymmetrical position of the two toes, already described. Since they no longer lie side by side, the two toes no longer have the same relation to the environment as they have in a bilaterally symmetrical animal. 
This similar relation to the environment is usually assigned as a reason for the similarity of paired organs, and the lack of such similar relation to the environment may become an equally good ground for loss of similarity in structure. The lower, orjginally left, toe is now next to the bottom when the animals are creeping (as they sometimes still do), and will more often come in contact with the bottom than will the right one. When a thread of mucus drips from the toes and catches on some object on the bottom, suspending the animal, it will more often be that from the lower (left) toe. The conditions for a change in structure are therefore present.

It is clear, however, that the reasons for the change in the relative length of the toes is not so strikingly evident as those for the other changes above described. The same may be said a fortiori in the case of the asymmetry of the lateral antenna. I am unable to discover any reason for the change from bilateral symmetry to the excessively unsymmetrical condition found in Rattulus cylindricus Imhof and Diurella stylata Eyferth (Fig. E, 2).

On the whole, however, it is evident that the unsymmetrical form and structure of the Rattulidæ is an adaptation to their method of life and movement. The question may be asked why this unsymmetrical form has not been developed in other free-swimming rotifers, which revolve on their long axes and swim in a spiral course, just as do the Rattulidæ. But it must be remembered that the same question may be asked in regard to almost any adaptation. Why are there certain creeping animals, such as the starfish, that are not bilaterally symmetrical? The general answer to such a question must be, that we find some animals adapted to their conditions in one way, some in another; that all are not adapted in the same manner does not alter the fact that certain adaptations exist in given cases. On the specific question as to why many of the other rotifers have not become unsymmetrical, there is perhaps one consideration which furnishes a partial answer. All the rotifers which have become unsymmetrical belong to the loricate groups; the soft-bodied Rotifera have remained bilateral. The latter are flexible, and in the process of swimming in a spiral the body can by its flexibility adapt itself directly to the spiral course. There is therefore no necessity for the spiral form to become fixed. With the loricate rotifers the form is fixed, hence it must become permanently adapted to the method of movement, if it becomes adapted at all. 


\section{SUMMARY.}

In addition to the usually recognized general types of structure-the radially symmetrical, characteristic of a fixed life; the bilaterally symmetrical, characteristic of animals which keep dorsal and ventral surfaces in different relations with the environment-we may distinguish a third type of structure, equally characteristic of a certain method of life and movement. This is an unsymmetrical or spiral type of structure; it is characteristic of animals which swim in spirals, and is to be considered an adaptation to the spiral course.

The spiral course is the simplest device for permitting an organism to make progress in a given direction through the free water, without having the parts of the body elaborately adjusted so as to balance each other accurately. Not having such elaborate adjustment, small organisms would swim in circles, were it not for their revolution on the long axis of the body. This converts the circle into a spiral course, permitting progress to be made.

In such a spiral course the organism maintains its body in a definite relation to the axis of the spiral, the same surface always facing outward, the opposite surface facing the axis of the spiral.

Many organisms which swim in this manner have the body structurally adapted to this movement, the form approximating in some degree to a segment of a spiral. An unsymmetrical structure results.

Such unsymmetrical structure, adapted to a spiral path, is found in most of the free-swimming flagellate and ciliate Infusoria.

This unsymmetrical form is somewhat modified in some of the Ciliata. In the Hypotricha we have a group in which, owing to the habit of creeping along surfaces, bilateral symmetry is becoming superposed upon the primitively spiral form, though the process has not gone far. In the Peritricha, with their fixed method of life, radial symmetry is becoming superposed on the primitively spiral form, though the latter is still very evident.

In the Rattulida we have an analogous case, where in a group of primitively bilateral organisms (Rotifera) the spiral form, as an adaptation to spiral movement, is becoming superposed on the originally bilateral form. The animal swims in a spiral, of which its twisted body forms a segment.

The twisted form, the oblique ridge, the teeth on the right side at the anterior dorsal edge of the lorica, the oblique position of the foot and toes, and most of the other unsymmetrical features of many species of the Rattulidæ become intelligible 
from this point of view; they are adaptations to the movements and behavior of the organisms.

In these unsymmetrical organisms moving in spirals, the method of reaction to most stimuli is closely correlated with the unsymmetrical form.

\section{BIBLIOGRAPHY.}

Buitschli, 0 .

'S7-'S9. Protozoa. Bronn's Klassen und Ordnungen des Thierreichs, Bd. 1, Abt. 3, vii, 1098-2035 pp.; Taf. $56-79$.

Jennings, H. S.

'97-:02. Studies on Reactions to Stimuli in Unicellular Organisms: 1, Jour. of Physiol., vol. 21, nos. 4-5; pp. 258-322; 2, Amer. Jour. Physiol., vol. 2, no. 4, pp. 311-341; 3, Amer. Nat., vol. 33, no. 389, pp. 373-389; 4, Amer. Jour. Physiol., vol. 2, no. 4, pp. 355-379; 5, Amer. Jour. Physiol., vol. 3 , no. 6, pp. 229-260; 6, Amer. Jour. Physiol., vol. 3, no. 9, pp. 397-403; 7, (with J. H. Crosby) Amer. Jour. Physiol., vol. 6, no. 1, pp. 31-37; 8, (with E. M. Moore) Amer. Jour. Physiol., vol. 6, no. 5, pp. 233-250; 9, Amer. Jour. Physiol., vol. 8, no. 1, pp. 23-60.

Jennings, H. S.

:01. On the Significance of the Spiral Swimming of Organisms. Amer. Nat.; vol. 35, no. 413, pp. 369-378. 
XVII.

A CONTRIBUTION TO THE NERVOUS CYTOLOGY OF PERIPLANETA ORIENTALIS, THE COMMON COCKROACH.

(PLATES XXV-XXVIII.)

ROLFE FLoyd. 


\section{INTRODUC'TION.}

The recent and extensive investigations of the intimate structure of nervous cytoplasm and of the changes occurring in it, dating from the use of the aniline dyes for staining purposes by Nissl and others, have yielded vast and profoundly important results. The work has been done almost entirely on man and the higher vertebrates. The present research was undertaken to find out if similar conditions exist in invertebrates.

In the higher animals the motor cells have been the easiest ones to study in this connection. The cockroach, therefore, on account of its active habits and abundance was available invertebrate material for such work. Its nervous system, following the arthropod type, consists of supra- and sub-œsophageal ganglia united by circumœsophageal comnectives, and a series of single segmental ganglia lying in a median ventral position and connected, each with the next, by a double connective. There are three thoracic ganglia, larger than the abdominal ones, and presumably controlling, among other organs, the three pairs of legs. These three ganglia were used indiscriminately in studying the cells. These ganglia, like the connectives, are enveloped in a sheath of areolar tissue; they are dorsoventrally flattened and show a tendency to division into symmetrical lateral halves. Their central and major portion is formed of interlacing fibres, while on their peripheries, especially on the ventral surface near the anterior and posterior ends, lie the nerve-cells embedded in loose areolar tissue. The cells vary greatly in size, their longest diameters being from 10 to 80 micra; they are oval and regularly unipolar, only one bipolar cell having been observed. No dendritic processes were seen, but fine ones may exist, as no impregnation preparations were studied.

\section{CELLS FIXED IN VOM RATH'S OSMIC FLUID.}

I. Technique.-A living roach was decapitated, opened along the back, and the ganglia dissected out under water, the manipulation taking eight minutes. The animal moved its legs for two or three minutes after decapitation. (The same method was used in getting out all the subsequent material, the only modifications being 
the occasional substitution of physiological salt solution for water, which apparently in no way affected the result, and the shortening of the manipulation to five minutes and under, after practice.) The ganglia were placed at once in vom Rath's fixing fluid * for one-half hour, thoroughly washed in water, run through graded alcohols to absolute, then through creosote and xylol to paraffin. They were embedded and cut into sections from 1.5 to 3.3 micra in thickness. They were attached to the slide with albumen fixative, mounted in xylol damar, no stain having been used. Other ganglia were prepared in the same way, with the exception that they were only left in the fixing fluid ten minutes.

2. Observations. - The cells lay naked in their connective-tissue spaces, whose walls were regularly somewhat wavy and shrunken in appearance. The nuclei were surrounded by a distinct membrane, which was usually indented at one or two points and occasionally badly shrunken. The nuclei themselves presented a very fine and uniformly granular appearance and contained one or more dense nucleoli. The cell bodies presented, throughout their central and major portions, a blurred granulation, varying in density and in the size and number of the granules. Their periphery, however, exhibited regularly at some part, and not infrequently throughout the entire circumference, a lighter zone, composed of fibrillæ (Pl. XXV, Fig. 1). These were almost always observed at the point of origin of the nerve-fibre, lying parallel with the long axis of the cell. They sometimes extended from this region partly or all the way along one border of the cell, giving the appearance of an unsymmetrical entrance of the nerve-fibre and more or less completely enveloping one side of the granular portion of the cytoplasm (Figs. 2,3). Often they formed a broken network, with its main strands centripetally disposed, and occasionally they lay in irregular whorls (Figs. 4, 5). The grouping of individual fibrillæ into bundles caused the strands presenting the above appearances to vary markedly in thickness. The fibrillæ regularly invaded the granular area to some extent, thus making a gradual transition. In a few of the cells, subjected to the action of the reagent for only ten minutes, the peripheral network was more even and could be seen to acquire more and more granules along its strands until it was lost in the granular area (Fig. 6). The cells of various sizes presented essentially the same appearances after this, as after all other plans of technique.

In cross-section the nerve-fibres (Figs. 7, 9) exhibited in most specimens a shrunken sheath, and within it an irregular and unsymmetrically disposed bunch of granules, connected to the sheath by two or three fine strands. In more favorable

* Vom Rath's Fluid : Sat. aq. sol. picric acid, 80 cc.; $10 \%$ aq. sol. osmic acid, 10 cc.; $10 \%$ aq. sol. platinic chloride, 4 cc.; glacial acetic acid, 0.8 cc. 
sections, however, only the outer part of the pith of the fibre was so shrunken and the central portion showed a fine reticulum, with enlargements at the nodal points. In longitudinal sections (Fig. 8,10 ) most of the fibres presented appearances corresponding to the first condition described above, but the best specimens exhibited a number of granules elongated in the clirection of the fibre, and an indistinct appearance of longitudinal striation, the striæ often starting from the granules.

\section{CELLS FIXED IN PICROFORMALIN.}

r. Technique.-The ganglia, obtained in the manner already described, were placed in picroformalin * for twenty minutes. The subsequent treatment was the same as that described for vom Rath preparations except for the addition of staining. The sections were overstained in Nissl's methylen blue $†$ or Unna's polychrome, and then decolorized to the proper point in passing through the alcohols. A number were counterstained in alcoholic eosin as well.

2. Observations. - The cell-spaces again appeared somewhat shrunken in outline. The nuclear membrane was distinct, and its outline regularly plump and even. It varied somewhat in thickness, due to slight nodular enlargements, and in some cases was apparently deficient in part, the cytoplasm passing over into the nucleus without its interposition (Pl. XXV, Fig. 13). The nucleus was occupied by a more or less incomplete network of fine fibrils with considerable nodal enlargements, and by some irregular masses of amorphous matter. It regularly contained one or two deeply staining nucleoli. The nucleus, as a whole, stained very much more faintly than the adjoining cytoplasm. The cell-body, while still divisible into an inner granular and an outer fibrillar zone, exhibited far more detail of structure than after fixation with vom Rath's fluid. The inner granular zone took an intense blue stain. The granules varied only moderately in size, but markedly in quantity (Figs. 11-13). When very numerous they formed a blue granular mass of areolar structure, but when less copious they were seen to be definitely arranged along the strands of a fine network (Figs. 12,13). This difference was not an artifact of staining, as cells lying next each other in the same section exhibited it quite as markedly as any others (Fig. 13). The granular zone was regularly most dense next the nucleus, fading towards the outer margin. Sometimes it varied in density in different parts of the cell, and in one or two instances a double granular zone was observed (Fig. 12). The outer fibrillar zone, which took a red stain when eosin was used, was larger in proportion and more

* Picroformalin: Sat. aq. sol. picric acid, 50 pts.; $5 \%$ or $8 \%$ aq. sol. formalin, 50 pts.

$\dagger$ Nissl's methylen blue: Methylen blue, 3.75 pts.; castile Eoap, 1.75 pts.; distilled water, 1000 pts. 
delicate in appearance than after osmic fixation. It always entirely enveloped the granular zone. The main strands were disposed, for the most part, in a centripetal direction, though the fibrillæ from the point of origin of the nerve-fibre sometimes passed some distance down one border of the cell (Fig. 11). There was less of a tendency for the individual fibrillæ, which were very fine and clear of granules, to collect into bundles. The network varied markedly in the size of its spaces, often giving the appearance of being under centripetal tension, and it gave evidence of different degrees of damage. The nodal points were but very slightly enlarged. As this reticulum passed over into the inner zone, the granules and masses which appeared first at the nodal points and then along its strands finally obscured it more or less completely (Pl. XXVI, Fig. 14).

\section{CELLS FIXED IN CORROSIVE SUBLIMATE.}

I. Technique.-Fresh ganglia were immersed in Lang's solution * for 45 minutes. The subsequent treatment was identical with that used after picroformalin, with the exception that iodine was added to the alcohols to remove all traces of mercury.

2. Observations.-The appearances were practically identical with those presented after picroformalin, with the exceptions that the walls of the cell-spaces were more shrunken and the reticulum of the outer zone of the cell-body much more evidently lacerated and distorted (Pl. XXVI, Fig. 15).

\section{CELLS FIXED IN CHROM-OXALIC.}

1. Technique.-Fresh ganglia were immersed in chrom-oxalic $\dagger$ fluid for 10 minutes. The subsequent treatment was identical with that for picroformalin preparations.

2. Observations.-The cells showed a degree of damage to the reticulum intermediate between that produced by picroformalin and corrosive sublimate, and besides this they took the stain reluctantly. There was also more tendency to matting of the fibrils of the outer zone. Otherwise the appearances were in no way different from those already described for picroformalin (Fig. 16).

* Lang's solution: Sodium chloride, 120 pts.; mercuric chloride, 60 pts.; glacial acetic acid, 120 pts.; distilled water, 2000 pts.

† Chrom-oxalic fluid: $1 \%$ aq. sol. chromic acid, 30 pts.; $95 \%$ alcohol, 30 pts.; 10\% aq. sol. oxalic acid, 40 pts. 


\section{CELLS FIXED IN ABSOLUTE ALCOHOL.}

I. Technique.-Fresh ganglia were immersed in absolute alcohol for several hours, embedded, cut, and stained as above described for picroformalin preparations.

2. Observations. - The walls of the cells-spaces were much more shrunken and distorted than by any previous method. The nuclear membrane was regularly burst outward, and often its remnants could not be identified. The clear area (Figs. 17, 18), representing the previous site "of the nucleus, was thus somewhat larger than the nucleus itself had been. It was sometimes quite empty and sometimes contained some irregular amorphous masses. The granular area of the cell-body was represented by a rather narrow perinuclear ring of granules, rarely showing any tendency to areolar or reticular disposition, but usually denser on one side of the nucleus than on the other, and occasionally exhibiting irregular condensations even near the periphery. The outer zone of the cell-body was replaced, for the most part, by empty spaces containing a few shredded remnants of reticulum, most frequently seen at the transition between the outer and inner zones (Figs. 17-19).

\section{CELLS FIXED IN VAN GEHUCHTEN'S FLUID.}

r. Technique.-Fresh ganglia were immersed in Van Gehuchten's fluid * for one minute, then in $95 \%$ alcohol. The subsequent treatment was as already described.

2. Observations.-The appearances, though somewhat more farorable than those obtained with picroformalin, were so similar as to need no separate description.

\section{THE FRESH CELLS.}

The various appearances occurring after the different methods of fixation, all suggestive of some degree of damage to the cell structure, indicated the necessity of some standard for comparison, and this could only be satisfactorily obtained by studying the cells as they appeared during life.

r. Technique.-A fresh ganglion, dissected out as rapidly as possible, was teased apart on a slide, flooded with equal parts of Nissl's methylen blue and a $0.5 \%$ solution of sodium chloride, and examined at once. A number of ganglia were subsequently handled in the same way, the only modification being the substitution in

* Van Gehuchten's fluid: Absolute alcohol, 300 pts.; chloroform, 150 pts.; glacial acctic acid, 50 pts. 
some cases of polychrome or of Van Gieson's 5\% solution of methylen blue for the Nissl solution.

2. Observations.-The appearances of the cells obtained in this way were indeed striking. The blue cells (Figs. 20-23), teased out of their connective-tissue spaces, and entirely devoid of a cell-wall, exhibited an even outline, giving no evidence of shrinkage or other distortion. The nuclear membrane, though buried in the cytoplasm, could be made out intact, with even outline, like that of the whole cell. The nucleus itself presented a homogeneous blue substance, entirely filling its membrane and containing one or more nucleoli, that took a deep-blue color. There was no evidence of any reticulum in the nucleus. The cytoplasm was occupied throughout its entire extent by a sharply defined anastomosing blue network with slight concave nodal enlargements, but no granules or masses either at the nodes or on the strands (Fig. 24). Its spaces were of equal size and its strands of equal thickness throughout the entire cell. Different cells, however, varied considerably both in the thickness of the strands and the size of the meshes, but the smaller cells by no means regularly presented the smaller-meshed network. Except for this structure, the cell-body was entirely clear and transparent. There was no division into the two zones, seen after the various fixing methods (Pl. XXVI, Figs. 20, 21; Pl. XXVII, Figs. 22-26).

After about one hour the cell began to shrink and the network to lose its definition. These changes were regularly preceded by the shrinkage of the nucleus within its membrane. The above appearances were uniformly obtained in a number of similar subsequent preparations.

The nerve-fibres were seen to be composed of fibrillx disposed for the most part longitudinally, but anastomosing with each other, the nodal points being prominent; in other words, like the cell-body, they contain a network of fibrillæ (Pl. XXVII, Fig. 26). In preparations of teased specimens fixed in formalin vapor, as will be described, there were no granules or masses of deeply staining particles to be seen upon the strands of the network in the nerve-fibre, although these strands stood out with great sharpness. It was also to be noted that in such preparations the fibrillæ in the nerve-fibre anastomose at very acute and not at right angles (Fig. 28).

Satisfactory permanent preparations of whole cells in approximately this condition were obtained by two methods. In neither was the network as clear as in the fresh condition, but slightly obscured by an irregular granular deposit at the nodes and along the strands. The first one was more simple and yielded better results.

3. Technique.-(1) The slide with the teased cells on it was exposed to the vapor of strong formalin (10\% or over), stained, dehydrated, and mounted in the usual manner. 
(2) The teased cells were first stained with a $0.5 \%$ solution of methylen blue, then flooded with a saturated solution of ammonium molybdate, and then with Bethe's solution Number 3 (see Bethe, '96, p. 444). They were eventually dehydrated and mounted in the regular manner. The ammonium molybdate solution was best applied as a hanging drop, for crystals tend to separate out, and if they are allowed to settle on the specimen they are difficult to remove.

In order to observe, if possible, the action of the methods of fixation previously described, a group of fresh cells under the microscope were flooded with Lang's solution. Instantaneous shrinkage and distortion occurred, and a few cells whose margins had apparently become adherent to the slide exhibited appearances strikingly similar to those of fixed preparations (Pl. XXVII, Fig. 29).

\section{INTRA-VITAM STAINING.}

Three attempts were made to stain the cells during the animal's life. They all failed completely. They were as follows:

I. Technique.-(1) Two minims of a solution of three parts physiological salt solution and one part polychrome were injected through a lypodermic needle into the back of a cockroach; one and a quarter hours later decapitation was performed; the body-cavity, containing the dye, was laid open and the animal was put in an ice-box for twelve hours. The ganglia were then teased and examined.

(2) Ten minims of a solution of equal parts of physiological salt solution and Van Gieson's blue were injected through the ventral wall of a cockroach; one hour and ten minutes later the animal was killed, and the body-cavity was found full of the dye. The ganglia were teased out and examined at once.

(3) A roach was fed on molasses containing a considerable amount of Nissl's methylen-blue solution, and four and one-half hours after eating this the animal was killed. The anterior end of the alimentary tract contained some of the blue dye; two ganglia were fixed and sectioned and the other was teased.

It was now necessary to obtain a method for preserving the cells as nearly as possible in the condition seen in the fresh specimens, in order that they might be studied in section. Three methods were tried. 


\section{CELLS FIXED IN VAPOR OF FORMALIN.}

I. Technique.-Fresh ganglia were exposed to the vapor of concentrated formalin for one hour and twenty minutes, then passed through the alcohols, embedded, cut, stained, and mounted as described for picroformalin.

2. Observations.-The results of this method were eminently satisfactory. The cell-spaces were evenly filled by the cells. The nuclear membrane was even, distinct, and entire. The nucleus presented a homogeneous appearance, took a pretty even stain, and contained deeply stained nucleoli. It presented no evidence of reticular structure. In some cases its substance had shrunk a little, leaving a small clear space just inside the nuclear membrane. The cell-body was occupied throughout by an anastomosing network of fine fibrils staining clearly, but not intensely. Under strong magnification small gramules and masses were seen at the nodal points and along the strands. The rest of the cell-body (i.e., the interstices of the network) was clear. While the different cells varied both in the thickness of the fibrils and the size of the meshes (just as the fresh specimens did), the most striking difference in their appearance was caused by the varying quantities of the deeply staining granules and masses. Thus some of the cells were pale, and composed of a fine granulated reticulum, while others took a strong stain and presented a mass of granules, disposed in areolar fashion, somewhat as in the granular zone of picroformalin preparations. In none of the cells was there any peripheral laceration of the reticulum or any tendency to the formation of two zones, both the reticulum and the deposit upon it being evenly distributed (Pl, XXVII, Figs. 30-33).

\section{CELLS FIXED IN GRADED FORMALIN SOLUTION.}

I. Technique.-The ganglia were immersed successively in $1 \%, 2 \%, 3 \%$, and $4 \%$ formalin solutions, remaining in each solution one-half hour. The subsequent treatment was like that in the preceding method.

2. Observations. - The whole tissue gave evidence of considerable swelling, the interfibrillar spaces were considerably enlarged, and the cell-spaces, of course, partook of this change. The nuclei exhibited a reticulum with amorphous matter and nodal enlargements upon it (Fig. 34). The nuclear membrane was even and usually spherical in outline, as though distended. The outlines of the cell-body were irregular on account of the adhesion of some parts of its periphery to the wall of the cell-space, thus causing long processes in various directions. The reticulum was very clear and 
gave the appearance of being stretched. There was upon it, evenly distributed, the deeply staining granules and masses. There was no perinuclear condensation and no peripheral laceration of the reticulum, except from stretching. The appearance of the individual cells was very much like those fixed in formalin vapor, except for the differences just enumerated, and some of them, in which less stretching had occurred, were almost identical in appearance, except for the nuclear reticulum.

\section{CELLS FIXED IN DIFFUSED ALCOHOL.}

I. Technique.-By the use of a simple diffusion-bottle the ganglia were placed in water to which alcohol was gradually added till a concentration of between $80 \%$ and $90 \%$ was reached at the end of three or four hours. The subsequent treatment was the same as in the preceding method.

2. Observations. - The results (Pl. XXVII, Figs. 35-37) were similar in the main to those of formalin vapor and graded formalin. The cell-spaces were not much distorted, but moderate shrinkage of the cells prevented them from filling their spaces, and caused some of their margins to present the same appearance as after graded formalin. The nuclei exhibited a reticulum as after graded formalin. Its membrane was distinctly indented and shrunken. This shrinkage was evident also in the wrinkling and kinking of the individual strands of the cytoreticulum and the narrowing of each interstice, a change which was present to about the same extent in all parts of the cell-body. The strands and nodes of the reticulum presented the same deeply staining substance as with the formalin methods, but it occurred in somewhat different form, there being fewer granules and more irregular masses along the fibrils. There was no perinuclear condensation and no centripetal arrangement or laceration of the reticulum, except for the marginal shrinkage above described.

Some experiments were next undertaken in the hope of throwing additional light on the nature of the substance which exhibited such a strong affinity for methylen blue and appeared in granules and masses upon the cytoreticulum in all specimens of the fixed cell. Held ('97, p. 204) has stated that the chromophilic plaques of the nerve-cells in higher vertebrates do not exist as such during life, but are formed by the post-mortem precipitation of certain bodies contained in the cell lymph, that this precipitation is due to the post-mortem change in the chemical reaction of the tissues from alkaline to acid, and that by immersing such cells in alkaline solutions these plaques can be dissolved out. On this suggestion two experiments were performed. 


\section{POST-MORTEM CHANGES IN THE CELLS.}

I. Technique.-A roach was decapitated, opened along its back, and placed in a small bottle of distilled water containing a piece of blue litmus paper. Seventeen hours later, the litmus paper having become red, the ganglia were removed. One was fixed in graded formalin solutions $(1 \%, 2 \%, 3 \%, 4 \%)$, one in picroformalin, and one was teased and fixed with formalin vapor. The first two were then sectioned and all were treated according to the usual methods already described. In each of the following experiments the same three methods were used. The first afforded thin sections of cells in very nearly the fresh state. The third gave a view of the whole cell in a similar condition. The second yielded sections showing the action of a reagent tending to cause perinuclear concentration of the chromophilic substance together with peripheral laceration and distortion of the reticulum. The superiority of formalin vapor over the graded formalin method for fixing material for sectioning was not appreciated at the time these experiments were begun or it would have been used instead.

2. Observations. - The cells fixed in graded formalin (Pl. XXVII, Figs. 38, 39) showed some loss of definition of the cytoreticulum, and upon it a very even and granular-looking deposit of the blue staining substance. The different cells did not vary as much in the amount of this substance as in normal preparations. The picroformalin preparation (Pl. XXVIII, Figs. 40, 41) gave a result in no way different from that just described, there being no perinuclear concentration and no laceration of the peripheral portion of the reticulum. No previous picroformalin preparation had exhibited any such appearance. The teased specimens fixed in formalin vapor showed the same features. In other words, the cells had already been fixed and the deeply staining blue substance had been deposited upon the reticulum before the fixing reagents were ever applied to them.

One slide of a series of normal material, fixed in graded formalin, was next taken and its cover removed. It was then immersed in a $0.4 \%$ solution of sodic hydrate for four hours, after which it was restained and mounted. The general pallor of the cells was striking. The cytoreticulum had lost some of its clear definition, and the sparse and irregular deposit of blue staining substance upon it had lost much of its affinity for the dye. In many cells there was a blotch of blue stain suggesting a large colloid coagulum (Pl. XXVIII, Figs. 42-45). The alkali possessed an evident solvent action over the blue staining substance. Thus this substance reacts as Held found the chromophilic substance in vertebrate nerve-cells to do. 


\section{CELLS SUBJECTED TO PROLONGED FARADIZATION.}

I. Technique.-A roach, placed in a chamber devised for the purpose, was subjected to a strong Faradaic current at frequent intervals for three hours. At the end of this time there was almost no reaction to a current that could scarcely be borne through the hand. The ganglia were then removed, and fixed, one in graded formalin, one in picroformalin, and the third teased and fixed in formalin vapor as already described.

2. Observations.-In the graded formalin preparations (PI. XXVIII, Figs. 46, 47) many of the nuclear membranes were slightly wrinkled and uneven. This change was so moderate in degree as not to warrant the statement that it constituted a definite pathological change. The nucleus itself appeared as in normal material. The great majority of the cell-bodies, however, showed a considerable pallor, due to a marked diminution of the deposit of the deeply staining substance. The network itself stood out very sharply and presented a somewhat flaccid appearance. A very few cells, especially along the lateral edges of the ganglion, took a very intense blue stain, owing to an excess of the chromophilic deposit. Such cells could be found in normal tissue, but their appearance was so strikingly in contrast with that of the majority of the cells just described that they have been mentioned in this connection. The picroformalin preparations showed the usual perinuclear condensation and peripheral distortion, thus obscuring the appearances occurring after graded formalin fixation. The teased specimens, however, corroborated the observations above described. The network was very much clearer than in normal cells teased and fixed in the same way, and it exhibited also the flaccid appearance.

\section{CELLS FROM ROACHES POISONED BY STRYCHNINE.}

I. Technique.-A roach was fed on equal parts of $1 \%$ strychnine nitrate solution and molasses. Considerable twitching of the legs was observed. Three and one-half hours later the animal was moribund. The alimentary tract contained molasses. The ganglia were removed at once and fixed by graded formalin, picroformalin, and one was teased and fixed in formalin vapor as in the other experiments.

2. Observations.-The graded formalin preparations and the teased cells showed the changes just described for Faradized cells, but in a much less pronounced degree. While I believe there is no question of the results obtained with Faradization, I should be quite unwilling to set down the changes after strychnine as unquestionably demon- 
strated, although I am inclined to believe they are real. The picroformalin preparations were, as with those produced by Faradization, too much distorted to yield any definite results.

\section{CELLS FROM ROACHES POISONED BY CORROSIVE SUBLIMATE.}

I. Technique. $-\mathrm{A}$ roach was fed on equal parts of a $5 \%$ solution of corrosive sublimate and molasses. Fifteen hours later the animal was found on its back in general flexion, with fæces oozing from the anus, and exhibiting spasmodic movements of the limbs from time to time. The alimentary tract contained molasses. The ganglia were removed and prepared by the same three methods as in the other experiments.

2. Observations.-None of the preparations exhibited any appearances differing from normal material.

\section{CELLS FROM ROACHES POISONED BY ARSENIC.}

I. Technique.-A roach was fed on molasses with which a considerable amount of Paris green had been mixed. The animal was moribund in one-half hour. The alimentary tract contained Paris green. The ganglia were fixed by the same three methods as in the other experiments.

2. Observations.-The graded formalin and teased preparations showed nothing abnormal. The picroformalin specimens, however, showed a most unusual condition. Perinuclear condensation of the chromophilic material and peripheral laceration and distortion of the reticulum were practically absent, though some tendency to the usual artificial condition after the use of this reagent was seen in the cells with comparatively scant amounts of deeply staining deposit. For the most part the network and its deposit were evenly disposed throughout the cell-body (Pl. XXVIII, Figs. 48, 49). In other words, the deposit had occurred during life and so reinforced the reticulum as to protect it from the mechanical violence of the fixing reagent. There was, of course, no more time for post-mortem changes to occur in this case before the application of the reagent than in any other, as this particular dissection was completed in five minutes. 


\section{A REVIEW OF THE TECHNIQUE.}

The most important result of this work, so far as methods are concerned, is, I believe, the demonstration of the emphatic necessity of examining the cells, whenever possible, in the fresh state. A control over all the rest of the technique, that can be obtained in no other way, is thus secured.

So far as fixing reagents are concerned, it seems to be sufficiently demonstrated that the fluids in common use for this purpose may do grave damage to delicate cellular structures. This damage, moreover, is, in great part, physical in nature; in other words, it is largely due to osmosis and diffusion currents. If two aqueous solutions of different osmotic tension are situated on opposite sides of a membrane, water will tend to pass through that membrane from the solution of lower towards that of higher osmotic influence, until enough has passed to render the osmotic values of the two solutions approximately equal. A solution of a given osmotic power has thus a dehydrating power over all solutions of a lower osmotic power than itself and vice versa. The osmotic power of a solution depends, first, on the number of molecules in a given volume, and, secondly, upon the dissociation of these molecules into their ions. Proteids therefore in solution, since they have a very large and very heavy molecule and never dissociate, have a much lower osmotic power than solutions of equal percentage by weight of the simpler inorganic substances. Moreover, the proteid substances in the cell-sap do not constitute a solution in the strict physical sense of the term, but possibly occur in a semifluid condition, and under these circumstances their osmotic influence is reduced to a minimum.

Hence when a mass of protoplasm enclosed in a membrane is surrounded by a fluid of greater osmotic power than that of protoplasm, the mass shrinks with a wrinkling of its membrane. If, on the other hand, the surrounding fluid is of lower osmotic value than the protoplasm, the mass will swell. These facts are well illustrated by the behavior of red-blood cells, which in a $2 \%$ solution of sodic chloride rapidly crenate, while in distilled water they gradually swell and finally burst, probably chiefly on account of the inorganic salts which they contain. The same phenomenon in plant-cells is used to compare the osmotic values of different solutions.

The problem in the nerve-cell of the roach is not quite as simple, for here we have to deal with a mass of practically naked protoplasm, containing a definite reticulum, and, embedded in it, a second mass surrounded by a membrane. It is to be expected that the outer mass, being more exposed both by reason of its position 
and its lack of an investing membrane, will be more rapidly affected by osmotic forces. It is to be remembered that all fixing agents by their chemical action precipitate the protoplasmic constituents of the cell, thus rendering its structure more firm and arresting the action of osmotic currents so far as altering its shape is concerned. It is also to be noted that the osmotic influence of the fixing fluid is exerted before actual contact between it and the cell occurs, while its chemical influence must be delayed until that time, and also that the first traces of precipitation are probably flocculent in character and admit of being carried inward with the mass action toward the nucleus before the whole mass becomes solid.

When the nerve-cells of the roach, then, are immersed in picroformalin, Lang's solution, or chromoxalic, water is at once withdrawn from the cytoplasm on all sides in a centrifugal direction and the colloid matter of the cell-body and most of the reticulum are carried inward in a mass against the nucleus; a few radially disposed shreds and bundles of the reticular fibrils remaining adherent to the connective-tissue wall of the cell-space alone are left to represent the outer parts of the cell-body. It is probable that precipitation now happens before the more gradual withdrawal of water through the nuclear membrane and its consequent shrinkage can occur. There is also a shrinkage of the supporting connective tissue through the withdrawal of water from its spaces. Little violence is done to it, however, because its areolar structure permits the water to leave it without laceration. In vom Rath's fluid for some reason there is less violence from osmotic action, but the process seems to be more prolonged, for here the nuclear membrane regularly shows some shrinkage. The theory that the damage done to the cell by the fluids just discussed is thus produced by osmotic action is very strongly supported by the fact that Van Gehuchten's fluid, not having a very high osmotic power, but possessing a strong dehydrating influence from the alcohol and glacial acetic acid that it contains, causes almost identically the same results as picroformalin, and that absolute alcohol, also of low osmotic influence, but with still stronger dehydrating power, causes a result similar in kind but greater in degree. In this instance the elements of the cell-body are more closely huddled in a perinuclear ring and the water is drawn from the nucleus with such rapidity as to cause the sudden rupture of its membrane, the process being too sudden for the more gradual escape of the water through the membrane and the consequent shrinkage of the mass of the nucleus. The gradual introduction of alcohol by the diffusion-bottle caused a slow and even withdrawal of water from the cell-body with a shrinkage of each fibril of the reticulum, and the diminution in area of each interstice, together with distinct shrinkage of the nucleus.

Graded formalin, on the other hand, caused an imbibition of water, distending 
both the connective-tissue spaces and the reticulum of the cell-body, besides causing a bulging of the nuclear membrane. How formalin solutions cause this taking up of water is, I believe, not yet explained, although their swelling action on all masses of tissue has been recognized since their first use in anatomical technique.

The diffused alcohol and graded formalin methods, although far superior to those previously used and described, each causes some slight mechanical violence to the cell-structure, that is, the protoplasmic elements are not fixed with sufficient firmness until osmosis and diffusion have caused some damage. They both cause a nuclear network to appear which does not exist in the fresh state.

It is unquestionably true that a somewhat new set of methods has to be worked out for each new kind of material studied, but I venture to predict that vapor of concentrated formalin, or any other reagent possessing similar advantages, will prove a most satisfactory fixing reagent for small and readily penetrable masses of tissue, being entirely free from the dangers of mechanical damage by rapid dehydration, besides leaving the nucleus approximately as in life. For larger and less penetrable masses some combination of graded formalin and diffused alcohol methods, yet to be elaborated, may prove thoroughly satisfactory. Some eight years ago I worked with Dr. G. H. Parker in determining the requisite proportions of these two reagents for preserving mammalian brains in exactly their natural proportions (see Parker and Floyd, '95).

A comparison of the actions of the fixing reagents of different groups is shown in Figures 50 to 54 (Pl. XXVIII)

\section{SUMMARY.}

This research demonstrates that the nerve-cells in the thoracic ganglia of the roach possess no evident cell-walls, that their nuclei, though exhibiting a reticulum, with enlarged nodal points and irregular amorphous deposits, after most fixing reagents, are homogeneous in appearance in the fresh condition and after fixation in formalin vapor. They contain nucleoli and are surrounded by an entire nuclear membrane, the instances of its apparent interruption in fixed specimens being clue, I believe, either to its lying in the plane of section, on account of wrinkling, etc., or to its rupture by the fixing reagent. The cell-body contains a fine anastomosing reticulum whose fibrils show no more ultimate structural divisions. Its interstices show no structure or staining affinities in the fresh condition. There are, however, one or more substances, presumably existing in the cytolymph in the normal living cell, that may change in character and form deposits upon the cytoreticulum under 
various circumstances. This deposit is caused by every fixing reagent used in the foregoing work, by post-mortem changes (possibly from the acid reaction that they induce), and during life by acute arsenic poisoning. It, or rather the material from which it is derived, is reduced by prolonged nervous activity, as indicated by the strychnine experiments and demonstrated by the results of Faradization, which seems to indicate that it in some way represents the potential energy of the cell. It is soluble in a $0.4 \%$ solution of sodium hydrate. In electing the strands of the reticulum as its location when precipitated it follows the usual law in such matters. It seems to correspond with the chromophilic substance of the nerve-cells in higher vertebrates. Its occurrence during life under the influence of arsenic suggests one of the ways in which this drug may affect nervous tissues, for such a change in the protoplasm would necessarily affect and possibly entirely arrest its functions. Whether the reticulum indicates an actual network anastomosing in space or an emulsiform structure I do not know, but the appearance of the fibrillary zone after picroformalin, etc., the appearance of the fresh cells, and especially the acute-angled anastomosis in the nervefibre, all point to a true reticulum.

No classification of the cells could be arrived at, as their relative sizes, the appearance of their network, and the amounts of chromophilic deposit all showed all gradations between the extreme limits of variation in each instance.

The nerve-fibres show essentially the same reticular structure as the cell-body. No chromophilic deposit was observed in them.

In closing I wish to acknowledge my indebtedness to Dr. Ira Van Gieson, who originally suggested the work and afforded the facilities for its execution, besides giving most helpful advice at many critical points.

\section{BIBLIOGRAPHY.}

Bethe, A. Held, $\mathbf{H}$.

'96. Eine neue Methode der Methylenblaufixation. Anat. Anz., Bd. 12, No. 18, pp. 438-446.

'97. Beiträge zur Structur der Nervenzellen und ihrer Fortsätze. Zweite Abhandlung. Arch. f. Anat. Physiol., Jahrg. '1897, Anat. Abt., pp. 204-294, Taf. 9-12.

Parker, G. H., and Floyd, R.

'95. The Preservation of Mammalian Brains by Means of Formol and Alcohol. Anat. Anz., Bd. 11, No. 5, pp. 156-158. 

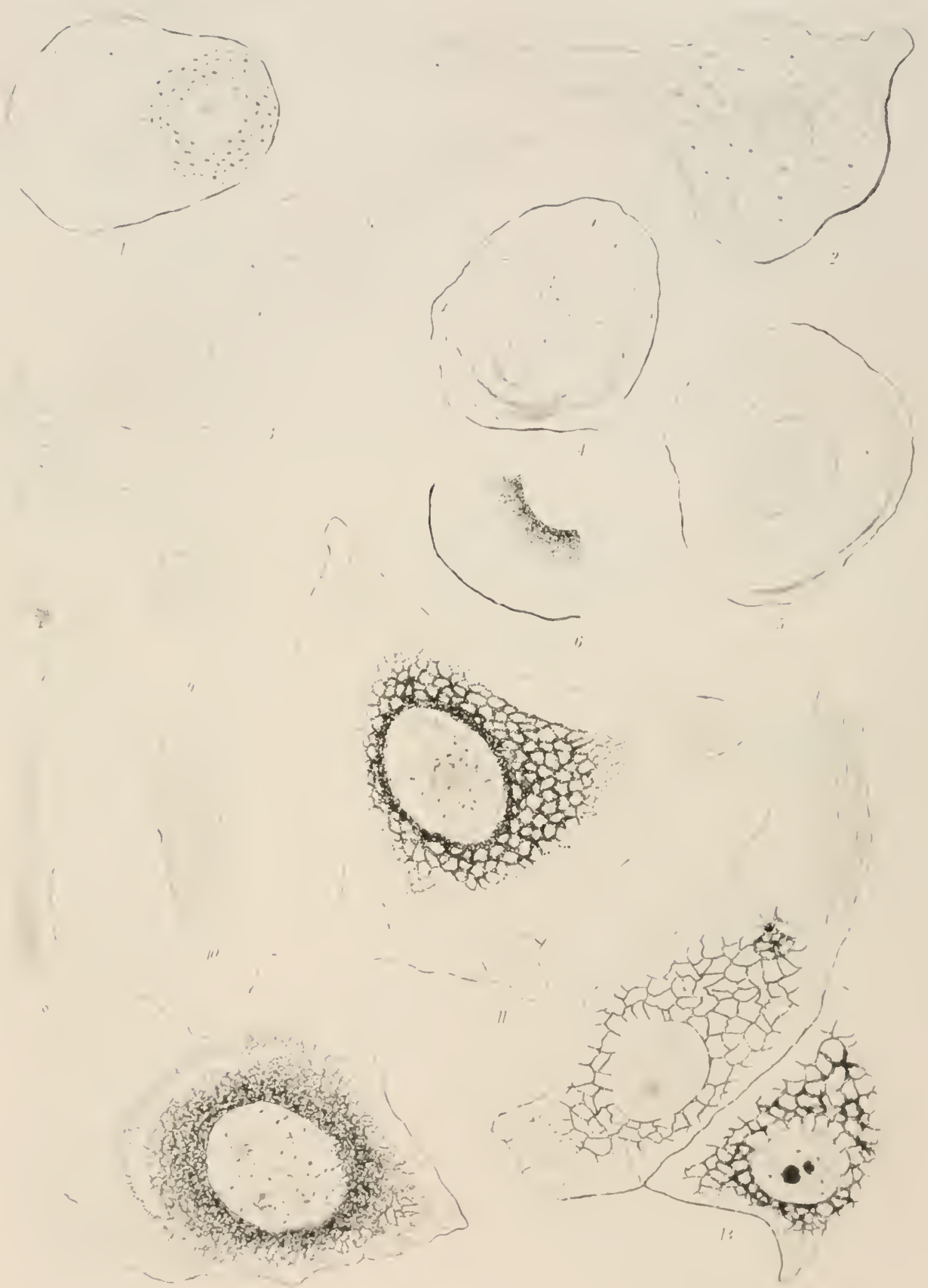

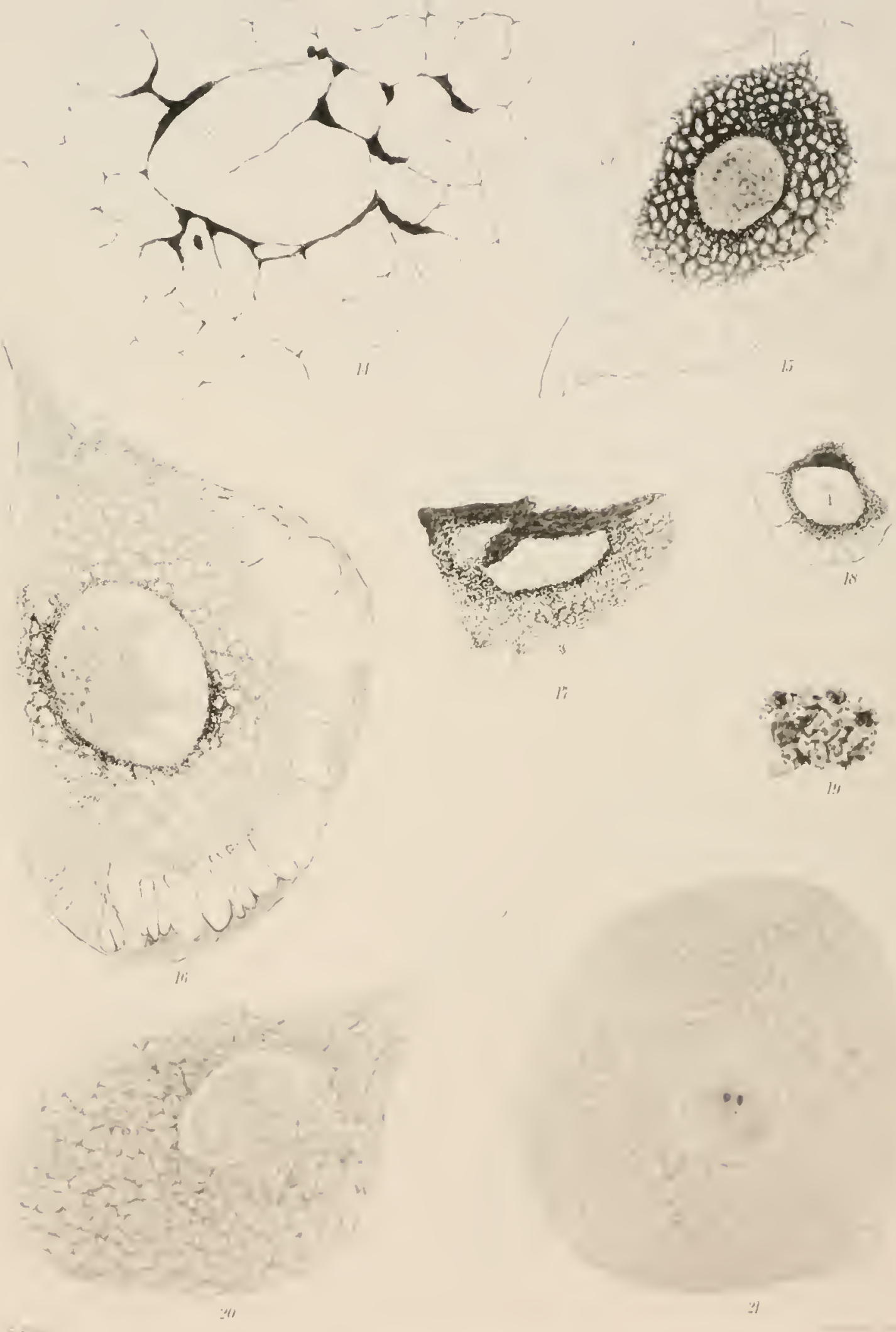


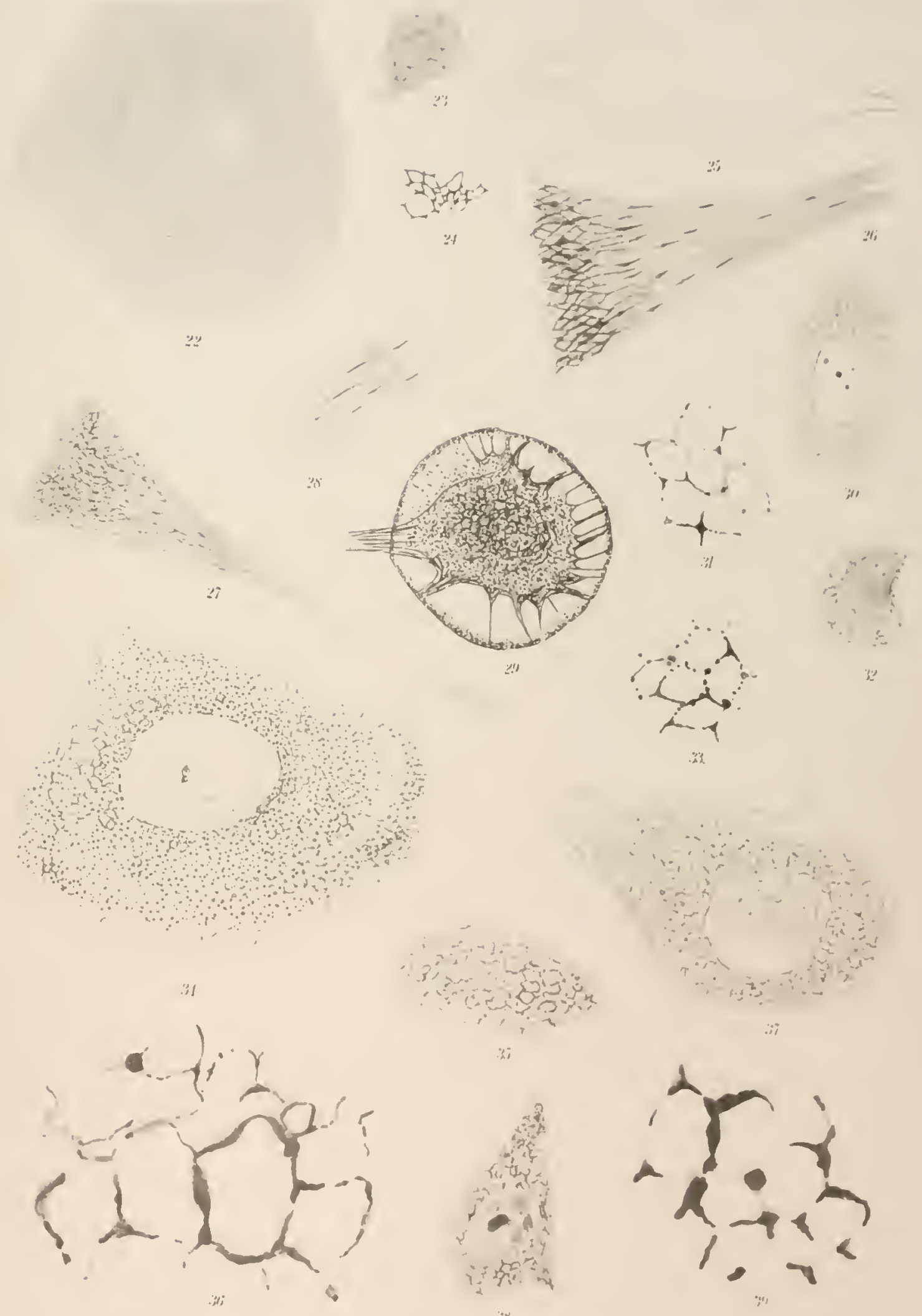





\section{EXPLANATION OF PLATES XXV-XXVII.}

All figures represent nevous elcments, usually cell-bodics, from the thoracic ganglia of the common cockroach, Periplaneta orientalis. The different colors of the stains used are not represented bceause the relative appearances of the cells, etc., can be better compared in monochrome.

\section{PLATE XXV.}

Fig. 1. Vom Rath preparation. Scction of a cell at right angles to its chicf axis. $\times 1000$.

Figs. 2, 3. Vom Rath preparations. Longitudinal scetions of two different cells, showing the distribution of the fibrillæ from the nerve-fibre. $\times 1000$.

Figs. 4, 5. Vom Rath preparations. Two scctions of a cell showing whorls of fibres. $\times 1000$.

Fig. 6. Vom Rath preparation. A part of a ccll-body with a favorable view of the cytoreticulum and the granulations. $\times 1300$.

Figs. 7, 8, 9, 10. Vom Rath preparations. Transverse and longitudinal scetions of nerve-fibres showing differcnt degrees of damage duc to the methods of fixation. $\times 1000$.

Figs. 11, 12. Picroformalin preparations (Nissl and eosin stains). Cells slowing the two zoncs, the varying sizes of the meshes of the reticulum, and the varying amounts of dccply staining substance. $\times 1000$.

Fig. 13. Picroformalin preparations (Nissl and cosin stains). Two adjacent cclls containing different amounts of deeply staining substance. $\times 1400$.

\section{PLATE XXVI.}

Fig. 14. Picroformalin preparation (Nissl and eosin stains). Tangential section at the junction of the two zones. $\times 4000$.

Fig. 15. Lang preparation (Nissl and eosin stains), showing a grcater laceration of the outer zonc tlian after picroformalin. $\times 1100$.

Fig. 16. Chromoxalic preparation (Nissl and eosin stains), showing considerable matting of fibrillx; takes dye reluctantly. $\times 1000$.

Figs. 17, 18. Absolute alcohol preparations (polychrome stain). Nuclear membrane ruptured; cytoplasm crowded into a perinuclear ring. $\times 1000$.

Fig. 19. A portion of the cell-body near the nuclcus of the preparation from which Figure 17 was drawn. $\times 4000$.

Fig. 20. Fresh preparation. In this and in other fresh preparations the outline and portions of the network were rapidly sketched with the camera and the drawings finished witl other fresh cells under the microscope for reference. $\times 1300$.

Fig. 21. Fresh preparation. $\times 500$.

\section{PLATE XXVII.}

Figs. 22, 23. Fresh preparations. $\times 700$.

Fig. 24. Fresh preparation. Camcra drawing of a part of the cytoplasmic reticulum. $\times 700$.

Fig. 25. Outline of a fresh preparation of the only bipolar cell scen. $\times 1300$.

Fig. 26. Fresh preparation showing the origin of a nerve-fibre. The individual fibrillæ arc coarser than they actually appeared. $\times 1300$.

Fig. 27. Teased preparation fixed in formalin vapor (polychrome stain) and showing the apex of the ccll and a nerve-fibre. $\times 1000$.

Fig. 28. Enlarged view of the fibre shown in Figure $27 . \times 4000$.

Fig. 29. Fresh preparation after treatment with Lang's solution. $\times 1000$.

Fig. 30. Vapor of formalin preparation (polychrome stain). $\quad \times 900$.

Fig. 31. Part of the cytoplasm of the preparation from which Figure 30 was drawn. $\times 3500$.

Fig. 32. Vapor of formalin preparation (polychrome stain). $\times 900$.

Fig. 33. Part of the cytoplasm of the preparation from which Figure 32 was drawn. $\times 3500$. 
Fig. 34. Graded formalin preparation (polychrome stain). $\times 1800$.

Fig. 35. Diffused alcohol preparation (polychrome stain). $\times 1000$.

Fig. 36. Part of the cytoplasm of the preparation from which Figure 35 was drawn. $\times 4000$.

Fig. 37. Diffused alcohol preparation (polychrome stain). $\times 1800$.

Fig. 38. Graded formalin preparation (polychrome stain). Post-mortem material. $\times 1000$.

Fig. 39. Part of the cytoplasm of the preparation from which Figure 38 was drawn. $\quad \times 4000$.

\section{PLATE XXVIII.}

Figs. 40, 41. Picroformalin preparation (polychrome stain). Post-mortem material. $\times 1000$.

Figs. 42, 44. Graded formalin preparation (polychrome stain). Normal material sectioned and then soaked in $4 \%$ sodic hydrate for four hours. $\times 1000$.

Figs. 43, 45. Parts of the cytoplasm of the cells from which Figures 42 and 44 respectively were drawn. $\times 4000$.

Fig. 46. Graded formalin preparation (polychrome stain). Cell from a roach subjected to prolonged Faradization. $\times 1000$.

Fig. 47. Part of the cytoplasm of the cell shown in Figure 46. $\times 4000$.

Figs. 48, 49. Picroformalin preparations (polychrome stain). Cells of roaches poisoned by Paris green. $\times 1000$.

Fig. 50. Diagrammatic camera sketch of a group of cells fixed in the vapor of formalin. $\times 345$.

Fig. 51. Diagrammatic camera sketch of a group of cells fixed in graded formalin, showing the distention of the tissue and the stretching of the cells. $\times 345$.

Fig. 52. Diagrammatic camera sketch after diffused alcohol fixation, showing a fraying of the cell edges similar in appearance to that shown in Figure 51, but apparently due to the shrinkage of the cells rather than to the swelling of the spaces. $\times 345$.

Fig. 53. Diagrammatic camera sketch after picroformalin fixation, showing perinuclear condensation. $\times 345$.

Fig. 54. Diagrammatic camera sketch after absolute alcohol fixation, showing laceration of the nuclear membrane in addition to extreme perinuclear condensation. $\times 345$. 

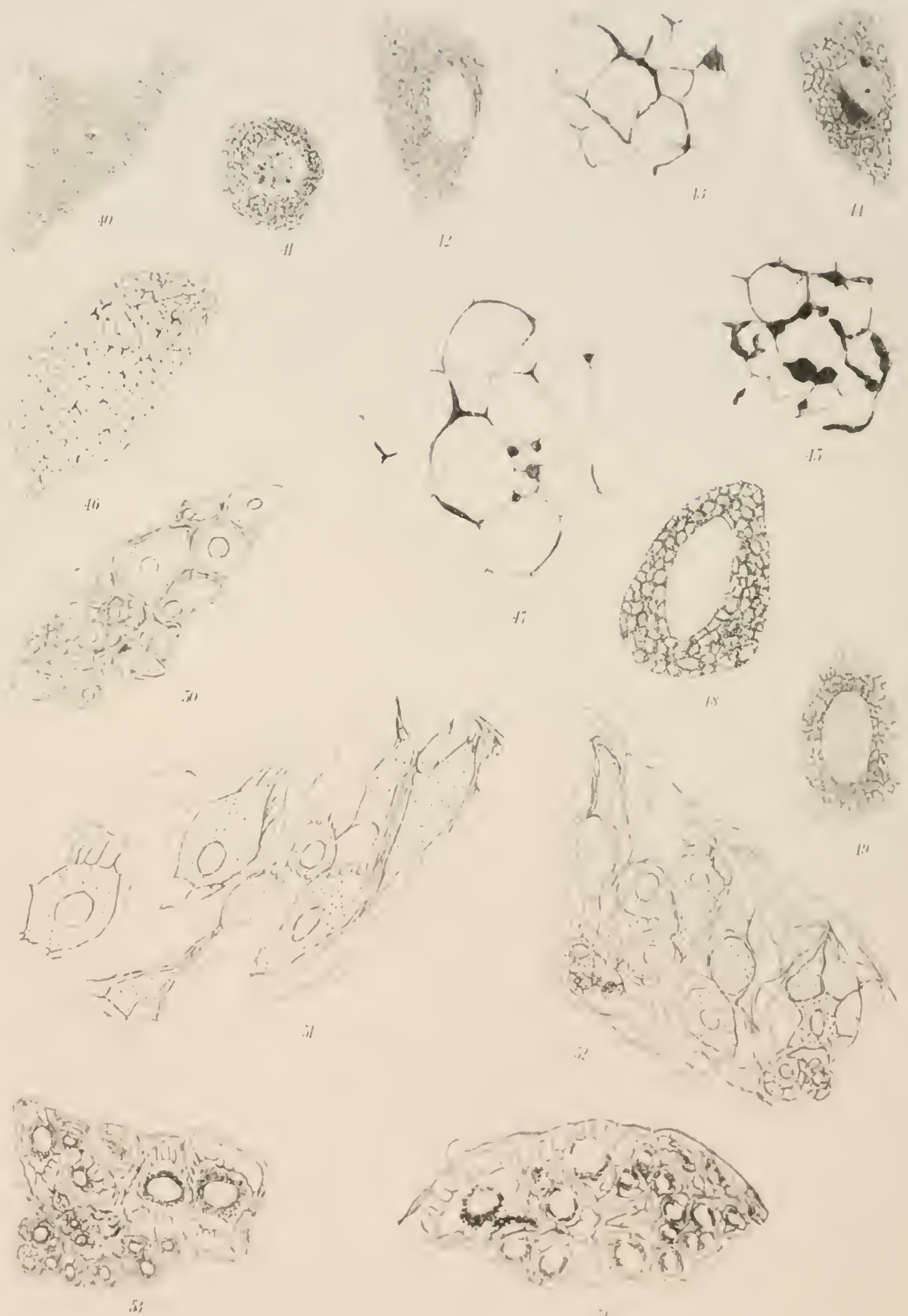

XVIII.

REACTIONS OF DAPHNIA PULEX TO LIGHT AND HEAT.

Robert Mearns Yerkes. 



\section{PHOTOTAXIS AND PHOTOPATHY.}

The motor reactions of organisms to light, so far as known at present, are of two kinds: phototactic and photopathic. In both intensity of the light, not the direction of the rays, is the determining factor. All those reactions in which the direction of movement is determined by an orientation of the organism which is brought about by the light are phototactic;* and all those reactions in which the movement, although due to the stimulation of light, is not definitely directed through the orientation of the organism are photopathic. $\dagger$

Photopathic reactions are supposedly due to the fact that certain animals are forced by light so to orient themselves that symmetrical points on the surface of the body are equally stimulated. This, the so-called "orientation theory" of Loeb ('93, p. 86) and of Verworn ('99, p. 499 et seq.), accounts for those cases in which animals seek or avoid light. Evidently a bilaterally symmetrical organism receives equal stimulation on symmetrical points when the long axis of its body is parallel with the rays of light, the head being directed either toward or away from the source of light. When, as a result of orientation with the head toward the light, an animal moves toward the source of light the reaction is said to be positively phototactic; when the movement is away from the light it is negatively phototactic. These reactions may be either primary or secondary. They are primary when the animal moves in the axis of the rays, and secondary when, prevented from so doing, it moves at right angles to the axis, but at the same time into regions of increasing (positive secondary phototaxis) or diminishing (negative secondary phototaxis) intensity.

An organism which selects a particular intensity of light and confines its movements to the region illuminated with that intensity is photopathic. $\ddagger$ The so-called "optimal intensity" is usually found by means of a phototactic reaction. Photopathic

* See Holt and Lee (:01) for the theory of phototactic reaction.

$\dagger$ It is to be noted that the terms phototaxis and photopathy are here given new meanings. Previously phototaxis has been applied to those reactions which were supposed to be determined by the direction of the rays of light, and photopathy to those due to differences in the intensity of the light.

$\ddagger$ Strassburger ('78, p. 572) has described this kind of reaction for the swarm-spores of Ulothrix and Hæmatococcus. 
reactions are in all probabilty frequent because of difference of sensitiveness to light in different regions of the body.*

\section{STATEMENT OF PROBLEMS.}

Davenport and Cannon ('97), Yerkes (:00), and Towel (:00) have shown that Daphnia is positively phototactic.

The experiments reported in this paper bear upon the following problems:

1. Does Daphnia react photopathically as well as phototactically? Is there any evidence of an "optimal intensity"?

2. Does the radiant heat accompanying light influence the movements of the animals?

3. Does heat, in the absence of light, have a directive influence upon the movements of Daphnia?

4. How does light in its effects upon Daphnia differ from heat? Are both effective only as they change the temperature of the organism?

\section{EXPERIMENTS.}

I. Tests for Photopathic Reactions.-A. METHoD.-As a means for discovering whether there is an "optimal intensity" of light for Daphnia an apparatus was devised which enabled the experimenter to observe, in a dark chamber, the movements of the animals in a glass dish the middle region of which was illuminated by a band of light which varied in intensity from zero at one end to as much as 20 candlepower at the other.

Figure $\mathrm{A}$ is a vertical section of the apparatus used for this work. It consisted of a cylindrical lens, $L, 25$ centimetres long, 10 centimetres wide, with a radius of curvature of 25 centimetres. One surface of the lens (Fig. B) was flat. This lens was fastened, for convenience of focussing, in a movable holder, $H$, and so placed that it focussed certain of the parallel rays proceeding from two 16-candle-power lamps (in some tests a 100-candle-power lamp was used), C. B., in a line upon the bottom of a glass box, $T$, in which the Daphnia were placed. Just above the lens and in contact with its plane surface was a screen of black cardboard containing a triangular opening through which the rays reached the lens. This triangular opening permitted many rays to fall upon the lens at one end, and at the other none, as a result of which

* Parker and Arkin (:01,p. 156) call attention to the possibility of this kind of reaction in case of the earthworm. 


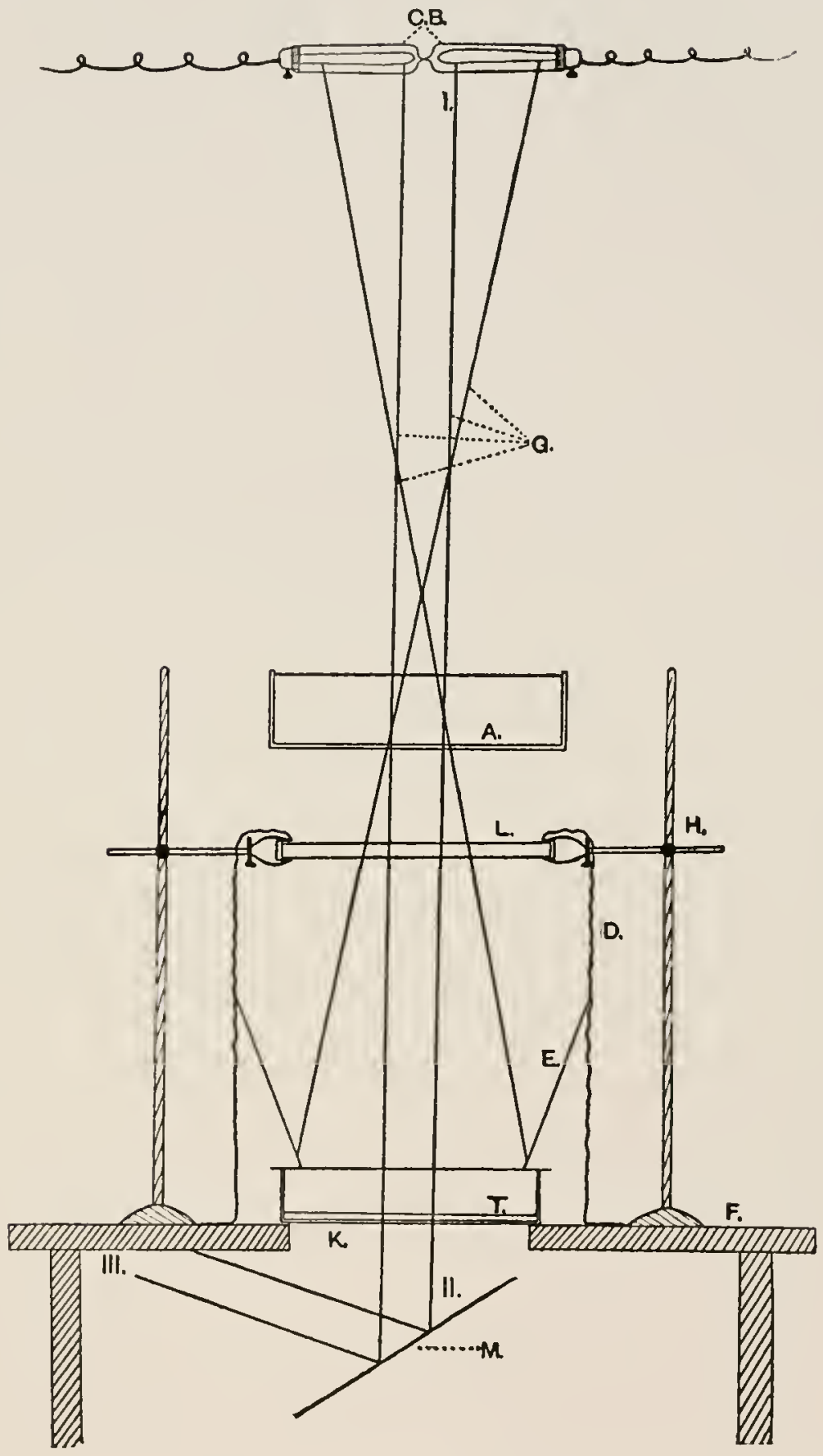

FIgURe A.-Apparatus for Giving a Band of Light Regularly Graded in Intensity.

C. B., two 16-candle-power eleetrie lamps; $G$, rays of light; $I, I I, I I$, eourse of rays; $A$, a dish eontaining solution of alum $10 \mathrm{em}$. deep; $H$, frame for lens, $L ; E$, sereens to eut off light from ends of glass box, $T$; $D$, eloth eurtains to exelude light; $F$, table for apparatus; $K$, slit in table for passage of rays; $M$, mirror. Seale $\frac{1}{8}$. 
a line of light perfectly graded in intensity was obtained. Figure $\mathrm{B}$, an oblique side view of the lens, will make clear the form of the lens and its relation to the screen.

On its way to the lens the light passed through a solution of alum, 10 centimetres deep, in a glass dish, $A$ (Fig. A). By this solution the heat-rays were cut off. From the box the rays, in order that the results might not be complicated by reflection, were allowed to pass through a slit, $K$, in the table, $F$, to a mirror, $M$, by which they were reflected to the side of the room. Further, all end and side light was shut off from the experiment-box by black cardboard screens, $E$, and heavy cloth curtains, $D$.

In the experiments the plate-glass experiment-box, 25 centimetres long, 5 centimetres broad, and 4 centimetres deep, was filled with water to a depth of .5 centimetre, and so placed that the band of light from the lens, which was 16 centimetres

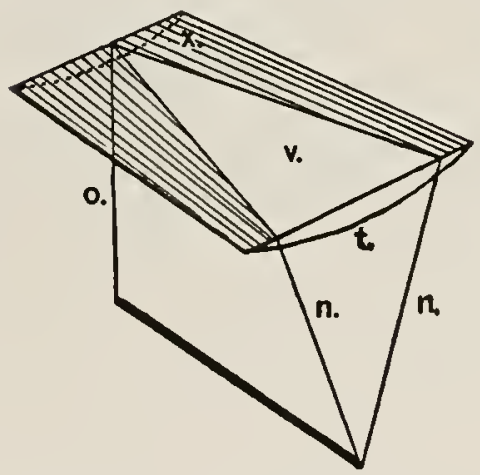

Frgure B.-Cylindrical Lens and Screen with Triangular Opening.

$X$, horizontally placed screen of black cardboard resting upon the plane surface of the lens, with a triangular opening, $V$, bcneath which is seen, at $t$, the curved outline of one end of the lens; $n, n$ indicate the course of rays of light at the + end of the band of light; $o$ indicates the course of the rays at the - end. long and about 1 centimetre wide, illuminated the middle region of it, whereas the remainder of the box was dark. The Daphnia were, therefore, free to move either in the relatively dark regions or in the band of light. The smallest angle made by any ray, with the bottom of the box, $T$, was approximately $81^{\circ}$, hence the animals moved almost at right angles to the rays, so long as their movements were parallel to the bottom of the box.

By varying the size of the triangular opening through which light was admitted to the lens, and by using lamps of different powers, it was possible to increase or diminish the intensity of the band of light.

$B$. Observations.-Daphnias when placed in the experiment-box wander into the band of light. Having entered the band they move from side to side in it, but seldom go outside; as soon as they reach the edge of the band and the anterior portion of the body comes into the dark region of the box, while at the same time the posterior portion is in the band of light, they turn back into the illuminated area. This reaction occurs repeatedly during the progress of an animal from one end of the box to the other. It is strikingly similar to the chemotactic reactions of Paramecium as described by Jennings ('97, p. 269).

Furthermore, the animals when once they have entered the band of light move very quickly to the region of greatest intensity of illumination, and remain there most of the time. It is to be remarked that the animals in moving from the lower to the higher intensity of light endeavor to orient themselves so that the long axis of the 
body is parallel with the rays of light. Because of the slight depth of the water in the box it was impossible for them to move far in a straight line when thus oriented without reaching the surface of the water or the bottom of the box. As a result of this condition the animals orient themselves with their heads toward the higher intensity region and swim upward at an angle of about $45^{\circ}$ with the surface until they reach the surface; they then cease swimming and by reason of gravity sink toward the bottom of the box; in a few seconds they again swim upward. This is repeated, and thus the animal approaches, by a very indirect, zigzag path, the region of greatest illumination.

To the highest intensity (about 20 candle-power) which was obtainable with the apparatus from a 100-candle-power lamp, the Daphnia were uniformly positive in their phototaxis. And apparently when they had reached the + end of the band of light they were still trying to move on to a higher intensity. There is therefore no evidence from these experiments of an "optimal intensity."

As it seemed possible that a higher intensity might reveal the "optimal," further tests were made by simply placing a 100-candle-power lamp at one end of the glass experiment-box. Under these conditions the animals moved directly to the + end of the box. When no adiathermal screen was interposed between the lamp and the box the heat was so great as to kill them within a few seconds after they reached the point nearest to the lamp. But notwithstanding the fact that they were thus directed by the light into a region of exceedingly violent thermic stimulation the Daphnia never turned back. When a screen was used the animals after reaching the + end remained there, moving about in a very irregular jerky manner as if under the influence of a strong stimulus. They have been observed to move about in this way for as long as thirty minutes, within a few centimetres of a lamp whose light was almost too bright for the human eye to endure, without giving any signs of a tendency to become negative to the light. To all appearances the organisms are wholly unable to resist the directive influence of light, even though it lead them into intensities of stimulation far greater than those to which they are accustomed, or into the presence of positively harmful stimuli. In a previous paper (Yerkes, :00, p. 419) I have described the phenomenon of Daphnia being directed by light into harmful chemical solutions.

From these observations we learn that Daphnia is positively phototactic to light up to an intensity of 100 candle-power, and that there is no evidence of an "optimal intensity" between 0 and 100 candle-power.

2. The Influence of Heat Accompanying Light.-The following experiments were made to determine (1) whether the radiant heat which accompanies the light from a 16candle-power incandescent lamp has any influence upon the motor reactions of 
Daphnia; (2) whether the directive influence of light tends to diminish during the period for which an animal is subjected to it; (3) whether Daphnia shows any signs of fatigue in long-continued motor reaction to light and heat; and (4) whether, under conditions different from those of the previously described photopathic experiments, Daphnia exhibits any preference for a particular intensity of light.

A. Method.-The Daphnias to be observed were placed, one at a time, in a tin trough 60 centimetres long, 6 centimetres wide, and 8 centimetres deep, painted dead black inside and out to prevent reflection. The ends of the trough were glass, so that light from electric lamps could enter parallel to the long axis of the trough. A 16-candle-power lamp, in the circuit of which a key enabled the experimenter to turn the light on or off quickly, was placed 5 centimetres from each end of the trough. All side and all end rays, except those passing through the glass ends, were cut off by screens. At one end a glass vessel, having parallel vertical sides 15 centimetres square and 5 centimetres apart, filled with distilled water, was so placed as to interpose 5 centimetres of water between the lamp and the end of the trough in order that the heat-rays might not enter. At the opposite end of the trough both heat and light were permitted to enter.

The apparatus was set up in a dark room. The experiments consisted in placing a Daphnia at one end of the trough, turning on the light at the opposite end, and noting, with the aid of a stop-watch, the time taken by the animal to move from a line 5 centimetres distant from the end at which it started to the middle point of the trough, and, again, from there to a line 5 centimetres from the end nearer to the light. The first period mentioned may be designated as the time of migration for the "First Half" of the trip, the second as the time for the "Second Half," and the sum of the two as the time for the "Whole Trip." These expressions are used in the tables which follow. As soon as the animal had reached the light end the light was turned off at that end, and that at the other at once turned on. In the same way as for the first trip the time for the return trip was noted. This was repeated ten times in succession, thus giving records for ten trips toward the end of the trough at which the adiathermal screen was placed, and for ten toward the screenless end. In the tables the trips are marked "Water Screen," indicating those toward the screen, and "No Screen," those in the opposite direction. After an animal had made ten trips in each direction, the water screen was shifted to the other end of the trough and another series of ten trips in each direction recorded. This was done in order to eliminate any differences in the time of the trips toward the screen and those away from it which might arise because of slight intensity differences between the two lights or from other differences in the conditions of the halves of the trough. 
The three columns of Table I marked "(Left) Water Screen" contain records of the times, in seconds, for ten trips toward the screened end of the trough when the screen was on the left of the experimenter as he faced the trough. The next three columns, marked "(Right) No Screen," contain results for the ten return trips of the same series. Likewise "(Left) No Screen" indicates that the screen had been transferred to the right end of the trough. The trips are numbered 1, 2, 3, etc., in the order in which they were made. From this description it appears that each animal used was permitted, under the directive influence of the light from a 16-candle-power lamp, to make 40 trips each 50 centimetres in length, in rapid succession. Half of these 40 trips were made under the influence of light accompanied by heat, the other half under the influence of light alone.

$B$. Observations.-Table $I$ is a representative series of results gotten with Daphnia Number 1.

It is to be noted (1) that the time of the trips rapidly decreases throughout the series; it being for the first two trips 125 and 185 seconds respectively, and for the last two 58 and 57 seconds; (2) that the time for the "First Half" is always considerably less than that for the "Second Half"; and (3) that the average time for all trips toward the Screened End (both the right and the lcft), 74.9 seeonds, is practically the same as that for all trips toward the Unscreened End, 73.3.

Similar series of results were gotten with four other animals, and in Table II the averages for the five are given. Each column in this case contains the averages for ten trips for each of the animals. The general averages at the bottom of the table are therefore for 50 trips under each of the four conditions, i.e., toward the left when the screen was on the left, toward the right when the screen was on the left, toward the left when the screen was on the right, and toward the right when the screen was on the right. In all 200 trips were made. Of these 100 were toward the water screen, and 100 away from it. At the bottom of Table II the average for each of these 100 trips is given.

In answer to the first question proposed at the beginning of this section, Does the heat accompanying light influence the movements of Daphnia? the experiments do not furnish a definite reply. From the general averages it appears that the time for the "Whole Trip" toward the Unscreened End (73.8 seconds) was 3.8 seconds less than for that toward the Screened End (77.6 seconds). One might conclude from this that the heat increased the rate of movement. But examination of the individual averages shows that in two cases out of five the average timc of movement toward the Unscreened End was longer than that toward the Scrcencd. For this reason, and also because of the slight difference of the general averages, we are forced to 
TABLE I.

TIME (IN SECONDS) REQUIRED BY DAPHNIA NUMBER 1 TO SWIM 50 CM., WHEN INFLUENCED BY LIGHT ALONE AND WHEN INFLUENCED BY LIGHT ACCOMPANIED BY HEAT.

7 P.u., Dee. 11, 1901. Temperature of Water $20^{\circ} \mathrm{C}$.

\begin{tabular}{|c|c|c|c|c|c|c|c|c|c|c|c|c|c|c|c|}
\hline \multirow{2}{*}{$\begin{array}{l}\text { Number } \\
\text { of Trip. }\end{array}$} & \multicolumn{3}{|c|}{ (Left) Water Screen. } & \multirow{2}{*}{$\begin{array}{l}\text { Num- } \\
\text { ber of } \\
\text { Trip. }\end{array}$} & \multicolumn{3}{|c|}{ (Right) No Screen. } & \multirow{2}{*}{$\begin{array}{c}\text { Num- } \\
\text { ber } \\
\text { of } \\
\text { Trip. }\end{array}$} & \multicolumn{3}{|c|}{ (Left) No Screen. } & \multirow{2}{*}{$\begin{array}{c}\text { Num- } \\
\text { ber } \\
\text { of } \\
\text { Trip. }\end{array}$} & \multicolumn{3}{|c|}{ (Right) Water Screen. } \\
\hline & $\begin{array}{l}\text { First } \\
\text { Half. }\end{array}$ & $\begin{array}{l}\text { Second } \\
\text { Half. }\end{array}$ & $\begin{array}{l}\text { Whole } \\
\text { Trip. }\end{array}$ & & $\begin{array}{l}\text { First } \\
\text { Half. }\end{array}$ & $\begin{array}{l}\text { Second } \\
\text { Half. }\end{array}$ & $\begin{array}{l}\text { Whole } \\
\text { Trip. }\end{array}$ & & $\begin{array}{l}\text { First } \\
\text { Half. }\end{array}$ & $\begin{array}{c}\text { Second } \\
\text { Half. }\end{array}$ & $\begin{array}{l}\text { Whole } \\
\text { Trip. }\end{array}$ & & $\begin{array}{l}\text { First } \\
\text { Half. }\end{array}$ & $\begin{array}{l}\text { Second } \\
\text { Half. }\end{array}$ & $\begin{array}{l}\text { Whole } \\
\text { Trip. }\end{array}$ \\
\hline 1 & 53 & 72 & 125 & 2 & 61 & 81 & 142 & 21 & 32 & 39 & 71 & 22 & 23 & 26 & 49 \\
\hline 3 & 88 & 97 & 185 & 4 & 45 & 87 & 132 & 23 & 22 & 46 & 68 & 24 & 25 & 29 & 54 \\
\hline 5 & 68 & 77 & 145 & 6 & 35 & 55 & 90 & 25 & 16 & 33 & 49 & 26 & 15 & 25 & 40 \\
\hline 7 & 30 & 53 & 83 & 8 & 42 & 70 & 112 & 27 & 17 & 30 & 47 & 28 & 23 & 33 & 56 \\
\hline 9 & 42 & 69 & 111 & 10 & 38 & 49 & 87 & 29 & 19 & 38 & 57 & 30 & 16 & 27 & 43 \\
\hline 10 & 32 & 41 & 73 & 12 & 35 & 40 & 75 & 31 & 17 & 43 & 60 & 32 & 20 & 39 & 59 \\
\hline 13 & 33 & 49 & 82 & 14 & 23 & 29 & 52 & 33 & 16 & 30 & 46 & 34 & 18 & 24 & 42 \\
\hline 15 & 26 & 42 & 68 & 16 & 39 & 45 & 84 & 35 & 19 & 35 & 54 & 36 & 17 & 29 & 46 \\
\hline 17 & 30 & 39 & 69 & 18 & 30 & 32 & 62 & 37 & 20 & 47 & 67 & 38 & 21 & 37 & 58 \\
\hline 19 & 19 & 34 & 53 & 20 & 20 & 21 & 41 & 39 & 25 & 46 & 71 & 40 & 19 & 38 & 57 \\
\hline Average & 42.1 & 57.3 & 99.4 & & 36.8 & 50.9 & 87.7 & & 20.3 & 38.7 & 59.0 & & 19.7 & 30.7 & 50.4 \\
\hline
\end{tabular}

\begin{tabular}{|c|c|c|c|c|c|}
\hline \multicolumn{2}{|c|}{$\begin{array}{c}\text { Averages for all Trips } \\
\text { (20) } \\
\text { Toward Screened End. } \\
\text { (Right and Left.) }\end{array}$} & \multicolumn{2}{|c|}{$\begin{array}{c}\text { Averages for all Trips } \\
\text { (20) Toward Unserened } \\
\text { (Right and Left.) End. }\end{array}$} \\
\cline { 1 - 4 } \begin{tabular}{c|c|c|c|c|} 
First \\
Half.
\end{tabular} & $\begin{array}{c}\text { Second } \\
\text { Half. }\end{array}$ & $\begin{array}{c}\text { Whole } \\
\text { Trip. }\end{array}$ & $\begin{array}{c}\text { First } \\
\text { Half. }\end{array}$ & $\begin{array}{c}\text { Second } \\
\text { Half. }\end{array}$ & $\begin{array}{c}\text { Whole } \\
\text { Trip. }\end{array}$ \\
\hline 30.9 & $\mathbf{4 4 . 0}$ & 74.9 & 28.5 & 44.8 & 73.3 \\
\hline
\end{tabular}

TABLE II.

THE AVERAGES FOR FIVE SERIES OF EXPERTMENTS LIKE THAT OF TABLE I. EACH COLUMN CONTAINS tHe AVERAGEg FOR TEN TRIPS MADE BY EACH OF FIVE DAPHNiA (NUMBERS 1 TO 5).

\begin{tabular}{|c|c|c|c|c|c|c|c|c|c|c|c|c|}
\hline \multirow{2}{*}{$\begin{array}{l}\text { Nuraber of } \\
\text { Animal. }\end{array}$} & \multicolumn{3}{|c|}{ (Left) Water Screen. } & \multicolumn{3}{|c|}{ (Right) No Screen. } & \multicolumn{3}{|c|}{ (Left) No Screen. } & \multicolumn{3}{|c|}{ (Right) Water Sereen. } \\
\hline & $\begin{array}{l}\text { First } \\
\text { Half. }\end{array}$ & $\begin{array}{l}\text { Second } \\
\text { Half. }\end{array}$ & $\begin{array}{l}\text { Whole } \\
\text { Trip. }\end{array}$ & $\begin{array}{l}\text { First } \\
\text { Half. }\end{array}$ & $\begin{array}{l}\text { Second } \\
\text { Half. }\end{array}$ & $\begin{array}{l}\text { Whole } \\
\text { Trip. }\end{array}$ & $\begin{array}{l}\text { First } \\
\text { Half. }\end{array}$ & $\begin{array}{l}\text { Second } \\
\text { Half. }\end{array}$ & $\begin{array}{l}\text { Whole } \\
\text { Trip. }\end{array}$ & $\begin{array}{l}\text { First } \\
\text { Half. }\end{array}$ & $\begin{array}{l}\text { Second } \\
\text { Half. }\end{array}$ & $\begin{array}{l}\text { Whole } \\
\text { Trip. }\end{array}$ \\
\hline 1 & 42.1 & 57.3 & 99.4 & 36.8 & 50.9 & 87.7 & 20.3 & 38.7 & 59.0 & 19.7 & 30.7 & 50.4 \\
\hline 2 & 33.8 & 53.4 & 87.2 & 32.2 & 37.6 & 69.8 & 21.9 & 32 & 54.5 & 18.6 & 31.6 & 50.2 \\
\hline 3 & 36.4 & 57.6 & 94.0 & 33.9 & 44.1 & 78.0 & 27.6 & 48.5 & 76.1 & 28.0 & 52.1 & 80.1 \\
\hline 4 & 28.6 & 34.0 & 62.6 & 256 & 36.5 & 62.1 & 29.7 & 36.6 & 66.3 & 24.9 & 32.6 & 57.5 \\
\hline 5 & 49.3 & 66.8 & 116.1 & 45.8 & 55.3 & 101.1 & 24.9 & 58.9 & 83.8 & 23.3 & 55.2 & 78.5 \\
\hline Gen. Aver. & $38.0+$ & 53.8 & $91.9-$ & 34.9 & 44.9 & $79.7+$ & $24.9-$ & $43.1-$ & $67.9+$ & 22.9 & 40.4 & 63.3 \\
\hline
\end{tabular}

\begin{tabular}{|c|c|c|c|c|c|}
\hline \multicolumn{2}{|c|}{$\begin{array}{c}\text { Averages for all Tripg } \\
\text { (100) } \begin{array}{c}\text { Toward Screened End. } \\
\text { (Right and Left.) }\end{array}\end{array}$} & \multicolumn{2}{|c|}{$\begin{array}{c}\text { Averagea for all Trips } \\
(100) \text { Toward Unscreened End. } \\
\text { (Right and Left.) }\end{array}$} \\
\cline { 1 - 2 } \cline { 1 - 2 } \begin{tabular}{c|c|c|c|c|} 
First \\
Half.
\end{tabular} & $\begin{array}{c}\text { Second } \\
\text { Half. }\end{array}$ & $\begin{array}{c}\text { Whole } \\
\text { Trip. }\end{array}$ & $\begin{array}{c}\text { First } \\
\text { Half. }\end{array}$ & $\begin{array}{c}\text { Second } \\
\text { Half. }\end{array}$ & $\begin{array}{c}\text { Whole } \\
\text { Trip. }\end{array}$ \\
\hline 30.4 & 47.1 & 77.6 & 29.9 & 44.0 & 73.8 \\
\hline
\end{tabular}


conclude that there is no decisive evidence of any influence upon the movements of Daphnia of the heat accompanying light.

To the second question, Does the directive influence of light tend to diminish during the experiments? we are able to answer, No; for throughout the period of observation the rate of movement, in each of the five animals, gradually increased. This was apparently the to an increase in sensitiveness to changes in the intensity of the light. As the experiments with an indivichal were continued there was a noticeable quickening in the orientation movements, and an increase in the rapidity of the swimming. From the evickence of the experiments it may be said that under the conditions with which we are dealing the sensitiveness of Daphnia to changes in light intensity and to the directive influence of light does not diminish but, on the contrary, increases.

In studies of Daphnia made by Davenport and Cannon ('97, p. 31), and by me (Yerkes, :00, pp. 407-414), the rate of movement was found to increase with the intensity of the light. Davenport and Cannon concluded that the difference was due almost entirely to difference in the precision of orientation. Although it is true that precision of orientation is the chief cause of the increase in rate, I find that the rapidity of the swimming movements also varies with the changes in the intensity of the light.

In view of the well-established fact that Daphnia moves more rapidly in strong than in weak light, how are the results of the experiments just described to be explained? In them, it will be remembered, the time for the "Second Half" of the trip toward the light was longer than that for the "First," when just the opposite was to be expected. It might be said that as the animals approached the light the intensity became too great for them, hence a hesitation which increased the time. This explanation is, moreover, supported by the fact that, whereas the path taken in the "First Half" of a trip was fairly straight, it became zigzag in the "Second Half."

But there is another fact to be considered. It should be remembered that when the animal in an experiment reached the end of the trough toward which it had been swimming, it was in a region of very strong light; then suddenly the light was turned off at that end, and tumed on at the opposite end. This sudden and great change in the stimulus always caused the animal to start off toward the light at high speed. It seemed not improbable, therefore, that the shortness of the time for the "First Half" as compared with the "Second" might be due to this initial stimulus. For the purpose of settling this matter, observations were made in which the animals were started toward the light without the initial stimulus of the sudden change from strong to weak light. These experiments proved conclusively that the time for the 
"First Half" was shorter than that for the "Second" only by reason of the initial stimulus. There was still some evidence, however, that the intense illumination of the end next the light somewhat retarded the animals in that they were forced by it to take a less regular course, and, although moving more rapidly if anything, because of the zigzag path followed they progressed, on the whole, more slowly.

In one instance an animal on its first trip swam to about the middle of the trough, then, ceasing to move toward the light, it swam about in circles. It looked as if the reaction was given to an "optimal intensity," and I at first thought that it was photopathic. Further experimenting showed that the animal would swim toward the end from which it had come, when the light was turned on there, but that toward the other end it would not swim farther than the spot already mentioned. Search for an explanation of the phenomenon revealed the presence of a number of bubbles (air?) at the bottom of the trough at the point beyond which the animal would not go, even when directed by strong light. The reaction therefore was not photopathic but chemotropic.

This single observation is of special interest and importance since Daphnias are usually so strongly positive in their phototaxis that they will pass through harmful chemical solutions, and even attempt to go through a drop of strong acid in their efforts to approach a light (Yerkes, :00, p. 419).

The question, Is there any evidence of fatigue? must also be answered in the negative. Although the animals in these experiments moved almost continuously for an hour, covering during that interval at least a distance of 2000 centimetres, if not 2500 centimetres, there was throughout an increase in the rate of movement, and no evidence whatever of fatigue.

The fourth question formulated has already been answered. There is no evidence of an "optimal intensity," and no clearly demonstrated photopathic reaction.

3. The Reactions of Daphnia to Radiant Heat.--Does radiant heat have any directive influence upon the movements of Daphnia? In the previously described experiments for testing the value, for the movements of the organism, of the heat accompanying light, there was little evidence of the influence of heat; but since light is itself an exceedingly strong directive agent, it may be that the effect of the heat was obscured by it. To determine in a more satisfactory and conclusive manner whether heat is a directive stimulus the following experiments were made.

A. Metrod.-Over a V-shaped glass trough 24 centimetres long, 2 centimetres wide, and 1.5 centimetres deep was swung a frame bearing five partitions, cut to fit the $\mathrm{V}$ shape of the trough. This frame could be raised above the trough or lowered so that the partition divided it into six equal portions. The trough was placed hori- 
zontally upon a table in a dark room. At 5 centimetres from one end of it was an electric heater, consisting of a metal frame which held coils of high-resistance wire. The heater presented to the end of the trough a radiating surface 10 centimetres square, and the heat from this surface could be felt by the hand at a distance of 40 centimetres.

The trough was filled with water to a depth of .5 centimetre, and the partitions lowered; then two Daphnia were placed in each of the spaces except those at the ends. In the accompanying Tables III, IV, and $V$ the spaces are numbered 1 to 6 , and the number of animals in each is indicated. When all was in readiness for an experiment the partitions were raised and the animals permitted to swim freely, or as the stimulus to be tested might direct them, for a period of three minutes. The partitions were then lowered, and an electric light turned on so that the positions of the animals could be recorded. This record having been made, the animals were again distributed as at the beginning of the experiment, i.e., two in each of spaces 2 to $5 . *$

It was necessary, in order that no undetected factors enter as directive influences, that check experiments be made just before each of the series of experiments to test the influence of heat. In these prehiminary observations the conditions were, so far as cleterminable precisely the same as in case of the immediately following series, except for the absence of heat, the influence of which it was the purpose of the experiments to determine. $\uparrow$

B. OBservations.- Table III is a record of the check series of ten observations preliminary to the experiments of Table IV. 'The vertical columns in the table give the number of animals in the various spaces at the end of each experiment. The result of the experiments is expressed by comparing the mean position of the animals at the beginning with the mean position at the end of the experiment; the difference of these means expresses the amount of movement toward either end $\left(+\mathrm{or}^{*}\right)$ in terms of spaces. At the beginning of an experiment, since the spaces $2,3,4$, and 5 each contained two animals, the mean position as determined by the formula

\section{Product of space $\times$ Number of animals \\ Total number of animals!}

* All of the observations were made at night in a room from which light was excluded.

$\dagger$ As it seemed possible that heat might cause currents in the water of the trough which would change the positions of the animals, check experiments were made by placing a number of Daphnia in a glass tube, filled with water, one end of which was placed in snow, and the othcr over the clectric heater. Under these conditions the animals collected near the snow end, although no movement of light particles of material suspended in the water could be detected. 
was 3.5. After experiment 1 of Table III the mean position was 4, which indicates that there had been an average movement of half a space toward the end of the trough

TABle III.

CHECK EXPERIMENTS IN DARKNESS. NO HEAT.

Period 3 min. Dec. 12, 1901, 7 P.M.

\begin{tabular}{|c|c|c|c|c|c|c|c|}
\hline $\begin{array}{l}\text { Spaces ................................. } \\
\text { of Each Experiment. }\end{array}$ & $\begin{array}{c}1 \\
+ \text { End. }\end{array}$ & $\begin{array}{l}2 \\
2\end{array}$ & $\begin{array}{l}3 \\
2\end{array}$ & $\begin{array}{l}4 \\
2\end{array}$ & $\begin{array}{l}5 \\
2\end{array}$ & $\begin{array}{c}6 \\
\text { - End. }\end{array}$ & $\left\{\begin{array}{c}\text { Average } \\
\text { Movement }\end{array}\right.$ \\
\hline 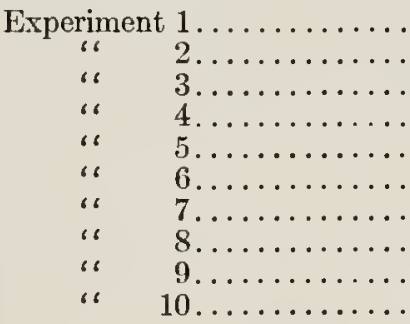 & $\begin{array}{l}0 \\
0 \\
4 \\
1 \\
2 \\
1 \\
1 \\
0 \\
3 \\
2\end{array}$ & $\begin{array}{l}3 \\
2 \\
2 \\
1 \\
2 \\
2 \\
3 \\
3 \\
2 \\
2\end{array}$ & $\begin{array}{l}0 \\
1 \\
1 \\
0 \\
0 \\
1 \\
0 \\
1 \\
1 \\
1\end{array}$ & $\begin{array}{l}0 \\
2 \\
1 \\
3 \\
3 \\
2 \\
2 \\
2 \\
1 \\
0\end{array}$ & $\begin{array}{l}4 \\
0 \\
0 \\
1 \\
0 \\
0 \\
0 \\
2 \\
1 \\
1\end{array}$ & $\begin{array}{l}1 \\
3 \\
0 \\
2 \\
1 \\
2 \\
2 \\
0 \\
0 \\
2\end{array}$ & $\begin{array}{r}-0.500 \\
-0.375 \\
+1.375 \\
-0.500 \\
+0.500 \\
0.000 \\
+0.125 \\
+0.125 \\
+1.125 \\
+0.250\end{array}$ \\
\hline
\end{tabular}

Movement for series +.3125 (i.e., .3125 of a space toward the + end).

marked space 6 . Since in the experiments heat was applied at the end next space 1, it will be convenient to designate that as the + end, and the opposite as the - end, in order that without confusion movement of the animals toward the heat may be designated as + , and away from it as - (see Table III). For this reason the movement in experiment 1, Table III, is expressed as -0.50 (i.e., the average movement of the eight Daphnia was a half-space toward the - end of the trough).

The check series of ten experiments in Table III resulted in six + movements, with an average for the series of +0.3125 . There is therefore indication of a slight tendency toward the + end. This may have been due to undetected rays of light or to slight jarring of the trough. The movement is so slight, however, that it is not of great importance; a large number of observations would in all probability have resulted in an average of 0 .

As soon as this check series was ended the heat was turned on and a similar series of experiments made to test the influence of heat upon the movements of the animals. At the beginning of the heat series the temperature of the water throughout the trough was about $21^{\circ} \mathrm{C}$. At the end of the series it was $28^{\circ}$ at the + end of the trough, and $25^{\circ}$ at the - end.

Table IV gives the result of this test of the effect of radiant heat. The first experiment resulted in a marked movement toward the heated $(+)$ end, but thereafter every experiment resulted in a movement in the opposite (-) direction. In experiment 1 it is almost certain that the heat had not yet had time to affect the water to 
a sufficient degree to influence the animals. The averages for the series is -0.475 . This shows clearly that Daphnia is negatively thermotactic at a temperature of $28^{\circ}$. It is noteworthy that all except the first experiment resulted in - movements.

For the purpose of determining the relation of the amount of heat to the extent of the animals' migration, the trough was now removed to a distance of 20 centimetres from the heater (i.e., four times as far as in the experiments of Table IV). Table V contains the records for five check experiments, and ten heat experiments with the heater at this distance. For the check experiments the average movement was +0.65 ; for the heat experiments it was -0.15. If in this case, as in the previous series, we consider the + tendency, as indicated by the check series, which had to be overcome before there could be any - movement, it is clear that the influence of the heat should be expressed by 0.65 , the positive tendency, plus 0.15 , the negative result, or 0.80 . In the previous series it would be 0.31 plus 0.475 or 0.785 .

Examination of the experiments of Table $V$ shows that a positive tendency gradually gave place to a negative. This would appear, in the light of the previous series, to be the result of the gradual increase in the temperature of the water, and especially of the increase in the difference of the temperatures of adjacent regions. At the end of the series of Table $\mathrm{V}$ there was only $1^{\circ}$ difference in the temperatures of the end spaces, 1 and 6.

C. Thermotaxis.-Now, as to the evidence for the directive influence of heat, the experiments described prove conclusively that in the absence of light Daphnia moves away from the source of heat at a temperature of $28^{\circ}$ or thereabouts. Is this merely a random wandering into regions of lower and more favorable temperatures, or is it a definitely directed movement similar to the phototactic reaction?

Loeb ('90, p. 43) proved that the larvæ of Porthesia wander into the warmer end of a dark box; and other investigators have demonstrated migration with reference to heat in the case of Myxomycetes, Protozoa, and certain larvæ of the Metazoa; but thus far no definitely directed movements in response to heat have been described.

In the first place it seems fairly certain that Daphnia, in the experiments of this paper, was affected by the heat-rays only as the temperature of the water changed; for at the beginning of the series there was no evidence of a directive influence, whereas just as soon as the temperature of the water began to rise at the + end the animals tended to migrate toward the - end.

As a matter of observation, the movements of Daphnia toward the - end were exceedingly irregular, being zigzag and indirect, and thus sharply contrasted with the usual photopathic movements. Notwithstanding this I believe that the two reactions are in principle the same; in both cases difference in intensity of stimulation 
TABLE IV.

EXPERIMENTS TO TEST THE INFLUENCE OF HEAT UPON THE MOVEMENTS OF DAPHNIA.

Heated Surface $5 \mathrm{~cm}$. from + End of Trough.

Temperature of Water at Beginning of Experiments $21^{\circ} \mathrm{C}$. for all Regions of Trough. Temperature of Water at End of Experiments $28^{\circ} \mathrm{C}$. at + End of Trough, $25^{\circ} \mathrm{C}$. at - End.

Period 3 min. Dec. 12, 1901, 7.45 P.M.

\begin{tabular}{|c|c|c|c|c|c|c|c|}
\hline $\begin{array}{l}\text { Location of Animals at Beginning } \\
\text { of Each Experiment. }\end{array}$ & $\begin{array}{c}\text { Region of } \\
\text { Highest } \\
\text { Tempera- } \\
\text { ture. } \\
1 \\
\text { + End. }\end{array}$ & $\begin{array}{l}2 \\
2\end{array}$ & $\begin{array}{l}3 \\
2\end{array}$ & $\begin{array}{l}4 \\
2\end{array}$ & $\begin{array}{l}5 \\
2\end{array}$ & $\begin{array}{c}\text { Region of } \\
\text { Lowest } \\
\text { Tempera- } \\
\text { ture. } \\
6 \\
\text { - End. }\end{array}$ & $\left\{\begin{array}{c}\text { Average } \\
\text { Movement }\end{array}\right.$ \\
\hline 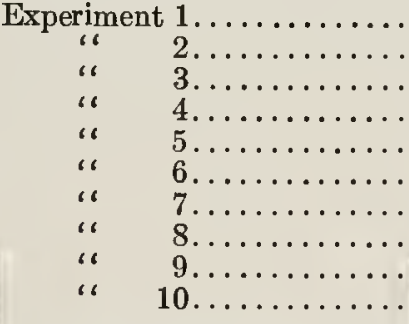 & $\begin{array}{l}3 \\
0 \\
0 \\
1 \\
0 \\
0 \\
1 \\
0 \\
1 \\
0\end{array}$ & $\begin{array}{l}1 \\
2 \\
0 \\
1 \\
1 \\
0 \\
1 \\
1 \\
1 \\
1\end{array}$ & $\begin{array}{l}2 \\
2 \\
1 \\
0 \\
1 \\
3 \\
1 \\
1 \\
1 \\
2\end{array}$ & $\begin{array}{l}\mathbf{1} \\
\mathbf{1} \\
2 \\
2 \\
2 \\
1 \\
2 \\
4 \\
2 \\
1\end{array}$ & $\begin{array}{l}1 \\
1 \\
3 \\
1 \\
3 \\
1 \\
2 \\
2 \\
2 \\
2\end{array}$ & $\begin{array}{l}0 \\
2 \\
2 \\
3 \\
1 \\
3 \\
1 \\
0 \\
1 \\
2\end{array}$ & $\begin{array}{l}+1.000 \\
-0.375 \\
-1.250 \\
-0.750 \\
-0.750 \\
-1.250 \\
-0.250 \\
-0.375 \\
-0.250 \\
-0.750\end{array}$ \\
\hline
\end{tabular}

Movement for series - -475 (i.e., .475 of a space toward the - end, away from heater).

TABLE V.

CHECK EXPERIMENTS

Period 3 min. Dec. 13, 1901, 8 P.M.

\begin{tabular}{|c|c|c|c|c|c|c|c|}
\hline $\begin{array}{l}\text { Spaces ................................... } \\
\text { Location of Animals at Beginning } \\
\text { of Each Experiment. }\end{array}$ & $\begin{aligned} & 1 \\
+ & \text { End. }\end{aligned}$ & $\begin{array}{l}2 \\
2\end{array}$ & $\begin{array}{l}3 \\
2\end{array}$ & $\begin{array}{l}4 \\
2\end{array}$ & $\begin{array}{l}5 \\
2\end{array}$ & $\begin{array}{c}6 \\
- \text { End. }\end{array}$ & $\left\{\begin{array}{c}\text { Average } \\
\text { Movement. }\end{array}\right.$ \\
\hline \begin{tabular}{|cc} 
Experiment & $1 \ldots \ldots \ldots \ldots$ \\
، & $2 \ldots \ldots \ldots \ldots \ldots$ \\
" & $3 \ldots \ldots \ldots \ldots \ldots$ \\
" & $4 \ldots \ldots \ldots \ldots \ldots$
\end{tabular} & $\begin{array}{l}0 \\
1 \\
3 \\
4 \\
3\end{array}$ & $\begin{array}{l}2 \\
0 \\
1 \\
2 \\
2\end{array}$ & $\begin{array}{l}2 \\
2 \\
3 \\
0 \\
0\end{array}$ & $\begin{array}{l}0 \\
3 \\
1 \\
1 \\
1\end{array}$ & $\begin{array}{l}4 \\
2 \\
0 \\
\mathbf{1} \\
\mathbf{1}\end{array}$ & $\begin{array}{l}0 \\
0 \\
0 \\
0 \\
1\end{array}$ & $\begin{array}{l}-0.250 \\
-0.125 \\
+1.500 \\
+1.375 \\
+0.750\end{array}$ \\
\hline & & & & & & & Av. +.650 \\
\hline
\end{tabular}

EXPERIMENTS TO TEST INFLUENCE OF HEAT WHEN HEATED SURFACE WAS 20 CM. FROM + END OF TROUGH.

Temperature of Water at Beginning of Experiments $22^{\circ} \mathrm{C}$.

Temperature of Water at End of Experiments $26^{\circ}$ C. at + End of Trough, $25^{\circ}$ at - End.

\begin{tabular}{|c|c|c|c|c|c|c|c|}
\hline & $\begin{array}{c}\text { Region of } \\
\text { Highest } \\
(+) \\
\text { Tempera- } \\
\text { ture. }\end{array}$ & & & & & $\begin{array}{c}\text { Region of } \\
\text { Lowest } \\
(-) \\
\text { Tempera- } \\
\text { ture. }\end{array}$ & \\
\hline 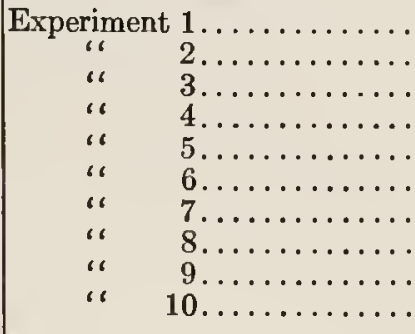 & $\begin{array}{l}2 \\
2 \\
1 \\
1 \\
1 \\
2 \\
2 \\
3 \\
0 \\
0\end{array}$ & $\begin{array}{l}1 \\
1 \\
1 \\
1 \\
2 \\
0 \\
1 \\
1 \\
1 \\
2\end{array}$ & $\begin{array}{l}\mathbf{1} \\
\mathbf{1} \\
\mathbf{0} \\
2 \\
2 \\
0 \\
0 \\
2 \\
3 \\
1\end{array}$ & $\begin{array}{l}0 \\
2 \\
2 \\
3 \\
0 \\
2 \\
2 \\
0 \\
1 \\
0\end{array}$ & $\begin{array}{l}3 \\
2 \\
3 \\
0 \\
0 \\
1 \\
0 \\
2 \\
2 \\
2\end{array}$ & $\begin{array}{l}1 \\
0 \\
1 \\
1 \\
3 \\
3 \\
3 \\
0 \\
1 \\
3\end{array}$ & $\begin{array}{r}0.000 \\
+0.375 \\
-0.500 \\
+0.125 \\
-0.125 \\
-0.625 \\
-0.250 \\
+0.875 \\
-0.375 \\
-0.875\end{array}$ \\
\hline
\end{tabular}

Movement for series -0.150 . 
for different regions of the body determines the direction of movement. I have therefore used the term thermotactic to refer to a motor reaction which is determined by difference in the degree of stimulation of different parts of the animal.

D. The Relation to Each Other of Heat and Light as Stimuli.-These experiments have some bearing upon the theory that light stimulates an organism in essentially the same way as heat, that is, by altering the chemical processes of the tissues through changes in the temperature of the regions affected. Such a theory receives some support from the fact that the reactions of certain animals to light can be changed from positive to negative, or the reverse, by changing the temperature. Groom and Loeb ('90, pp. 166, 167) found that the nauplii of Balanus react differently to light at different temperatures; Loeb ('93, p. 91) has proved that Polygordius larvæ which are positively phototactic at $24^{\circ} \mathrm{C}$. are negative at $29^{\circ}$; Massart ('91, p. 164) states that a flagellate, Chromulina, is positive at $20^{\circ} \mathrm{C}$. and negative at $50^{\circ}$, and Strassburger ('78, p. 605) noticed that certain swarm-spores that were positive at $16^{\circ}$ to $18^{\circ}$ were negative at $40^{\circ}$.

Thus far in experiments with Daphnia I have been unable to change the sense, of the reaction to light by changing the temperature. Yet, if light affects the organism as does heat, one would expect that an organism which avoids high temperatures, as these experiments have shown that Daphnia does, would become negatively phototactic in the presence of strong light. But even light which is accompanied by sufficient heat to kill the animals is sought by Daphnia. For this reason, and also because the reaction to light is exceedingly quick, whereas that to heat is slow, I feel justified in concluding that light acts upon Daphnia otherwise than does heat. It may well be, however, that the difference is one of degree rather than kind.

\section{SUMMARY.}

1. Daphnia pulex is strongly positively phototactic to all intensities of light from 0 to 100 candle-power.

2. There is no evidence of preference for a certain intensity, the "optimal."

3. So far as the experiments described in this paper indicate, the heat accompanying the light from a 16-candle-power incandescent lamp does not have any noticeable influence upon the direction or rate of movement of Daphnia.

4. Subjection of Daphnia to 16-candle-power light for a period of one hour, during which interval the animal was kept in almost constant motion, showed a gradual increase in the rate of movement, and in the sensitiveness to clranges in the intensity 
of light throughout the period. There was no evidence of fatigue in animals that had moved at least 2000 centimetres in an hour.

5. Heat in the absence of light has a directive influence upon the movements of Daphnia. In a trough containing water of $28^{\circ} \mathrm{C}$. at one end and $25^{\circ}$ at the other they migrated toward the region of lowest temperature.

6. The movement is not direct, but irregularly wandering. It is, however, in all probability due to differences in the intensity of stimulation for different regions of the animal's body, and is therefore in principle the same as the photopathic reaction. Daphnia may therefore be said to be negatively thermotactic at a temperature of about $28^{\circ} \mathrm{C}$.

7. The fact that in the case of Daphnia phototactic reactions cannot be changed from positive to negative or the reverse by changes in temperature indicates that light does not act upon the organism in the same way as does heat.

I am indebted to Prof. W. C. Sabine for the suggestion of the cylindrical lens as a means of obtaining a uniformly graded line of light, and to Professors E. L. Mark and G. H. Parker for assistance in the work.

\section{BIBLIOGRAPHY.}

Davenport, C. B., and Cannon, W. B.

'97. On the Determination of the Direction and Rate of Movement of Organisms by Light. Jour. of Physiol.; vol. 21 , no. 1 , pp. 22-32.

Groom, T. T., und Loeb, J.

'90. Der Heliotropismus der Nauplien von Balanus perforatus und die periodischen Tiefenwanderungen pelagischer Tiere. Biol. Centralbl., Bd. 10, No. 5-6, pp. 160-177.

Holt, E. B., and Lee, F. S.

:01. The Theory of Phototactic Response. Amer. Jour. Physiol.; vol. 4, no. 9, pp. 460-481.

Jennings, H. S.

'97. Studies on Reactions to Stimuli in Unicellular Organisms. I. Reactions to Chemical, Osmotic; and Mechanical Stilmuli in the Ciliate Infusoria. Jour. of Physiol., vol. 21, nos. 4-5, pp. $258-322$.

Loeb, J.

'90. Der Heliotropismus der Thiere und seine Uebereinstimmung mit den Heliotropismus der Pflanzen. Würzburg, $8^{\circ}, 118 \mathrm{pp}$.

Loeb, J.

'93. Ueber künstliche Umwandlung positiv heliotropischer Thiere in negativ heliotropische und umgekehrt. Arch. ges. Physiol., Bd. 54, pp. 81-107.

Massart, J.

'91. Recherches sur les organismes inférieurs (1); La sensibilité a la concentration chez les ètres unicellulaire marins. Bull. Acad. roy. Belgique, sér. 3, tom. 22, pp. 148-167.

Parker, G. H., and Arkin, L.

:01. The Directive Influence of Light on the Earthworm Allolobophora fœetida (Sav.). Amer. Jour. Physiol.; vol. 5 , no. 3 , pp. 151-157. 


\section{REACTIONS OF DAPHNIA PULEX TO LIGHT AND HEAT.}

Strass burger, E.

'78. Wirkung des Lichtes und der Wärme auf Schwarmsporen. Jena. Zeitschr., Bd. 12, pp. 551-625. Towle, E. W.

:00. A Study in the Heliotropism of Cypridopsis. Amer. Jour. Physiol., vol. 3, no. 8, pp. 345-365.

Verworn, M.

'99. Gencral Physiology. English translation by F. S. Lee, New York, $8^{\circ}$, xvi +615 pp.

Yerkes, R. M.

'99. Reaction of Entomostraca to Stimulation by Light. Amer. Jour. Physiol., vol. 3, no. 4, pp. $157-182$.

Yerkes, R. M.

:00. Reaction of Entomostraca to Stimulation by Light. 2. Reactions of Daphnia and Cypris. Amer. Jour. Physiol., vol. 4, no. 8, pp. 405-422. 



\section{XIX.}

MENDEL'S LAIV AND THE HEREDITY OF ALBINISM.

W. E. Castle and Glover M. Allen. 



\section{INTRODUCTION.*}

Albinism, or the absence of the normal pigmentation of an organism, is a not infrequent phenomenon in both animals and plants, yet its occurrence in nature is sporadic and has usually been interpreted as an indication of organic weakness. But this interpretation is probably erroneous, for albino races of domesticated animals are apparently not inferior in vigor to other races. Such is demonstrably the case with albino mice.

The idea that albinos lack constitutional vigor may have its origin in the observation that, in crosses between albinos and normal individuals, no albino offspring are produced. But the disappearance of albinism in this case is not final. The albino character has not ceased to exist, but has merely become latent in the offspring. It will reappear unimpaired in the next generation if the cross-bred individuals be mated inter se.

The disappearance of the albino character for a generation, and its subsequent reappearance under close breeding, show that it is inherited in conformity with Mendel's law of heredity, and that it is, in the terminology of that law, a recessive character.

\section{MENDEL'S PRINCIPLES OF HEREDITY.}

The Mendelian principles of heredity, stated in the phraseology of present-day biology, are as follows:

1. Every gamete (egg or spermatozoön) bears the determinants of a complete set of somatic characters of the species. When two gametes meet in fertilization, there are accordingly present in the fertilized egg the representatives of two sets of somatic characters, which may or may not be the same. If they are the same for a given character, as, for example, coat-color in mammals, the individual which develops from the egg must inevitably have that same character. Thus, when gametes

* Tlis paper eontains a preliminary statement of eertain results of breeding experiments with miec, guineapigs, and rabbits, which have been eondueted in the Zoölogieal Laboratory of Harvard University during the last two and a half years. The experiments with inice are the work prineipally of the junior author; those with guineapigs and rabbits, of the senior author. 
formed by one white mouse, meet in fertilization gametes formed by another white mouse, the offspring are invariably white. Similarly, when a wild gray mouse is bred to another wild gray mouse, the offspring are invariably gray. And when a purebred spotted black-white mouse is bred to a mouse like itself, the offspring are all spotted black-white.

2. But when the two gametes uniting bear each what represents a different somatic character, only one of these characters may be manifested by the individual (or zygote) formed. Thus, when wild gray mice are mated with white mice, only gray offspring are produced. The gray character is, in Mendel's terminology, dominant; the white character, recessive. Or, when wild gray rats are mated with black-white rats, only gray rats are produced. The wild gray character is, accordingly, dominant not only over white, but also over black-white.

3 . Sometimes the zygote formed by the union of two unlike gametes (heterozygote, Bateson, : 02) develops the character of neither parent in its purity. It may have a character intermediate between those of its parents, or something entirely different from either. Thus, when black-white mice are mated with white mice, the offspring are gray like the wild house-mouse.

4. Whatever the somatic character of the zygote is, the germ-cells which it forms will be, like those which united to produce it, half like the maternal and half like the paternal gamete. Thus a gray mouse obtained by crossing a wild gray mouse with a white one forms in equal numbers gametes which bear the gray character and those which bear the white character. This is conclusively shown by two simple breeding tests: (1) When a cross-bred (or hybrid) gray mouse is bred to a white mouse half the offspring are hybrid grays, half are white. This is precisely the result we should expect if the cross-bred gray mouse forms, as we have supposed, in equal numbers, gametes which bear the gray and those which bear the white character. For the gray mouse will produce

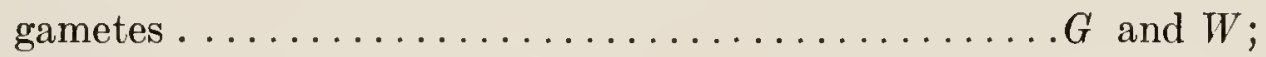

the white mouse forms gametes..............W and $W$;

the possible combinations of these two sets are...... $2 G W+2 W W$.

But, as we have already stated, when a zygote contains both the gray character and the white character, only the former will be visible. This may be indicated by placing the $W$ within a parenthesis. Further, in the expression $2 W W$, one of the identical letters may be dropped as superfluous. Our formula then reads $2 G(W)+2 W$, and signifies that two in every four of the offspring produced will be gray hybrids, and 
the remaining two white. (2) When two cross-bred (or hybrid) gray mice are bred together, the offspring consist of gray mice and white mice in the ratio of three gray to one white. Moreover, breeding tests show that of the three gray mice thus obtained one is pure, that is, will form only gametes bearing the gray character, while two are hybrid, that is, will form gametes some of which bear the gray character, others the white character. This is precisely the result expected under our hypothesis that each hybrid individual forms gametes, $G$ and $W$, in equal numbers. For the possible combinations of two sets of gametes, each $G$ and $W$, are represented by their product, $G G+2 G W+W W$, or, simplified as already explained, $G+2 G(W)+W$.

The principle illustrated by these examples is, as pointed out by Bateson (:02), the most fundamental and far-reaching of the Mendelian ideas. It is known as the "law of segregation," or "splitting" (de Vries, :00) of the parental characters at gameteformation, or as the "principle of gametic purity" (Bateson, :02). Dominance is purely a secondary matter; it may or may not occur along with segregation, though the latter can be more easily demonstrated in cases where it is associated with the former. The principle of gametic purity rests upon the assumption that gameteformation is the reverse of fertilization. In fertilization gametes $A$ and $B$ unite to form a zygote $A B$; when this zygote in turn forms gametes, they will be again $A$ and $B$. From a knowledge of the somatic form alone of pure $A$ 's and $B$ 's, one can make no trustworthy prediction as to the form of $A B$. (Here is the fundamental error of the "law of ancestral heredity" as stated by Galton ('97) and by Pearson (:03). $A B$ may have invariably the somatic form of $A$ or of $B$ (cases of simple dominance, as of gray over white in mice); or it may have sometimes the form of $A$, sometimes that of $B$ (cases of alternative dominance-see Tschermak, :00); or, finally, the somatic form of $A B$ may be different from both that of $A$ and that of $B$ (cases like that of the gray hybrid formed by the cross of black-white with white mice). But, no matter what the somatic form of $A B$ is, we may with confidence predict that its gametes will be essentially pure $A$ 's and $B$ 's, and in equal proportions. This is the Mendelian expectation in all cases of alternative inheritance. Whether it applies to other cases also, and, if so, to what extent, is not yet known.

\section{COMPLETE ALBINISM A RECESSIVE CHARACTER.}

I. In Mice.-The recessive nature of complete albinism in mice has been conclusively demonstrated by Cuénot (:02), who, on crossing wild gray house-mice with albinos, obtained always gray mice indistinguishable in appearance from the pigmented parent. Yet these gray hybrids, when bred inter se, produced both gray 
and white offspring approximately in the Mendelian ratio, $3: 1$. The exact numbers recorded are 198 gray : 72 white, or 26.6 per cent. albinos. According to Mendelian principles the grays of this second filial generation should consist in part of pure grays, which would not transmit the albino character, and in part of hybrid grays like their parents,- - the first filial generation,--which would transmit alike the pigmented and the albino characters. This Cuénot demonstrated to be actually so, for certain pairs formed by random selection of the grays gave only gray offspring (189 individuals); the remaining pairs produced albino as well as gray offspring, and in the expected ratio, 3 grays : 1 albino. The precise numbers recorded are 162 grays : 57 albinos, or 26 per cent. albinos.

Cuénot's observations are fully substantiated by our own experiments, the results of which may be summarized as follows: Wild gray mice were crossed with albino mice; the offspring, sixty-four in number, were all gray like the wild parent, though a single litter of three young, which died without attaining their full growth, were of a somewhat lighter gray than the wild parent. Certain of the cross-breds were paired together, and produced 66 offspring, 42 of which were gray, 24 white. This is a considerable deviation from the expected ratio, $3: 1$, but it should be remembered that the total number is relatively small. The result is of the nature expected, in that both gray and albino offspring are produced, and of the former a larger number than of the latter.

To determine whether the grays are, as expected, of two sorts, one hybrid, the other pure, six pigmented individuals have been crossed with the parental white stock. Three of the six have thus far produced only pigmented offspring, indicating that they are pure; the other three have produced both gray offspring and white offspring, showing that they are hybrids. The two sorts of offspring produced in the case last mentioned should, according to Mendelian expectation, be equally numerous. The numbers thus far recorded are 35 pigmented individuals: 23 albinos, a result agreeing with expectation in that both gray and white offspring are produced, though these are not in the exact proportions demanded by Mendel's laws.

If we combine the results of this cross with those obtained by interbreeding hybrids of the first filial generation, we get for the whole a close agreement between expectation and observation. The expectation is 78.5 gray : 45.5 white; the observed result is 77 gray : 47 white.

White mice obtained by one or the other of these crosses have repeatedly been bred together, but without the occurrence of a single exception to the expected Mendelian result, the offspring being invariably albinos.

A further test of the Mendelian hypothesis as applied to albinism in mice was 
made by Cuénot. By back-crossing hybrid grays with the ancestral white stock he obtained gray as well as white individuals, which in the phraseology of breeders should be $\frac{1}{2}, \frac{3}{4}, \frac{7}{6}$, etc., white "blood," yet all the grays, irrespective of ancestry, gave precisely similar results in crosses with whites, viz., equal numbers of gray and white offspring.

It is evident, then, that when a pure gray race of mice is crossed with a pure white race, the gray character invariably dominates in the offspring, and in subsequent generations both gray individuals and white individuals occur approximately in the proportions demanded by Mendel's principles of dominance and segregation. No better illustration of Mendel's law has yet been produced than is afforded by the cross between gray and white mice.

2. In Other Mammals, in Fishes, and in Plants. - In the case of guinea-pigs, we have many times mated together albinos born of mottled parents, or obtained by mating a mottled with a white animal, but never with any but the expected Mendelian result, all the young being albinos.

In the case of rabbits, the same law appears to hold. Professor R. T. Jackson kindly placed at our disposal last summer three white rabbits, a male and two females, all born in the same litter, of spotted parentage. The two females have borne by their brother, in three litters, seventeen young, all albinos.

In man, Farrabee (:03) and Castle (:03) have recently shown albinism to be in all probability recessive.

As to fishes, Dr. Hugh M. Smith, of the United States Fish Commission, informs us that in one of the State fish-hatcheries of this country there is bred as a curiosity a race of albino trout which "breed true," indicating that the albino character is recessive.

In plants more than two-thirds of the Mendelian cases mentioned by de Vries $(: 02$, p. 146) are cases of "depigmentation" of flowers or fruit, the depigmented condition being invariably recessive in crosses with the normal condition.

It appears, then, that in organisms in general albinism behaves as a recessive character in heredity.*

* The only exeeption known to the nriters is the dominanee of white plumage, in eertain erosses of poultry, as reeorded by Bateson and Saunders (:02). Yet the dominant eharaeter in this ease is one of partial albinism only, and its dominanee is not invariable. We suspeet that the dominanee of white plumage results from its coupling in the gametes with some other eharaeter strongly dominant by nature. 


\section{PARTIAL ALBINISM A MOSAIC OF DOMINANT AND RECESSIVE CHARACTERS, AND A UNIT IN HEREDITY.}

Darbishire (:02,:03) finds that in crosses between a peculiar race of partial albino mice and true albinos, the albinism does not entirely disappear in the offspring, and he thinks that this weighs heavily against the entire Mendelian hypothesis. In reality Darbishire's observations, when rightly interpreted, afford strong evidence in favor of that hypothesis. It may be well, therefore, to examine them with some care. But before doing so one or two earlier observations should be noticed.

Haacke ('95) crossed spotted blue-[black-]and-white Japanese dancing mice with albino mice, and obtained offspring uniformly gray in color, like the wild housemouse, or uniformly black. Occasionally, however, one of the gray or black offspring bore a fleck of white on forehead or belly.

Von Guaita ('98, :00) repeated the experiment, crossing spotted black-and-white Japanese dancing mice with an inbred stock of albinos. He obtained twenty-eight young, all uniformly gray like the house-mouse. These gray mice bred inter se yielded in subsequent generations gray, gray-white, black, black-white, and white offspring.

Darbishire's experiment consisted in crossing albino mice with a peculiar race of Japanese dancing mice which had pink eyes and were uniformly white except for patches of pale fawn-color on the cheeks, shoulders, and rump. The dancing mice had been tested and found to breed true inter se. From the cross between these partial albinos and true albinos a total of 203 young was obtained, all dark-eyed and with bodies more or less extensively pigmented. As to color, which is recorded for all except the latest litters, the hybrids show the following distribution: 7 yellow: 138 gray : 9 black. Of these, seventy-eight gray and six black mice were spotted more or less extensively with white, while the seventy unicolored mice were, all except one, of a lighter color on the belly and tail. In only three out of the entire one hundred and fifty-four for which a full record of the coloration is given, is the pigmentation less extensive than in the pigmented parent. Even in these three the intensity of the pigmentation had been increased by the cross, for the offspring were gray pigmented, whereas the pigmented parent had been merely spotted with light fawn.

Darbishire's experiment is instructive in a number of ways:

1. It completely confirms the conclusion based upon the experiments of Crampe ('85), Haacke ('95), von Guaita ('98,:00), Cuénot (:02), and ourselves (Castle and 
Allen, :03) that, in crosses between pure races of pigmented and albino mice, the pigmented character invariably dominates in the offspring.

2. It shows that cross-breeding may bring into activity latent characters or latent elements of a complex dominant character. The pigmented parent in Darbishire's crosses bore only yellowish ("fawn") pigment, but the hybrid offspring produced by a cross with albinos, in all except sixteen out of one hundred and fiftyfour cases, bore also black pigment, which when present with yellow produces the complex character gray. In nine of the sixteen cases mentioned black pigment alone was present, and in the remaining seven cases yellow pigment alone was present.

3. These facts show that cross-breeding may cause one element of a clominant character to disappear (become latent), while a different element (previously latent) takes its place. This is what happened in nine of the sixteen cases mentioned; in these nine cases fawn (present in the pigmented parent) disappeared, while black (undoubtedly latent in one or both parents) became active.

Darbishire is unable to regard albinism as beyond qualification recessive, in the Mendelian sense, because white does not entirely disappear from the bodies of the offspring in his first cross. The condition observed by him is indeed somewhat unusual, though entirely in harmony with Mendelian principles. The thing which demands explanation in such cases as this is, not that the offspring are spotted, for this may be regarded as a case of simple dominance of the character of the pigmented parent, but the fact that the dominant and recessive characters occur together in the spotted parent. Two explanations have been offered for such (mosaic) conditions. Correns (:03) regards mosaic individuals as due to alternative dominance of the two parental characters. He considers the anlagen of both characters to be present together throughout the soma, but in one region of the body one character dominates, in another region the other. He supports this idea with the observation that in particolored flowers which bear stamens, some in the pigmented, others in the unpigmented parts of the flower, pollen taken from stamens of either region transmits both the pigmented (dominant) and the unpigmented (recessive) characters. This observation, however, proves only that the germ-cells may have a character different from that of the soma. The assumption made by Correns that soma and germ-cells are of the same nature in particular regions of the flower is, in our opinion, without sufficient warrant.

The facts observed by Darbishire, as well as certain observations of our own, accord better with a different explanation, suggested by Bateson and Saunders (:02). On this view, which one of us has recently elaborated (Castle, :03 $3^{\mathrm{a}}$, a mosaic condition of the soma is due to a mosaic condition of the germ which produced the mosaic 
individual. Strong evidence in support of this view is afforded by the experiments of Haacke, von Guaita, and Darbishire, as well as by our own experiments, in crossing spotted with albino mice. We bred to albino females two spotted males of a blackwhite stock whose individuals bred true inter se. The offspring were like those obtained by Haacke in crossing Japanese dancing mice with albinos, namely, mice uniformly gray or black in color, though sometimes with a fleck of white on the belly, or with one or more white bands on the tail. Of the forty-three young produced by this cross, twenty-eight were gray and fifteen black. The fact that no albino offspring were produced shows that the spotted males formed no recessive gametes, but only those which were either mosaic or else purely dominant in character. But if dominant gametes had been formed by segregation from a dominant-recessive mosaic, we should expect that by a residual process recessive gametes would be formed also. The latter not having been formed, it is safe to suppose that the former were not formed either, but that all the gametes formed by these spotted males were mosaic.

That the albino character entered as a latent constituent into the gray or black hybrids formed by the cross just described is shown conclusively by the character of their offspring. When bred inter se they produced albino as well as pigmented offepring, and approximately in the ratio, 1:3; or, when bred to albinos, in the ratio $1: 1$.

Accordingly, in the original cross described, we have a case of simple dominance of the pigment-forming over the albino character. This dominance is attended, in about two cases out of three, by reversion to the particular form of pigmentation found in the wild house-mouse. The reversion is due to the coming into activity of a capacity (previously latent) to form yellow pigment, which with black pigment forms gray. This latent capacity must have been present in one or the other or possibly in both of the parents crossed.

Darbishire's results differ from ours only in degree, not in kind. He, too, gets invariably dominance of the pigment-forming over the albino character, and this is associated in all except sixteen out of one hundred and fifty-four cases with reversion to the ancestral kind of pigmentation, gray. The chief differences between his results and our own are as follows:

1. In our experiments yellow was the latent constituent of gray which was brought into activity by a cross with albinos; in the experiments of Darbishire black was the latent constituent brought into activity.

2. In our experiments white disappeared for the most part from the bodies of the hybrids; but in Darbishire's experiments the disappearance of white was much less complete. There was a strong tendency for the mosaic gamete to dominate as 
a unit without serious disturbance of the balanced relationship of pigmented and unpigmented areas in the mosaic structure. This tendency is observable in eightyfour of the one hundred and fifty-four cases recorded. Of the remaining seventy cases, sixty-seven are quite comparable with our own. In sixty of them the black character, latent in one or possibly in both parents, has become active and combining with yellow (fawn) visible in the pigmented parent, has formed gray. In seven cases black, if present, has remained latent, and the offspring are simply yellow-pigmented. But in the case of three black and of six black-white hybrids, this curious result is observed: the pigmented character (yellow) visible in the dark parent disappears entirely, while black takes its place.

In Darbishire's experiments, as in our own, the effect of a cross with albinos is to release the dominant character from the strict localization which it had in the mosaic parent. In Darbishire's mosaic mice the localization of pigment was much more rigid than in our own. His mice bore pigment only on the shoulders and rump and had pink eyes; ours were pigmented over at least half of the body and had black eyes. It is not surprising, then, that the pigmentation should be less extensive in Darbishire's hybrid mice than in our own. Yet it is evident that in all his hybrids there occurred release, more or less complete, of the pigment-forming character from its localization in the original mosaic. In every case the hybrid had pigmented eyes, though neither parent possesser this character.

\section{PURE AND HYBRID MOSAICS.}

In our experiments in crossing spotted with albino mice, a third black-white male was employed. He was a half-brother to the two spotted males previously mentioned, born of the same mother but by a different sire. The white areas on his body were less extensive than those on his two brothers. He was bred to the same stock of white females as they, but with different results. By him the albinos bore albino as well as pigmenter offspring; of the former twenty-one, of the latter twelve, ten being gray and two black. The albino offspring were found in this case, as in all others tested, to breed true inter se.

It is evident that the third black-white male differed in nature from his two half-brothers, for he formed recessive gametes, whereas they did not.

Examination of other breeding records of spotted mice kept by us during the past two years shows that it is possible in these also to distinguish two different sorts of mosaic individuals. These are: 
1. Pure mosaics, spotted and forming only mosaic gametes, DR. They breed true inter se, but when crossed with albinos produce only individuals of the following class.

2. Hybrid mosaics, usually more extensively pigmented than pure mosaics, often pigmented all over. (Compare the results of Haacke, von Guaita, and Darbishire.) They form, in approximately equal numbers, mosaic and recessive gametes, $D R$ and $R$, respectively. Accordingly, when bred inter se, they produce offspring of three different sorts, $D R, D R \cdot(R)$ [or $D(R) \cdot(R)]$,* and $R$, that is, pure mosaics, hybrid mosaics, and recessives. Theoretically these three classes of offspring should be numerically as $1: 2: 1$. There is reason to believe that these proportions are approximated in our experiments, but this matter has not yet been fully tested. When bred to albinos, hybrid mosaics produce (in equal numbers) hybrid mosaic and albino offspring.

It is possible to recognize in the experiments of von Guaita and Darbishire also these two different classes of mosaics. Von Guaita's original stock of dancing mice consisted of pure mosaics, for they bred true inter se, and when bred to albinos produced only pigmented offspring. These offspring, though not themselves spotted, were clearly hybrid mosaics, for when bred inter se they produced spotted as well as albino offspring, of the former nine, of the latter fourteen, in a total of forty-four young; the expectation on our hypothesis is eleven of each!

The evidence afforded by Darbishire's mice is even more convincing because of a visible difference between the heterozygous (hybrid mosaic) form and both of the pure parental forms. The parents were, as we have seen, in every case pinkeyed, whereas the hybrids were as invariably dark-eyed. Hybrids bred inter se should in this case, according to our hypothesis, produce pure mosaics (pink-eyed), hybrid mosaics (dark-eyed), and albinos, in the proportions, $1: 2: 1$. These three sorts of individuals were actually observed by Darbishire, and in very nearly the theoretical proportions. In a total of sixty-six young the observed numbers are 17 pink-eyed mosaics : 36 dark-eyed individuals : 13 albinos; the expectation is $16.5: 33: 16.5$. By crossing hybrids with albinos Darbishire obtained, as we should expect on the hypothesis stated, only two of the three classes produced by intercrossing hybrids, namely, dark-eyed individuals (hybrid mosaics) and albinos; no pink-eyed pigmented individuals were produced. The expectation is that the two classes formed will in this case be approximately equal; the observed numbers are 94 dark-eyed individuals, 111 albinos.

* The pcriod is used to indicate the distinctness, in the zygote, of the gametes which united to form that zygote, as well as to show that, when in the hybrid individual segregation of characters takes place at gamete-formation, splitting will occur at the point marked by the period, producing gametes $D R$ and $R$. 
The idea that there are, as just explained, two different sorts of mosaic individuals originated with the junior author of this paper. It constitutes a discovery of no small importance, one which lends strong support to the Mendelian hypothesis of essential gametic purity. It shows that alternative parental characters, when united in fertilization, do not mix, but that each retains its own identity and subsequently separates from the other when gametes are formed. This takes place even when one of the parental characters is itself a mosaic! Herein we have a confirmation of the conclusion based upon morphological observations, that the paternal and maternal contributions to the zygote retain each a distinct individuality. Further, the idea of Bateson receives confirmation, that the gray color of mice obtained by crossing black-white with white mice is itself a "heterozygote" character.

\section{PURE AND IMPURE RECESSIVES.}

Although certain of Darbishire's conchusions are, as we have seen, untenable, he has made observations of great significance, one of which deserves particular notice. In his crosses with dancing mice he employed two different stocks of white mice, and with results somewhat different in the two cases. The two stocks were (1) "purebred" albinos purchased from breeders, and presumably descended from white parents, and (2) "cross-bred" albinos known to be descended from spotted (i.e., hybrid mosaic) parents. The latter when crossed with the fawn-white dancing mice produced twenty-five offspring spotted with white, and only four which were pigmented all over. The "pure-bred" albinos when similarly mated produced thirty-six spotted mice and sixty-one mice pigmented all over. In other words, the cross with "purebred" albinos produced a much smaller proportion of spotted mice than did that with "cross-bred" albinos.

Apparently the primary effect of a cross between a mosaic and an albino individual is to release in the soma of the offspring the dominant character either latent or tied up in a firm mosaic with the recessive character in the gametes of the spotted parent. The dominant character is thus free to extend its influence over the entire soma of the hybrid offspring. This release seems to be the more complete the more free the albino stock has been kept from crosses with pigmented animals.

It follows from Darbishire's observation that not all albinos breed alike when crossed with the same pigmented stock, a conchusion which our own experiments fully substantiate. This indicates that the gametes formed by different albino stocks are not 
all alike, and raises the question whether all are equally pure as regards the pigmentforming character.

Construed in the strictest sense, the doctrine of gametic purity is untenable. We cannot accept that interpretation of it which requires that the gametes formed by an individual be the precise equivalents, in all particulars, of the respective gametes which united to form that individual. Mendel himself would not have assented to such an interpretation, for in the latter part of his original paper ('66) he clearly states the important principle that a composite character may undergo resolution into its elements in consequence of crossing. This allows a part of a complex character to pass into one gamete, while the remaining parts pass into another; in other words, it makes possible the formation of mosaic gametes, into whose composition the dominant and recessive characters may both enter in varying degree. All gametes which contain any portion of a dominant or of a recessive character associated with its opposite, are in reality mosaic; yet if a gamete essentially recessive contains only traces of the dominant character, it may be convenient to recognize this fact in its designation, which we do by calling it an impure recessive.

In guinea-pigs the impurity of recessives tainted with the dominant character is commonly visible. Ordinary white guinea-pigs with pink eyes, though they invariably produce albinos when bred inter se, have a greater or less amount of sooty black pigment in the skin and hair of their ears, nose, and feet, showing the presence of a trace of the dominant character. Rarely is it possible to obtain an animal free from this visible taint, and even when obtained, we are informed by breeders, such individuals are likely to produce offspring with a certain amount of pigment on their ears or feet.

The so-called Himalayan rabbit is another illustration of a mosaic with a predominantly recessive (albino) character, in which the dominant (pigment-forming) character is localized precisely as in the impure albino guinea-pig, namely, at the extremities. Himalayan rabbits have brownish-black noses, ears, fect, and tails, being elsewhere snowy white and having pink eyes. They breed true inter se, yet, according to Darwin ('76, p. 114), may occasionally produce a silver-gray animal, in which the pigment is not restricted to the extremities. This condition must result from liberation of the dominant character from the strict localization which it has in ordinary individuals and which it must have also in the gametes that produce them.

In mice, on the other hand, impurity in recessive individuals is not visible, though doubtless sometimes present. So long as the breeder wishes only to obtain white mice, it makes no difference what the ancestry of his breeding animals is. All albinos alike will produce only white offspring when bred to albinos. But if the breeder 
desires to cross his albinos with colored mice, the pedigree of the former is of consequence. Different albinos will, in crosses with the same pigmented stock, yield different results. This is shown both by Darbishire's experiments and by our own. In October, 1900, we began a breeding experiment in which a family of black-white mice was crossed with two different stocks of albino mice. All three stocks bred true among themselves; but in crosses with the black-whites one albino stock produced only gray or black offspring, whereas the other produced no gray offspring, but only black or fawn-colored ones, often extensively spotted with white. Manifestly the gametes formed by the two albino stocks, though all predominantly recessive, were not all alike. It is probable that some of them at least were impure, containing traces of a latent pigment-forming character. Such a latent character is apparently not liberated, in the case of mice, by a cross with a different stock of albinos; but this result can be secured, probably, by a cross with dominants. We infer this not only from the observed result in crosses between black-white and albino mice, but also from what has been observed to take place in guinea-pigs. On crossing a "dark-pointed" albino guinea-pig with a stock of red guinea-pigs which for a number of generations had bred true inter se, there were obtained offspring which in every instance were predominantly black in color, yet with a certain proportion of red hairs mixed with the black, which gave them a "brindle" or finely mottled black-and-red appearance. This result must be attributed to a liberation of the black-pigmentforming character either from its visible, strict localization in the albino parent, or from a possible latent and invisible occurrence in the red parent. We incline at present toward the former explanation, but the matter has not yet been fully tested. The complete disappearance of the albino character in this cross is noteworthy as being parallel to its behavior in the cross between black-white and white mice.

Darbishire's pink-eyed, fawn-white dancing mice were mosaics predominantly recessive, and might with some propriety be designated impure recessives, but they differed from impure guinea-pig recessives and from Himalayan rabbits in that, when crossed with ordinary recessives, they did not produce pink-eyed animals like themselves, but rather animals which were in a majority of cases extensively pigmented. It seems more appropriate, therefore, to designate them mosaics.

"Dutch-marked" varieties of guinea-pigs, rabbits, and mice, and the somewhat similarly marked Holstein and Hereford cattle, though they do not breed so true inter se as dark-pointed albino guinea-pigs or Himalayan rabbits or, perhaps, as pink-eyed dancing mice, nevertheless indicate a fairly precise localization of the pigmentforming and albino characters within mosaic germs.

If we adopt the Roux-Weismannian idea of the nature of the chromosomes, it 
is probable that particular chromosomes, or part chromosomes, in the mosaic germ, contain the dominant character, while the remaining chromosomes, or part chromosomes, contain the recessive character.

\section{CROSS-BREEDING, REVERSION, AND THE DOCTRINE OF GAMETIC PURITY.}

Union with a recessive gamete usually, though not always, serves to break up this localization, allowing the dominant character to extend its influence throughout the entire body. This is the case, for example, in the cross between spotted and white mice in the experiments of Haacke, von Guaita, and in part of Darbishire, as well as in our own. It is possible to suppose in such cases either (1) that the resolving effect of the cross is restricted to the soma of the cross-bred, or (2) that it extends also to the germ-cells of the cross-bred. If theformer hypothesis is correct, the crossbred should form gametes $D R$ and $R$ in equal numbers; if the latter, then only gametes $D$ and $R$ should be formed, and these in equal numbers. A simple test is afforded by the breeding inter se of hybrid mice produced by crossing pure mosaics with recessives. On the first hypothesis suggested, the offspring of the hybrids should consist, in at least one case out of four, of spotted mice formed by the union of two pure $D R$ gametes; on the second hypothesis no spotted mice should be produced, but only classes $D, D(R)$, and $R$, as in breeding together hybrids between wild gray mice and white mice. Von Guaita's experiments show the formation at the second filial generation of nine spotted mice, twenty-one uniformly gray or black mice, and fourteen white mice. The expectation on hypothesis (1) is 11 spotted : 22 gray or black : 11 white mice, which approximates closely the observed result; whereas on hypothesis (2) there should be no spotted mice, but only such as are pigmented all over or else are albinos. The result is conclusive in favor of hypothesis (1)-that a mosaic gamete, on uniting in fertilization with a recessive gamete, does not lose its own identity nor undergo resolution into its constituent parts.*

Yet we must not fail to observe that a cross of the sort just described is not without its effects on the nature of the gametes; these do not retain their original character. For whereas the mosaic gametes of the original spotted parents produced, on union in pairs, invariably black-white offspring, the mosaic gametes formed by their hybrid offspring, when similarly combined, formed in von Guaita's experiments eight graywhite offspring, but only one black-white. Accordingly, though it seems certain that mosaic gametes may in crosses retain their mosaic character, the cross is nevertheless

* Compare the results of Darbishire, as stated on p. 390. 
able to bring into activity characters latent in the parents, and to add these to the previous visible total of the mosaic, giving it thus a new character. In the original black-white stock the mosaic consisted of the active characters, black and white, while the character yellow was latent either in the mosaic gametes or in the recessive gametes with which they united when the cross was made. The cross brought at once into activity the latent character, yellow; and this combined with black to form the composite dominant character, gray, while white, though present in both gametes uniting, usually became for the time being altogether latent. But the gametes formed by the gray hybrid were not, as we should expect on the principle of strict gametic purity, black-white and white, but gray-white and white respectively. The character yellow, latent previous to the cross, having once become active remained so*

In Darbishire's experiments the cross with albinos served in most cases to bring latent black into activity along with yellow (seen in the pigmented parent), but in a few cases yellow (previously active) disappeared in the offspring, while black (previously latent) replaced it.

By these experiments we are put in possession of a principle of great importance, both theoretical and practical. It modifies essentially the Mendelian doctrine of gametic purity as commonly understood, yet without denying the soundness of that doctrine at core. It allows the breeder (as breeders habitually do) to reap substantial benefit from crosses, for, in addition to permitting him to secure new combinations of the elementary characters visible in the parents crossed, it places at his disposal characters latent in the parents, and particularly facilitates the reacquisition of lost characters.

The gray of hybrid mice obtained as in von Guaita's experiments is a composite character resulting from the combination of visible black with latent yellow. In Darbishire's experiments it results from the combination of visible yellow with latent black. In either case gray is obtained by synthesis (Bateson) of black and yellow. This view is supported by the observation of the reverse of this process, in crossing wild gray with white mice. In the second and later hybrid generations black pigmented as well as gray pigmented mice are obtained. These must result from a resolution of gray into its constituent elements, black and yellow, of which the latter then becomes latent.

It is not necessary to suppose, as Mendel apparently did, that the segregated elements of a composite character pass invariably into different gametes. There is reason to believe that yellow is frequently, if not always, latent in black mice, and black in yellow mice, though such an occurrence has not yet been conclusively demonstrated. 
We would not, however, deny the possible correctness of Mendel's explanation in other cases. This should be indicated in breeding experiments by the simultaneous appearance in different individuals of the segregated elements of the composite character, and in particular numerical proportions. Each new sort should be incapable of producing the other, under either close or cross breeding. This is a subject well meriting more careful investigation.

\section{SUMMARY.}

1. Complete albinism, without a recorded exception, behaves as a recessive character in heredity.

2. Partial albinism is a mosaic condition in which the dominant pigment-forming character and the recessive albino character are visible in different parts of the same individual.

3. Pure mosaic individuals form only gametes which partake of their own mosaic nature. They and their gametes may be designated $D R$.

4. Hybrid mosaics result from the union of a mosaic gamete, $D R$, with a recessive gamete, $R$, as in a cross between a pure mosaic and a recessive individual. Such crosses are made when a race of spotted mice which breeds true is crossed with albinos.

5. Hybrid mosaic mice are usually more extensively pigmented than pure mosaics, Jrequently they are pigmented all over. When they are spotted with white, we may consider this the result of dominance of the mosaic gamete as a unit and may designate them accordingly, $D R \cdot(R)$. When they are pigmented all over, it is clear that the dominant element only of the mosaic gamete is visible in them. They should then be designated $D(R) \cdot(R)$.

6. The gametes formed by a hybrid mosaic are of two sorts, like those which united to produce it, namely, $D R$ and $R$. Accordingly when hybrid mosaic individuals breed together they produce offspring of three different sorts-pure mosaics, hybrid mosaics, and recessives. We should expect these three classes to be numerically as $1: 2: 1$, and this is probably the case. When a hybrid mosaic is bred to a recessive, two sorts of offspring are produced-hybrid mosaics and recessives. These classes should be of approximately equal size.

7. Albinism apparently complete may in reality conceal traces of the pigmentforming character either in an active or in a latent condition. Albinos that are thus constituted are in reality mosaics of the contrasted characters, but with the pigmentforming character (ordinarily dominant) occurring in a condition of partial or com- 
plete latency. When bred to other albinos they uniformly produce albinos, hence they may for convenience be distinguished as impure recessives. In guinea-pigs and rabbits the impurity of recessive individuals is, in certain cases at least, visible; in mice it apparently is not.

S. Cross-breeding is able to bring into activity latent characters or latent elements of a complex character. This is probably the true explanation of many cases of reversion. Conversely, it is able to cause one or another element of a complex character to become latent and to remain so under close breeding. This principle probably explains how races of black or yellow mice may be obtained by crossing wild gray mice with albinos.

9. The Mendelian doctrine of gametic purity is fully substantiated by experiments in breeding mice, guinea-pigs, and rabbits, but with the important qualification stated under 8 , a qualification which really enhances the practical utility of that doctrine in its every-day application by breeders.

\section{BIBLIOGRAPHY.}

Bateson, W.

:02. Mendel's Principles of Heredity: a Defence. With a Translation of Mendel's Original Papers on Hybridisation. Cambridge, Eng., $16^{\circ}$, xiv +212 pp.

Bateson, W., and Saunders, E. R.

:02. Experimental Studies on the Physiology of Heredity. Reports to the Evolution Committee of the Royal Society. Report I. 160 pp. London.

Castle, W. E.

:03. Lote on Mr. Farabce's Observations [on Negro Albinism]. Science, n. ser., vol. 17, no. 419, pp. 75-76.

Castle, W. E.

:03 ${ }^{\text {a }}$ Mendel's Law of Heredity. Proc. Amer. Acad. Arts and Sci., vol. 38, no. 18, pp. 535-548.

Castle, W. E., and Allen, G. M.

:03. The Heredity of Albinism. Proc. Amer. Acad. Arts and Sei., vol. 38, no. 21, pp. 603-622.

Correns, $\mathrm{C}$.

:03. Ueber Bastardirungsversuche mit Mirabilis-Sippen. Erste Mittheilung. Ber. Deutsch. Bot. Gesell. Bd. 20, Heft 10, pp. 591-608.

Crampe, [H.]

'85. Dic Gesetze der Vercrbung der Farbe. Landwirtsch. Jahrbücher, Bd. 14, Hcft 4, pp. 539-619.

Cuénot, $\mathbf{L}$.

:02. La loi de Mendel et l'hérédité de la pigmentation chez les souris. C. R. Acad. Sei., Paris, tom. 134, pp.; $779-781$.

Darbishire, A. D.

:02. Notes on the Results of Crossing Japanese Waltzing Mice with European Albino Races. Biometrika, vol. 2, pt. 1, pp. 101-104.

Darbishire, A. D.

:03. Second Report on the Results of Crossing Japancse Waltzing Mice with European Albino Races. Biometrika, vol. 2, pt. 2, pp. 165-173. 
Darwin, C.

'76. The Variation of Animals and Plants under Domestication. Second Edition, revised. New York; $8^{\circ}, 2$ vols., xiv $+473, \mathrm{x}+495 \mathrm{pp}$.

Farabee, W. C.

:03. Notes on Negro Albinism. Science, n. ser.; vol. 17, no. 419, p. 75.

Galton, F.

'97. The average Contribution of each several Ancestor to the total Heritage of the Offspring. Proc. Roy. Soc. London, vol. 61, pp. 401-413.

Guaita, G. $\mathbf{v}$.

'98. Versuche mit Kreuzungen von verschiedenen Rassen der Hausmaus. Ber. naturf. Gesellsch. zu Freiburg, Bd. 10, pp. 317-332.

Guiata, G. $\nabla$.

:00. Zweite Mittheilung über Versuche mit Kreuzungen von verschiedenen Rassen der Hausmaus. Ber. naturf. Gesellsch. zu Freiburg, Bd. 11, pp. 131-138, 3 Taf.

Haacke, W.

'95. Ueber Wesen, Ursachen und Vererbung von Albinismus und Scheckung und übcr deren Bedeutung für vererbungstheoretische und entwicklungsmechanische Fragen. Biol. Centralbl., Bd. 15, pp. 44-78.

Mendel, G.

'66. Versuche über Pflanzenhybriden. Verh. naturf. Vereins in Brünn, Bd. 4, Abt.; pp. 3-47. [Translation in Bateson, :02.]

Pearson, Karl.

:03. The Law of Ancestral Heredity. Biometrika, vol. 2, pt. 2, pp. 211-236.

Tschermak, E.

:00. Ueber künstliche Kreuzung bei Pisum sativum. Zeitsch. f. landwirths. Versuchswesen in Oesterreich, Jahrg. 3, pp. 465-555.

Vries, H. de.

:00. Sur la loi de disjonction des hybrides. C. R. Acad. Sci., Paris, tom. 130, pp. 845-847.

Vries, H. de.

:02. Die Mutationstheorie. Leipzig, $8^{\circ}$, Bd. 2, Die Bastardirung, Lief. 1, 240 pp.. 2 Tat. 


\section{XX.}

THE TORUS LONGITUDINALIS OF THE TELEOST BRAIN: ITS ONTOGENY, MORPHOLOGY, PHYLOGENY, AND FUNCTION.

$$
\text { (PLATE XXIX.) }
$$

Porter Edward Sargent. 



\section{INTRODUCTION.}

The vertebrate brain has long been regarded as made up of transverse rings or segments of morphological significance. Burckhardt ('94) first pointed out that the neural tube may be considered as made up of longitudinal plates, or zones for the most part bilaterally arranged. In the primitive brain, as in the cyclostomes, the median dorsal zone is essentially ependymal and non-nervous, while the bordering lateral zones are highly nervous (Pl. XXIX, Figs. 8, 10, 15). This median zone retains to a greater degree than any other portion the primitive characteristics of the neural tube, remaining fairly constant both in its ontogeny and phylogeny throughout the vertebrate series. This is particularly true of the pars intercalatus, that portion of the median roof of the diencephalon lying anterior of the posterior commissure and between it and the base of the epiphysis, and designated by Burckhardt as the "Schaltstück" (Figs. 15, 20-24, prs. $i$ "cal.). It is made up of elongated ependymal cells inclined obliquely cephalad. In the teleosts it is in an especially primitive condition containing no nervous elements except the fibres of the epiphysial decussation which pass through it near its dorsal surface (Fig. 24, dec. e'phy.).

The median zone of the mesencephalon is in most teleosts, however, probably more complex than in any other group, due to the development of the dorsal decussation of the tectum opticum (Figs. 20, 24, 25, dec. d.) and the crowding into the median plane of the structures derived from the lateral zones.

The teleost brain presents a structural form considerably removed from the more generalized types found in ganoids, selachians, and amphibians. This large and variable group presents many types of brain structure, assuming in the more highly differentiated members of the group a considerable degree of complexity.

The mesencephalon is complicated by the presence of the torus longitudinalis. In the adult this consists typically of a medianly grooved ridge extending downward from the thin median portion of the mesencephalic roof (Figs. 6-19, tor. Ig.). It usually extends from the posterior commissure through the length of the optic lobes, but is best developed at its anterior end (Figs. 20-23). The form and relative size of the torus and consequently its relations to the surrounding structures (tectum opticum, posterior commissure, valvula cerebelli, etc.) vary greatly in the different 
groups of teleosts. The manifold forms which the torus assumes presents in itself an interesting study in variation, in which it is often possible to correlate closely cause and effect.

The torus longitudinalis was first observed in the herring, and described by Carus ('14), who believed it to be the homologue of the fornix of higher vertebrates and applied that, name to it. Gottsche ('35) subsequently agreed as to this homology, and described it, occurring in somewhat variable form, in a number of species. Fritsche ('78) maintained that the optic lobes of fishes represented the cerebral hemispheres, and considered the torus longitudinalis homologous with the fornix and corpus callosum.

Sanders ('78) in his brief description of this organ also alludes to it as the fornix. $\mathrm{He}$ is the first to give any description of its internal structure. He describes the cells as small and spherical, arranged in radiating rows separated by bundles of fibrillæ to which the cells are attached by short branchlets.

Stieda ('68), Bellonci ('80, '81, '82), Mayser ('82), Wright ('84), Auerbach ('88), and Herrick ('91, '92, '93) treat of the optic lobes, but have little or nothing to say of the torus, and nothing whatever of its finer structures. Among the more recent writers who deal with this region the torus longitudinalis is wholly ignored by Fusari ('87), Burckhardt ('94), Van Gehuchten ('94), Neumeyer ('95), Mirto ('95), Haller ('98), Pedaschenko (:01), and it receives mere mention from Ramsay (:01).

Rabl-Rückhard ('82, '84), from embryological and comparative anatomical studies, proved that the earlier writers were in error as to the homology of the fornix and torus, and showed the torus longitudinalis to be a structure peculiar to fishes. Later this author ('87), while studying the development of the torus in the salmon, found it to be developed from the roof of the mesencephalon as a longitudinal thickening, by the multiplication of the cells of the inner layer of the tectum. This paper was a brief preliminary announcement, but no later paper has appeared. Wright ('84) briefly described and figured the torus longitudinalis in the catfish.

Herrick ('91, p. 172) made brief mention of the torus, but added nothing to our knowledge of it. In a later paper ('92, p. 44) he described tracts of fibres running from the torus to the tectum. These he called the "gelatinous tracts" and believed them to be not nerve-fibres but neuroglia. In common with previous observers he did not consider the torus a nerve centre.

Sala ('95) studied the torus of the young of Tinca vulgaris by the method of Golgi and demonstrated the presence of (1) nerve-cells with characteristic processes, (2) a nerve-net distributed through the whole area of the torus, and (3) ependymal cells. He added greatly to our knowledge of the finer anatomy of the torus, and 
was the first to establish the fact that it is a true nerve centre. Catois (:01) follows Sala in his ideas of the torus.

Johnston (:01, pp. 48, 145) has described in Acipenser certain small fusiform cells "bordering on the cavity near the dorsal decussation" which he designates as "Type C: cells of the torus longitudinalis Halleri," and which he believes are homologous with the cells of the torus described by Sala ('95). I have elsewhere shown (Sargent, :03) that the cells of the "nucleus magnocellularis" of Johnston are homologous with Sala's torus cells. Johnston's "Type C" cells are more properly elements of the tectum opticum. Johnston draws some erroneous generalizations from this incorrect homology, and follows Rabl-Rückhard ('87) in believing the torus to be represented in higher vertebrates by the ependymal thickening.

\section{ONTOGENY.}

The torus longitudinalis is developed from the mesencephalon as a longitudinal thickening of its roof, as was pointed out by Rabl-Rückhard ('87). More exactly each lateral lobe of the torus is differentiated from the mesal edge of the tectum of the corresponding side. The precise mode of development, however, differs somewhat in the different groups of teleosts.

In the primitive Siluridæe and degenerate Amblyopsidæ the median roof of the mesencephalon is very thin, almost membranous. As a result of the rapid development of the cells in the mesal edges of the tectum, they become differentiated from it and partially constricted off from the tectum, by the formation of two longitudinal grooves on either side of the median plane (Figs. 8, 9). The two incipient torus lobes thus formed are widely separated and connected only by the thin median roof (Fig. 8). As they increase in size they become more closely associated, but never unite except at their anterior extremity. This development is earliest at the anterior end of the mesencephalon and continues progressively posterior. The torus longitudinalis is late in development in the Siluridæ and Amblyopsidæ; and in the adult it is of small size and simple structure. In Amiurus nebulosus the torus is not developed as an independent structure until the larva have attained a length of 15 millimetres.

In most of the other groups of teleosts where the two halves of the tectum are closely appressed and the median fissure narrow or closed, the rapidly developing cells of the mesal edges of the tectum crowd into the median plane and there form a longitudinal thickening (Figs. 1,2) which presses down into the median fissure between the halves of the tectum (Figs. 2,4). Usually, as in the sculpin (Fig. 5), 
the median sulcus of the torus is early formed. The growth of the torus pushes apart the halves of the tectum (Fig. 5), and eventually the torus comes to project below the level of the tectum (Fig. 7).

In the Salmonidx this longitudinal thickening develops into an almost cylindrical rod-like structure embedded between the halves of the tectum (Fig. 2). The median fissure of the torus develops in this secondarily, and never becomes accentuated (Figs. 2,3). Later the torus becomes dorsoventrally elongated, but in the Salmonidæ it never projects below the tectum (Fig. 3).

In every case the first differentiation of the torus is at the anterior end of the mesencephalon and progresses caudad with advancing development. A series of transverse sections will therefore show many different stages of development (Figs. 6,7 ). In nearly all teleosts the torus is early to develop and usually has attained its typical form at the time of hatching, but continues to increase in size up to the adult stage.

\section{MORPHOLOGY.}

In the Siluridæ the brain is of relatively simple morphological structure, recalling the generalized ganoid type. The optic lobes are not more highly developed than in Amia. The median portion of the roof of the mesencephalon is thin, almost membranous and without nerve elements. The mesal portion of the tectum opticum of each side becomes differentiated from the rest of the tectum and separated from it by a shallow, longitudinal groove (Fig. 8). The torus lobes so formed never have a thickness greater than the tectum, with which they are intimately associated. Anteriorly the lobes of the torus are almost in contact, being separated only by the narrow fissure. Caudad of the commissura posterior the fissure widens and the lobes diverge, until in the middle portion of the optic lobes they are widely separated (Fig. 8), and connected only by the thin membranous roof of the mesencephalon. This is here made up of ependymal cells and contains no other nerve elements than the fibres of the dorsal decussation of the tectum which pass through it from side to side. Posteriorly the lobes diminish in size and disappear.

In the Cyprinidxe (Notropis) and Pœciliidæ (Fundulus) the torus longitudinalis has a form typical of it in a large number of teleosts. It is a conspicuous and welldefined structure, and attains its greatest development anteriorly, diminishing in size posteriorly (Fig. 23). It hangs freely suspended in the median plane, projecting into the mesencephalon below the level of the tectum. The torus lobes are in close proximity throughout their length, the median fissure between them being much reduced. 
In transverse section each lobe is triangular or pear-shaped, the narrow end being at the place of connection with the tectum.

In the Salmonida the optic lobes are of great size. The tectum opticum has a relatively enormous development both in area and thickness. It extends cephalad of the posterior commissure so as to overlie partly the diencephalon. The mesocole is prolonged cephalad into a recessus (Fig. 20, rec. ms'col.) above the posterior commissure. The torus attains its greatest development anteriorly above the posterior commissure, but extends caudad nearly to the posterior limit of the mesencephalon. The tectum has so great a thickness that the torus does not reach to the level of the roof of the mesocole, but lies entirely between the two halves of the tectum (Figs. $2,3)$. Through the anterior half of the mesencephalon the mesal edges of the two halves of the tectum meet below the torus so that the torus is embedded between them (Fig. 2). As the result of lateral pressure the torus has become laterally flattened so as to appear in transverse section dorsoventrally elongated and the median ventral longitudinal fissure dividing the torus into two lateral halves is almost obliterated. Auerbach ('s8) failed to recognize the torus in this form and asserted that it was absent. In his figures of young trout he has obviously shown the torus, describing it as "in das Tectum eingebettete Zellstrang." That which he designates as the "Anlage des Torus longitudinalis" is the inner and ventral edge of the tectum where it meets the mesal edge of the tectum of the opposite side below the torus (Figs. 1, 2, 3, $\alpha$.).

The Amblyopsidæ is a group of small fishes, mostly cave-inlabiting, having degenerate eyes, some of which are totally blind (compare Eigenmann, '99). The degeneration of the eye is accompanied by profound changes in the central nervous system, more especially the atrophy of the structures of the dorsal portion of the mesencephalon. In Chologaster papilliferus, which has degenerate eyes though still functional, the optic lobes are much smaller than in the closely related Fundulus, which has normal eyes. The tectum is thin and the torus lobes are but little developed. In three other genera which are totally blind, having only vestigeal eyes, the torus is scarcely developed as an independent structure.

The optic centres of the central nervous system of Amblyopsis have recently been studied by Ramsay (:01), who finds the optic lobes and tracts distinctly degenerate. The tectum is only one-half to one-third as thick as in the normal brain. The torus longitudinalis is in a state of arrested development, resembling the condition in other teleosts before hatching, and reminiscent of its form in the Siluridæ. It equals the thin tectum in thickness, but does not extend below it as in most teleosts. It is marked off from the tectum by a shallow fissure, about equal in depth to its median ventral fissure. The dorsal decussation of the tectum passing through it 
transversely occupies the greater part of its thickness (Fig. 8, dec. d.). It contains few or no nerve cells, but consists almost wholly of ependyma.

In the Gasterosteidæ the mesencephalon is short and very compact. The tectum is so thick and the torus and valvula cerebelli so largely developed that the mesocœle is greatly reduced. The valvula is pushed forward into the mesocœle so that the torus is crowded down and partly around the posterior commissure (Fig. 22). As a result the torus is short and much thickened, extending through only half the length of the mesencephalon.

In the Atherinidæ (Menidia) the torus longitudinalis is of large size, its dorsoventral thickness being equal to that of the tectum, below which it projects into the mesocœle. As the torus hangs suspended freely in the mesocœle, there is no lateral pressure on it as in the Salmonidæ, and its form is consequently flatter and the lobes remain distinct (Fig. 10).

In the Sciænidx (Cynoscion) the optic lobes are of great size, and project forward overlying the diencephalon. The torus longitudinalis is of large size and extends through the length of the mesencephalon. It is suspended freely in the spacious mesocœle entirely below the level of the tectum. The two lobes of the torus are wholly distinct. Above the posterior commissure they have a peculiar and characteristic form in transverse section, which may perhaps be likened to that of a comma (Fig. 18). Posteriorly above the valvula they diminish in size and are kidneyshaped in transverse section (Fig. 19). Anteriorly the lobes of the torus extend forward into the lateral anterior horns of the mesocœle (Figs. 15, 16, 17).

In the Labridæ (Tautogolabrus) the lobes of the torus are relatively small; they remain distinct and are separated by a wide median fissure, being connected only by the thin bridge of tissue through which passes the dorsal decussation (Fig. 6). Through the anterior half of the mesencephalon they are suspended below the level of the tectum and have in transverse section a rounded cushion-like form. Posteriorly they taper away and come to lie more completely on the level with and between the halves of the tectal roof (Fig. 7). Above the posterior commissure they fuse with it, taking on a triangular outline in section.

In the Pleuronectidæ the tor'us is small and well developed only through the anterior half of the mesencephalon. The torus lobes are distinct, flattened, and padlike, having a somewhat rounded rectangular outline in transverse section, and hang in the mesocole wholly below the level of the mesencephalic roof (Figs. 11, 12). Posteriorly they are in close contact with the large valvula cerebelli (Fig. 13) and taper away at about the middle of the mesencephalon (Fig. 14). 


\section{THE FINER ANATOMY AND INTERNAL STRUCTURE OF THE TORUS.}

ז. Neuroglia.-The torus longitudinalis has a strong radialframework of ependyimal fibres, of the same general type as those in the tectum from which the torus is derived. These neuroglia elements are most numerous and best developed near the median plane, which always retains to a considerable extent its primitive ependymal structure. The cells are small, conical, or cylindrical in form, and located on the convex boundary of the torus. Their internal ends are prolonged into long fibrils of varying degrees of coarseness which extend dorsad along the radii of the torus lobes towards the point of attachment to the tectum. Those arising from the sulcus between the torus lobes are usually coarser. The ependymal fibres are most conspicuous at the anterior end where they radiate from the recessus above the posterior commissure, dorsad and laterad, through the torus lobes. These ependymal fibres were first seen by Sanders ('7S), who, failing to recognize their true nature, described them as radiating "bundles of fibrillx." Herrick ('91) failed to distinguish these ependymal fibres from the nerve fibres issuing from the torus, and classed both sets of fibres together as the "gelatinous tracts." They were finally correctly described by Sala ('95) from his Golgi impregnations.

2. Torus Cells.-The cells of the torus are almost uniformly of small size. They are generally arranged in parallel rows or series (Figs. 1, 2) between the radiating ependymal fibres. But the definiteness of this arrangement varies greatly in different species. This serial arrangement is most conspicuous where the ependymal fibres are most numerous; in the lateral portions of the torus it is not apparent.

In general the cells are spherical or ovoid in form, but the form is subject to variation. In the brook trout they are spindle-shaped and bipolar, the long axis extending vertically. The nuclei are relatively large, making up the greater portion of the cell-body. The cytoplasm is small in amount, stains lightly, and is not sharply outlined except at the poles of the cell where the neurites pass off. The cells are usually bipolar, but may be unipolar or multipolar. In every case, however, three neurites ultimately arise from the cell, either directly, or indirectly by the division of a chief process.

Sanders ('7S) first described the cells of the torus in Mugil as follows: "The cells which constitute the fornix are inostly of a spherical form, consisting almost entirely of nuclei with only a narrow rim of protoplasm around them. . . Occasionally larger cells occur which present a triangular shape from the greater quantity of protoplasm belonging to them." I have failed to find the second class of cells 
mentioned by Sanders, and he was doubtless in error as to this. His methods did not permit him to distinguish the nerve fibres arising from the cells. He describes the cells as arranged in rows and attached to the radiating neuroglia fibres "sometimes by short branchlets and sometimes they are sessile." Sala ('95) described the "cellules nerveuses speciales" of the torus of Tinca as globular or pear-shaped, 10 to 14 micra in diameter, and having large nuclei.

3. Tractus Toro-tectalis. - In the typical bipolar cells the dorsally directed processes are fine delicate non-medullated fibres. They form fascicles which run dorsad and cephalad to the anterior portion of the torus, where they turn laterally into the tectum, below the dorsal decussation (Figs. 17, 18). Here the fibres of this common bundle separate into two tracts. This division may result from the separation of the two sets of neurites which arose independently from the multipolar cells, or from the spliting of the single process from the cell, into two neurites.

One bundle so formed, which may be called the tractus toro-tectalis (Figs. 2025 , trt. tor. tct.), continues laterally into the tectum, its fascicles or fibres passing between the fascicles of the dorsaldecsatius on. Within the superficial fibre zone of the tectum the fascicles break up diffusely, ending in contact with the endings of the retinal fibres of the optic nerve (Figs. 24, 25).

This fibre-tract from the torus to the tectum was first seen by Bellonci ('81, p. 27) who described it as follows: "Von dieser Schicht" (the superficial layer of the tectum) "gehen sehr feine blasse Faserbündel aus, welche, nachdem sie parallel der Oberfläche des Tectum verlaufen sind, dieselbe in schräger Richtung durchziehen, und sich theils in der darunter befindlichen Region nach dem Tectum zu, theils im Torus longitudinalis allmählich auflösen, und zum Theil dazu beitragen, die obere Commissur des Tectum zu bilden." This tract was also seen by Fusari ('87), who, however, did not trace its origin to the torus. It is the same as that which Herrick ('92, '92 , p. 43) somewhat vaguely described as the "gelatinous tract" and believed to be made up of neuroglia fibres.

Sala ('95) described the course of this tractus toro-tectalis correctly as "un faisceau de fibres nerveuses qui, se continue lateralement dans le toit optique." $\mathrm{He}$ believed, however, that the fibres of this tract passed out from the superficial layer of the tectum into the optic nerve. As Johnston (:01, p. 145) has pointed out, "the fact that they enter the superficial fibre-zone is not sufficient evidence that they go, to the optic nerve." Recent investigations on the origin of the optic nerve fibres (Ramón y Cajal, '96, p. 104, Fig. 46) show the impossibility of this.

4. Tractus Toro-cerebellaris. - The other set of fibres already alluded to, which pass from the torus laterad into the tectum, does not traverse the dorsal decussation, 
but continues laterad with it (Fig. 25, trt. tor. cbl.), and then, bending ventrad from the junction of the tectum and torus, follows for a distance parallel with the fibres of the posterior commissure. This fibre tract is followed with great difficulty because of its proximity to other fibre bundles, with which it is easily confused. I believe it, however, to be identical with a fibre tract which has been described by several writers as running from the anterior portion of the tectum to the cerebellum. The cells of origin of this tract have never been determined. Johnston (:01) has described such a tract in Acipenser as the tractus tecto-cerebellaris. It "courses obliquely around the lateral border of the tectum" and enters the cerebellum. Moreover, I have in other groups (selachians and birds) traced completely, and elsewhere described (Sargent, :01,$: 04$ ), the homologue of this tract. Sala showed in his figures the incompletely impregnated fibres which form this tract, running a short distance into the tectum, but he did not distinguish them from the fibres of the toro-tectal tract.

5. Tractus Toro-fibræ Reissneris. - The chief centrifugal neurite, or axon, of the torus cell is a little coarser than the neurites previously described. The axons of the torus cells may, in general, be said to have a cephalo-ventral direction. In young larval stages of many teleosts the axons of the ventral and median cells of the torus enter the ventricle directly from the ventral surface of the torus, and particularly in the median sulcus dividing the two lobes. But in older and adult stages the axons are aggregated into more definite tracts which enter the ventricle by one of two paths.

The axons from cells in the ventral, lateral, and posterior portion of the torus lobes form the tractus toro-fibræ Reissneris posterior which runs forward through the torus lobes to a position above the posterior commissure where it curves ventrad and caudad and, joining the corresponding tract from the opposite side, enters the recessus of the mesocœle above the posterior commissure (Figs. 24, 25, trt. fbr. Reis. p.). This tract usually enters the recessus in several fasciculi of varying sizes formed by the fusion of the axons, and in which the separate axons cannot be distinguished.

The axons coming from the cells of the torus which are located in the dorsal, median, and anterior portions of the torus lobes form the tractus toro-fibræ Reissneris anterior (Figs. 20, 24, 25, trt. fbr. Reis. a.). These tracts run cephalad through the dorsal portion of the torus lobes on either side the median plane and anterior to the posterior commissure; they converge in the median plane and enter the ventricle in compact fasciculi in which the constituent axons can be recognized only in very early stages of development. Caudad of the posterior commissure all these separate branches unite to form the fibre of Reissner (Fig. 24, fbr. Reis.) which runs posterior into the canalis centralis and through the posterior portion of its course gives off 
branches which enter the ventral portion of the cord and probably run to the musculature (see Sargent, :04).

Sala describes and shows in his figures a third process coming off from the torus cells, of greater diameter than the others. He found it took an irregular course and terminated freely in a slight enlargement. It is usually directed towards the median plane. He makes no attempt to explain the relations or functions of this process. After studying his figures and description it is quite evident to me, from the manner of its ending, and failure to establish connections with other nerve elements, that this is an incompletely impregnated fibre. I think there can be little doubt that this is the partly impregnated axon of the cell, which runs caudad and cephalad to emerge into the ventricle, either in the ventral fissure of the torus or anterior to the posterior commissure. Unfortunately all his figures are of transverse sections, and apparently from the posterior part of the torus. In such sections it would be very difficult to determine the true course and relations of these axons even if they were completely. impregnated.

\section{FUNCTION.}

We have seen that the cells of the torus longitudinalis are in connection by their different processes with the endings of the optic nerve, and probably by another process, with the cerebellum. They send their axons into the ventricle to form by their union the so-called fibre of Reissner. Elsewhere I have shown (Sargent, :01 :04) that this constitutes a nerve path between the optic centres and the musculature, and acts as a short circuit for the transmission of motor impulses arising from optic stimuli. The torus, then, is the nerve-centre for the receipt of those impulses coming in over the optic nerves, which call for quick reflexes.

\section{HOMOLOGY.}

It follows, then, that the cells of the torus which give rise to Reissner's fibre constitute a nidulus of cells of common function, and are homologous with the cells of the same function which occur in the anterior, dorsal portion of the optic lobes of other vertebrates, and have been variously designated as the "Dachkern" and "nucleus magnocellularis," and which I have fully described in another paper as the cells of the optic reflex apparatus (Sargent, :04).

The cells of the torus of teleosts are small, while the homologous cells in other groups of vertebrates are conspicuous for their great size. Why there is this marked 
difference is not easy to explain, but I would at least suggest that there is no constant relation between the size of the cell and the length of its axon, as has been supposed. Rabl-Rückhard ('94, p. 703) described in reptiles a peculiar growth of ependyma ("Ependymwucherung"), under the posterior commissure, horseshoe-shaped in transverse section. It had previously been noticed by Herrick ('93, p. 97) as follows: "The posterior commissure is underlaid by a remarkable thickening of the epithelium that can be traced far ventrad." Rabl-Rückhard ('87) had found this occurring in other groups of vertebrates, amphibia, reptiles, and birds, and believed it to represent a rudiment of the torus longitudinalis. This erroneous interpretation has been accepted by Gage ('93), Johnston (:01,:03), and others, and has led to considerable confusion. Aside from the fact that the torus is the homologue of the "Dachkern," this homology fails to hold, as I have elsewhere shown (Sargent, :03 ${ }^{a}$ ), for (1) this ependymal thickening lies morphologically cephalad of the commissure posterior (Figs. 15, 24, cras. e'end.), while the torus is caudad of it; (2) the ependymal thickening occurs in a modified form in teleosts. In a later paper I shall treat of the interesting relations of this ependymal thickening more fully and present a theory as to its function.

\section{PHYLOGENY.}

The nidulus of cells which gives rise to Reissner's fibre is one of the most archaic elements of the vertebrate brain, occurring in the Cyclostomes and in a rudimentary way in Amphioxus. The tolus longitudinalis as an independent structure, however, has its beginnings phylogenetically in the ganoids. With the increasing complexity of the adult ganoid brain, and the development of the dorsal decussation of the tectum, the cells of the "nucleus magnocellularis" are crowded downward so as to form two longitudinal ridges on either side of the median plane extending backward for a short distance from the posterior commissure. These ridges are scarcely apparent in Amia, but in adult Lepidosteus and Acipenser they are quite pronounced.

The Sihuridæ naturally supply the necessary connection, in the phylogeny of the torus, between the primitive condition in ganoids and the highly differentiated state in the higher teleosts. The torus of Amiurus is intermediate both in its form (Fig. S) and in the large size of its cells. In Amblyopsis the torus as a result of arrested development has reverted to the primitive ganoid condition (Fig. 9). In the Sahmonidx and related forms the torus is still of small size and its cells relatively large (Fig. 3). The climax of teleostean aberrancy is reached in the Sciænidæ, where the torus becomes of enormous size (Fig. 1S) and its cells very small. 


\section{CONCLUSION.}

The torus longitudinalis is, then, an archaic portion of the mesencephalic roof formed in the teleosts from the mesal and primitive portion of the tectum opticum, constricted off, and, as it were, left behind in the enormous development of the tectum of this aberrant group. In its early development in the ganoids it is the result of purely mechanical causes, the rapid growth in the adult of the "nucleus magnocellularis" producing a downward bending of the mesencephalic roof on either side of the median plane. Mechanical causes are still plainly operative in the Siluridæ, but in other teleosts the torus appears, at an early stage of ontogenetic development, as the result of phylogenetic causes. Though the torus longitudinalis is a structure which first attains an independent and definite form in the teleosts and in that group only, its essential elements are perhaps the most archaic of the mesencephalic roof.

\section{BIBLIOGRAPHY.}

\section{Auerbach, L.}

'88. Die Lobi optici der Teleostier und die Vierhügel der höher organisirten Gehirne. Morph. Jahrb., Bd. 14, pp. 373-393, Taf. 16.

Bellonci, G.

'80. Ricerche comparative sulla struttura dei centri nervosi dei Vertebrati. Atti R. Accad. Lincei Roma, Mem. sci. fis. math. nat., anno 277, ser. $3^{\mathrm{a}}$, tom. 5, pp. 157-182, 1 tav.

Bellonci, G.

'81. Ueber den Ursprung des Nervus opticus und den feineren Bau des Tectum opticum der Knochenfische. Zeit. wiss. Zool., Bd. 35, pp. 23-29, Taf. 1-2.

Bellonci, G.

'82. Intorno al tetto ottico dei Teleostei. Zool. Anz., Bd. 5, pp. 480-483.

Burckhardt, R.

'94. Der Bauplan des Wirbelthiergehirns. Morph. Arb., Bd. 4, Heft. 2, pp. 131-150, Taf. 8.

Carus, C. G.

'14. Versuch einer Darstellung des Nervensystems insbesondere des Gehirns nach ihrer Bedeutung, Entwickelung und Vollendung im thierischen Organismus. Leipzig, $4^{\circ}, x+322$ pp., 6 Taf.

Catois, E.

:01. Recherches sur l'histologie et l'anatomie de l'encephale chcz les poissons. Lille, $172 \mathrm{pp}$.

Eigenmann, C. H.

'99. The Eyes of the Blind Vertebrates of North America. I. The Eyes of the Amblyopsidæ. Arch. Entwickelungsmech., Bd. 8, pp. 545-617, pls. 11-15.

Fritsch, G.

'78. Untersuchungen über den feineren Bau des Fischgehirns. Berlin, $4^{\circ}, 94+x v$ pp., 13 Taf. 
Fusari, R.

's7. Untersuchungen über dic feinere Anatomie des Gehirnes der Teleostier. Intern. Monatsehr. f. Anat. u. Physiol., Bd. 4, pp. 275-300, Taf. 9-11.

Gage, S. P.

'93. The Brain of Dicmyetylus viricleseens, from Larval to Adult Lifc and Comparisons with the Brain of Amia and Petronyzon. The Wilder Quarter-Century Book, Ithaca, N. Y., pp. 259-313, 8 pls.

Gottsche, C. M.

'35. Verglcichende Anatomie des Gehirns der Grätenfisehe. Areh. f. Anat. u. Physiol., Jahrg. 1835, pp. 244-294, 433-4S6, Tab. 4-6.

Haller, $B$.

'98. Vom Bau des Wirbelthiergehirns. I Theil. Salmo und Seyllium. Morph. Jahrb., Bd. 26, pp. 345641, Taf. $12-22$.

Herrick, C. L.

'91. Topography and Histology of the Brain of Certain Ganoid Fishes. Jour. Comp. Neurol.; vol. I, pp. 149-182, pls. 10-13.

Herrick, C. L.

'92. Additional Notes on the Telcost Brain. Anat. Anz., Bd. 7, No. 13 u. 14, pp. 422-431.

Herrick, C. L.

'92a. Studies on the Brain of Some American Freshwater Fishes. Jour. Comp. Neurol.; vol. 2, pp. 20-72, pls. 4-12.

Herrick, C. L.

'93. Topography and Histology of the Brain of Certain Reptiles. Jour. Comp. Neurol., vol. 3, pp. 77-140, pls. $15-20$.

Johnston, J. B.

:01. The Brain of Aeipenser. Zool. Jahrb., Abt. Anat., Bd. 15, pp. 59-260, Taf. 2-13.

Johnston, J. B.

:03. Das Gehirn und die Cranialnerven der Anamnier. Ergebn. Anat. u. Entwiekgs., Bd. 11, pp. 973-1112.

Mayser, P.

'S2. Verglcichend-anatomische Studien über das Gehirn der Knochenfische mit besonderer Berücksiehtigung der Cyprinoiden. Zcit. wiss. Zool., Bd. 36, pp. 259-364, Taf. 14-23.

Mirto, D.

'95. Sulla fina anatomia del tctto ottieo dei Pesei teleostei e sull' origine reale del nervo ottieo. Riv. Sperim. Freniatr., tom. 21, pp. 136-148, 2 tav.

Neumeyer, $\mathrm{L}$.

'95. Histologische Untersuchungen übcr den fcineren Bau des Centralnervensystems von Esox Lucius, mit Berücksichtigung verglciehend-anatomischer und physiologiseher Verhältnisse. Arch. mikr. Anat., Bd. 44, pp. 345-365, Taf. 23.

Pedaschenko, D.

:01. Zur Entwieklung des Mittclhirns der Knoehenfisehc. Areh. mikr. Anat., Bd. 59, pp. 295-314, Taf. $15-17$.

Rabl-Ruickhard, $\mathrm{H}$.

'82. Zur Deutung und Entwiekclung des Gehirn der Knoehenfisehe. Areh. f. Anat. u. Phys., Jahrg. 1882, Anat. Abt., pp. 111-138, Taf. 6-7.

Rabl-Ruickhard, H.

'S4. Das Gehirn der Knochenfisehe. Biol. Centralbl., Bd. 4, pp. 499-510, 528-541.

Rabl-Rtickhard, H.

'S7. Zur onto- und phylogenetischen Entwickelung des Torus longitudinalis im Mittelhirn der Knoehenfisehe. Anat. Anz., Bd. 2, No. 17, pp. 549-551. 
Rabl-Rückhard, $\mathrm{H}$.

'94. Einiges über das Gehirn der Riesenschlange. Zeit. wiss. Zool., Bd. 58, pp. 694-717, Taf. 41.

Ramon y Cajal, s.

'96. Beitrag zum Studium der Medulla oblongata des Kleinhirns und des Ursprungs des Gehirnnerven. Leipzig, $8^{\circ}$, vii +139 pp., 40 Abbildungen.

Ramsey, E. E.

:01. The Optic Lobes and Optic Tracts of Amblyopsis spelæus De Kay. Jour. Comp. Neurol., vol. 11, pp. 40-47, pls. 3-4.

Sala, L.

'95. Sur la fine structure du "Torus longitudinalis" dans le cerveau des Téléostéens. Arch. Ital. Biol., tom. 24 , pp. $78-88,5$ figs.

Sanders, A.

'78. Contributions to the Anatomy of the Central Nervous System in Vertebrate Animals. Phil. Trans. Roy. Soc. London, vol. 169, pp. 735-776, pls. 58-65.

Sargent, P. E.

:00. Reissner's Fibre in the Canalis Centralis of Vertebrates. Anat. Anz., Bd. 17, No. 2-3, pp. 33-44, Taf. 1-3, 1 Fig.

Sargent, P. E.

$: 00^{a}$. Reissner's Fibre in the Canalis centralis of Vertebrates. Science, n. ser., vol. 11, pp. 180.

Sargent, P. E.

:01. The Development and Function of Reissner's Fibre and its Cellular Connections. Proc. Amer. Acad Arts and Sci., vol. 36 , pp. 445-452, pls. 1-2, 1 fig.

Sargent, P. E.

:01a. An Apparatus in the Central Nervous System of Vertebrates for the Transmissionof Motor Reflexes Arising from Optical Stimuli. Biol. Bull., vol. 2, pp. 340-342.

Sargent P. E.

:03. The Structure, Development, and Function of the Torus longitudinalis of the Teleost Brain. Scicnce n. ser., vol. 17 , pp. 253-254.

Sargent, P. E.

:03a. The Ependymal Grooves in the Roof of the Diencephalon of Vertebrates. (Amer. Morph. Soc.) Science, n. ser., vol. 17, p. 487.

Sargent, P. E.

:04. The Optic Refex Apparatus of Vertebrates for Short-circuit Transmission of Motor Reflexes over Reissner's Fibre: Its Morphology, Ontogeny, Phylogeny, and Function. Bull. Mus. Comp. Zoöl. Harvard Coll. (In press.)

Stieda, L.

'68. Studien über das centrale Nervensystem der Knochenfische. Zeit. wiss. Zool., Bd. 18, pp. 1-70, Taf. $1-2$.

Van Gehuchten, A.

'94. Contributions a l'étude du système nerveux des Téléostéens. La Cellule, tom. 10, pp. 255-295, pls. 1-3. Wright, R. R.

'84. On the Nervous System and Sense Organs of Amiurus. Proc. Can. Inst., Toronto, vol. 2, no. 3, pp. 352386. 



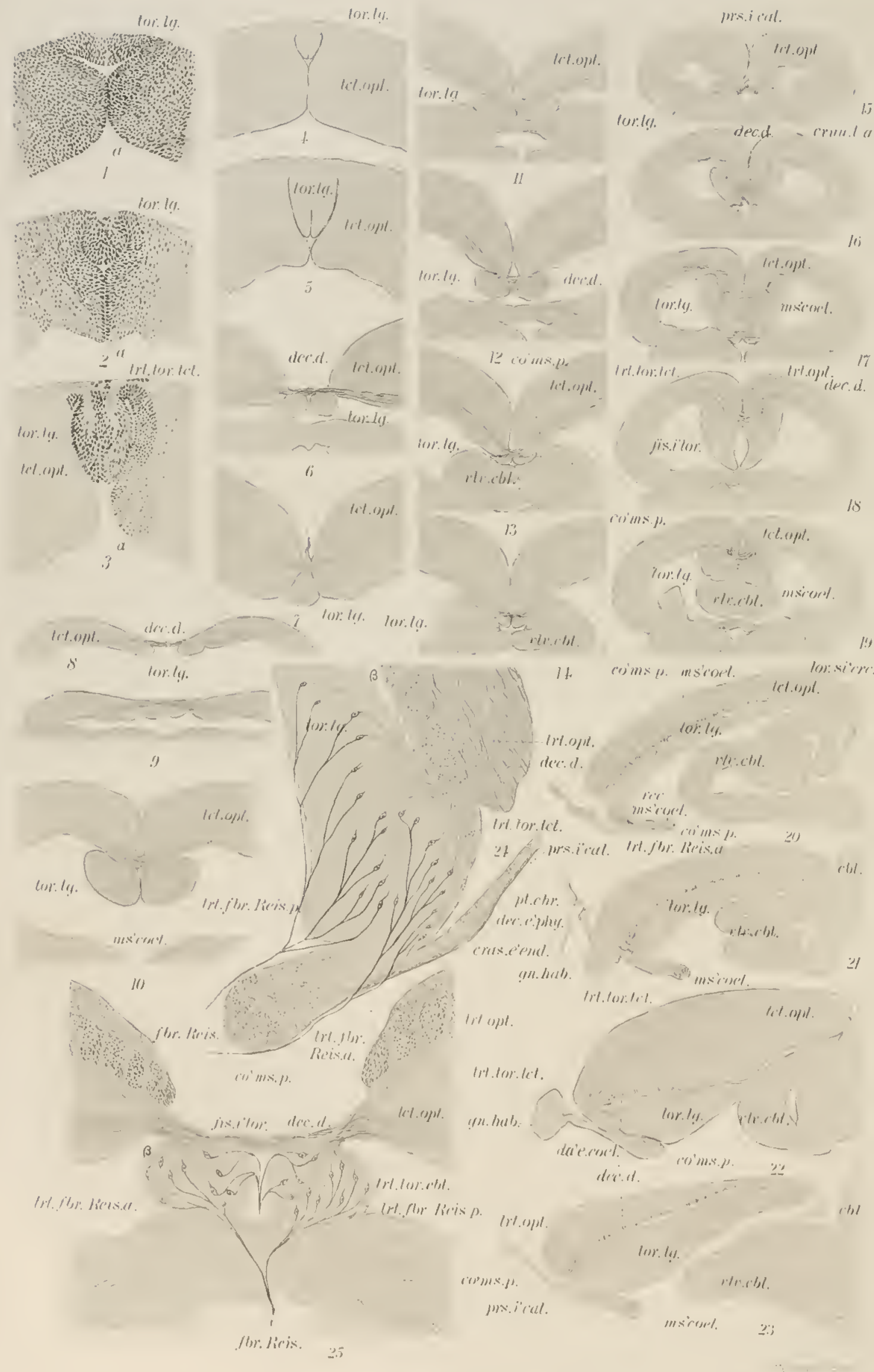




\section{EXPLANATION OF THE PLATE.}

\section{ABBREVIATIONS.}

\begin{tabular}{|c|c|c|c|}
\hline$a x$. & Axon. & prs. ïcal. & Pars intercalatus (Schaltstück). \\
\hline$c b l$. & rebellum. & rcc. $m s^{\prime} c a l$. & d anterior \\
\hline co'ms. p. & Commissura posterior. & & terior commissure. \\
\hline cras. e'cnd. & Ependymal thickening. & tct. opt. & Tectum opticum. \\
\hline crnu.l.a. & Anterior lateral horn of the mesocole. & tor. $\lg$ & nalis. \\
\hline da'c cal. & Diaenle. & tor. sïcrc. & Torus semicireularis. \\
\hline dec. $d$. & $\begin{array}{l}\text { Dorsal decussation of the tectum } \\
\text { opticum. }\end{array}$ & $\begin{array}{l}\text { trt. fbr. Reis. } a \text {. } \\
\text { trt. fbr. Reis. } p \text {. }\end{array}$ & $\begin{array}{l}\text { Tra } \\
\text { Tra }\end{array}$ \\
\hline dcc. c'phy. & Epiphysial decussation. & trt. opt. & us op \\
\hline icis. & Reissuer's fibre. & trt. tor. cbl. & erebellaris. \\
\hline fis. & $\begin{array}{l}\text { Median ventral fissure between the lat- } \\
\text { eral lobes of the torus Iongitudi- }\end{array}$ & $\begin{array}{l}\text { trt. tor. tct. } \\
v l v . c b l\end{array}$ & talis. \\
\hline gn. hab. & $\begin{array}{l}\text { Ganglion habenula. } \\
\text { Mesocnele. }\end{array}$ & $a$ & $\begin{array}{l}\text { Mesal edge of tectum optieum (con- } \\
\text { sidered by Auerbach the "Anlage" of } \\
\text { the torus). }\end{array}$ \\
\hline pl. chr. & Plexus choroideus. & $\beta$. & Mesencephalic groove above the torus. \\
\hline
\end{tabular}

\section{PLATE XXIX.}

In all figures the dorsal edge of the section is uppermost. All figures are from transverse sections, except Figures 20 to 24 inclusive which are from parasagittal sections. In Figures 20 to 23 inclusive the anterior end is at the left. In Figure 24 the anterior end is at the right. All the figures were outlined with the camera lucida.

Fig. 1. Salvelinus fontinalis, at time of hatching. Section through the anterior portion of the mesencephalon caudad of the posterior commissure, showing the median longitudinal fold from which the torus develops. The mediaur sulcus of the torus is indicated by the absence of cells in that region. $\times 87$.

Fig. 2. Salvehinus fontinalis, one day older than that shown in Figure 1. The section was taken a little anterior to that for the preceding figure. $\times S 7$.

Fig. 3. Salvelinus foutinalis, $4 \mathrm{~cm}$. long. Section through the same region as that shown in Figure $2 . \quad \times 40$.

Fig. 4. Acanthocottus ancus, newly hatched. Section through the anterior part of the meseneephalon showing the torus longitudinalis in an early stage of development.

Fig. 5. Acanthocottus aneus, a little older than that seen in Figure 4. Section through the same region as in the preceding figure. $\times 87$.

Fig. 6. Tautogolabrus adspersus, young specinen $6 \mathrm{~cm}$. long. The torus presents tle adult condition. $\times 15$.

Fig. 7. Tautogolabrus adspersus. Section from the same specimen as that from which Figure 6 was taken, but from a position considerably posterior to that of Figure 6. The torus is seen in an early stage of development. $\times 15$.

Fig. 8. Amiurus nebulosus, young specimen. Section through the anterior portion of the mesenceplalon, caudad of the posterior commissure. $\times 30$.

Fig. 9. Amblyopsis spelæus, adult. Section through the same region as in the preceding figure. $\times 30$.

Fig. 10. Menidia notata, young specimen. $\times 20$.

Figs. 11-14. Pseudopleuronectes americanus, adult. Four sections from the median portion of the mesencephalon. Figure 11 represents the most posterior of the four scetions, and the others follow in sequence. $\times 15$.

Figs. 15-19. Cynoscion regalis, adult. Five sections of the mesencephalon; that shown in Figure 15 is the most anterior, and the others follow in sequence. $\times 10$. 
Fig. 20. Salvelinus fontinalis, adult. Parasagittal section through the mesencephalon, cutting the right lobe of the torus longitudinalis. The anterior end is toward the left. $\times 10$.

Fig. 21. Morone americana, adult. Section as in Figure 20. $\times 10$.

Fig. 22. Gasterosteus bispinosus, adult. Section as in Figure $20 . \times 30$.

Fig. 23. Notropis cornutus, adult. Section as in Figure $20 . \times 30$.

Fig. 24. Tautogolabrus adspersus, adult. Parasagittal section through the anterior portion of the roof of the mesencephalon and left lobe of the torus longitudinalis. The anterior end is toward the right. The details of this and the next figure are filled in diagrammatically. $\times 50$.

Fig. 25. Tautogolabrus adspersus, adult. Transverse section through the anterior portion of the mesencephalon; torus longitudinalis, and posterior commissure. $\times 50$. 
XXI.

IMPLANTATION OF THE OVUM IN SPERMOPHILUS TRIDECEMLINEATUS MITCH.

(PLATES XXX-XXXI.)

Thomas G. Lee. 
. 


\section{INTRODUCTION.}

Desirous of making a study of the so-called inversion of the germinal layers in rodents, and wishing for purposes of comparison to use a family of the order other than those usually studied, I determined several years ago to work upon the suborder Sciuromorphi, for the reason that it had been almost entirely neglected. Thereupon I began collecting Spermophilus as the most easily obtained representative. In the first collections there were many stages lacking; but I soon discovered that Spermophilus was not in accord with the descriptions of inversion then published, and that it had developmental features peculiar to itself, which were far from being easily understood owing to want of material. For several seasons I collected specimens in large numbers, believing that in this way I could secure a series with few stages lacking. This has proved to be the case, and I now have material from which I am working out in detail the complete development of this animal. In a preliminary notice (Lee, :02), read before the American Morphological Society, Dec. 29, 1901, I briefly outlined the subject-matter of this paper.

I. Material.-The small striped gopher, Spermophilus tridecemlineatus Mitch., is found abundantly throughout Minnesota living in burrows in pasture-lands and grain-ficlds. While a timid animal, it has a fatal curiosity which is of the utmost service to the collector, for, after retreating, it soon reappears at the mouth of its burrow to be caught in the snare or shot with the rifle. At the imitation of its shrill whistle the gopher will often stop when running to its burrow and stand erect to discover the source of the whistle; or, if in its burrow, its reappearance may be hastened by this means. In the breeding season the whistle acts as a challenge to the males, and one can often bring them within a few yards. In this way needless shots are avoided. The gopher has the habit of sitting at the margin of its burrow so that it can tumble in at the least alarm. It has astonishing powers of vitality, for even when mortally wounded it often reaches its burrow. One should endeavor to shoot them through the head or back, as otherwise a large percentage is lost. It breeds in the spring, the males making their appearance as soon as they cease hibernating, usually between April 10 and 25. The period of gestation, as near as I can determine, is about one month. I have not been able to breed it in captivity, consequently I do not know the exact duration of this period. At any given time the majority of 
females are at about the same stage of gestation. While the later stages of pregnancy are quite easily obtained, it has taken much labor in the field at the beginning of the breeding season for a number of years to secure a complete series of stages. The preplacental stages have been by far the most difficult to secure, as there are only a few days in each season in which they can be obtained. During this period the majority of the animals killed are males, the females for the most part remaining under ground. Again a day or so of cloudy or rainy weather at this particular time may almost ruin the chances of securing early stages for that year. However, the fact that they carry a large number of young is a compensating feature.

The following tables may prove of interest in showing the number and distribution of embryos in the uterus. They are compiled from notes based on collections made at the height of the season of 1900, an unusually favorable year for this purpose.

TABLE I.

NUMBER OF EMBRYOS PER ANIMAL.

\begin{tabular}{|c|c|c|}
\hline $\begin{array}{c}\text { Total Number } \\
\text { of Embryos } \\
\text { in an } \\
\text { Animal. }\end{array}$ & $\begin{array}{c}\text { Number of } \\
\text { Animals. }\end{array}$ & $\begin{array}{c}\text { Total } \\
\text { Number of } \\
\text { Embryos } \\
\text { Collected. }\end{array}$ \\
\hline 5 & 1 & 5 \\
6 & 7 & 42 \\
7 & 26 & 182 \\
8 & 36 & 288 \\
9 & 31 & 279 \\
10 & 14 & 140 \\
11 & 11 & 121 \\
12 & 2 & 24 \\
13 & 1 & 13 \\
& 129 & 1094 \\
\hline
\end{tabular}

TABLE II.

DISTRIBUTION OF EMBRYOS IN RIGHT AND LEFT HORNS OF UTERUS.

\begin{tabular}{|c|c|c|c|}
\hline $\begin{array}{c}\text { Number of } \\
\text { Embryos } \\
\text { in a } \\
\text { Uterine } \\
\text { Horn. }\end{array}$ & $\begin{array}{c}\text { Number of } \\
\text { Animals. }\end{array}$ & Left Horn. & Right Horn. \\
\hline 0 & 2 & 1 & 1 \\
1 & 10 & 7 & 3 \\
2 & 24 & 14 & 10 \\
3 & 43 & 18 & 25 \\
4 & 79 & 33 & 46 \\
5 & 53 & 26 & 27 \\
6 & 22 & 14 & 8 \\
7 & 13 & 10 & 3 \\
8 & 5 & 2 & 3 \\
9 & 7 & 4 & 3 \\
\hline
\end{tabular}

It will be seen from these tables that the 129 pregnant females averaged nearly 8.5 embryos with a total variability of from 5 to 13 . As regards the distribution in the two horns of the uterus, the right horns had 537 embryos and the left 557 , averaging over 4 for each horn, the range of variability being the same, from 0 to 9 for each side.

This record is based on one week's collecting during the middle of May, all the embryos being fairly well advanced. Only 4 non-pregnant females were taken during this week, showing that most of the females are pregnant at this time. It is also interesting to note that in 14 cases some one embryo was abortive, and, acting as a plug, effectually prevented the delivery of the remaining embryos in the ovarial 
portion of that horm and would-unquestionably have caused the death of the mother. The mortality of old and young from a variety of causes must be enormous, as the number of adults does not materially increase from year to year.

2. Methods.-Most of the material was obtained by shooting with a small rifle. The body was opened at once, and, cutting through the vagina and mesometrium, the whole uterus, oviducts, and ovaries were removed and transferred to a jar of fixing-solution. A careful record of each indivichual was kept. Upon returning to the laboratory the day's collection was again examined and clealt with according to the technique required in each case. Zenker's fluid penetrates easily, causes little shrinkage, gives good results with a variety of stains, and is extremely satisfactory in fixing the specimens. Picro-sulphuric acid, Hermann's fluid, and other fluids were also used with goor results.

The exact age of any embryo not being ascertainable, all the uteri far enough advanced to show swellings visible to the eye were carefully separated and classified according to the size of the uterine segments. In early stages the segments are practically spherical, later they become oval, and then oblong. These were calipered and arranged in stages with a variation of a half to one millimetre in diameter to each stage. It is interesting to note that segments from different years and various uteri when grouped in this way were found on sectioning to be very similar in their development; consequently little difficulty has been experienced in tracing the transition from stage to stage after the gaps had been filled by repeated collections. Some forty stages were thus made by measurement, and a large number of series of each stage are now in the reference collection.

The segments were sketched, dehydrated, carried into cedar oil, then into xylolparaffine, then into soft paraffine in the oven, then into hard paraffine, and finally embedded. While in the soft paraffine the dish containing the segment was connecter with an exhaust-pump and the air carefully removed from all cavities in the segment; this is very essential in getting a good infiltration. The blocks were sectioned in various planes; the ribbon was placed on an abumenized slide, a few drops of distilled water added, flattened on a hot table, dried, stained on the slide (unless previously stained in toto), and mounted in xylol-balsam. The principal stains used were hæmatoxylin and eosin, or iron hxmatoxylin on the slide; and very good results were also obtained by staining in toto with paracarnme followed by counter-staining on the slide with picric acid addeck to the xylol used in clearing the sections.

The order of the segments in each horn of a given utcrus was preserved as far as possible; the ovarial segment, tube, and ovary were put in one series, the next segment numbered 2, etc. In this way much of interest was noted in the rariation 
in development between the ovarial and vaginal segments of a given uterine horn containing, for instance, five to six pregnancies.

In the very early stages of development the entire uterus had to be sectioned, the series examined under a microscope, and the portion of ribbon containing the embryo mounted; more of ten the whole ribbon was mounted, examined, and only the important slide retained.

\section{PREPLACENTAL HISTORY OF SPERMOPHILUS TRIDECEMLINEATUS.}

I. Period Prior to Fixation.-A. Uterus.-Spermophilus tridecemlineatus has a two-horned uterus, each horn being suspended from the dorsal wall of the abdominal cavity by a fold of peritoneum, which closely adheres to the outer muscular layer, except dorsally where the two sides of the fold come together, forming the broad ligament or mesometrium. This mesometrium contains the rich vascular and nervous supply of the uterus supported by a loose connective tissue. Of the two muscular tunics the external longitudinal one is prolonged into the mesometrium; the inner layer, circular and slightly thicker, is separated from the outer one by a small amount of vascular connective tissue; both coats are relatively slight and become gireatly thinned during pregnancy. The inner tunic envelops the connective-tissue stroma of the mucosa, which forms a well-marked layer surrounding the uterine lumen. The connective-tissue cells vary from round to spindle-shaped or branched, have large round nuclei, and show in the non-pregnant animal a dense inner and looser outer zone. The stroma is highly vascular, numerous blood and lymph capillaries extending in all directions and in close relation with the basement membrane and glands.

The lumen of the uterus has a characteristic shape and is peculiar in some respects (PI. XXX, Fig. 11. Compare Burckhard, :01, Taf. XXVI, Fig. 1, mouse; v. Spee, : 01, p. 133, Fig. 1, guinea-pig). It consists of a long rather narrow T-shaped slit extending dorsoventrally, in which it is necessary to distinguish three portions. The first of these is the dorsal or mesometrial third and is flattened and extends horizontally to the principal transverse axis of the lumen, forming the top of a capital $\mathrm{T}$. This constitutes the placental chamber (Scheibenhöhle, Fleischmann, '93; Placental region, Minot, '89).

At the antimesometrial or ventral end of the lumen is the second part, consisting of an irregular cavity or pocket, which may frequently extend at an angle to the long axis and whose floor at intervals shows a more or less well-marked groove (PI. XXX, Figs. 5, 11, 12). This cavity, which receives the ovum soon after its entrance 
into the uterus, corresponds to the fundus of the human uterus. It is to some portion of the walls of this chamber that the blastocyst becomes attached. This will be referred to as the fixation-chamber (Nebenkammer, Fleischmann; Obplacental region, Minot).

The remainder of the lumen connecting these two chambers, the third part, will be called the intermediate portion (Schlussspalt, Fleischmann; Periplacental region, Minot).

The uterine epithelium forms an unbroken layer of simple columnar cells, for the most part ciliated, which rests on a well-marked basement membrane. The glands are tubular with ducts opening upon the free surface; the convoluted tubes extend radially through the connective-tissue layer almost to the circular musclecoat, and the distal portions are twisted into rather close clumps or knots. The cellular lining of the ducts is continuous with the uterine epithelium, the cells becoming cubical in the gland. The lumen of the gland-tube shows in section a coagulum of secretion which stains with eosin. In the non-pregnant uterus the glands are quite uniformly distributed; but with the beginning of pregnancy the ducts become dilated and prominent in the placental chamber and intermediate portion, and almost disappear in the region of the fixation-chamber, being obliterated by the rapidly multiplying cells of the connective tissue. Cell-division does not occur in the epithelium of the uterine lumen and gland-ducts; but mitoses may be noticed in the cells at the distal ends of the glands. The ovum shortly after leaving the oviduct sinks into the fixation-chamber. From this region its path towards the vagina is a tortuous one, due to the many lateral projections of the mucous membrane. Figure 15 (Pl. XXX) shows a free ovum in a longitudinal horizontal section of the fixationchamber. D'Erchia (:01, Tav. 1, Fig. 2) has shown a similar condition in the uterus of the mouse.

B. Blastocyst and Zona Pellucida.-The ovum in most cases enters the uterine cavity still surrounded by the zona pellucida, which may disappear very soon or persist until after the fixation of the ovum to the uterine wall (Pl. XXXI, Figs. 2431). Before disintegration it is, in section, a well-marked band, rather thick, homogeneous and brittle, and is closely adherent to the trophoblast layer. As it disintegrates the outer portion softens and disappears first, the inner portion persisting for a time as a thin rather horny memlorane (Pl. XXX, Figs. 17, 18, 23). Sobotta (:01) describes the zona in the mouse as beconing lost while the ovum is still in the oviduct. Spee ('\$3) describes and figures the cells at the fixation-pole in the ovum of the guinea-pig as extending protoplasmic processes through the zona and suggests that these processes may aid in the attachment of the ovum to the uterine wall. Spee 
(:01) further describes a porous condition in the zona and calls attention to the destructive action of many fixing fluids, which no doubt explains many discrepancies in the various accounts heretofore given regarding the zona. All the specimens showing zona in the accompanying plates were fixed by having been kept one day in Zenker's fluid. At the stage immediately preceding fixation is found a blastocyst with an outer layer of cells, the trophoblast of Hubrecht. These ectodermal cells are irregularly rounded or cubical in shape; their nuclei are large and rounded and show numerous mitoses. Figures 12 and $13(\mathrm{Pl}$. XXX) represent two sections from the same blastocyst showing the trophoblast layer and within it the "inner cell-mass," whose cells are beginning to be differentiated into formative ectoderm and entoderm. In Figure 5 there is shown another blastocyst, slightly older, but still prior to fixation, which has the formative ectoderm on the right closely applied to the inner surface of the trophoblast, while the entodermal cells are beginning to arrange themselves on the opposite wall. In Figures 16, 17, 21, 22, 25, 30, and 32 interesting details in the gradual differentiation of the entodermal layer may be noticed. The formative ectoderm in the younger stages (Pl. XXX, Figs. 17, 18, 21, 22; Pl. XXXI, Fig. 25) consists of a rounded clump of cells closely applied to each other and to the inner side of the trophoblast layer, whose cells, it will be noticed, tend to become flattened and here constitute what is known as Rauber's layer, or Deckschicht. In the older stages (Pl. XXXI, Fig. 32) the formative ectoderm has by cell-multiplication grown in all directions peripherally and has been brought to the free surface by the loss of the cells of Rauber's layer. At the junction of the trophoblast with the borders of the germinal area the differentiation is very distinct, both in the shape and structure of the cells and their reaction to stains. In this respect there is a close resemblance to similar stages in the development of tupaja as figured by Hubrecht ('95). Compare, for example, Figures 21 and 32 in this paper with Hubrecht's Figures 54 and 68 respectively. Very many interesting and important details in the differentiation of the germ-layers of Sphermophilus must be left for consideration at another time, as many of the sections which illustrate these points are not correspondingly good in regard to the problem of fixation, and so are not figured here.

2. Beginning of the Process of Fixation.-A. Utenus.-Profound physiological changes are inaugurated in the uterus with the impregnation of the female. The uterine horns, which were small and pale in the resting condition, now become enlarged and lengthened. The blood-vessels are congested, and there is a new growth of capillaries in the connective tissue of the mucosa. The connective-tissue cells themselves rapidly divide and increase in volume, becoming rounded or oval with thickened borders; they become closely massed together, giving a denser zone next the epithelium, 
and these changes gradually extend into the outer layer of connective tissue. The intercellular lymph-spaces and budding capillaries extend close up to the basement membrane. The growth of the mucosa is most marked in the lateral and antimesometrial portions of the uterine tube. In the placental chamber and the intermediate portion the gland-ducts become dilated; while in the lower and ventral portions surrounding the fixation-chamber both glands and ducts are lost to a large extent, and the connective-tissue stroma of the mucosa is increased in volume by the rapid cellproliferation.

What determines the point of attachment of the ovum to the uterine wall? Is it accidental or predetermined? These questions cannot yet be fully answered. In the guinea-pig Spee ('83) has figured protoplasmic processes extending from the trophoblast cells at the fixation-pole (Gegenpol, Spee), which may attach themselves to the uterine epithelium. Born, shortly before his death, suggested the theory that, during the time the ovum remains in the oviduct, the corpus luteum acts as a gland whose internal secretion is carried by the blood-vessels to the uterine mucosa and causes the cell-growth and prepares for the attachment of the ovum. The experiments by Fraenkel und Cohn (:02) in this direction are suggestive as far as they have been carried.

In Spermophilus, I believe, the power of attachment resides very largely in the blastocyst. It will be remembered that the path through the fixation-chamber along the length of the uterine horn is a tortuous one with many lateral projections on either side (Pl. XXX, Fig. 15), and at intervals grooves or depressions in the floor (Figs. $5,11,12$, etc.). The blastocyst is probably aided by a peristaltic movement in making its way along the uterus. It is most certainly undergoing profound structural differentiation during this journey; and it seems quite reasonable that the fixationmass may be acquiring chemotactic properties which when sufficiently developed will cause the blastocyst to come into contact with the epithelial wall at once. Any part of the wall of the fixation-chamber may be the focal point, the sides as well as floor (compare Figs. 4, 6, and 27 with Figs. 7, 8, and 30). In several cases where the fixation-chamber was narrow the blastocyst made a double attachment, setting up the same series of changes in the epithelium of both sides at the points of contact.

$B$. Blastocyst. - It is the trophoblast or extragerminal ectoderm that is of most interest at this time. This outer cell layer of the blastocyst, which at first envelops the inner cell-mass but is independent of it, undergoes many changes in the various mammals which have been studied. In the present paper one more is added to the list.

In Figures 5, 12, $13(\mathrm{Pl} . \mathrm{XXX})$ the blastocyst is shown in its free condition 
the trophoblast is complete and structurally similar at all points. There must now be distinguished in the blastocyst what may be called the placental or embryonal pole, the point where the inner cell-mass is attached; and on the opposite side what will be referred to as the fixation-pole (Gegenpol, Spee). This is not necessarily diametrically opposite to the embryonal pole, but is approximately so. The first change noted at the fixation-pole is a thickening of the cell-layer, the loss of cell-boundaries, and an increase and enlargement of the nuclei until a syncytium, or giant cell-mass, the fixation-mass, has been produced which projects from the trophoblast layer at this point. Compare Figures 10,14,16, and 29, where the fixation-mass is seen in close proximity to the uterine epithelium, but has not yet penetrated it. It will be noted that the cells of the trophoblast on either side of the fixation-mass are not altered, but continue to divide rapidly and extend as flattened cells, causing an increase in the size of the blastocyst. Where the fixation-mass comes into contact with the uterine epithelium there is a breaking down of the epithelium, a dissolving or absorption process. Very early stages (Pl. XXX, Fig. 16; Pl. XXXI, Fig. 29) show a depression caused by the destruction of the free end of the epithelial cells. One is reminded frequently of the formation of Howship's lacunæ in developing bone by the osteoclasts. This process continues and the fixation-mass bores or eats its way, as it were, through the epithelium until it comes into contact with the subepithelial connective tissue (Pl. XXX, Figs. 20, 21; Pl. XXXI, Figs. 27, 28). In a slightly older stage (Pl. XXX, Fig. 19) the entire fixation-mass has passed through the epithelium. The fixation-mass now becomes convex on the surface next to the connective tissue, while the edges become much thinned and begin to extend between the epithelium and connective tissue (Pl. XXX, Fig. 23; Pl. XXXI, Figs. 30, 31).

3. Completion of the Process of Fixation.-A. Uterus.-Both external and internal changes are to be noted in the uterus. The uterine tube is increasing in length and diameter, and now swellings begin to show externally which indicate the points of attachment of the blastocysts. These swellings are most marked on the ventral side of the uterine horns, the mesometrial portion not being affected until later. Internally there is a further increase in the capillaries, many of them are dilated and in closer relation with the fixation-mass (Pl. XXX, Fig. 19; Pl. XXXI, Fig. 34), while thickenings are observed in many of the endothelial cells. The connectivetissue cells are increasing in number and in volume; their edges, slightly thickened and closely packed together, present an epithelial-like appearance. The fixationchamber is increasing in size to accommodate the enlarging blastocyst. This is accomplished at the expense of the intermediate portion, whose lower margins are gradually incorporated into the upper part of the fixation-chamber. The dilated ends of the 
ducts opening upon the intermediate portion become flattened, increasing the size of the chamber still further.

B. Blastocyst.-The blastocyst is rapidly increasing in size because of the multiplication of cells in the trophoblast and it changes from an almost spherical to a more and more oval shape. The outer border does not yet reach the walls of the fixationchamber. Rauber's layer may be still complete or in process of disintegration. The germinal area is becoming slightly oval and rapidly increases in size. The unequal growth of the trophoblast walls causes the germinal area to shift gradually from its place nearly opposite the fixation-pole, so that sections through the centre of the fixation-mass may not cut the germinal area at all (Pl. XXXI, Figs. 32-34). The fixation-mass increases greatly in volume; its nuclei are larger and more numerous. The mass still presents a convex surface to the vascular connective tissue, while its thin edges have penetrated in all directions between the epithelium and the connective tissue. Later from the convex surface of this mass are developed root-like processes which extend in all directions into the connective-tissue stroma (Pl. XXXI, Figs. 36-38). These roots branch and subdivide again and again. The adjacent connective-tissue cells become flattened and later form sheaths around the larger roots. Accompanying these changes there is a hollowing of the inner surface of the fixation-mass until a distinct cup is formed. The thin walls of this cup contain the nuclei, which do not extend into the roots (Pl. XXX, Fig. 6; Pl. XXXI, Fig. 36). The protoplasm of the cup and roots now becomes distinctly fibrillated, resembling a mass of delicate fibrin threads (Pl. XXXI, Figs. 36-38). From this time the fixation-mass begins to degenerate.

- 4. Separation of the Fixation-mass.-A. Utwerus.-The external swellings of the uterus are now very pronounced; internally the fixation-chamber shows a large cavity with smooth walls, except where it is deeply pitted by the cup of the fixationmass just described. From the margins of this cup the walls of the chamber are lined with a continuous layer of epithelium whose cells have undergone no change. The enlargement of the chamber has involved nearly all of the intermediate portion of the uterine lumen, leaving only a narrow strip between the now enormously dilated fixation-chamber and the still slightly altered placental chamber. During these changes the enlarging blastocyst comes into contact with the epithelium lining the fixation-chamber, resulting in histolysis of the cells of the epithelium. By this means the blastocyst is now brought into contact with the connective-tissue walls of what will be called the decidual cavity. The remnant of the intermediate portion next to the placental chamber becomes dilated and merged into the walls of the decidual cavity, the placental chamber becomes expanded, the trophoblast cells surrounding 
the germinal area come into contact with the hitherto unaltered epithelium of the placental chamber, and the beginnings of the true placenta are inaugurated. The many interesting details connected with the placenta will be described and illustrated at another time.

B. Blastocyst.-The blastocyst is now a large, oval vesicle whose walls are coming into closer relation with the epithelium of the fixation-chamber. The trophoblast cells in many places are flattened into very large and extremely thin scales (Pl. XXXI, Figs. 32, 33). The deeply cupped fixation-mass now undergoes marked changes. The root-like processes gradually atrophy and disappear, the cup becomes more and more shallow, the nuclei decrease in number, and finally, with the loss of the processes, the fixation-mass separates from the connective tissue; and once more for a short time the blastocyst is free in the uterine cavity. The attachment at the embryonal pole to the borders of the placental chamber soon follows.

5. Comparison of the Implantation in Spermophilus and that in other Mammals.-It is desirable first of all to consider the fixation of Spermophilus in comparison with that of other rodents. This order is a primitive one, very widely distributed, and contains a larger number of families, genera, and species than any other order of mammals. The ease with which certain species may be kept in captivity, the frequency with which they breed, and the large number in a brood, have resulted in a few species becoming the subjects of a long and extensive series of investigations upon the stages preceding and during placentation. It will be impossible, here, to give any extensive review of the literature, and I shall confine myself to calling attention to certain particular points and to some of the more important monographs. Sclater states that the order Rodentia contains 21 families, 159 genera, and 1400 species. The development of scarcely a dozen species, representing four families, has been studied in any great detail. Much more work must be done on this order before we can apply embryological facts in any other than a tentative manner to the problems of classification. It will be convenient, in our discussion, to use the old grouping of the rodents into Sciuromorphi, Myomorphi, Hystricomorphi, and Lagomorphi.

The early development of the Myomorphi has been carefully studied in several species of mouse and rat by Kupffer ('82), Selenka ('83), Duval ('89-'91), Cristiani ('92), Robinson ('92), Sobotta ('95, :01), Jenkinson (:00), D'Erchia (:01), Burckhard (:01), and many other's.

In the mouse and rat Selenka ('83), Duval ('89-'91), Sobotta (:01), and Burckhard (:01) have most carefully described and figured the first relationship of the blastocyst to the uterine epithelium. The young blastocyst sinks into the ventral portion of the slit-like uterine lumen, but does not reach the floor by the end of the fourth 
day after impregnation. During the fifth day there is a dilation of the ventral portion of the lumen accompanied with a flattening of the lining epithelium. During the sixth day the epithelium of the decidual chamber disintegrates; that in the extreme ventral portion persisting for a time as a clump of cells (Epithelreste). In the region of the embryonal pole the uterine lumen closes by the union of its epithelium and the fusion of the connective-tissue walls above the region of the "Träger" or ectoplacentarconus. The remainder of the epithelium surrounding the blastocyst disappears, and the blastocyst is contained in a decidual chamber derived from the ventral portion of the uterine lumen. The trophoblast comes into close contact with the connective-tissue stroma. Selenka and Duval figure enlarged cells of the trophoblast as extending out and attaching the blastocyst to the uterine epithelium. Burckhard does not show this. Sobotta's figures in his preliminary paper are somewhat schematic, but his Figure 12 suggests this. His forthcoming monograph will probably determine this point.

The Lagomorphi are represented only by the rabbit, the subject of scores of important investigations. Here we may particularize only those of Van Beneden ('80), Kölliker ('82), Minot ('89), Masius ('89), and Duval ('89-'91).

In this species the uterine lumen shows six longitudinal folds. Minot ('89) terms the mesometrial pair the placental folds or lobes; the lateral pair, one on either side the periplacental folds; and the antimesometrial pair, the obplacental folds. The ovum, entering the uterus about the end of the third day, rapidly increases in size, and during a period of about four days it remains free and unattached. In the uterine cavity the blastocyst increases in size from about 0.9 millimetre on entrance to 4.5 or 5 millimetres by 3.5 to 4 millimetres at the end of the seventh day. Fixation takes place during the eighth day by the attachment of a horseshoe-shaped area of the trophoblast, external to the germinal area, to the two placental folds of the uterus. The germinal area is opposite the space between these folds.

This space and the placental folds correspond to the cavity and borders of what I have called the placental chamber in Spermophilus, in which the true placenta is developed much as in the rabbit. The periplacental and obplacental folds of the rabbit correspond closely to the intermediate portion in Spermophilus, and the space between the obplacental folds in the rabbit to the fixation-chamber of Spermophilus. In the rabbit the uterine epithelium becomes lost from the surface of the peri- and obplacental folds, and the blastocyst finds itself in a connective-tissue decidual chamber occupying the whole uterine lumen. The distal portions of the glands persist in the obplacental portion and give rise to a regenerating epithelium. Our knowledge of the Hystricomorphi is also limited to one species, the guinea- 
pig. This has been extensively studied, but we owe to Bischoff ('52, '70), Reichert ('62), Hensen ('76, '83), Selenka ('84), Duval ('89-'91), and particularly to Graf Spee ('83, '96, :01) most of our knowledge of its early development. Bischoff first noted the passage of the ovum either through the uterine epithelium or into the mouth of a gland which after closing up shut off the blastocyst from the uterine lumen. Selenka also describes and figures the blastocyst as entering a gland-mouth. Hensen, followed by v. Spee ('83), showed that the trophoblast cells at the anti-embryonal pole (Gegenpol) gave off protoplasmic processes which perforated the zona and possibly aided in the attachment of the ovum to the uterine epithelium. V. Spee in his preliminary paper ('96) and in the full paper (:01) gives a detailed description and many figures of the process of implantation.

At the time of entrance into the uterus, the ovum of the guinea-pig is extremely small, having a diameter of 0.1 millimetre less 0.08 millimetre, the thickness of the zona, and is in a late morula or beginning blastula stage. Surrounded by the zona, it passes into the ventral portion of the slit-like uterine lumen during the seventh day. It is only a matter of two to eight hours before the ovum has passed through the uterine epithelium and become encapsulated in the subepithelial connective tissue. The trophoblast cells of the blastocyst where it comes into contact with the uterine epithelium cause the destruction of the epithelial cells and the whole blastocyst passes through into the connective tissue. The adjacent connective-tissue cells become softened and fused into a finely fibrillated granular mass with free nuclei, the symplasma of v. Spee. This symplasma extends irregularly into the connective-tissue stroma and later becomes vacuolated and thin, leaving a lymph-space-or extra-uterine decidual chamber in which the blastocyst will complete its development.

The symplasma of the guinea-pig has certain resemblances to the fixation-mass of Spermophilus in its general syncytial character, its fibrillæ, and the extension of its processes into the adjacent stroma (compare Figs. 37, 38, Pl. XXXI, of this paper with v. Spee's, :01, Figs. 13a, 13b, Taf. X). However, the fixation-mass of Spermophilus differs in showing no vacuolation and in being derived from the trophoblast instead of from the connective tissue.

Regarding the early development of the Sciuromophi little work has been done except by Fleischmann ('92, '93), who has described certain stages in the development of Sciurus vulgaris and the badjing, a Javanese squirrel, and has given an account of the placentation of Spermophilus citillus. This is the only paper known to me on the development of Spermophilus. I can in the main confirm Fleischmann's results in the later stages, but he did not have young enough material at his disposal to give any description of the preplacental conditions. 
From the above it will be seen that Spermophilus differs from the other rodents and, further, from any other mammal yet described in the temporary fixation-mass. It agrees with the rabbit in using the whole uterine cavity as the true decidual chamber, in having a eorresponding site for placental attachment, and in the loss of Rauber's layer from the germinal area. In the Myomorphi only the ventral portion of the uterine cavity is used; and in the Hystricomorphi the decidual chamber is outside the uterine cavity altogether. Spermophilus resembles the guinea-pig in many details of the perforation of the epithelium; but, while this process is permanent in the guinea-pig, it is only temporary in Spermophilus. Spermophilus agrees with the rabbit and differs from the mouse and guinea-pig in the absence of the so-called inversion of the germinal layers.

Regarding the other discoidal placental mammals, Insectivora, Cheiroptera, Primates, a number of very important contributions to our knowledge of the preplaeental or early stages of development in each of these groups have been publislicd during the last few years. In the Insectivora the investigations of Heape ('83-'86), Strahl ('89), and Vernhout ('94) on Talpa, and Hubrecht ('89, '90, '95, '96) on Erinaeeus, Sorex, Tupaja, and Galeopithecus, show that in this group there are also pronounced variations in the size of the ovum, the site and manner of implantation, and the beginning of the placental formation. As in the rodents, so here, the trophoblast plays the active, the uterine epithelium the passive rôle. The Cheiroptera, as represented by several European species studied by Van Beneden ('S8), Duval ('95-'96), Frommel ('88), and Nolf ('96), and in Pteropus, studied by Goehre ('92), show in like manner generic differences in the details of implantation. Hubrecht ('96) has given us further important details along these lines for Tarsius, and Selenka ('92, '99, :00) and Strahl ('99) for apes.

Selenka has shown in some of the apes that implantation takes place by means of the attachment of the trophoblast to the ventral wall of the uterus, and that later the trophoblast on the opposite side of the blastocyst develops a secondary placental attachment to the dorsal wall.

As is to be expected, there is not perfect harmony in all the details of the results obtained, nor in the hypotheses based on these results. And when we consider liow few genera and fewer families have been studied in these orders, one sces the great need of further investigations in the early stages of development extended over a wide range of genera in each of these great groups.

These investigations have yielded important results, and have given a better and clearer understanding of mammalian development in general. They have done away with many old and faulty theories and given a basis for theories probably more 
accurate concerning the details of that very important but still undescribed stage, the preplacental period of the human embryo.

In the youngest human embryo yet described Peters ('99) has shown that the blastocyst passes through the uterine epithelium into the connective-tissue stroma; this is unquestionably due to the perforatory action of the trophoblast cells, as has been demonstrated for Cavia and is now shown in Spermophilus. It may not be unreasonable to suppose that in many tubal pregnancies the trophoblast by some precocious development or by reason of delay in the passage of the ovum through the oviduct reaches a condition of maturity whereby it attaches itself to and perforates the epithelium of the tube in a manner similar to that just described.

\section{BIBLIOGRAPHY.}

Bischoff, T. L. W.

'52. Entwicklungsgeschichte des Meerschweinchens. Giessen, $8^{\circ}, 56$ pp., 8 Tab.

Bischoff, T. L. W.

'70. Neue Beobachtungen zur Entwicklungsgeschichte des Meerschweinchens. Abl. math.-phys. Cl. bayer. Akad. Wiss. (München), Bd. 10, pp. 115-166, Taf. 7-10.

Burckhard, G.

:01. Die Implantation des Eies der Maus in die Uterusschleimhaut und die Umbildung derselben zur Decidua. Arch. mikr. Anat., Bd. 57, pp. 528-569, Taf. 26-28.

Cristiani, H.

'92. L'inversion des feuillets blastodermiques chez le Rat albinos. Arch. Physiol. norm. et pathol., année 24 , pp. 1-11, pls. 1-2.

D'Erchia, F.

:01. Sull' annidazione dell' uovo e sullo sviluppo e struttura della placenta allantoidea e vitellina nel Topo bianco. Ann. Ostetr. Ginec. Milano, anno 23, pp. 173-214, tav. 1-2.

Duval, M.

'89-'91. La placenta des Rongeurs. Jour. Anat. et Physiol., année 25, pp. 309-342, pls. 14-15, pp. 573-627, pls. 18-19; année 26, pp. 1-4S, pls. 1-2, pp. 273-344, 521-592; année 27, pp. 24-73, pls. 1-4, pp. $344-395$, pls. $15-18$, pp. $515-612$, pls. $23-25$.

Duval, M.

'95-'96. Études sur l'embryologie des Chéiroptères. Jour. Anat. et Physiol., année 31, pp. 93-160, pl. 3, pp. 427-474, pls. 11-12; année 32, pp. 105-164, pp. 420-454, pls. 10-11.

Fleischmann, A.

'92. Der einheitliche Plan der Placentarbildung bei Nagethieren. Sitz. k. Akad. Wiss. Berlin, Jahrg. 1892, pp. 445-457, Taf. 3.

Fleischmann, A.

'93. Die Morphologie der Placenta bei Nagern und Raubtieren. Embryologische Untersuchungen, Wiesbaden, Heft 3, pp. 153-213, Taf. 9-13.

Fraenkel, L., und Cohn, F.

:02. Experimentelle Untersuchungen über den Einfluss des Corpus luteum auf die Insertion des Eies. Anat. Anz., Bd. 20, No. 12, pp. 294-300.

Frommel, $\mathbf{R}$.

'88. Ueber die Entwickelung der Placenta von Myotus murinus. Wicsbaden, 4, 41 pp., 12 Taf. 
Goehre, R.

'92. Dottersack und Placenta von Ptcropus edulis, L. Studien über Entwiekelungsgeschichte der Ticre (E. Selenka), IIeft 5, pp. 218-233, Taf. 42.

Heape, W.

'S3-'S6. The Development of the Mole (Talpa europea). Quart. Jour. Mier. Sei., vol. 23, no. 91, pp. 412452 , pls. 28-31; vol. 26 , no. 102, pp. 157-174, pl. 11; vol. 27, no. 106, pp. 123-163, pls. 11-13.

Hensen, V.

'76. Beobachtumgen über die Befruchtung und Entwieklung des Kaninehens und Meerschweinchens. Zeit. Anat. u. Entwick., Bd. 1, pp. 213-273, 353-423, Taf. 8-12.

Hensen, $\mathrm{V}$.

'S3. Ein frühes Stadium des im Uterus des Meerselwweinchens festgewachsenen Eics. Arch. f. Anat. u. Physiol., Jahrg. 1883, Anat. Abt., pp. 61-70, Taf. 3.

Hubrecht, A. A. W.

'89. Studies in Mammalian Embryology. I. The Placentation of Erinaceus Europaus, with Remarks on the Phylogeny of the Placenta. Quart. Jour. Micr. Sci., vol. 30, no. 119, pp. 283-404, pls.15-27.

Hubrecht, A. A. W.

'90. Studies in Mammalian Embryology. II. The Development of the Germinal Layers of Sorex vulgaris. Quart. Jour. Micr. Sei., vol. 31, no. 124, pp. 499-562, pls. 36-42.

Hubrecht, A. A. W.

'95. Die Phylogenese des Amnions und die Bedeutung des Trophoblastes. Verh. Akad. Wetensch. Amsterdam, scc. 2, dl. 4, no. 5, 66 pp., 4 taf.

Hubrecht, A. A. W.

'96. Die Keimblase von Tarsius. Festschrift für Gegenbaur, Bd. 2, pp. 147-178, 1 Taf.

Jenkinson, J. W.

:00. A Reinvestigation of the Early Stages of the Development of the Mouse. Quart. Jour. Mier. Sci., vol. 43, no. 169 , pp. 61-81, pls. 5-6.

Kölliker, A. $\nabla$.

'S2. Die Entwicklung der Keimblätter des Kaninchens. Festschrift 300jährigen Bestehens der Universität Würzburg, 51 pp., 6 Taf., Leipzig, 1882.

Kupffer, C.

'82. Das Ei von Arvicola arvalis und die vermeintliche Umkehr der Keimblätter an demselben. Sitzb. math.-phys. Classe Akad. Wiss. München, Bd. 13, pp. 621-637, 1 Taf.

Lee, T. G.

:02. On the Early Devclopment of Spermophilus tridecemlineatus, a New Type of Mammalian Placentation. Science, n. ser., vol. 15 , no. 379 , p. 525 .

Masius, J.

'89. De la genèse du placenta chez le lapin. Arch. de Biol., tom. 9, pp. 83-121, pls. 5-8.

Minot, C. S.

'89. Uterus and Embryo: I. Rabbit; II. Man. Jour. Morph., vol. 2, no. 3, pp. 341-462, pls. 26-29.

Nolf, P.

'96. Étude des modifications de la muqueuse utérine pendant la gestation elıez le Murin (Vespertilio murinus). Arch. de Biol., tom. 14, pp. 561-693, pls. 26-32.

Peters, H.

'99. Ueber die Einbettung des menschliehen Eies und das früheste bisher bekannte mensehliche Placentations-stadium. Leipzig u. Wien, $\mathrm{S}^{\circ}, 143$ pp., 14 Taf.

Reichert, C. B.

'62. Beiträge zur Entwickelungsgeschichte des Mecrschweinchens. Phys. Abh. Akacl. Wiss. Merlin, Jahrg. 1861, pl. 97-216, S Taf. 
Robinson, A.

'92. Observations upon the Development of the Segmentation Cavity, the Archenteron, the Germinal Layers, and the Amnion in Mammals. Quart. Jour. Micr. Sci., vol. 33, no. 131, pp. 369-455, pls. $23-27$.

Selenka, E.

'83. Keimblätter und Primitivorgane der Maus. Studien über Entwickelungsgeschichte der Thiere, Heft 1, pp. 2-23, Taf. 1-4.

Selenka, E.

'84. Die Blätterumkehrung im Ei der Nagethicre. Studicn über Entwickelungsgeschichte der Thiere, Heft 3, pp. 63-99, Taf. 11-16.

Selenka, E.

'92. Affen Ostindiens. Studien über Entwickelungsgeschichte der Tiere, Heft 5, pp. 195-208, Taf. 35-40. Selenka, E.

'99. Entwickelung des Gibbon (Hylobates und Siamanga). Studien über Entwickelungsgeschichte der Tiere, Heft 7, pp. 163-172.

Selenka, E.

:00. Entwickelung des Gibbon (Hylobates und Siamanga), Fortsctzung. Studien über Entwickelungsgeschichte der Ticre, Hcft 8, pp. 173-208, Taf. 11.

Sobotta, J.

'95. Die Befruchtung und Furchung des Eies der Maus. Arch. mikr. Anat., Bd. 45, pp. 15-93, Taf. 2-6.

Sobotta, J.

.01 Die erste Entwickelung des Mäuseeies nach der Furchung. Anat. Anz., Bd. 19, Frgänzungsheft, pp. 4-11.

Spee, Graf F. $\nabla$.

'83. Beitrag zur Entwickelungsgeschichte der früheren Stadien des Meerschweinchens bis zur Vollendung der Keimblase. Arch. f. Anat. u. Physiol., Jahrg. 1883, Anat. Abt., pp. 44-60, Taf. 2.

Spee, Graf F. v.

'96. Vorgänge bei der Implantation des Meerschweincheneies in die Uteruswand. Anat. Anz., Bd. 12, Ergänzungsheft, pp. 131-136.

Spee, Graf F. v.

:01. Die Implantation des Meerschweincheneies in die Uteruswand. Zeit. Morph. Anthrop., Bd. 3, pp. 130-182, Taf. 5-11.

Strabl. H.

'89. Untersuchungen über den Bau der Placenta. I. Die Anlagerung des Eies an die Uteruswand. Arch. f. Anat. u. Physiol., Jahrg. 1889, Anat. Abt., pp. 213-230, Taf. 14.

Strahl, H.

'99. Der Uterus gravidus von Galago agisymbanus. Abh. Senckenb. naturf. Gesell., Bd. 26, Heft. 1, pp. 153-199, Taf. 18-25.

Van Beneden, E.

'80. Recherches sur l'embryologie des mammifères. La formation des feuillets chez le Lapin. Arch. de Biol., tom. 1, pp. 137-224, pls. 4-6.

Van Beneden, E.

-88. De la fixation du blastocyste à la muqueuse uterine chez le Murin (Vespertilio murinus). Bull. Acad. Sci., Bruxclles, annéc 58, sér. 3, tom. 15, pp. 17-27, 1 pl.

Van der Stricht, 0 .

'99. La fixation de l'œuf de chauve-souris à l'intérieur de l'utérus (V. noctula). Anat. Anz., Bd. 16, Ergänzungsheft, pp. 76-88.

Vernhout, J. H.

'94. Ueber die Placenta des Maulwurfs (Talpa curopæa L.). Anat. Hefte, Abt. 1, Arb. aus Anat. Inst., Bd. 5, pp. 1-49, Taf. 1-8. 

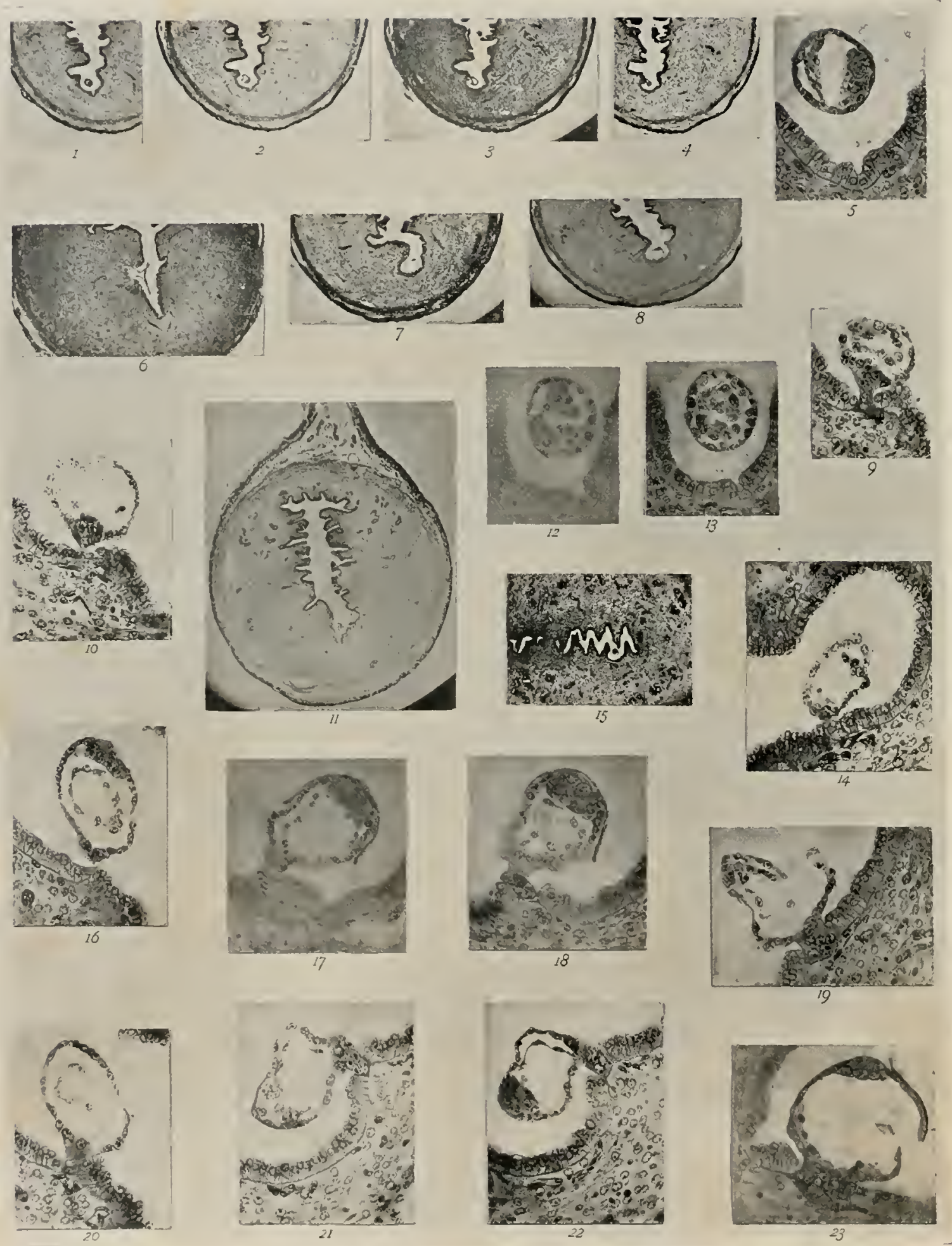


\section{EXPLANATION OF PLATES XXX-XXXI.}

All the figures are photomicrographs from sections of the uterus of Spermophilus tridccemlineatus and were made by the writer with a Zeiss photomicrographic stand, optical bench, and equipment, a Thompson $90^{\circ}$ dircetcurrent, self-feeding arc lamp and a $11 \times 14$ enlarging and reducing camera; the whole was supported by a swinging table to get rid of vibrations. For the lower magnification a Zeiss micro-planar and for the higher a Zciss 4-mnı. apochromatic objective without eyepicce were used. The sections were stained in toto with paracarmine and counterstained with picric acid. A color screen consisting of a cell containing Zettnow's fluid was used, as were several varieties of Seed's plates. Figures 1-8, 11, and 15 arc magnified about 16 diameters; all others about 185 diameters.

\section{PLATE XXX.}

Figs. 1 to 4 . Four consecutive transverse sections of the uterus showing the ventral half of its lumen. Beginning dilation is shown in the fixation-chanber in which there is a young blastocyst just beenming attachedThe few glands in the region of the fixation-chamber and the clilated gland-clucts in the intermediate portion are well shown. Compare also Figures 6 to 8 , and 11.

Fig. 5. Ventral portion of the fixation-ehamber shortly before the attachment of the blastocyst. The ventral groove can be seen and the blastocyst shows distinctly the trophoblast, the inncr cell-inass, and the entoderm.

Fig. 6. Ventral portion of the uterine lumen with a lateral implantation at the completion of the fixation process. Note the roots of the fixation-mass extending into the stroma and the deep cupping of its inner wall. Owing to the plane of section the enlargement of the fixation-chamber and extension of the blastocyst walls are not shown.

Figs. 7, 8. Sections from two uteri showing the more usual implantation in the floor of the fixation-chamber.

Figs. 9, 10. Consecutive sections showing the fixation-mass, which in Figure 9 is just perforating the epithclium.

Fig. 11, Transverse section across the whole utcrus at the beginning of pregnancy, showing the characteristic form of the uterus. The size and relations of the placental chamber, the intermediate portion, and the fixation-chamber are well shown.

Figs. 12, 13. Consecutive sections of the fixation-cliamber, containing a younger blastocyst than that in Figure 5 . Fig. 14. Section of a blastocyst at the beginning of attachment.

Fig. 15. Longitudinal horizontal section of the uterus at the level of the fixation-chamber and containing a free blastocyst. Note the lateral folds of mucous membrane projecting into the lumen.

Fig. 16. Section of a blastocyst slightly older than that shown in Figure 14. Note the cupping of the epithelium at the point of contact with the fixation-mass.

Figs. 17, 18. Two sections from a blastocyst at a stage slightly older than that shown in Figure 16. The blastocyst, which shows perforation, has attached to it the disintegrating zona.

Fig. 19. The fixation-mass nearly through the epithelium. Note the intimate relations of the capillaries to the mass.

Fig. 20. Fixation-mass just perforating epithelium. Compare with Figures 9 and 18.

Figs. 21, 22. Consecutive sections through the blastocyst in the perforation stagc. Figure 21 shows clearly the differentiation of the trophoblast into Rauber's layer and at the opposite pole the fixation-mass.

Fig. 23. A blastocyst at a stage older than that shown in Figure 19. Note the incrcase in size of blastocyst and the beginning of the extension of the fixation-mass under the epithelium. A bit of the disintcgrating zona is still attached to the blastocyst.

\section{PLATE XXXI.}

Figs. 24 to 28 . Consecutive sections through a blastocyst which shows the fixation-mass breaking through the zona to perforate the epithelium.

Fig. 29. A blastocyst at the beginning of the perforation stage similar to the one shown in Figure 16.

Figs. 30, 31. Consecutive sections of the blastocyst at a stage similar to the one shown in Figure 23. Note the burrowing of the fixation-mass, and the zona attached to one side of the blastocyst. 


\section{IMPLANTATION OF OVUM IN SPERMOPHILUS TRIDECEMLINEATUS MITCH.}

Figs. 32 to 34 . Threc scctions at intervals out of some twenty-five into which the oval blastocyst was cut. The germinal area is no longer opposite the fixation-mass; Rauber's layer has disappeared from the surface; the fixation-mass is larger and about to develop roots. In Figure 33 the beginning of the cupping of the inner side of the fixation-mass is seen. Note also that the adjacent stroma has become more vascular.

Fig. 35. Section through the cup of the fixation-mass just before its separation. Note the thinned wall of the fixation-mass, the diminished nuclei, and the disintegrating roots. The epithelium of the fixation-chamber adjacent to the fixation-mass is beginning to undergo retrograde changes from contact with the blasto. cyst.

Figs. 36 to 33. Three sections at intervals from a series of thirty-six sections through a blastocyst at the completion of the fixation process. All show details of the branching root-like processes of the fixation mass extending into the stroma. Figure 36 shows the roots and the cupping of the fixation-mass. Figurc 37 , taken near the bottom of the cup, shows roots extending in all directions. Figure 38, still farther on in the series, shows sections of the roots free in the stroma, whose cells in some places are seen to form sheaths around the roots. 

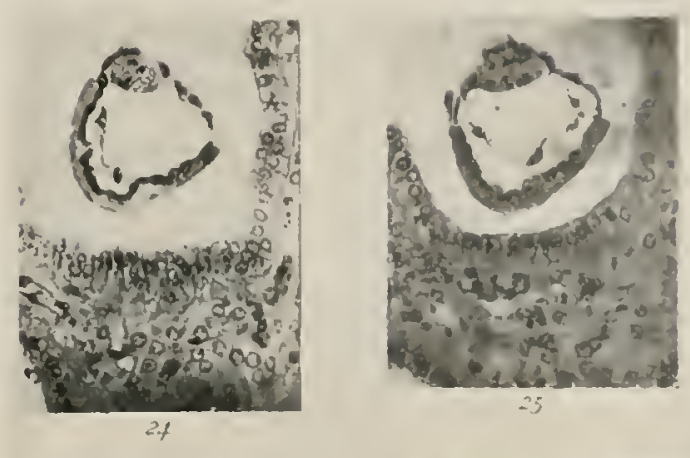

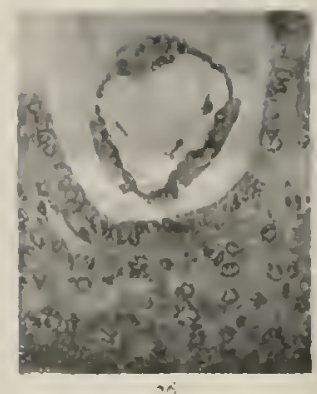

20
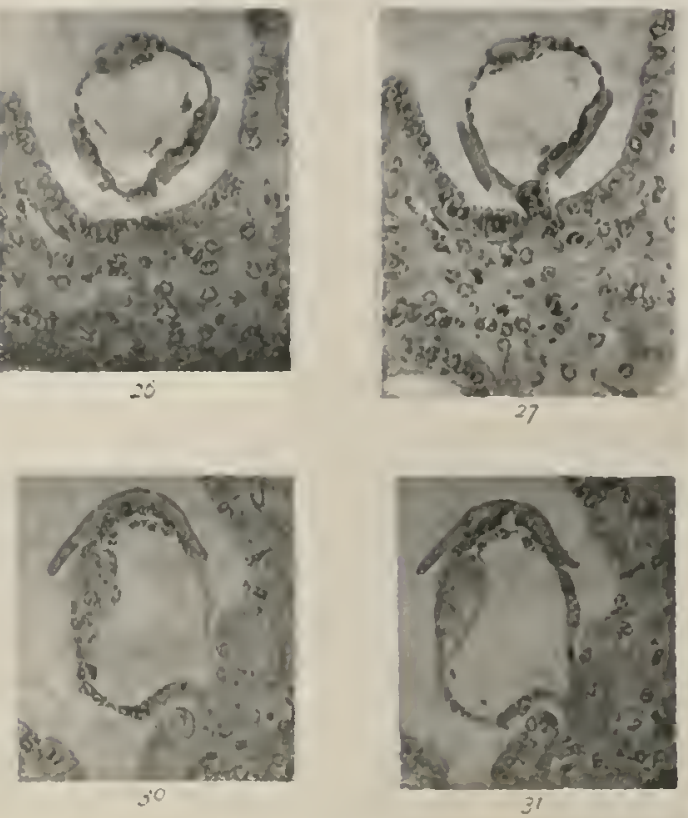
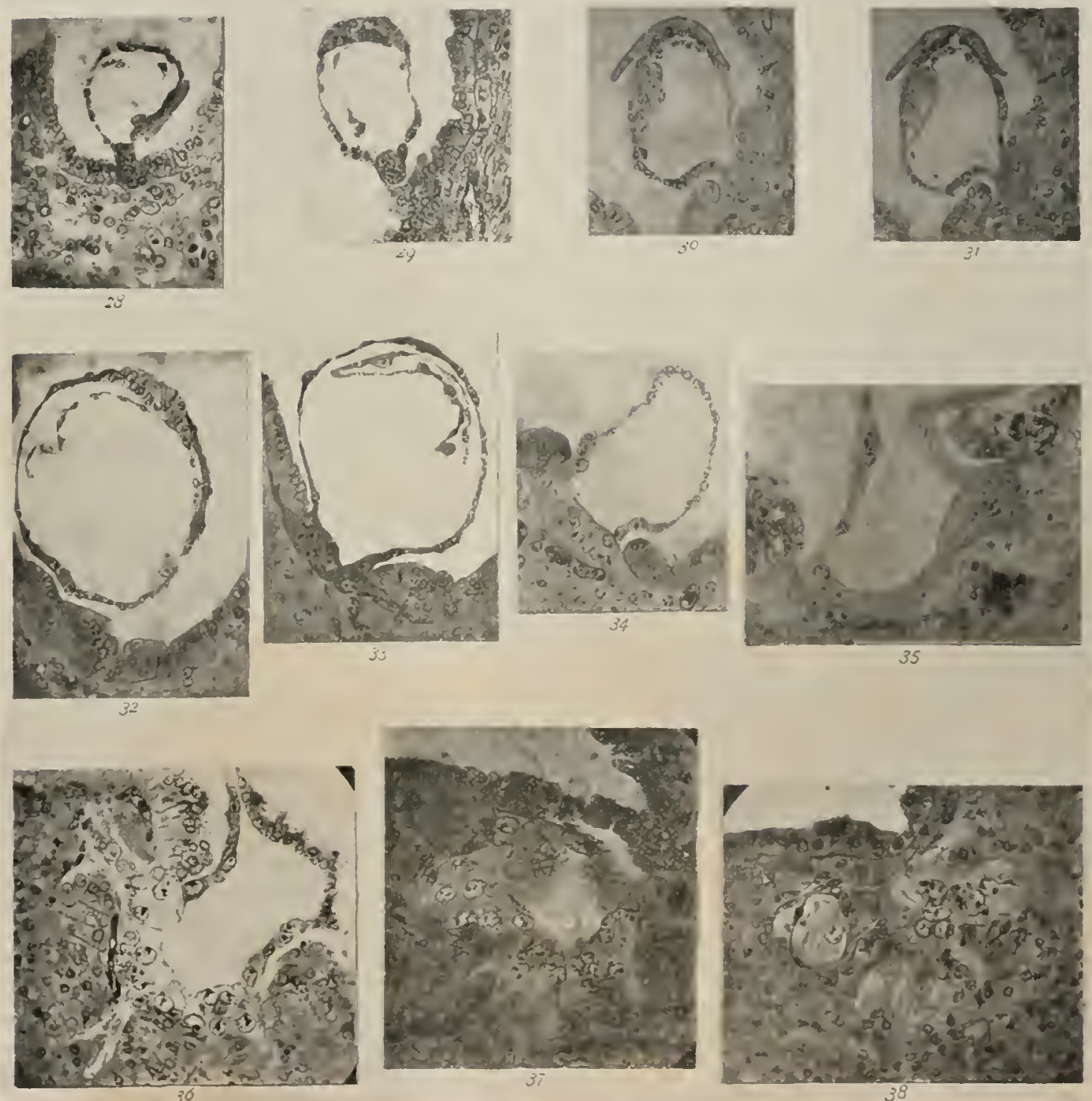

XXII.

STUDIES ON THE EMBRYOLOGY OF THE SIPUNCULIDA.

I. THE EMBRYONAL ENVELOPE AND ITS HOMOLOGUE.

(PLATE XXXII.)

John H. Gerould. 



\section{INTRODUCTION.}

The peculiar embryonal envelope of Sipunculus nudus, with its associated amniotic cavities described by Hatschek ('83), has hitherto been regarded as a structure suigeneris.

Hatschek ('s0) discovered nothing of a similar nature in Echiurus; and yet among the annelids the Echiuride may perhaps be regarded as the nearest allies of the sipunculids. Nor did the observations of Selenka ('75) upon Phascolosoma throw any light upon this remarkable feature in the development of Sipunculus.

So little has been known of the embryology of this interesting group that at the suggestion of my friend Dr. C. A. Kofoid I undertook the study of the development of Phascolosoma gouldii Diesing. My work was begun in the summer of 1893 at the laboratory of Dr. Alexander Agassiz at Newport, R. I. Observations made at Newport proved this locality to be so favorable for my work that on the succeeding year by the kindness of Mr. Agassiz I continued my studies there, and was able to follow the development of the trochophore and larva until the latter had reached the age of thirty days. My first attempts to study the cleavage stages, while still a student under Dr. Mark at Harvard University, met with only a partial success, owing to the difficulty presented by the thick and highly refractive yolk-membrane (zona radiata) to staining and preparing in balsam the somewhat opaque eggs and embryos of this species. After repeated attempts at Wood's Hole, Mass., during the summers of 1896 and 1897 to obtain material for this study, I went to the Laboratoire Lacaze-Duthiers at Roscoff in Finistère, where I enjoyed the hospitality of the founder. There in the summers of 1898 and 1899 I was able to work out somewhat in detail the cleavage of the beautifully transparent egg of Phascolosoma vulgare Blainville, to compare the larva of this species with those of $\mathrm{P}$. gouldii, and to collect material for further investigation. The work was extended by studies in P. gouldii at Wood's Hole during the summers of 1900 and 1902.

I have made several attempts to fertilize the eggs of Sipunculus, once on October 1 at the laboratory of the College de France at Concarneau in lower Brittany, once in July at Roscoff with specimens collected at Trez Hir near Brest, and several times during the winter months at Naples. There is reason to believe that renewed efforts at Concarneau and Trez Hir, where Sipunculus is abundant, or possibly at Naples, 
would meet with success. The studies should be carried on, whether in Brittany or at Naples, during the spring or early summer. I have been unable to verify the observations of Hatschek ('83) upon Sipunculus except as regards a single stage in the larval development of S. tessellatus Kef. taken in the tow at Naples.

I wish here to make hearty acknowledgment to all who have aided me in various ways in carrying on these studies, especially to Mr. Alexander Agassiz and likewise to Dr. Mark, whose interest in the work and helpful advice have been of great value to me. I am indebted also to the members of the respective staffs of the Zoological stations at Roscoff and at Naples, to Professor Fabre-Domergue, and not least to Professor Korschelt, who generously extended to me, while in Europe, the privileges of his laboratory at Marburg.

The present paper deals especially with those facts in the development of Phascolosoma which throw light upon the nature of the embryonal envelope in Sipunculus, and hence is limited in scope to a consideration of the ectoderm of the trochophore. A more complete account of the embryology of Phascolosoma will soon be published.

\section{THE EMBRYONAL ENVELOPE IN SIPUNCULUS.}

To make clear the nature of the embryonal envelope of Sipunculus, it will be well to remind the reader of the main features of the development of that form as described by Hatschek ('83). After a cleavage in which the blastomeres are of nearly equal size, the slightly larger cells at the vegetative pole become invaginated, and the embryo assumes the shape of a gastrula which has the more essential features of a trochophore (Pl. XXXII, Fig. 1). There is an apical plate which bears long cilia, and a circular band, composed of two or three rows of ciliated cells, corresponding in position to a prototroch. At the posterior pole is the invagination of endoderm, and a pair of mesoderm pole-cells project from the dorsal lip of the blastopore into the well-marked segmentation-cavity.

At this stage not only do the cells at the vegetative pole become separated from the zona radiata, but at the active pole the marginal cells of the apical area, which surround the four characteristic rosette cells, become separated from the zona radiata and sink, forming a deep ring-shaped furrow-the amniotic cavity of the head (Pl. XXXII, Figs. 1-5, cav. am. ce.).

Thereupon the closure of the blastopore ensues by a growth ventrad and forward of the ectoderm of its dorsal lip, at which point the mesoderm cells are situated (Figs. $2,3,4)$. This process results in the formation of a median somatic plate (Rumpf- 
platte), which is to furnish the whole of the definitive ectoderm of the trochophore except the apical plate.

Simultineously with this process occurs the formation of the embryonal envelope or serosa. The cells of the body between the apical and somatic plates go to form this membrane. These cells, which are arranged in two or three rows as seen in optical section, are not only shown by their position and number to be prototroch cells, but their probable nutritive function and final dissolution are phenomena that are strangely similar to the function and fate of the prototroch cells of Phascolosoma, as will be shown in the next section. In brief these cells in Sipunculus become flattened out against the egg-membrane, spreading backward past the somatic plate till they reach the posterior pole and completely enclose the embryo (Figs. 2, 3, 4).

In the process of closure the cells become thinner and thinner, in marked disproportion to that decrease in thickness which is due to their spreading out. The process of wasting away continues even in later stages, so that Hatschek is inclined to the opinion that the serosa is giving off material which serves to nourish the embryo, a belief which my studies on Phascolosoma tend to corroborate. Meanwhile the boundaries of the cells in the serosa and even the nuclei disappear. The cells thus degenerate, and their substance seems to be in part absorbed.

Even before the closure of the serosa at the vegetative pole the ring-shaped furrow which surrounds the four characteristic cells at the centre of the apical plate (Kopfamnionhöhle) is continued backward in the median line by a mid-dorsal furrow (Amnioncanal), which is formed by the sinking of a double row of cells and their consequent separation from the zona radiata (Figs. 7, 8). This furrow passes backward into a wide cavity beneath the somatic plate at the posterior or vegetative pole of the embryo (Rumpfamnionhöhle). In other words, all of the ectoderm cells except those which bear cilia have become detached from the zona radiata and sunken beneath the surface; these areas, as I shall show presently, are exactly represented in Phascolosoma by characteristic small cells, which, however, do not sink from the surface.

The somatic plate of Sipunculus, over which lies the amniotic cavity of the trunk (Figs. 2-6, 8), extends forward in the mid-ventral line of the embryo to the blastopore, and, after the closure of the latter, to the apical plate (Figs. 4, 5). It consists along this ventral side of a narrow tongue-shaped band (Fig. 6, tab. so.v.). At the posterior end of the embryo, and especially on the dorsal side, it is, however, expanded into a broad sheet (tab. so. d.), from which the double row of sunken cells extends forward along the mid-dorsal line through a break in the serosa to the apical plate (Fig. 8).

It is necessary here to summarize only in part Hatschek's observations, and it 
will be sufficient to point out in conclusion that, by the growth of the somatic plate chiefly from the dorsal side forward and laterally, the definitive surface of the young larva is completed. The mid-dorsal double row of cells first disappears, possibly to form a part of the serosa. The broad dorsal part of the somatic plate then begins to extend forward and laterally, becoming thinner than the ventral, the lateral line of union of the two being situated far toward the ventral side. It should be noted in passing that in its growth the somatic layer of mesoderm outstrips the ectodermal somatic plate, so that for a time even after the cœlom is established, the serosa forms the ectodermal covering of the body proper, beneath which lie the two layers of mesoderm enclosing the cœlom and beneath them the endoderm (Fig. 6), a stage corresponding exactly to the trochophore of Phascolosoma before shedding the eggmembrane.

\section{THE PROTOTROCH OF PHASCOLOSMA.}

In a form so closely related to Sipunculus as Phascolosoma we should expect to find a similarity in the main features of development, and it has seemed very remarkable to me that a structure of such prominence as the embryonal envelope or serosa of Sipunculus should not have its homologue in Phascolosoma.

I shall endeavor to nake it clear that in Phascolosoma not only the serosa is represented, but that the rest of the ectoderm is disposed in an essentially similar manner to that in the Sipunculus embryo, the most obvious differences being those due to the presence in the egg of Phascolosoma of a much larger amount of yolk than in that of Sipunculus. The two species of Phascolosoma to which I have given most attention, namely, P. gouldii Diesing of the American coast and P. vulgare Blainv. of the British Channel, differ from each other in their development in slight details; the egg and trochophore of the former are more opaque than in the European form, owing to a difference in the amount of yolk.

The cleavage in Phascolosoma is very unequal. The egg like that of certain of the nemerteans (Micrura cæca, Cerebratulus leidyi, and C. lacteus) is remarkable for the large size of the first set of micromeres and their descendants; these "micromeres" in the eight-cell stage slightly exceed in size the macromeres, except in quadrant D. Thus a preponderance of yolk is located in the "active" half of the egg; and the prototroch cells of the trochophore, which arise from this half, are laden with large yolk-granules coarser and more abundant than those of the endoderm.

In the 48-cell stage of $P$. vulgare at the age of about ten hours, cilia begin to 
make their appearance upon the sixteen large "primary" prototroch cells, $*$ and a little later a tuft of long flagella appears upon the apical plate. The latter consists at this stage (Fig. 9) of a comparatively large rosette in the angles of which are four cross-cells, while radiating outward from its four points are two intermediate cells in each quadrant. Thus the active half of the egg in the 48-cell stage consists not of 24 cells but of 32 , leaving only 16 cells at the vegetative pole.

The changes which ensue at the anterior pole in the establishment of a complete trochophore involve the division of the cross and intermediate cells into a large number of very small cells. The rosette cells, however, divide probably only once, leaving a definitive diamond-shaped rosette composed of four comparatively large cells which give rise to long sensory flagella (Fig. 11, ros.). This definitive rosette becomes surrounded during the next ten hours by the small cells of the apical plate, like an island in the midst of a circular pool (Fig. 11). A dorsal cord (Fig. 12, cd. d.) composed of similar small cells extends backward in P. vulgare from the apical plate through a mid-dorsal break in the prototroch to the somatic plate behind the prototroch. Thus the ectodermal areas in the embryo of Phascolosoma correspond in all respects to those in Sipunculus (Figs. 7, 8), except that in Phascolosoma the cells which surround the definitive rosette, those of the mid-dorsal cord, and those of the somatic plate of ectoderm do not sink away from the zona radiata to form amniotic cavities as the corresponding cells do in Sipunculus. $\dagger$ That the latter should sink away from the surface in Sipunculus is not extraordinary, since even in the early cleavage stages the blastomeres are separated from the egg-membrane (zona radiata) by an obvious space. The blastomeres of the vegetative pole in Sipunculus apparently never touch the adjacent zona radiata. The yolk-laden egg of Phascolosoma on the other hand completely fills the zona radiata; and all of the blastomeres, whether ciliated or not, are at all times closely applied to the inner surface of the yolk-membrane (compare Figs. 1 and 10).

Having observed that the cells of the apical plate, those of the mid-dorsal cord, and those of the somatic plate correspond closely in the two forms, the only other ectoderm cells that remain to be considered are those of the prototroch of Phascolosoma and of the serosa of Sipunculus. It is impossible to compare these two structures cell by cell until we have some knowledge of the cell lineage of Sipunculus, but there cannot be the slightest doubt that the serosa in Sipunculus represents in

* A fuller account of the lincage of the prototroch cclls in Phascolosoma, including the three "secondary" cclls, will be presented in a later paper.

$\dagger$ It is hardly neccssary to call the reader's attention to the striking rescmblance between the sipunculid and the annelid trochophore, as regarls the arrangement of the ectoderm. 
general the prototroch of Phascolosoma. The arrangement of the cells of these structures in two or at most three rows in an equatorial band, separated in front, dorsally, and behind by tracts which correspond essentially in the two forms, as well as their large size and uniformly ciliated condition in each form, make the general homology certain.

Before describing the fate of the prototroch in Phascolosoma, it will be well to point out the fact that in $\mathrm{P}$. vulgare a zone of prominent cells bearing a postoral circlet of long cilia is formed behind the prototroch and separated from it by a narrow interval (Figs. 13, 14). This postoral circlet is quite independent of the prototroch proper, and is retained long after the latter has ceased to exist. Thus it develops earlier than the postoral circlet in Sipunculus, which appears in a similar position only after the prototroch cells have slipped back over the somatic plate and formed the embryonal envelope. In Sipunculus the postoral circlet is formed within the amniotic cavity, and appears from Hatschek's observations to become functional as a locomotor organ only after the casting off of the serosa; in Phascolosoma, on the other hand, the cilia, like those of the aboral band covering the prototroch proper, penetrate the zona radiata and serve even before the shedding of that membrane as the organs of locomotion for the trochophore. During the shedding of the zona radiata they either slip through its pores like the flagella of the apical plate in both Sipunculus and Phascolosoma, or the membrane itself splits open along the line of their connection with the body. The postoral circlet in Phascolosoma gouldii is vestigial and in most individuals entirely absent; but a preoral circlet in front of the adoral band of the prototroch (Fig. 15) serves in this species for a short time as the chief organ of locomotion.

Our entire knowledge of the development of Phascolosoma, with the exception of a few scattering notes, has been based upon a single brief paper by Selenka ('75) in which he describes in an excellent manner for that time, but in a primitive and incomplete way, a few of the cleavage stages, the trochophore and two stages in the development of the young larva. In this paper he asserts that the zona radiata (Dotterhaut) is never shed, but becomes transformed gradually into the cuticula of the larva. Similar statements that have been made in regard to various annelids seem to me to be open to the suspicion that there has been a failure to observe that critical stage in which the zona radiata and cuticula are both present. My experience with Phascolosoma has shown how readily this stage may be overlooked, and I quite agree with Eisig ('98, p. 98) that "sobald nur das Augenmerk speciell hierauf gerichtet wird, auch noch weitere Fälle von Häutungen des Embryos zur Beobachtung gelangen und dementsprechend die Angaben über die Verwandlung der Eihaut in die Cuticula der Larve oder des Wurmes allmählich aus der Litteratur verschwinden werden." 
I have conclusive evidence that both the trochophore of $\mathrm{P}$. gouldii and that of $P$. vulgare at the time of their transformations into the young larvæ (forty-eight to fifty-eight hours approximately) shed the zona radiata, for not only have I watched the whole process and made preparations which show clearly the ruptured membrane still clinging to the head, but sections of trochophores from forty to forty-five hours old uniformly show beneath the old yolk-membrane, which still retains its characteristic pore-canals, a rell-marked cuticula (Fig. 15). The latter is not as highly refractive as the zona radiata, and at its first appearance is slightly granular. During the process of shedding the zona radiata, the strong cilia of the postoral band in $P$. vulgare and the similar cilia of the preoral band in P. gouldii slip through the pores of the membrane. Some of the flagella of the apical plate do likewise, but only remnants of the prominent apical cilia of the trochophore remain upon the larva.

\section{DISSOLUTION OF THE PROTOTROCH IN PHASCOLOSOMA AND COM- PLETION OF THE DEFINITIVE BODY-WALL OF THE LARVA.}

At the age of about forty-four to fifty hours the trochophore is still enclosed within the thick zona radiata and covered by a thin cuticula. The thickness of this cuticula is greatest at the posterior end of the body, where it is about half that of the zona radiata. It entirely covers the anterior end of the body, including the prototroch cells, which are soon to disappear.

The retractor muscles have already made their appearance at this time, with their origin in the ectoderm of each side of the posterior end of the trochophore and their insertion in each side of the apical plate (Figs. 15, 16). These muscles soon begin to operate, repeatedly drawing the head backward against the endoderm of the newly formed archenteron. This process results in a pressure upon the surrounding prototroch cells, which are of extraordinary size and completely enclosed by the thin cuticula (Fig. 15).

The somatic plate of ectoderm at this time forms a continuous layer over the subumbrellar region of the trochophore, which we may henceforth call the trunk. It is extended forward on the dorsal side and is united in P. vulgare to the apical plate by the dorsal cord of ectoderm, which has been already clescribed as composed at its narrowest part at first of only two rows of cells. On the ventral side it consists at this time of a band of cells which extends forward on each side of the stomodæum. Thus the prototroch cells occupy two large areas, one on each side of the anterior part of the body, and these are connected ventrally in front of the stomodxum (Figs. 12, 14). 
These cells now degenerate; their yolk, and finally even their nuclei pass backward into the newly formed coelom (Fig. 15). The somatic plate or ectoderm of the trunk meanwhile is growing forward and ventrad beneath the prototroch on each side as in Sipunculus, dorso-lateral proliferations of the apical plate extend backward, and thus the definitive body-wall of the larva is finally completed. The dissolution of the prototroch cells in P. gouldii is effected as follows: The inner side of the cells first shows signs of breaking down in that the cell-wall is dissolved, and the yolkgranules pass inward and backward into the colom (Fig. 15). The outer parts of the cells, however, remain intact for a considerable time and still contain nuclei. When their dissolution is complete and their contents in the form of yolk-granules have found their way backward into the body-cavity, the ectoderm of the trunk closes over the gap left by the passage backward of the substance of the prototroch cells, and becomes united to the apical plate laterally, as was previously the case upon the dorsal and ventral sides (Fig. 16).

I am of opinion that the mechanical pressure of the apical plate upon the disintegrating prototroch cells during the periods of contraction of the retractor muscles has an important part to play in crowding the remnants of the cells back into the cœlom.

The shedding of the zona radiata occurs simultaneously with the end of the process of dissolution ?of the prototroch and of the engulfing of its substance into the cœlom. The remnants of the zona radiata may be found still clinging to the heads of embryos in which the remains of the prototroch cells have sunken away from the surface. This appears to be a period fraught with considerable danger of rupture of the lateral walls of the head region, and individuals are not infrequently seen in which the substance of the prototroch has oozed out upon the surface of the body through the premature tearing of the zona radiata, the cuticula in that region being exceedingly thin. Hence it happens that the young larva, no longer a trochophore, remains for a longer time than usual in a condition of contraction as regards the retractor muscles until the prototroch region has healed over, so to speak, by the growth of the ectoderm of the sides of the trunk forward to the apical plate and over the region of the dissolving prototroch. 


\section{FATE OF THE PROTOTROCH IN THE SIPUNCULIDS.}

From the foregoing account it is evident that there is an essential similarity between the prototroch of Phascolosoma and the serosa of Sipunculus. This similarity holds not only in the position and probable number of the cells and the arrangement of these between correspondingly apical and somatic regions of ectoderm, but also in the transitory nature of each structure and their common function. The cells which I regard as the prototroch in Sipunculus spread backward past the margin of the somatic plate, and form a complete embryonal envelope or serosa in which nuclei can no longer be seen; the serosa dwindles into an exceedingly thin layer, and its substance, according to Hatschek, is probably absorbed by the embryo. The remnant is finally cast off with the zona radiata.

Its homologue in Phascolosoma, on the other hand, appears as a typical prototroch of relatively huge size, which likewise becomes flattened out against the zona radiata, and covers a broad equatorial region of the trochophore; but it never forms an embryonal envelope, and at the time of the shedding of the zona radiata it is not cast off with this structure, but disintegrates and passes into the body-cavity.

Thus in Sipunculus probably, and in Phascolosoma surely, it is a nutritive organ. In Phascolosoma the cytoplasm of each prototroch cell becomes converted, before its final disintegration, into yolk-granules which, passing into the cœlom, completely fill the cœlomic fluid (Fig. 16) and form the chief source of nourishment for the larva during the first week. At the end of this period most of the yolk has been absorbed.

\section{PHYLOGENETIC SIGNIFICANCE OF THE PROTOTROCH.}

Since no embryonal envelope was apparent in Phascolosoma, according to Selenka's brief account of the development, Hatschek raised the question as to whether the serosa of Sipunculus had been acquired during a comparatively short phylogenetic period from conditions like those in Phascolosoma without a serosa or whether, on the other hand, there had been an atrophy and loss of the structure in the latter form. We are now in a position to answer this question with some degree of certainty, or at least to form some definite opinions in regard to the matter, which is all that embryological evidence alone can enable us to do with questions of phylogeny.

The prototroch of Phascolosoma resembles in many respects that of annelids. The large primary prototroch cells of the former correspond precisely in origin to those of the annelids. There is evidence also that the prototroch cells of anne- 
lids undergo a degeneration similar in some respects at least to that in Phascolosoma. Thus Mead ('97, p. 261) states that in Amphitrite "The prototroch and paratroch before their actual disappearance undergo a marked degeneration. The cells shrink and become filled with yellow granules." The process of dissolution of the prototroch and the replacement of it by definitive ectoderm has not been described in Amphitrite, but aside from the question whether its substance is gradually absorbed in situ, as appears to be the case, or passes in the form of visible yolk-granules into the coelom as in Phascolosoma, it is clear that there is in respect to the prototroch a remarkable similarity between the two forms.

Shedding of the prototroch, moreover, occurs both in the annelids and the mollusks. Eisig ('98, pp. 81, 108) describes the degeneration and casting off of the peripheral part of the prototroch in Capitella, and suggests that it may perhaps occur normally in Polygordius, in which Hatschek has observed that groups of ciliated prototroch cells, undergoing degeneration, are sloughed off. Hatschek, however, regards this as a pathological process and maintains $(78$, p. 50) that the prototroch cells in Polygordius gradually diminish in height and assume the characters of other epithelial cells.

Meisenheimer (:01) sets forth the general homology between the velum of Dreissensia and the prototroch of annelids, which is evident if the former term be restricted to the two posterior rows of cells of the velum, so as to exclude the apical plate and "Dach des Velums" of Dreissensia. The vacuolization and flattening of the cells of the prototroch proper and the attenuation of those which form the roof of the velum, all of which are finally cast off, furnish some interesting points of similarity in the fate of the prototroch in a mollusk and in a sipunculid.

I have endeavored to show that the serosa of Sipunculus represents the remains of a degenerating prototroch equivalent to that of Phascolosoma, which in turn is homologous to the prototroch of mesotrochal annelids. Which of the three types represents the most primitive condition? Clearly it is the prototroch of the annelids. Waiving for the present the question as to whether the sipunculids have been derived from segmented or unsegmented ancestors, there can be little doubt that they sprang from forms in which the prototroch was, like that of the annelids, of moderate size and without the specially acquired functions of protection and nutrition which it performs in the sipunculids.

It is quite conceivable that the differences between the prototroch in Phascolosoma and in Sipunculus may have arisen as an effect of the presence or absence of yolk. The adaptation of form and habit to various quantities of yolk is evident even in the different species of Phascolosoma. Thus in P. gouldii there is a compara- 
tively sluggish trochophore, the prototroch cells of which are heavily laden with yolk, so that this species rises little from the bottom. In this form the postoral circlet of cilia is only feebly developed. In P. vulgare there is less yolk, and the trochophore is more active; it remains at the surface for a longer time than the American form, and moves vigorously by means of a postoral circlet of cilia, even after the zona radiata has been cast off. There is, however, much yolk both in the prototroch and in the endoderm of this species, and consequently an epibolic gastrulation. In Sipunculus nudus, on the other hand, there is very little yolk, and the trochophore is markedly pelagic. It seems probable that the ancestors of Sipunculus possessed more yolk than at present exists in the embryo, and that during the acquisition of the pelagic habit the amount of yolk in the prototroch cells has been gradually reduced. The large superficial extent of the serosal or prototroch cells, the fact that their substance gradually wastes away, probably to be absorbed by the embryo, and the further consideration that in Phascolosoma the corresponding structure is an organ of nutrition lend favor to this assumption.

If this supposition is true, it is readily understood how it has come about that the non-ciliated cells of the body in Sipunculus lose their connection with the zona radiata and sink beneath it, thus giving rise to amniotic cavities. This supposition also offers an explanation of the invagination of the endoderm and the infolding of the somatic plate; nor is it difficult to imagine how the prototroch cells under these supposed conditions became spread out backward, slipping past the somatic and endoderm plates till they covered the inside of the entire zona radiata and formed the ciliated serosa. Accordingly the zone on which the postoral cilia were and still are developed in Sipunculus lies no longer behind the prototroch, as is the case in Phascolosoma, but beneath it; and the appearance of cilia upon this zone is deferred until the remnants of the surrounding prototroch or serosa are about to be cast off.

\section{SUMMARY.}

A comparison of the development of Sipunculus, as described by Hatschek, with that of Phascolosoma leads to these results:

1. The following regions of the ectoderm of the trochophore are homologous in the trochophore stages of Sipunculus and of Phascolosoma:

(A) the apical region, with a characteristic definitive rosette at its centre;

(B) the mid-dorsal cord, which extends backward from the apical region through a break in the prototroch to the somatic plate; 
(C) the somatic plate, which, owing to the yolk within the endoderm, in Phascolosoma never sinks away from the zona radiata as in Sipunculus:

(D) the prototroch, which in Sipunculus spreads out forward over the edge of the apical plate and backward over the somatic plate and forms the serosa. In Phascolosoma the sixteen huge primary prototroch cells are derived from the anterior half of the egg (first group of "micromeres," which, however, in the 8-cell stage exceed in size the "macromeres" except in quadrant D). They become flattened out against the zona radiata as in Sipunculus, though to a less extent. They are covered with the short adoral cilia, and contain the greater part of the yolk of the entire trochophore.

2. The prototroch cells in Phascolosoma undergo rapid dissolution from within outward, at the time when elongation of the trunk begins and shedding of the zona radiata occurs. Their substance, which has been largely converted into yolk, is now passed into the fluid of the newly formed cœlom, whence it is gradually absorbed during the growth of the larva. The serosa of Sipunculus according to Hatschek also appears to be in some measure a nutrient organ, though its remnant is cast off with the zona radiata, and not passed into the colom.

In Phascolosoma, as in Sipunculus, the dorsal ectoderm of the somatic plate grows forward and ventrad on each side of the body, closing over the region vacated by the prototroch (=the serosa) and joining two dorso-lateral proliferations of the apical plate which take part with it in the closure.

3. The prototroch of Phascolosoma and the serosa of Sipunculus have probably arisen from what may be called a typical prototroch, such as occurs in mesotrochal annelids, from which type the prototroch in Phascolosoma departs less than does that in Sipunculus.

The differences in the structure and fate of the prototroch in the two forms appear to be the immediate result of the presence or absence of yolk. Reasons are presented for believing that the ancestors of Sipunculus were provided with a yolk-laden prototroch, like that which occurs to-day in Phascolosoma.

\section{BIBLIOGRAPHY.}

Eisig, $\mathrm{H}$.

'98. Zur Entwicklungsgeschichte der Capitelliden. Mitth. Zool. Sta. Neapel, Bd. 13, Heft 1-2, pp. 1-292, Taf. 1-9.

Gerould, J. H.

:04. The Development of Phaseolosoma (Preliminary note). Arch.Sde?Zool. expérim. et gén., notes et revue, sér. 4 , tom. 2, no. 2 , pp. xvii-xxix.

Hatschek, B.

'78. Studien :über? $277-404,8$ Taf. 
Mark Annive Rsari Volume.
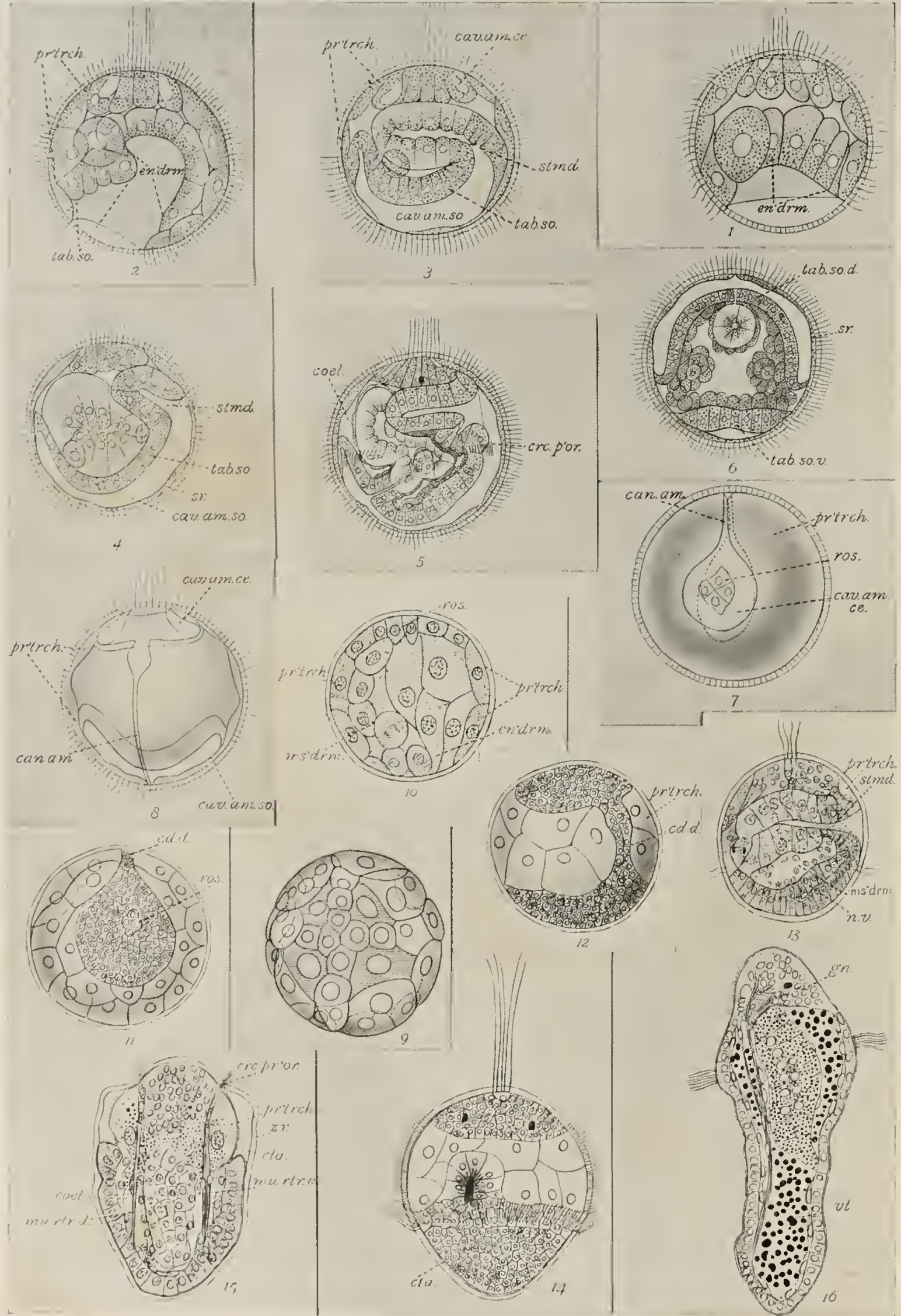
Hatschek, B.

'S0. Ueber Entwickelungeschichte von Echiurus und die systematische Stellung der Echiuridæ (Gephyre chaetiferi). Arb. zool. Inst. Wien, Tom. 3, Icft 1, pp. 45-78, Taf. 4-6.

Hatschek, B.

'S3. Ueber Entwicklung von Sipunculus nudus. Arb. zool. Inst. Wicn, Tom. 5, Hcft 1, pp. 61-140, Taf. 4-9. Mead, A. D.

'97. The Early Development of Marine Annelids. Jour. Morph., vol. 13, no. 2, pp. 227-326, pls. 10-19.

Meisenheimer, J.

:01. Entwicklungsgeschichte von Dreissensia polymorpha Pall. Zcit. wiss. Zool., Bd. 69, Heft 1, pp. 1-137, Taf. 1-13.

Selenka, E.

'75. Eifurchung und Larvenbildung von Phascolosoma elongatum Kef. Zeit. wiss. Zool., Bd. 25, Heft 4, pp. 442-450, Taf. 29-30.

\section{EXPLANATION OF PLATE XXXII.}

$\begin{array}{ll}\text { bl'po. } & \text { Blastopore. } \\ \text { can. am. } & \text { Amniotic canal. } \\ \text { cav. am. ce. } & \text { Amniotic cavity of the head. } \\ \text { cav. am. so. } & \text { Amniotic cavity of the trunk. } \\ \text { cd. } d . & \text { Dorsal cord of ectoderm. } \\ \text { coel. } & \text { Coelom. } \\ \text { crc. p'or. } & \text { Postoral circlet. } \\ \text { crc. pr'or. } & \text { Preoral circlet. } \\ \text { cta. } & \text { Cuticula. } \\ \text { en'drm. } & \text { Endoderm. } \\ \text { gn. } & \text { Supracesophageal ganglion. } \\ m s^{\prime} d r m . & \text { Mesoderm. } \\ m u . r t r . d . & \text { Dorsal retractor muscle. }\end{array}$

bl'po. Blastopore.

can. am. Amniotic canal

cav. am. ce. Amniotic cavity of the head.

cav. am. so. Amniotic cavity of the trunk.

$c d . d$. Dorsal cord of ectoderm.

Coelom.

crc. $p$ 'or. Postoral circlet.

pror.

en'drm. Endoderm.

$m s^{\prime} d r m$. Mesoderm.

$m u . r t r . d$. Dorsal retractor muscle.
ABBREVIATIONS.

$m u . r i r . v$. Ventral retractor muscle.

n.v. Ventral nerve-cord.

pr'trch. Prototroch cells.

ros. Rosette.

sr. Serosa.

stmd. Stomodxum.

tab. apx. Apical plate.

tab. so. Somatic plate of ectoderm.

tab. so. d. Dorsal somatic plate of ectoderm.

tab. so. $v$. Ventral somatic plate of ectoderm.

$v t$ Yolk-granules.

z.r. Zona radiata.

\section{PLATE XXXII.}

Figures 1 to 8 of Sipunculus nudus were copied from Hatschek ('83). Figurcs 10 and 15 are of Phascolosoma gouldii. Figures 9, 11 to 14 , and 16 are of P. vulgare. Figures 9 to 16 were drawn with the aid of an Abbé camera at a magnification of 250 diameters; Hatschek's figures were copied for a magnification of 210 .

Fig. 1. Optical sagittal section of an embryo of Sipunculus nudus, showing the beginning of the invagination of the cndoderm plate. The cells which surround the rosette at the animal pole show a tendency to sink, forming the amniotic cavity of the head (Hatschek, '83, Taf. I, Fig. 8).

Fig. 2. Optical sagittal section of an older embryo, showing the establishment of the somatic plate of ectoderm; the cells of the serosa have slipped over and past the cdge of the somatic plate (Hatschek, '83, Taf. II, Fig. 17).

Fig. 3. Optical sagittal section, immediately beforc the elosure of the blastoporc (Hatschek, 'S3, Taf. II, Fig. 23).

Fig. 4. Optical sagittal section, after closure of the blastopore and formation of the stomodrum (Hatschek, 'S3, Taf. III, Fig. 25).

Fig. 5. Side view combined with optical section, showing the postoral circlet of cilia (Hatschek, 'S3, Taf. IV', Fig. 37).

Fig. 6. Optical cross-section through a similar embryo, taken immediately behind tle postoral circlet (IIatseliek, '83, Taf. IV, Fig. 33). 
Fig. 7. Sipunculus embryo seen from the active pole (Hatschck, '83, Taf. II, Fig. 14). The rosette, surrounded by the amniotic cavity of the head, and the mid-dorsal amniotic canal are shown; the further course of this canal toward the vegetative pole and the transition of its margin into the free rim of the serosa are shown in broken lines; the position of the serosa (= prototroch) is defined. This figure should be compared with Figure 11.

Fig. 8. An older embryo of Sipunculus than that shown in Figure 7. It is seen from the dorsal side, and shows the amniotic cavities of the head and of the trunk, and the connecting mid-dorsal canal (Hatschek, '83, Taf. III, Fig. 31). The cells which underlie these spaces correspond respectively to the apieal and the somatic plates and to the connecting mid-dorsal cord of ectoderm in Phascolosoma. The prototroch or serosa cells at this stage have slipped backward past the somatic plate and closed together at the posterior polc. This figure should be compared with Figure 12.

Fig. 9. Egg of Phascolosoma vulgare in the 48-cell stage, 6 hours and 40 minutes after fertilization. Drawing of an unstained egg in glycerine, showing the cells of the active pole. The rosette is stippled; the cross-cells are marked with parallel lines; the intermediate cells are shaded very lightly, and the primary prototroch cells upon the margin are shaded more deeply.

Fig. 10. Longitudinal sagittal section of egg of Phascolosoma gouldii, between 15 and 20 hours old, showing the rosette and intermediate cells of the apical plate and cells of the prototroch. Within are shown endo. derm and mesoderm cells. Compare with Figure 1.

Fig. 11. Surface view of a young trochophore of P. vulgare, 25.5 hours after fertilization, showing the definitive rosette in the middle of the apical plate, which in turn is surrounded by the cells of the prototroch. The prototroch consists of nineteen cells. The mid-dorsal cord is shown at its junetion with the apical plate. Compare with Figure 7.

Fig. 12. Left-dorsal view of a trochophore of $P$. vulgare, 25.5 hours after fertilization, showing apical plate, middorsal cord and somatic plate of ectoderm, besides the intervening prototroch. Compare with Figure 8.

Fig. 13. Section of a trochophore of P. vulgare 39 hours after fertilization. The plane of section is approximately sagittal. Compare with Figure 5.

Fig. 14. Ventral view of a trochophore of P. vulgare, about 45 hours old, to show the prototroch. The adoral cilia which cover it are represented only along the margin. The postoral circlet of cilia appears behind the prototroch, and is separated from it by a distinet interval. The apical region, with rosette, eyespots, and sensory flagella, and the rapidly growing trunk are shown. A distinet cuticula is already to be seen in the trunk region beneath the zona radiata. Drawn from a living specimen, with details added from a preparation of a specimen of the same age. Compare with Figure 5.

Fig. 15. Parasagittal section of a young larva of P. gouldii, 57 hours old, just previous to the casting off of the zona radiata, under which a continuous cuticula has already been secreted. The dorsal and ventral retractors of the right side of the body are shown in a state of partial contraction. Yolk-granules are seen passing out of the prototroch into the clœom, where the entire substance of the prototroch is soon to be engulfed.

Fig. 16. Parasagittal section of a larva of P. vulgare, 51 hours old but more advaneed in development than the larva represented in Figure 15. Yolk-granules of different sizes are seen in the cœlomic fluid, in which they flow freely back and forth at every contraction and elongation of the body, which attend the oft-repeated introversions of the head. The postoral circlet of cilia are still active; a single (leftventral) retractor muscle, and other features are shown. 
XXIII.

THE PHOTOTROPISM OF THE MOURNING-CLOAK BUTTERFLY, VANESSA ANTIOPA LINN.

(PLATE XXXIII.)

G. H. Parker. 


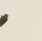




\section{IN'TRODUCTION.}

Although more than a century and a half ago Réaumur (1734) recorded some of the earliest observations on the reactions to light of butterflies and moths, it was possible for Loeb ('90, p. 46) to declare recently that a satisfactory explanation had had not yet been found for the paradox that moths, which avoid daylight, fly into a flane at night, while butterflies, which fly by day, do not possess this fatal instinct. From his own observations Loeb maintained that butterflies as well as moths are positively phototropic, a conclusion supported in a measure by the previous observations of Graber ('\$4, p. 20S) and of Plateau ('\$9, p. 76) and subsequently confirmed by Seitz ('91, p. 337). He further believed that butterflies and moths show in their capacity to be stimulated by light a rhythmic change corresponding in periodicity to day and night, and that butterflies are positively plototropic in the daytime but not at night, and inoths the reverse. Thus a butterfly would fly towards the light in the daytinne but not at night, and a moth would fly toward a lamp at night, but remain unaffected by daylight. Davenport ('97, p. 197) questioned the accuracy of this explanation because even during the daytime moths will fly toward the light, and he expressed the opinion that the two sets of animals were attuned to different light intensities. According to Davenport moths fly toward a weak light, such as that of a candle, but away from a strong light, like that of the sun, while butterflies respond only to strong light, such as bright sunlight, into which they fly. Since Davenport has shown good reason for doubting Loeb's explanation, but has left his own hypothesis untested, it follows that there is still no satisfactory explanation for the condition of affairs first pointed out by Loeb.

The following observations on the phototropism of the mourning-cloak butterfly, Vanessa antiopa Limmeus, will show, I believe, that this problem, at least so far as butterflies are concerned, is much more complex than was suspected by either Loeb or Davenport. The reactions of $\mathrm{V}$. antiopa to light cannot be satisfactorily considered without dealing with the influence of heat, food, and gravity; and, though it is not intended in this paper to cliscuss at length the effects of these stimuli, their relations to phototropism will of necessity be taken into account.

In New England V. antiopa ordinarily produces two broods a year; the imagos of one of these hatch in midsummer, those of the other emerge in the late autiumn 
and hibernate till the next spring. The individuals on which most of my observations were made were hibernated ones from the region about Cambridge, Massachusetts, though I have also studied the reactions of butterflies of the summer brood.

\section{OBSERVATIONS ANDDEDUCTIONS.}

The observations that led me to study the phototropism of $V$. antiopa was made in a piece of 'open woodland on a bright sunny day toward the end of March. On this occasion several of these butterflies that had hibernated were seen flitting about, and it was observed that when they settled on the ground their orientation with reference to the sun's rays was extremely exact. A straight stick held vertically at an appropriate point cast a shadow that fell exactly on the length of the butterfly's body, but the butterfly instead of being oriented with the head toward the sun, as might have been expected, took up its position with the head away from the source of light, that is, it was negatively phototropic (Plate XXXIII, Figs. 1, 2). This unusual orientation at once attracted my attention and led me to study further the reactions of this species to light.

Subsequent observations made on more than eighty of these butterflies demonstrated that this method of orientation was almost invariable. Whenever a butterfly alighted on a piece of level ground in full sunlight, it oriented accurately with the head away from the sun. Now and then an individual in settling would be thrown slightly out of position by some accidental irregularity of the ground, but such an individual invariably readjusted itself to an exact orientation before coming finally to rest. In one instance I observed a butterfly that repeatedly settled with the head some thirty degrees to the right of the position of exact orientation, but this individual invariably turned its body into correct orientation immediately after alighting. As I could discover no constant irregularity on the surfaces on which it settled, I assumed that the initial divergence was due to some peculiarity in the butterfly's organization, such as a distorted leg or other defect, but the insect was so wary that I was unable to catch it to ascertain if this was the correct explanation.

So constant was the orientation of these butterflies in full sunlight that any divergence from the usual conditions was easily noted. What seemed at first sight to be an exceptional position was noticed often when a butterfly settled on the vertical trunk of a tree in sunlight. Under such conditions the axis of its body was held vertical and the head was pointed downward. This inverted position had long been familiar to me, but I had never thought of an explanation of it till I observed the accurate orientation of this species on horizontal surfaces. If on level ground the 
butterfly rests with its head away from the source of light, we should expect that on a vertical surface, such as a tree-trunk, it would rest vertically, with the head directed downward. For the inverted position assumed on tree-trunks and on other vertical surfaces brings the butterfly into the same relation to the source of light as the position taken on the level does.

A second position, which was often observed and which for some time puzzled me, was one in which all evidence of orientation disappeared. A butterfly, that on several previous occasions had alighted with perfect orientation, came to rest entirely out of position and, after turning once or twice, it remained quiet in what seemed to be an entirely irregular position. On watching such instances carefully I found that they often occurred on rocks, and further that they happened only when the rock surface was approximately at right angles to the sun's rays, so that any position assumed by a butterfly alighting on this surface was like every other one so far as the direction of the rays was concerned. That such butterflies were entirely capable of orienting in the usual way was proved in half a dozen instances by driving the insects to a level situation where all were found to orient with perfect accuracy.

A factor that in all cases overruled phototropism was the chemotropic response to food. When a butterfly alights on a bough, it orients in the sunlight with the usual precision. Should the sap be running from a near stem, the insect is very soon attracted to the spot, begins feeding, and moves about from that time on with no reference to the direction of the sun's rays. Thus when feeding or near food the butterflies do not respond phototropically. When, however, food is absent and the butterfly alights in bright sunlight on a surface where orientation can be accomplished, it places the axis of its body as nearly as possible parallel with the rays of light, with the head away from the source of light, its negative phototropism being of a pronounced and unequivocal kind.

That similar conditions obtain among some other species of butterflies seems probable from the fact that some members of the closely allied genus Grapta orient with as much precision and in the same way as Vanessa antiopa. This peculiarity may also occur among some of the hesperids, but such of the papilios, pierids, and lyc:nids as I have observed have given no sign of this form of phototropism.

So far as I am aware, Rádl (:01, p. 457) is the only observer who has recorded similar observations on the orientation of butterflies. According to him, one butterfly that he observed, an undetermined satyrid, oriented almost invariably with the head to the east when the sun was in the west, but in other instances so much irregularity was shown that Rádl refrained from drawing any general conclusions. Had he paid attention to the exact direction of the sun's rays in relation to the surfaces 
on which the butterflies alighted, it is possible that the irregularities that he so frequently noticed might have been explained.

On the bright spring morning when I first observed the orientation of the mourning-cloak butterfly, the sun was from time to time obscured by rapidly drifting, welldefined clouds. Of the dozen or more butterflies observed that morning, not a single one exhibited any noticeable irregularity in its orientation in full sunlight. When, however, the sun was under a cloud, the animals settled in any position; but as soon as it shone forth again, all such animals, if not by accident properly oriented, turned at once into the characteristic position. The reaction was extremely striking, especially when three or four butterflies that had settled during an overcast period could be watched simultaneously as sunlight broke upon them; all oriented immediately and accurately, as though they had been quickly brought under the influence of some force like that of a magnet. In fact when the sun was on the meridian the heads of these butterflies pointed with greater precision to the true north than does the needle of a common pocket-compass in this latitude.

This orientation could be experimentally controlled by an artificially produced shadow. If, while the sun was under a cloud, a hat was held so that when the light burst forth the butterfly would still be in shadow, the insect would remain unoriented, and, if it did not fly before the shadow of the hat was removed, it oriented immediately when the direct sunlight was allowed to fall on it.

The orientation occurred only when the sun was unobscured. It was remarkable how even a small amount of haziness would interfere with the reaction. With a clear sky, however, the reaction never failed to occur. One may, therefore, conclude that the negative phototropism of $\mathrm{V}$. antiopa is dependent upon strong sunlight.

To test this phototropism under conditions that I could control, I collected a number of butterflies and carried them to the laboratory alive. From the accuracy of their responses in the field, I believed it would be very easy to show their negative phototropism within doors. When, however, a few were liberated in a black box one end of which had a glass window in it, they immediately flew to the window and acted in other respects like positively phototropic animals. I then carried them to a photographic room the walls and ceiling of which were painted black, and liberated them one at a time some twenty feet from the only window by which light entered the room. In every instance they flew toward the window. The course that they took was not a straight one, but they flew as in the field, in irregular curves, the result of which was progress towards the window. I was much surprised that their phototropism should be so pronouncedly positive, and it occurred to me that possibly they had been influenced by heat, for the room in which I had experimented was much 
warmer $\left(22^{\circ}\right.$ C. $)$ than out of doors $\left(13^{\circ} \mathrm{C}\right.$.). I therefore opened the window and door of the photographic room till it was approximately as cool as outside, and after having exposed the butterflies for over an hour to this temperature, I repeated my former experiments. But the insects were as strongly positive as at first.

The negative orientation observed in the field took place in full sunlight; the experiments in the laboratory were made with diffuse daylight. Hence it occurred to me that light intensity might have something to do with the sense of the phototropism. I therefore repeated my experiments in a cool room, into which sunlight entered by several windows. But here also the butterflies flew even through the sunlight to the windows. The sunlight entered the room at angles of approximately $45^{\circ}$ with the vertical windows and with the floor, and it was interesting to observe that as the butterfly entered the direct sunlight from a window, it did not change its course in reference to the sun's rays, but cut their path even at right angles, flying straight on toward the window. In this respect my observations are quite different from those of Loeb ('90, p. 51) on Papilio machaon, which is said to fly in the direction of the rays of light.

To test the influence of light intensity more accurately, I liberated several butterflies, one at a time, in a room lighted only by an incandescent lamp of about two candle-power. The insects, which were liberated at a distance of two metres from the light, flew toward it in all instances and circled irregularly about it. A similar reaction was observed toward light from a small are lamp of about 250 candle-power. When an ordinary gas-flame was used as the source of light the butterflies flew into it and singed their wings much as moths would do. Not infrequently the butterflies, on their way to a window or a distant light, would settle on the floor or on a table and would creep before beginning flight again. In all such instances they crept toward the source of light, that is, they showed positive phototropism, and never even when resting in the sunshine in the room did they show the least evidence of negative phototropism. Thus whether creeping, flying, or resting, in weak or in strong light, in a warm or a cool room, the butterflies tested in the laboratory were always positively phototropic.

To discover the reason for the apparent contradiction between my observations made in the field and those made in the laboratory, I caught in a neighboring wood on a sunny day two specimens that I observed to settle in the characteristic manner with the head away from the source of light, and transported them at once to the laboratory for experimental observations. When liberated in the photographic room, they flew toward the window; they likewise flew and crept toward artificial light. When placed in a large black box with electric lights one at either 
end, they flew or crept toward the end which was at the moment illuminated. In other words, they were as positively phototropic as the individuals previously tested in the laboratory. But when they were placed on the floor of the laboratory, in the bright sunshine, they oriented negatively with as much accuracy and precision as they had shown in the woods. In fact, when they did not fly from the sunlit floor to the window, it was very interesting to see them creep over the floor in the direction of the sun and, just before stopping, make a turn of $180^{\circ}$, coming to rest with the head directed away from the sun. It thus was clear that while in their flight and creeping they were positively phototropic, in their resting position they were negative; and further, that although their positive phototropism could be demonstrated either in weak or in strong light, their negative phototropism was observable only in strong sunlight.

Other arthropods are known that show also this double phototropism with uniform intensity of light. Thus the young king-crab, Limulus, according to Loeb ('93, p. 98), swims toward the light but creeps away from it, even when the intensity remains unchanged; and Cole (:01, p. 202) has discovered an interesting though not wholly parallel instance in the pycnogonid Anoplodactylus, which either swims backward or creeps forward toward a light. These double forms of response make the case of $\mathrm{V}$. antiopa appear less exceptional.

Having ascertained that $V$. antiopa may orient negatively to bright sunlight in the laboratory, I was puzzled to know why the animals with which I had first experimented had not yielded similar results. On reflection the only marked difference that I could think of between the specimens that had shown negative phototropism in the laboratory and those that had not done so was that the first lot had been kept overnight in the laboratory, while the second lot had been experimented upon directly on arriving indoors. I therefore captured more individuals, that I had seen orienting negatively in the sunlight, and kept them in a box overnight in the laboratory. On testing them the next morning in sunlight, I found that, though they flew and crept toward the light, they did not orient negatively in the sunlight as they had done the day before. In these respects they were precisely like the first lot with which I had worked. An obvious difference between these individuals and those that were still in the woods was that the former had not had the vigorous exercise of flight, and I therefore determined to try whether exercise would bring them into a state in which negative orientation would take place. I took to the back of a large room a butterfly that did not orient negatively in the sunlight, and let it fly some fifty feet to a distant window. This I repeated five times, after which the insect, on being placed in the sunlight on the floor, crept a short distance toward the sun and then, turning through 
$180^{\circ}$, came to rest in the characteristic negative position. After a few minutes I made it creep again in the sunlight, but this time it merely crept toward the light and failed to orient negatively. I soon learned, by repeating this experiment on three other butterflies, that the state of irritability, in which negative orientation takes place in consequence of exercise, is of very brief duration. For, though I could bring it about often by only two or three excursions, instead of five, I seldom found it to last more than a few minutes. Nevertheless the experiment made clear to me that the negative phototropism of this species, as shown in its position of rest, is dependent not only upon strong sunlight, but also upon previous vigorous exercise, whereby, doubtless, a state of metabolism is established different from that of the resting insect.

These observations give some support to the opinion of Loeb that there is a rhythmic change in the state of a butterfly, and that this change influences its phototropism. But in $\mathrm{V}$. antiopa the response involved is a negative one, whereas in the case observed by Loeb it was positive. My observations, however, give no support to Loeb's idea of a daily rhythm that controls phototropism; in fact I found, as lrad already been observed by Scudder ('74), Murtfeldt ('84), Edwards ('85), Howard ('93, '99), and others, that butterflies liberated at night fly toward a lighted lamp as they do in the day. Neither do my observations give support to Davenport's contention, that butterflies are attuned to light of only great intensity, for, at least in V. antiopa, the individuals will congregate about the dim light of a candle or lamp, as well as about a strong arc light; in this respect they are precisely like moths.

It is not unnatural to ask why $V$. antiopa orients negatively when it comes to rest in sunlight, though in all other light reactions it is positive. One very striking accompaniment of its negative orientation is the spreading of its wings. When a butterfly orients in the sunshine it ahnost invariably spreads its wings, and they are as a rule kept open unless the insect is disturbed by an observer or by a lengthy withdrawal of sunlight. Under these conditions the insect is likely to close its wings and remain an inconspicuous object until the disturbance has ceased. But when it is undisturbed in the sunlight, the wings are usually kept broadly open and the foreand-aft slope that they have exposes them much more effectually to the bright light than would be the case if the insect were oriented with the head toward the source of light. They thus are placed in a position of extreme conspicuousness, so far as the wing patterns are concerned, and since the imago is the stage in which the sexes pair, I am inclined to believe that the position described is one taken for display, as a means of bringing males and females together. I have been, however, unable to find any differences between the sexes in respect to orientation, for males and females orient alike, and I am sure from direct observations that females, as well as males, 
will circle around an oriented and expanded individual of either sex, till both fly off together.

Having determined that both negative and positive phototropism are manifested by V. antiopa in sunlight, it may properly be asked whether these reactions are dependent upon the so-called heat-rays or upon the light-rays of the sunlight. To test this I passed a large beam of sunlight through a glass jar having parallel sides three inches apart and containing a saturated solution of alum. This beam, when it fell on the floor, illuminated an area of about two square feet. When the butterflies were placed in this area they both crept toward the sun, and upon coming to rest oriented negatively as they did in ordinary sunlight. Consequently the heat-rays from the sun are not essential for either the positive or the negative reactions of $\mathrm{V}$. antiopa.

If this species is negatively phototropic only when resting in bright sunlight, and positively phototropic when creeping or flying in light of a considerable range of intensity, it may be asked why it is that these butterflies remain near the ground on a sunny day, why, in other words, they do not fly upward toward the sun. Some marine animals, like the copepod Labidocera (compare Parker, :02), swim upward through the water toward a source of light of moderate intensity. But their positive phototropism is held in check by their inability to pass above the surface of the water. No such barrier holds the butterfly to the earth, and since it, like the copepod, is positively phototropic, one might expect it to fly upwards toward the source of light. An answer to the question why V. antiopa does not do this can be found, I believe, by studying the parts of the butterfly that are stimulated by light. When the sun is shining brightly I have never observed butterflies to alight in a shady spot. If, as they settle toward the ground, they come by accident into a small shadow, they flutter a little farther till they can settle in sunlight. If a butterfly about to alight is cautiously followed with the shadow of a hat or other object, it can be made to flutter a long distance, but can never, in my experience, be brought to settle in the shade when sunny spots are near at hand. If a butterfly oriented in the sunlight is put in shadow by holding some object between it and the sun, it remains quiet a short time, and then invariably flits away. In ten trials of this kind the following timeintervals in seconds were observed between the moment when the shadow was thrown on the butterfly and that when it began to move preparatory to flight: $6,8,8,8,15$, $17,8,9,9,8$. That the reactions were due to the shadow produced, and not to the movement of the hand, could be shown in several ways. The hand might be moved freely and quickly, but so long as the shadow cast by it did not touch the animal, even though very close to it, a reaction was almost never observed. When the butterfly 
was resting in the shadow of a cloud, a movement of the hand might be made much more extensive and much nearer the insect than that used in the shadow experiment, without causing any disturbance. Hence I believe the reaction to be due to the shadow. When the shadow was made to pass on or off the butterfly with great quickness, the animal usually made some sudden movement, as, for example, a momentary closing of the wings, but these responses would be repeated only once or twice, after which quick shadow movements had no apparent effect. These slight reactions were observed not only when artificially produced shadows were used, but also when natural shadows, like those of a well-defined cloud, passed on or off the butterfly. In fact on several occasions I have observed resting butterflies thrown into flight by the sudden coming or going of a well-defined cloud-shadow.

By means of the finger or, better, by a lead-pencil, in very clear sunlight, a shadow of sufficient sharpness could be thrown to allow one to test the sensitiveness of different parts of the butterfly's body. When a butterfly was resting in full sunlight and a shadow was thrown on its wings, no reactions were ever observed rith certainty. The same was true when the shadow was thrown on the abdomen or the thorax. When the shadow covered the head, however, the butterfly reacted much as it did to shadows covering its whole body. Thus a butterfly, with its abdomen and thorax in shadow, but with the rest of its body in full sunlight, remained quiet for 120 seconds; but when the shadow was transferred to the head the animal showed signs of uneasiness at the end of 18 seconds. On repeating this experiment the periods intervening between the moment when the shadow was applied and when the first sign of uneasiness was observed were found to be respectively 14, 17, 15, and 16 seconds. Although these are longer intervals than those obtained when the whole animal was in shadow, I do not think that they indicate that the general surface of the body is sensitive to light, but that the shadow of the hand is deeper and hence more effective than that of the pencil. Conclusive evidence on this point will be given farther on.

Since the head is the portion stimulated by light, it is natural to suspect that the eyes are the particular parts concerned. Loeb ('97) has pointed out that the orientation of an organism in light is dependent upon the equal stimulation of symmetrical points on its body. Should the eyes be the parts stimulated, any interference with one of these ought to result in a disturbance of the direction of the butterfly's locomotion. Thus, if the cornea of one eye were blackened, the insect in locomotion, being positively phototropic, ought to move as though that eye were in shade, namely, in a circle, with the unaffected eye toward the centre. Specimens prepared by blackening the cornea of one eye showed the expected response. When the right 
eye was covered the insects crept or flew in a circle, with the left side invariably toward the centre; and the reverse took place when the other eye alone was blackened. These circus movements agree with those observed by Holmes (:01, p. 220) in other positively phototropic arthropods.

When both eyes were blackened, the butterflies invariably flew upward in irregular circles, sometimes with the right side toward the centre, sometimes with the left. This upward flight has long been known and has been interpreted by some investigators as indicating that the general integument of the insect is sensitive to light. V. antiopa, however, did not fly toward the sun, which, when these experiments were tried, was in the west, but flew directly upward. I therefore suspected that this reaction was due not to the light but to negative geotropism, which, as Loeb ('90, p. 53) has shown, is well developed in butterflies. To test this hypothesis I liberated a number of normal individuals of $\mathrm{V}$. antiopa in an absolutely dark room, and after they had come to rest I turned on the light, and almost invariably found them clinging to the ceiling or rafters. I therefore concluded that this species is negatively geotropic and that the upward flight observed after both eyes of the insect had been blackened is a geotropic response, and not a reaction to light. That the skin is not stimulated by light, at least in any observable degree, is shown by the fact that when the wings of a butterfly are clipped so that it cannot fly it orients in creeping and in resting as a normal individual does; but when, under these conditions, its eyes are blackened, all orientation in reference to light, so far as I can observe, ceases. I therefore believe that the eyes are the organs stimulated when V. antiopa orients to the light, and that its upward flight when both eyes are blackened is a geotropic response.

Having determined that the eyes are the organs stimulated in the phototropism of $\mathrm{V}$. antiopa, it remains to ascertain something of their use. Like the similar organs of many other insects they are well-developed image eyes. They receive light from a large portion of the surrounding field, and, judging from the studies of Exner ('91), this forms an image of considerable richness in detail. It has already been shown that these butterflies are sensitive to light from various parts of the field. If a shadow is cast on an individual settled in sunlight, it invariably rises within a short time and flies to a neighboring patch of sunlight. This patch is found not through the accidental wandering of the butterfly into it, but by the butterfly's taking a direct course to it, precisely as the insect finds a single light window in an otherwise dark room. The directive influence, then, is not the intense sunlight that makes the patch, but the much" less! intense reflected light radiating from the patch. This must form a 
localized spot on each retina of the butterfly, and it is the position of these spots that determines the direction of flight.

It is my belief that $V$. antiopa reacts very slightly, if at all, to differences in the intensity of light of considerable brightness. When a butterfly is liberated midway between two bright lights of different intensities, such as an incandescent lamp of sixteen candle-power and one of fifty candle-power, it is about as likely to fly toward one as toward the other, and the same is true of windows differently illuminated. With relatively strong lights, intensity, then, is a factor that may be varied without noticeably influencing the reactions of the butterfly.

If, in a room illuminated at one end by an open window and at the other by an incandescent lamp, a butterfly is liberated where the intensity of the light from these two sources is about equal, the insect flies almost invariably toward the window. As the light from the window must make a large spot on the retina and that from the incandescent lamp a small one, it is probable that the size of the spot is the factor that determines the direction of flight. This and the indifference shown by the butterflies to variations in the intensity of bright light offers, I believe, an explanation for the fact that in bright sunlight the butterflies do not fly toward the sun. To them the sun is only one of the hundreds of spots of bright light about them, and, though the retinal image of the sun must be vastly brighter than those of all other spots, the butterflies do not respond to this difference, but rather to the larger size of the images of the sunlit spots in the woods. I therefore believe that V. antiopa stays near the ground on bright sunny days because its flight is directed by large bright retinal spots rather than by small ones, even though the latter are of vastly greater intensity.

If the intensity of light plays so insignificant a part in the habits of this species, how does it happen that the butterflies retreat with the setting of the sun and emerge again only with its rising? The explanation of these conditions depends, I believe, upon temperature. These butterflies remain during cool spring nights in places similar to those in which they hibernate in the winter, viz., in openings in stone walls, in old outhouses, in openings under the bark of trees, etc. They retire to these places with considerable regularity, so that in the open woods, where dozens of individuals may have been seen flitting about, all may have disappeared a quarter of an hour later. I have watched their retreat with some care. On a clear afternoon in early April I took my stand in a woodland where many mourning-cloak butterflies were to be seen on the wing. They continued actively flying about till approximately four o'clock, when I began to notice a diminution in their numbers. By a quarter past four not a butterfly was to be seen. During the fifteen minutes from four o'clock 
on, I followed two to their hiding-places. One alighted on the trunk of a fallen tree and, without expanding its wings, crept immediately into a large crack in the bark. The second settled on a stone fence and crept into a hole between some loose stones. The period during which this occurred was marked not so much by a diminution of light as by a rapid fall in temperature. I can judge of this only by the coolness I felt myself, for I was unfortunately without a thermometer, but the rapid cooling of the air was unmistakable. I therefore believe that the most important factor in inducing a retreat of these butterflies is a decrease in temperature rather than in light, and that the butterflies remain under cover at night because of coolness rather than because of lack of light.

That this explanation is probably correct may be seen from the following experiment. A cage made of fine wire gauze and containing half a dozen mourning-cloak butterflies was placed opposite a west window in a cool $\left(7^{\circ} \mathrm{C}\right.$.) basement room. The day was overcast so that only diffuse daylight entered the window. In about ten minutes all the butterflies had taken up resting positions with their wings closed, and they remained in these positions even when the cage was shaken. After they had been in this quiescent state over an hour, the cage was transferred to a warm $\left(21^{\circ} \mathrm{C}\right.$.) basement room and placed opposite a west window whose light relations were almust exactly like those in the first room. Within ten minutes all the butterflies were actively fluttering about, though the only significant change in their surroundings had been that of temperature. On transferring the cage to its original position in the cool room the insects in a few minutes again became quiescent. I therefore believe that the states of repose and of activity are subject to control through temperature. This problem, however, is one for further experimentation.

The retreat of the butterflies as coolness comes on must not be confused with their sudden disappearance, often observed even at midday. If, while the woods are warm, the sun is suddenly overcast and remains so for some time, the butterflies disappear. They, however, have not crept into holes and other hiding-places, but have simply folded their wings, and in this inconspicuous condition they remain quiet. Soon after the sun comes out they are on the wing again. This reaction seems to depend on sudden light diminution, and I believe it to be essentially different from the retiring of the animals for the night or for the winter hibernation. 


\section{SUMMARY.}

1. Vanessa antiopa, in bright sunlight, comes to rest with the head away from the source of light, that is, it is negatively phototropic, when the surface on which it settles is not perpendicular or very nearly perpendicular to the direction of the sun's rays. When, however, this surface is perpendicular to the sun's rays the insect settles without reference to the direction of the rays.

2. This negative phototropism is seen only in intense sunlight and after the butterfly has been on the wing, i.e., after a certain state of metabolism has been established.

3. V. antiopa creeps and flies toward a source of light, that is, it is positively phototropic in its locomotor responses.

4. Its positive phototropism occurs with lights varying in intensity from 2 candlepower at 2 metres distance ( 0.5 candle-metre), to 250 candle-power at 2 metres distance (62.5 candle-metres). Positive phototropism also occurs in intense sunlight, and is not dependent upon any particular phase of metabolism.

5. Both negative and positive phototropism in this species are independent of the "heat-rays" of sunlight.

6. The position assumed in negative phototropism exposes the color patterns of the wings to fullest illumination, and probably has to do with bringing the sexes together during the breeding season.

7. No light reactions are obtained from the butterfly when shadows are thrown upon any part of the body except the head.

8. When one eye is painted black the butterfly creeps or flies in circles with the unaffected eye always toward the centre.

9. When both eyes are painted black all phototropic responses cease and the insect flies upward. Butterflies with normal eyes liberated in a perfectly dark room come to rest near the ceiling. This upward flight in both cases is due to negative geotropism, not to phototropic activity.

10. V. antiopa does not discriminate between lights of greater or less intensity provided they are all of at least moderate intensity and of approximately equal size.

11. V. antiopa does discriminate between light derived from a large luminous area and that from a small one, even when the light from these two sources is of equal intensity as it falls on the animal. These butterflies usually fly toward the larger areas of light.

12. This species remains in flight near the ground because it reacts positively to large patches of bright sunlight rather than to small ones, even though the latter, as in the case of the sun, may be much more intense. 
13. V. antiopa retreats at night and emerges in the morning, not so much because of light differences, as because of temperature changes. On warm days it will, however, become quiet or active, without retreating, depending upon a sudden decrease or increase of light.

\section{BIBLIOGRAPHY.}

Cole, L. J.

:01. Notes on the Habits of Pyenogonids. Biol. Bull., vol. 2, no. 5, pp. 195-207.

Davenport, C. B.

'97. Experimental Morphology. Part First: Effects of Chemical and Physical Agents upon Protoplasm. New York, $8^{\circ}$, xiv $+280 \mathrm{pp}$.

Edwards, $\mathrm{H}$.

'85. [Butterflies attracted to the electric light.] Entomologica Americana, vol. 1, no. 8, p. 160.

Exner, $\mathrm{S}$.

'91. Die Physiologie der facettirten Augen von Krebsen und Insecten. Leipzig und Wien, $8^{\circ}$, viii +206 pp., 7 Taf.

Graber, v.

'84. Grundlinien zur Erforschung des Helligkeits- und Farbensinnes der Tiere. Prag und Leipzig, viii + $322 \mathrm{pp}$.

Holmes, S. J.

:01. Phototaxis in the Amphipoda. Amer. Jour. Physiol., vol. 5, no. 4, pp. 211-234.

Howard, L. O.

'93. The Tityrus Butterfly attracted to Light. Insect Life, vol. 5, no. 5, pp. 355-356.

Howard, L. O.

'99. Butterflies attracted to Light at Night. Proceed. Entomol. Soc. Washington, vol. 4, no. 3, pp. 333-334.

Loeb, J.

'90. Der Heliotropismus der Thiere und scine Uebereinstimmung mit dem Heliotropismus der Pflanzen. Würzburg, $8^{\circ}, 118 \mathrm{pp}$.

Loeb, J.

'93. Ueber künstliche Umwandlung positiv heliotropischer Thiere in negativ heliotropische und umgekehrt. Arch. ges. Physiol., Bd. 54, pp. 81-107.

Loeb, J.

'97. Zur Theorie der physiologischen Licht- und Schwerkraftwirkungen. Arch. ges. Physiol., Bd. 64, pp. $439-466$.

Murtfeldt, M. E.

'84. A Butterfly attracted by Lamplight. Psyche, vol. 5, p. 206.

Parker, G. H.

:02. The Reactions of Copepods to Various Stimuli and the Bearing of this on Daily Depth Migrations. Bull. U. S. Fish Comm. for 1901, pp. 103-123.

Plateau, F.

'89. Recherches expérimentales sur la Vision chez les Arthropodes (quartième partic). Mém. cour. Acad. roy. Belgique, tom. 43 , pp. 1-91.

Rádl, E.

:01. Untersuchungen über die Lichtreactionen der Arthropoden. Areh. ges. Physiol., Bd. 87, pp. 418-466.

Reaumur, R. A. F. de.

1734. Memoires pour servir de l'histoire des insectes. Tome 1, Paris; iii +654 pp. 


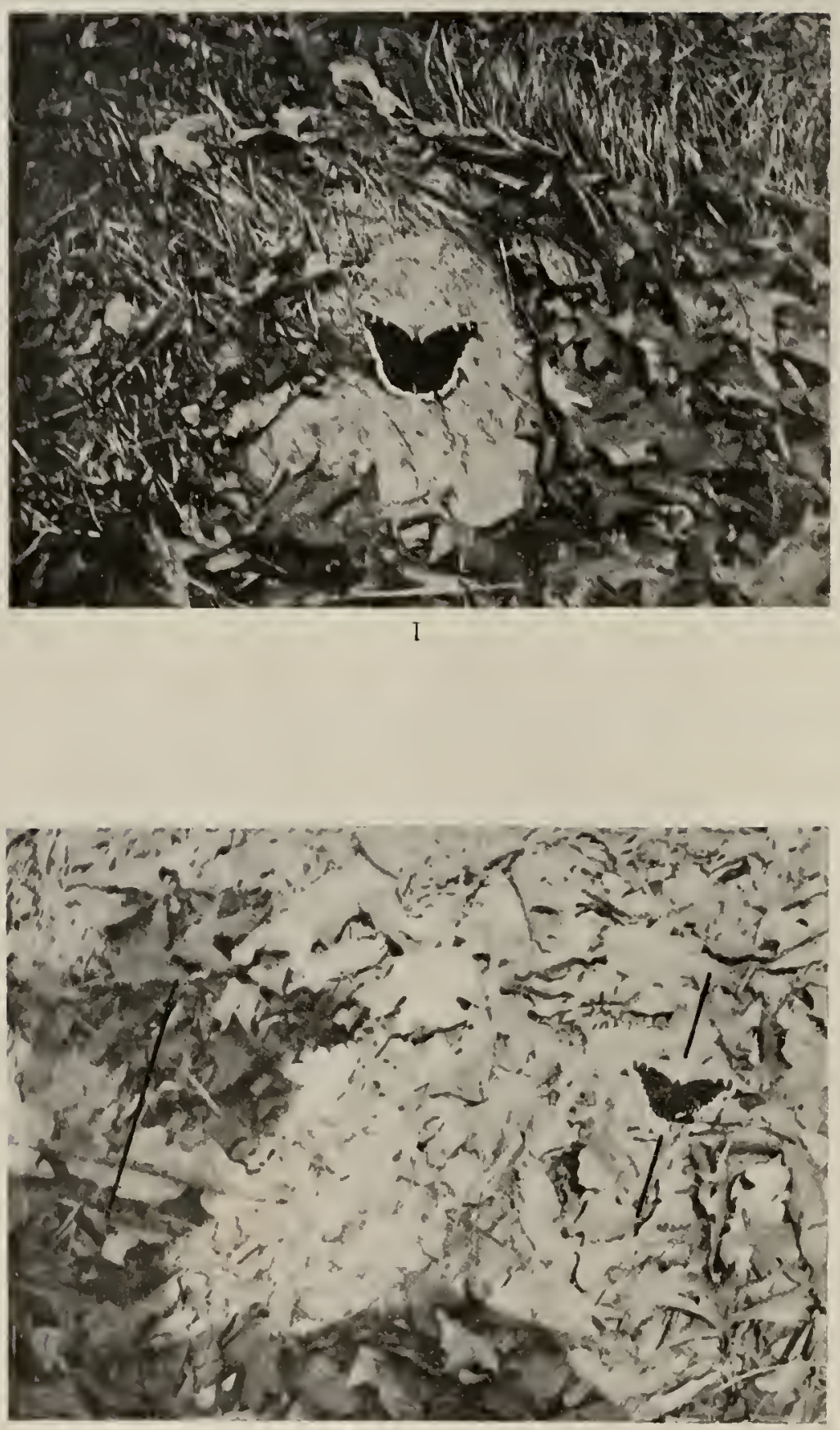

2 
Scudder, S. H.

'74. Butterflies attracted by Lamplight. Psyche, vol. 1, p. 28.

Seitz, A.

'91. Allgemeinc Biologie der Sehmetterlinge. Zool. Jahrb./ Abt. f. Syst., Bd. 5, pp. 281-343.

\section{EXPLANATION OF PLATE XXXIII.}

Fig. 1. Photograph of Vanessa antiopa resting on level ground in bright sunlight and showing negative phototropism. The sunlight, as the shadows of the wings show, comes from above and behind the butterfly,

Fig. 2. Photograph of Vanessa antiopa oriented in full sunlight as in Figure 1. This photograph ineludes part of the shadow of the photographer on the left. The imaginary shadow of his vertical axis is drawn as a blaek line within his own shadow. If transferred to the butterfly, as scen in the black line to the right, it coincides with the longitudinal axis of this animal. Sinee the sun is behind the photographer the butterfly is oriented with its head away from the source of light, that is, it is negatively phototropic. 

XXIV.

THE NERVE DISTRIBUTION IN THE EYE OF PECTEN IRRADIANS.

(PLATE XXXIV.)

IDA H. HYde. 


\section{INTRODUCTION.}

The structural elements of the eye of Pecten and its nerve distribution have been described in great detail by Patten ('86) in his article "Eyes of Molluses and Arthropods," and before him by Hensen ('65) and by Hickson ('80). Since these publications, however, improved methods for the impregnation of nerves have been developed, with the aid of which more correct views and interpretations of structures have been gained, leading not only to broader morphological comparisons and generalizations, but also to the necessity of repeating the investigation of organs concerning which there are differences of opinion. Among the latter is the eye of Pecten, for the earlier descriptions of the retinal nerve-endings in this sense-organ have been questioned. It becane necessary, therefore, to subject this eye to a renewed study with modern methods.

The study of the nerve-endings in the eyes of some Molluses which I began in 1897 under Dr. Mark at Radcliffe College was continued on marine forms, especially on Pecten, during the summer of 1898 at the Marine Biological Laboratory at Wood's Hole, Mass. Much material was examined and preserved for sections and for maceration. Now after four years it is taken up for completion. Besides the Golgi and methylenblue, most of the later methods used in neurological work were employed. Of the hardening fluids used for control study, Apáthy's osmic sublimate, Niessing's platinoosmic sublimate, and Vom Rath's picro-platin-osmic mixture gave good results, and iron hæmatoxylin proved to be the best stain. Of the methylen-blue, a modification of Bethe's'method proved most satisfactory. The animals were either injected with a $.5 \%$ solution of methylen-blue in Pecten-serum that was diluted with a $0.6 \%$ solution of sodium chloride, and after ten hours their eyes were removed and hardened; or the eyes were removed from an uninjected animal, put into a dilute solution of methylenblue in Pecten-serum for two hours, and then exposed in a fresh solution for two hours longer. They were then hardened for two hours either in $10 \%$ ammonium molybdate, or in ammonium molybdate containing hydrogen peroxide and hydrochloric acid, or in $10 \%$ ammonium molybdate to which one-tenth its volume of $3 \%$ formol and a drop of $2 \%$ osmic acid to every 5 cubic centimetres of the solution were added. They were washed in water for an hour, dehydrated, and finally put into oil of bergamot or xylol. All solutions were kept cool by placing them near ice. Eosin dissolved in a 
few drops of absolute alcohol, and then poured into xylol and filtered, was used for a contrast stain. The use of an alcoholic dye which weakens or destroys the methylenblue impregnation was thus avoided.

Reliable information of the structural elements that compose the eye of Pecten can best be gained from material hardened and stained with special nerve methods supplemented by general cytological treatment. An examination of material thus prepared and of macerated specimens reveals the nervous as well as the supporting tissue. Although I centred my attention on the nervous tissues, I also recorded the condition of the other structures that were present.

\section{GENERAL DESCRIPTION OF THE EYE.}

The eye may be considered as composed of three divisions: an anterior, dioptric division consisting of cornea, lens, and iris (Pl. XXXIV, Fig. 1, crn., lns., ir.); a median or retinal division enclosed in a retinal sac (sac. rtn.); and a posterior division containing the vitreous humor, argentea, and red tapetum (hum. vit., arg., tap.). Regarding the anterior division I can add but little to Patten's descriptions. Some of the component parts were not exactly as Patten described them, but this no doubt was due to the fact that the elements vary somewhat in different species. For instance, in Pecten irradians the cells that form the cornea and iris do not possess the plicated bases. The pigment layer, or red tapetum (Figs. 1, 2, tap.), that lines the posterior part of the eye and the double-layered argentea which Patten described as independent structures, I consider products of the same cells, and the vitreous network (Figs. 1, 2, hum. vit.) is in my opinion nothing more than a fluid of the nature of a vitreous humor. The red tapetum and double-layered argentea may be homologous to the pigmented epithelium, the basal part containing the nuclei and stroma-like pigment particles, while the argentea overlying the pignent corresponds to the clear refractive distal part of the epithelial cells. It consists of layers that appear to be the result of secretions of the pigmented red tapetum, formed of stroma-like particles devoid of pigment and compressed into scales or platelets. The thinnest of these occur on the distal side and like the proximal ones are regularly arranged in thin parallel layers. They are traversed by the finest nerve-fibres, brought out by methylen-blue. While some of the stains and hardening fluids act alike on the argentea, platelets, and stroma scales of the pigment layer, either dissolving them in part and loosening their connections or leaving them unaffected by the stain, as hyaline refractile or iridescent scales, others act only on the pigment-scales. The thinner peripheral layer may be torn in sectioning from the proximal or both may be torn from the pigment-cells, in which 
case some of the colored pigment may adhere in places to the argentea, while along the edge of some of the pigment-cells clings the refractive fringe of argentea. The vitreous network is not reticular, but a homogeneous fluid that assumes a vacuolated appearance only when treated with certain hardening fluids, especially such as contain acetic acid.

\section{GENERAL DESCRIPTION OF THE RETINA.}

The retina has somewhat the form of a concavo-convex disk. It is enclosed by a retinal sac (ommateal sac) and divided into three unequal layers of cells by two membranes disposed parallel to the anterior wall of the sac. The three layers of cells are the anterior, middle, and posterior. The four membranes of the retina are designated as the anterior or septal wall of the retinal sac (Fig. 1, mb. sep.), the anterior limiting membrane $(m b . a$.$) , the median limiting membrane (m b . m$.$) , and$ the posterior membrane. Four sets of nerve elements represent the chief morphological constituents of the retina. The rods, forming the posterior layer of cells (Fig. 3, bac.), the bipolar cells ( $n l . b^{\prime}$ pol.) lying in the middle layer; the external ganglionic celts (gn.ex.) in the anterior layer, and connected with the side branch of the optic nerve; and the marginal ganglionic cells ( $g n$. marg.) connected with the basal optic nerve and lying around the margin of the retina. Other elements of the retina are the anterior (Fig. 2, sst. a.) and the middle supporting cells (sst. m.).

\section{STRUCTURAL ELEMENTS OF THE RETINA.}

A rod (Fig. 2, bac.) consists of a nerve-cell whose small anterior end projects slightly beyond the median limiting membrane and whose much elongated posterior portion is tubular and terminated bluntly. This portion is encased in a hyaline sheath and its end is capped by a homogeneous cuticular substance, that in methylenblue preparations seems like the matrix that separates the rods. In specimens otherwise prepared this matrix appears to be granular like the cytoplasm of the median supporting cells, a continuation of which it then appears to be. A small nucleus surrounded by refractive protoplasm lies in the anterior end of the rod, and from this an axial fibre surrounded by a layer of granular striations extends to the posterior end. The rod in fact is a sensory nerve-cell with its sheathed axon.

The bipolar cells extend from the median limiting membrane outwards toward the margin of the retina and form curves that decrease in extent from the middle 
toward the periphery of the eye. Their large granular elliptical nuclei (Figs. 2, 3, nl. b'pol.) may be seen in longitudinal sections extending in a row a short distance from the median limiting membrane. The whole cell with its afferent and efferent axon is encased in a hyaline sheath under which are scattered blue granules of different sizes. In methylen-blue sections under magnification of 2,500 diameters may be seen small dendritic fibres at the end of the afferent axon in contact with the anterior end of the rod-cell. Between this dendritic termination and the knob-like endings of the rod-axon is a spherical mass of highly refractive protoplasm. In sections stained with iron hæmatoxylin, the hyaline sheath does not show, and only the bipolar nucleus and its axons are visible. Near the median limiting membrane, where the axon terminates is seen the small rod nucleus (Fig. $3, n l$. bac.) surrounded by a refractive elliptical capsule. Several of the efferent axons of the bipolar cells terminate at the periphery in a common large ganglionic cell.

The marginal ganglionic cells (Fig. 3, gn. marg.) not only make connections with the axons of the bipolar cells but with other axons, and from them, noreover, fibres extend toward the base of the eye, forming thus a hemispherical cage of fibres that encloses the posterior part of the eye from the margin to the base of the retina. Here they unite to form the large basal optic nerve that goes to the brain.

The nerve-fibres of the basal optic nerve are somewhat varicose and wavy and with nodular thickenings. Several of them may proceed from a marginal ganglionic cell surrounded by a thin sheath and soon separate into fine fibres (Fig. 3, fbr. opt. ba.). The marginal ganglionic cells are arranged in several rows around the border of the median layer. Sections cut from near the margin show that each large ganglionic cell contains a nucleus and several nucleoli, and that the protoplasm around the nucleus is arranged in granular striations except where the bipolar cell makes connection; here a hillock of granular neurosomes and reticular fibrillæ exist (Fig. 3, gn. marg.). Near the base of the eye, a side branch (Fig. 1, rm. l.) of nerve-fibres arises from the large basal nerve-trunk. It proceeds in a connective-tissue sheath along one side of the eye to the septal membrane. It extends along this membrane giving off fibres in its path. These as well as its remaining fibres radiate to end in the external ganglionic cells.

In good methylen-blue sections the external ganglionic cells are seen to form a one-layered plate of contiguous blue masses (Figs. 1, 2, 3, gn. ex.) proximal to the septal membrane. They are very peculiar structures, having the appearance of a much entangled coil of characteristically beaded fibres, surrounded by a spheroidal membrane. From each ganglionic cell many beaded fibres pass, not only to the neighboring ganglionic cells, forming thus a continuous layer of nerve-tissue at the 
anterior end of the retina, but also to the marginal ganglionic cells and upward along the side toward the cornea. The most important distribution of their fibres is the network formed of several fibres from each cell. These fibres meet near the cells and then send out niany very fine beaded branches that form an arborescent network around the cells of the anterior, middle, and posterior layers to encl on the bipolar cells and rod-cells (Fig. 2). These fibres can be seen in well-stained methylen-blue sections at a magnification of 2,500 diameters. They form, as seen in some sections, a fine weblike tissue surrounding the outside of the rods (Fig. 1, fbr. mot.).

In addition to the four nerve elements thus briefly described, the retina possesses a middle and an anterior layer of supporting cells that can best be studied from sections other than those impregnated with methylen-blue. The middle supporting cells extend from the median limiting membrane between the bipolar cells, whose curved courses they follow toward the periphery of the anterior limiting membrane, and form thus a disk of a single layer of cells (Fig. 2, sst. $m$.). They too clescribe curved lines that grow more curved and shorter as they approach the periphery of the retina. From their broad bases that abut against the median limiting membrane, they gradually become more attenuated, curving under the anterior limiting membrane to end at the margin of the retina. They are filled with granular protoplasm and have large spherical nuclei near their thin peripheral ends. They are easily distinguished from the elliptical bipolar nuclei which lie nearer the median limiting membrane. The anterior supporting cells (Figs. 1, 2, 3, sst. a.) form a single row of pyramidal bodies that extend from the anterior limiting membrane to the septal membrane. They are granular and possess large spherical basal nuclei. Among the bases of these cells are occasionally seen what seems to be dark nuclei with refractive capsules. They may possibly be transverse sections of some of the bipolar cells.

\section{DISCUSSION OF RESULTS.}

In comparing the results of Hensen ('65), of Hilger ('85), and especially of Patten ('s6) with mine, it will be noticed that their descriptions and interpretations of the nerve distribution in the eye of Pecten and consequently of the morphological elements, differ markedly from those advanced in this article. Patten classifies the structural elements of the eye under two heads: First, a posterior wall consisting of four layers, namely, an outer vitreous network, two layers of argentea, and a red tapetum; second, an anterior wall of four layers as follows: rods containing the retinidia, retinophoræ, inner ganglionic cells, and outer ganglionic cells. In my 
opinion the posterior wall consists of a homogeneous vitreous humor and a pigment layer with its constituent layers of argentea, while the anterior wall is made up of rods, bipolar and supporting cells, and external ganglionic and supporting cells. Sufficient has been said regarding the comparisons of the elements of the posterior wall. In reference to the anterior wall let us begin the comparison with the rods. The rods have been described by Patten and others as cuticular secretions of the retinophoræ, of columnar form and penetrated by the axial nerve-fibre of the retinophora. The nerve-fibre passes out at the end of the rod to divide into two branches, one joining with a neighboring fibre the other encircles the rod. From the axial fibre, moreover, radiating branches are given off and these constitute the greater part of the rod substance. Some of these fibres penetrate the sheath to connect with the encircling fibres on the surface, while others join branches from the external ganglionic layer. Patten also described the core of the rod as filled with granules produced by the coagulation of fibrillæ. His complex description of the arrangement of the three series of nerve-fibres innervating the rods has been justly criticised, judging from the methylen-blue preparations. It will be seen from my description that the axial rod-fibre is the axon of a rod-cell and not a continuation of the axial fibre of a retinophora; that it does not branch inside the rod nor penetrate it to divide into two branches, but terminates in the end of the rod. The striæ that Patten regarded as coagulated fibrillæ in the rod, I consider stainable nerve substance like that which is also seen in the bipolar cells and parallel with their length. The strix are, as a rule, not in the form of continuous fibrils or varicose threads. They are abundant in bipolar and rod-cells in which the axon has been broken up during the preparation of the material, and are not fibrillar. The surfaces of the rods are not covered with two systems of nerve-fibres, derived from the axial branches and the external ganglionic.layer. I was able to see that only the finest beaded fibrillæ that characterize the branches of the external ganglionic layer terminate on the rod-cells. These on the outside of the rod and the axon in the inside constitute, I believe, the only nerve-fibres of the rod-cells. Patten describes the retinophoræ as long curved cells filled with fine granular protoplasm and surrounding an axial nerve-fibre. The inner expanded ends contain a minute vacuole and terminate at an undulating line of division or pseudomembrane (median limiting membrane) above the rod layer. The outer attenuated ends are transformed at the periphery into fibres that turn and form the optic axis. The most superficial of these describe long curves that bend at the expanded inner end almost at right angles to terminate in the centre of the retina, while those at the periphery describe semicircles almost. They thus form a saucer-shaped layer of cells whose large nuclei are crowded to the periphery of the retina. This description 
for the retinophoræ answers perfectly for the supporting cells of the median layer, with the exception that the supporting cells do not contain axial nerve-fibres. In some sections the axial nerves of bipolar cells appear to be in supporting cells, that lie either above or below the bipolar cells, and it must have been these that Patten mistook for the axial fibre of the retinophora, while the refractive vacuole at the inner end of the cell must have been the refractive membrane and protoplasm of the nuclei of the rod-cells, that lie, however, between the bases of the supporting cells. The third elements in Patten's list of the parts of the anterior wall are the inner ganglionic cells. According to his description they are flat cells that form a single row squeezed between the retinophoræ. They send out several fibres toward the rod, the largest of which extend over the surfaces of these structures, while on the outer side two large fibres extend toward the lens and become continuous with the side branch of the optic nerve. These ganglionic cells were mistaken by Hensen ('65), Carrière ('89), and others for nuclei of the retinophoræ. The inner ganglionic cells are in fact the bipolar cells. They form a single layer between the supporting cells and send fibres both toward the lens and toward the rods, but these fibres do not on the one side continue with the side branch of the optic or on the other extend over the surfaces of the rods. In sections stained by other means than methylen-blue they do have this deceptive appearance. Since the large marginal ganglionic cells that give off fibres to form the basal optic trunk and the rod-cells with their nuclei were not seen by the other investigators, and since the character of the bipolar cells was unknown to them, it is not strange that their descriptions and interpretations regarding these elements should have been incorrect. It is almost impossible to obtain a true idea either of the peculiar structure of the external ganglionic layer or of the distribution of its fibres without the aid of some means like methylen-blue, which brings out distinctly the nerve structure. Consequently it is not surprising that Patten and others believed that several rows of two kinds of ganglionic cells formed the outer layer of the retina, and that the broad ends of the outer cells terminated in many fibres that penetrated the septal membrane to unite with the side branch of the optic nerve, while their inner ends radiated inwards to terminate at the inner ends of the retinophoræ and rods. The outer row of cells (Fig. 3, gn. ex.) with broad ends that connect by several fibres with the side branch of the optic nerve and send fibres inward to form a network in the median and posterior layer over the bipolar and rod cells are the true outer row of external ganglionic cells; while the inner row of cells (sst. a.) with broad bases that lie proximal to the anterior limiting membrane are the anterior supporting cells. Having passed in critical review the morphological elements of the retina as described by different investigators, it seems that the retina is not so 
extremely coniplex nor the internal relations of its structural elements as complicated as was supposed. Making allowances for the fact that different species have been studied I believe that the previous descriptions and interpretations of the retinal cells in Pecten are in some important particulars misleading, a condition of affairs that has been partly remedied by the employment of new methods.

\section{CONCLUSIONS.}

1. I conclude that the rods have been inadequately described, and that they are not innervated by fibres from at least three series of nerves.

2. The so-called retinophoræ are not the visual sensory cells whose peripheral fibres form the basal optic nerve, but they are the supporting cells of the median layer of the retina.

3. The inner ganglionic cells do not connect with the side branch of the optic nerve, but are the nerve-cells of the bipolar nerve elements.

4. The outer ganglionic cells form a single layer whose inner fibres are disposed in a special reticular structure in the retina and whose outer fibres make direct connection with the side branch of the optic nerve.

5. The existence of the large marginal ganglionic cells and their relations to the bipolar and optic nerve were not known to other investigators of the eye of Pecten.

6. I believe that the visual apparatus of the retina is composed of afferent and efferent neurones, and agree with von Lenhossék ('96) that the rods are true peripheral visual neurones. The distal ends of their axons represent, therefore, retinal sensory endings. Their proximal terminal spherules and the terminal tufts of the afferent axon of the bipolar cells establish conduction relations between rods and bipolar cells, and by means of the efferent axons of the latter connection is made with the marginal ganglionic cells. Through the latter and their nerve-fibres impulses are thus transmitted from the rods through the bipolar cells and marginal ganglionic cells to the brain. The efferent paths are, I believe, through the side branch of the optic nerve to the external ganglionic cells and their efferent beaded fibrils. The latter, due to their method of branching, have an arborescent appearance in the median layer, and as finest fibrils terminate in tiny flat nodules on the different retinal elements. 
Mark Anniversary Volume.

Plate : XXIV.

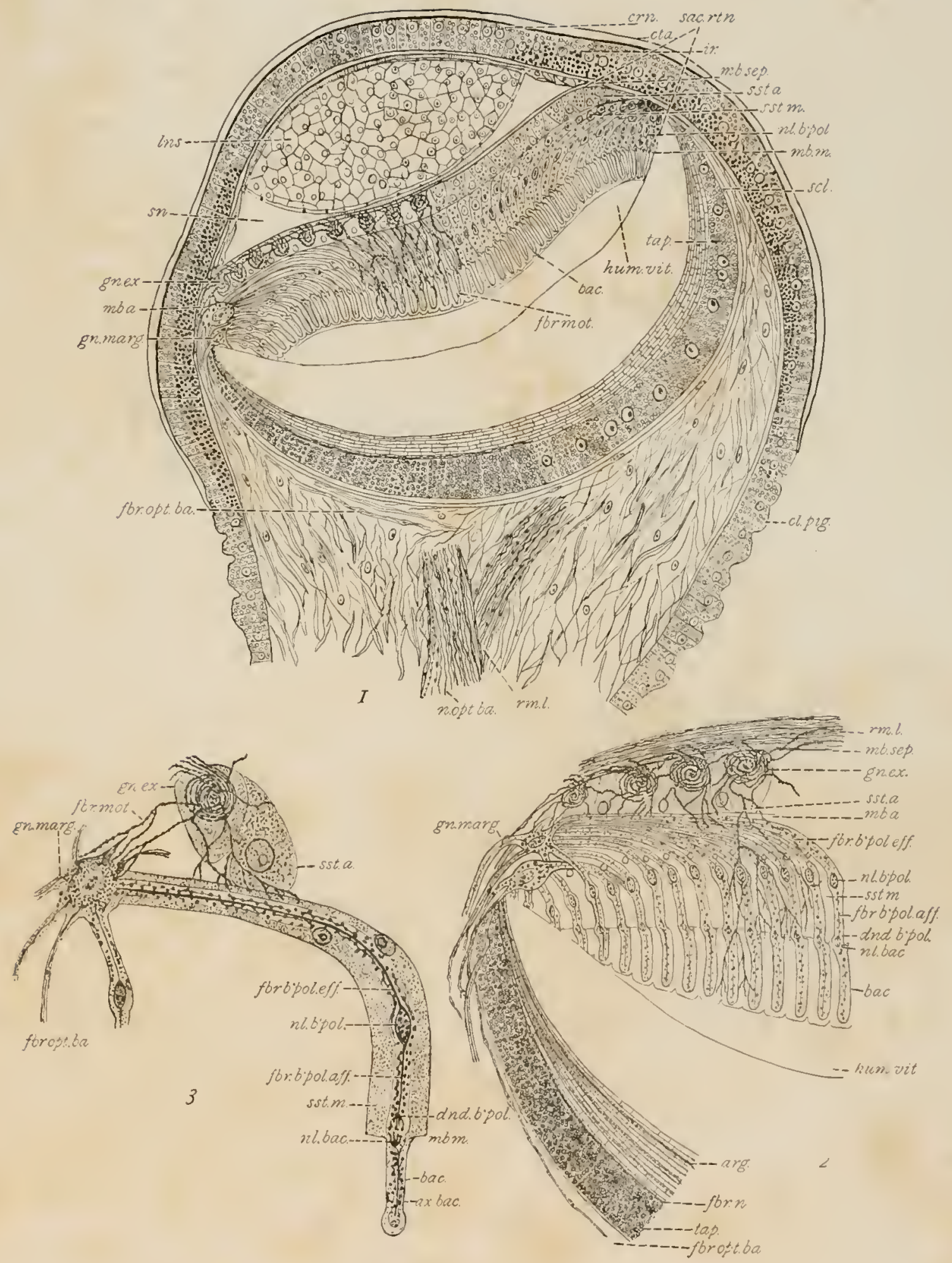

HydE-PECTEN EYE 


\section{BIBLIOGRAPHY.}

Carrière, J.

'S9. Ueber Molluskenaugen. Areh. mikr. Anat., Bd. 33, pp. 378-402, Taf. 23.

Hensen, V.

'65. Ueber das Auge einiger Cephalopoden. Zeit. wiss. Zool., Bd. 15, pp. 155-242, Taf. 12-21.

Hickson, S. J.

'So. The Eye of Peeten. Quart. Jour. Micr. Sei., vol. 20, pp. 443-445, 2 pls.

Hickson, S. J.

'82. The Eye of Spondylus. Quart. Jour. Mier. Sci., vol. 22, pp. 362-364.

Hilger, $\mathrm{C}$.

'85. Beiträge zur Kenntnis des Gastropodenauges. Morph. Jahrb., Bd. 10, pp. 353-371, Taf. 16-17.

Lenhossék, M. v.

'96. Histologische Untersuehungen am Sehlappen der Cephalopoden. Areh. mikr. Anat., Bd. 47, pp. 45120, Taf. 6-8.

Patten, W.

'86. Eyes of Molluses and Arthropods. Mitth. Zool. Sta. Neapel, Bd. 6, pp. 542-756, Taf. 28-32.

\section{EXPLANATION OF PLATE XXXIV.}

\begin{tabular}{|c|c|c|c|}
\hline & \multicolumn{2}{|c|}{ ABBREVIATIONS. } & \multirow[b]{2}{*}{ Lens. } \\
\hline $\arg$. & Argentea. & lns. & \\
\hline$a x . b a c$. & Rod-axon. & $m b . a$ & Anterior limiting membrane. \\
\hline bae. & Rod. & $m b . m$ & Median limiting membrane. \\
\hline b'pol. & Bipolar eell. & $m b . p$ & Posterior membrane. \\
\hline cl. pig. & Epithelial pigment-cell. & $m b$. sep. & Septal membrane. \\
\hline crn. & Cornea. & $n l .^{\prime}$ & Nucleus of supporting cell. \\
\hline cta. & Cutieula. & $n l .^{\prime \prime}$ & Nucleus of anterior supporting cell. \\
\hline dnd. b'pol. & Bipolar dendrites. & nl. bac. & Rod nucleus. \\
\hline fbr. b'pol. aff. & Bipolar afferent fibre. & $n l . b^{\prime}$ pol. & Bipolar nucleus. \\
\hline fbr. b'pol. eff. & Bipolar efferent fibre. & n. opt. ba. & Basal optic nerve. \\
\hline fbr. mot. & Motor-fibre. & $r m . l$. & Side branch of optic nerve. \\
\hline$f b r . n$. & Nerve-fibre. & sac. rtn. & Retinal sac. \\
\hline fbr. opt. ba. & Basal optic fibre. & scl. & Sclera. \\
\hline$g n . e x$. & External ganghionic eells. & $s n$. & Sinus. \\
\hline gn. marg. & Marginal ganglionic cells. & sst. $a$. & Anterior supporting eells. \\
\hline hum. vit. & Vitreous humor. & sst. $m$. & Middle supporting cells. \\
\hline & Iris. & tap. & Tapetum. \\
\hline
\end{tabular}

\section{PLATE XXXIV.}

Fig. 1. A median section of the eye of Peeten irradians, selematic. The left portion of the drawing shows the elements as they appear in methylen-blue preparations, the right portion as they are seen in lamatoxylin preparations. In the latter, the outlines and nuelei of the eells are brought to view. In the former these are not seen for all of the cells, but the ganglionie eells, nerve-eells and fibres are all well shown. In order not to obscure other struetures only a few of the fibres from the external ganglia are drawn. 
482 THE NERVE DISTRIBUTION IN THE EYE OF PECTEN IRRADIANS.

Fig. 2. The peripheral part of a median section stained with methylen-blue. The side branch of the optic nerve docs not really show in this position. It was added to show its relation to the external ganglionic cclls. A few only of the fibres of one of the external ganglionic cells are drawn to show their appearance and distribution.

Fig. 3. The chief morphological elements of the retina, drawn from preparations stained by methylen-blue and other means, and studied with an oil immersion and magnification of 2,500 diameters. 
XXV.

ON THE DEVELOPMENT OF DERMATOBIA HOMINIS.

(PLATES XXXV-XXXVI.

Henry B. Ward. 



\section{INTRODUCTION.}

During the early months of 1902 a collecting party from the University of Nebraska spent several weeks in Costa Rica. One nember of the party, Mr. M. A. Carriker, Jr., did not return with the rest, but remained some months longer to make collections in the wild. On his return to Nebraska he gave me three specimens of an interesting parasitic larva with the following history: The specimens were obtained in May, 1902, near Pozo Azul in the province of Perrio, which is located on the extreme western coast of Costa Rica. The smallest one he removed from a toucan (Rhamphastos tocard) which he had shot and the other two were taken from the axillary region of a man in the party. While both of the latter were probably of the same age, the larger of them was at least five weeks old and the host had endeavored to kill them about two weeks previous to their removal, by the use of a toothpick saturated with nicotine from a pipe-stem, a method recommended and generally employed by the natives. According to a native guide the parasite is designated in that region as the torcel, or screw-worm, a name already well known in the literature on the subject.

Mr. Carriker reported that in his collecting he had met with the same species rarely in a large red nionkey (Cebus sp.), about one individual in thirty being infected, and that the larva also occurs as a parasite, though still more rarely, in an ant-thrush (Formicarius sp.). He also stated that it was common in pigs and dogs in this province, and in fact all through the low country of the west coast, but it did not occur higher up, being unknown in the mountains.

The three larva were in a perfect state of preservation, and careful examination has revealed some details of structure which add to our present knowledge of this species and serve to throw light on the confused or apparently contradictory reports regarding the life histnry. One of these specimens was also just on the point of molting, so that I enjoyed the unusual opportunity of studying old and new skins with their full armature in related positions. In addition to these three specimens I have had for study two of those described by a previous student of the species in the United States. The larva represent different stages in the development of an a'strid, or bot$\mathrm{fly}$, which has long been the subject of note owing to its habit of parasitizing the human subject at times. 


\section{HISTORICAL REVIEW}

Most of the authers who have contributed to our knowledge of this species have been French, though we owe the splendid monographic treatment of the family to a German, F. Brauer, and a number of most important contributions lave come recently from Spanish Americans. It has seemed to me important in a special later section of the paper to review critically all cases recorded in the United States. A similar detailed consideration will not be necessary in other cases. Of the seventy or eighty papers which deal more or less with this form, most are based on observations drawn from the study of a single specimen, and too of ten without due regard to previous work on the part of others, and are often inaccurate and repetitive. Since Blanchard in a series of papers ('92, '94, '97) has covered the historical part of this subject so thoroughly and critically, an historical review beyond a few brief notes and an account of Blanchard's work itself will not be necessary here.

The form under consideration has been known for more than a century and a half, for Blanchard begins the first of his splendid series of contributions on the subject with a citation from de la Condamine (1749) which not only gives the nane, ver macaque, still used to designate the larva, but also states distinctly the habitat and general effects of the parasite. In this paper Blanchard ('92) reviews analytically and in chronological order thirty-one supposed records of this parasite. He adds a careful description of ten larvæ which came from five widely separated localities; among these he was able to distinguish four forms in accordance with the synopsis quoted below. While the larvæ previously described could generally be assigned to one of these forms, there remained recorded fifteen cases, a determination of which could not be nuade for lack of distinctive evidence. Two of these, Blanchard's cases 24 and 30 (Verrill, '72, and James, '89), must certainly be striken from the list, as Blanchard suggested and as I shall show later. The synopsis given by Blanchard is as follows:

Somites II and III:

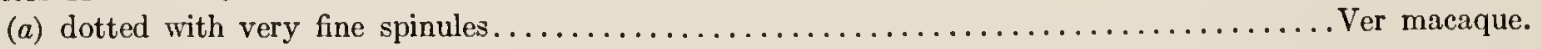

$\left(a^{\prime}\right)$ or smooth, without spinules.

Posterior margin of somite VIII:

(b) with rows of hooks in anteversion on dorsal face $\ldots \ldots \ldots \ldots \ldots \ldots \ldots \ldots \ldots \ldots \ldots \ldots$ Berne.

$\left(b^{\prime}\right)$ or without rows of hooks.

Anterior margin of somite III:

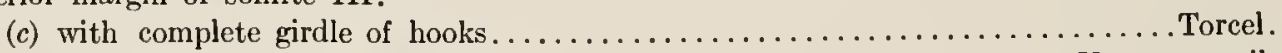

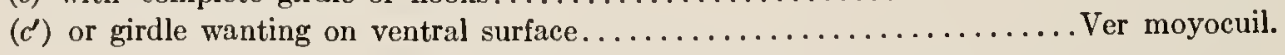

Blanchard inclined to the view that these represented four distinct species, but regarded their assignment to definite adults as pure presumption. Since they occurred 
in both wild and domesticated mammals as well as in man he held that the ancient belief in the existence of a specific (Estrus hominis had been definitely set aside.

In a second paper ('94) Blanchard added many points to our knowledge of the larva on the basis of studies on a large number of specimens received from Brazil, mostly of the form designated as torcel. He was able to show that the armature of the seventh and eighth somites was subject to considerable modification; thus while the anterior row of the seventh somite preserved its general arrangement, the posterior series might be lacking, or on the contrary very numerous; in the latter case hooks in anteversion might also appear on the ventral face. When the seventh somite is well supplied with hooks, the eighth also tends to develop these structures; but this is precisely the condition which obtains in the larva designated as berne, whence one is forced to conclude that the distinction between the torcel and the berne is not real. The berne is only a torcel with a maximum development of the armature on the seventh and eighth somites.

In a third paper Blanchard ('96), after an historical introduction and summary of the present state of knowledge regarding these larvæ, reported on the examination of a specimen of the ver moyocuil from Mexico which he found to be absolutely identical with the berne from Brazil. The paper contains further data regarding the examination of a considerable number of specimens from Brazil, Guiana, and Colombia; one of these was about to molt and combined on the outer and inner skins characteristics of the ver macaque and of the torcel. Blanchard then summarizes his studies on the larve of Dermatobia as follows:

" $1^{\circ}$ La Dermatobia noxialis (Goudot) est répandue dans toute l'Amérique intertropicale. Elle dépasse même plus ou moins la zone intertropicale, vers le nord et vers le sud, puisqu'on l'a observée jusque dans le sud des États-Unis. Aucune observation moderne ne permet d'affirmer qu'elle existe aussi dans cette zone étroite qui s'étend a l'ouest des montagnes Rocheuses et de la Cordillière des Andes, mais le témoignage de Linné junior et celui de Jimenez de la Espada, cité antérieurement par moi, rendent cette opinion très vraisemblable."

" $2^{\circ}$ Malgré la multiplicité des observations faites dans les pays les plus variés et sur les animaux les plus divers; malgré la variété des noms locaux sous lesquels on le désigne, les larves cuticoles du genre Dermatobia, observées jusqu'à ce jour chez l'Homme et les animaux domestiques, appartiennent à une seule et unique espèce: la Dermatobia noxialis (Goudot)."

" $3^{\circ}$ Les deux formes larvaires, dont j'ai précisé précédemment les caractères distinctifs, ne sont que deux états successifs de cette même espèce, séparés l'une de l'autre par une mue qui s'accomplit au sein même de la tumeur où la larve évolue." 
“Le 'Ver macaque,' toujours de plus petite taille, est le premier état larvaire; le 'Torcel' ou 'Berne,' toujours plus grand, est le deuxième état larvaire."

Blanchard's last contribution to this subject ('97) demonstrated the identity of the adult Dermatobia noxialis (Goudot 1845) with D. cyaniventris (Macquart 1843), so that the former falls into the list of synonyms. Meanwhile Magalhães ('96) had established by breeding experiments that the berne (s. str.) was the last larval stage of D. cyaniventris and consequently according to Blanchard's earlier work, of the entire series of larval forms previously known.

\section{NAME OF THE PARASITE.}

The popular designations applied to this species have varied in every country and the general term in any region came to be used for that stage of development manifested by the first specimen from the given region which happened to be studied, so that Blanchard ('92) was led to designate the various larvæ as ver macaque, torcel, berne, etc., so long as he believed them to represent distinct species rather than stages of development in one species. That these names apply locally to the parasite rather than to any particular stage of development is sufficiently demonstrated by the fact that Blanchard himself received a consignment of the berne from Brazil, in which there was not a single specimen of that stage, while the specimens which I had from Costa Rica were all designated torcel, though one was a ver macaque according to the usage of Blanchard.

The scientific name appears also to be somewhat uncertain. Gmelin was the first to give the species a definite name and diagnosis, which in Turton's edition of the "Systema Naturæ," translated from the thirteenth edition according to Say ('22, p. 354), is as follows:

"CEstrus hominis. Body entirely brown. Inhabits South America. Linné ap. Pall. nord. Beytr. p. 157. Deposits its eggs under the skin, on the bellies of the natives; the larva, if it be disturbed, penetrates deeper and produces an ulcer which frequently becomes fatal." After a somewhat extended description and careful discussion of the relationship of the form in question Say declared ( $p .358$ ) that the Linnwan CEstrus hominis should be restored to its place in the system and believed it might be safely referred to the newly established genus Cuterebra of Clark.

Goudot ('45), who was the first to breed the adult form from the larva, denominated it Cuterebra noxialis and rejected the earlier name as that of an imaginary species, since it indicated that man had a parasite peculiar to himself. Some time later Brauer (' $\left.60^{a}\right)$ divided Clark's genus Cuterebra and established a new genus, 
Dermatobia, to include this species, which thus became Dermatobia noxialis (Goudot). In the face of the eminently satisfactory description of Say, however, it does not appear that any reason yet offered can justify the introduction in preference to Say's name of Dermatobia noxialis (Goudot 1845) or of the slightly earlier form Dermatobia cyaniventris (Macquart 1843) which Blanchard has shown to be equivalent to it. This form must be called Dermatobia hominis (Say 1822), or if the non-existence of any conflicting form is established it may carry as authority (Gmelin 1788).

\section{DESCRIPTIONS OF THE LARVE.}

r. Larva A.-The smallest larva, that one, namely, which was obtained from the flesh of the toucan, measures 9.9 millimetres in length by 1.8 millimetres in breadth at its widest part, about at the fifth somite. It is evidently in a state of nearly maximum extension and the furrows between adjacent somites show only as broad shallow depressions (Pl. XXXV, Figs. 1-3).

Each of the anterior somites from the first to the fourth inclusive bears a band of small hooks on its anterior margin. This band is separated from that of the next succeeding somite by a smooth hookless area. The hooks are smallest on the first somite and increase so as to become largest on the fourth. The band also is narrowest on the first somite and widest on the third and fourth, where it exceeds in width the clear area mentioned. On the fourth somite a semicircle of large hooks, interrupted on the ventral surface, introduces an alternate series of complete and incomplete circles of such hooks, of which there are three each. The fifth and sixth somites each carry an anterior complete and a posterior incomplete circle, while the seventh somite has the former but lacks the latter. In this specimen the incomplete row of large hooks on the posterior region of a somite is separated by a maximum distance from the anterior complete row of the succeeding somite, so that in dorsal view all the rows appear almost equally spaced (Pl. XXXV, Fig. 1).

One may distinguish readily from this anterior region which bears the hooks a smooth almost unsegmented region which is destitute of those structures except on the terminal portion. There is a small decrease in diameter just behind the last row of hooks, but the entire body tapers nearly uniformly from the fifth somite to the posterior end. In the alcoholic specimen the body has a light brownish-yellow color and the brown-black hooks stand out sharply as conspicuous objects on the surface, even the smallest appearing as distinct dots under a hand lens. The hooks on the terminal somites are much lighter in color, being dark reddish brown, and are less 
distinct under a low power than those of the anterior region, although larger than many of the latter. Although superficially classifiable as large and small hooks the structures on the anterior somites are in reality decidedly variable among themselves. These differences will be outlined later, but they concern size rather than form. At the anterior end one may note the chitinous oral hooks, of which only the points project from the mouth opening; their further course in the body may be indistinctly followed. At the posterior end the ultimate somite projects well beyond the penultimate and the stigmata and tracheal sacs appear in ventral or terminal view. A more detailed examination demonstrates the following points in the structure and armature of each somite.

Somite I. The hooks on the external surface are few in number, scantily distributed, and also the smallest found anywhere. They vary from such as are simply a small dot under a magnification of 100 diameters to what may be called the standard size of hook on this somite and to this the majority conform. This measures about 20 micra in length with a circular base 10 to 13 micra in diameter. These hooks are few in number and so local in arrangement that one can hardly characterize them as forming a band encircling the somite near its anterior angle and leaving the lateral face entirely free, as on the more posterior somites. Here the hooks are most numerous in the dorso-lateral regions and near the mid-ventral line, where they form thin cheek and chin patches which are joined only by an irregular scattering line of hooks of small size. They are also scanty on the dorsum. The points of the hooks are all directed posteriad and slightly ventrad.

From the dorsal half of the anterior face of this somite projects a low rounded eminence which is distinctly divided into right and left mammiform protuberances that suggest rudimentary antennæ. The tip of each bears a small sensory tubercle and dorso-median to each of these is an insignificant ring of pigment or possibly two such. The mouth forms a transverse slit ventral to the projection just described and is provided with a distinct ventral lip. It leads into a cavity, conical in ventral view, the walls of which are abundantly supplied with muscle fibres. The ventral wall of this cavity is thickly strewn with teeth which immediately follow those of the chin patch already noted. These teeth begin at the oral margin as fine hooks only 5 to 10 micra in length and increase towards the fundus of the cavity, where they are slightly larger than the characteristic external hooks of the somite. In appearance they simulate the hooks of the external surface, while their arrangement recalls the radula of a snail. On first examination they would easily be taken for teeth grouped on the external surface with points directed caudād; upon more careful study their true position was definitely determined. 
The single pair of mouth parts consists of conspicuous heavy black hooks, strongly recurved in a ventral and posterior direction. Their points, which alone project, are close together, but their deep-seated bases diverge slightly towards the sides of the body. They measure about 200 micra from base to bend. In a lateral view (Pl. XXXV, Fig. 4) one can distinguish most clearly their general form. From the base of each hook a large accessory piece, shaped somewhat like an anvil in lateral aspect, extends caudad into the body, as far as the posterior margin of the second somite. In longest diameter, that is, on its ventral extension, which forms the base of the anvil, this piece measured 430 micra.

There certainly are no anterior stigmata in this specimen, for it is well expanded, and one can examine with ease the entire surface of the first somite, in the lateral groove of which the stigmata are figured in later stages. Fxamination of it also by transmitted light shows the entire absence of the large respiratory sacs such as are conspicuous in a later stage among the internal organs.

Somite II. The denticles of the second somite are decidedly larger than those of the first, measuring 25 to 40 micra in length and 15 to 20 micra in diameter at the circular base. Among them there are, however, those which have attained only onethird to one-fourth of this size. The form of the individual denticle is the same as that of those on the first somite, and like the latter these also all point caudad, and slightly ventrad as well. 'They are, however, noticeably more numerous, the band being everywhere about four rows deep, while on the dorsal and lateral aspects this increases to six or eight rows; there is also a slight increase on the mid-ventral line. The anterior margin of the band of denticles is nearly a straight line parallel to the somite groove, but the posterior margin is very irregular and isolated denticles or groups of two or three stand here and there behind the main band. Within the band, the hooks do not stand in circular rows, but in short series, traversing the band at an oblique angle; in the series the dorso-posterior hooks are usually appreciably larger, though numerous exceptions to the general rule may be noticed. This band covers roughly one-third to one-half the width of the somite.

Somite III. Here again the denticles have gained appreciably in size; for while those near the anterior margin are not larger than those of the preceding somite, they grow larger as the series proceed towards the posterior nıargin, and the average hooks of this somite measure 50 to 55 micra in length and 30 to 35 micra in diameter at the base. The largest hooks occur on the posterior lateral aspect of the somite, where they are also most numerous. On this somite the band of denticles covers three-fourths or more of the entire width and the arrangement of the denticles in irregular oblique series is also evident. On the lateral and dorsal aspects of the somite the posterior 
margin of the band is very definite and marked by a range of hooks noticeably larger than the general run of those in the band. Dorsally the anterior hooks of the band are also a little larger than those proximately posterior to them.

Somite IV. The individual hooks here are again a little larger than those on the preceding sonite, as they measure 50 to 65 micra in length and 30 to 35 micra in diameter at the base, though numerous smaller hooks occur irregularly among the number. The band is somewhat narrower than on the last somite, since it covers only two-thirds or less of the somite width. In one respect its appearance is noticeably modified; the anterior margin is marked by a line of hooks which though not uniform include the largest of the band and are at least twice the size of those which stand next to them. They suggest in a striking manner the conditions of the next somite. The hooks on the lateral aspect are also larger on the average than those which fill the ventral region of the band, though one does not find them more numerous in the former region than in the latter. In a small area on the mid-dorsal line the hooks extend further caudad than on the lateral or ventral aspects of the somite.

In one respect this somite presents a radically new condition. Near the posterior margin is found an incomplete circular row of hooks, much larger than any heretofore noted. They measure 130 to 140 micra in diameter at the base and 180 to 200 micra in length, and point unifornily caudad. The series begins on either side about $60^{\circ}$ from the mid-ventral line and extends in a single row around the dorsum. It contains nine hooks on the right and the same number on the left side. Near the middorsal line are intercalated two small hooks.

Somite V. A complete circle of large hooks, similar in form and size to those in the posterior row of the last somite, marks here the anterior margin. The single hook in the mid-ventral line is of only half size; posterior to it stands a pair of the same size and around these are grouped five small hooks on the right and eight on the left in an irregular supplementary row. In the main row there are six large hooks on either side of the median line and before the incomplete row begins, and from that point there are eight hooks on the right side and nine on the left, making a total of twenty-nine in the entire circle.

Along the dorsum this row is supplemented by a row of small hooks just posterior and parallel to it, which contains five hooks on the right and seven of the same size on the left, together with two very small hooks.

The incomplete row on the posterior margin of the somite is present here also. Its hooks correspond roughly to those of the preceding and succeeding series of large hooks. This is most evident in lateral aspect where the antero-posterior ranges may be traced entirely through the six circular series with exceptional breaks only. The 
hooks of this incomplete circular series number fifteen, of which eight are on the right side and seven on the left. In the mid-dorsal line two small hooks are intercalated and on the left a single small hook also.

Somite VI. Here again a row of large hooks marks the anterior margin. At the mid-rentral line is a distinct gap opposite the small hook of the preceding somite and behind this gap stand three hooks of half size, flanked on the right by two single small hooks at some little distance; while on the left two such small hooks are present. In the main row there are five hooks on either side before the beginning of the partial row and from that point seven on the right and eight on the left, making twenty-five hooks in the entire circle.

Three small hooks on the left represent all there is of a supplementary row on the dorsal side parallel to the main circle and posterior to it. They all stand to the left of the median line.

The posterior incomplete row begins at the same point as in the two preceding somites. It contains six hooks on the right and seven on the left. In addition to these one hook of half size is located in the series near the mid-dorsal line and surrounded by an irregular group of ten small hooks which are scattered in the open space between the series.

Somite VII. The anterior circle of large hooks is complete except for a small gap in the mid-ventral line corresponding to that of the last somite. There is posterior to this gap a single hook of half size, but no smaller ones on either side in the ventral aspect, while on the dorsal side the surface of the body posterior to this series of hooks is entirely devoid of any subsidiary denticles. In this last circle the large hooks number twenty-four, arranged as follows: On the left five from the mid-ventral line to the level of the incomplete series, seven to the mid-dorsal line, six to the end of the incomplete series on the left, and six more from this point to the mid-ventral line.

Neither an incomplete range of hooks nor a somite furrow indicates the posterior margin of this somite, which merges insensibly into an undivided region without appendages or somite limits. This tapers gradually toward the posterior end, where one may distinguish evidence of two somites (Pl. XXXV, Fig. 5). These may be interpreted as the tenth and eleventh, according to Brauer ('63).

Somite X. The anterior margin of this somite (Pl. XXXV, Fig. 5) is not distinct, but the general form is that of a collar, 270 micra broad on the ventral surface and 360 micra broad on the dorsal, which is directly continuous with the preceding undivided region of the body. It is covered with fine hooks 33 to 40 micra long and not more than 10 micra broad at the base, being slender and less curved than those of the anterior somites. They are also less heavily chitinized, as is shown by the lighter 
color and translucent appearance. These hooks are very regularly arranged in lines parallel to the length of the body. The posterior margin of this somite is invaginated more deeply on the ventral line than on the dorsal, which seems to be connected with its varied width as noted above. But the entire circumference is turned back within itself so as to form a complete collar, from within which the succeeding somite protrudes. The denticles are continued over the margin and occur on the infolded region. The groove formed by this infolding is not deep, measuring only about 30 to 50 micra on the mid-dorsal line, but decidedly more on the mid-ventral. No doubt it is also the greater depth of the groove in the ventral region that tilts the succeeding somite ventrad at an angle with that just described, as is shown in the figure.

Somite XI. The ultimate somite may evidently be retracted within the penultimate to a considerable extent, but in this specimen it was in a state of almost complete eversion. It shows two very distinct regions; a proximal portion of lesser caliber and with a smooth wall and a distal inflated region which is covered with spines like those of the penultimate somite, but somewhat more thickly set.

The smooth region is of uniform caliber throughout and is connected anteriorly with the inturned margin of the tenth somite. The distal inflated region has much the form of the glans penis, consisting of a uniformly rounded unbroken dorsal portion and two latero-ventral lobes separated by a shallow median furrow. Internally one may distinguish musculi retractores attached to the inner face of the posterior surface.

A view of the terminal aspect of the somite discloses the anal orifice as a transverse crescentic slit near the ventral margin, and just dorsal to it and near the median line the two small stigmata. Each stigmal field appears as a group of two fimbriated slots, set closely together and connecting with an elongated subjacent cylinder, with heavy chitinous walls, chestnut-brown in color, in the alcoholic specimen. The cylinder extends back through this last segment and at its anterior limit connects with the characteristic spiral walled tracheæ of the larva.

The larva just described agrees in all essential particulars with that discussed by Blanchard ('92, p. 136) under the name of ver macaque. The armature of the first four somites is described here for the first time, as also the morphological identity of the various hooks in contrast to the previous view which regarded those of the first to fourth somites as spinules. The observation of Brauer is partly confirmed, that a complete circle of smaller hooks occurs at the anterior margin of the fourth somite comparable to those of the posterior half circle save in size. This is the row noted above as the forerunner of the prominent row in the corresponding position on the fifth somite. No previous desciption of the last tro scnites tes kcen accurate, ard 
Blanchard says specifically that the stigmal plates were not apparent although one can see them indicated in his own figure of this stage (Blanchard, '92, p. 137, Fig. 10e).

2. Matas' Larvæ.-Through the kindness of Dr. L. O. Howard, United States Entomologist, Washington, D. C., the two specimens from the case of Matas ('87), which are now in the collection of the United States National Museum, were loaned me for examination. One of these was evidently the one figured in the original paper (Matas, 'S7, p. 166) and also in the excerpt in the first volume of "Insect Life" (p. 79). There are, however, a number of flocculent masses of coagulated pus adherent to the surface, and the body has a sharp bend at the point of transition from the segmented anterior portion to the smooth, attenuated posterior portion. Both these features contribute to give the specimen an unnatural appearance which is even heightened in the figure by the method of reproduction employed, so that one night question the agreement of the larva represented in the figure with the form under consideration in this paper. The following notes will make the character of the Matas' specimens clear.

The larger one, that mentioned above, measured 2.2 millimetres in breadth at the fifth somite by 9 millimetres in length; about two-thirds of the length is occupied by the smooth unsegmented posterior region, a proportion which seems unduly large. This may have been caused by the inordinately thick skin of the gluteal region of the host from beneath which the parasite was extracted by Matas. The specimen makes a sharp angular bend ventrad just behind the last complete row of hooks, which may have led to the error of Matas in estimating the length at 5 millimetres.

The various types of hooks are in agreement, both as to size and arrangement, with those already described for the smallest larva of my series. One notes at once the cheek and chin patches of minute hooks on the first somite, the bands of small hooks on the second, third, and fourth somites. The anterior row on the fourth somite, which was noted as composed of larger hooks than those in the rest of the band, is even more prominent in this specimen than in my own and suggests more distinctly the conditions of the subsequent somites and also of later stages in development. The complete and incomplete rows of large hooks are similar in position and number to those of the larva mentioned above; they contain the following numbers of hooks:

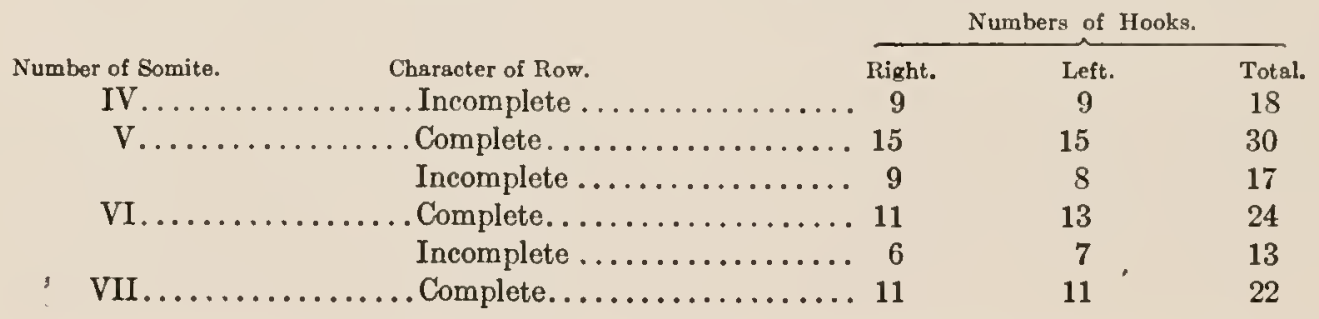


On the ventral side parallel rows of smaller scattered hooks accompany the complete rows on the fifth and sixth somites, as also in the other specimens, and one finds a few such hooks on the dorsal surface as well. There are no hooks posterior to the complete row of the seventh somite save a single small hook immediately next the gap on the mid-ventral line, although the figure given by Matas appears to show four large hooks on the smooth constricted region. The large hooks measure 240 to 270 micra in length over all by 180 to 200 micra in diameter at the base. The smaller hooks agree closely with the sizes given for those of the smallest larva of my series. Finally, as regards the character of the terminal somites I find substantial agreement with the description already given.

One or two minor points need correction in the otherwise excellent description given by Matas. As already noted, the size is incorrectly stated and the figure does not represent the true form of the larva, since even the proportions of different regions, the number of somites, and the number of large hooks are not accurately reproduced. The first four somites are very clearly shown by the specimen, though incorrectly numbered in the description, and the statement that "the stigmata are hidden within the anal fissure" is also an error; they agree perfectly in position with those shown in Figure 5 (Pl. XXXV). Finally, the "Punctiform and blackish tuberosities on the two [four] upper segments" are true hooks, as already described in detail.

The other specimen obtained by Matas measures 2.5 millimetres in breadth at the fifth somite by 6.3 millimetres in length, of which a little less than one-half $\left(\frac{5}{11}\right)$ falls on the constricted posterior portion. From the transverse folding which this region presents it is evidently contracted, and this is further evinced by the fact that the terminal somite is almost entirely withdrawn within the preceding one. The hooks are throughout of the same size and arrangement as in the specimens previously described. The circles of large hooks are constituted as follows:

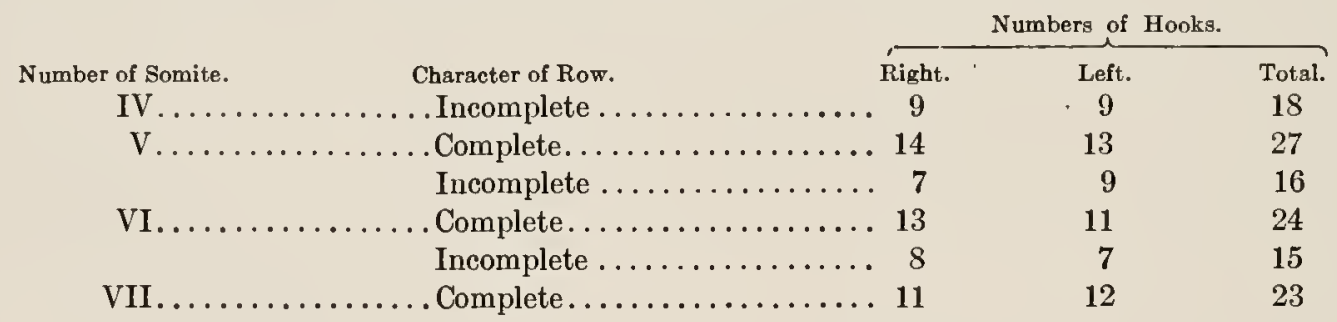

In the first incomplete circle of large hooks the two median dorsals are, as in the other specimens, somewhat smaller in!size and noticeably out of line. Supplementary parallel rows of small scattered hooks lie posterior to the complete circles on the fifth and sixth somites and are most perfect on the ventral surface; the mid-ventral hook 
is intermediate in size between those of this row and those of the large circles. Behind the last complete circle, that of the seventh somite, only two very small hooks occur in the mid-ventral line.

3. Larva B.-The second larva of my series from the human host, which is also the largest of all three, measures 12.7 millimetres in length by 6.2 millimetres in breadth at the fifth somite. Less than one-third the entire length, about 4 millimetres, falls in the constricted portion. This larva (Pl. XXXV, Figs. 6, 7, 8) is the most contracted of all, as the anterior somites are forcibly drawn in and the tip of the ultimate somite barely projects beyond the penultimate, within which it is in large part concealed. In consequence of this the segmentation is more distinct, but the armature is difficult to determine and the terminal somites are so contracted that they can hardly be studied at all. The slenderer posterior portion also manifests the contracted condition in the numerous irregular but deeply marked transverse folds or constrictions which are conspicuous throughout its entire aspect.

On the dorsal surface of this larva (Fig. 6) one finds in the median line a row of peculiar structures which are modifications of the general chitinous covering. They are ellipsoidal in form, with the major axis transverse to the length of the body, and are in general clearly marked off from the surrounding surface although the exact line of demarcation is not sharp. From the furrow which limits them they rise as low oval bosses, more transparent in character than the rest of the external surface. The rows of hooks turn slightly forward or backward to pass around these areas, on which no hook nor irregularity of the surface occurs. Their size is somewhat variable, but this as well as their location is clearly given in the figure, which also shows their remarkable transparency in that a partial row of hooks in the furrow between the second and third somite may be faintly seen through one of these structures. They occur, one on each somite from the second to the seventh inclusive. All are single, but a faint shadow as of a coming line of division separates one into anterior and posterior halves. The cuticula on these bosses is extremely delicate, for in the specimen at hand it was accidentally punctured by a light touch from a dissecting-needle.

Somewhat similar mammiform projections which appear to be just forming are also evident on the somites elsewhere. They are not regular in outline, definite in location, or smooth in surface like those just described, nor is their cuticula of the same delicate character. Whether they are the beginnings of the bosses described by Blanchard and others for later stages of the animal I must leave undecided. The median ovals are, however, unquestionably the structures which these authors have found heavily chitinized in later development. The other important external structural features are given in the following description. 
Somite I. The two lateral mammiform protuberances (Pl. XXXV, Fig. 10), which may be regarded as rudimentary antennæ, are much more distinct than in the earlier stage. Each of these bears two clearly marked annular pigment spots near its tip. The two hooks which project their tips from the dorsal wall of the mouth are longer and much less sharply curved than in the earlier stage, although they are both somewhat more flexed and notably more pointed than in the unformed condition shown in the transforming larva (Pl. XXXVI, Fig. 15). Neither on the ventral portion of this somite which forms a distinet lip, nor on the dorsal which projects like a broad undivided forehead, have I been able to detect a trace of the minute denticles that formed conspicuous cheek and chin patches in the earlier stage of development. The external surface of the first somite is apparently entirely unarmed. But on the ventral wall of the infundibuliform oral cavity one can distinguish with difficulty a few small denticles. It was impossible to make out their arrangement or to ascertain definitely their number. Although a little larger than those described in the same region in the previous stage of development, they are apparently not so numerous, and the difficulty of demonstrating their presence would cause them to be overlooked in most cases.

The first somite was considerably retracted and it was impossible to see the stigmata figured by Blanchard ('92, p. 141, Fig. 11e) on the lateral face and nearly in the groove. A pair of large respiratory sacs lie within the body extending back to the third and fourth somites; these may open here, though no connection could be found nor even an indication of one.

Somite II. Only about one-third of the surface of this somite was exposed. One could distinguish three small teeth near the mid-ventral line and two groups of seven to nine teeth each in the dorso-lateral groove. These teeth measure 120 micra in length by 90 micra in diameter at the base.

Somite III. The denticles were much more numerous than on the preceding somite, being about seventy in all. They were arranged in a single row in the ventral region and in two or three rows on the dorso-lateral surface where the denticles are largest. A few are also seen in a single row in the dorsal groove. The denticles of this somite vary in size as compared with those on the preceding somite and may measure as much as 210 micra in length by 150 micra in diameter at the base; the average size is 180 micra in length by 120 micra in basal diameter.

Somite IV. Here a complete band encircles the anterior margin of the somite with the exception of a short distance on the dorsal surface. There are about seventy denticles in all, and these are arranged in an irregular double row which is somewhat open and broken, forming in part only a single series on the ventral surface, but which 
becomes more crowded on the dorso-lateral face of the somite. These denticles are of the same size as those on the preceding somite. In the incomplete circle of large hooks which is situated near the posterior margin of this somite there are twenty-seven hooks, fourteen on the right and thirteen on the left side. These hooks measure 330 to 390 micra in length by 210 to 240 micra in diameter at the base. It is thus noticeable that while these hooks are actually larger than the corresponding hooks of the preceding stage they have lost their conspicuous character since the smaller hooks have increased in size far more strikingly. Thus it is that the large hooks no longer contrast so strikingly with the smalker ones, and with the size of the body and somites. One notes also that the rows are less symmetrically placed and the hooks less uniform in size. On the dorsal surface a supplemental row of two hooks of good size on either side lies just behind the incomplete row. These hooks are pointed not backward but forward; that is, they are in anteversion.

Somite V. The row on the anterior margin of the somite, which corresponds to the first complete circle of large hooks in the preceding stage, contains here twentyseven hooks on the left half of the body and twenty-four on the right. This row is not so regular nor are the individual hooks so uniform in size as in the preceding ones. In general, these hooks conform in size to the measurements given for the hooks of the preceding incomplete series, but smaller hooks, measuring only 240 to 300 micra in length by 150 to 180 micra in diameter at the base, are intercalated at irregular intervals. A parallel row of distinctly smaller hooks lies immediately posterior to the series just mentioned. It contains nineteen hooks on the right and twenty-one on the left and is complete only on the ventral surface. The lateral and dorsal aspects how it to be much interrupted. The incomplete row near the posterior margin of this somite contains fourteen hooks on the left and sixteen on the right and has a supplementary dorsal row of ten hooks just posterior and parallel to it. This supplemental row has the hooks pointed forward.

Somite VI. The anterior complete circle consists of twenty-three hooks on each side of the body. The same irregularity which characterized the corresponding row of the somite just described may be noted here also, and the hooks are of about the same size, although a few exceptionally large ones measure 420 to 450 micra in length. The parallel row of smaller hooks just posterior is present here also, but it is continuous only on the ventral surface and occurs in patches elsewhere. The posterior incomplete series of this somite contains fifteen hooks on the right side and thirteen on the left; it is interrupted on the mid-dorsal line and is supplemented by a short series of smaller hooks posterior to this gap and extending laterally a short distance beyond it. The contraction of the body and the consequent involution at the limit of the somite 
makes this series of hooks appear to run into the anterior row of the succeeding somite when the body is viewed dorsally. The hooks of this small supplemental row point forward.

Somite VII. The anterior row of this somite appears even more irregular than those already mentioned. Its composition cannot be accurately ascertained on account of the infolded margin of the somite as already noted, but there are about twenty hooks on either side of the body. A scattered row parallel to the main series and posterior to it occurs on the ventral surface and is represented by isolated hooks or small groups on the sides and dorsum. The hooks vary in size here as on the preceding somites. It seems as if the posterior margin of this somite were marked out by a furrow separating it from the unsegmented contracted portion of the body; such a limit was not present in the earlier stage. There is also a suggestion of further segmentation in that among the transverse folds of the constricted portion which follows this somite there are two or three regions deep enough to represent the limit of successive somites. I am, however, entirely unable to find any further evidence of segmentation in this region than the indistinct indication just noted.

Somite XI. This somite is almost entirely contracted within the tenth somite, as there appears beyond the collar of the latter only an irregular narrow rim of hooks. The smooth part has entirely disappeared and by retractor muscles attached to the inner surface of the face the convex tip has been withdrawn so as to form an irregular hollow (Pl. XXXV, Fig. 9). This represents the maximum of contraction and agrees with some figures of the larva previously given. Evidently it shows nothing of the true form of the somite, and of internal structures one can distinguish only the distorted sacs into which the stigmata open.

In general one may say of this larva that the differences between the large and small hooks are by no means so marked as in the preceding stage. The rows of large hooks are not so regular in position and size and the armature of the larva has in general a more confused aspect. The dorsal ovals are a conspicuous and characteristic feature, which appears for the first time at this stage.

Three short supplemental rows, those just posterior to the incomplete series on the fourth, fifth, and sixth somites, are new formations at this stage and are composed of hooks directed forward (in anteversion-Blanchard). The meaning of these structures is doubtless to be found in the migration of the larva, which occurs at the end of this stage of development.

Again it may be said that this larva agrees in all essential details with that described by Blanchard ('92, p. 140) under the name of torcel. Its noticeably lesser length is certainly due to excessive contraction. The hooks in this specimen are 
much more numerous than on Blanchard's, which came from Colombia, and the bosses are less mature, for he speaks of them as more or less advanced in chitinization, whereas these are very delicate. In one particular which I regard as important this description differs from that of Blanchard. This author speaks of the anterior girdle of hooks on somites IV to VII as consisting of a double row of hooks, irregular in size and arrangement. I have preferred to speak of the two rows separately because they differ in size and in completeness, as already described; and as will be demonstrated later, they also differ in origin, for the anterior row corresponds to the single circle of large hooks in the earlier larva, to which alone Blanchard applies the corresponding term of girdle at that stage. So far as can be determined, the posterior region, though somewhat corrugated, has no annulations. Whether they are obscured by contraction or are not yet definitely formed I must leave undecided.

4. Larva C.-The larva of intermediate size in my series (Pl. XXXVI, Figs. 11, $12,13)$, the smaller of the two from the human subject, measured 12.8 millimetres in length by 4 millimetres in breadth at the fifth annulus; of the length, 6.8 millimetres fell in the anterior and 6 millimetres in the posterior region. It is also somewhat curved ventrad, as Figure 12 shows. Like that first described it is well expanded and at first sight is characterized only by a noticeable blackness and distinctness on the part of the individual denticles. A closer examination of the specimen discloses the important fact that it is about to molt, and the new skin with its armature already perfect lies just beneath the old skin, so that careful study enables one to compare with exactness corresponding regions on the two forms. In a few places opacity or the interference of internal organs prevents an exact enumeration of the hooks, but for the most part the specimen is fortunately transparent and hence easily studied. Neither skin carries structures which can be properly designated as spines, for the projections, even though minute as they are on the first three somites, are clearly uncinate. In general, the size of these structures increases from the first to the fourth somite, though the difference between those on the first and those on the second is much greater relatively than in the other somites noted. The denticles on the outer skin are uniformly so dark brown as to appear black and are very irregular in basal outline, while those of the new skin are clear chestnut-brown and throughout symmetrical in outline, their bases being relatively smaller. On the old skin all denticles are directed caudad or nearly so; on the new skin a few to be noted later are in anteversion. A detailed description of the specimen may be given somite by somite.

Somite I. The surface forms a low, rounded projection, looking obliquely ventrad, on which one cannot distinguish the antennary protuberances noted in the other larvie. On the outer surface (Fig. 14) are distributed irregularly in oblique crescentic 
rows a number of very minute denticles, 10 to 15 micra in diameter at the base and of about the same length. These denticles form a distinct group below the oral aperture and an equally noticeable group on each lateral face. These are the chin and cheek patches already described for the same somite on the first larva. None of these denticles appear to be replaced on the new skin save a very few near the mid-ventral line, and these are not on the external surface, but within the mouth cavity, where, however, conditions are somewhat confused, so that an exact determination of their number and position cannot be made; yet they may be followed down inside the cavity as far as the anterior margin of the third somite.

Two sets of mouth parts are easily seen (Fig. 15). The smaller hooks, ventral in location, more sharply uncinate, and so placed that their points are almost directed caudad, are the mouth parts of the earlier stage and agree in full with those described in the first larva. Dorsal to these are two hooks, much less sharply curved and two to four times as long and heavy. They are the mouth parts of the later stage. It is not easy to determine their exact size in the confused mass of structures which surrounds them. In the anterior region a pair of large respiratory sacs, which were lacking in the earlier stage, are conspicuous; there is, however, at this time no connection with the exterior completed, or even begun, as one can easily trace the unbroken periphery of the sacs throughout. Possibly an indistinct lobing of the anterior margin indicates the position from which the connection is to grow out.

Somite II. The external skin carries many small hooks, measuring 20 to 30 micra in diameter at the base and about the same in length. These hooks are distributed irregularly in a band along the anterior border of the somite, covering one-half to threefourths of its width. The band is broadest in dorso-lateral aspect, where also the individual denticles are somewhat larger. To replace the denticles just described one finds on the new skin a group of about six in the mid-ventral line and two other groups of about fifteen hooks each at the dorso-lateral angles of the body, while the surface of the somite otherwise is devoid of any projections. These new hooks are three or four times as large as those on the outer skin.

Somite III. On the outer skin the small denticles, which are only a little larger on the average than those of the previous somite, form a band covering the major portion of the surface. On the mid-ventral line the band is narrowest, about half the width of the somite, and the individual denticles are also decidedly smaller than at the sides of the body. The anterior row of hooks forms a fairly distinct line along the anterior margin of the somite and a few of these are directed outward or even cephalad as if the somite had begun to roll in by some slight contraction at this point. The larger hooks occur in the lateral and posterior portions of the band. 
On the new skin the looks which replace those already described are much less numerous. They stand in an irregular row near the anterior margin of the somite, and are most abundant on the lateral and dorsal aspects where the row is of ten double or triple. Though fewer, they are, however, much larger than the old hooks of this somite, as they measure 100 to 150 micra in length and 60 to 90 micra in diameter at the base. Their smaller number in spite of greater size causes them to leave a much larger portion of the surface of the somite uncovered.

Somite IV. The band of small hooks on the outer skin covers less than the anterior half of this somite. Here the hooks stand in several indistinct rows, of which the anterior is the most regular and also most prominent by virtue of the regularity and size of the hooks, a feature most conspicuous in dorsal aspect. These hooks are replaced by a few which are much larger, being from 150 to 210 micra in length and 90 to 120 micra in diameter at the base. The new hooks form an irregular double row save in dorsal aspect where the series is single. They are most numerous in lateral view. The contrast between old and new hooks is clearly illustrated by the camera drawing (Fig. 17) of a small area from the lateral face of this somite.

On this somite occurs the anterior incomplete row which contains on the outer skin in this specimen ten hooks on the left side of the body and nine on the right. These hooks measure 120 to 150 micra in basal diameter and 240 to 300 micra in length. They are replaced by hooks on the inner skin which are slightly smaller and decidedly more numerous; of new hooks there are sixteen (?) on the right side and eighteen on the left. It is also noticeable that the new hooks are not so uniform in size or regular in position as those of the old skin. The inner skin also bears a supplemental row of four or five hooks which are distinctly directed forwards.

Somite V. In the outer skin the anterior complete row consists of five hooks on either side ventral to the incomplete row and eight hooks on either side parallel to it, making twenty-six hooks in all. On the ventral surface there are one median hook of half size and about fifteen others of minute size and irregular distribution. On the ventral surface the five left hooks of the main row are replaced by eight new, the five right by nine new, and the dorso-lateral eight are replaced by sixteen on the left and fifteen (?) on the right, making about forty-eight in the entire circle. These show the irregularity in size and position already noted. The subsidiary ventral row is replaced by twenty-five to thirty hooks of half size, forming an irregular row parallel to the main row in general and closely set in ventral aspect. Dorsally a group of six replaces three minute hooks behind the main row on one side and other minute hooks are not replaced at all.

The half row on this somite comprises on the old skin eight hooks right and ten 
left. The new skin carries sixteen hooks on the right and twenty on the left. It is noteworthy that in general two new hooks correspond to one old one since one appears beneath the old one and a second in the gap between it and the next. This relation which obtains very generally between the large hooks of this and other rows on the old and new skins respectively is not an absolute one and departures from the rule appear occasionally. An accessory row posteri $\mathrm{i}_{\text {or }}$ to this incomplete row and parallel with it contains on the new skin ten to twelve hooks of half size in place of six or eight minute denticles of the old skin. The new hooks are clearly directed cephalad.

Somite VI. The complete row near the anterior margin bears in the case of the old skin ventrally five hooks on either side and dorso-laterally eight on the left and seven on the right, making twenty-five in all. There is also a single small isolated hook on the mid-ventral line just behind the main row. The left five are replaced on the new skin by nine of about the same size, and the right five by eight, while the single small hook is supplanted by two of half size. Dorso-laterally the right seven are placed by fourteen and the left eight by fifteen, making a total in the row on the new skin of forty-six. On the dorsal side a short series of five hooks of half size appears just behind the complete row as a new formation. On the ventral surface one of half size and two minute denticles posterior to this complete row are succeeded by an almost continuous though slightly irregular row of twenty-five or more hooks of half size posterior and parallel to the main series. The incomplete row on the old skin has eight hooks on the right side and seven on the left, of which the two mid-dorsals are notably smaller than the others. There is also a gap near the mid-dorsal line and posterior to it a series of a few small denticles. The seven hooks of the left side are succeded by sixteen and the eight on the right by fourteen of similar size though more variable. The posterior parallel row contains more denticles and much larger ones also on the new skin, while in this row all the new hooks are also directed forward.

Somite VII. On the outer skin the complete row contains on the right five hooks and on the left six, in both instances ventral to the incomplete series, and seven on each side beyond that point, or twenty-five in all. There is also one small hook near the mid-ventral line and posterior to the row just described. On the new skin the five right hooks are succeeded by nine not so regularly placed nor so uniform in size; the six left are succeeded by nine new hooks, the seven dorso-laterals by eleven variable large hooks on the left and by twelve on the right, making a total for this row on the new skin of forty-one. The largest of the new hooks do not exceed 420 micra in length and their variability is well shown in the camera drawing (Fig. 16).

The single hook posterior to the row is replaced by an accessory row of eight about 
twice as large; they run nearly parallel to the main series and on the dorsum a single such hook appears anew in a similar relation.

The posterior limit of this somite is faintly indicated and near it one finds two small hooks on the new skin, one on each dorso-lateral corner. These are directed forward. Almost immediately behind these hooks there is an indication of what may be the limit of the succeeding somite (VIII). In view of the close correspondence between this groove and that shown on the largest larva of my series I am led to regard them both as somite limits and not as chance folds. Other somite limits do not appear in this posterior constricted region until one reaches the end.

Somite X. The form of the old skin is that of a collar, and this seems to be equally true of the new. The hooks on both are distinctly visible. They depart somewhat in form from those found on the rest of the body, as already described for the first larva, and they differ on the two skins only in size. Those of the outer skin measure 20 to 25 micra in length and 12 to 15 micra in basal diameter; the new hooks are 40 to 50 micra in length and 20 to 25 micra in basal diameter.

Somite XI. The general form of this somite is precisely that already described for the first larva and is well shown in the drawing (Fig. 12). The hooks are visible on both outer and inner skin, and agree in form and size with those just described for the preceding somite. The spiracles of the old skin have the form of two small slits in a circular field located on the posterior face of this somite just dorso-lateral to the anus. This field measures 55 micra in diameter. Just within these orifices one may see a tubular cavity corresponding in diameter to the field and continuing some little distance cephalad in the body without change of diameter. On the new skin one sees three slits of similar appearance, though much larger, measuring 250 micra in length. The relative positions and size of these spiracles is well shown in the camera drawing (Fig. 19). The slits of one side are connected internally with a sac in the form of a truncated cone whose transverse diameter at the surface is 300 micra and at the inner end nearly twice this. The posterior margin of these sacs has a curious fringe of small chitinous rings, and the entire wall is heavily chitinized as shown by the color.

It is worth notice that in the anterior somites (II to V) one finds a pair of sacs of very similar appearance but certainly without external orifices. I have been unable to find the anterior stigmata postulated for this larva by some observers. Perhaps they are developed later than the stages described in this paper. The other internal organs could not be made out satisfactorily.

Between the outer skin of this larva and that of the smaller larva first described there is an evident agreement in armature which extends even to details, so that one 
cannot hesitate to pronounce them identical. Similarly the inner skin of this larva agrees perfectly with that of the largest larva described second, so that no one can doubt of their identity. Thus the larva from the toucan is proved to be of the same species as that from man, and another host has been added to the list of those in which this Dermatobia parasitizes. At the same time two successive stages in the development of the Dermatobia hominis have been positively identified. There remain now to consider critically the other American cases of this parasite and to determine precisely, if possible, the relation of these larvæ to other well-described specimens.

\section{OTHER CASES RECORDED IN THE UNITED STATES.}

I. Historical and Critical.-The earliest reference in American writings to the species under consideration was made by Say ('22), who had received a specimen extracted from the leg of a Dr. Brick during a journey in South America. Say's description of the larva is faulty in that he regarded the anterior end as posterior and vice versa, but otherwise it is very satisfactory and permits one to assert with some confidence that his specimen was identical with the smallest larva described in this paper, or the stage designated by Blanchard as ver macaque. The size given by Say has been wrongly quoted by some authors; it was 14 millimetres long by 3.8 millimetres broad. The specimen was deposited in the cabinet of the Philadelphia Academy of Natural Sciences, but is not now in existence, according to information kindly furnished by the curator.

The description quoted by Say from a letter gives an interesting clinical history of the case, especially valuable on account of the observer's profession. Dr. Brick was stung by some insect while bathing and the larva was extracted after about six weeks. It gave rise to excruciating pain at intervals, owing, as he inferred even before the determination of the cause, to "something alive beneath the skin." It was at first "a considerable tumefaction over the tibia, which had the appearance of an ordinary bile (Phlegmon); in the centre there was a small black speck." The tumor began to discharge at about four weeks, and was so serious that he was "scarcely able to walk." Scarifying the tumor yielded no results, and finally poulticing with cigarashes and rum for five days resulted in the extraction of the larva dead. Dr. Brick records that "it had travelled on the periosteum along the tibia for at least two inches." While later authors hold very generally that the larva always inhabits a fixed spot in the subcutaneous tissues, I do not find that any one has referred to this record of migration made by a most competent observer. 
Say quotes the description of Gmelin and definitely assigns this specimen to Estrus hominis. He asserts positively its distinct character, especially as against E. bovis, to which some would refer it, and points out clearly its differences from other species of the genus, while inclining to refer it to the recently established genus Cuterebra which Clark had formed at the expense of the older genus Estrus.

The second observation recorded in the United States is that of Penniston ('44). The larva was removed from a sailor in the Charity Hospital at New Orleans, who had acquired it in a trip to the provinces of Vera Cruz and Tabasco, Mexico. The larva is not now in existence. It measured 21 millimetres in length and 8.4 millimetres in maximum width. From the figures as well as from the careful description given by the author it can be recognized as a Dermatobia larva in a late stage of development. The mammellated elevations, ten to twelve on each segment, into which each was divided indicate an older larva than the second stage described in this paper. It was not old enough, however, to undergo metamorphosis when removed from the arm of the host, though it remained alive four days. Penniston regarded the form as certainly an (Estrus and asserts, after "comparing it with the imperfect description hitherto given of the larva of the Fistrus found in the human body, that several varieties of this insect have already been observed, and that this constitutes another perfectly distinct." It is, however, evidently a well-developed larva of the stage designated by Blanchard as torcel. Penniston's paper was reprinted in French as part of another contribution (Coquerel et Sallé, '59).

The case recorded by Verrill ('72) was cited by Blanchard as one the specific character of which could not be definitely determined. The citation is incorrect, in that the paper noted by Blanchard (Verrill, '70) makes only bare mention of the occurrence in Central and South America of such a parasite, and the review cited deals with another paper by the same author in the same volume and does not include any reference of any sort to this form. In a later paper, however, Verrill refers ('72, p. 342) to the earlier report, and cites a "similar case in the United States" which afflicted a young woman of Meridian, Miss. "The larvæ, developed from eggs deposited in the skin by the fly, caused great irritation and pain in the subcutaneous tissues, resulting in large abscesses, from which the mature larvæ finally escaped." As Verrill examined some of the larvæ one may infer from absence of remarks that they certainly did not possess the striking form of Dermatobia larvæ; the description also corresponds well to other forms, and does not seem to belong to the species under consideration, so that I unhesitatingly strike it from the list of cases of Dermatobia.

In 1887 Matas reported the case of an Englishman from Spanish Honduras upon 
whom he operated in the Charity Hospital at New Orleans for the removal of three * larvæ from the gluteal region. The sinus in which the larvæ lay was oblique and in subdermal tissue. The patient was stung by a fly on June 11 and the larvæ were removed on June 27. I have given above a careful description of these larvæ, which Blanchard has already rightly interpreted as of the stage designated as ver macaque.

Matas states that "similar instances of larval deposits in the skin have not been rare in the hospital, at least since the Panama Canal and other enterprises have increased the traffic between this port [New Orleans] and the Central American Republics." These cases were not more precisely studied to determine the species concerned, and I find no further records of them in print. In Matas's paper, however, is the record of a previous case in the same hospital in which similar parasites were removed from a Frenchman, also from Honduras. This paper also includes very complete references to the chief contributions by previous authors and a discussion of the taxonomy and nomenclature of this form, much of which is credited to L. O. Howard. The major part of this contribution was afterwards reprinted in "Insect Life" (vol. 1, pp. 76-80).

In a brief note James ('89) refers to an unnamed article or address by Riley which records the occurrence of "a small larva of some species of bot-fly" in the skin of the neck of a woman stung by some insect in Washington, D. C. There is absolutely no evidence for interpreting this as a case of Dermatobia, and one remarks the absence of any note upon the peculiar form of the larva by one so familiar with the common bot larva as Riley was. About this time also Riley reprinted the major part of an article on the real Dermatobia larva by Matas ('87) which he recognized at once as peculiar and important. On these grounds I am forced to conclude that this case cannot concern Dermatobia.

Blanchard ('97, p. 649) has referred to several other cases from the United States. He records a communication from L. O. Howard in which was described the case of a sailor from Brazil, from whose arm a larva was extracted at Newport News, Va.; this case has not been published here. According to a personal communication to Blanchard the larva sent by Baron Osten-Sacken to Brauer and described by him ('63, p. 259, Pl. X, Fig. 2) had been given Baron Osten-Sacken by Dr. John L. Le Conte, of Philadelphia. It came from Honduras, and is referred to in the complete edition of Say's works in a note which Le Conte appended to Say's description of the specimen obtained from Dr. Brick. Le Conte regarded the two larvæ as identical.

Some part of the life history of this species appears now to be reasonably well established. How the eggs or embryos are deposited, how the young gain their place

* Blanchard ('92, p. 133) wrongly says the number was not indicated. 
beneath the skin, whether they change in form,-these earlier details are entirely unknown, but within about two weeks after the infection the larva has in the human host arrived at the stage designated by Blanchard as ver macaque; the date is positive in the case reported by Matas ('87), in which I have studied the larvæ. The host was stung by a fly June 11 and the larvæ removed on June 27 . At the end of about fire weeks the larva molts or has just passed that epoch, as in the case of the two larvæ from man described in this paper. Data are lacking in most cases for a more precise determination of these limits and no doubt external factors modify them somewhat at least, but no larvæ of the ver macaque stage have been obtained which were known to be older than this and none of the torcel stage which were definitely younger.

The fully developed specimens of the torcel stage are more than two months old, and it may be even that another molt intervenes between the older specimen that I have described and the form from the same country illustrated by Grube and construed as the mature form of the torcel stage. Numerous minor details which cannot be profitably enumerated here favor this hypothesis, but it must be established by evidence of another kind. According to Coquerel et Sallé ('59) the larva remains ordinarily three months in the flesh; at the end of that time it drops to the ground and transforms. This was also the age of the larvæ described by Magalhães (Blanchard, '92, pp. 144-145), which he thought ready to pupate. The pupal period has been determined by Goudot ('45), who collected larvæ from the ground where infested cattle had passed the night and raised the perfect insect. In Colombia this required in the single instance about six weeks.

No doubt the life cycle is periodic, and yet there is not sufficient positive evidence to warrant drawing conclusions. It is suggestive that the cases of human parasitism bear dates, so far as I have been able to find any at all in the accounts at hand, which fall in the months of April to July, inclusive.

2. $\mathrm{H}$ (st-The most diverse animals are at times the host of the species under consideration. Commonly the larva parasitizes in the skin of cattle, pigs, and dogs; it occurs less frequently in man and rarely in the mule, and writers have commented upon its absence from the horse. It also occurs in the agouti (Bonnet), jaguar (Roulin), in various monkeys as the guariba, or Mycetes ursinus (Bates), and a species of Cebus (Carriker). I have also to record the observations of Carriker on its occurrence in the toucan (Rhamphastos tocard) and in an ant-thrush (Formicarius sp.). At first I thought that this was the initial record of its presence in birds, but this appears to be incorrect. Guyon ('36), whose paper is known to me only by the citations given by Coquerel et Salle ('62), refers to the fact that these larvæ occur in birds as well as 
in mammals. He speaks particularly of "les grosses larves qui se trouvent dans la peau mammelonnée qui garnit la tête et le cou du Dindon et de quelques autres volatiles." This possibility has passed unnoted by later writers and finds its confirmation in the observations recorded here in which the species was found as a parasite in two other birds. It occurs thus in birds both under natural conditions and in domestication.

In man it has been reported from various regions of the body, namely, head, arm, back, abdomen, scrotum, buttocks, thigh, axilla; and the adult fly appears consequently to depend upon opportunity rather than choice of definite location in oviposition.

A veritable plague to cattle in those regions where it exists, its more occasional presence in the human host is, on the testimony of many sufferers, accompanied by excruciating pains, especially at times when the larva is moving; the early morning and evening hours appear to be those in which the pain is most severely felt. Most authors believe it is doubtful if it reaches full development in man, and in no case on record has the adult been developed from any larva taken from human flesh. Yet Magalhães (quoted by Blanchard, '92, p. 145) obtained four which were old, one of them indeed very dark brown and immobile, so that he thought it had begun to pupate, constrained by circumstances from leaving as usual its larval seat.

3. Geographical Distribution.-The species enjoys a wide range on this continent. It is common in Brazil, extending at least to $18^{\circ}$ south latitude and west to the mountains. Cases are recorded from French and British Guiana, Venezuela, and the island of Trinidad. In Colombia it appears to be frequent, and in his last paper Blanchard ('97, p. 647, note) refers to a record of its presence in Peru, that is, west of the great chain of the Cordilleras, where one of the earliest of reports (C. Linnæus, $\mathrm{J}^{\circ}$.) had also located it. Its discovery in intervening territory in South America with suitable climatic conditions is thus evidently only a matter of attention.

Farther northward previous records of this species are at hand from Costa Rica, Honduras, Guatemala, and from the Mexican States-Yucatan, Tabasco, Vera Cruz, and many others even as far north, if the determination of the parasite is correct, as Tamaulipas and Sinaloa, about $25^{\circ}$ north latitude, where it is signalized, according to Altamirano. Blanchard, who records this, says that if the localities are correct the Dermatobia occurs to the westward of the great Rocky Mountains, on the Pacific slope. Its presence on this slope is placed beyond all doubt by the confirmatory evidence of this paper, as the specimens were taken well down below the forests on the coastal plain itself. Blanchard adds that it does not occur in the great central plateau 
of which the altitude is excessive and the mean temperature insufficient, a view which accords with the observations of Carriker in Costa Rica.

While the habitat approaches closely to the borders of the United States, it does not appear that any evidence has been offered for its presence within our country. Blanchard emphasizes (' 97, p. 649) his inability to secure any such, and an extensive correspondence on my own part with societies and individuals in Texas and Louisiana has been equally negative. As noted above, all the local contributions to the subject in the Unitedt Sates have dealt with specimens of undoubted foreign origin.

\section{BIBLIOGRAPHY.}

Altamirano, F.

'96. Datos para el estudio de la Myiasis cutánea causada por el Moyocuil. Anales del Instituto merlico nacional (Mexico), vol. 2, pgs. 64-69, 82-91, 3 láminas.

Blanchard, R.

'92. Sur les Oestrides américains dont la larve vit dans la peau de l'Homme. Ann. soc. entomol. France, vol. 61 , trimestre 1 , pp. 109-154.

Blanchard, R.

'94. Contributions à l'étude des Diptères parasites (sér. 2). Ann. soc. entomol. France, vol. 63, trimestre 1, pp. 142-160.

Blanchard, R.

'96. Nouvelles observations sur les larves de Dermatobia noxialis. Bull. soc. centr. méd. vét., sér. 2, tom. 14, pp. $527-538$.

Blanchard, R.

'97. Contributions à l'étude des Diptères parasites (sér. 3). Ann. soc. entomol. France, vol. 65, trimestre, 4 , pp. 641-677, pls. 17-19.

Brauer, $\mathrm{F}$.

'60. Ueber den sogenannten Ocstrus hominis und die oftmals berichteten Verirrungen von Oestriden der Säugcthiere zum Menschen. Verh. zool.-bot. Gesell. Wien, Bd. 10, pp. 57-72.

Brauer, F.

'6033. Ueber die Larven der Gattung Cuterebra Clk. Verh. zool.-bot. Gesell. Wien, Bd. 10, pp. 777-786. Brauer, F.

'63. Monographie der Oestriden. Wien, $8^{\circ}$, vi +292 pp., 10 Taf.

Condamine, de la.

1749. Relation abrégée d'un voyage fait dans l'intérieur de l'Amérique méridionale. Hist. Acad. Sci., 1745, p. 391. (See Blanchard, '92, p. 110.)

Coquerel, C., et Sallé, A.

'59. Note sur des larves d'Oestrides développées chez l'homme, au Mexique et à la Nouvelle-Orlćans. Rev. et Mag. zool., sér. 2, tom. 11, pp. 361-367, pl. 12.

Coquerel, C., et Sallé, A.

'62. Notes sur quelques larves d'Oestrides. Ann. soc. entomol. France, sér. 4, vol. 2, pp. 781-794, pl. 19. Goudot, J.

'45. Observations sur un diptère exotique dont la larve nuit aux bœufs (le cutérčbre nuisible). Ann. sci. nat., Zool., sér. 3, vol. 3, pp. 221-230.

Guyon.

'36. Mémoire pour servir à l'histoire naturelle et médicalc du Ver Macaque, écrit à la Martinique en 1823. Bull. soc. sci. lettr. arts départ. du Var (Toulon), année 3, no. 2, 3, et 4. (See Coquerel et Sallé, '62, p. 791.) 
James, J. F.

'89. A "Human Parasite." Amer. Nat., vol. 23, no. 265, p. 65.

Magalhães, P. S. de.

'96. Observations sur les Dermatobies. Bull. soc. zool. France, vol. 21, pp. 178-179.

Matas, R.

'87. Report of the Case of a Patient from whose Subcutaneous Tissue Three Larvæ of a Species of Dermatobia were removed, with Remarks. New Orleans Med. Surg. Jour., vol. 15, pp. 161-179. (Reprinted in part as A Man-infesting Bot. Insect Life, vol. 1, no. 3, pp. 76-80.)

Penniston, $T$.

'44. A Case of Malis Oestri, or Gadfly Bite, Occurring in the Human Subject. New Orleans Med. Surg. Jour., 1844, pp. 24-27, 1 pl.

Say, T.

'22. On a South American species of Oestrus which inhabits the human body. Jour. Acad. Nat. Sci. Philadelphia, vol. 2, pp. 353-360.

Verrill, A. E.

'70. The Extcrnal Parasites of Domestic Animals, their Effects and Remedies. Rep. Connecticut Board Agric. 1870, pp. 111-251.

Verrill, A. E.

'72. Additional Observations on the Parasites of Man and Domestic Animals. Rep. Connecticut Board Agric. 1871-72, pp. 321-342.

\section{EXPLANATION OF PLATES XXXV-XXXVI.}

All the figures are taken from three larvæ of Dermatobia hominis collected in Costa Rica by Mr. M. A. Carriker, Jr. Larva No. 1 was taken from a toucan (Rhamphastos tocard); larvæ Nos. 2 and 3 from a human being.

\section{PLATE XXXV.}

Figs. 1 to 3. Dorsal, lateral, and ventral views respectively of larva No. 1 , from the toucan. $\times 6$.

Fig. 4. Lateral view of anterior somites from larva No. 1, showing arrangement of hooks on first and second somites, and mouth parts of right side. $\times 25$.

Fig. 5. Terminal somites of same larva, No. 1, in lateral aspect, showing form and armature of penultimate and ultimate somites. The anal orifice appears as a crescentic slit and the two stigmal fields just dorsal to it are also shown. $\times 25$.

Figs. 6 to 8. Dorsal, lateral, and ventral views respectively of larva No. 2, the larger larva from a human being. Note in Figure 6 the arrangement of the hooks and bosses about the median line. $\times 6$.

Fig. 9. Posterior end of larva No. 2. $\times 12$.

Fig. 10. Anterior end of larva No. 2, viewed en face. $\times 12$.

\section{PLATE XXXVI.}

All figures on this plate are drawn from larva No. 3, the smaller onc of the two from the human being. The specimen was molting.

Figs. 11 to 13. Dorsal, lateral, and ventral views respectively of larva No. 3. Only the hooks on the outcr skin are represented. $\times 6$.

Fig. 14. Anterior end to show mouth parts, rudimentary antennæ and arrangement of hooks on the first two somites. $\times 15$.

Fig. 15. Mouth parts viewed as transparent objects to show the short sharply curved hooks of the earlier stage and the longer, heavier, and less bent hooks of the next later stage. $\times 33$. 

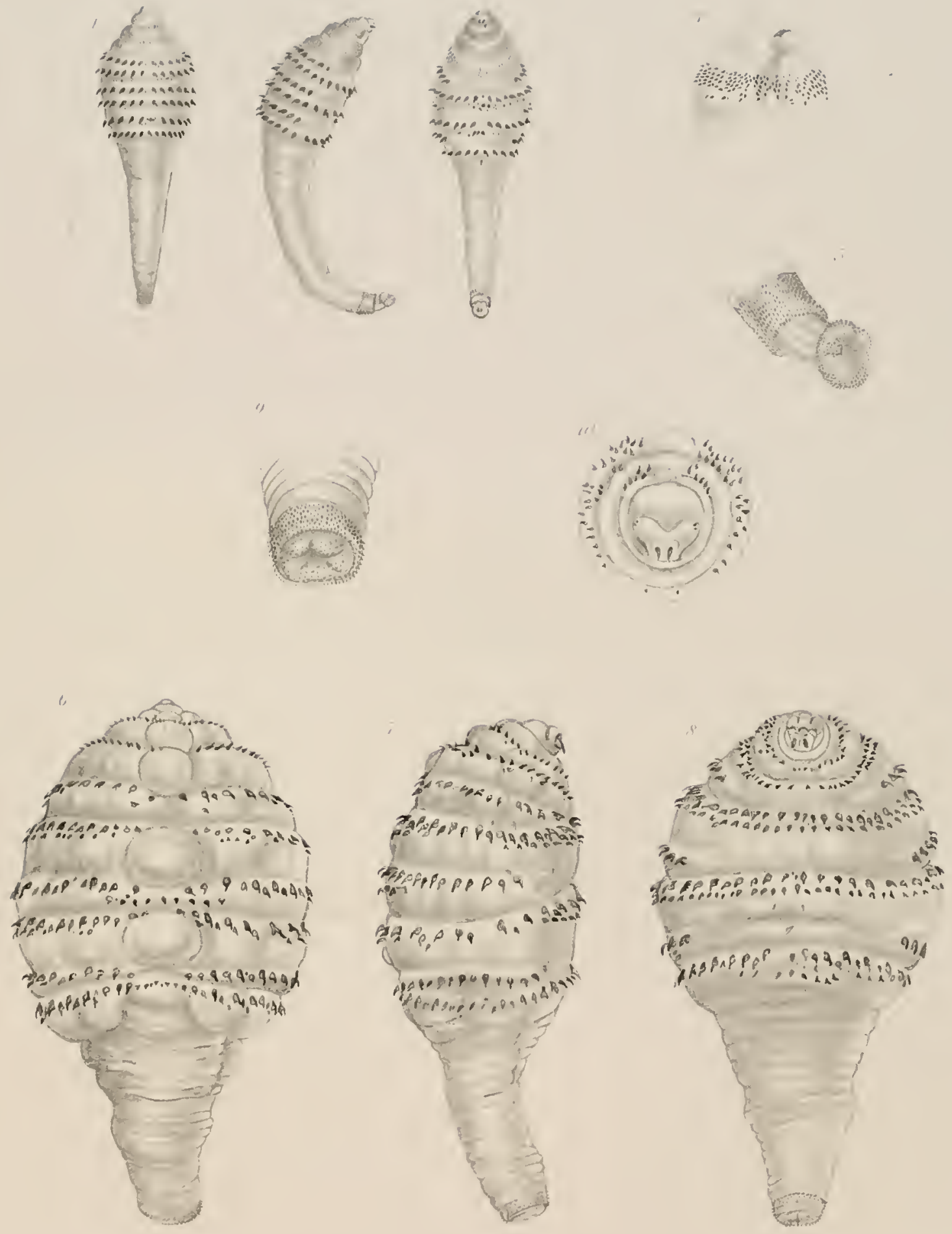

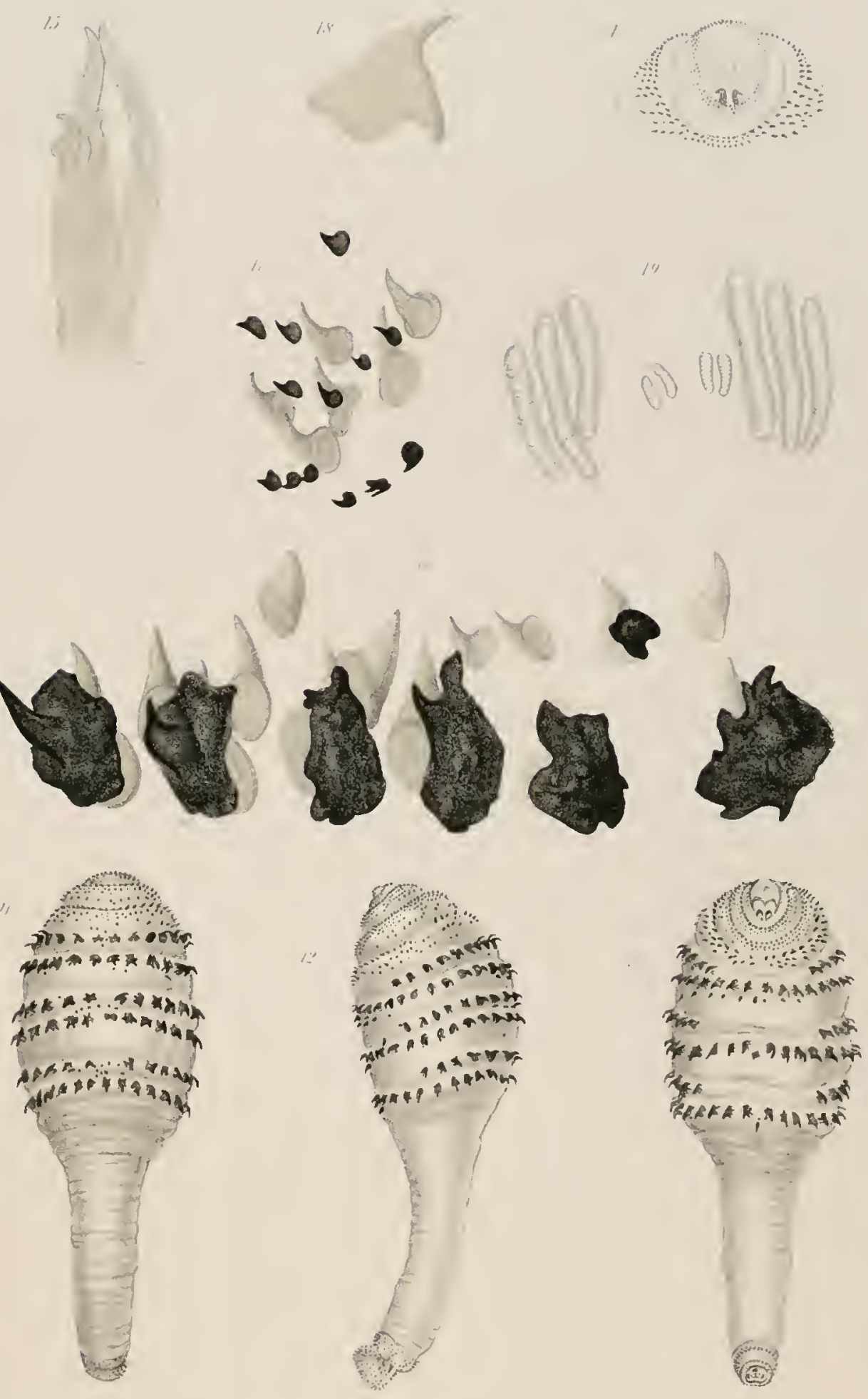

Fig. 16. Hooks from the median ventral area of the seventh somite in surface view, showing the number and relative size in the two sets, one on the outer and the other on the inner skin. $\times 64$.

Fig. 17. Hooks from the left anterior region of the fourth somite in surface view, showing the number and relative size in the two sets, one on the outer and the other on the inner skin. $\times 64$.

Fig. 18. Isolated hook from the outer skin of the seventh somite in profile view. $\times 64$.

Fig. 19. Stigmal fields in the last somite viewed on face as a transparent objeet. The small stigmata belong to the outer skin and the larger ones to the inner skin. $\times 95$. 

. 




